\title{
The Evolutionary Origins OF Vibratory Signals in DRePanidae Caterpillars: A CoMParative Study ON MORPHOlogy, Phylogenetics ANd Behaviour
}

\author{
by \\ Jaclyn L. Scott
}

A thesis submitted to the Faculty of Graduate and Postdoctoral Affairs in partial fulfillment of the requirements for the degree of

\author{
Doctor of Philosophy \\ in \\ Biology \\ Carleton University \\ Ottawa, Ontario, Canada
}

(C) 2012 Jaclyn L. Scott 
Library and Archives

Canada

Published Heritage

Branch

395 Wellington Street

Ottawa ON K1A ON4

Canada
Bibliothèque et

Archives Canada

Direction du

Patrimoine de l'édition

395 , rue Wellington

Ottawa ON K1A ON4

Canada
Your file Votre référence

ISBN: 978-0-494-93689-4

Our file Notre référence

ISBN: $978-0-494-93689-4$
NOTICE:

The author has granted a nonexclusive license allowing Library and Archives Canada to reproduce, publish, archive, preserve, conserve, communicate to the public by telecommunication or on the Internet, loan, distrbute and sell theses worldwide, for commercial or noncommercial purposes, in microform, paper, electronic and/or any other formats.

The author retains copyright ownership and moral rights in this thesis. Neither the thesis nor substantial extracts from it may be printed or otherwise reproduced without the author's permission.
AVIS:

L'auteur a accordé une licence non exclusive permettant à la Bibliothèque et Archives Canada de reproduire, publier, archiver, sauvegarder, conserver, transmettre au public par télécommunication ou par l'Internet, prêter, distribuer et vendre des thèses partout dans le monde, à des fins commerciales ou autres, sur support microforme, papier, électronique et/ou autres formats.

L'auteur conserve la propriété du droit d'auteur et des droits moraux qui protege cette thèse. $\mathrm{Ni}$ la thèse ni des extraits substantiels de celle-ci ne doivent être imprimés ou autrement reproduits sans son autorisation.
In compliance with the Canadian Privacy Act some supporting forms may have been removed from this thesis.

While these forms may be included in the document page count, their removal does not represent any loss of content from the thesis.
Conformément à la loi canadienne sur la protection de la vie privée, quelques formulaires secondaires ont été enlevés de cette thèse.

Bien que ces formulaires aient inclus dans la pagination, il n'y aura aucun contenu manquant. 


\begin{abstract}
Animal communication signals can be highly elaborate, and researchers have long sought explanations for their evolutionary origins. Animal communication theory holds that many signals evolved from non-signalling behaviours through the process of ritualization. Empirical evidence for ritualization is limited, as it is necessary to examine living relatives with varying degrees of signal evolution within a phylogenetic framework. I examined the origins of vibratory signals in Drepanidae caterpillars using comparative and molecular phylogenetic methods. I demonstrated that variation exists in morphology of signalling structures, general life-history characteristics related to signalling, and territorial behaviour by studying morphology in 19 species and behaviour in 11 species. I developed a molecular phylogeny of the Drepanidae onto which these characters could be mapped to test specific hypotheses on to the origin of signalling. These hypotheses included: 1) anal scraping derives from crawling towards an intruder; and 2) mandible scraping derives from lateral head hitting. My results support these hypotheses based on morphological, behavioural and kinematic data, thereby providing strong empirical evidence for the origins of communication signals. My thesis also demonstrates that vibratory communication is widespread and variable in this group of caterpillars, adding much needed information on this mode of communication in larval insects. Finally, I provide several lines of evidence to suggest that larvae that invest in leaf shelters defend these shelters from conspecifics using vibratory communication, which contributes to a growing body of information on this topic in caterpillars.
\end{abstract}




\section{ACKNOWLEDGEMENTS}

First and foremost, I would like to thank my friends and family for their endless support and guidance throughout the years. In particular, I will be forever grateful to my wonderful husband, James, for always being there for me, in the good times and the bad, and for fully supporting me throughout this stressful endeavour. I could not have done this without you! A big thank-you to my loving parents for always encouraging me to excel in everything I do, and for providing me with the solid foundation I needed to accomplish my goals. You are not only my parents, but also my mentors, role models, and friends. I would also like to thank my sister for being my best friend and constant support system throughout the years, and my brother for reminding me not to take life so seriously. Finally, probably the most important members of my family, I would like to thank my dogs, Lexie, Penny, and Meesha (in that order), and my cats, Bagheera and Üter, for providing me with their infinite love and devotion, and for spending many hours sleeping beside me as I wrote my thesis.

I would also like to extend my gratitude to all of the past and present members of the Yack lab, who are not only my lab mates, but I have grown to be some of the most important people in my life. A special thanks to Veronica (Ron) Bura and Sarah Matheson, for helping tremendously with my project, for being my best friends, my support system, my sentence structure helpers, and for making learning fun! I don't know what I would have done without you! Thank you to Alan (AJ) Fleming for being my goto entomology expert, and for taking me out for a drink whenever I needed it most. I would also like to thank Katie Lucas, Amanda Lindeman, Laura McMillan, J-P Fournier, 
and Sen Sivalinghem for their advice and support along the way; to Abeer Sami, Shannon Henderson, Sarah Davis, Tamara Nevills and Tiffany Eberhard for help with data collection; and to members of the Smith lab, Robert Smith, Dénis Lafontaine and Melissa Bégin, in particular, for help with the molecular genetics portion of my research.

A well-deserved thank-you to all others that helped with data collection and analysis for my project. Thanks to K. Silvonen, S. Corver, T. Muus, L. Scott, J. Miall, H. Beck, Y.L. Chen, K. Eda, C.H. Wei, S. Wu, and J. Sohn for collecting wild moths; to C. Mittner, K. Mittner, J. Heppner, and P. Gentili-Poole for providing specimens in alcohol; to Dr. Shen Horn Yen for providing specimens from Asia and for conceptual advice on behaviour and morphology; to Dr. Ivar Hassenfuss for providing unpublished observations on Drepanidae caterpillars; to Dr. Jeff Skevington for help with phylogenetic analysis; to Dr. Jeff Dawson for help with acoustic analysis; and last but not least, to Dr. Akito Kawahara for his immense help with molecular phylogenetic data collection and analysis. I also wish to thank my committee members: Dr. Myron Smith for allowing me use of his lab for my molecular genetic work, and for providing me with lots of advice on molecular genetics and all other aspects of my project; and Dr. Charles Darveau for his invaluable comments and input on my project.

Last, but certainly not least, I am forever grateful to my supervisor, Dr. Jayne Yack, for pushing me all these years to succeed and for always having my best interest at heart. Thank you for challenging me, for providing me with the opportunity to work on this wonderful project, for keeping me interested in science, for correcting my grammar, and for all the advice you have given me throughout the years. You will always be like a second mother to me (a very picky mother, but a loving one, all the same!). 
Funding for this research was provided by the Natural Science and Engineering Research Council of Canada (NSERC) Discovery Grant, and the Canadian Foundation for Innovation (CFI) to Dr. Jayne Yack. Additional funding was provided by NSERC (PGS-M and CGS-D), Carleton University, the David and Rachel Epstein Foundation, and a Wyndham Scholarship for Graduate Students in Biology to Jaclyn Scott. 


\section{TABLE OF CONTENTS}

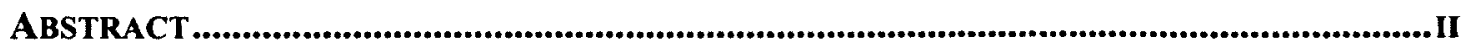

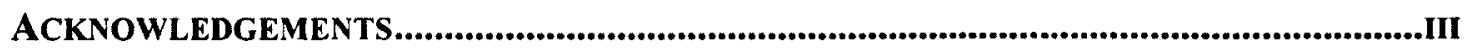

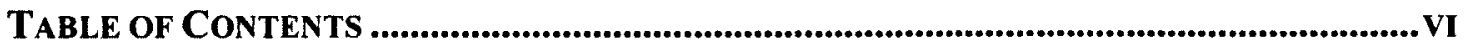

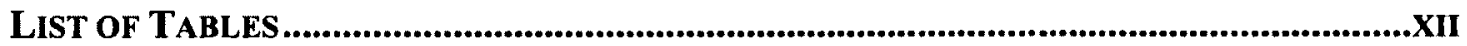

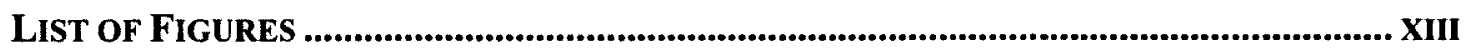

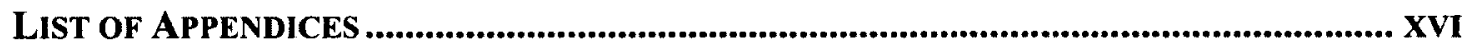

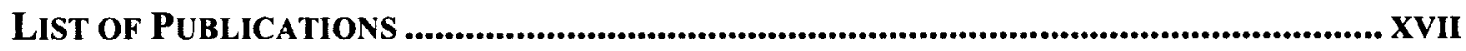

ChAPTER 1: GenERAL INTROdCTION

1.1 The evolutionary origins of animal communication signals ............................. 2

1.2 Drepanoidea as a model system for studying signal origins ............................. 6

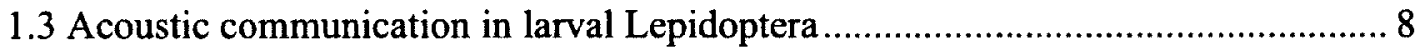

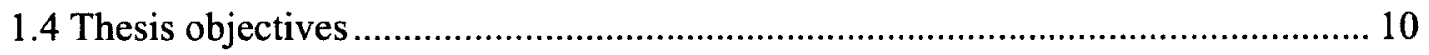

Chapter 2: VARiation in MoRPhOlogy aNd Behaviour ASSOCIATEd WiTh

VibRATORY Signalling IN DREPANIDAE CATERPILlaRS ..................................... 12

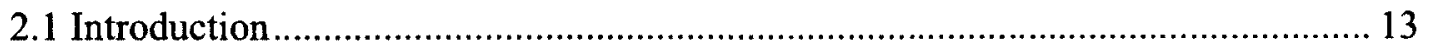

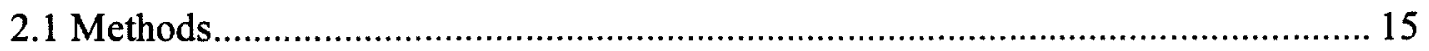

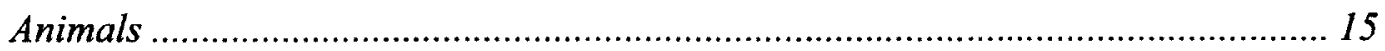

General life history observations relevant to conspecific interactions .................. 16

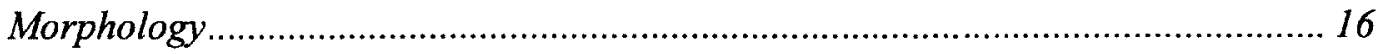

Behavioural trials between conspecifics......................................................... 18

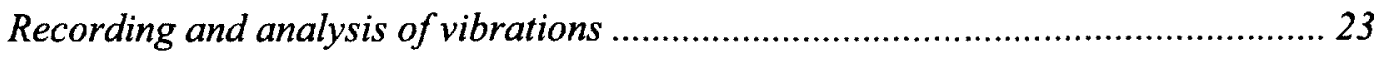

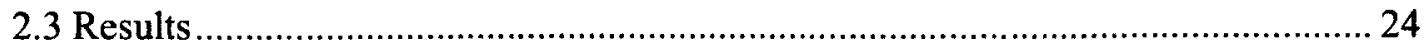




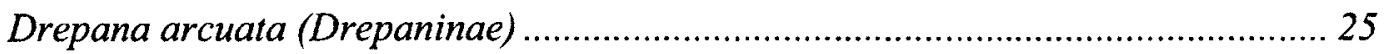

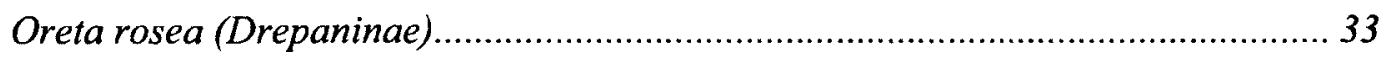

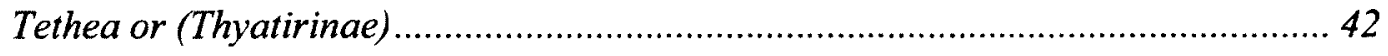

Cyclidia substigmaria (Cyclidiinae) ............................................................. 50

A summary of morphology and behaviour observed in all studied species............. 56

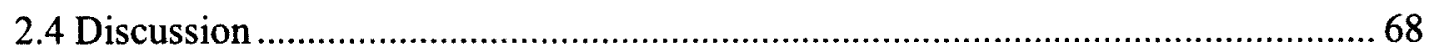

Variation in vibrational signalling in caterpillars..........................................6 68

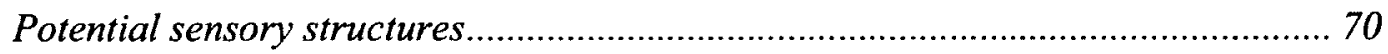

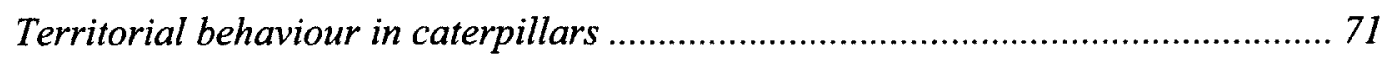

Chapter 3: Molecular Phylogeny of the Drepanidae ................................. 73

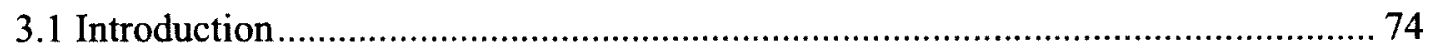

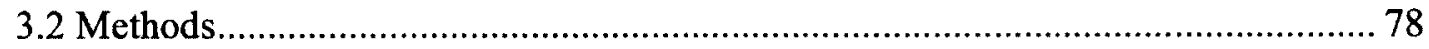

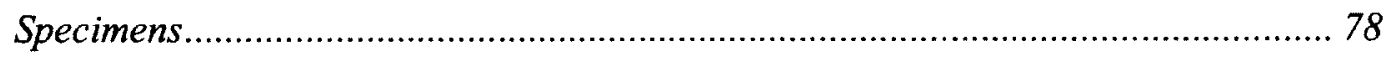

DNA Extraction, Amplification and Sequencing ........................................... 82

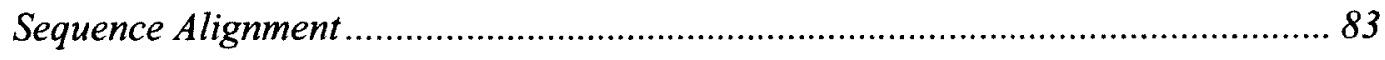

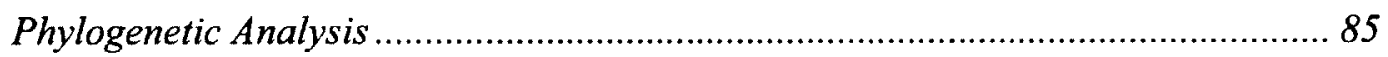

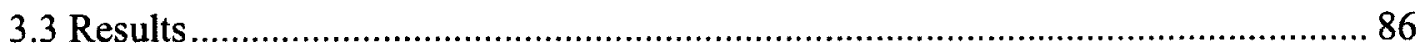

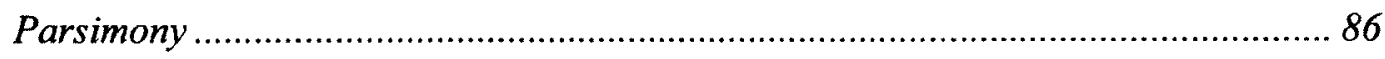

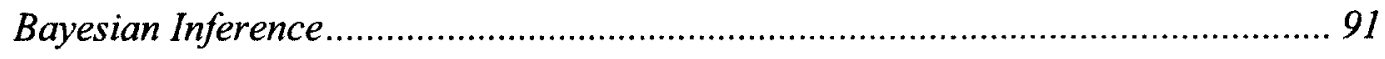

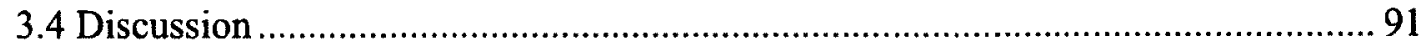

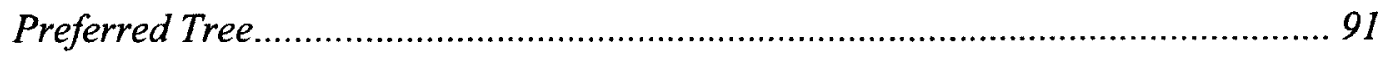

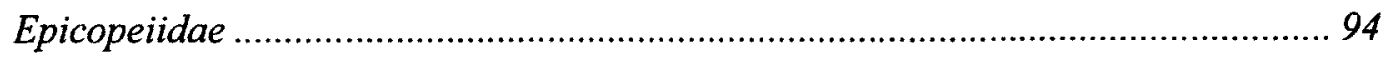

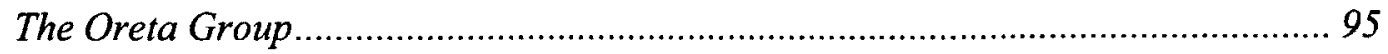




\section{Chapter 4: From Walking to Talking: The Evolutionary ORIgin OF ANal}

SCRAPING SIGNALS IN DREPANIDAE CATERPILLARS ........................................................ 97

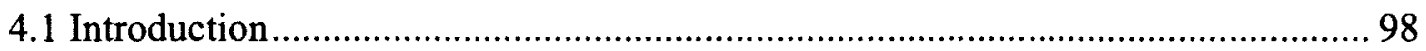

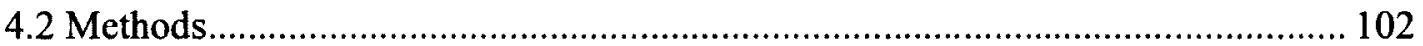

Phylogenetic mapping of anal segment behaviour and anatomy ......................... 102

Comparison of vibrations to assess signal ritualization ……………..................... 103

Comparison of behavioural sequences .............................................................. 105

Kinematics and musculature of anal segment movement ..................................... 105

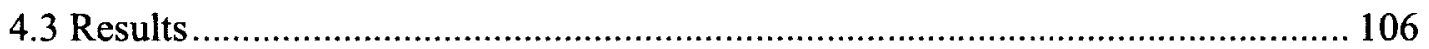

Comparative anatomy of the anal segment for mapping ....................................... 106

Phylogenetic mapping of anal segment anatomy ................................................ 109

Comparative behaviour of the anal segment during conspecific interactions ....... 116

Mapping of behavioural characters................................................................. 122

Comparison of vibrations to assess ritualization................................................. 125

Comparison of behavioural sequences to test the hypothesis that anal scraping

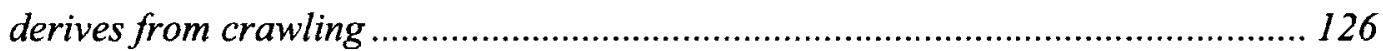

Kinematics of anal segment movements in Tethea or (crawling) and Drepana

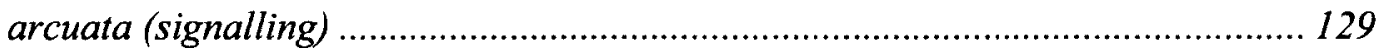

Comparison between crawling and signalling ................................................ 133

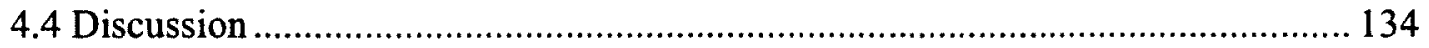

Testing the hypothesis that anal scraping derives from crawling ........................ 135

The evolutionary transition from crawling to signalling ...................................... 139

Mechanistic transition from walking to talking .................................................... 145 


\section{Chapter 5: From HitTing TO SCRAPING: The Evolutionary ORIGiN OF}

Mandible Scraping in Drepanidae Caterpillars................................................ 149

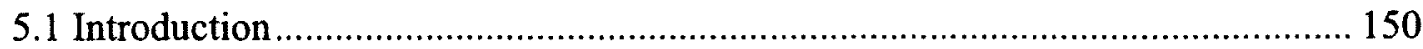

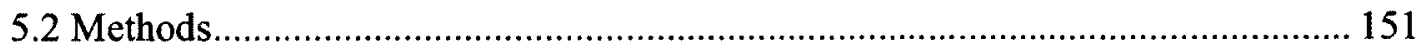

Phylogenetic mapping of anterior segment behaviour and mandible morphology 151

Comparison of kinematics of movements between anterior body behaviours....... 152

Comparisons of vibrations to assess signal ritualization ............................... 153

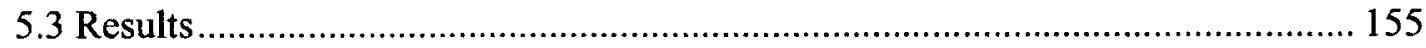

Comparative morphology of the mandibles for mapping ................................ 156

Phylogenetic mapping of mandible morphology ........................................... 156

Comparative behaviour of the anterior body segments during conspecific

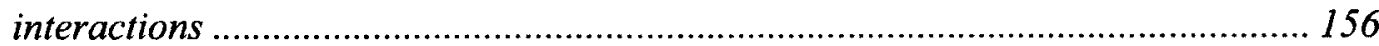

Phylogenetic mapping of behavioural characters ........................................... 165

Comparison of movements between behaviours .............................................. 168

Comparisons of vibrations to assess ritualization ......................................... 169

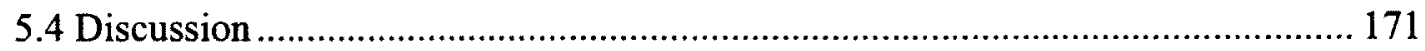

Mapping mandible morphology and anterior body behaviours ....................... 171

Testing the hypothesis that mandible scraping derives from lateral head hitting.. 174

Proposed evolutionary transitions in behaviour........................................... 176

Comparison of vibrations to assess ritualization.......................................... 177

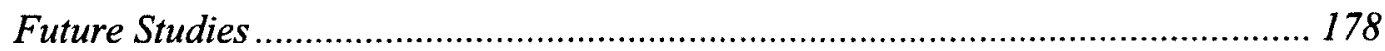

Chapter 6: The Evolution OF Vibratory Communication Signals in

DRePanidae CaterPillars: Ultimate QUESTIONS................................................. 179 


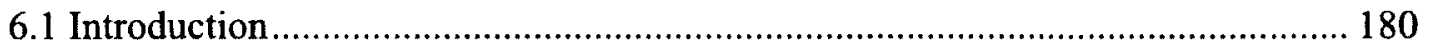

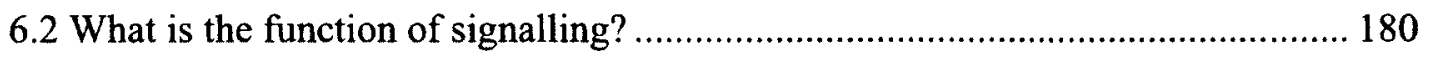

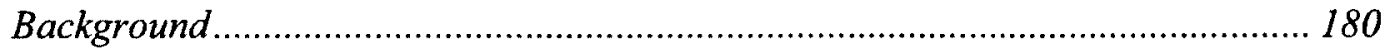

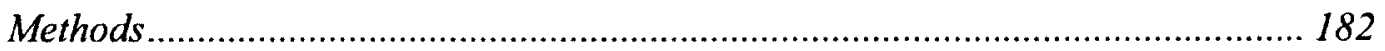

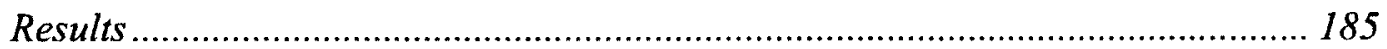

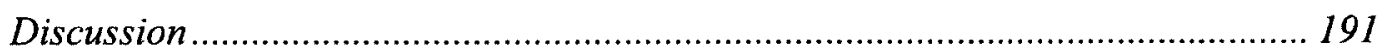

6.3 Why produce more than one type of signal? .................................................. 194

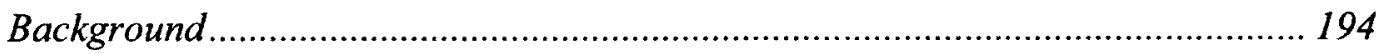

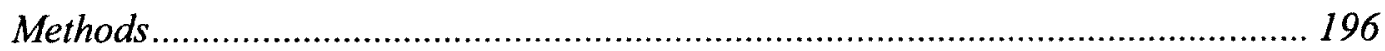

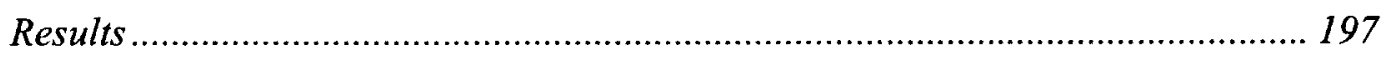

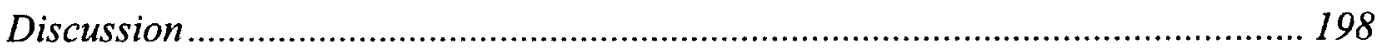

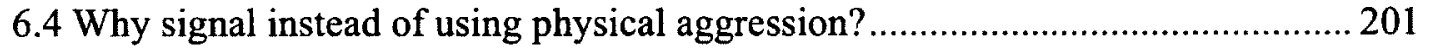

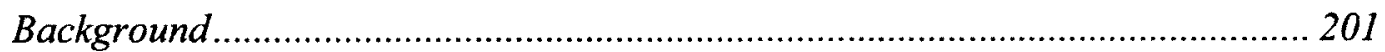

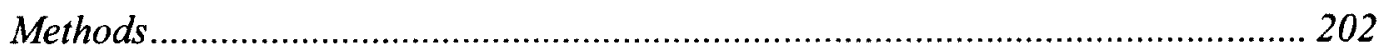

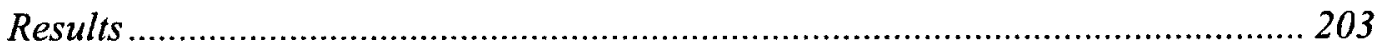

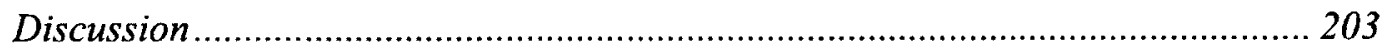

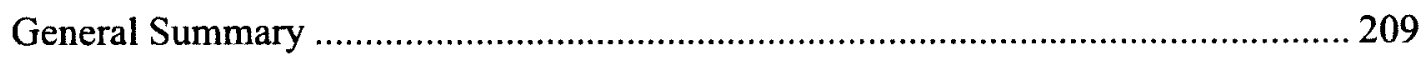

CHAPTER 7: GENERAL SUMMARY AND CONCLUSIONS...................................................... 211

REFERENCES............................................................................................................................. 217

APPENDIX A: GENERAL LIFE-HistoRy, MORPHOLOGY AND BEHAVIOUR OF

ADDITIONAL DREPANIDAE SPECIES …........................................................................ 235

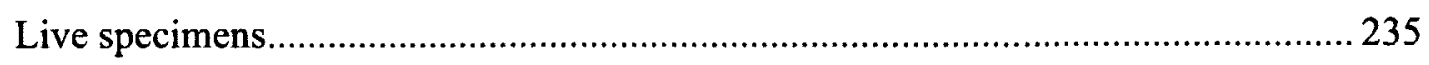

Drepana curvatula (Drepaninae) ...................................................................... 235 


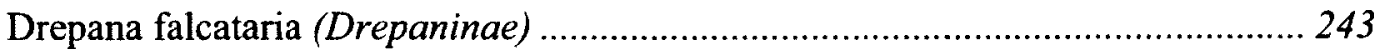

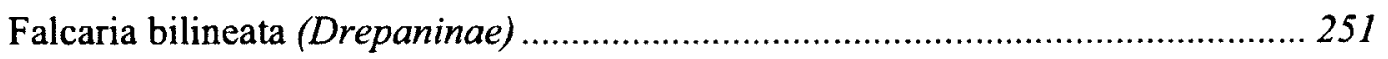

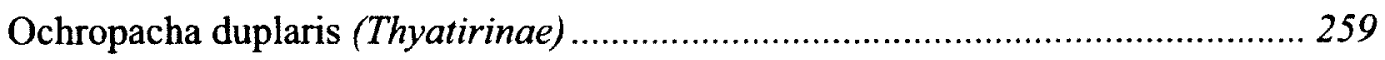

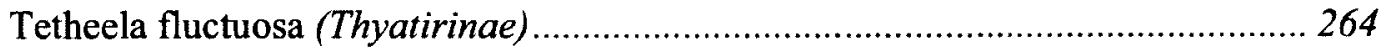

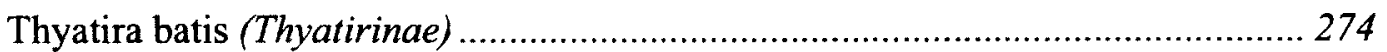

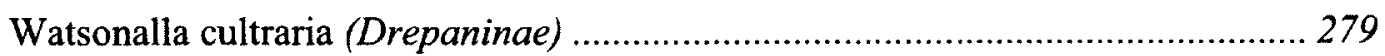

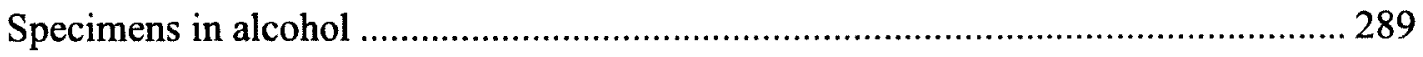

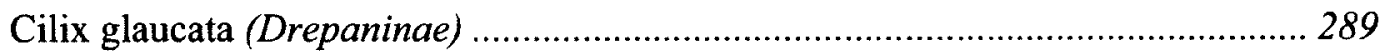

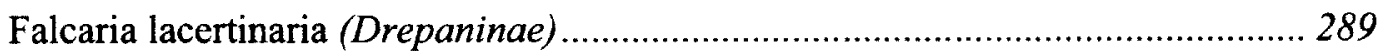

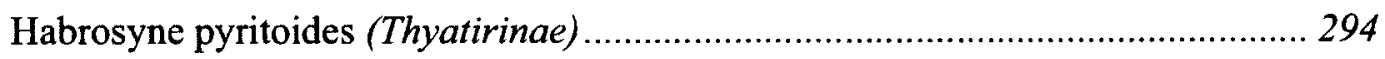

Watsonalla binaria (Drepaninae) ...................................................................... 294

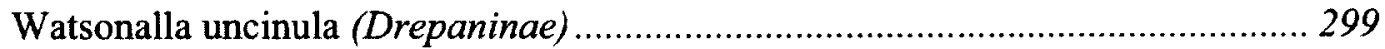

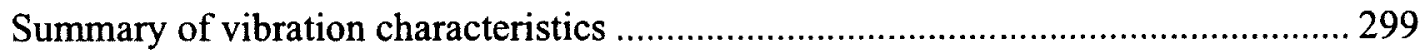

APPENDIX B: Sequence DATa USEd for Phylogenetic ANALYSIS............................ 306 APPENDIX C: MUSCleS Of THE ANAL SEgMENT IN DREPANA ARCUATA AND TETHEA OR 329

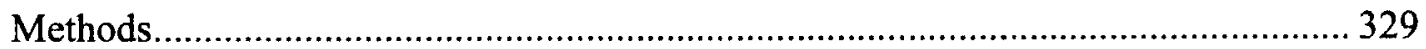

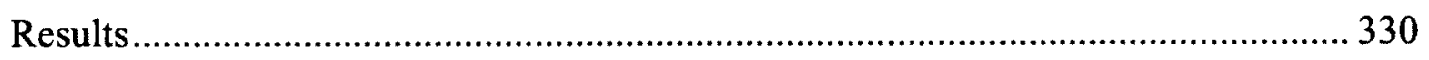

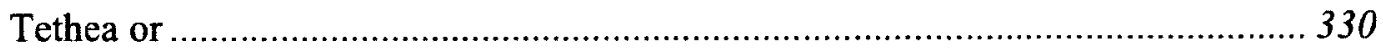

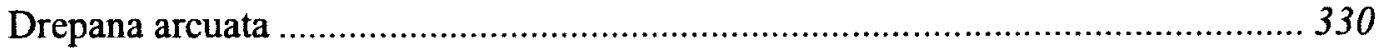




\section{LIST OF TABLES}

2.1 SOURCES OF SPECIMENS.......................................................................................................... 17

2.2 SUMMARY OF LIFE-HISTORY CHARACTERS FOR ALL SPECIES ....................................... 59

2.3 SUMMARY OF MORPHOLOGY CHARACTERS FOR ALL SPECIES ....................................... 62

2.4 OUtCOMES AND OTHER DETAILS OF TRIALS IN 10 SPECIES ............................................. 65

2.5 SUMMARY OF BEHAVIOURAL REPERTOIRES FOR 10 SPECIES ........................................ 67

3.1 Molecular GeneTIC SPECIMEN DaTA .......................................................................... 79

3.2 PRIMER SEQUences USEd for MOLECULAR PhYLOGENETICS ....................................... 84

3.3 SUMMARY OF RESULTS FROM PARSIMONY ANALYSIS ................................................... 87

4.1 CATEGORIES OF VARIATION IN PP1 SETAE ....................................................................... 112

4.2 Summary of ANAL Segment Behavioural Characteristics AND Associated

VIBRATIONS........................................................................................................................... 120

5.1 SUMMARY OF ANTERIOR BODY BEHAVIOURAL CHARACTERISTICS AND ASSOCIATED

VIBRATIONS................................................................................................................................ 162

6.1 Summary of Ultimate Questions, HyPotheSES AND PREDICTIONS ........................ 181

6.2 Dominant Signal TYPES By StAGE OF INTRUDER APPROACH.................................... 199

6.3 SUMMARY OF UlTIMATE QUESTIONS AND FINDINGS ................................................... 210

A.1 Summary of Behavioural ChaRACTERISTICS for 10 SPECIES ................................ 302 


\section{LIST OF FiguRES}

2.1 EXPERIMENTAL SET-UP FOR BEHAVIOURAL TRIALS ............................................. 21

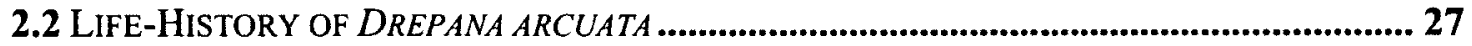

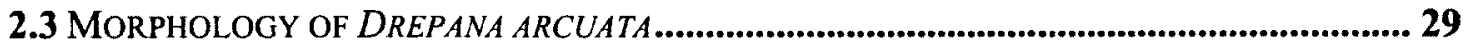

2.4 TERRITORIAL BEHAVIOUR OF DREPANA ARCUATA...................................................... 32

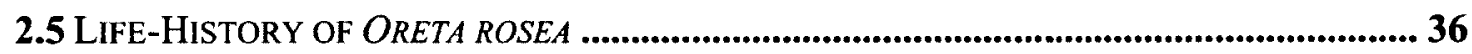

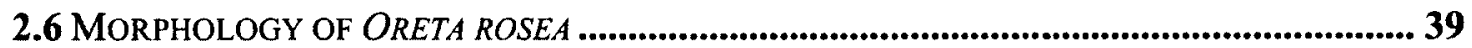

2.7 TERRITORIAL BEHAVIOUR OF ORETA ROSEA .............................................................. 41

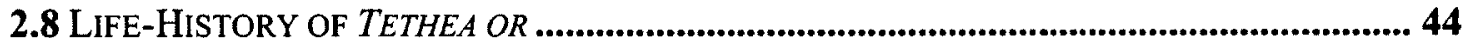

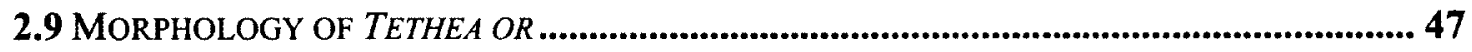

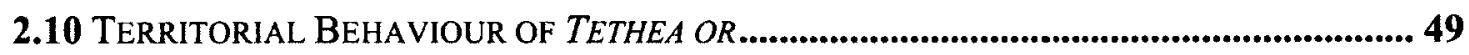

2.11 LIFE-HISTORY OF CYCLIDIA SUBSTIGMARIA ................................................................ 53

2.12 MORPHOLOGY OF CYCLIDIA SUBSTIGMARIA ........................................................... 55

2.13 TERRITORIAL BEHAVIOUR OF CYCLIDIA SUBSTIGMARIA .......................................58

3.1 Phylogenetic TRee of Drepanidae USing Parsimony ........................................ 89

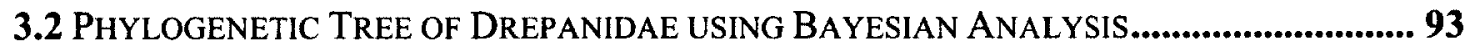

4.1 SUMMARY OF SIGNALLING IN DREPANA ARCUATA

4.2 SumMaRy OF MORPhOlOGICAL CONDITIONS OF THE ANAL SEGMENT ....................... 108

4.3 SUMMARY OF MORPhOlogiCAl CONDITIONS OF THE PP1 SETAE ............................. 111

4.4 MAPPING OF MoRPhological CONDITIONS OF THE ANAL SEGMENT ....................... 114

4.5 SUMMARY OF ANAL SEGMENT BEHAVIOURS AND THEIR ASSOCIATEd VibRATIONS.. 118

4.6 MAPPING OF ANAL SEGMENT BEHAVIOURS.................................................... 124 
4.7 COMPARISON OF KINEMATICS OF ANAL SCRAPING AND CRAWLING IN Two

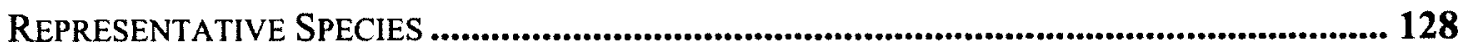

4.8 COMPARISON OF SEQuences OF BeHAVIOUR IN Two RePrESENTATIVE SPECIES ..... 131

4.9 MODEL FOR THE EVOLUTIONARY TRANSITION FROM CRAWLING TO ANAL SCRAPING142

5.1 SUMMARY AND MAPPING OF MANDIBLE MORPHOLOGY.......................................... 158

5.2 SUMMARY OF BEHAVIOURS OF THE ANTERIOR BODY AND THEIR ASSOCIATED

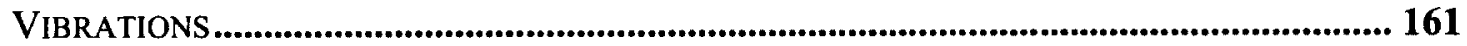

5.3 MAPPING OF ANTERIOR BODY BEHAVIOURS ....................................................... 167

6.1 REPRESENTATIVE AND AVERAGE TRIALS IN FALCARIA BILINEATA ............................. 187

6.2 COMPARISON OF Signalling AND AGgREsSive BeHAVIOUR RATES By SHELTER TyPE

6.3 COMPARISON OF RATIO OF SIGNALLING TO AGgRESSIVE BEHAVIOUR BY EgG-LAYING

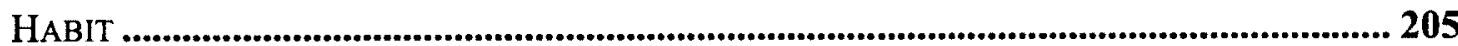

6.4 COMPARISON OF RATIO OF SigNALLING to AGGRESSIVE BEHAVIOUR BY

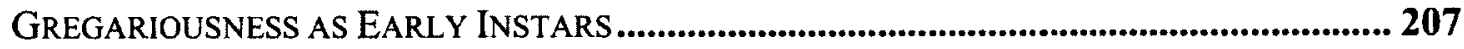

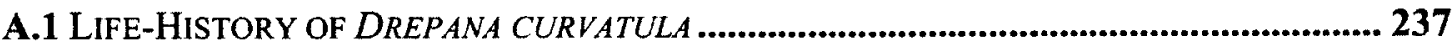

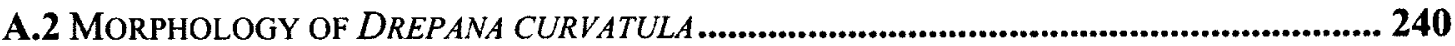

A.3 TERRITORIAL BEHAVIOUR OF DREPANA CURVATULA .............................................. 242

A.4 LIFE-HISTORY OF DREPANA FALCATARIA _.................................................................... 245

A.5 MORPHOLOGY OF DREPANA FALCATARIA _................................................................ 247

A.6 TERRITORIAL BEHAVIOUR OF DREPANA FALCATARIA ............................................. 250

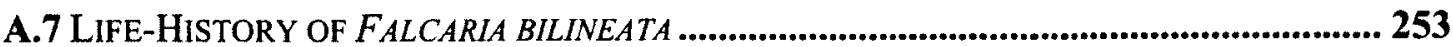

A.8 MORPHOLOGY OF FALCARIA BILINEATA .................................................................... 255 
A.9 TERRITORIAL BEHAVIOUR OF FALCARIA BILINEATA .................................................. 258

A.10 LIFE-HISTORY OF OCHROPACHA DUPLARIS ........................................................ 261

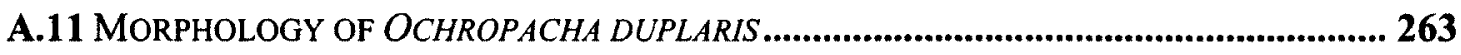

A.12 TERRITORIAL BeHAVIOUR OF OCHROPACHA DUPLARIS ..................................... 266

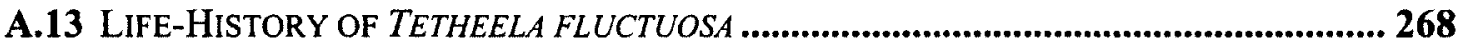

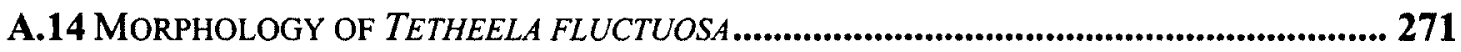

A.15 TERRITORIAL BeHAVIOUR OF TETHEELA FLUCTUOSA ........................................ 273

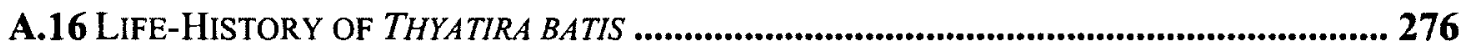

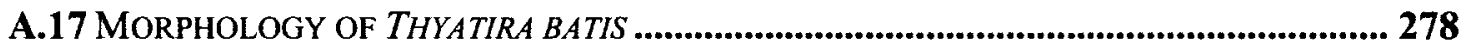

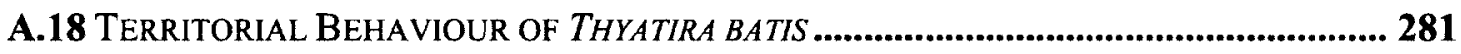

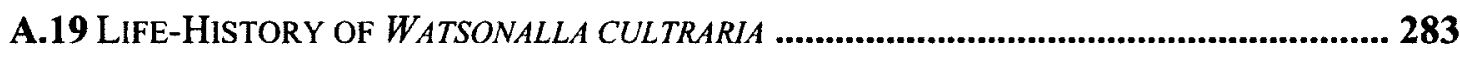

A.20 MORPHOLOGY OF WATSONALLA CULTRARIA ............................................................. 286

A.21 TERRITORIAL BEHAVIOUR OF WATSONALLA CULTRARIA ........................................ 288

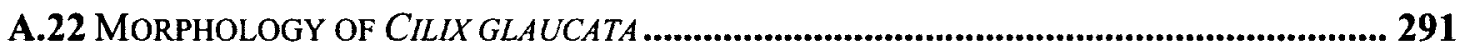

A.23 MORPHOLOGY OF FALCARIA LACERTINARIA …................................................... 293

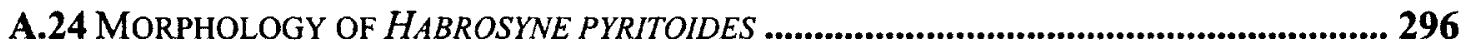

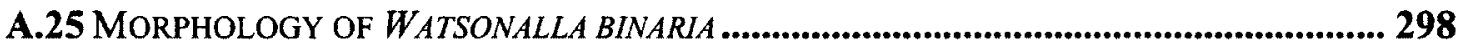

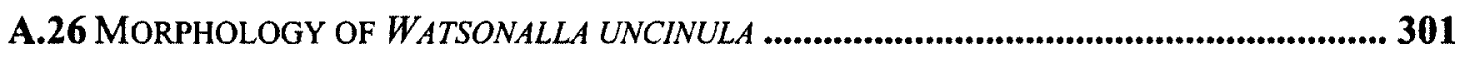

C.1 Muscles of the AnAL Segment in DREPANA ARCUATA AND TETHEA OR................ 332 


\section{LIST OF APPENDICES}

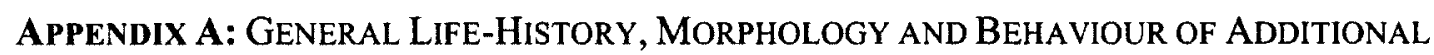

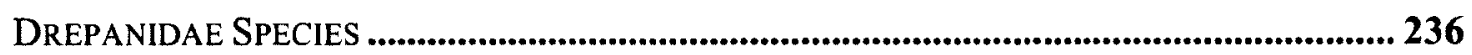

APPENdix B: SEquence DAta USEd for Phylogenetic ANALYSIS ........................... 307

APPENDix C: MUSCLES OF THE ANAL SEgMENT IN DREPANA ARCUATA AND TETHEA OR 330 


\section{List of Publications}

\section{This thesis forms the following published manuscripts:}

1. Scott, J. L., Matheson, S. M. \& Yack, J. E. (2010). Variation on a theme: Vibrational signalling in the rose hook-tip moth caterpillar, Oreta rosea. Journal of Insect Science 10, 54; available online: insectscience.org/10.54

Statement of Contribution: J. Scott collected and analyzed most of the data, prepared the figures and helped write the paper; S. Matheson contributed to data analysis; and J. Yack developed the concepts and helped write the paper.

2. Scott, J. L., Kawahara, A. K., Skevington, J. H., Yen, S. -H., Sami, A., Smith, M. L. \& Yack, J. E. (2010). The evolutionary origins of ritualized acoustic signals in caterpillars. Nature Communications 1, 4; doi: 10.1038/ncomms 1002.

Statement of Contribution: J. Scott collected and analyzed most of the data, performed phylogenetic analyses, prepared the figures and helped write the paper; A. Kawahara helped with taxa and gene choice, provided specimens and helped with phylogenetic analysis; J. Skevington helped with phylogenetic analysis; S.-H. Yen provided specimens and helped with logistics; A. Sami helped sequence some of the taxa; M. Smith contributed to molecular data collection and phylogenetic analysis; and J. Yack helped develop concepts and write the paper.

3. Scott, J. L. \& Yack, J. E. (2012). Vibratory territorial signals in caterpillars of the poplar lutestring, Tethea or (Lepidoptera: Drepanidae). European Journal of Entomology, 109: 411-417.

Statement of Contribution: J. Scott collected and analyzed all of the data, prepared the figures and helped write the paper; and J. Yack developed the concepts and helped write the paper.

\section{This thesis will also form the following manuscripts:}

4. Scott, J. L. \& Yack, J. E. Caterpillars talk their walk: How vibratory signals evolved from crawling movements in caterpillars (Lepidoptera: Drepanidae) (in preparation for submission to the Journal of Experimental Biology in October, 2012)

Statement of Contribution: J. Scott collected and analyzed all of the data, prepared the figures and helped write the paper; and J. Yack developed the concepts and helped write the paper. 
5. Scott, J. L., Kawahara, A. K., Skevington, J. H., Yen, S. -H., Sami, A., Smith, M. L. \& Yack, J. E. Molecular phylogeny of Drepanidae (in preparation, journal to be decided)

Statement of Contribution: J. Scott sequenced most of the taxa, helped performed phylogenetic analyses, prepared the figures and helped write the paper; A. Kawahara helped with taxa and gene choice, provided specimens, helped with phylogenetic analysis, and helped write the paper; J. Skevington helped with phylogenetic analysis; S.H. Yen provided specimens and helped with logistics; A. Sami helped sequence some of the taxa; M. Smith contributed to molecular data collection and phylogenetic analysis; and J. Yack helped develop concepts and write the paper. 


\section{LIST OF ABBREVIATIONS}

\begin{tabular}{|c|c|}
\hline Abbreviation & Full Name \\
\hline A & abdominal segment \\
\hline ANOVA & analysis of variance \\
\hline AS & anal scraping \\
\hline B & buzzing \\
\hline BS & Bremer support \\
\hline $\mathrm{CAD}$ & $\begin{array}{l}\text { gene that encodes carbamoyl phosphate synthase II, } \\
\text { aspartate carbamoyltransferase, and dihydroorotase }\end{array}$ \\
\hline $\mathrm{CI}$ & consistency index \\
\hline $\mathrm{COI}$ & cytochrome oxidase I \\
\hline COII & cytochrome oxidase II \\
\hline CTAB & cetrimonium bromide \\
\hline $\mathrm{D}(1,2)$ & dorsal seta (1 or 2) \\
\hline $\mathrm{dB}$ & decibel \\
\hline df & degrees of freedom \\
\hline $\mathrm{dH}_{2} \mathrm{O}$ & distilled water \\
\hline $\mathrm{DL}$ & dorsal longitudinal muscles \\
\hline DNA & deoxyribonucleic acid \\
\hline dNTP & deoxyribonucleotide triphosphate \\
\hline EDTA & ethylenediaminetetraacetic acid \\
\hline $\mathrm{EF}-1 \alpha$ & elongation factor 1 alpha \\
\hline $\mathrm{EtOH}$ & ethanol \\
\hline $\mathrm{GTR}+\mathrm{G}$ & generalized time reversible + gamma model \\
\hline $\mathrm{GTR}+\mathrm{I}+\mathrm{G}$ & $\begin{array}{l}\text { generalized time reversible }+ \text { proportion invariant }+ \\
\text { gamma model }\end{array}$ \\
\hline HMDS & hexamethyldisilazane \\
\hline I & intruder \\
\hline JKS & jackknife support \\
\hline $\mathrm{L}$ & treelength \\
\hline$L(1-3)$ & lateral seta $(1,2$, or 3$)$ \\
\hline LDV & laser doppler vibrometer \\
\hline LHH & lateral head hitting \\
\hline LT & lateral tremulation \\
\hline LTH & lateral tail hitting \\
\hline M & molar \\
\hline MD & mandible drumming \\
\hline $\mathrm{mg}$ & milligrams \\
\hline $\mathrm{MgCl}_{2}$ & magnesium chloride \\
\hline $\mathrm{mL}$ & millilitres \\
\hline $\min$ & minutes \\
\hline $\mathrm{mm}$ & millimetres \\
\hline MPT & most parsimonious tree \\
\hline MS & mandible scraping \\
\hline
\end{tabular}




$\begin{array}{ll}n & \text { sample size } \\ \mathrm{NaCl} & \text { sodium chloride } \\ \mathrm{NADH} & \text { nicotinamide adenine dinucleotide } \\ \mathrm{ND} 1 & \text { NADH-dehydrogenase subunit } 1 \\ \mathrm{nt3} & \text { third codon position } \\ P & \text { probability } \\ \mathrm{PCR} & \text { polymerase chain reaction } \\ \mathrm{PP} & \text { posterior probability } \\ \mathrm{PP} 1 & \text { posterior proctor seta 1 } \\ \mathrm{PRM} & \text { planta retractor muscle } \\ \mathrm{rDNA} & \text { nuclear ribosomal DNA } \\ \mathrm{R} & \text { resident } \\ \mathrm{rel} & \text { relative } \\ \mathrm{RI} & \text { retention index } \\ \mathrm{rRNA} & \text { ribosomal ribonucleic acid } \\ \mathrm{S} & \text { seconds } \\ \mathrm{SEM} & \text { scanning electron micrograph } \\ \mathrm{SD} & \text { standard deviation } \\ \mathrm{SD}(1,2) & \text { sub-dorsal seta }(1 \text { or } 2) \\ \mathrm{SPL} & \text { sound pressure level } \\ \mathrm{SV}(1-4) & \text { sub-ventral seta }(1,2,3, \text { or } 4) \\ \mathrm{TBR} & \text { tree bissection-reconnection } \\ \mathrm{V} 1 & \text { ventral seta 1 } \\ \mathrm{VL} & \text { ventral longitudinal muscles } \\ 28 \mathrm{~S} \text { D2 } & \text { D2 expansion segment of the 28S rRNA gene } \\ \mu \mathrm{L} & \text { microlitre } \\ \mu \mathrm{m} & \text { micrometres } \\ { }^{\circ} \mathrm{C} & \text { degrees Celsius }\end{array}$


CHAPTER 1

GENERAL INTRODUCTION 


\subsection{The evolutionary origins of animal communication signals}

Communication can play an important role in the survival and reproduction of all animals. Although there has been significant debate on a formal definition of animal communication (reviewed in Scott-Phillips, 2008; Carazo \& Font, 2010), most authors agree that it should center around an adaptationist approach (as opposed to an informational approach; e.g. Dawkins \& Krebs, 1978; Krebs \& Dawkins, 1984; Grafen, 1990; Krebs \& Davies, 1993; Hasson, 1994; Bradbury \& Vehrencamp, 1998; Greenfield, 2002; Maynard Smith \& Harper, 2003; Scott-Phillips, 2008) and that it must involve the transmission of a signal from a sender to a receiver. The most widely used definition of a signal was put forth by Maynard Smith \& Harper in 2003 as: 'any act or structure which alters the behaviour of other organisms, which evolved because of that effect, and which is effective because the receiver's response has also evolved'. Recent reviews have suggested that this standard definition should be modified to include the stipulation that the signal is effective because the effect (the response) has evolved to be affected by the act or structure (and not simply evolved due to other factors) (Scott-Phillips, 2008) to distinguish communication from other phenomena, and that it is effective because it transfers (functional) information to receivers (Carazo \& Font, 2010) to incorporate an informational approach.

Distinguishing signals from 'cues' has also been a topic of debate. A cue can be defined as 'any feature of the world, animate or inanimate, that can be used by an animal as a guide to future action' (Hasson, 1994). Authors distinguish cues from signals in three main ways: i) some believe cues are permanently 'on', while signals can be switched 'on' and 'off' depending on the circumstances (Hauser, 1996); and ii) that once a cue has been 
produced, it costs nothing extra to express it, whereas signalling can impose additional costs (Hauser, 1996); iii) others agree that cues have not evolved to alter the behaviour of other animals (Galef \& Giraldeau, 2001). This latter distinguishing feature concurs with Maynard-Smith and Harper's (2003) definition of a signal in that 'it has evolved for that effect' and suggests that signals are intentional, while cues are not. Signals that are conspicuous, highly redundant, stereotyped, and carrying alerting components (Wiley, 1983; Johnstone, 1997) are said to have undergone 'ritualization', an evolutionary process whereby cues are converted to signals (Tinbergen, 1952). These characteristics make signals more efficient by increasing the reliability of detection (Wiley, 1983; Johnstone, 1997). An increase in conspicuousness, such as an increase in the amplitude of an acoustic signal, can improve the chance a receiver will detect a signal, even in noisy environments. High redundancy, which can involve repeating a signal or using multiple signals for the same function, can reduce errors in the detection and recognition. An increase in stereotypy, such as a reduction in the variation of the duration of a signal, allows receivers to better distinguish signals from other similar behaviours. Finally, ritualized signals are often preceded by alerting components, a conspicuous component that alerts the receiver of the impending signal. For example, orangutans will violently throw tree branches to the ground, making a loud noise, before calling to conspecifics (Galdikas, 1979), and many lizards will begin head-bobbing signals with large amplitude, fast movements, followed by more subtle, species-specific movements (Fleishman, 1992).

Ethologists have been interested in the evolutionary origins of communication signals since Darwin's seminal book "The Expression of the Emotions in Man and 
Animals". This paper motivated early ethologists such as Lorenz, Tinbergen and Huxley to start thinking about how animal communication signals have originated and evolved. It is hypothesized that many signals are derived from non-signalling behaviours, or cues, that have undergone ritualization (Tinbergen, 1952; Johnstone, 1997; Bradbury \& Vehrencamp, 1998; Maynard Smith \& Harper, 2003). Animals can provide cues to other individuals in a variety of contexts, and receivers may pick up on those associated with both physiological (thermoregulation, respiration, urination and defecation, pupil dilation, and yawning) and behavioural (intention movements, protective movements, redirection, and displacement behaviours) states of the signaler (Morris, 1956; Brown, 1975; Bradbury \& Vehrencamp, 1998; Maynard Smith \& Harper, 2003). For example, cues associated with preparing for flight in birds are often ritualized into many different types of signals, including alerting the flock of an imminent attack (Maynard Smith \& Harper, 2003).

The process of signal evolution can be thought of as an evolutionary arms race between the signaler and receiver. Krebs and Dawkins (1984) suggested the notion of mind-reading and manipulation, whereby, simply put, the receiver acts as a mind-reader, anticipating the future behaviours of the sender using behavioural cues. Manipulation evolves as a response to mind-reading, whereby the sender exploits the mind-reading capabilities of the receiver to alter their behaviour. For example, a dog tends to uncover its teeth in preparation for a bite. If receivers are able to pick up on this cue, no matter how subtle, they can predict the future behaviour of the sender (an attack) and retreat. The sender, or manipulator, can then alter the behaviour of the receiver, by causing the receiver to retreat by simply baring its teeth. As such, baring teeth evolves as a signal of 
aggression in dogs, and becomes more conspicuous, redundant and stereotyped through ritualization.

Many signals have been traced back to their non-signalling origins through a comparative analysis of behaviours. Early reports on signal origins tend to be quite anecdotal, where similarities in movements between a behaviour and a signal, often involving comparisons within a species, would suffice as evidence. For example, threat displays in Herring gulls, Larus argentatis, have been hypothesized to originate from behaviours associated with physical aggression. By comparing movements within a single species, it has been proposed that the 'upright threat posture' is derived from movements associated with striking an opponent, including a downward pointing of the bill and slightly raised wings, and movements involved in appeasement (Tinbergen, 1959). Researchers then began to expand their comparative analysis to include multiple closely-related species. One such study focuses on fiddler crabs from the genus Uca, which employ a variety of threat displays, involving the major cheliped, to defend burrows from conspecifics (Crane, 1966). By highlighting similarities between movements associated with territoriality between species, Crane suggests that fiddler crab threat displays derive from grasping movements, more specifically behaviours associated with seizing food, prey, or predators. Another study examining the evolutionary origins of a signal by looking at the variation in behaviours between closely-related species concentrated on the tail-fan display of the peacock, Pavo cristatus, which functions in courtship (Schenkel, 1956). Schenkel observed variation in courtship displays between species of Phasianidae, ranging from ground-pecking and offering food to females, mock-pecking and manipulation of food without presenting it to females, rhythmical 
pecking followed by posing with the head bowed and tail feathers fanned, to a low bow and tail-fan with extreme tail elongation, as seen in peacocks. Although these behaviours do not constitute an evolutionary series as the phylogenetic relationship between species is unknown, it has been hypothesized that the peacock tail-fan display derives from pecking at the ground and offering food to females, and that multiple intermediate stages exist between the basal behaviour and ritualized signal. The former two studies provide more concrete evidence for the origins of a signal by comparing behaviours across many closely-related species, but specifics on the phylogenetic relationships between taxa were unknown. Phylogenetic information is important for studying the evolutionary origins of a signal, as it provides a framework onto which one can trace the evolutionary history of a behaviour. Most studies of this nature also do not attempt to characterize and compare kinematics of movements in any detail between signals and their basal behaviours, relying on superficial similarities to hypothesize on signal origins. Therefore, studies focusing on the evolutionary origins of signals that combine phylogenetic analysis with detailed comparisons of movements and behaviours across closely-related taxa are currently needed.

\subsection{Drepanoidea as a model system for studying signal origins}

The superfamily Drepanoidea, a large assemblage of moths containing more than 1400 described species (Minet \& Scoble, 1999), provides an excellent model system for studying the origin and evolution of communication signals. In a previous study it was shown that the larvae of one species, Drepana arcuata, use vibratory signalling to resolve territorial disputes with conspecifics over silken leaf shelters (Yack et al., 2001). Solitary 
late instar caterpillars occupying shelters produce three distinct signals - mandible drumming, mandible scraping and anal scraping - that escalate as the intruder approaches the resident. This was the first experimental study to demonstrate that caterpillars employ acoustic signals to advertise ownership of a territory. Although vibratory signals have only been studied in one Drepanidae species to date, there is abundant indirect evidence from various descriptive morphological reports (Nakajima, 1970; 1972; I. Hasenfuss, personal communication) and behavioural observations (Dyar, 1895; Federley, 1905; Bryner, 1999; Sen \& Lin, 2002; I. Hasenfuss, personal communication; personal observations) that signalling and signalling structures are both widespread and highly variable in the Drepanidae. Previously documented territorial behaviours range from physical aggression, including biting and hitting (I. Hasenfuss, personal communication) to complex signalling, as in $D$. arcuata (Yack et al., 2001). This range of territorial behaviours has led me to the hypothesis that vibratory signals in the Drepanidae are derived from movements associated with more physically aggressive behaviors, including hitting, biting and pushing, perhaps to avoid the costs of physical damage. Due to the purported high degree of variation in behaviour and morphology within the Drepanidae, this system provides an excellent opportunity for testing hypotheses on the ultimate and proximate origins of communication signals. Drepanidae larvae are also ideal study organisms as they are widely distributed, several species have proven to be relatively easy to rear, and many build open shelters allowing for observations to be made without disturbance. 


\subsection{Acoustic communication in larval Lepidoptera}

An additional goal of this research is to provide some much needed general information on acoustic communication in caterpillars. Lepidoptera are highly successful constituents of most terrestrial ecosystems and include some of the most effective pests of economically important plants (Stamp \& Casey, 1993). In order to fully understand the extent of their success, it is important to study all aspects of their biology, including how they communicate with other individuals in their environment. Caterpillars rely on communication at some point in their development to facilitate behaviours associated with foraging, defense, aggregation, shelter building, and/or competition for resources (Costa \& Pierce, 1997; Fitzgerald \& Costa, 1999; Cocroft, 2001; Costa, 2006). Despite the importance of communication, surprisingly little is known about the mechanisms used to broadcast and receive information in caterpillars (Costa \& Pierce, 1997). There is evidence that several species, particularly those travelling in processions, use chemical and tactile cues for communication (e.g. Fitzgerald, 1995; Ruf et al., 2001; Fitzgerald \& Pescador-Rubio, 2002; Colasurdo \& Despland, 2005; Pescador-Rubio et al., 2011). Vision is unlikely to play an important role, as caterpillars have fairly simple eyes capable of discerning crude images only (Warrant et al., 2003). Lepidopteran larvae have also been shown to be capable of discriminating colours (Castrejon \& Rojas, 2010), suggesting that they may use this sense to locate hostplants. However, a recent study demonstrates that this is not the case in the larvae of the Apollo butterfly, Parnassius apollo (Fred \& Brommer, 2010). One sensory modality that remains relatively unexplored in caterpillars is an acoustic sense, and in particular, vibratory communication. 
Acoustic communication in adult Lepidoptera has been broadly studied and serves a variety of social and defensive functions (Minet \& Surlykke, 2003). Research on acoustic communication in larval Lepidoptera is currently limited, but there is increasing evidence that caterpillars use airborne communication during interactions with heterospecifics. Some caterpillars are capable of using filiform sensilla, sensitive to particle displacement, to perceive near-field airborne sounds produced by the wing-beats of approaching predators and parasitoids (Minnich, 1936; Tautz \& Markl, 1978; Taylor, 2009 and references therein). Less is known about sound production in caterpillars, but recent studies and anecdotal reports have shown that silk and hawkmoth (Bombycoidea) caterpillars are capable of producing a variety of airborne sounds (Reed, 1868; Sanborn, 1868; Heinrich, 1979; Brown, 2006; Brown et al., 2007; Bura et al., 2009; Bura, 2010; Bura et al., 2010). These sounds can be produced using a number of mechanisms (reviewed in Bura, 2010) and have been found to function in predatory defense - as acoustic aposematism (e.g. Antheraea polyphemus: Brown et al., 2007; Saturnia pyri: Bura et al., 2009) or to startle vertebrate predators (e.g. Amorpha juglandis: Bura et al., 2011).

Acoustic signals communicated through solids (vibrations) are widespread in small herbivorous insects and are reported in at least 18 orders to date (Cocroft, 2001; Virant-Doberlet \& Cokl, 2004; Cocroft \& Rodriguez, 2005; Hill, 2009). These vibrations are mostly inaccessible to humans without specialized recording equipment, and therefore many vibratory signals in insects have yet to be described. In larval Lepidoptera there is increasing experimental evidence for vibrational communication in a number of species from different taxa. The functions of these signals include facilitating mutualistic 
relationships with ants (Lycaenidae and Riodinidae butterfly larvae: (DeVries, 1990; 1991; Travassos \& Pierce, 2000; Pierce et al., 2002) and advertising territorial ownership (Tortricidae: Sparganothis pilleriana (Russ, 1969); Drepanidae: D. arcuata (Yack et al., 2001), Falcaria bilineata (Bowen et al., 2008); and Gracillariidae: Caloptilia serotinella (Fletcher et al., 2006)). Beyond these examples, there is abundant inferential evidence for vibrational communication in caterpillars (e.g. Packard, 1890; Federley, 1905; Dumortier, 1963; Hunter, 1987), and the phenomenon is thought to be widespread. More research in this field is required to determine the extent and variation of vibrational communication in caterpillars.

\subsection{Thesis objectives}

The overarching goals of my research are two-fold: 1) to use the superfamily Drepanoidea to study the proximate and ultimate mechanisms involved in the evolution of communication signals; and 2) to provide novel information on vibratory signalling in different species of caterpillars. In order to test hypotheses on the evolutionary origins of signalling in the Drepanoidea, it is necessary to first gain an understanding of the extent of variation in territorial behaviour, signalling and signalling structures in this group. This will be the primary focus of Chapter 2, which will also provide much needed information on vibratory signalling in caterpillars. In Chapter 3, I will present a molecular phylogeny of the Drepanoidea that will be used in later chapters to test hypotheses related to the evolutionary origins of signals. By comparing morphology, behaviours, movements, and signal characteristics within a phylogenetic context, Chapters 4 and 5 will respectively test the hypotheses that the anal scraping signal derives from crawling, and that mandible 
and other anterior body signals derive from physically aggressive movements involving the head and mouthparts. Finally, Chapter 6 will examine some of the ultimate questions that arose throughout the course of my studies, including: What is the function of signalling? Why produce more than one type of signal? Why signal instead of using physical aggression?

This study will be the first to resolve phylogenetic relationships within the Drepanoidea using molecular markers, and to use a combination of molecular phylogenetic, behavioural, and morphological data to provide evidence for the mechanisms underlying the evolution and ritualization of a signal from non-signalling origins. It will also advance our knowledge of the function and evolution of vibratory signalling in caterpillars in general, since little is known to date about this form of communication in larval holometabolous insects. 


\title{
ChAPTER 2
}

\author{
VARIATION IN MORPHOLOGY AND BEHAVIOUR ASSOCIATED WITH \\ VIBRATORY Signalling IN DREPANIDAE CATERPILlaRS
}

Parts of this chapter are included the following manuscripts:

Scott, J. L., Matheson, S. M. \& Yack, J. E. (2010). Variation on a theme: Vibrational signalling in the rose hook-tip moth caterpillar, Oreta rosea. Journal of Insect Science 10, 54; available online: insectscience.org/10.54

Scott, J. L., Kawahara, A. K., Skevington, J. H., Yen, S. -H., Sami, A., Smith, M. L. \& Yack, J. E. (2010). The evolutionary origins of ritualized acoustic signals in caterpillars. Nature Communications 1, 4; doi: 10.1038/ncomms 1002.

Scott, J. L. \& Yack, J. E. (2012). Vibratory territorial signals in caterpillars of the poplar lutestring, Tethea or (Lepidoptera: Drepanidae). European Journal of Entomology, 109: 411-417.

Scott, J. L. \& Yack, J. E. Caterpillars talk their walk: How vibratory signals evolved from crawling movements in caterpillars (Lepidoptera: Drepanidae) (in preparation for submission to the Journal of Experimental Biology in October, 2012) 


\subsection{Introduction}

As indicated in Chapter 1, the purpose of this thesis is to study the evolutionary origins of vibratory communication in Drepanoidea caterpillars, as well as to expand the knowledge of the prevalence of vibrational signalling in larval Lepidoptera, since at present, little is known about this mode of communication in larval holometabolous insects. A previous study demonstrated that one species of Drepanoidea, Drepana arcuata, produces three signals (mandible drumming, mandible scraping, and anal scraping) during interactions with conspecifics; these signals function in territorial defense of silken leaf shelters (Yack et al., 2001). Based on my own preliminary observations, and indirect evidence from literature, there is evidence to suggest that vibratory signalling is not only widespread, but also highly variable within the Drepanoidea (see references below). I hypothesize that vibratory signals derive from more physically aggressive behaviours. The first step, and the goal of this chapter, is to characterize the diversity of behaviour and morphological characters related to signalling (or lack thereof) in representative species of the Drepanoidea.

The Drepanoidea comprises two families, Drepanidae and Epicopeiidae, that include species distributed throughout the Northern Hemisphere, but mostly in Palearctic Asia and the Orient (Minet \& Scoble, 1999). The Drepanidae is a large assemblage of moths with approximately 120 genera including three subfamilies: Drepaninae, Thyatirinae, and Cyclidiinae (Minet \& Scoble, 1999). Drepanidae larvae are mostly arboreal feeders that may be gregarious when young (Minet \& Scoble, 1999). Various descriptive morphological reports (Nakajima, 1970, 1970; I. Hasenfuss, personal communication) and behavioural observations (Dyar, 1895; Federley, 1905; Bryner, 
1999; Riegler, 1999; Sen \& Lin, 2002; I. Hasenfuss, personal communication) have suggested that other species, in addition to $D$. arcuata, may produce vibratory signals, while some appear to lack the structures associated with at least one form of signalling. For example, based on morphological descriptions, it appears that the anal prolegs (those occurring on the last abdominal segment), can be fully formed, bearing crochets used for grasping the substrate; reduced, but still bearing crochets; or completely absent (Minet \& Scoble, 1999), as we see in D. arcuata, which uses its anal appendage instead for signalling (Yack et al., 2001). Also, the morphology of a seta, used for signal production in D. arcuata, appears to vary between taxa (Nakajima, 1970, 1972; I. Hassenfuss, personal communication). Although mandibles have been implicated in signalling in some species (Yack et al., 2001; Sen \& Lin, 2002; Bowen et al., 2008; I. Hasenfuss, personal communication), morphology of mandibles has not been described or compared between species. Finally, based on these preliminary reports and my own behavioural observations, there appears to be very interesting variation with respect to how different species interact with conspecifics; while $D$. arcuata exhibits vibration-mediated territorial behaviour (Yack et al., 2001), other species appear to be more physically aggressive (e.g. hitting, biting) (I. Hasenfuss, personal communication).

The variation in the morphology and behaviour associated with signalling or territorial encounters has not been formally documented in most Drepanoidea species, and to do so will be the purpose of this chapter (Chapter 2). This chapter is necessarily descriptive in nature, but forms an important basis for testing hypotheses in later chapters. The information from this chapter will be used in subsequent chapters (Chapters 4 and 5) that focus on the evolutionary origins of signals produced by the anal segment 
and anterior segments, respectively. In this chapter I will also describe some life-history characters that may be relevant to territorial behaviour (e.g. egg-laying, gregarious or solitary behaviour of early and late instars, and shelter-building), and this information will used in Chapter 6 to begin to answer ultimate questions on the evolution of signalling in Drepanidae larvae. In addition, the external morphology of setae on the abdominal prolegs, suggested to be putative vibration receptors (I. Hasenfuss, personal communication), has been noted, since one would expect variation in these structures to differ between those species that do and do not use vibrational communication.

I have collected information on as many species as possible, representing all three subfamilies, from both my own experiments with live caterpillars, and from collections of preserved specimens, as well as from previous literature cited in this introduction. Due to the large amount of data collected on multiple species, I have selected four species that represent all three subfamilies, and exhibit the range of morphology and behaviours that were documented in different species across this study, to describe in detail. Specific details of other species are summarized in tables within this chapter, in subsequent chapters that focus on the origins of different signals, as well as in an appendix (Appendix A). This chapter will be mainly descriptive, and the results will be used to test hypotheses in other chapters.

\subsection{Methods}

Animals

Living and preserved larvae used in this study were obtained from a variety of sources (Table 2.1); as well, some information was obtained from the literature (see 
Tables 2.2, 2.3). When species were reared from eggs, gravid females were collected from the wild at ultraviolet collecting lights and females oviposited on cuttings of their respective hostplant. Larvae were reared indoors on cuttings of their hostplant under a L:D $18: 6 \mathrm{~h}$ photoperiod at $21-26^{\circ} \mathrm{C}$ in an insect rearing facility. When possible, early instars (1-2) were studied for life-history traits. Late instars (3-5) were studied for lifehistory traits, as well as their morphological and behavioural characteristics.

General life history observations relevant to conspecific interactions

Selected life history traits were documented if they were deemed to be relevant to conspecific interactions. These included notes on egg-laying behaviour (whether adults lay eggs in rows, groups or singly), gregariousness as early or late instars, shelterbuilding behaviours as late instars (type of shelter, including no shelter, mat of silk, folded/rolled leaf, or two leaves sewn together), and hostplants. In 11 species I obtained most of this information from live specimens, and in others, from the literature (see Table 2.2).

\section{Morphology}

External morphology of the anal segment (abdominal segments 7-10), mandibles, head, and abdominal prolegs were examined in larvae preserved in $80 \%$ ethanol in 19 species (using between one and five specimens per species). Drawings of the anal segment and abdominal prolegs were made using a drawing tube (attached to a Wild Heerbrugg M7A microscope; Aargau, Switzerland). Setae of the anal segment were identified and labeled following the nomenclature described by Stehr (1987). 
Table 2.1. Sources of living and preserved specimens used for morphological and behavioural data.

\begin{tabular}{|c|c|c|c|c|}
\hline \multirow[t]{2}{*}{ Taxon } & \multicolumn{2}{|c|}{ Morphology } & \multicolumn{2}{|c|}{ Live Larvae for Behaviour } \\
\hline & Origin & Collector & Origin & Collector \\
\hline \multicolumn{5}{|l|}{$\begin{array}{l}\text { INGROUP TAXA } \\
\text { Cyclidiinae }\end{array}$} \\
\hline $\begin{array}{l}\text { Cyclidia substigmaria } \\
\text { substigmaria }\end{array}$ & $\begin{array}{l}\text { Chuncheon, Gugok- } \\
\text { Pokpo, Gangwong } \\
\text { Province, Korea }\end{array}$ & J. C. Sohn & China & S-H. Yen \\
\hline \multicolumn{5}{|l|}{ Drepaninae } \\
\hline Cilix glaucata & $\begin{array}{l}\text { Erlangen, Northern } \\
\text { Bavaria, Germany }\end{array}$ & I. Hasenfuss & NA & NA \\
\hline Drepana arcuata & Ottawa, Canada & J. Yack & Ottawa, Canada & various collectors \\
\hline Drepana curvatula & Netherlands & $\begin{array}{l}\text { S. Corver \& T. } \\
\text { Muus }\end{array}$ & Netherlands & $\begin{array}{l}\text { S. Corver \& T. } \\
\text { Muus }\end{array}$ \\
\hline Drepana falcataria & $\begin{array}{l}\text { Erlangen, Northern } \\
\text { Bavaria, Germany }\end{array}$ & I. Hasenfuss & Netherlands & $\begin{array}{l}\text { S. Corver \& } \mathrm{T} \text {. } \\
\text { Muus }\end{array}$ \\
\hline Falcaria bilineata & Ottawa, Canada & J. Yack & Ottawa, Canada & various collectors \\
\hline Falcaria lacertinaria & $\begin{array}{l}\text { Erlangen, Northern } \\
\text { Bavaria, Germany }\end{array}$ & I. Hassenfuss & NA & NA \\
\hline Oreta rosea & Ottawa, Canada & L. Scott & Ottawa, Canada & L. Scott \\
\hline Tridrepana flava & Taiwan & J. Heppner & NA & NA \\
\hline Watsonalla binaria & $\begin{array}{l}\text { Erlangen, Northern } \\
\text { Bavaria, Germany }\end{array}$ & I. Hasenfuss & NA & NA \\
\hline Watsonalla cultraria & $\begin{array}{l}\text { Erlangen, Northern } \\
\text { Bavaria, Germany }\end{array}$ & I. Hasenfuss & Switzerland & J. Miall \\
\hline Watsonalla uncinula & $\begin{array}{l}\text { Boulu, Pyrenees, } \\
\text { France }\end{array}$ & H. Beck & NA & NA \\
\hline \multicolumn{5}{|l|}{ Thyatirinae } \\
\hline Euthyatira pudens & Unknown & Unknown & NA & NA \\
\hline Habrosyne pyritoides & $\begin{array}{l}\text { Erlangen, Northern } \\
\text { Bavaria, Germany }\end{array}$ & I. Hassenfuss & NA & NA \\
\hline Ochropacha duplaris & Sipoo, Finland & K. Silvonen & Sipoo, Finland & K. Silvonen \\
\hline $\begin{array}{l}\text { Pseudothyatira } \\
\text { cymatophoroides }\end{array}$ & Unknown & Unknown & NA & NA \\
\hline Tethea or & Sipoo, Finland & K. Silvonen & Sipoo, Finland & K. Silvonen \\
\hline Tetheela fluctuosa & Sipoo, Finland & K. Silvonen & Sipoo, Finland & K. Silvonen \\
\hline Thyatira batis & Sipoo, Finland & K. Silvonen & Sipoo, Finland & K. Silvonen \\
\hline
\end{tabular}


Photographs were obtained with an Olympus dissection microscope (SZX12;

Olympus, Japan) equipped with a Zeiss camera (AxioCam MRc5; Zeiss, Germany), or with a digital camera (various models; Nikon, Japan). Whole caterpillars, anal segments, and mandibles were prepared for scanning electron microscopy by air drying, critical point drying (Bio-Rad Polaron Division; Watford, England), or using HMDS (hexamethyldisilazane) (Rumph \& Turner, 1998). Dried specimens were sputter-coated with gold-palladium and examined using a JEOL (JSM-6400; Tokyo, Japan) or a Tescan Vega-II scanning electron microscope (XMU VPSEM; Brno, Czech Republic).

Morphological characters for another 20 species were obtained from the literature (see Table 2.3). Although plasticity between individuals was observed for some of these morphological characters, characters were assigned to each species using the best of my knowledge and information was confirmed in the literature when possible.

\section{Behavioural trials between conspecifics}

In order to document the diversity of behaviours and associated vibrations that occur during interactions with conspecifics, encounters were staged between a resident and an introduced conspecific intruder in 11 species (using between 3 and 50 individual residents, depending on the species) representing all three sub-families of Drepanidae (Table 2.1). A late instar larva was selected at random and matched with another larva of approximately the same size, as it was shown in a previous study (Yack et al., 2001) that differences in resident and intruder weights affects the outcome of trials. A 'resident' was placed on a leaf of a twig and left undisturbed for at least 60 minutes prior to the trial to construct a shelter. Leaves were selected based on size and the absence of feeding scars, 
or other types of leaf damage. A fresh leaf was used for each trial. Once the caterpillar was established, the twig of the caterpillar's hostplant was stripped of all leaves except the occupied leaf, and the twig was cut to a length of $8-12 \mathrm{~cm}$ and placed in a water-filled vial through a hole in its lid. The resident was left to settle for a minimum of $10 \mathrm{~min}$ immediately before the trial. During the trial, the vial containing the twig and occupied leaf was held in position with a clamp such that the larval interaction could be viewed with a video camera (Fig. 2.1a). In species whose leaf shelters were made between two leaves, which prevented me from observing behaviour directly, a light was shone through the leaves to observe the outlines of the residents (Fig. 2.1b). Prior to the trial, intruders were isolated in a container with bare twigs for 15-20 min. Residents were videotaped for at least $1 \mathrm{~min}$ before the intruders were introduced to determine if signals were produced in the absence of an intruder. Using a paintbrush, an intruder was carefully transferred to the twig a few $\mathrm{cm}$ below the point where the petiole attaches to the twig, minimizing mechanical disturbance. Trials were videotaped until $1 \mathrm{~min}$ after one contestant left the leaf (i.e. when one contestant 'won' the encounter). If there was no winner within $30 \mathrm{~min}$, the trial was deemed a "tie". This time was chosen based on previous trials with another species, D. arcuata (Yack et al., 2001). Caterpillars were not reused in subsequent trials. All trials were monitored simultaneously with a Sony High Definition Handicam (HDRHC7; Tokyo, Japan) and remote Sony audio microphone (ECM-MS907) placed 1-2 cm behind the leaf and/or a laser-doppler vibrometer (LDV; Polytec PDV 100; Walbronn, Germany). Behaviour for one species, Drepana arcuata, was collected and analyzed in a previous paper (Yack et al., 2001).

In addition to direct recordings of live species, some behavioural characters were 
Figure 2.1. Experimental set-up for behavioural trials. (a) General set-up with LDV. The leaf (arrow), in a water-filled vial is held in place by a clamp, and recorded with a videocamera and LDV (scale bar $=6 \mathrm{~cm}$ ). (b) Trial set-up in a species that lives in the space between two leaves. A light is shone through the leaf in order to see the outline of the resident (arrow; scale bar $=2.5 \mathrm{~cm}$ ). 


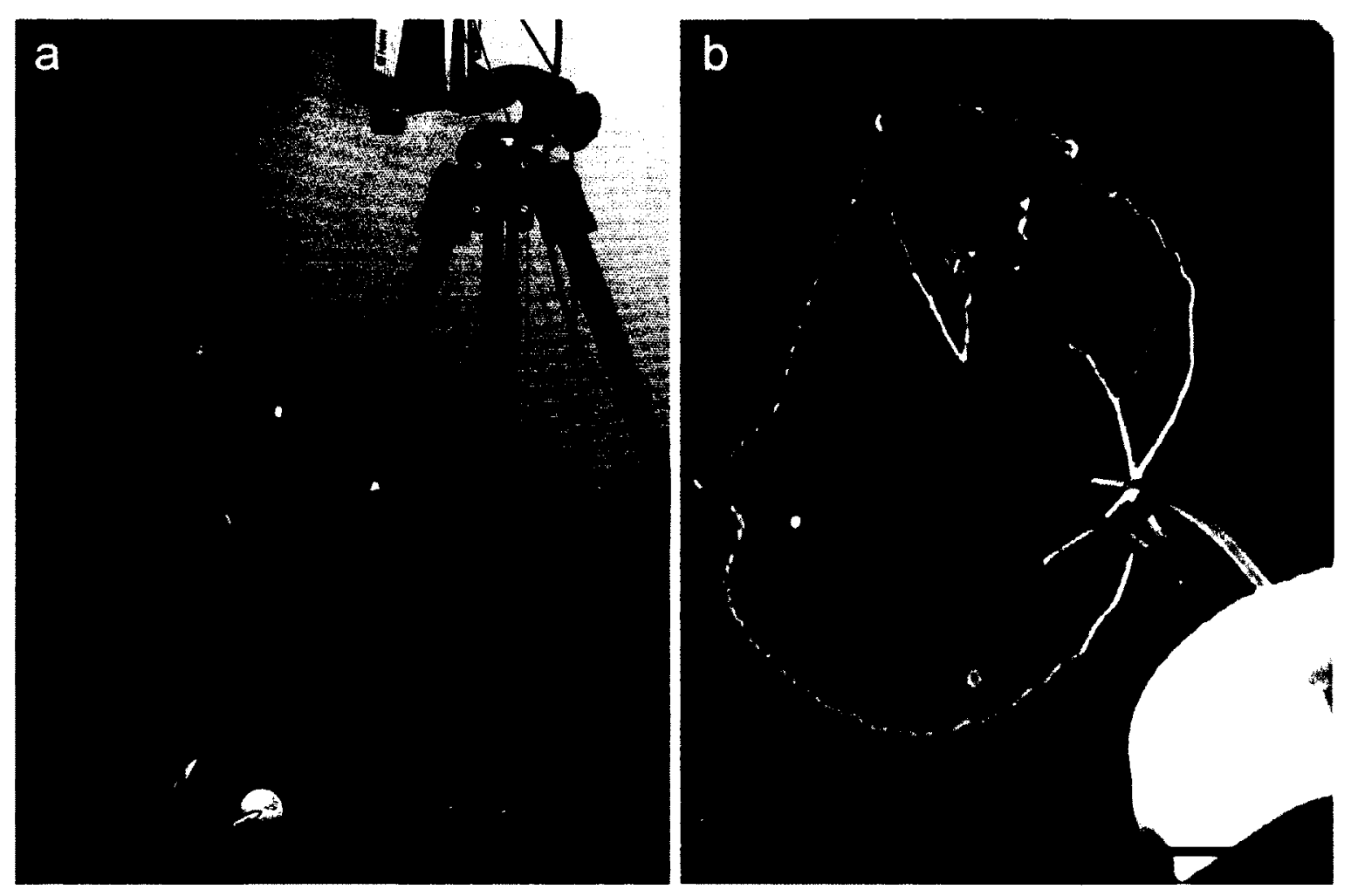


obtained through personal communication (I. Hasenfuss) for three ingroup taxa (Watsonalla binaria, W. uncinula and Falcaria lacertinaria) and from the literature (Accinctapubes albifasciata: Solis \& Styer, 2003; Epicopeia hainesii: Yen et al., 1995) for two outgroup taxa.

Videotapes of behavioural interactions, along with daily observations, were used to determine the types of territorial behaviour produced by each species. Videotapes were also analyzed to measure the durations and outcomes of contests, and to monitor change in behaviour rates in both residents and intruders throughout each trial, in order to test a prediction on ritualization for hypotheses concerning the origin of signals (Chapters 4 and 5) and to help answer questions on the evolution of signalling (Chapter 6). Trial durations were measured from the moment the intruder's head crossed the leaf-petiole junction to when one of the caterpillars crossed that junction while exiting the leaf. To determine how signalling and other territorial behaviours changed with respect to distance between individuals, rates were measured at three stages of intruder approach-FAR (when the head of the intruder passed the junction of the petiole), MID (the mid-way point between the far and close distances) and CLOSE (the point when the intruder first made contact with the resident, or if the intruder did not make contact, when it came within $0.5 \mathrm{~mm}$ of the resident). Rates were measured by counting the number of behaviours over a 20 second period from the beginning of the stage and calculated as the number of events per 5 seconds. Grand means of rates for each behaviour type at each distance category were calculated, were checked for normal distribution using the Shapiro-Wilk W test, and were compared accordingly using an ANOVA for normal data and a Kruskal-Wallis one-way analysis of variance for non-normal data to test for changes in signal rates as the intruder 
approached. Post hoc analyses were either performed using pair wise a Tukey-Kramer HSD (normal data) or pair wise Wilcoxen Rank Sum Tests (non-normal data). The number of trials in which intruders signaled was also counted for each species, in order to test a prediction on the function of signalling in Chapter 6. Finally, distance between the head of the intruder and closest point of the resident was measured at the time of the first signal using ImageJ software (1.40g; National Institute of Mental Health, Maryland, U.S.A.) to test another prediction on the function of signalling in Chapter 6.

Recording and analysis of vibrations

The data from my vibration analysis will be used in three main ways: i) to provide information on vibrational signalling in caterpillars; ii) to compare vibrations between behaviours in order to test for signal ritualization in Chapters 4 and 5; and iii) to test a hypothesis on why caterpillars produce more than one signal type (Chapter 6). Vibrations were measured with the LDV by reflecting the laser beam from a circular disc of reflective tape $(2.0 \mathrm{~mm})$ positioned on the leaf within $1 \mathrm{~cm}$ of the resident's leaf shelter, or within $1 \mathrm{~cm}$ of the resident's resting position in species that did not produce a leaf shelter. Laser signals were digitized and recorded onto a Marantz Professional portable solid-state recorder (PMD 671; Kanagawa, Japan; 44.1 kHz sampling rate). LDV and microphone recordings in conjunction with videotapes were analyzed to determine if vibrations were associated with different behaviours, and to measure temporal characteristics, and information on signal content of bouts. A bout was defined as any combination of signals that was preceded or followed by feeding, walking or at least $1 \mathrm{~s}$ of inactivity. Spectral characteristics were measured using LDV recordings only. Power spectra were generated (15892-point Fourier transform; Hann window), and dominant 
frequencies and bandwidths around the dominant peak (at $-3 \mathrm{~dB}$ SPL and $-10 \mathrm{~dB}$ SPL) were calculated from 5 individuals ( 5 signals per individual) per taxa when possible. Amplitudes of vibrations associated with each behaviour were measured relative to background levels. All signals were analyzed using Raven Bioacoustics Research Program (Cornell Laboratory of Ornithology; New York, U.S.A.) and recordings were conducted in an acoustic chamber (Eckel Industries, Massachusetts, U.S.A.).

\subsection{Results}

In total, I collected morphological information from 19 species and behavioural information from 11 species, and was able to obtain some information from the literature for 43 species (whether it be morphological, behavioural, or both) (see Tables 2.2, 2.3). I noted variation with respect to the following: i) life-history characters associated with territoriality (egg-laying behaviour, gregariousness, and shelter-building); ii) the morphology of the anal segment, with respect to the anal prolegs and modification of the dorsal region; iii) modifications of setae on the abdominal prolegs and anal segment; iv) morphology of the mandibles; and iv) behaviours associated with encounters between conspecifics. This information is summarized below, in Tables $2.2-2.13$, and in Appendix A. The following results will begin by focusing on four species of Drepanidae representing all three subfamilies (Drepaninae: D. arcuata and Oreta rosea; Thyatirinae: Tethea or; and Cyclidiinae: Cyclidia substigmaria). I will then generally describe the variation observed in other species of Drepanidae. Further details can be found in Appendix A, and Chapters 4, 5 and 6. 
Drepana arcuata (Drepaninae)

I am using $D$. arcuata as a representative of the Drepaninae subfamily. It illustrates the following conditions, which may or may not be found in other species of this group: it builds a shelter, lacks anal prolegs, possesses modified setae on the anal segment, and produces vibrational signals during encounters with conspecifics.

General life history observations relevant to conspecific interactions

Previous observations (summarized in Table 2.2) have shown that adult females of the arched hook-tip moth, Drepana arcuata Walker (Fig. 2.2a), oviposit in rows (Yack et al., 2001; Fig. 2.2b) on species of birch (Betula) and alder (Alnus) (Dyar, 1895; Beutenmüller, 1898). Early instars (Fig. 2.2c) typically form communal silk shelters within which they feed, expanding the nest as they grow (Yack et al., 2001; Fig. 2.2d). As the leaf is consumed, late instar caterpillars (Fig. 2.2e) establish solitary folded leaf shelters by tying leaf edges with silk threads and laying a silk mat on the leaf surface (Yack et al., 2001; Fig.2.2f).

\section{Morphology}

The head capsule of late instar larvae is not flattened dorsally (Fig. 2.3a,b) and the mandibles possess six distal teeth on the incisor region with two ridges on the oral surface (Fig. 2.3c). The outer planta region of the abdominal prolegs (excluding the anal prolegs) bears three setae (SV1, SV2, SV3; Fig. 2.3d,e). SV1 and SV3 are modified into a peg shape, with the SV2 seta unmodified. Larvae lack prolegs on the terminal abdominal segment (Fig. 2.3a,f,g). The pair of PP1 setae (used for scraping the leaf) on 
Figure 2.2. Photographs demonstrating life-history characteristics relevant to territorial behaviour in the arched hook-tip moth, Drepana arcuata. Photo credits: J. Yack. (a) Dorsal view of two adult moths in resting position (scale bar $=1 \mathrm{~cm}$ ). (b) Row of eggs laid on a leaf of Betula papyrifera (scale bar $=3 \mathrm{~mm}$ ). (c) Dorsal view of an early instar larvae (scale bar $=1 \mathrm{~mm}$ ). (d) Whole leaf view of a group of early instar caterpillars on a skeletonized feeding spot (scale bar $=2 \mathrm{~mm}$ ). (e) Lateral view of a late instar caterpillar in resting position (scale bar $=3 \mathrm{~mm}$ ). (f) Late instar caterpillar in a leaf-shelter with a mat of silk (scale bar $=3 \mathrm{~mm}$ ). 

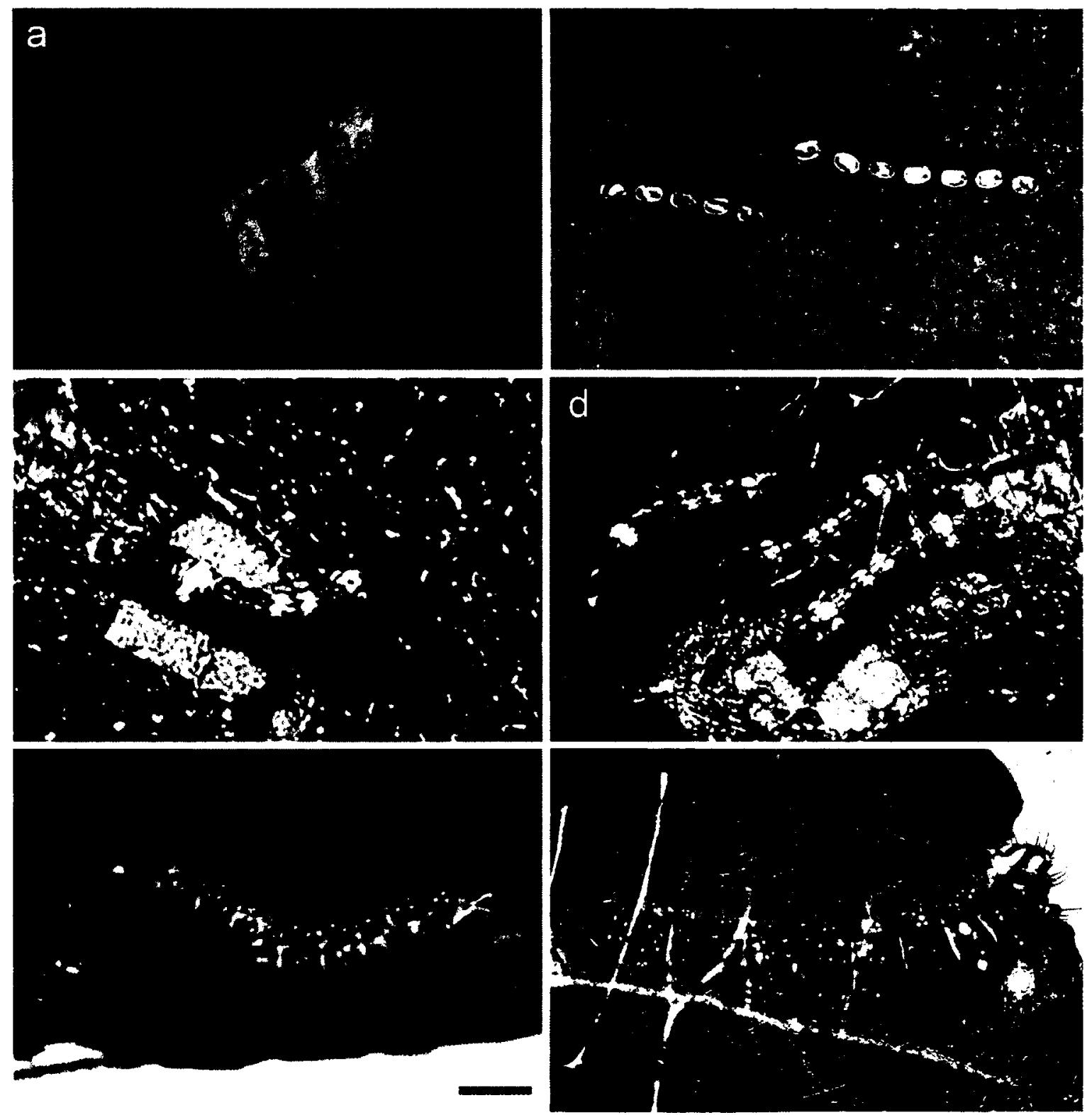
Figure 2.3. Morphological characters related to territorial behaviour in Drepana arcuata. (a) Lateral view of the whole caterpillar (scale bar $=1 \mathrm{~mm}$ ). (b) Anterior view of the head capsule (scale bar $=500 \mu \mathrm{m}$ ). (c) SEMs of lateral and ventral (inset) views of the mandibles (scale bars $=100 \mu \mathrm{m}$; photo credit: J. Yack). (d) Drawing of a lateral view of the proleg on the third abdominal segment (A3). (e) SEM of a lateral view of the proleg on A3 (scale bar $=100 \mu \mathrm{m}$; photo credit: T. Nevills). (f) Drawing of a lateral view the terminal abdominal segment (A10) with named setae. (g) SEM of a posterior view of A10 showing the location of the PP1 seta (arrow) with a close-up of the PP1 modified seta (inset; arrow) (scale bars $=100 \mu \mathrm{m}$; photo credit: J. Yack). 


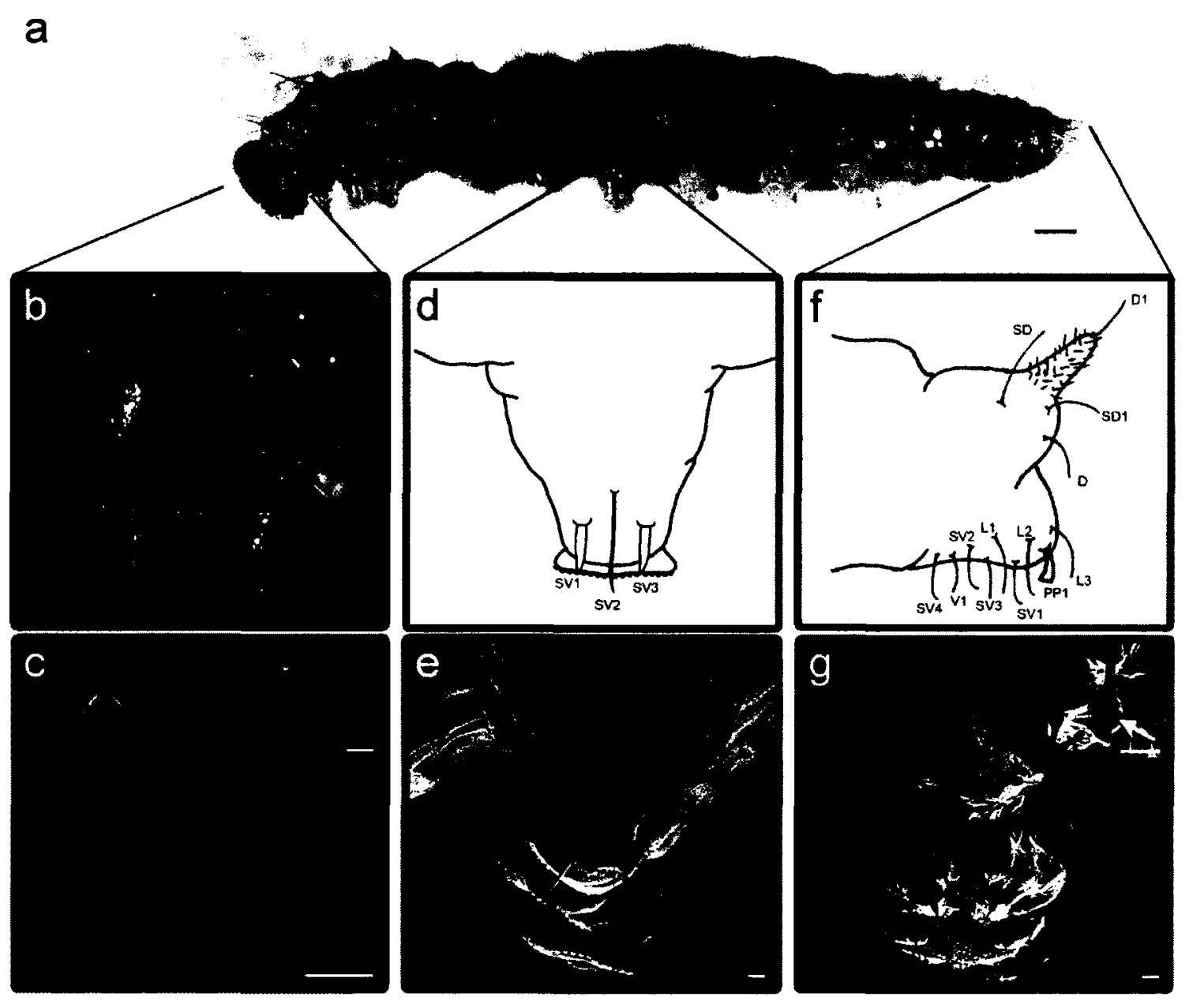


the anal segment is modified into an oar shape (Figure $2.3 \mathrm{f}, \mathrm{g}$ ). All other setae are normal to the group (Fig. 2.3f). Details on morphological characters are summarized in Table 2.3 .

Behavioural trials between conspecifics

Information on behavioural trials, including mean trial duration, outcome of trials, intruder signalling and distance between the resident and intruder at first signal is summarized in Table 2.4 below. In brief, a total of 53 encounters were staged between a resident and an intruder of similar weight (Yack et al., 2001). The resident produced four types of behaviours during encounters with conspecifics, including mandible drumming, mandible scraping, anal scraping and lateral head hitting (Fig. 2.4; described briefly below, and in detail in Chapters 4 and 5). Residents won $86.8 \%$ of the trials, intruders won $7.5 \%$ and in three trials, intruders built shelters on the occupied leaf (Yack et al., 2001). Residents were silent until they detected an intruder (Fig. 2.4a). The resident typically began an encounter with anal scraping followed by signalling with the mandibles (see Chapter 4 for details). The rate of all behaviours changes significantly as the intruder approached the resident (Fig. 2.4b; see Table A.1 for details). Intruders signaled in $37.7 \%$ of trials.

Analysis of vibrations

Late instar larvae produce vibrations associated with four types of behaviours during encounters with conspecifics - mandible scraping, mandible drumming, anal 
Figure 2.4. Vibration characteristics and territorial behaviour in Drepana arcuata. (a) Microphone trace (exported from a video file) of an entire behavioural trial with corresponding video frames below. Numbers correspond in both the trace and the video frames, illustrating the approach of the intruder $(1=\mathrm{FAR}, 2=\mathrm{MID}, 3=\mathrm{CLOSE}, 4=$ Intruder leaves, $F=$ First resident signal; scale bar $=4 \mathrm{~mm}$; video credit: $\mathrm{J}$. Yack). (b) Laser vibrometer trace illustrating a series of bouts, with an enlargement of single bout and corresponding spectrogram below. Power spectra demonstrating the dominant frequencies of each vibration (right panel). (c) Mean (+SD) behavioural rates of residents at three stages of intruder approach (FAR, MID, CLOSE). Asterisks denote significant differences within each behaviour between stages of the encounter. All colours throughout the figure correspond to those in the box describing territorial behaviours. 

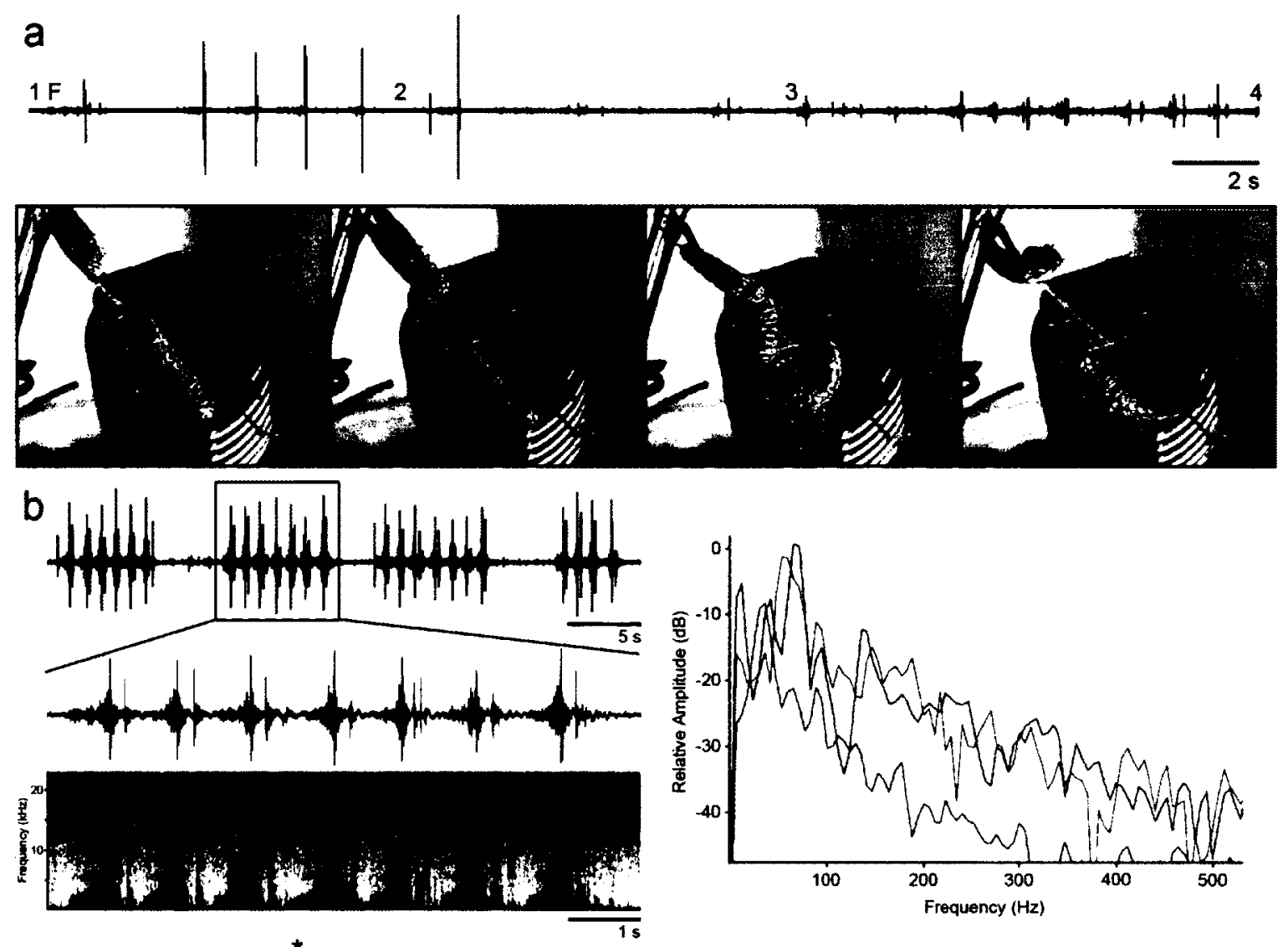

C

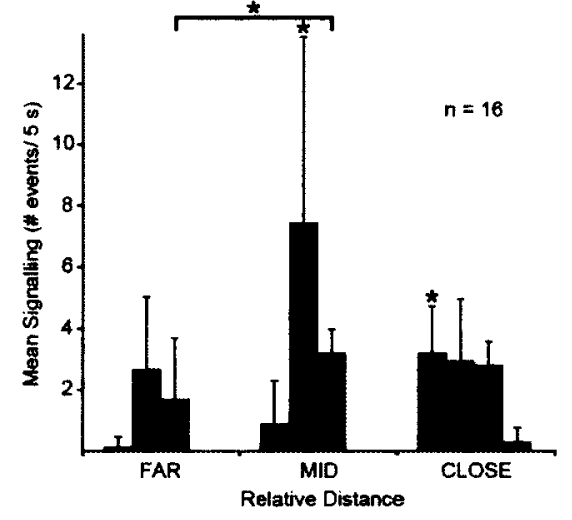

Territorial Behaviours

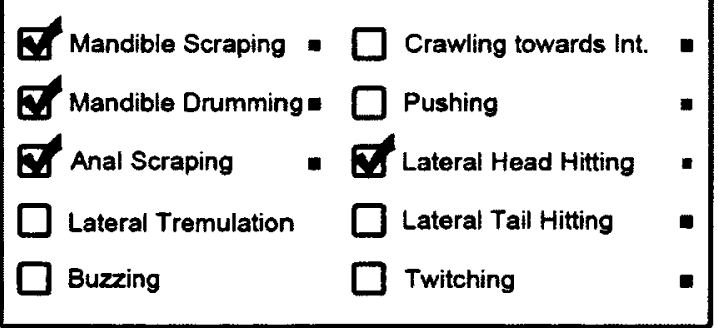


scraping and lateral head hitting (Fig. 2.4c). Mandible scraping, mandible drumming and anal scraping typically occur in bouts that comprise many behaviours.

Details on vibration characteristics, including mean duration, mean relative amplitude, mean dominant frequency and mean bandwidths at $-3 \mathrm{~dB}$ SPL and $-10 \mathrm{~dB}$ SPL are summarized in Table A.1. Mandible scraping involves a movement of the head, thorax and first two abdominal segments in a lateral arc in one direction, while dragging the mandibles across the leaf surface to produce a scratching sound. Mandible drumming is produced by striking the leaf with the serrated edges of open mandibles to create a short, percussive vibration (Fig. 2.4c). Anal scraping is produced by dragging modified PPl setae across the leaf surface (Fig. 2.4c). Lateral head hitting is similar in movement to mandible scraping, but the mandibles do not make contact with the leaf surface, and the head makes contact with the intruder. Lateral head hitting typically occurs after the intruder has made contact with the anterior end of the resident's body. Vibrations produced by lateral head hitting could not be analyzed spectrally for $D$. arcuata because this behaviour was rarely observed during encounters.

\section{Oreta rosea (Drepaninae)}

I am using $O$. rosea as a representative of the Drepaninae subfamily. This species illustrates the following conditions which may or may not be found in other species in this group: it does not build a shelter, does not possess anal prolegs, does not possess modified setae on the anal segment and during encounters with conspecifics produces vibrational signals with the mandibles only. 
General life history observations relevant to conspecific interactions

Personal observations (summarized in Table 2.2) demonstrate that adult females

(Fig. 2.5a) of the rose hooktip moth, Oreta rosea Walker 1855 lay eggs singly or in small rows on the upper and under surface of the leaf (Fig. 2.5b). All instars live solitarily on the leaf. Early instars (Fig. 2.5c) occupy individual feeding areas at leaf edges, skeletonizing the leaf surface (Fig. 2.5d). Late instar larvae (Fig. 2.5e) occupy their own leaf and will lay down a mat of silk on the leaf surface, but make no shelter (Fig. 2.5f).

\section{Morphology}

The head capsule of late instar larvae is not flattened dorsally (Fig. 2.6a,b) and the mandibles have six distal teeth on the incisor region with a small ridge on the oral surface (Fig. 2.6c). The outer planta region of the abdominal prolegs (except the anal prolegs) bears many secondary setae, with no modified primary setae (Fig. 2.6d,e). Larvae do not possess prolegs on the terminal abdominal segment and have a long, fleshy caudal process protruding from their anal shield (Fig. 2.6a). They possess many small secondary setae on the anal segment, with no modified primary setae (Fig. 2.6f,g). The primary setae on the anal segment are normal to the group, except for the pair of SD2 setae, which is absent (Fig. 2.6f,g). Details on morphological characters are summarized in Table 2.3.

Behavioural trials between conspecifics

Detailed information on behavioural trials is summarized in Table 2.4. A total of 22 encounters were staged between a resident and an intruder of equal weight. Residents produced four types of behaviours during trials with conspecifics, including mandible 
Figure 2.5. Photographs demonstrating life-history characteristics relevant to territorial behaviour in the rose hooktip moth, Oreta rosea. (a) Dorsal view of an adult moth in resting position (scale bar $=5 \mathrm{~mm}$ ). (b) Eggs laid on the underside of a Viburnum lentago leaf (scale bar $=5 \mathrm{~mm}$; photo credit: J. Yack). (c) Dorso-lateral view of an early instar larvae (scale bar $=3 \mathrm{~mm}$ ). (d) Whole leaf view of an early instar caterpillar on a skeletonized feeding spot (scale bar $=10 \mathrm{~mm}$ ). (e) Lateral view of a late instar caterpillar in resting position (scale bar $=10 \mathrm{~mm}$ ). (f) Late instar caterpillar on a mat of silk (scale bar $=10 \mathrm{~mm}$ ). 


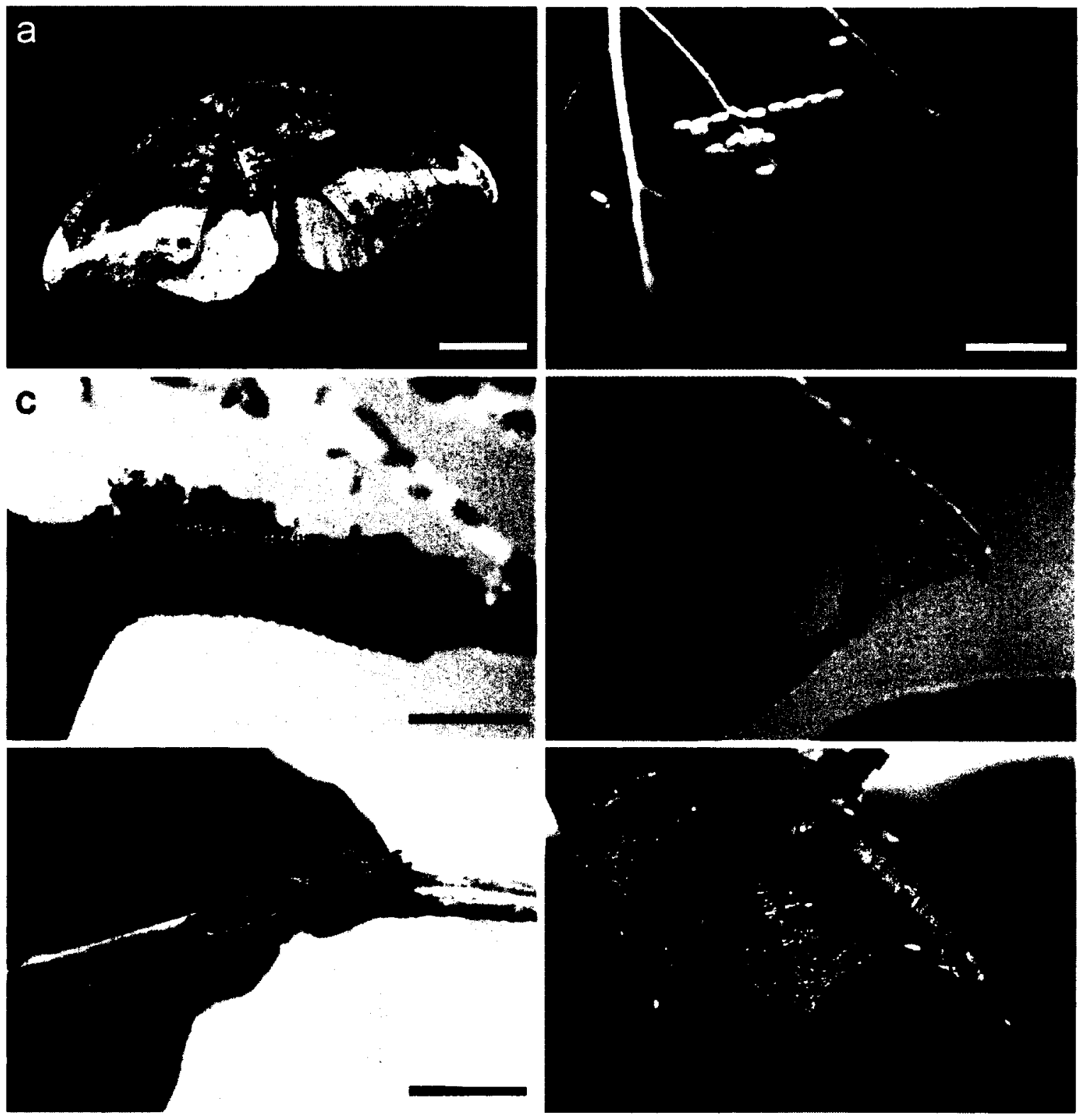


scraping, mandible drumming, lateral tremulation and lateral tail hitting (Fig. 2.7; described briefly below, and in detail in Chapters 4 and 5). Residents won $91.0 \%$ of trials, intruders won $4.5 \%$, and $4.5 \%$ were ties. Residents remained silent until they detected an intruder and remained in the same approximate position on the leaf during trials (Fig. 2.7a). The rate of mandible scraping, mandible drumming and lateral tail hitting increased significantly as the intruder approached the resident; however the rate of lateral tremulation did not change with distance between the resident and intruder (Fig. 2.7b; see Table A.1 for details). Intruders signaled in about half of the trials where signalling occurred, but at a significantly lower rate (paired $t$-test, $t=-3.84, P=0.001, n$ $=21)$.

Analysis of vibrations

Microphone and LDV recordings revealed that $O$. rosea larvae produce vibrations associated with four types of behaviours during interactions with conspecifics - mandible scraping, mandible drumming, lateral tremulation and lateral tail hitting (Fig. 2.7c). Mandible scraping, mandible drumming and lateral tremulation typically occur in bouts, beginning with a lateral tremulation event followed by any combination of behaviours, with time intervals between bouts being highly variable (see Table 2.6 for details).

Details on temporal and spectral characteristics of vibrations are summarized in Table A.1. Lateral tremulation was only observed in about half the individuals (in $40.9 \%$ of trials) and consists of quick, short, successive lateral movements of the head and thorax while the rest of the body remains motionless. A lateral tremulation event is distinguished from a mandible scrape by its much shorter, highly repetitive lateral 
Figure 2.6. Morphological characters related to territorial behaviour in Oreta rosea. (a) Lateral view of the whole caterpillar (scale bar $=1 \mathrm{~mm}$ ). (b) Anterior view of the head capsule (scale bar $=500 \mu \mathrm{m}$ ). (c) SEMs of lateral and ventral (inset) views of the mandibles (scale bars $=100 \mu \mathrm{m}$ ). (d) Drawing of a lateral view of the proleg on the third abdominal segment (A3). (e) SEM of a lateral view of the proleg on A3 (scale bar $=100$ $\mu \mathrm{m}$; photo credit: T. Nevills). (f) Drawing of a lateral view the terminal abdominal segment (A10) with named setae. (g) SEM of a lateral view of A10 showing the location of the PP1 seta (arrow) with a close-up of the PP1 seta (inset; arrow) (scale bars $=100$ $\mu \mathrm{m})$. 


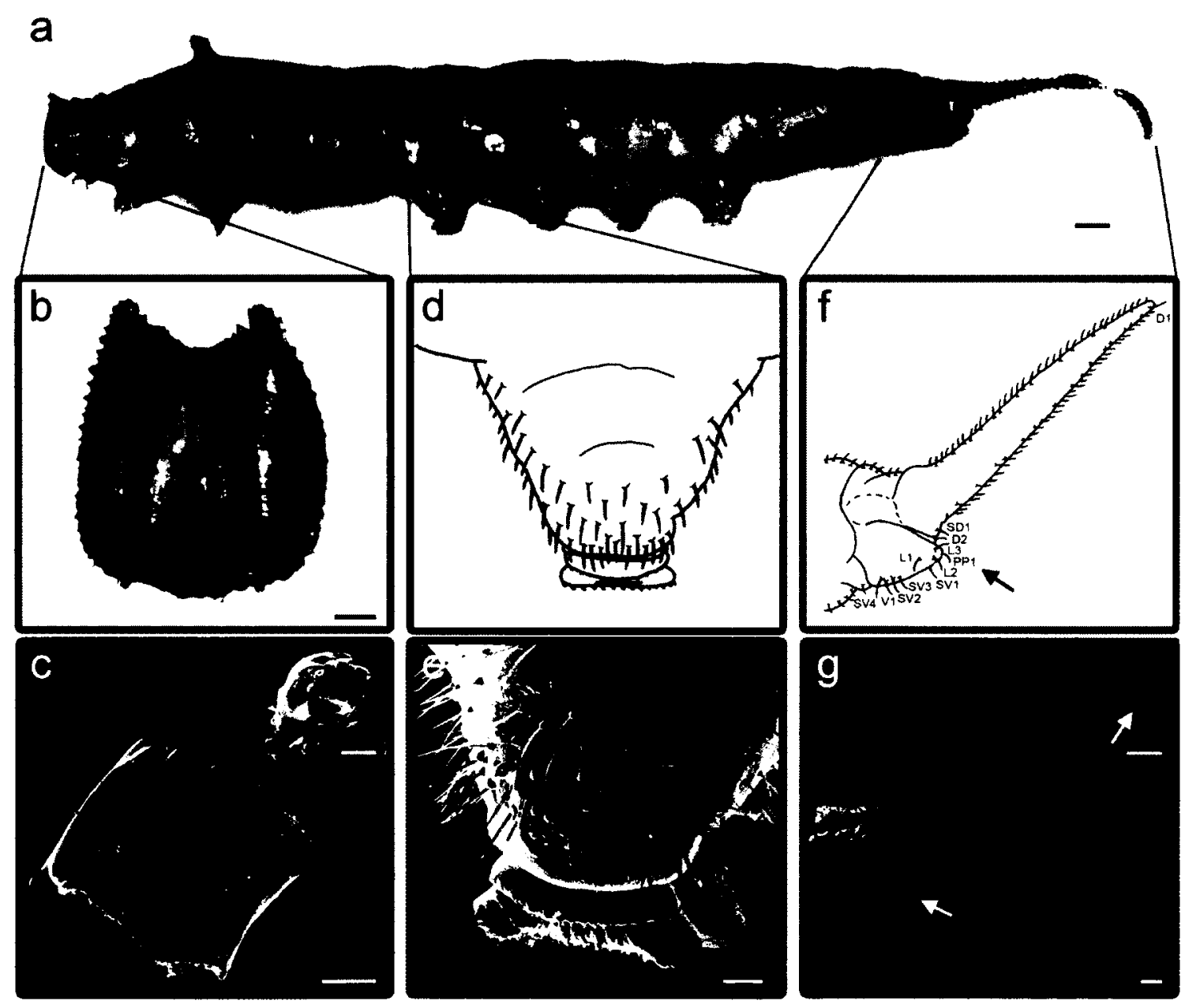


Figure 2.7. Vibration characteristics and territorial behaviour in Oreta rosea. (a) Laser vibrometer trace of an entire behavioural trial with corresponding video frames below. Numbers correspond in both the trace and the video frames, illustrating the approach of the intruder $(1=\mathrm{FAR}, 2=\mathrm{MID}, 3=\mathrm{CLOSE}, 4=$ Intruder leaves, $\mathrm{F}=$ First resident signal; scale bar $=10 \mathrm{~mm}$ ). (b) Laser vibrometer trace illustrating a series of bouts, with an enlargement of single bout and corresponding spectrogram below. Power spectra demonstrating the dominant frequencies of each vibration (gray) (right panel). (c) Mean $(+\mathrm{SD})$ behavioural rates of residents at three stages of intruder approach (FAR, MID, CLOSE). Asterisks denote significant differences within each behaviour between stages of intruder approach. All colours throughout the figure correspond to those in the box describing territorial behaviours. 

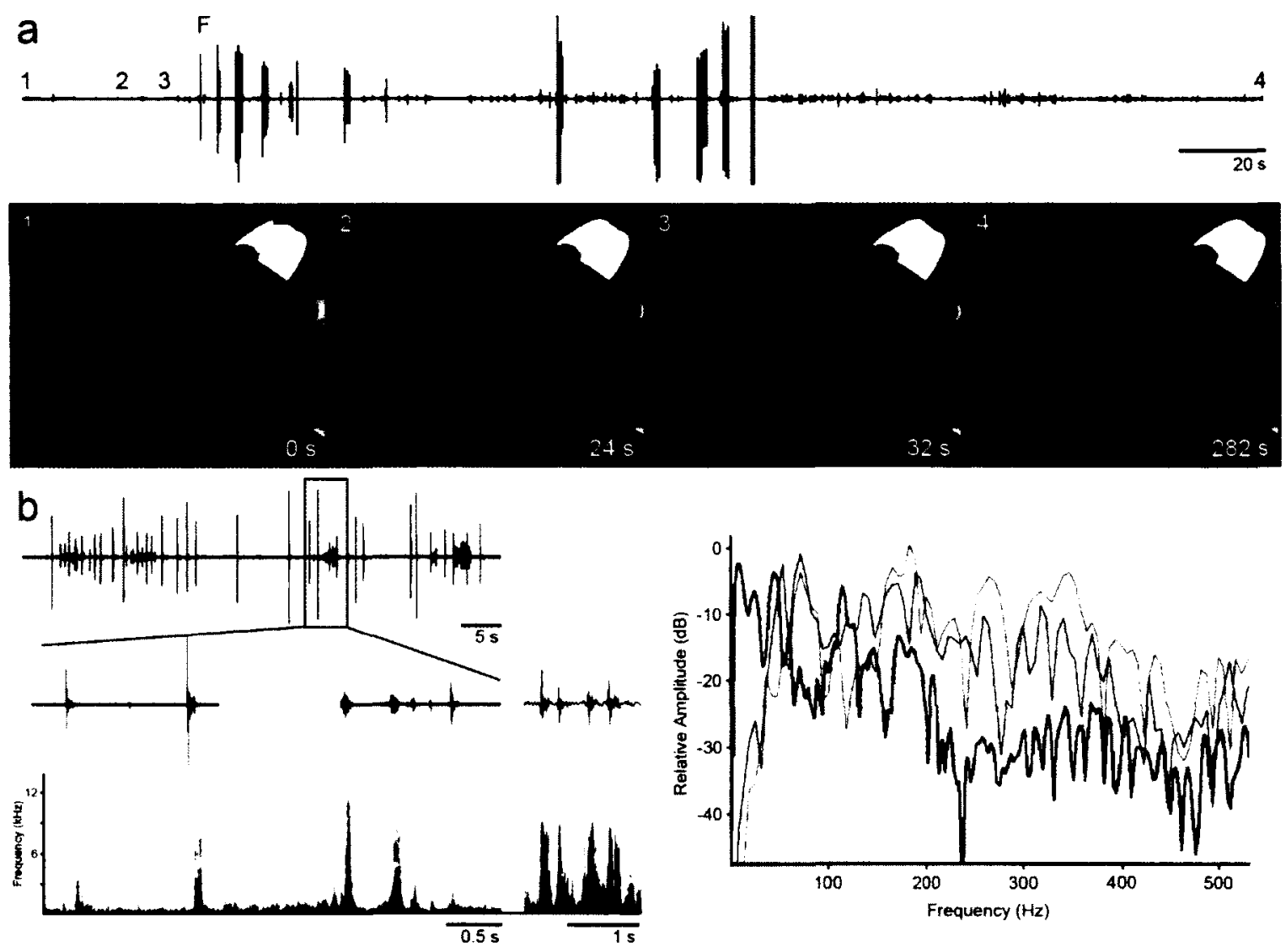

C
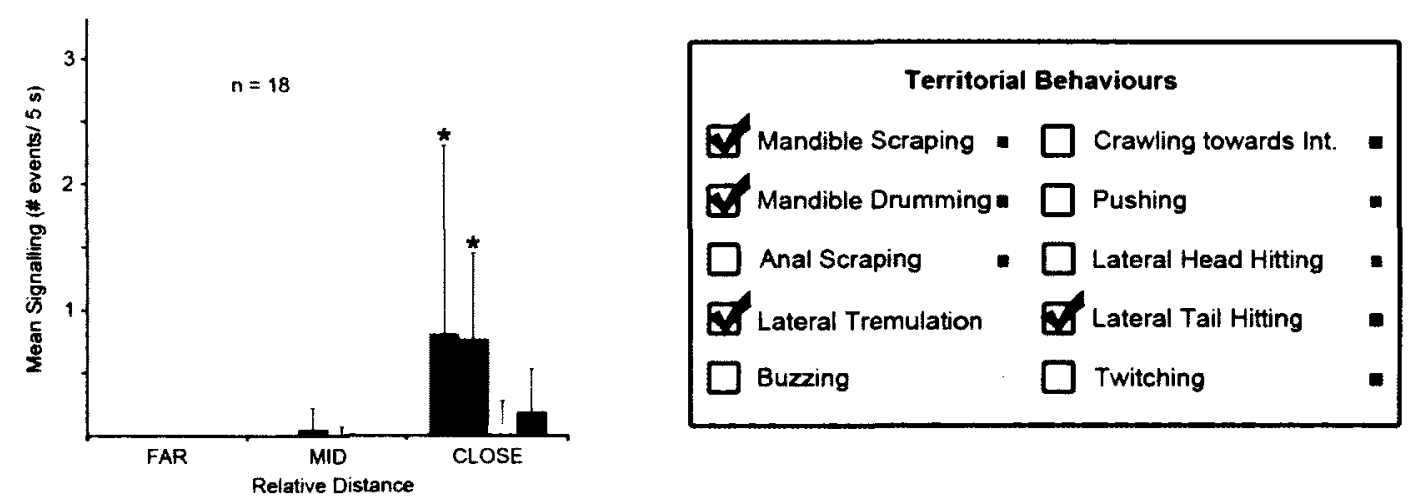
movement, where the mandibles never touch the leaf surface. Finally, lateral tail hitting was observed in $31.8 \%$ of trials and involves a quick lateral movement of the elongated caudal projection, usually directed towards the intruder. Lateral tail hitting is typically observed when the intruder touches the resident near its abdominal end, and the resident swings its caudal projection back and forth multiple times, making contact with the intruder. Spectral properties of lateral tail hitting could not be analyzed because it was rare and I do not have laser files of this behaviour.

Tethea or (Thyatirinae)

Tethea or is being used as a representative of the Thyatirinae subfamily. It demonstrates the following conditions that may or may not be found in other species of this group: it builds a leaf shelter, possesses anal prolegs, lacks modified setae on the terminal abdominal segment and produces vibrational signals and other territorial behaviours during interactions with conspecifics.

General life history observations relevant to conspecific interactions

Previous observations (summarized in Table 2.2) have shown that adult females of the poplar lutestring moth, Tethea or Denis \& Schiffermüller 1775 (Fig. 2.8a), lay eggs singly or in small groups on the underside of leaves on poplar (Populus spp.) (Newman, 1884; Stokoe et al., 1948; Riegler, 1999; Fig. 2.8a,b). Caterpillars of all instars are solitary and build a shelter by tying two leaves together with silk (Theakston, 1866; Newman, 1884; Stokoe et al., 1948; Riegler, 1999; personal observations; Fig. 2.8c-f). Late instars rest inside their shelters in a U-shaped position (Fig. 2.8e; personal observations). Riegler (1999) also noted that when disturbed, caterpillars shake within 
Figure 2.8. Photographs demonstrating life-history characteristics relevant to territorial behaviour in the poplar lutestring moth, Tethea or. (a) Lateral view of an adult moth in resting position (scale bar $=0.5 \mathrm{~mm}$; photo credit: J.C. Schou, leps.it). (b) Dorsal view of a single egg (scale bar $=0.2 \mathrm{~mm}$; photo credit: R. Fry, ukleps.org). (c) Lateral view of an early instar larvae (scale bar $=1 \mathrm{~mm}$; photo credit: R. Fry, ukleps.org). (d) View of an early instar shelter with skeletonized feeding spot (scale bar $=2 \mathrm{~cm}$; photo credit: A. Watson Featherstone, treesforlife.org.uk). (e) Dorsal view of a late instar caterpillar in resting position (scale bar $=3 \mathrm{~mm}$ ). (f) Late instar caterpillar leaf-shelter (scale bar $=1$ $\mathrm{cm})$. 

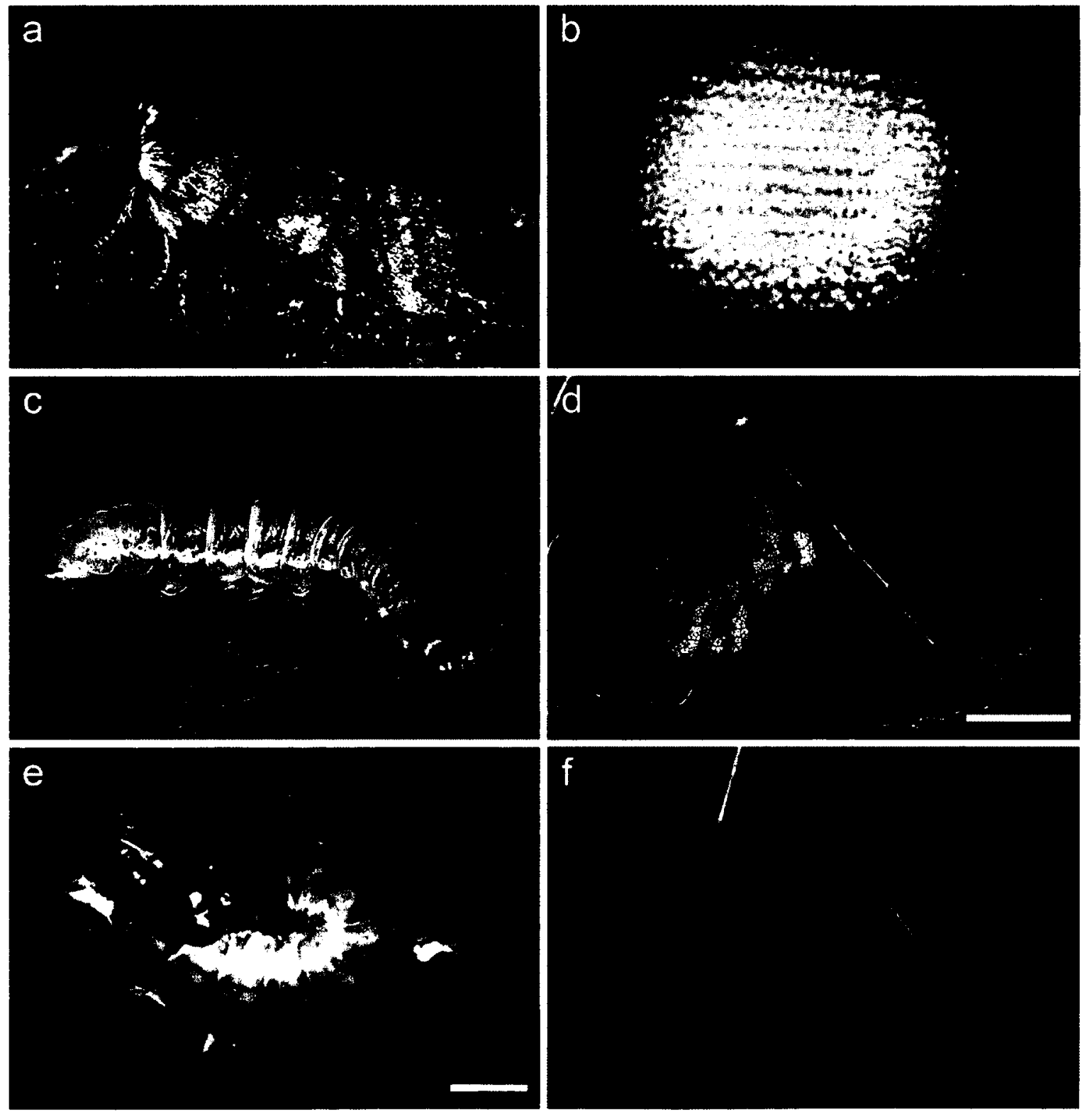
their shelters, making a "sifflement" (whistling) or "raclement" (scraping) noise.

Morphology

The head capsule of late instar larvae is flattened dorsally (Fig. 2.9a,b). Mandibles have four rounded distal teeth on the incisor area and no ridges on the oral surface (Fig. 2.9c). The abdominal prolegs (excluding the anal prolegs) bear three unmodified setae on the outer planta region (SV1, SV2, SV3; Fig. 2.9d,e). Larvae possess reduced prolegs onthe terminal abdominal segment (smaller than the abdominal prolegs) that bear crochets (Fig. 2.9a,f,g). On the anal segment there are no modified primary setae and all setae are normal to the group (Fig. 2.9f,g). Morphological characters are summarized in Table 2.3 .

Behavioural trials between conspecifics

Details on encounters with conspecifics are summarized in Table 2.4. A total of 11 encounters were staged between a resident and an intruder of similar size. Residents produced four types of behaviours during encounters, including mandible scraping, crawling towards the intruder, pushing and lateral head hitting (Fig. 2.10; described briefly below, and in detail in Chapters 4 and 5). In all trials the intruder left the leaf (i.e. the resident 'won' the trial). Residents did not respond until the intruder crossed the leafpetiole junction (Fig. 2.10a). A typical behavioural sequence begins with the resident crawling toward the intruder, followed by head movements including pushing and mandible scraping (see Chapter 4 for details). The rate of resident behaviours, including mandible scraping, crawling towards the intruder, and pushing changed significantly as 
Figure 2.9. Morphological characters related to territorial behaviour in Tethea or. (a) Lateral view of the whole caterpillar (scale bar $=1 \mathrm{~mm}$ ). (b) Anterior view of the head capsule (scale bar $=500 \mu \mathrm{m})$. (c) SEMs of lateral and ventral (inset) views of the mandibles (scale bars $=100 \mu \mathrm{m}$ ). (d) Drawing of a lateral view of the proleg on the third abdominal segment (A3). (e) SEM of a lateral view of the proleg on A3 (scale bar $=100$ $\mu \mathrm{m}$; photo credit: T. Nevills). (f) Drawing of a lateral view the terminal abdominal segment (A10) with named setae. (g) SEM of a lateral view of A10 showing the location of the PP1 seta (arrow) with a close-up of the PP1 seta (inset; arrow) (scale bars $=100$ $\mu \mathrm{m})$ 


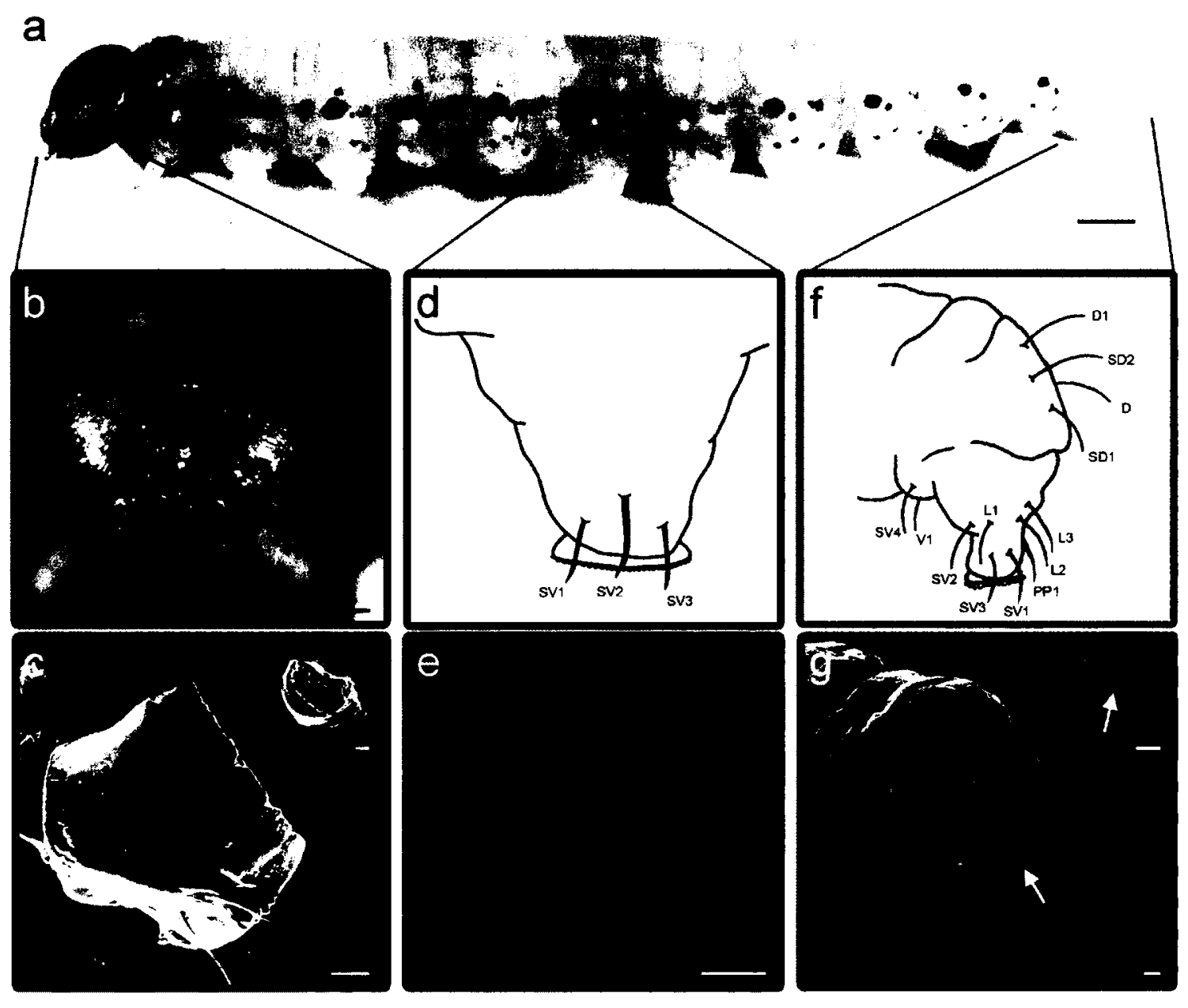


Figure 2.10. Vibration characteristics and territorial behaviour in Tethea or. (a) Laser vibrometer trace of an entire behavioural trial with corresponding video frames below. Numbers correspond in both the trace and the video frames, illustrating the approach of the intruder $(1=\mathrm{FAR}, 2=\mathrm{MID}, 3=\mathrm{CLOSE}, 4=$ Intruder leaves, $\mathrm{F}=$ First resident signal; scale bar $=1 \mathrm{~cm}$ ). (b) Laser vibrometer trace illustrating a series of bouts, with an enlargement of single bout and corresponding spectrogram below. Power spectra demonstrating the dominant frequencies of each vibration (right panel). (c) Mean (+SD) behavioural rates of residents at three stages of intruder approach (FAR, MID, CLOSE). Asterisks denote significant differences within each behaviour between different stages of intruder approach. All colours throughout the figure correspond to those in the box describing territorial behaviours. 

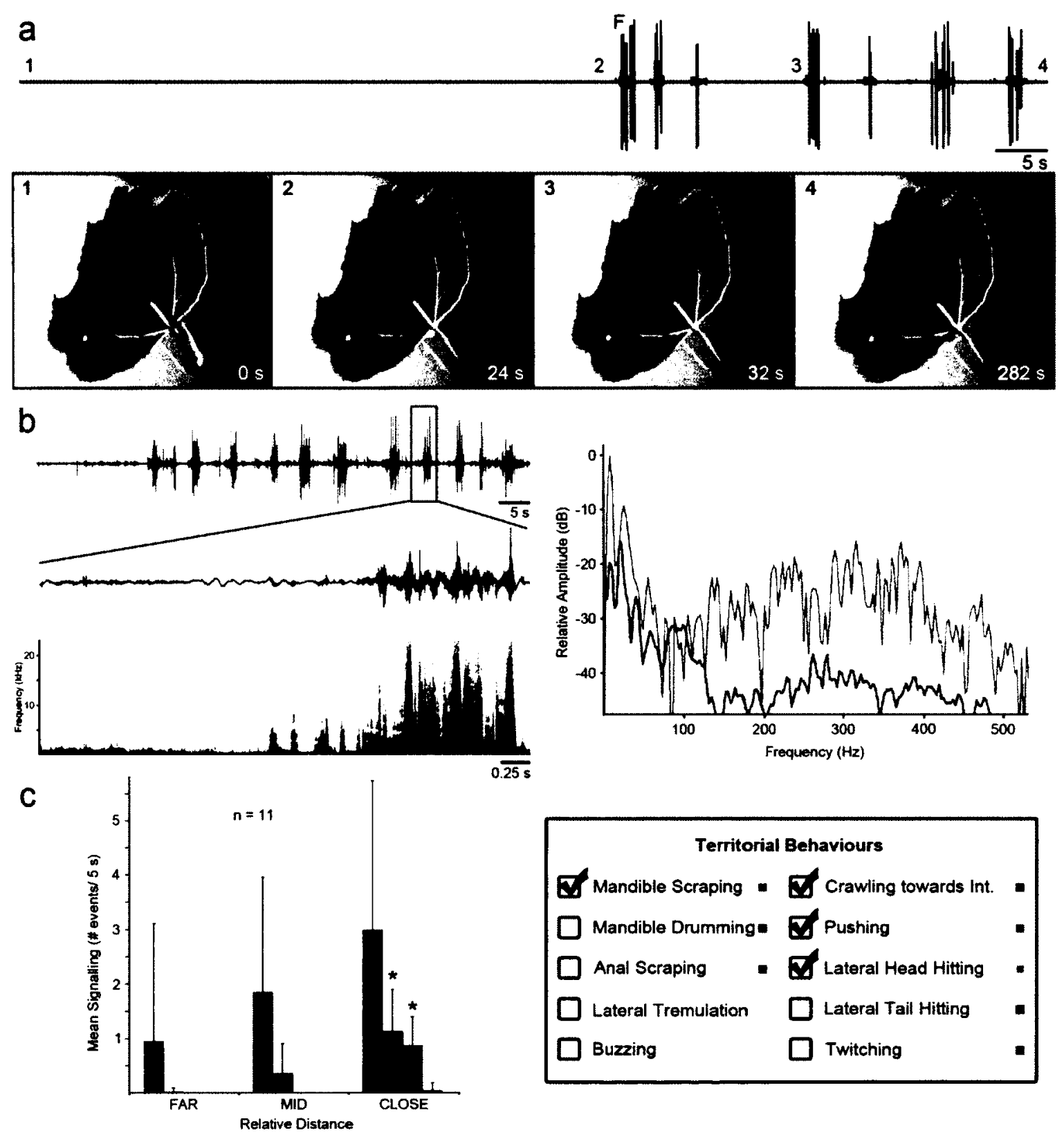
the intruder approached the resident (Fig. 2.10b; see Table A.1 for details). Residents ceased mandible scraping within a few seconds after the intruder left the leaf. When two caterpillars encountered each other on a leaf without a shelter, no signalling or physically aggressive behaviours were observed. Intruders were never observed to mandible scrape during formal trials or during general observations of interactions.

\section{Analysis of vibrations}

Plant-borne vibrations are associated with four behaviours in late instar larvae during conspecific interactions - mandible scraping, crawling, pushing and lateral head hitting (Fig. 2.10c). Mandible scraping typically occurs in bouts with about 4 signals per bout, ranging between $0.10-4.07 \mathrm{~s}$ ( $n=48$ bouts from 11 individuals) (more details in Table 2.6).

Details on temporal and spectral characteristics of vibrations are summarized in Table A.1. Mandible scraping involved scraping the mandibles laterally back and forth on the leaf surface. Forward crawling was performed during encounters as residents crawled towards intruding conspecifics. Pushing is a variation of crawling, where the head of a resident makes physical contact with another caterpillar; therefore the temporal and spectral characters are the same for both behaviours.

\section{Cyclidia substigmaria (Cyclidiinae)}

I am including Cyclidia substigmaria as a representative of the Cyclidiinae subfamily. It illustrates the following conditions which may or may not be found in other species in this group: it does not build a shelter, possesses fully formed anal prolegs, does 
not have modified setae on the anal segment and is gregarious as late instars.

General life history observations relevant to conspecific interactions

Previous studies and personal observations (summarized in Table 2.2) show that adult females of Cyclidia substigmaria Hübner 1831 (Fig. 2.11a), lay eggs in large groups of around 30 eggs (S.-H. Yen, personal communication; Fig. 2.11b) on Alangium platanifolium (Minet \& Scoble, 1999). Early instars (Fig. 2.11c) are gregarious (S.-H. Yen, personal communication; Fig. 2.11d). Late instar larvae (Fig. 2.11e) were also observed to be gregarious, living in small groups of 3-5 on a single leaf (Fig. 2.11f). Late instars did not construct a shelter or lay a silk mat (Fig. 2.11f).

Morphology

The head capsule of late instar larvae is not flattened dorsally (Fig. 2.12a,b). Mandibles are small and have three rounded distal teeth on the incisor region and three ridges on the oral surface (Fig. 2.12c). The outer planta region of the abdominal prolegs (excluding the anal prolegs) bears many small secondary setae with no modified primary setae (Fig. 2.12d,e). Larvae possess fully formed prolegs on the terminal abdominal segment (equal in size to the other abdominal prolegs and bearing crochets; Fig. 2.12a). There are two absent dorsal/subdorsal setae, one extra subventral seta, and no modified primary setae on the anal segment (Fig. 2.12f,g). Details on morphology are summarized in Table 2.3 . 
Figure 2.11. Photographs demonstrating life-history characteristics of Cyclidia substigmaria. (a) Dorsal view of an adult moth in resting position (scale bar $=2 \mathrm{~cm}$; photo credit: jpmoth.org). (b) Dorsal view of a group of eggs (scale = unknown; photo credit: S.-H. Yen). (c) Dorsal view of early instar larvae (scale = unknown; photo credit: S.-H. Yen). (d) A group of early instar caterpillars on a leaf (scale = unknown; photo credit: S.-H. Yen). (e) Lateral view of a late instar caterpillar (scale bar $=1 \mathrm{~cm}) .(\mathrm{f}) \mathrm{A}$ group of late instar caterpillars (scale bar $=4 \mathrm{~cm}$ ). 

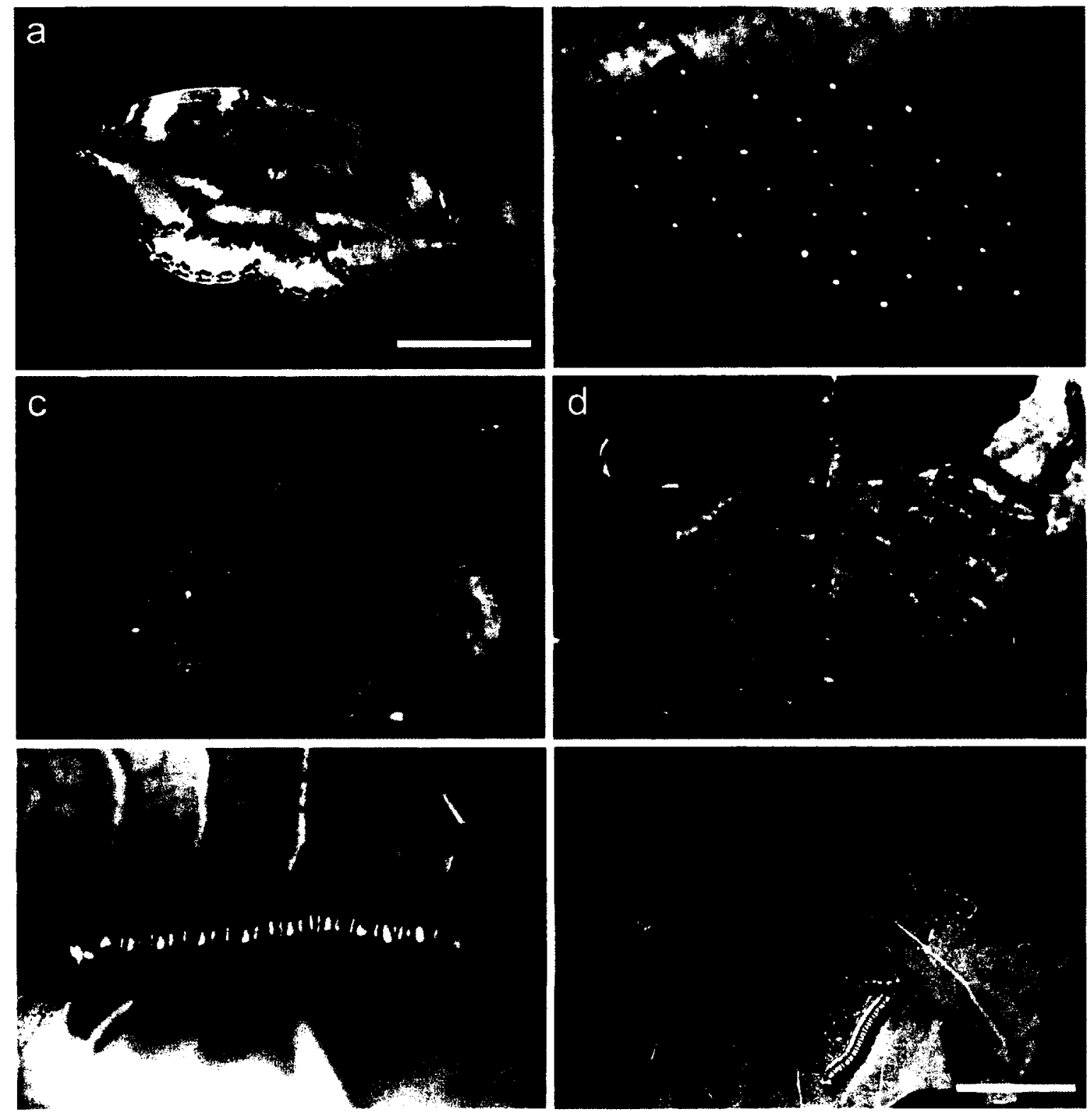
Figure 2.12. Morphological characters related to territorial behaviour in Cyclidia substigmaria. (a) Lateral view of the whole caterpillar (scale bar $=1000 \mu \mathrm{m})$. (b) Anterior view of the head capsule (scale bar $=500 \mu \mathrm{m}$ ). (c) SEMs of lateral and ventral (inset) views of the mandibles (scale bars $=100 \mu \mathrm{m}$ ). (d) Drawing of a lateral view of the proleg on the third abdominal segment (A3). (e) SEM of a lateral view of the proleg on A3 (scale bar $=100 \mu \mathrm{m}$; photo credit: T. Nevills). (f) Drawing of a lateral view the terminal abdominal segment (A10) with named setae. (g) SEM of a lateral view of A10 showing the location of the PP1 seta (arrow) with a close-up of the PP1 setae (inset; arrow) (scale bars $=100 \mu \mathrm{m})$. 


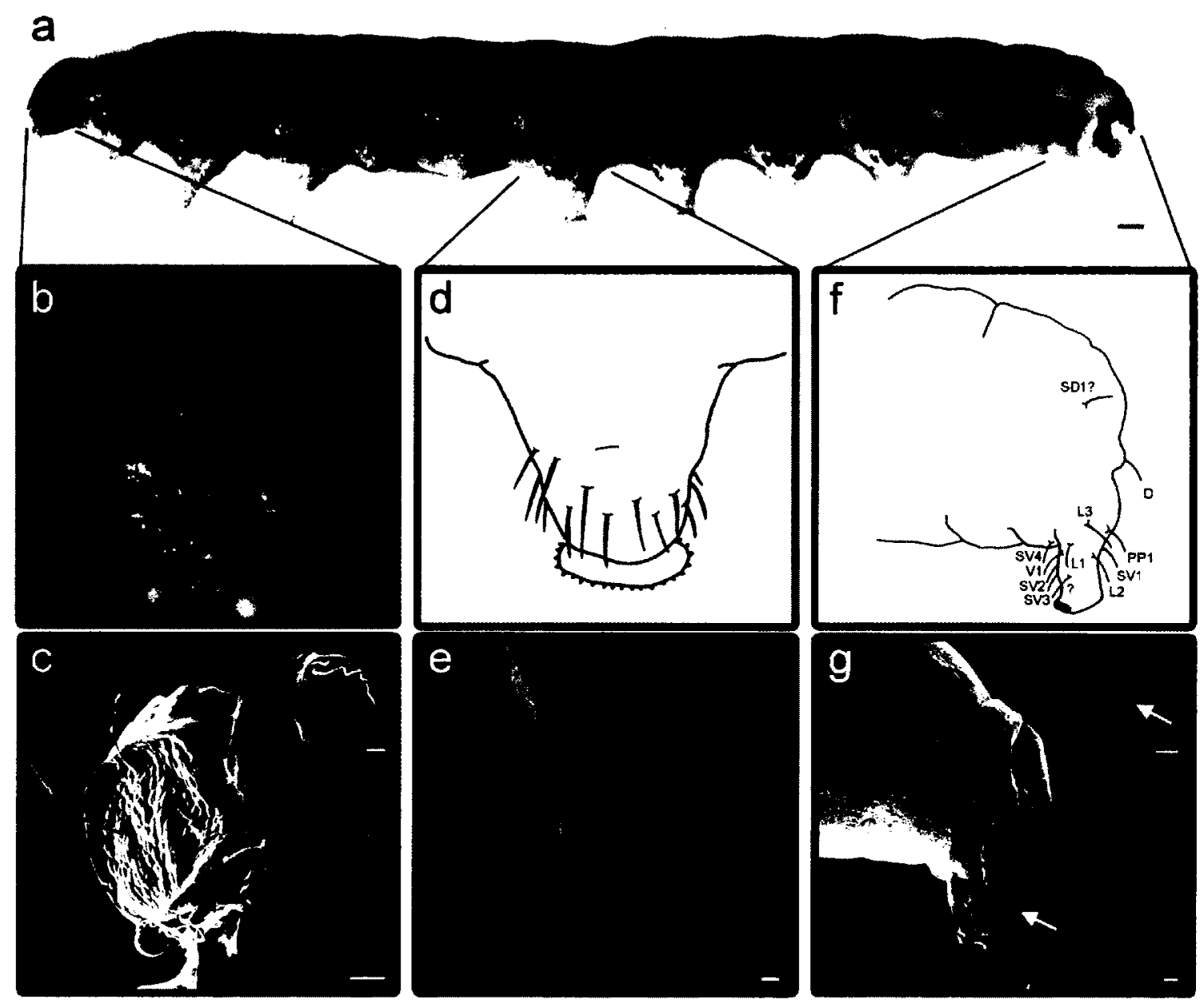


Behavioural trials between conspecifics

A total of 7 encounters were staged between a resident and a conspecific of similar size. Residents did not produce any behaviours during interactions with conspecifics (Fig. 2.13). Intruding caterpillars always crawled towards the resident and remained resting beside the resident for the duration of the trial (Fig. 2.13a). Neither the resident nor the intruder left the leaf.

Analysis of vibrations

Late instar larvae do not produce any vibrations specifically in the context of encounters with conspecifics (Fig. 2.13). They do however, like all other species, produce vibrations while crawling on the leaf. These vibrations are described in Fig. $2.13 \mathrm{~b}$ and Table A.1.

A summary of morphology and behaviour observed in all studied species

General life history observations relevant to conspecific interactions

Variation in life-history traits such as egg-laying habit, gregariousness, shelterbuilding behaviour and hostplants was observed between species included in this study (Table 2.2). Thirteen out of 21 species were found to lay eggs singly, whereas 16 species were found to lay in small groups or rows of up to 11 eggs. Five species were observed to live in small groups of up to 29 as early instars, while 8 species are solitary at this stage. Only one species (Cyclidia substigmaria) is gregarious as a late instar. Two out of 18 species do not build any type of leaf shelter, while the rest either only lay a silk mat (5 species), fold or roll a single leaf and attach it with silk strands 6 species), or tie two 
Figure 2.13. Vibration characteristics and territorial behaviour in Cyclidia substigmaria. (a) Laser vibrometer trace of an entire behavioural trial with corresponding video frames below. Numbers correspond in both the trace and the video frames, illustrating the approach of the intruder $(1=\mathrm{FAR}, 2=\mathrm{MID}, 3=\mathrm{CLOSE}, 4=$ Intruder leaves; scale bar $=$ $1.5 \mathrm{~cm}$ ). (b) Laser vibrometer trace illustrating vibrations produced by general context with corresponding spectrogram below. Power spectra demonstrating the dominant frequencies of general context crawling (right panel). 
a
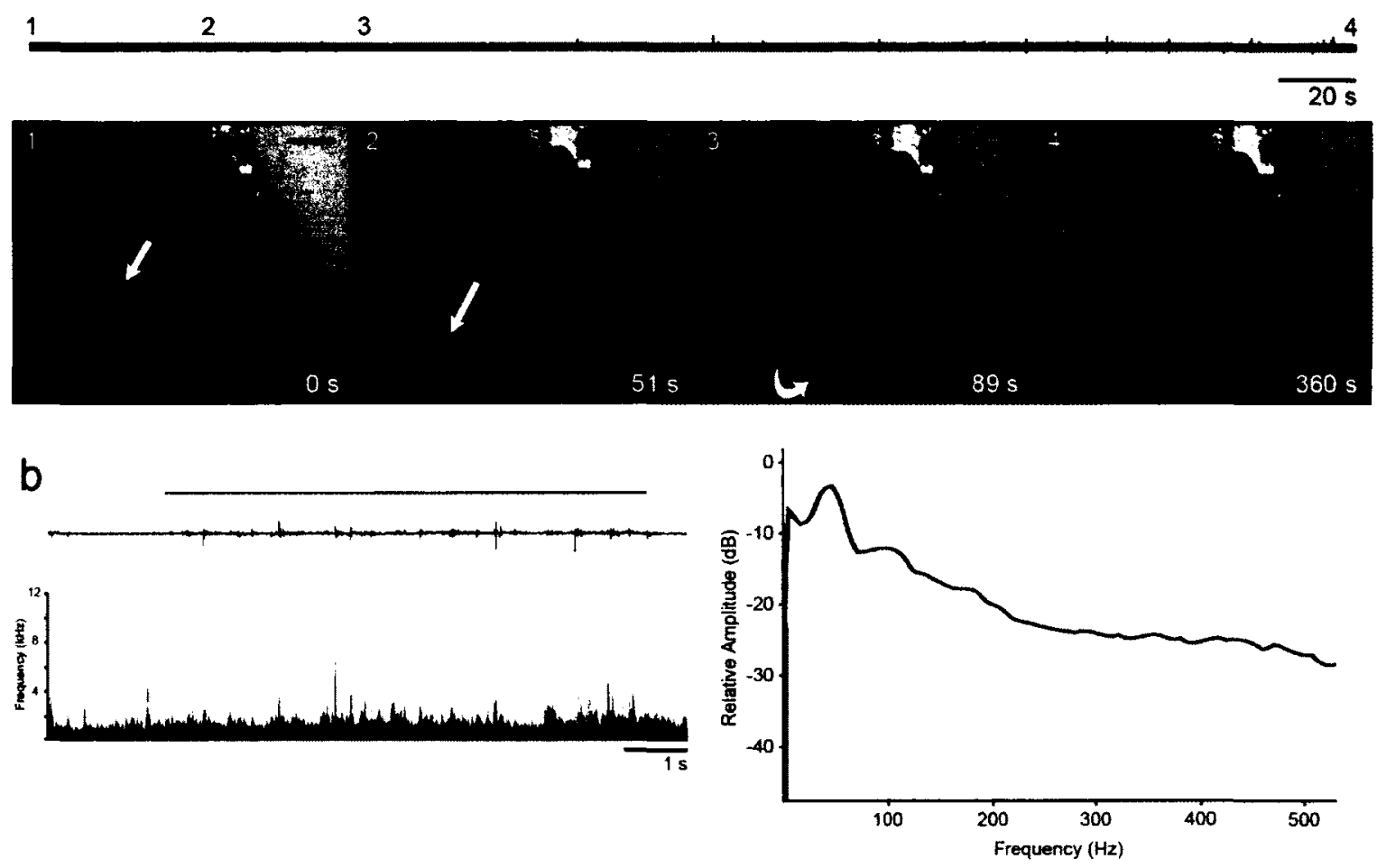

\begin{tabular}{|lll|}
\hline \multicolumn{3}{|c|}{ Territorial Behaviours } \\
$\square$ Mandible Scraping $=\square$ Crawling towards Int. & $=$ \\
$\square$ Mandible Drumming= $\square$ Pushing & $=$ \\
$\square$ Anal Scraping & $\square$ Lateral Head Hitting & - \\
$\square$ Lateral Tremulation & $\square$ Lateral Tail Hitting \\
$\square$ Buzzing & $\square$ Twitching
\end{tabular}


Table 2.2. Life-history traits relevant to territorial behaviour in Drepanidae species.

\begin{tabular}{|c|c|c|c|c|c|}
\hline Taxon & Egg Laying & $\begin{array}{c}\text { Early instar } \\
\text { Gregariousness }\end{array}$ & $\begin{array}{c}\text { Late instar } \\
\text { Gregariousness }\end{array}$ & $\begin{array}{c}\text { Leaf } \\
\text { Shelter }\end{array}$ & Hostplant \\
\hline Cyclidiinae & 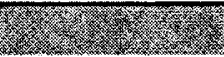 & 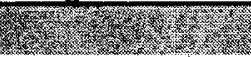 & shem & Nes & (x) \\
\hline $\begin{array}{l}\text { Cyclidia } \\
\text { substigmaria } \\
\text { Drepaninae }\end{array}$ & $\begin{array}{l}\text { Groups of } \\
\text { approx } 30^{1}\end{array}$ & Large groups' & Groups of 3-5 & None & $\begin{array}{l}\text { Alangium } \\
\text { platanifolium }^{2}\end{array}$ \\
\hline Ausaris palleolus & Singly ${ }^{3}$ & - & - & - & $\begin{array}{l}\text { Rhus } \\
\text { trichocarpa, } R \text {. } \\
\text { ambigua } ; R . \\
\text { succedanea, } R \text {. }_{\text {amigus }^{3}}\end{array}$ \\
\hline Auzata superba & Rows of $4-11^{4}$ & - & - & - & $\begin{array}{l}\text { Cornus } \\
\text { controversa }\end{array}$ \\
\hline Cilix glaucata & Singly ${ }^{5}$ & - & - & None $^{5}$ & $\begin{array}{l}\text { Prunus spp., } \\
\text { Crataegus spp., } \\
\text { Malus spp., } \\
\text { Pyrus spp., } \\
\text { Sorbus } \\
\text { aucuparia, Rubus } \\
\text { fruticosis s. } l^{5}\end{array}$ \\
\hline Drepana arcuata & Rows of $2-10$ & Groups of 3-29 & Solitary & $\begin{array}{l}\text { Folded } \\
\text { leaf }\end{array}$ & $\begin{array}{l}\text { Birch } \\
\text { alder }^{7} \text { Birch, }\end{array}$ \\
\hline D. curvatula & $\begin{array}{l}\text { Rows of } 4- \\
11^{4} ; \text { Rows up } \\
\text { to } 12^{5}\end{array}$ & Small groups ${ }^{5}$ & Solitary & $\begin{array}{l}\text { Folded } \\
\text { leaf }\end{array}$ & $\begin{array}{l}\text { Alnus hirsuta var. } \\
\text { sibirica }{ }^{4} \text {; Birch, } \\
\text { alder, sometimes } \\
\text { oak and willow }\end{array}$ \\
\hline D. falcataria & Short rows ${ }^{5}$ & Solitary $^{5}$ & Solitary & $\begin{array}{l}\text { Folded } \\
\text { leaf }\end{array}$ & $\begin{array}{l}\text { Birch, alder, oak, } \\
\text { willow, poplar, } \\
\text { but raised } \\
\text { successfully on } \\
\text { birch }^{5}\end{array}$ \\
\hline Falcaria bilineata & Rows of $2-10$ & Solitary & Solitary & Silk mat & $\operatorname{Birch}^{8}$ \\
\hline$F$. lacertinaria & $\begin{array}{l}\text { Groups of } 2 \text { or } \\
\text { rows of } 3-5^{5}\end{array}$ & - & - & Silk mat ${ }^{9}$ & Birch, alder ${ }^{5}$ \\
\hline Oreta loochooana & Singly ${ }^{3}$ & - & - & - & $\begin{array}{l}\text { Viburnum } \\
\text { odoratissium, } V . \\
\text { luzonicus var. } \\
\text { formosanum }\end{array}$ \\
\hline O. rosea & $\begin{array}{l}\text { Short rows or } \\
\text { singly }\end{array}$ & Solitary & Solitary & Silk mat & Viburnum $^{7}$ \\
\hline Sabra harpagula & Singly ${ }^{5}$ & Solitary ${ }^{5}$ & Solitary ${ }^{5}$ & $\begin{array}{l}\text { Folded } \\
\text { leaf }\end{array}$ & $\begin{array}{l}\text { Linden-tree } \\
\text { (Tilia), oak, } \\
\text { alder, birch }\end{array}$ \\
\hline Tridrepana flava & Singly $^{3}$ & - & - & - & Eurya japonica $^{3}$ \\
\hline T. unispina & Singly ${ }^{3}$ & - & - & - & $\begin{array}{l}\text { Castanopsis } \\
\text { formosana }\end{array}$ \\
\hline $\begin{array}{l}\text { Watsonalla } \\
\text { binaria }\end{array}$ & $\begin{array}{l}\text { Singly or in } \\
\text { groups of } 2-5^{5}\end{array}$ & $\begin{array}{l}\text { Small groups of } \\
2-5^{5}\end{array}$ & & $\begin{array}{l}\text { Folded } \\
\text { leaf }\end{array}$ & $\begin{array}{l}\text { Oak, beech, } \\
\text { alder, birch }\end{array}$ \\
\hline W. cultraria & $\begin{array}{l}\text { Singly or in } \\
\text { groups of } 2-4^{5}\end{array}$ & $\begin{array}{l}\text { Small groups of } \\
2-5^{5}\end{array}$ & Solitary & Silk mat & Beech $^{5}$ \\
\hline W. uncinula & - & $\begin{array}{l}\text { Small groups of } \\
2-5^{5}\end{array}$ & - & - & Oak $^{5}$ \\
\hline
\end{tabular}




\begin{tabular}{|c|c|c|c|c|c|}
\hline Taxon & Egg Laying & $\begin{array}{c}\text { Early instar } \\
\text { Gregariousness }\end{array}$ & $\begin{array}{c}\text { Late instar } \\
\text { Gregariousness }\end{array}$ & $\begin{array}{c}\text { Leaf } \\
\text { Shelter }\end{array}$ & Hostplant \\
\hline \multicolumn{6}{|l|}{ Thyatirinae } \\
\hline Euthyatira pudens & - & - & - & $\begin{array}{l}\text { Loose } \\
\text { shelters } \\
\text { or none }^{10}\end{array}$ & - \\
\hline $\begin{array}{l}\text { Habrosyne } \\
\text { pyritoides }\end{array}$ & $\begin{array}{l}\text { Small } \\
\text { groups }^{11}\end{array}$ & - & - & $\begin{array}{l}\text { Two } \\
\text { leaves }\end{array}$ & $\begin{array}{l}\text { Rubus spp. } \\
\text { especially Rubus } \\
\text { idaeus and } R \text {. } \\
\text { fruticosus }{ }^{11}\end{array}$ \\
\hline $\begin{array}{l}\text { Ochropacha } \\
\text { duplaris }\end{array}$ & $\begin{array}{l}\text { Singly or in } \\
\text { groups of } 2- \\
3\end{array}$ & Solitary ${ }^{11}$ & Solitary & $\begin{array}{l}\text { Two } \\
\text { leaves }\end{array}$ & $\begin{array}{l}\text { Betula pendula, } \\
\text { Alnus glutinosa, } \\
\text { Alnus viridis, } \\
\text { Quercus spp., } \\
\text { Populus spp. }\end{array}$ \\
\hline $\begin{array}{l}\text { Pseudothyatira } \\
\text { cymatophoroides }\end{array}$ & - & - & - & $\begin{array}{l}\text { Folded } \\
\text { leaf or } \\
\text { two } \\
\text { leaves }\end{array}$ & - \\
\hline Tethea or & $\begin{array}{l}\text { Singly or in } \\
\text { small groups }\end{array}$ & Solitary & Solitary & $\begin{array}{l}\text { Two } \\
\text { leaves }\end{array}$ & $\begin{array}{l}\text { Populus spp.; } \\
\text { Salix spp. }\end{array}$ \\
\hline Tetheela fluctuosa & $\begin{array}{l}\text { Singly or } \\
\text { rarely in } \\
\text { pairs }{ }^{11}\end{array}$ & Solitary ${ }^{11}$ & Solitary & $\begin{array}{l}\text { Two } \\
\text { leaves }\end{array}$ & $\begin{array}{l}\text { Betula pendula, } \\
\text { Populus tremula, } \\
\text { Alnus glutinosa }\end{array}$ \\
\hline Thyatira batis & $\begin{array}{l}\text { Small } \\
\text { groups }{ }^{\prime \prime} \\
\text { Singly or in } \\
\text { pairs }\end{array}$ & Solitary ${ }^{11}$ & Solitary & Silk mat & $\begin{array}{l}\text { Rubus spp. } \\
\text { especially Rubus } \\
\text { idaeus }{ }^{11}\end{array}$ \\
\hline
\end{tabular}

'S.-H. Yen, personal communication; ${ }^{2}$ (Minet \& Scoble, 1999); ${ }^{3}$ (Sen \& Lin, 2002); ${ }^{4}$ (Nakajima, 1970); ${ }^{5}$ (Bryner, 1999); ${ }^{6}\left(\right.$ Beutenmüller, 1898); ${ }^{7}$ (Dyar, 1895); ${ }^{8}$ (Dyar, 1884);

${ }^{9}$ (Newman, 1884); ${ }^{10}$ (Wagner, 2005); ${ }^{11}$ (Riegler, 1999) 
leaves together with silk strands, living in the space between ( 5 species). Often, species that fold leaves or tie two leaves together will also lay a silk mat. Hostplants were highly variable between species, with birch (Betula spp.) and alder (Alnus spp.) being the most common.

Morphology

Morphology of the mandibles, setae on the abdominal prolegs on A3-6, and morphology of the anal segment varied across taxa (Table 2.3). The distal edge of the incisor region of mandibles was found to be either completely smooth (four species) or have between three to eight teeth (14 species). The oral surface was also found to be completely smooth (four species) or contain between one and four ridges (12 species). Species that had smooth distal edges did not necessarily have smooth oral surfaces and vice-versa. Two species (O. rosea and $C$. substigmaria) had a group of small secondary setae on the outer planta region of the abdominal prolegs (excluding the anal prolegs), while 16 species had only three setae (SV1, SV2 and SV3). In nine of those species, the outer two (SV1 and SV3) were modified (wider than the SV2 setae), and SV2 was unmodified. All species that had modified seta were from the Drepaninae subfamily. The anal prolegs were categorized as being fully formed (equal in area (width at the widest part multiplied by total length from the body to the crochets) to the other abdominal prolegs and bearing full crochets; 8 species), reduced (smaller than the abdominal prolegs, but still bearing crochets; 12 species), or absent (and bearing no crochets; 23 species). Anal segments also varied in the presence or absence of a caudal projections (a single projection from the dorsal anal segment), and these were classified as being short 
Table 2.3. Morphology characteristics relevant to vibrational communication in

Drepanidae larvae and outgroups included in my study.

\begin{tabular}{|c|c|c|c|c|c|c|}
\hline \multirow[t]{2}{*}{ Taxon } & \multicolumn{2}{|c|}{ Mandibles } & \multirow{2}{*}{$\begin{array}{c}\text { Abdominal } \\
\text { Prolegs (A3) } \\
\text { SV1 \& SV3 } \\
\text { Setae }\end{array}$} & \multicolumn{3}{|c|}{ Anal Segment } \\
\hline & $\begin{array}{l}\text { Distal } \\
\text { Teeth }\end{array}$ & $\begin{array}{l}\text { Ridges } \\
\text { on Oral } \\
\text { Surface }\end{array}$ & & $\begin{array}{c}\text { Anal } \\
\text { Prolegs }\end{array}$ & $\begin{array}{c}\text { Caudal } \\
\text { Projection }\end{array}$ & PP1 Setae \\
\hline $\begin{array}{l}\text { INGROUP TAXA } \\
\text { Cyclidiinae }\end{array}$ & & $25=1$ & & 30 & & 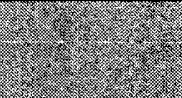 \\
\hline Cyclidia substigmaria & 3 & 3 & Unmodified & Full & None & Unmodified \\
\hline Drepaninae & s. & 8 & & & & \\
\hline $\begin{array}{l}\text { Agnidra scabiosa } \\
\text { scabiosa } \\
\text { Ausaris micacea }\end{array}$ & - & - & - & None & $\begin{array}{l}\text { Long, } \\
\text { filiform } \\
\text { Short fleshy }\end{array}$ & $\begin{array}{l}\text { Unmodified } \\
\text { Unmodified }\end{array}$ \\
\hline Ausaris palleolus & - & - & - & None $e^{1}$ & $\begin{array}{l}\text { Short, } \\
\text { fleshy }\end{array}$ & $\underset{1}{\text { Unmodified }}$ \\
\hline Auzata superba & - & - & - & None ${ }^{1}$ & $\begin{array}{l}\text { Short, } \\
\text { fleshy }\end{array}$ & $\underset{1}{\text { Unmodified }}$ \\
\hline Cilix glaucata & 0 & 4 & Modified & None & Short, fleshy & Double \\
\hline Drepana arcuata & 6 & 2 & Modified & None & Short, fleshy & Oar \\
\hline Drepana curvatula & 4 & 0 & Modified & None & Short, fleshy & Oar \\
\hline Drepana falcataria & 5 & 2 & Modified & None & Short, fleshy & Oar \\
\hline Falcaria bilineata & 3 & 2 & Modified & None & Short, fleshy & Rectangle \\
\hline Falcaria lacertinaria & 6 & 2 & Modified & None & Short, fleshy & Rectangle \\
\hline Macrauzata maxima & - & - & - & None ${ }^{l}$ & $\begin{array}{l}\text { Short, } \\
\text { filiform }\end{array}$ & Unmodified \\
\hline $\begin{array}{l}\text { Microblepsis } \\
\text { acuminata }\end{array}$ & - & - & - & None ${ }^{l}$ & $\begin{array}{l}\text { Long, } \\
\text { filiform }\end{array}$ & $\mathrm{Peg}^{2}$ \\
\hline Nordstromia grisearia & - & - & - & None $^{2}$ & $\begin{array}{l}\text { Short, } \\
\text { fleshy }^{2}\end{array}$ & $\mathrm{Peg}^{2}$ \\
\hline Oreta loochooana & - & - & - & None $^{3}$ & $\begin{array}{l}\text { Long, } \\
\text { fleshy }{ }^{3}\end{array}$ & $\underset{3}{\text { Unmodified }}$ \\
\hline Oreta pulchripes & - & - & - & None' & $\begin{array}{l}\text { Long, } \\
\text { fleshy }\end{array}$ & $\underset{1}{\text { Unmodified }}$ \\
\hline Oreta rosea & 6 & 1 & Unmodified & None & Long, fleshy & None \\
\hline Oreta turpis & - & - & - & None ${ }^{\prime}$ & $\begin{array}{l}\text { Long, } \\
\text { fleshy }\end{array}$ & Unmodified \\
\hline Sabra harpagula & - & - & - & None ${ }^{l}$ & $\begin{array}{l}\text { Short, } \\
\text { fleshy }\end{array}$ & Obtuse \\
\hline Tridrepana flava & - & - & - & None & Long, fleshy & Thick \\
\hline Tridrepana unispina & - & - & - & None $^{3}$ & $\begin{array}{l}\text { Long, } \\
\text { fleshy }\end{array}$ & Laminate $^{3}$ \\
\hline Watsonalla binaria & 0 & 0 & Modified & None & Short, fleshy & Unmodified \\
\hline Watsonalla cultraria & 0 & 0 & Modified & None & Short, fleshy & Unmodified \\
\hline Watsonalla uncinula & 0 & 1 & Modified & None & Short, fleshy & Unmodified \\
\hline
\end{tabular}




\begin{tabular}{|c|c|c|c|c|c|c|}
\hline \multirow[t]{2}{*}{ Taxon } & \multicolumn{2}{|c|}{ Mandibles } & \multirow{2}{*}{$\begin{array}{c}\text { Abdominal } \\
\text { Prolegs (A3) } \\
\text { SV1 \& SV3 } \\
\text { Setae }\end{array}$} & \multicolumn{3}{|c|}{ Anal Segment } \\
\hline & $\begin{array}{l}\text { Distal } \\
\text { Teeth }\end{array}$ & $\begin{array}{l}\text { Ridges } \\
\text { on Oral } \\
\text { Surface }\end{array}$ & & $\begin{array}{c}\text { Anal } \\
\text { Prolegs }\end{array}$ & $\begin{array}{c}\text { Caudal } \\
\text { Projection }\end{array}$ & PP1 Setae \\
\hline \multicolumn{7}{|l|}{ Thyatirinae } \\
\hline $\begin{array}{l}\text { Euparyphasma } \\
\text { maxima }\end{array}$ & - & - & - & Reduced $^{4}$ & None $^{4}$ & - \\
\hline Euthyatira pudens & $\mathrm{Y}^{*}$ & - & - & Reduced & None & Unmodified \\
\hline Habrosyne aurorina & - & - & - & Reduced $^{4}$ & None $^{4}$ & - \\
\hline Habrosyne pyritoides & 8 & 2 & Unmodified & Reduced & None & Unmodified \\
\hline Neodaruma tamanukii & - & - & - & Reduced & None & Unmodified \\
\hline Ochropacha duplaris & 6 & 1 & Unmodified & Reduced & None & Unmodified \\
\hline $\begin{array}{l}\text { Pseudothyatira } \\
\text { cymatophoroides }\end{array}$ & $Y$ & - & Unmodified & Reduced & None & Unmodified \\
\hline Tethea consimilis & - & - & - & Reduced $^{4}$ & None $^{4}$ & - \\
\hline Tethea oberthuri & - & - & - & Reduced $^{4}$ & None $^{4}$ & - \\
\hline Tethea or & 4 & 0 & Unmodified & Reduced & None & Unmodified \\
\hline Tetheela fluctuosa & 6 & 3 & Unmodified & Reduced & None & Thick \\
\hline Thyatira batis & 5 & 3 & Unmodified & Reduced & None & Unmodified \\
\hline \multicolumn{7}{|l|}{ OUTGROUP TAXA } \\
\hline $\begin{array}{l}\text { Accinctapubes } \\
\text { albifasciata (Pyralidae: } \\
\text { Epipaschiinae) }\end{array}$ & - & - & - & Full $^{5}$ & None $^{5}$ & None \\
\hline $\begin{array}{l}\text { Ennomos autumnaria } \\
\text { (Geometridae: } \\
\text { Ennominae) }\end{array}$ & - & - & - & Full $^{6}$ & None $^{6}$ & - \\
\hline $\begin{array}{l}\text { Epicopeia hainesii } \\
\text { hainesii (Epicopeiidae) }\end{array}$ & - & - & - & Full $^{7}$ & None $^{7}$ & - \\
\hline $\begin{array}{l}\text { Jodis putata } \\
\text { (Geometridae: } \\
\text { Geometrinae) }\end{array}$ & - & - & - & Full $^{6}$ & None $^{6}$ & None \\
\hline $\begin{array}{l}\text { Lyssa zampa zampa } \\
\text { (Geometridae: } \\
\text { Uraniinae) }\end{array}$ & - & - & - & Full $^{8}$ & None $^{8}$ & - \\
\hline $\begin{array}{l}\text { Psychostrophia } \\
\text { melanargia } \\
\text { (Epicopeiidae) } \\
\text { Nothus lunus } \\
\text { (Sematuridae: } \\
\text { Sematurinae) }\end{array}$ & - & - & - & Full $^{4}$ & None $^{4}$ & - \\
\hline
\end{tabular}

*In the distal teeth category, if the number of teeth could not be counted, a $\mathrm{Y}$ represents the presence of teeth and an $\mathrm{N}$ represents no teeth (or smooth).

${ }^{1}$ (Nakajima, 1970); ${ }^{2}$ Nakajima, 1972); ${ }^{3}$ (Sen \& Lin, 2002); ${ }^{4}$ (Stehr, 1987); ${ }^{5}$ (Solis \& Styer, 2003); ${ }^{6}$ (Skou, 1986); ${ }^{7}$ (Yen et al., 1995); ${ }^{8}$ (Holloway, 1998); ${ }^{9}$ S.-H. Yen, personal communication 
(17 species) or long ( 6 species) (long was quantified as longer than the length of A7A10), fleshy (20 species) or filiform (3 species) (as characterized by Nakajima, 1970, 1972, where fleshy represents thicker projections, and filiform represents projections that resemble a thread, or filament), or absent. In addition to these variables, the condition of the pair of posterior proctor (PP1) setae (one on each side) found on the anal segment differed between taxa, where the PP1 setae were broadly classified as unmodified (no wider than the surrounding seta found on the anal segment (L2, L3 and SV1); 17 species), thickened (cylindrically shaped, but wider than the L2, L3 and SV1 setae; 4 species), or paddle-shaped (four-sided with unequal adjacent sides, and wider than the L2, L3 and SV1 setae; 8 species). Within these general categories for PP1, further variation was observed, including two variations in thickened setae and six variations in paddle-shaped setae (described in more detail in Chapter 4).

Behavioural trials between conspecifics

The following data will be used to test the hypothesis that vibratory signals function for territoriality in Drepanidae caterpillars. Outcomes and details of contests varied between species (Table 2.4). On average, residents won $63.9 \pm 38.7 \%$ of trials, intruders won $1.7 \pm 3.0 \%$, and $34.4 \pm 39.2 \%$ ended in ties $(\mathrm{N}=7)$. In one species, all trials were won by the resident (Tethea or; $\mathrm{n}=11$ ), and in two others, all trials ended with both contestants remaining on the leaf (Cyclidia substigmaria, $\mathrm{n}=7$; Thyatira batis, $\mathbf{n}=7$ ). Residents of all species remained silent until they detected an intruder. Residents signaled at a mean distance of $12.85 \pm 10.86 \mathrm{~mm}(\mathrm{n}=6)$ from the intruder's head to the closest point on the resident's body. Resident signalling rates increased as the intruder 
Table 2.4. Outcomes and details of trials in 10 species of Drepanidae.

\begin{tabular}{|c|c|c|c|c|c|c|c|c|}
\hline Taxon & $\begin{array}{l}\text { \# of } \\
\text { Trials }\end{array}$ & $\begin{array}{c}\text { Mean Trial } \\
\text { Duration (s) }\end{array}$ & $\begin{array}{c}\text { \# of } \\
\text { Trials } \\
\text { Won by } \\
\text { R }\end{array}$ & $\begin{array}{c}\text { \# of } \\
\text { Trial } \\
\text { Won by } \\
\text { I }\end{array}$ & $\begin{array}{l}\text { \# of } \\
\text { Ties }\end{array}$ & $\begin{array}{c}\text { \# of } \\
\text { Trials in } \\
\text { which } R \\
\text { Signaled }\end{array}$ & $\begin{array}{c}\text { \# of } \\
\text { Trials in } \\
\text { Which I } \\
\text { Signaled }\end{array}$ & $\begin{array}{l}\text { Distance at } \\
\text { First Signal } \\
(\mathrm{mm})\end{array}$ \\
\hline \multicolumn{9}{|l|}{ Drepaninae } \\
\hline $\begin{array}{l}\text { Drepana } \\
\text { arcuata }\end{array}$ & 53 & $\begin{array}{l}339.2 \pm 381.06 \\
(\mathrm{n}=44)^{* *}\end{array}$ & 43 & 1 & 9 & 53 & 20 & $\begin{array}{l}23.9 \pm 12.4 \\
(n=10)\end{array}$ \\
\hline D. curvatula & 11 & $\begin{array}{l}574.3 \pm 466.3 \\
(\mathrm{n}=7)\end{array}$ & $\begin{array}{l}7 \\
(n=10)\end{array}$ & $\begin{array}{l}0 \\
(n=10)\end{array}$ & $\begin{array}{l}3 \\
(n=10)\end{array}$ & 11 & 8 & $28.1 \pm 19.7$ \\
\hline D. falcataria & 3 & $412.2 \pm 65.9$ & 3 & 0 & 0 & 3 & 0 & $12.3 \pm 13.9$ \\
\hline $\begin{array}{l}\text { Falcaria } \\
\text { bilineata }\end{array}$ & 54 & $\begin{array}{l}370.4 \pm 327.8 \\
(n=37)\end{array}$ & 33 & 4 & 17 & 46 & 20 & $\begin{array}{l}2.4 \pm 1.6 \\
(n=43)\end{array}$ \\
\hline Oreta rosea & 22 & $\begin{array}{l}457.4 \pm 330.7 \\
(n=21)\end{array}$ & 20 & 1 & 1 & 16 & 9 & $\begin{array}{l}7.7 \pm 9.1 \\
(n=19)\end{array}$ \\
\hline $\begin{array}{l}\text { Watsonalla } \\
\text { cultraria* } \\
\text { Thyatirinae }\end{array}$ & 3 & NA & NA & NA & NA & 3 & 1 & NA \\
\hline $\begin{array}{l}\text { Ochropacha } \\
\text { duplaris }^{*}\end{array}$ & 6 & NA & NA & NA & NA & 6 & 0 & NA \\
\hline Tethea or & 11 & $127.9 \pm 104.3$ & 11 & 0 & 0 & 10 & 0 & $\begin{array}{l}23.8 \pm 50.2 \\
(\mathrm{n}=10)\end{array}$ \\
\hline $\begin{array}{l}\text { Tetheela } \\
\text { fluctuosa }\end{array}$ & 5 & $\begin{array}{l}125.2 \pm 0.0 \\
(n=1)\end{array}$ & $\begin{array}{l}1 \\
(n=1)\end{array}$ & $\begin{array}{l}0 \\
(n=1)\end{array}$ & $\begin{array}{l}0 \\
(n=1)\end{array}$ & 2 & 0 & $\begin{array}{l}2.8 \pm 0.0 \\
(\mathrm{n}=1)\end{array}$ \\
\hline Thyatira batis & 7 & NA & 0 & 0 & 7 & 7 & 1 & NA \\
\hline
\end{tabular}

*No full trials were examined for $W$. cultraria and $O$. duplaris, therefore, some of the data for these species could not be measured; ${ }^{* *}$ Sample sizes are included in individual columns only when they differed from the total number of trials found in Column 2. 
approached in most species, where anal scraping was produced at the highest rates at CLOSE (2.29 \pm 0.50 signals $/ 5 \mathrm{~s} ; \mathrm{n}=4)$, and lateral tremulation being produced at the lowest rate $(0.33 \pm 0.49$ signals $/ 5 \mathrm{~s} ; \mathrm{n}=6)$. Specific details on behavioural rates can be found in Tables A.1. Intruders signaled in $22.0 \pm 25.69 \%$ of trials where signalling occurred, signalling first in $6.5 \pm 8.6 \%$ of trials.

Analysis of vibrations

Caterpillars produced vibrations on the leaf during territorial interactions by mandible scraping, mandible drumming, anal scraping, lateral tremulation, buzzing (similar to lateral tremulation but in the vertical direction), crawling towards the intruder, lateral head hitting, lateral tail hitting, twitching, and pushing. Each species had its own repertoire of vibration producing behaviours (Table 2.5). All caterpillars also produced vibrations by crawling in a general context. Mandible scraping, mandible drumming, anal scraping, lateral tremulation, and buzzing were produced in bouts. Properties of vibrations, including temporal and spectral characteristics, and relative amplitudes varied across taxa (Table A.1). Durations, amplitudes and spectral properties will be compared between behaviours in detail in Chapters 4 and 5 . Vibration properties for lateral tail hitting could not be analyzed due to a lack of laser files of this behaviour. Properties for pushing are the same as for crawling towards the intruder, and in some cases properties of anal scraping could not be measured as they were always accompanied by lateral tremulation events. 
Table 2.5. Behavioural repertoires in species of Drepanidae studied to date.

\begin{tabular}{|l|l|}
\hline Taxon & Behaviour(s) Produced \\
\hline Drepaninae & AS, LHH, MD, MS \\
Drepana arcuata & AS, B, LHH, MD, MS \\
D. curvatula & AS, B, LHH, MD, MS \\
D. falcataria & AS, LHH, LTH, MD \\
Falcaria bilineata & LT, LTH, MD, MS \\
Oreta rosea & AS, LHH, LT, LTH, MD \\
Watsonalla cultraria & C, LHH, LTH, MS, P \\
Thyatirinae & C, LHH, MS, P \\
Ochropacha duplaris & AS, C, LHH, LT, LTH, MS \\
Tethea or & AS, LHH, LT, LTH, T \\
Tetheela fluctuosa & Thyatira batis \\
Cyclidia substigmaria
\end{tabular}

$\mathrm{AS}=$ anal scraping; $\mathrm{B}=$ buzzing $\mathrm{C}=$ crawling towards intruder; $\mathrm{LHH}=$ lateral head hitting; $\mathrm{LT}=$ lateral tremulation; $\mathrm{LTH}=$ lateral tail hitting; $\mathrm{MD}=$ mandible drumming; MS = mandible scraping; $P=$ pushing; $T=$ twitching 


\subsection{Discussion}

My results demonstrate that variation exists in life-history traits, morphology, territorial behaviours and vibrations produced during encounters with conspecifics in caterpillars of the Drepanidae. Life-history, morphological, behavioural and vibration information obtained in this chapter will be used to test specific hypotheses in later chapters concerning the evolutionary origins of these signals (Chapters $4 \& 5$ ) and answer questions on the evolution of signalling (Chapter 6).

Variation in vibrational signalling in caterpillars

An additional goal of this chapter was to provide some much needed information on vibratory signalling in caterpillars. Vibratory signals are widespread in small herbivorous insects and are reported in at least 18 orders to date (Cocroft, 2001; VirantDoberlet \& Cokl, 2004; Cocroft \& Rodriguez, 2005; Hill, 2009). Drumming with the head or mandibles in a communicatory context is reported in a number of other insects, including termites (Röhrig et al., 1999; Rosengaus et al., 1999), death-watch beetles (Birch \& Keenlyside, 1991) and carpenter ants (Fuchs, 1976). In caterpillars, drumming has been described formally in two species of Drepaninae to date, D. arcuata (Yack et al., 2001) and F. bilineata (Bowen et al., 2008), and one species of Tortricidae, Sparganothis pilleriana (Russ, 1969). Behavioural observations of mandible drumming have been noted in six Drepaninae species to date (D. falcataria: Bryner, 1999, I. Hasenfuss, personal communication; D. lacertinaria, W. binaria, W. unicinula: I. Hasenfuss, personal communication; Nordstromia lilacina and Tridrepana arikana: Sen \& Lin, 2002), and I have added behavioural information on four species (D. curvatula, $D$. 
falcataria, $O$. rosea, and $W$. cultraria), suggesting that drumming may be ubiquitous in this subfamily of caterpillars.

Mandible scraping has been less frequently reported in insects, being noted in the larvae of the oriental hornet, Vespa orientalis, where they function as hunger signals (Ishay et al., 1974), and in only a few species of caterpillars to date. In larval Lepidoptera, mandible scraping has been experimentally tested and characterized in two species, D. arcuata (Yack et al., 2001) and the cherry leaf roller, Caloptilia serotinella (Fletcher et al., 2006). Behavioural observations of scraping have been noted in a few other Drepanidae species (D. falcataria, F. lacertinaria, W. binaria and $W$. uncinula: I. Hasenfuss, personal communication). In this thesis I observed and characterized mandible scraping in six species of Drepanidae (D. curvatula, D. falcataria, $O$. rosea, $O$. duplaris, T. fluctuosa, and T. or), which suggests that it may represent an important mechanism of vibrational signalling in this subfamily.

Anal scraping signals have been observed in larvae of the sawfly, Hemicroa crocea (possibly to orient other larvae to high-quality feeding sites (Hoegraefe, 1984)), and in some species of ants and caddisflies (reviewed in Virant-Doberlet \& Cokl, 2004). Other species of insects drum the tip of the abdomen on the substrate to produce percussion signals, such as in some sawfly larvae (Perga spp.) that tap a sclerotized portion of the abdominal tail on the substrate for group coordination (Carne, 1962; Fletcher, 2007). Anal scraping has been implicated from behavioural observations in a few other Drepanidae species to date (D. falcataria: Federley, 1905; Bryner, 1999, I. Hasenfuss, personal communication; D. curvatula: Federley, 1905; D. lacertinaria, $W$. binaria, and $W$. uncinula: Federley, 1905; I. Hasenfuss, personal communication; $D$. 
arcuata: Yack et al., 2001; N. lilacina and T. arikana: Sen \& Lin, 2002; F. bilineata: Bowen et al., 2008), and I have added behavioural information on five species ( $D$. curvatula, D. falcataria, W. cultraria, T. fluctuosa, and T. batis).

Tremulation (i.e. vibrating) is believed to be one of the most simple and widespread vibrational signal production mechanisms in insects (Virant-Doberlet \& Cokl, 2004). Tremulation has been reported in a number of insect orders, including species of Orthoptera, Plecoptera, Neuroptera, Coleoptera, Diptera, Trichoptera, Lepidoptera, Hymenoptera, and many others (reviewed in Virant-Doberlet \& Cokl, 2004). Tremulation has been reported in one other species of caterpillar, C. serotinella (Fletcher et al., 2006). In this thesis, I demonstrate tremulation occurs in at least six species of Drepanidae, in two different forms: lateral tremulation (lateral direction; $O$. rosea, W. cultraria, $T$. fluctuosa, and Thyatira batis) and buzzing (vertical direction; D. curvatula and D. falcataria).

Potential sensory structures

There is some evidence that Drepanidae caterpillars are able to detect vibrations on the leaf surface. For example, in D. arcuata, when leaves are cut leaving the resident and intruder on opposite sides, the resident does not produce territorial signals, but begins to signal if the leaf sections are taped back together (Guedes et al., 2012). This finding suggests that the resident is able to detect the vibrations produced by the crawling movements of the approaching intruder. Intruders also take over empty nests, or nests that contain a recently-killed resident, providing evidence that it is the signals produced by the resident that deters intruders (Yack et al., 2001). Although it is clear that vibrational communication plays an important role during territorial interactions in these 
caterpillars, it is currently unknown how they receive these vibrations. It has been suggested that setae present on the abdominal prolegs on A3-6 are putative receptor structures, as chordotonal organs have been identified in these prolegs in at least two species of Drepanidae larvae (D. arcuata and W. uncinula; I. Hasenfuss, personal communication). As such, I have examined the morphology of setae on the proleg on A3 and found that some species possess modified SV1 and SV3 setae, which are thicker than the SV2 setae, and sclerotized. These setae are in contact with the substrate while the caterpillar is at rest. Modified SV1 and SV3 setae are present in all species of Drepaninae that I examined, except $O$. rosea, and in none of the Cyclidiinae and Thyatirinae species. Since the Thyatirinae species also produce (and presumably receive vibrations), the role of these sclerotized setae in vibration reception remains unclear. Future studies should concentrate on locating other possible vibration receptors in these caterpillars, by ablating setae or other putative receptor structures and testing for loss of vibration reception. Territorial behaviour in caterpillars

In concordance with some Drepanidae species, other species of caterpillars have been found to defend territories using physical aggression, and in some cases, this can escalate to serious injury or death to one of the contestants (Weyh \& Maschwitz, 1982; Okuda, 1989; Berenbaum et al., 1993). Shelters are valuable to own, providing a more stable microclimate, protection from predators and displacement, and enhanced quality of food (Fukui, 2001). Shelters are also costly, requiring both time and energy to build (Ruggiero \& Merchant, 1986; Fitzgerald et al., 1991; Berenbaum et al., 1993; Cappuccino, 1993; Fitzgerald \& Clark, 1994). Therefore, caterpillars defend these shelters against intruding conspecifics using either physical aggression or ritualized 
signaling. Physically aggressive territorial behaviours observed in other caterpillars include striking with the head (e.g. Oecophoridae: Depressaria pastinacella; Berenbaum et al., 1993), biting (e.g. Noctuidae: Busseola fusca; Okuda, 1989) and even killing opponents (e.g. Pieridae: Anthocharis cardamines; Baker, 1983). If physical aggression is costly, leading to serious injury or death to either the resident or the intruder, ritualized signalling may have evolved in some species to avoid those costs. Physically aggressive behaviours, therefore, are likely candidates for the behavioural origins of signals. This, along with preliminary comparisons of characters studied in this chapter, has led me to the hypothesis that ritualized signals in the Drepanidae derive from physically aggressive behaviours. This will be tested using a comparison of morphological, behavioural, and vibrational data between species, within a phylogenetic framework in Chapters $4 \& 5$ of this thesis. Before testing these hypotheses, however, it is first necessary to develop a phylogeny of the Drepanidae in order to provide an evolutionary framework, which is the focus of Chapter 3 . 


\section{Chapter 3}

\section{Molecular Phylogeny of The DRePanidae}

\section{This chapter will form the following manuscript:}

Scott, J. L., Kawahara, A. K., Skevington, J. H., Yen, S. -H., Sami, A., Smith, M. L. \& Yack, J. E. Molecular phylogeny of Drepanidae (in preparation, journal to be decided)

The phylogeny was first introduced in the following manuscript:

Scott, J. L., Kawahara, A. K., Skevington, J. H., Yen, S. -H., Sami, A., Smith, M. L. \& Yack, J. E. (2010). The evolutionary origins of ritualized acoustic signals in caterpillars. Nature Communications 1, 4; doi: 10.1038/ncomms1002. 


\subsection{Introduction}

In order to formally test hypotheses on the evolutionary origins of animal communication signals, it is beneficial to understand the phylogenetic relationships between species used for behavioural comparisons. Phylogenetic trees provide a framework onto which behavioural and morphological characters can be mapped to determine the evolutionary history of a trait. Previous studies focusing on the origin of signals have often lacked this phylogenetic framework. For example, although Schenkel (1956) proposed through behavioural comparisons between species of Phasianidae that the peacock tail-fan display derives from pecking at the ground and offering food to females, he did not provide evidence that pecking behaviour and tail-fanning represent the basal and derived conditions, respectively. This study, and many others (see General Introduction), would have benefitted greatly from a solid phylogenetic framework to provide further evidence for their hypotheses. Since a major goal of my thesis is to determine the evolutionary origins of vibratory signals in the Drepanoidea, it is important to first gain an understanding of the relationships between species in this group.

Until very recently, relationships of Drepanoidea moths were not very well understood. The Drepanoidea is believed to be most closely related to the Geometroidea (Minet \& Scoble, 1999), and was even previously placed within the Geometroidea due to the presence of abdominal tympanal organs in the adults (Imms, 1934). The Drepanoidea was thought to comprise two families, Drepanidae and Epicopeiidae, Drepanidae being further divided into Drepaninae, Thyatirinae and Cyclidiinae subfamilies (Minet, 1991; Minet \& Scoble, 1999). In the past, authors have also considered Drepanidae, Thyatiridae and Cyclidiidae to be separate families (Inoue, 1954; Nakamura, 1981). Epicopeiidae was 
assigned to the Drepanoidea by Minet (1991), based on four autapomorphies, including the following: (i) setae of the larval mandible are inserted on a large, flat, lateral area delimited ventrally by a projecting line; (ii) at least one secondary seta is associated with L3 on the abdominal segments 1-8 of the larva; (iii) the femur of the pupal foreleg is concealed or very slightly exposed; and (iv) the adult abdomen has a lateral complete prespiracular sclerite, interconnecting the first sternite with the lateral bar of the first tergite, which is modified into tympanal organs in the Drepanidae. Despite the fact that other authors have placed Epicopeiidae within the Uranoidea (Imms, 1934; Inoue, 1954; Zhu \& Wang, 1991; Kuznetzov \& Stekolnikov, 2001), Minet's (1991) definition of the Drepanoidea has been widely accepted (Scoble, 1992; Holloway, 1998; Minet \& Scoble, 1999; Holloway et al., 2001; Kristensen et al., 2007). Contrary to this definition, recent molecular studies suggest that Epicopeiidae be placed either next to or within the Geometroidea, as a sister-group to Sematuridae (Regier et al., 2009) or Uraniidae (Wu et al., 2009). A molecular phylogenetic study by Mutanen et al. (2010) found that Epicopeiidae forms a sister-group with the Lasiocampoidea, which may also have some support from morphological findings. The taxonomic status of Epicopeiidae is therefore still under consideration, and needs to be further validated by other molecular phylogenetic studies.

There has been some debate on whether Drepaninae should be further divided into subgroups based on adult body colour, proboscis and frenulum, forewing colour and shape, hind tibial spurs, larval secondary setae, and supracoxal vesicle (reviewed in Wu et al., 2009). Based on these characters, many authors believe that Drepaninae should be either divided into two subfamilies, Drepaninae and Oretinae (Inoue, 1962; Nakajima, 
1970; Wilkinson, 1972; Zhu \& Wang, 1991; Smetacek, 2002), or into two subgroups at the tribal level, Drepanini and Oretini (Watson, 1965; Watson, 1967; Minet, 1985; Scoble, 1992; Holloway, 1998). More recent studies have even divided Drepaninae into three tribes, Nidarini, Oretini and Drepanini (Minet \& Scoble, 1999). Further investigation into the taxonomic status of the Oreta group is therefore still necessary. A preliminary phylogenetic study of the Drepanoidea using two molecular markers, EF-1 $\alpha$ and COI was conducted by Wu et al. (2009) to resolve some of the uncertainties surrounding the taxonomic status of the Drepanoidea and its groups. Although this study was deemed 'a pilot study' and included only 18 taxa, the results provided good support for the monophyly of each of Drepaninae, Thyatirinae, and Cyclidiinae subfamilies, and validated the sister relationship between Drepaninae and Thyatirinae as suggested by Minet (2002). Using molecular phylogenetic analysis, as well as morphological characters, Wu et al. (2009) suggested that Oreta should be separate from Drepaninae, with Oretinae restored as a sister-group, under the caveat that analysis of taxa that are not limited to China are required to provide further support. In terms of the taxonomic placement of Epicopeiidae, Wu et al. (2009) showed with both molecular and morphological support that Epicopeiidae has a closer phylogenetic relationship to Geometridae than to Drepanidae, and should therefore be placed within Geometroidea. This conclusion, however, was not supported by all of their molecular phylogenetic analyses, and still requires further consideration.

In order to further test some of the hypotheses on relationships within Drepanoidea, and also to surmise the evolutionary origin of vibratory signals in later chapters, I have chosen to construct a molecular phylogeny of Drepanoidea using three 
genes. There are several useful molecular markers for determining the relationships between groups of caterpillars and other insects. Some of the most widely used include the $16 \mathrm{~S}$ rDNA, 18S rRNA, 28S rRNA, elongation factor- $1 \alpha(\mathrm{EF}-1 \alpha)$, and cytochrome oxidases (COI and COII) (Caterino et al., 2000). Several studies in Lepidoptera have highlighted the importance of combined analyses of nuclear and mitochondrial genes, due to improved resolution of nodal support at both higher and intermediate systematic categories of divergence (Caterino et al., 2001; Monteiro, 2001; Wahlberg, 2003; Kandul et al., 2004; Zakharov et al., 2004). As such, I have chosen to create my trees using a combination of three genes that have proven to be useful in Lepidoptera, including one mitochondrial (ND1) and two nuclear genes (28S, CAD). The mitochondrial ND1 gene has been found to be useful below the superfamily level in Lepidoptera (Pashley \& Ke, 1992; Weller et al., 1994; Weller \& Pashley, 1995; Abraham et al., 2001). This gene is located between the 16S rRNA and the cytochrome $b$ genes in the Lepidoptera mitochondrial genome (Liao et al., 2010) and codes for a subunit of the enzyme NADHdehydrogenase, one of three enzymes responsible for the transport of electrons from NADH to oxygen to eventually form water (Weiss et al., 1991). The D2 expansion segment of the $28 \mathrm{~S}$ rRNA gene was chosen due to its high mutation rate and its known utility in insect phylogenetics (Gillespie, 2005). In insects, the 28S rRNA molecule consists of a set of conserved core elements, with 13 interspersed expansion segments (Hancock \& Dover, 1988; Hancock et al., 1988; Tautz et al., 1988). Unlike the core segments, the expansion segments are highly variable among insect orders (Hwang et al., 1998; Gillespie, 2005). The nuclear CAD gene, has also proven to be very informative for recovering deep relationships above the tribe level in other Lepidopteran taxa 
(Kawahara et al., 2009; Regier et al., 2009; Cho et al., 2011; Kawahara et al., 2011). CAD is a fusion protein that encodes for three enzymes of the de novo pyrimidine biosynthetic pathway and was first described for its utility in dipteran phylogenetics (Moulton \& Wiegmann, 2004).

The main goal of this chapter is to create a molecular phylogeny of the Drepanoidea using regions of the aforementioned three genes (28S, ND1 and CAD) including species that I will be studying in later chapters of this thesis to test hypotheses related to the origin of signals. Additionally, this chapter will also discuss, in light of this molecular phylogeny, some of the taxonomic issues still surrounding the Drepanoidea, including the status of Epicopeiidae and Oreta.

\subsection{Methods}

Specimens

Adult moths and larvae were obtained from a variety of sources (Table 3.1). Table 3.1 also specifies the collection localities, type of specimen and GenBank accession numbers for all sequences. Sequences from 35 ingroups in three sub-families of Drepanidae and 13 genera were obtained for phylogenetic analysis. Two representatives of Epicopeiidae, three representatives of Geometridae, and one representative each of Sematuridae and Pyralidae were used as outgroups. Outgroups were chosen based on the placement of Drepanoidea in morphological (Minet \& Scoble, 1999) and molecular (Regier et al., 2009) phylogenetic studies of greater lepidopteran relationships. The pyralid, Accinctapubes albifasciata, was used to root all trees, given the placement of Pyralidae in Lepidoptera (Regier et al., 2009; Mutanen et al., 2010; Cho et al., 2011). 
Table 3.1. Specimen collection data, voucher specimen data and GenBank accession numbers for 43 taxa used for phylogenetic analysis. Numbers in brackets represent different specimens.

\begin{tabular}{|c|c|c|c|c|c|c|c|c|c|}
\hline \multirow{2}{*}{ Taxon } & \multicolumn{4}{|c|}{ Specimen Data } & \multicolumn{2}{|c|}{ Voucher Specimen } & \multicolumn{3}{|c|}{ GenBank Accession Number } \\
\hline & $\begin{array}{l}\text { Adult } \\
\text { Larvae }\end{array}$ & Country & Locality & Collector & Location & $\begin{array}{l}\text { Accession } \\
\text { Number }\end{array}$ & $\overline{C A D}$ & $28 S$ D2 & ND1 \\
\hline $\begin{array}{l}\text { INGROUP TAXA } \\
\text { Cyclidiinae }\end{array}$ & & & & & & & & & \\
\hline $\begin{array}{l}\text { Cyclidia substigmaria } \\
\text { substigmaria } \\
\text { Drengninge }\end{array}$ & Adult & Taiwan & Uncertain & A. Kawahara & AToLep & AYK-04-0779-08 & GU174162 & GU174201 & GU174237 \\
\hline Agnidra scabiosa scabiosa & Adult & Japan & Honshu & A. Kawahara & AToLep & AYK-06-7252 & GU174158 & GU174197 & GU174233 \\
\hline Ausaris micacea & Adult & Taiwan & Nantou, Shanlinshi & A. Kawahara & AToLep & AYK-04-0889-05 & GU174160 & GU174199 & GU174235 \\
\hline Ausaris palleolus & Adult & Japan & $\begin{array}{l}\text { Shizuoka Pref., } \\
\text { Fujinomiya, Mt. Fuji, }\end{array}$ & A. Kawahara & AToLep & AYK-06-7263 & GU174161 & GU174200 & GU174236 \\
\hline Auzata superba & Adult & Taiwan & Uncertain & A. Kawahara & AToLep & AYK-041013-10 & GU174159 & GU174198 & GU174234 \\
\hline Cilix glaucata & - & - & - & - & - & - & - & $\mathrm{AF} 178907^{\prime}$ & AF $178859^{\prime}$ \\
\hline Drepana arcuata & Adult & USA & $\begin{array}{l}\text { Mathias, Hardy } \\
\text { County, West Virginia }\end{array}$ & C. Mitter & AToLep & CWM-96-0578 & GU174163 & GU174202 & GU174238 \\
\hline Drepana curvatula & Adult & Japan & $\begin{array}{l}\text { Yamanashi, Motosu- } \\
\text { shistugen, Osaka Trail }\end{array}$ & A. Kawahara & $\begin{array}{l}\text { Carleton (1) } \\
\text { AToLep (2) }\end{array}$ & $\begin{array}{l}\text { D0078 (1) } \\
\text { AYK-04-5230 (2) }\end{array}$ & $\begin{array}{l}\text { GU174165(1) } \\
\text { GU174166 (2) }\end{array}$ & $\begin{array}{l}\text { GU174204 (1) } \\
\text { GU174205 (2) }\end{array}$ & $\begin{array}{l}\text { GU174240 (1) } \\
\text { GU174241 (2) }\end{array}$ \\
\hline Drepana falcataria & Adult & Germany & $\begin{array}{l}\text { Erlangen, Northen } \\
\text { Bavaria }\end{array}$ & I. Hasenfuss & Carleton & D0069 & GU174167 & AF $178908^{1}$ & AF $178860^{\prime}$ \\
\hline Falcaria bilineata & Adult & Canada & Ottawa, Ontario & J. Yack & Carleton & D0084 & GU174164 & GU174203 & GU174239 \\
\hline Falcaria lacertinaria & - & - & - & - & - & - & - & AF $178906^{\prime}$ & AF1788658' \\
\hline Macrauzata maxima maxima & Adult & Japan & $\begin{array}{l}\text { Shizuoka, Fujinomiya, } \\
\text { Nonaka }\end{array}$ & A. Kawahara & AToLep & AYK-04-5709 & GU174174 & GU174213 & GU174246 \\
\hline Microblepsis acuminata & Adult & Japan & $\begin{array}{l}\text { Shizuoka Pref., } \\
\text { Fujinomiya, Mt. Fuji, } \\
\text { Second level trail } \\
\text { Uncertain }\end{array}$ & A. Kawahara & AToLep & AYK-06-7266 & GU174175 & GU174214 & GU174248 \\
\hline
\end{tabular}




\begin{tabular}{|c|c|c|c|c|c|c|c|c|c|}
\hline \multirow[t]{2}{*}{ Taxon } & \multicolumn{4}{|c|}{ Specimen Data } & \multicolumn{2}{|c|}{ Voucher Specimen } & \multicolumn{3}{|c|}{ GenBank Accession Number } \\
\hline & $\begin{array}{l}\text { Adult/ } \\
\text { Larvae }\end{array}$ & Country & Locality & Collector & Location & $\begin{array}{l}\text { Accession } \\
\text { Number }\end{array}$ & CAD & 28 S D2 & ND1 \\
\hline Oreta loochooana & Aduit & Japan & $\begin{array}{l}\text { Yamanashi, Motosu- } \\
\text { shistugen, Osaka Trail }\end{array}$ & A. Kawahara & Carleton & D0079 & GU174178 & GU174217 & GU174250 \\
\hline Oreta pulchripes & Adult & Japan & $\begin{array}{l}\text { Yamanashi, Motosu- } \\
\text { shistugen, Osaka Trail }\end{array}$ & A. Kawahara & AToLep & AYK-04-5328 & GU174179 & GU174218 & GU174251 \\
\hline Oreta rosea & Adult & USA & $\begin{array}{l}\text { Mathias, Hardy } \\
\text { County, West Virginia }\end{array}$ & C. Mitter & AToLep & CWM-95-0466 & GU174180 & GU174219 & GU174252 \\
\hline Oreto turpis & Adult & Japan & $\begin{array}{l}\text { Yamanashi, Motosu- } \\
\text { shistugen, Osaka Trail }\end{array}$ & A. Kawahara & AToLep & AYK-04-5733 & GU174181 & - & GU174253 \\
\hline Sabra harpagula & Adult & Japan & $\begin{array}{l}\text { Yamanashi, Motosu- } \\
\text { shistugen, Osaka Trail }\end{array}$ & A. Kawahara & Carleton & D0080 & GU174184 & GU174222 & - \\
\hline Tridrepana flava & Adult & Malaysia & $\begin{array}{l}\text { Pahang, Genting } \\
\text { Highlands }\end{array}$ & A. Kawahara & AToLep & AYK-04-0833-01 & GU174192 & GU174228 & GU174260 \\
\hline Tridrepana unispina & Adult & Japan & $\begin{array}{l}\text { Shizuoka, Shizuoka- } \\
\text { shi, Honkawane, } \\
\text { Kaminagao }\end{array}$ & A. Kawahara & AToLep & AYK-04-5363 & GU174193 & GU174229 & GU174261 \\
\hline Watsonalla binaria & Adult & Germany & $\begin{array}{l}\text { Erlangen, Northern } \\
\text { Bavaria }\end{array}$ & 1. Hasenfuss & Carleton & D0023 & GU174194 & GU174230 & GU174262 \\
\hline Watsonalla cultraria & Adult & Switzerland & CABI & J. Miall & Carleton & D0086 & GU17419S & - & GU174263 \\
\hline Watsonalla uncinula & Adult & France & Boulu, Pyrenees & H. Beck & Carleton & D0017 & GU174196 & GU174231 & - \\
\hline \multicolumn{10}{|l|}{ Thyatiringe } \\
\hline Euparyphasma maxima & Adult & Japan & $\begin{array}{l}\text { Shizuoka Pref., } \\
\text { Fujinomiya, Mt. Fuji, } \\
\text { Sccond level trail }\end{array}$ & A. Kawahara & AToLep & AYK-04-5376 & GU174170 & GU174208 & GU174244 \\
\hline Euthyatira pudens & Adult & Canada & Ottawa, Ontario & L. Scott & Carleton & D0081 & GU174171 & GU174209 & - \\
\hline $\begin{array}{l}\text { Hahrosyne aurorina } \\
\text { aurorina }\end{array}$ & Adult & Japan & $\begin{array}{l}\text { Shizuoka Pref., } \\
\text { Fujinomiya, Mt. Fuji, } \\
\text { Second level trail }\end{array}$ & A. Kawahara & AToLep & AYK-06-7260 & - & GU174210 & - \\
\hline Habrosyne pyritoides & Adult & Japan & $\begin{array}{l}\text { Yamanashi, Motosu- } \\
\text { shistugen, Osaka Trail }\end{array}$ & A. Kawahara & AToLep & AYK-04-5350 & GU174172 & GU174211 & - \\
\hline Neodaruma tamanukii & Adult & Japan & Uncertain & K. Eda & Carleton & D0074 & - & GU174215 & GU174247 \\
\hline Ochropacha duplaris & Larva & Finland & Sipoo & K. Silvonen & Carleton & D0100 & GU174177 & GU174216 & GU174249 \\
\hline $\begin{array}{l}\text { Pseudothyatira } \\
\text { cymatophoroides }\end{array}$ & Adult & USA & Clarkesville, Maryland & C. Mitter & AToLep & CWM-94-0380 & GU174182 & GU174220 & - \\
\hline Tethea consimilis & Adult & Japan & $\begin{array}{l}\text { Shizuoka, Shizuoka- } \\
\text { shi, Honkawane, } \\
\text { Kaminagao }\end{array}$ & A. Kawahara & AToLep & AYK-04-5374 & GU174186 & GU174224 & - \\
\hline
\end{tabular}




\begin{tabular}{|c|c|c|c|c|c|c|c|c|c|}
\hline \multirow[t]{2}{*}{ Taxon } & \multicolumn{4}{|c|}{ Specimen Data } & \multicolumn{2}{|c|}{ Voucher Specimen } & \multicolumn{3}{|c|}{ GenBank Accession Number } \\
\hline & $\begin{array}{l}\text { Adult/ } \\
\text { Larvae }\end{array}$ & Country & Locality & Collector & Location & $\begin{array}{c}\text { Accession } \\
\text { Number }\end{array}$ & CAD & $28 S$ D2 & ND1 \\
\hline Tethea oberthuri taiwana & Adult & Taiwan & Taitung, Lijia & A. Kawahara & AToLep & AYK-04-0786-06 & GU174187 & GU174225 & GU174256 \\
\hline Tethea or & Larva & Finland & Sipoo & K. Silvonen & Carleton & D0099 & GU174188 & GU174226 & GU174257 \\
\hline Tetheela fluctuosa & Larva & Finland & Sipoo & K. Silvonen & Carlcton & D0103 & GU174189 & GU174227 & GU174258 \\
\hline Thyatira batis & $\begin{array}{l}\text { Adult (1) } \\
\text { Larvae (2) }\end{array}$ & $\begin{array}{l}\text { Germany (1) } \\
\text { Finland (2) }\end{array}$ & $\begin{array}{l}\text { Erlangen, Northern } \\
\text { Bavaria (1) } \\
\text { Sipoo (2) }\end{array}$ & $\begin{array}{l}\text { I. Hasenfuss (1) } \\
\text { K. Silvonen (2) }\end{array}$ & Carleton & $\begin{array}{l}\text { D0007 (1) } \\
\text { D0097 (2) }\end{array}$ & $\begin{array}{l}\text { GU174190(1) } \\
\text { GU174191 (2) }\end{array}$ & - & GU174259(1) \\
\hline \multicolumn{10}{|l|}{ OUTGROUP TAXA } \\
\hline Accinctapubes albifasciata & unknown & unknown & unknown & unknown & AToLep & 06-smp-3517 & GU174157 & & GU174232 \\
\hline $\begin{array}{l}\text { Ennomos autumnaria } \\
\text { (Geometridae: Ennominae) }\end{array}$ & unknown & unknown & unknown & A. Kawahara & AToLep & AYK-06-7362 & GU174168 & GU174206 & GU174242 \\
\hline $\begin{array}{l}\text { Epicopeia hainesii hainesii } \\
\text { (Epicopeiidac) }\end{array}$ & Adult & Japan & $\begin{array}{l}\text { Yamanashi Perfecture, } \\
\text { Motosu }\end{array}$ & A. Kawahara & AToLep & AYK-06-7220 & GU174169 & GU174207 & GU174243 \\
\hline $\begin{array}{l}\text { Jodis putata (Geometridae: } \\
\text { Geometrinae) }\end{array}$ & & - & - & - & - & - & - & AF178920' & AF $178872^{1}$ \\
\hline $\begin{array}{l}\text { Lyssa zampa zampa } \\
\text { (Geometridae: Uraniinae) }\end{array}$ & unknown & unknown & unknown & A. Kawahara & AToLep & A-0581 & GU174173 & GU174212 & GU174245 \\
\hline $\begin{array}{l}\text { Psychostrophia melanargia } \\
\text { (Epicopeiidae) }\end{array}$ & Adult & Japan & $\begin{array}{l}\text { Yamanashi, Motosu- } \\
\text { shistugen, Osaka Trail }\end{array}$ & A. Kawahara & AToLep & AYK-06-7206 & GU174183 & GU174221 & GU174254 \\
\hline $\begin{array}{l}\text { Nothus lunus (Sematuridae: } \\
\text { Sematurinae) }\end{array}$ & unknown & unknown & unknown & R. Hutchings & AToLep & RWH-96-0877 & GU174185 & GU174223 & GU174255 \\
\hline
\end{tabular}

'Sequence obtained from Abraham et al. (2001) 
Sequences for $28 \mathrm{~S}$ and ND1 for four taxa were obtained from the literature (Abraham et al., 2001) (Table 3.1). Two individuals each (from two different sources) of two species (Drepana curvatula and Thyatira batis) were sequenced for at least one gene (Table 3.1).

In nearly all cases, live adults were collected at light traps and legs were removed and stored in $100 \%$ ethanol at $-80^{\circ} \mathrm{C}$. Adults were kept as voucher specimens. In some cases, adult females oviposited on cuttings of their hostplant and larvae were reared from eggs. Late instar larvae were injected with $100 \%$ ethanol and stored in $100 \%$ ethanol at $80^{\circ} \mathrm{C}$. Voucher specimens were deposited at either the AToLep Collection at the University of Maryland, USA, or in the Biology Department at Carleton University, Canada (Table 3.1). Wing voucher images for all adult exemplars located at the AToLep Collection are posted at http://www.leptree.net/voucher_image_list.

\section{DNA Extraction, Amplification and Sequencing}

Total genomic DNA was extracted from 43 taxa. A single leg of an adult, or the head capsule of a larva, was ground and digested at $58^{\circ} \mathrm{C}$ for 1 hour with $20 \mathrm{mg} / \mathrm{mL}$ proteinase $\mathrm{K}$ in $250 \mu \mathrm{L}$ of $0.1 \mathrm{M}$ Tris ( $\mathrm{pH} 8.0$ ), $10 \mathrm{mM}$ EDTA, and 2\% SDS. Samples were then incubated at $65^{\circ} \mathrm{C}$ for an additional 10 minutes in a solution containing $5 \mathrm{M}$ $\mathrm{NaCl}$ and $10 \% \mathrm{CTAB}$. The solutions were extracted using standard phenol-chloroform protocols and DNA was precipitated overnight in $95 \% \mathrm{EtOH}$.

DNA fragments were amplified by polymerase chain reaction (PCR) in a Biometra TGradient ${ }^{\circledR}$ thermocycler (Goettinger, Germany) using specific primers for three genes - CAD, ND1 and 28S. Amplifications were done in $20 \mu \mathrm{L}$ volumes containing $3 \mu \mathrm{L}$ of each primer, $2.0 \mu \mathrm{L} 10 \mathrm{X}$ Taq buffer $-\mathrm{MgCl}_{2}$ (Bioshop, Ontario, 
Canada), 1.2 $\mu \mathrm{L} \mathrm{MgCl}_{2}$ (Bioshop), $0.4 \mu \mathrm{L}$ of an equimolar solution of dNTPs (Invitrogen,

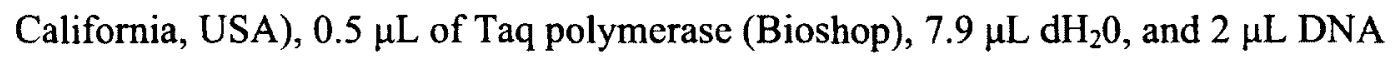
template. Negative controls were carried out using $2 \mu \mathrm{L} \mathrm{dH_{2 }} O$ in place of the DNA template.

A typical PCR procedure for all genes consisted of 3 min denaturation at $95^{\circ} \mathrm{C}$, followed by 30 cycles including denaturation $\left(30 \mathrm{~s}\right.$ at $\left.95^{\circ} \mathrm{C}\right)$, annealing $(30 \mathrm{~s}$, temperatures given in Table 3.2) and extension $\left(30 \mathrm{~s}\right.$ at $\left.72^{\circ} \mathrm{C}\right)$. An additional $10 \mathrm{~min}$ extension step at $72^{\circ} \mathrm{C}$ was included in the final cycle. Primers and specific annealing temperatures are listed in Table 3.2. It was often necessary to follow the initial amplification with a second amplification using nested primers for CAD (791F and 963R; see Table 3.2). We also designed Drepanidae-specific primer pairs based on Weller et al. (1994) for ND1 (Table 3.2). PCR products and controls were verified by agarose gel electrophoresis and either purified using a GenElute PCR Clean-Up Kit (Sigma-Aldrich, Missouri, USA) for direct sequencing, or cloned using a TOPO Cloning Kit (Invitrogen) prior to sequencing multiple clones of each fragment.

Both sense and anti-sense strands of gel-purified or cloned DNA fragments were sequenced with an Applied Biosystems 3730 DNA Analyzer (California, USA) at the Ottawa Health Research Institute (Ottawa, Canada), or at the McGill University and Genome Québec Innovation Centre (Montréal, Canada). Sequences of 28S and NDI from 20 taxa were obtained by A. Sami (unpublished).

\section{Sequence Alignment}

Sequence contigs were viewed, assembled, and edited using DNA Baser 
Table 3.2. Primers used for PCR amplification of selected gene fragments.

\begin{tabular}{|lllll|}
\hline $\begin{array}{c}\text { Gene } \\
\text { Locus }\end{array}$ & Primer & \multicolumn{1}{c}{ Sequence } & \multicolumn{1}{c|}{ Reference } & \multicolumn{1}{c|}{$\begin{array}{c}\text { Annealing } \\
\text { Temperature }\end{array}$} \\
\hline 28S & 28S D2F & AGAGAGAGTTCAAGAGTACGTG & $\begin{array}{l}\text { (Belshaw \& } \\
\text { Quicke, 1997) } \\
\text { (Belshaw \& } \\
\text { Quicke, 1997) }\end{array}$ & $59^{\circ} \mathrm{C}$ \\
\hline CAD & $743 \mathrm{nF}$ & GGNGTNACNACNGCNTGYTTYGARCC & (Regier, 2008) & $50^{\circ} \mathrm{C}$ \\
& $1028 \mathrm{R}$ & TTRTTNGGNARYTGNCCNCCCAT & (Regier, 2008) & \\
& $791 \mathrm{~F}$ & TTYGARGARGCNTTYCARAARGC & (Regier, 2008) & $50^{\circ} \mathrm{C}$ \\
& $963 \mathrm{R}$ & GCRCACCARTCRAAYTC & $\begin{array}{l}\text { (Regier, 2008) } \\
\text { NTGGTCCGTGTTTCAAGACGGG }\end{array}$ & \\
\hline ND1 & GAGCCAGGTTGGTTTCTATC & $\begin{array}{l}\text { Based on (Weller } \\
\text { et al., 1994) } \\
\text { Based on (Weller } \\
\text { et al., 1994) }\end{array}$ & \\
\hline & GAATTAGAAGATCAACCAGCAA & \\
\hline
\end{tabular}


(HeracleSoftware). Sequences were aligned in MAFFT (Katoh, 2009) using the E-INS-I setting with 1000 iterations, and verified by eye. Alignments of protein coding genes (CAD and ND1) were also checked for stop codons. Primer ends were removed from all genes, and 181 characters were removed from a non-coding region of the ND1 gene. Final character numbers and number of informative characters for each gene are included in Table 3.3. Sequence alignment data is included in Appendix B.

\section{Phylogenetic Analysis}

Parsimony

Parsimony analyses were conducted using the concatenated data set in PAUP* 4.0 (Swofford, 2003) with all characters treated as unordered. A heuristic search with tree bissection-reconnection (TBR) branch swapping in a random stepwise addition of taxa was repeated 1000 times. The information value of third positions of codons in the CAD gene and ND1 were evaluated by using two weighting schemes, the first with equal weighting and the second with the third codon position (nt3) weighted to zero. Gap treatment was also evaluated by treating them as either missing or as a fifth state. Based on these evaluations, nt 3 were not weighted, and gaps were treated as missing data, as these led to the least number of most parsimonious trees with the shortest tree lengths (see Results for details). Node support for the concatenated data set was determined by jackknife resampling with $36 \%$ of characters excluded and 100 random replicates. Total Bremer support values were also calculated using TreeRot v3 (Sorenson and Franzosa, 2007) and PAUP* 4.0 (Swofford, 2003) using a heuristic search and 1000 random replicates. 


\section{Bayesian Inference}

The optimal nucleotide substitution model for each gene partition was determined with the Akaike Information Criterion (Akaike, 1973) as implemented in ModelTest 3.7 (Posada \& Crandall, 1998). The best-fit models from ModelTest for each gene partition were $\mathrm{GTR}+\mathrm{G}(28 \mathrm{~S})$ and $\mathrm{GTR}+\mathrm{I}+\mathrm{G}(\mathrm{CAD}, \mathrm{ND} 1)$. Bayesian analysis was conducted on the concatenated data set in MrBayes 3.1.2 (Ronquist \& Huelsenbeck, 2003) with 8 chains, sampling every 1000 generations with a heating temperature of 0.12 . The Markov chain was terminated at $25 \mathrm{M}$ generations, determined by examining trace plots in AWTY (Wigenbusch et al., 2004).

\subsection{Results}

Parsimony

The concatenated dataset, comprised 43 taxa and 1617 characters, including 662 (40.9\%) constant characters and $760(47 \%)$ parsimony informative characters. Values for number of informative characters, number of most parsimonious trees, treelengths, consistency index, and retention index are shown for each gene separately and for combined analysis with different weighting schemes in Table 3.3. Parsimony analysis recovered one most parsimonious tree (MPT) with a length of 3793 steps when third codon positions were excluded and gaps were treated as missing data $(\mathrm{CI}=0.373, \mathrm{RI}=$ 0.504) (Fig. 3.1). This tree is well supported with jackknife support (JKS) values above $50 \%$ for 30 out of 41 nodes and values of $100 \%$ for 5 nodes. Bremer support (BS) values are high ( $>5)$ for 16 nodes. Drepanidae and Epicopeiidae are both recovered as monophyletic with high support values (Drepanidae: $\mathrm{JKS}=88.5, \mathrm{BS}=5$; Epicopeiidae: 
Table 3.3. Summary of results for individual and concatenated gene partitions from parsimony analysis. Equal - equal weighting; nt $3=0$ - nt 3 weighted to 0 ; missing - gaps treated as missing; 5th - gaps treated as 5th state.

\begin{tabular}{|c|c|c|c|c|c|c|c|}
\hline & \multicolumn{3}{|c|}{ Individual Genes } & \multicolumn{4}{|c|}{ Concatenated } \\
\hline & CAD & ND1 & $28 S$ & Equal/missing & Equal/5th & nt3 $=0 /$ missing & nt3 $=0 / 5$ th \\
\hline \# taxa included & 40 & 37 & 40 & 45 & 45 & 45 & 45 \\
\hline $\begin{array}{l}\text { \# characters } \\
\text { analyzed }\end{array}$ & 638 & 450 & 529 & 1617 & 1617 & 1617 & 1617 \\
\hline $\begin{array}{l}\% \text { characters } \\
\text { constant }\end{array}$ & 62.1 & 57.8 & 53.1 & 40.9 & 40.9 & 45.3 & 45.3 \\
\hline $\begin{array}{l}\% \text { characters } \\
\text { informative }\end{array}$ & 37.9 & 42.2 & 46.9 & 47.0 & 47.0 & 42.1 & 42,1 \\
\hline $\begin{array}{l}\text { Average nucleotide } \\
\text { frequencies }\end{array}$ & $=$ & & & & & & \\
\hline $\mathrm{A}$ & 37.4 & 33.2 & 21.7 & & & & \\
\hline $\mathrm{C}$ & 13.0 & 5.7 & 23.9 & & & & \\
\hline G & 17.2 & 12.2 & 25.4 & & & & \\
\hline $\mathrm{T}$ & 32.5 & 49.0 & 29.0 & & & & \\
\hline $\begin{array}{l}\text { \# most parsimonious } \\
\text { trees }\end{array}$ & 2 & 10 & 5 & 1 & 1 & 29 & 128 \\
\hline $\begin{array}{l}\text { Length of shortest } \\
\text { tree(s) }\end{array}$ & 1469 & 906 & 1142 & 3793 & 4213 & 1774 & 2171 \\
\hline $\begin{array}{l}\text { Consistency Index } \\
\text { (CI) }\end{array}$ & 0.322 & 0.397 & 0.511 & 0.373 & 0.399 & 0.484 & 0.512 \\
\hline $\begin{array}{l}\text { CI excluding } \\
\text { uninformative } \\
\text { characters }\end{array}$ & 0.299 & 0.354 & 0.447 & 0.331 & 0.363 & 0.415 & 0.462 \\
\hline Retention Index (RI) & 0.558 & 0.522 & 0.601 & 0.504 & 0.514 & 0.585 & 0.595 \\
\hline
\end{tabular}


Figure 3.1. Single most parsimonious tree of the Drepanoidea from combined 28S, ND1 and $\mathrm{CAD}$ sequences (treelength $=3793, \mathrm{CI}=0.373, \mathrm{RI}=0.504)$. Third codon positions not weighted and gaps treated as missing data. Numbers above nodes represent Bremer support value, numbers below nodes represent jackknife support value. 


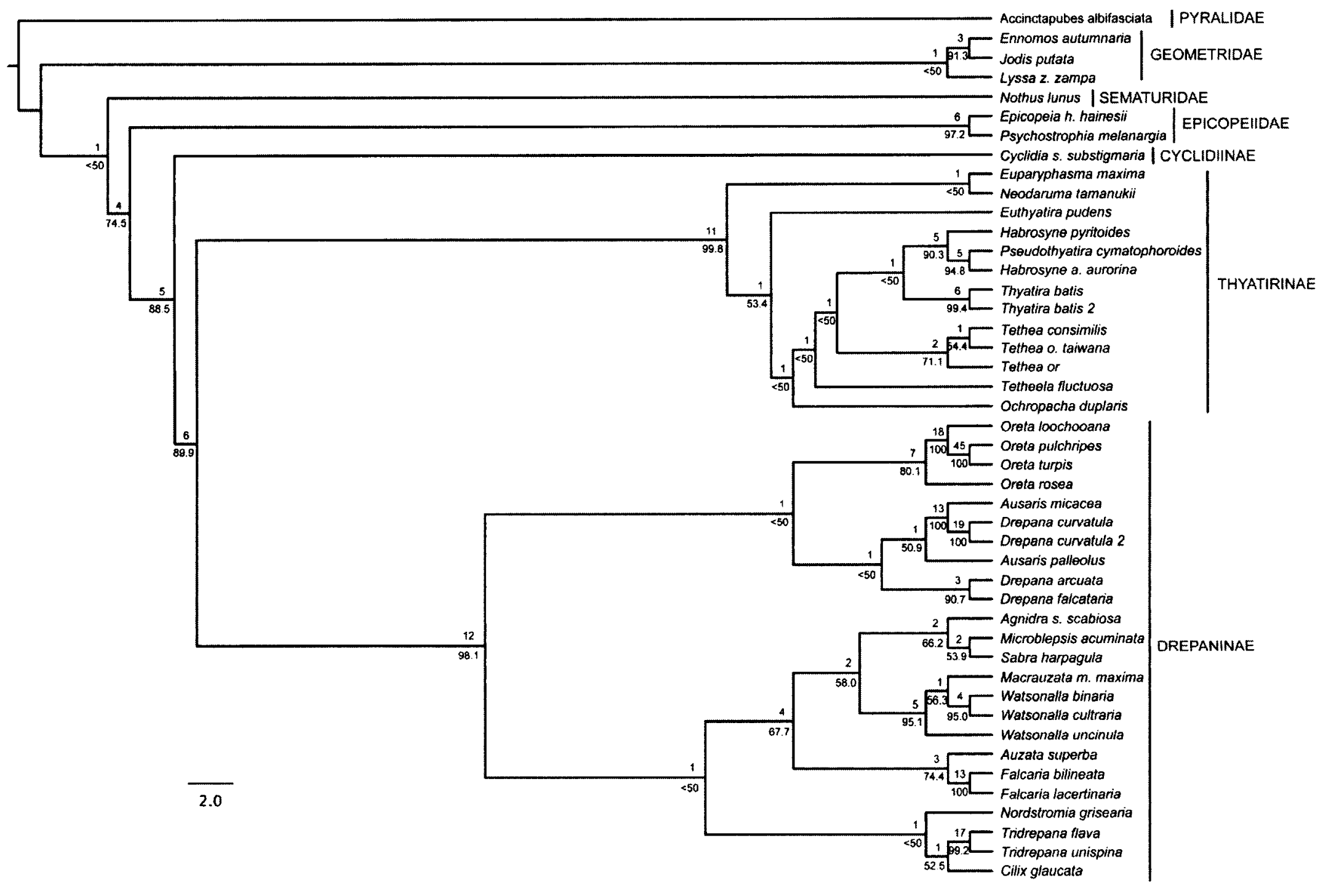


$\mathrm{JKS}=97.2, \mathrm{BS}=6$ ). Epicopeiidae forms a sister-group with Drepanidae with support values of JKS $=74.5$ and $\mathrm{BS}=4$ ). Cyclidiinae, Thyatirinae and Drepaninae are also recovered as monophyletic with high support values (Thyatirinae: $\mathrm{JKS}=99.8, \mathrm{BS}=11$; Drepaninae: JKS $=98.1$, BS $=12$ ), with Drepaninae and Thyatirinae emerging as a sistergroup with high support $(\mathrm{JKS}=89.9, \mathrm{BS}=6)$. Oreta is monophyletic with high support $(\mathrm{JKS}=80.1, \mathrm{BS}=7)$, but forms a monophyletic group with the Drepana + Ausaris clade with weak support (JKS $=<50, \mathrm{BS}=1)$. Drepana, Ausaris, Watsonalla, and Habrosyne are found to be paraphyletic. For two taxa in which sequences from two individuals were obtained (Thyatira batis and Drepana curvatula), individuals of the same species form monophyletic clades in both cases, with high support values (Thyatira batis: JKS $=99.4$, $\mathrm{BS}=6 ;$ Drepana curvatula: $\mathrm{JKS}=100, \mathrm{BS}=19$ ).

Parsimony analysis with gaps coded as a fifth state also recovers one most parsimonious tree with the same topology $(L=4213, \mathrm{CI}=0.399, \mathrm{RI}=0.514)$. Analysis with nt 3 weighted as zero and gaps coded as missing recovers 29 MPTs $(L=1774, \mathrm{CI}=$ $0.484, \mathrm{RI}=0.585$ ), and with $\mathrm{nt} 3$ weighted as zero and gaps treated as a fifth base recovers 128 MPTs $(L=2171, \mathrm{CI}=0.512, \mathrm{RI}=0.595)$. Topologies for these two alternate analyses (not shown) differ from the tree shown in Fig. 3.1. All key clades (i.e. Epicopeiidae, Drepanidae, Drepaninae, Thyatirinae) are recovered as monophyletic in both cases; however, there are more paraphyletic genera in trees from these two alternate analyses than in the tree shown in Fig. 3.1. 


\section{Bayesian Inference}

The tree generated from Bayesian inference differs from that of the parsimony MPT and has $100 \%$ posterior probabilities (PP) at 19 of 42 nodes (Fig. 3.2). Drepanidae is recovered as monophyletic with high posterior probability $(\mathrm{PP}=100 \%)$ with the Drepaninae and Thyatirinae emerging as sister-groups $(\mathrm{PP}=100 \%)$. This tree also supports each of Cyclidiinae, Drepaninae and Thyatirinae as monophyletic, with strong support $(\mathrm{PP}=100 \%$ in all cases $)$. Oreta is monophyletic with robust support $(\mathrm{PP}=$ $100 \%$ ), forming a sister relationship to the rest of Drepaninae ( $\mathrm{PP}=100 \%)$. Finally, Epicopeiidae is monophyletic with high posterior probability $(\mathrm{PP}=98 \%)$ and is closer to the Drepanidae than to the Geometridae (PP $=92 \%)$. Most of the genera within the Thyatirinae and Drepaninae are monophyletic, except Ausaris (Drepaninae). In Ausaris, A. micacea emerges with Drepana and A. palleolus emerges with Nordstromia, both with relatively high support $(\mathrm{PP}=100 \%$ and $65 \%$, respectively). In addition, Habrosyne (Thyatirinae), includes Pseudothyatira cymatophoroides with a high support value (PP = $100 \%$ ). Individuals of the same species form monophyletic clades, with high posterior probabilities ( $\mathrm{PP}=100 \%$ in both cases) for both taxa in which sequences from two individuals were obtained (T. batis and D. curvatula).

\subsection{Discussion}

\section{Preferred Tree}

Recovery and strong support for the monophyly of previously defined taxonomic groups is used to measure the strength of an analysis (Wild and Maddison, 2008; Winterton et al., 2007; Yoder et al., 2001). Therefore, in this study, recovery of 
Figure 3.2. Majority-rule consensus Bayesian tree (25 M generations) of the Drepanoidea reconstructed using combined 28S, ND1 and CAD sequences. Bayesian posterior probabilities are shown above the branches. 


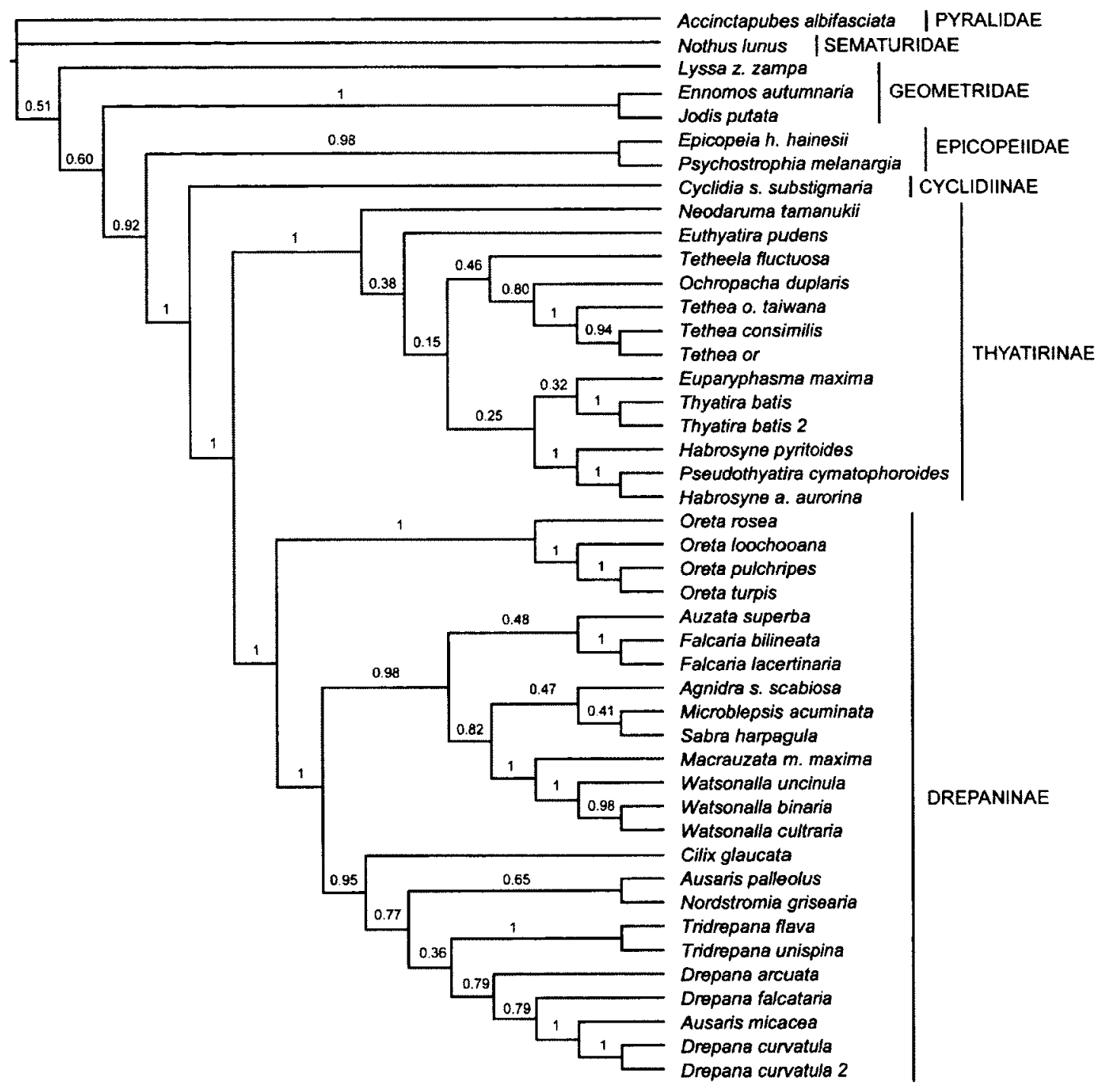


congeneric and confamilial nodes with high support values has been taken as evidence of a well-resolved tree. Both Bayesian and parsimony analyses recovered Epicopeiidae and Drepanidae as monophyletic sister-groups, as well as the monophyletic sub-families of Drepanidae (Cyclidiinae, Thyatirinae and Drepaninae) with strong branch support. Both types of analyses also grouped taxa in which two samples were available (Thyatira batis and Drepana curvatula) into monophyletic clades with high support, giving support to both types of analyses. However, the parsimony tree did not resolve relationships as well at the generic level, with four genera recovered as paraphyletic (compared to three in the Bayesian tree). As such, the Bayesian tree was chosen as the preferred tree. Since three of the paraphyletic genera (Drepana, Ausaris, and Habrosyne) are congruent between the parsimony and Bayesian analyses and have high support values, this suggests that the concepts for these genera require a subsequent revision.

\section{Epicopeiidae}

The taxonomic status of Epicopeiidae has long been debated and its position in the Drepanoidea remains uncertain. The results of my phylogenetic analysis reveal that Epicopeiidae is most closely related to Drepanidae (Cyclidiinae + Thyatirinae + Drepaninae) using both parsimony and Bayesian analyses, with high support values. This finding suggests that Minet (1999) was correct in placing Epicopeiidae within the Drepanoidea based on morphology. However, this is in direct contrast to recent molecular studies on ditrysian phylogenetics that recommended that Epicopeiidae be removed from the Drepanoidea and placed next to Sematuridae (Regier et al., 2009) or Lasiocampoidea (Mutanen et al., 2010). It also differs from the pilot study of Wu et al. (2009) that 
suggests Epicopeiidae is most closely related to Geometridae. The findings of Wu et al. (2009) may be due to low taxon and gene sampling, and future studies that include more taxa and genes may ultimately reveal the taxonomic position of Epicopeiidae.

\section{The Oreta Group}

In their paper on the phylogeny of the Drepanoidea, Wu et al. (2009) suggested based on molecular data that the Oreta group should be excluded from Drepaninae to form a separate subfamily, Oretinae. This also agrees with past morphological studies which suggested that Drepaninae be split into Drepaninae and Oretinae (Inoue, 1962; Nakajima, 1970; Wilkinson, 1972; Zhu \& Wang, 1991; Smetacek, 2002). Wu et al. (2009) however, cautioned that their molecular findings were limited due to taxon sampling as their taxa were selected based on their availability in China. They suggested that further studies, covering more genera and molecular markers were needed to test the strength of the support for Oretinae and Drepaninae. My study includes taxa found in a number of localities around the world, including North America, Europe and Asia and I have examined three additional genes. My results concur with the findings of Wu et al. (2009), in that Oreta forms an independent clade with robust support in both parsimony and Bayesian analyses and is separate from the rest of Drepaninae in the Bayesian tree. Based on this finding, as well as morphological evidence discussed in Wu et al. (2009), I suggest that Oreta be separated from Drepaninae and form its own subfamily, Oretinae.

The molecular phylogeny created in this chapter serves two purposes. First, it extends previous studies of the Drepanoidea phylogeny by using further molecular markers and more taxon sampling. In doing so, the results of this molecular phylogeny 
shed some light on the issues surrounding the taxonomic status of the Drepanoidea, including the placements of Epicopeiidae and Oreta. Second, I have determined the relationship between species that I will be examining for morphological and behavioural characters in subsequent chapters of this thesis. These morphological and behavioural characters will be mapped to test hypotheses on the evolutionary origin of vibratory signals in these caterpillars, more specifically that anal scraping derives from crawling (Chapter 4) and that mandible signals derive from aggressive behaviours involving the head (Chapter 5). The phylogenetic tree created in this chapter will provide a solid foundation to test these hypotheses. 


\section{ChAPTER 4}

\section{From Walking to Talking: The Evolutionary Origin of ANal SCRAPING SigNALS IN DREPANIDAE CATERPILlaRS}

This chapter forms the following manuscripts:

Scott, J. L., Kawahara, A. K., Skevington, J. H., Yen, S. -H., Sami, A., Smith, M. L. \& Yack, J. E. (2010). The evolutionary origins of ritualized acoustic signals in caterpillars. Nature Communications 1, 4; doi: 10.1038/ncomms1002.

Scott, J. L. \& Yack, J. E. Caterpillars talk their walk: How vibratory signals evolved from crawling movements in caterpillars (Lepidoptera: Drepanidae) (in preparation for submission to the Journal of Experimental Biology in October, 2012)

Note: Although these manuscripts differ in the amount of detail presented, they do not differ in major conclusions or findings. This chapter follows the format of the more detailed manuscript (Scott \& Yack, in prep). 


\subsection{Introduction}

Since Darwin's seminal paper "The Expression of the Emotions in Man and Animals", many scientists have sought explanations for the evolutionary origins of communication signals. Tinbergen (1952), Lorenz (1966) and Huxley (1966) hypothesized that signals are ultimately derived from behaviours previously unconnected with communication through the process of ritualization. During this process, cues generated by intention movements, displacement behaviours or physiological states are modified to enhance their efficacy through enhanced conspicuousness (e.g. increasing the amplitude of the signal), redundancy (e.g. repeating the signal or elements of the signal), stereotypy (e.g. a reduction in variation of the signal), and alerting components (e.g. a conspicuous component at the beginning of the signal) (Cullen, 1966; Wiley, 1983; Johnstone, 1997). Support for hypotheses on signal origins is generally based on comparisons of movement patterns and associated morphology within or between species. As explained in Chapter 1 of this thesis multiple species comparisons have been used to provide support for the hypothesis that the peacock tail-fan display originated from males leaning forward to present food to females (Schenkel, 1956). Although most comparative studies pose interesting hypotheses on signal origins, they are limited in that they lack a phylogenetic framework onto which one can trace the evolutionary history of behaviours (Brooks \& McLennan, 2002). Many studies have used a phylogeny to examine other aspects of signal evolution (e.g. Weller et al., 1999; Patek \& Oakley, 2003; Martins et al., 2004; Symonds et al., 2009), but studies on the origin of signals that base their results upon a phylogenetic framework are currently non-existant. Therefore, the 
major goal of my thesis is to provide evidence for the origin and ritualization of a communication signal using a combination of morphology, behaviour and phylogenetics.

Caterpillars of the family Drepanidae provide an excellent model system to study the evolutionary origin of signals because, as I have shown in Chapter 2 of this thesis, they show wide variation in morphology and behaviour associated with signalling across species. Furthermore, by knowing the relationships between species (see Chapter 3), one can gain a better understanding of the basal behaviours and transitional stages that play a role in the evolution of the signal. In the Drepanidae, certain species use vibration signals in the context of territory defence. For example, solitary late instar caterpillars of $D$. arcuata construct and occupy leaf shelters (Fig. 4.1a), and when approached by a conspecific, residents will produce territorial vibration signals (mandible scraping, mandible drumming, anal scraping) (Yack et al., 2001) (Fig. 4.1b). Variation has been noted in both the signalling behaviours and the morphology of structures involved in signal production associated with anal segments where some species lack signals and signalling structures altogether, while others produce large repertoires of signals and possess highly developed signalling structures (see Chapter 2).

The major goal of this chapter (Chapter 4) is to test the hypothesis that one of these signals, anal scraping, evolved from movements associated with crawling. The results of this chapter will be the first published empirical evidence for the origin and ritualization of a communication signal. To test my hypothesis, I will test the following predictions: 1) the possession of anal prolegs (used for crawling) represents the basal condition; 2) signalling structures found on the anal segment derive from unmodified PP1 setae; and 3) movements associated with anal scraping derive from crawling. I will test 
Fig. 4.1. An example of signalling in Drepana arcuata. (a) Two caterpillars within a partially made leaf shelter during a territorial encounter (scale bar $=6 \mathrm{~mm}$; photo credit: J. Yack). (b) The signalling repertoire of D. arcuata, including anal scraping (AS), mandible drumming (MD) and mandible scraping (MS), with scanning electron micrographs of signal-producing structures (anal oar, left, scale bar $=50 \mu \mathrm{m}$; and mandible, right, scale bar $=100 \mu \mathrm{m}$; photo credits: $\mathrm{J}$. Yack) $($ scale bar $=1.5 \mathrm{~mm}$; photo credit: S. Matheson). 


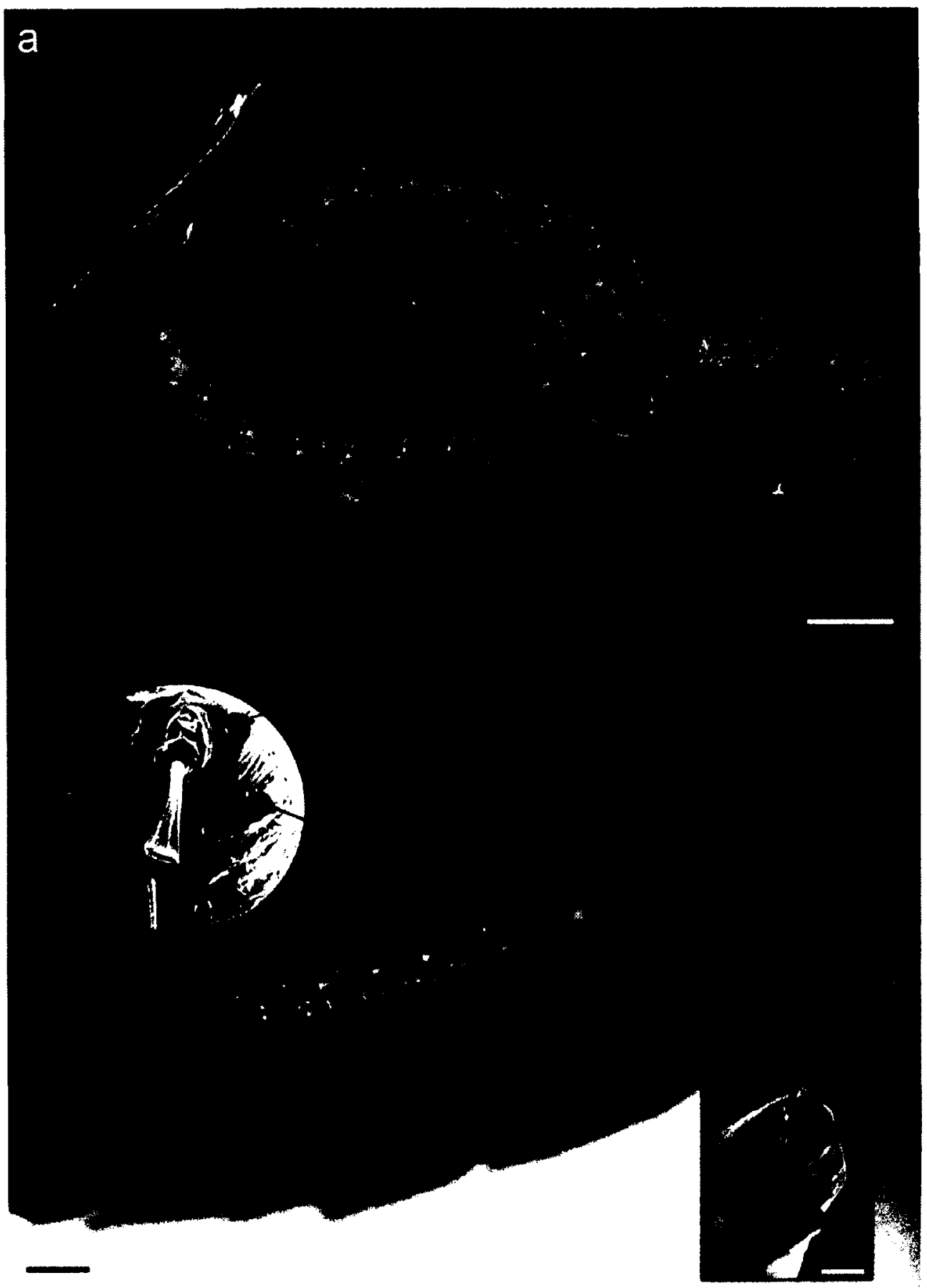


these predictions by mapping signalling and territorial behaviours, as well as anal segment morphology onto the phylogeny I created in Chapter 3 , and by examining basal and derived characters. I also predict: 4) that the vibrations produced by anal scraping will show an increase in conspicuousness, redundancy and stereotypy, and the presence of alerting components when compared to crawling vibrations. I will test this prediction by comparing vibration characteristics between anal scraping and crawling. Finally, I will test the prediction: 5) that anal scraping and crawling will be in the same order of events in a typical sequence of behaviours during encounters with conspecifics in anal scraping and non-anal scraping species. This will be tested by comparing sequences of behaviours between two representative species. Once basal and derived conditions are established, the second goal of this chapter is to propose a model on the evolutionary transition between crawling and anal scraping. This model will be used to explain how anal scraping evolved from a non-signalling behaviour and will be based on the results of mapping behaviour and morphology onto the phylogenetic tree. I will also propose a model for the changes in physiology and mechanisms that may have accompanied the transition from crawling to signalling. This model will be based on a detailed comparison of movements between two representative species- one that crawls and one that anal scrapes.

\subsection{Methods}

Phylogenetic mapping of anal segment behaviour and anatomy

Anal segment morphology, including the condition of the prolegs and caudal projection, shape of the PPI setae, as well as the behaviours associated with the anal 
segment have been described previously in Chapter 2 of this thesis. Variability of these traits were further categorized (see Results of this chapter), coded as discrete characters, and mapped onto the existing phylogeny of the Drepanidae (Chapter 3) in Mesquite (Maddison \& Maddison, 2009). All behaviours were scored as presence/absence binary characters. Behaviours were said to be present if they were observed at least one time in trials with conspecifics, except for crawling towards the intruder. Since crawling towards the intruder may occur periodically during an encounter just by chance, taxa were said to aggressively crawl towards the intruder only when this behaviour occurred at a frequency of at least $5 \%$ of all events recorded. Ancestral conditions of the anal prolegs, caudal projection and PP1 setae were inferred for selected nodes with high posterior probabilities in Mequite using the Mk1 model (Lewis, 2001), and ancestral behaviours were inferred for all nodes on a reduced phylogeny that included only those taxa for which behavior was known, using parsimony reconstruction $(n=13)$. BayesDiscrete, in BayesTraits (Pagel \& Meade, 2006), was used to determine whether morphological and behavioural characters were correlated over the phylogeny following the method outlined in Pagel and Meade (2006).

\section{Comparison of vibrations to assess signal ritualization}

Characteristics of ritualization (conspicuousness, redundancy, stereotypy and alerting components) were assessed for each type of anal segment behaviour by recording and comparing features of their associated vibrations. Conspicuousness was assessed by comparing the relative amplitude of vibrations associated with crawling and anal scraping within trials for 3 taxa (those that anal scrape - D. arcuata, D. curvatula and $D$. 
falcataria; $n=13$ ) using a paired $t$-test, as amplitudes could not be compared between taxa or even between recordings due to differences in leaf structure and size of individuals. Dominant frequencies and bandwidths were also compared between crawling $(n=10)$ and anal scraping $(n=3)$ using Kruskal-Wallis one-way analyses of variance to determine if a shift in dominant frequency may have accompanied the shift to signalling (to increase signal to noise ratio, and thus conspicuousness). Redundancy was assessed by comparing rates per $5 \mathrm{~s}$ of each anal segment behaviour type within the 20 -s period following the time of closest contact between the resident and intruder during encounters using an ANOVA $(\mathrm{n}=10)$. Post hoc analyses were performed using Tukey-Kramer HSD, where higher rates indicated high repetition of signals, and thus high redundancy. Stereotyped behaviours are those that vary little between events. In this chapter, I am testing for stereotypy of duration, or the variability in duration within a behaviour. Stereotypy of duration was measured as the inverse of variability, where variability was measured as the coefficient of variation, defined as the ratio between the standard deviation and the mean, expressed in percent of the mean. Stereotypy of duration was then compared between anal scraping and crawling behaviours using a Kruskal-Wallis one-way analysis of variance $(n=10)$ to determine whether anal scraping is a more stereotyped behaviour, which would support the prediction that it is a ritualized signal. Alerting components were assessed by examining signalling bout data (see Chapter 2) per species and determining if any of the anal segment behaviours are typically preceded by any other behaviour. All data were calculated as a mean per individual using 5 behaviours/vibrations per individual when possible. Grand means were then calculated per taxa and finally per behaviour type, to compare between behaviours, except for 
amplitude comparisons. All statistical comparisons used an alpha level of 0.05 , and data were checked for normal distribution using the Shapiro-Wilk W test.

\section{Comparison of behavioural sequences}

The typical sequence of behaviours during encounters were compared between species to test the prediction that anal scraping and crawling would be found in the same order of events between anal scraping and non-anal scraping species. Behaviours were scored using a computerized event recorder in 10 taxa (J-Watcher; Blumstein et al., 2006). Discrete time sequential analysis was performed to quantify the frequency and transition probabilities between behaviours (with accompanying z-scores and P-values; Blumstein et al., 2006). Transition diagrams were created using only transition probabilities of 0.10 or higher.

\section{Kinematics and musculature of anal segment movement}

The kinematics of movement patterns associated with the anal segments were compared in species representing ancestral non-signalling and derived signalling conditions to propose a model for the physiological changes that may have accompanied the transition from crawling to anal scraping. Movement patterns of segments A6-A10 were analyzed in D. arcuata (signalling species; $n=9$ ) and Tethea or (non-signalling species; $n=7$ ) using standard and high-speed videography. High-speed videos were recorded using a Lightning RDT high-speed camera (High Speed Imaging, Inc., Ontario, Canada) at 500 frames per second and MiDAS 2.0 software (Xcitex, Massachussetts, U.S.A.). Videos were analyzed in MiDAS to provide quantitative descriptions of the relative timing, duration, direction, displacement and velocity of each movement 
component. Surface points corresponding to the modified setae in D. arcuata (PP1) and the midline of the distal edge of the anal prolegs in $T$. or were placed in MiDAS and tracked manually through video frames. The mean duration, displacement and velocity for each movement was calculated for each individual ( 5 movements per individual) and the mean for all individuals was calculated to as a grand mean. Between species comparisons of duration, displacement and velocity were made using two-tailed independent $t$-tests and absolute values for displacements and velocities were used. These comparisons were made to help determine which parts of the movements were homologous in order to develop a model for the transition between crawling and anal scraping. All displacement values were normalized by the rest length of the sixth abdominal segment calculated as a mean in quiescent animals to correct for size differences between species.

\subsection{Results}

Variation in anatomy and behaviour of the anal segment, as described in Chapter 2, was further characterized in the current chapter in order to map these characters onto the phylogeny.

\section{Comparative anatomy of the anal segment for mapping}

Variation in anal segment morphology is described with respect to the anal proleg condition, PP1 setae morphology, and caudal projections (Fig. 4.2, 4.3).

The anal prolegs were categorized as being fully formed (equal in area (width at the widest part multiplied by total length from the body to the crochets) to the abdominal 
Fig. 4.2. The variation in general morphology of the anal segment in Drepanidae caterpillars. Left panel: Representative photos of the main morphological conditions.

Scale bars $=1 \mathrm{~mm}$. Right panel: Drawings of the main morphological conditions and the variations that occur in different species. 

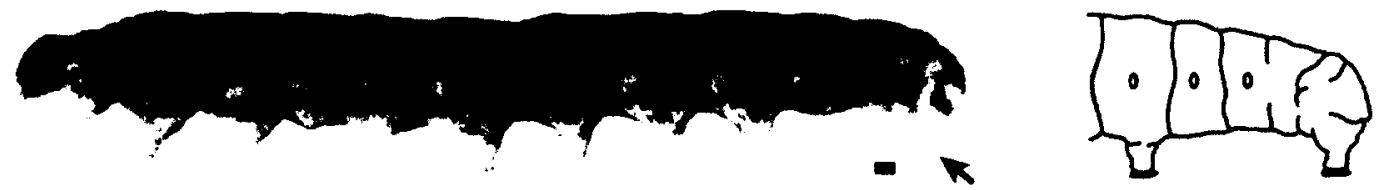

Cyclidia s. substigmaria

Fully formed

anal proleg

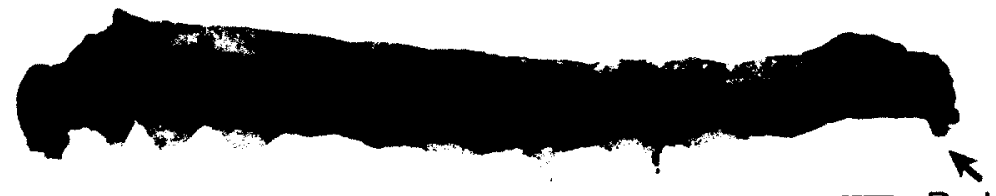

Thyatira batis

- Reduced

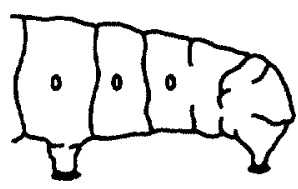

anal proleg
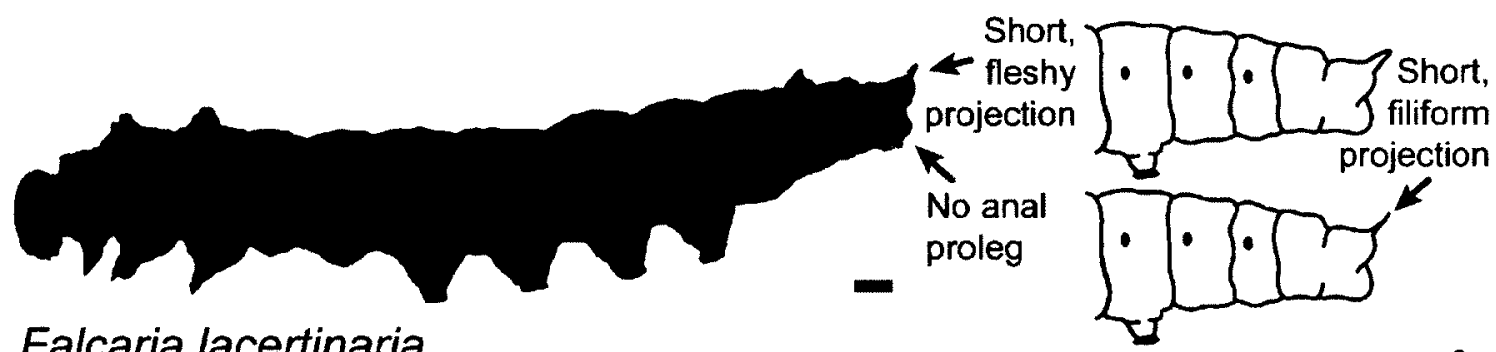

Falcaria lacertinaria

-
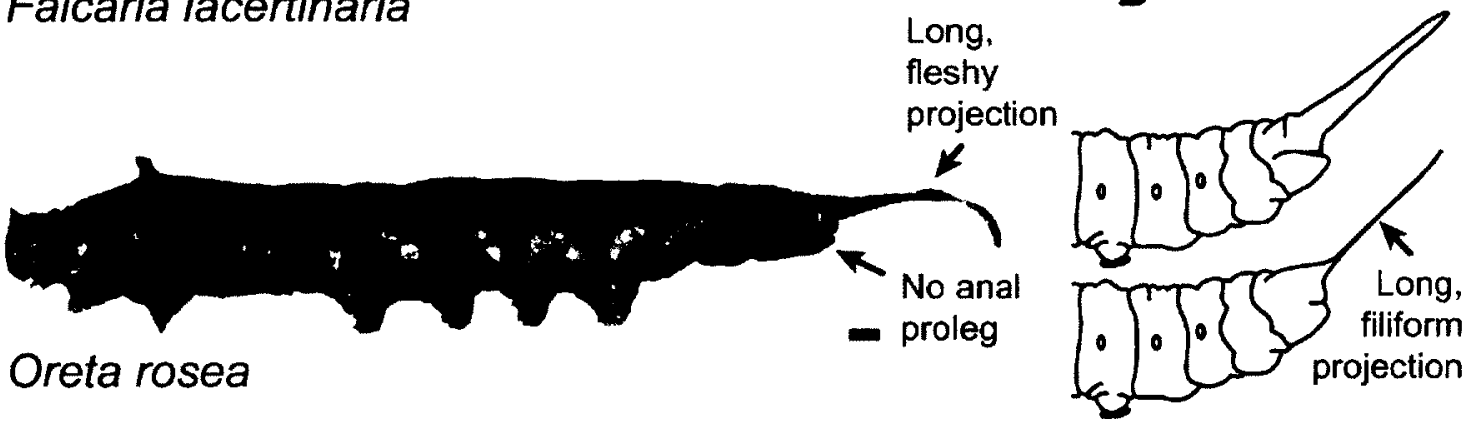

Oreta rosea 
prolegs on A3-A6 and bearing full crochets), reduced (smaller than the abdominal prolegs on A3-A6, but still bearing crochets), or absent (and bearing no crochets) (Fig. 4.2).

Caudal projections are single projections from the dorsal anal segment, and these were classified as being short or long (long was quantified as longer than the length of A7-A10), fleshy or filiform (as characterized by Nakajima, 1970, 1972, where fleshy represents thicker projections, and filiform represents projections that resemble a thread, or filament), or absent (Fig. 4.2). This character was included in my study because it was a prominent feature of the anal segment that varied across species, and I was curious to see if variability in its morphology was correlated with any of the territorial behaviours of the anal segment (described below).

The posterior proctor (PP1) setae (one on each side) were broadly classified as unmodified (no wider than the surrounding seta found on the anal segment (L2, L3 and SV1)), thickened (cylindrically shaped, but wider than the L2, L3 and SV1 setae), or paddle-shaped (four-sided with unequal adjacent sides, and wider than the L2, L3 and SV1 setae) (Fig. 4.3). Within these general categories for PP1, further variation was observed, including two variations in thickened setae and six variations in paddle-shaped setae (Table 4.1 and Fig. 4.3).

\section{Phylogenetic mapping of anal segment anatomy}

Mapping morphological traits of the anal segment shows that fully formed anal prolegs represent the basal condition, that they were reduced once in the common ancestor of the Thyatirinae clade (Fig. 4.4, Node A) and were subsequently lost in the 
Fig. 4.3. The variation in PP1 setae morphology observed in Drepanidae larvae. (a) The location of the PP1 setae on a species with reduced anal prolegs (left; Tetheela fluctuosa (which has a thickened seta); scale bar $=500 \mu \mathrm{m}$ ), no anal prolegs (middle; Drepana curvatula (which has a paddle-shaped seta); scale bar $=500 \mu \mathrm{m}$ ), and no anal prolegs with a caudal projection (right; Oreta rosea (which has an unmodified seta); scale bar = $250 \mu \mathrm{m}$ ). (b) Schematics showing three categories of PP1 setae and their respective variations in morphology with representative scanning electron micrograph (SEM) images below. SEMs include, from left to right, Tethea or (unmodified seta), T. fluctuosa (thickened seta), Falcaria bilineata (rectangular seta), Drepana arcuata (oar-shaped seta), and Cilix glaucata (double paddle-shaped seta). All scale bars for SEMs $=100 \mu \mathrm{m}$. 
a

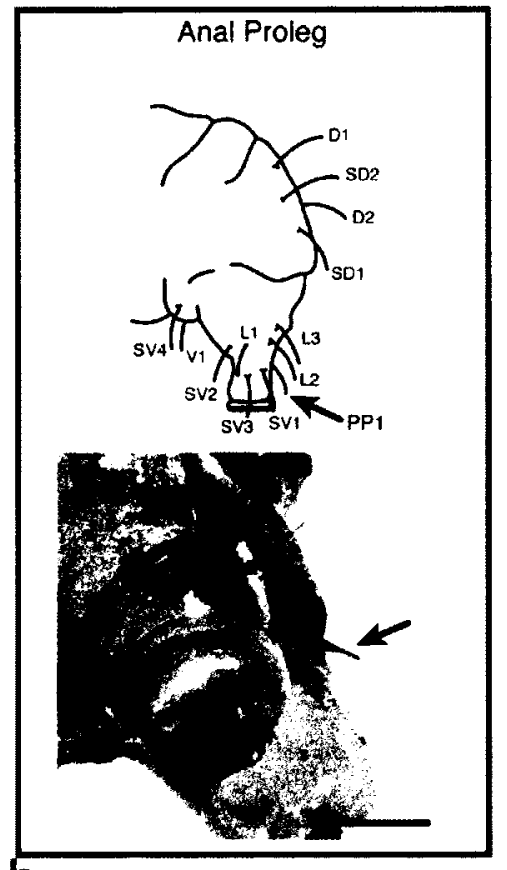

$b$

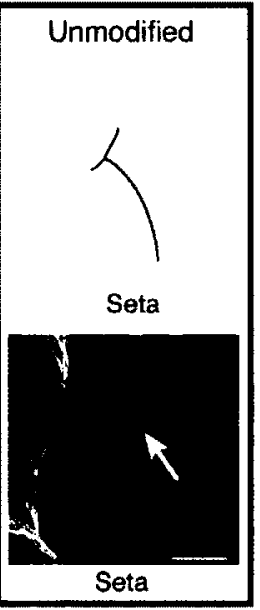

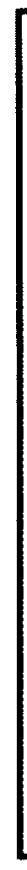

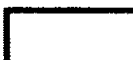

No Anal Proleg,
Short Projection

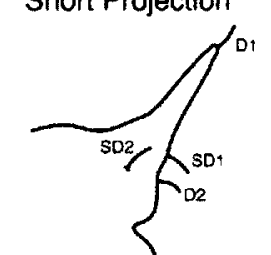

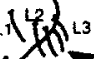
${ }_{S V 4} \underbrace{N_{S V 3}}_{S V 2} \underbrace{}_{P P 1}$
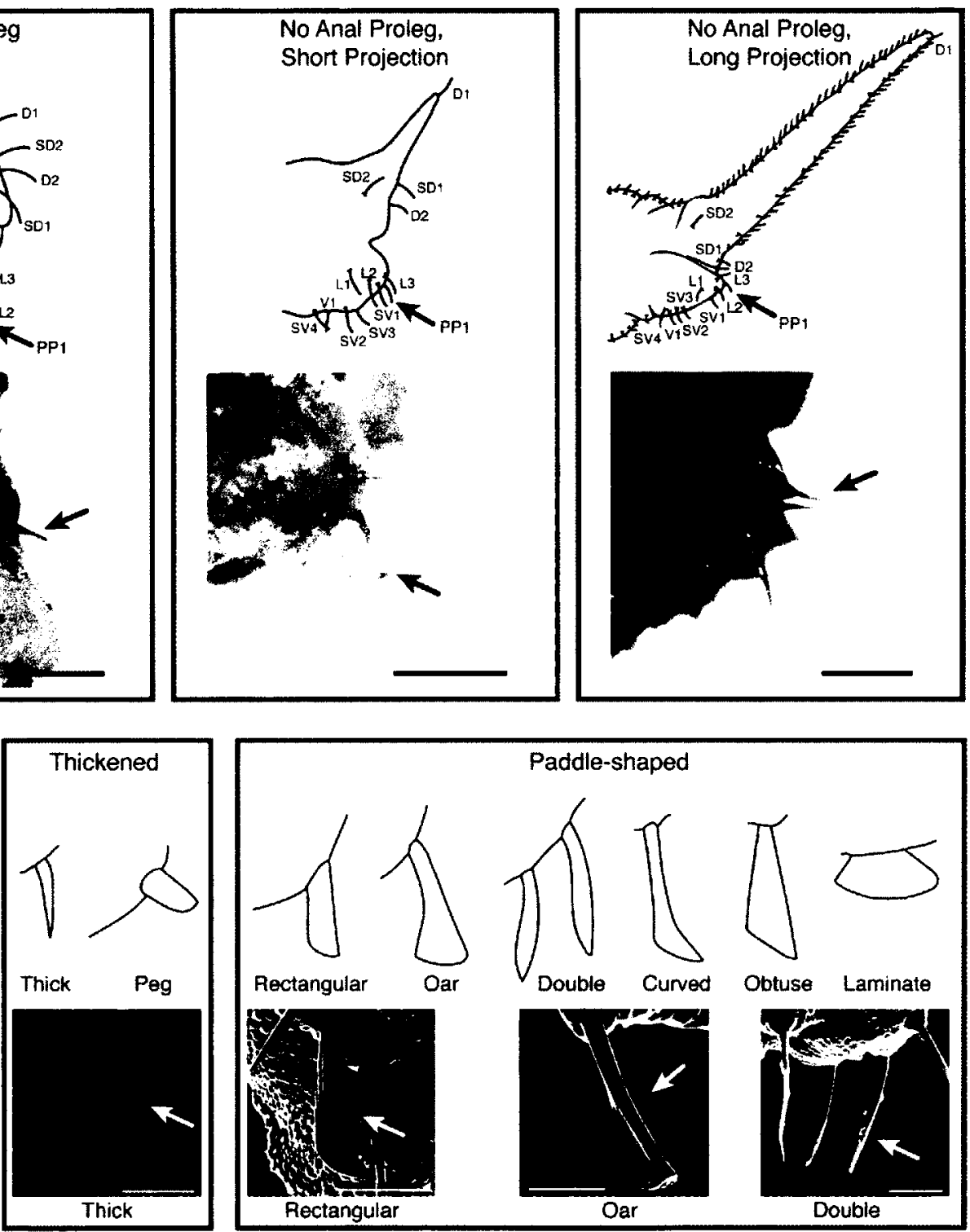

Obtuse Laminate

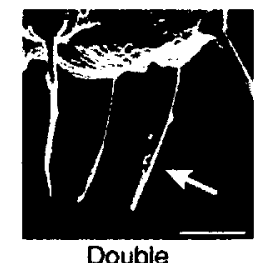


Table 4.1. Definitions of the variation in shape of PP1 setae observed in the Drepanidae.

\begin{tabular}{|c|c|c|}
\hline General Shape & Variation & Description \\
\hline Unmodified & & typical filiform seta \\
\hline Thickened & $\begin{array}{l}\text { Thick seta } \\
\text { Peg }\end{array}$ & $\begin{array}{l}\text { shaped like typical filiform seta, pointed at the } \\
\text { distal end, but thicker } \\
\text { wider and shorter than a typical seta with a blunt } \\
\text { edge at the distal end }\end{array}$ \\
\hline Paddle-shaped & $\begin{array}{l}\text { Rectangular } \\
\text { Obtuse } \\
\text { Curved } \\
\text { Oar } \\
\text { Laminate } \\
\text { Double }\end{array}$ & $\begin{array}{l}\text { shaped like a rectangle with one curved distal } \\
\text { comer } \\
\text { shaped like an obtuse triangle with the shortest } \\
\text { edge at the distal end } \\
\text { composed of a slender shaft with a right-angle } \\
\text { curve at the distal end } \\
\text { shaped like the oar of a boat, with a slender shaft } \\
\text { that widens at the distal end } \\
\text { equilateral triangular shape with one point at the } \\
\text { proximal end and a rounded corners on the distal } \\
\text { edge } \\
\text { two modified setae on each side of the body }\end{array}$ \\
\hline
\end{tabular}


Fig. 4.4. Bayesian tree showing the ancestral and derived conditions of the anal prolegs, caudal projection and PP1 setae morphology. Posterior probabilities are shown above branches. Pie charts are maximum likelihood probabilities of ancestral states at selected nodes. 


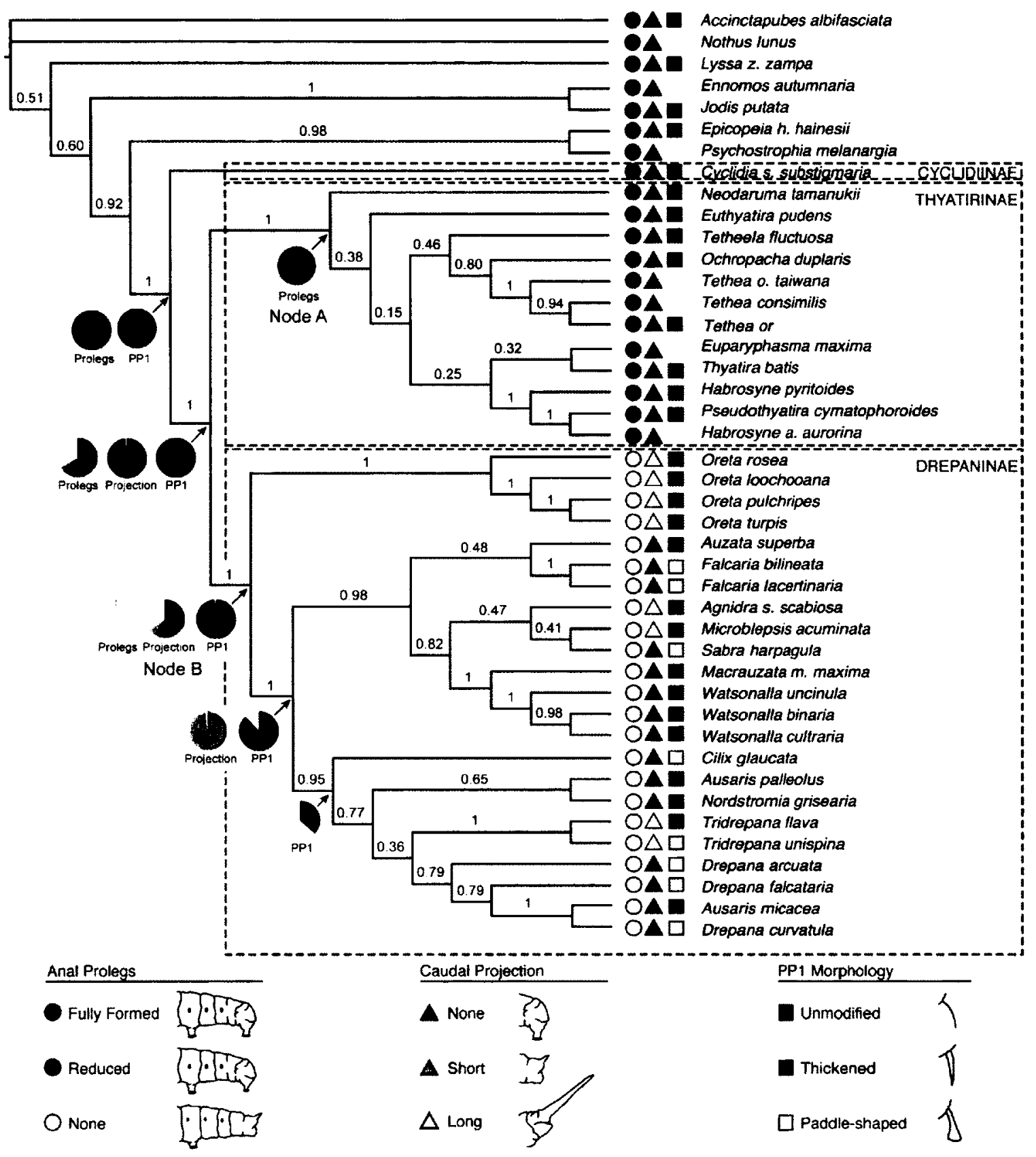


monophyletic Drepaninae (Node B). The caudal projection evolved once in the common ancestor of Drepaninae (Fig. 4.4, Node B) and variations in length and width evolved multiple times within Drepaninae (Fig. 4.4). Unmodified PP1 setae represent the basal condition, occurring in all outgroup species and most species of the basal Drepanidae subfamilies (Cyclidiinae and Thyatirinae) (Fig. 4.4). The one exception is in Tetheela fluctuosa (Thyatirinae) that has a thickened seta (see Fig. 4.3). Modified setae evolved independently multiple times and were subsequently lost multiple times within Drepaninae (excluding the Oretini tribe, the basal group of Drepaninae, which have unmodified setae). Variations in the shape of modified setae were usually restricted to independent evolutionary origins, where rectangular-shaped setae evolved once in the Falcaria clade, oar-shaped setae evolved once in the Drepana + Ausaris micacea clade (being subsequently lost in $A$. micacea), and peg, obtuse, double and laminate-shaped setae evolved independently in Microblepsis acuminata, Sabra harpagula, Cilix glaucata, and Tridrepana unispina, respectively. Thickened setae, on the other hand, evolved at least three times independently, in T. fluctuosa, Nordstromia grisearia, and Tridrepana flava (Fig. 4.4, Table 4.1).

Several correlations between morphological characters were observed (Fig. 4.4). Paddle-shaped setae were only observed in taxa that lacked anal prolegs. Species that possessed fully formed or reduced anal prolegs did not possess modified PP1 setae, except for one species, $T$. fluctuosa, which has a thickened seta and reduced anal prolegs. However, the condition of the anal proleg (reduced vs. absent) was not significantly correlated with the condition of the PP1 setae (unmodified vs. modified) over the phylogeny using BayesDiscrete analysis $(\operatorname{lnL}$ difference $=6.12, \mathrm{DF}=4, \mathrm{p}=0.19)$. The 
presence or absence of caudal projections, on the other hand, was significantly correlated with anal proleg condition (presence vs. absence) over the phylogeny ( $\ln L$ difference $=$ $11.41, \mathrm{DF}=4, \mathrm{p}=0.022$ ), where caudal projections were only found in taxa that lacked anal prolegs altogether (i.e. only in Drepaninae).

Comparative behaviour of the anal segment during conspecific interactions

In Chapter 2, four notable behaviours involving the anal segment were identified during conspecific interactions in 11 species, and information on the behaviour of two outgroup species was obtained from the literature. These include: general crawling, crawling toward an intruder (in an aggressive context), anal scraping movement, and lateral tail hitting. Each of these behaviours was described in detail in Chapter 2 with respect to which species produce them, the general context in which they are performed, as well as characteristics of the behaviours, movements, and vibrations on a species by species basis. In this Chapter, I will map behaviour associated with the anal segment onto the phylogenetic tree and will provide further details on the vibrational and kinematic characteristics of each behaviour. Mapping results and comparisons between movements and vibrations will be used to test predictions for the hypothesis that anal scraping derives from crawling and to propose a model for the evolutionary transitions between crawling and anal scraping. Representatives of all 4 behaviours are shown in Figure 4.5.

\section{General Crawling}

Crawling was performed in a general context to move forward and occurred in both species that possessed and did not possess anal prolegs (Fig. 4.5a). Crawling 
Fig. 4.5. The variation in anal segment behaviours observed in the Drepanidae.

Schematics summarizing the movements (and possible variations in anal proleg and PP1 setae morphologies (left panel)), representative oscillograms and spectrograms of the vibrations produced by each behaviour (black lines above traces show when each behaviour occurs) (middle panel), and representative power spectra (black line) with background noise (gray line) included for comparison (right panel) for general context crawling (a), aggressive crawling towards an intruder (b), 'pseudo' anal scraping (accompanied by lateral tremulation) (c), anal scraping (d), and lateral hitting (e). 
a
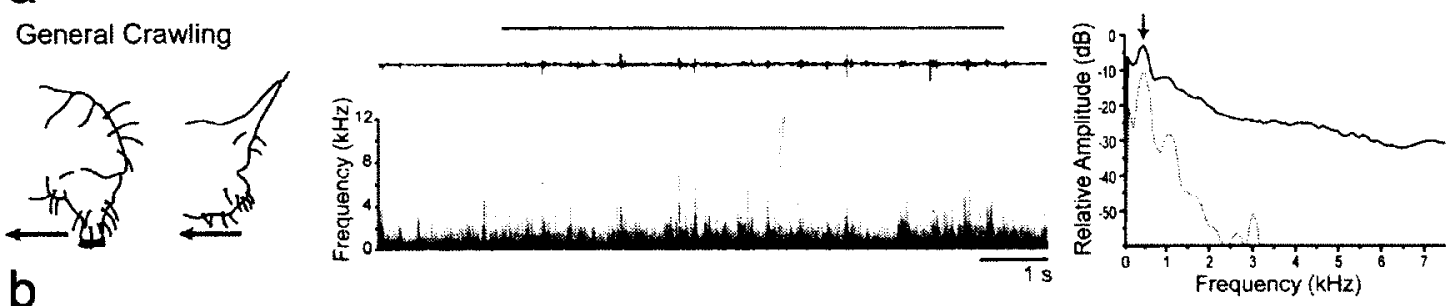

Crawling towards Intruder
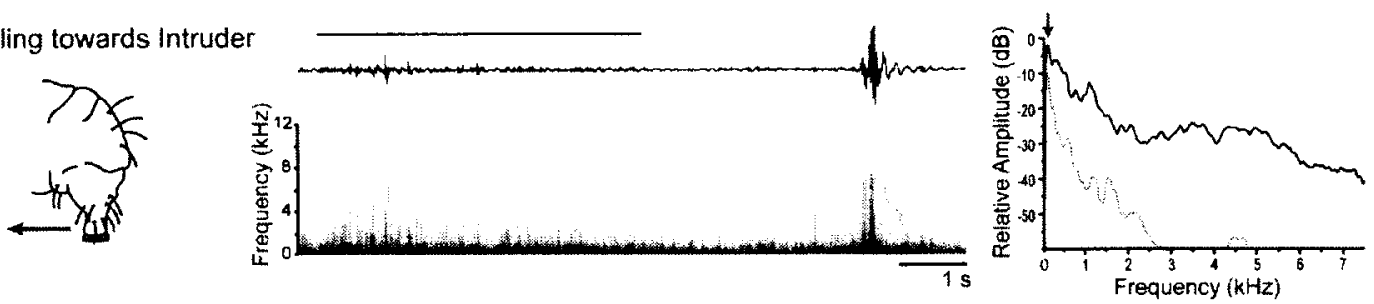

C

Pseudo Anal Scraping (with Lateral Tremulation)
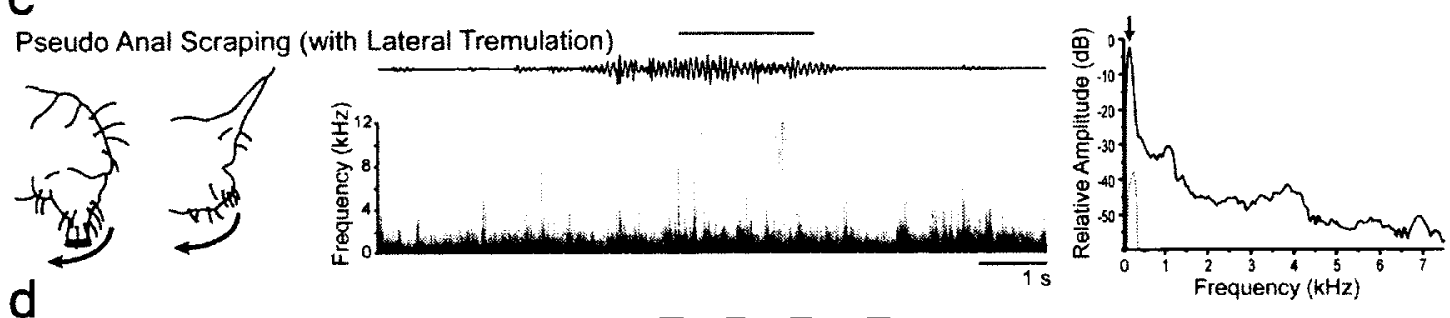

Anal Scraping
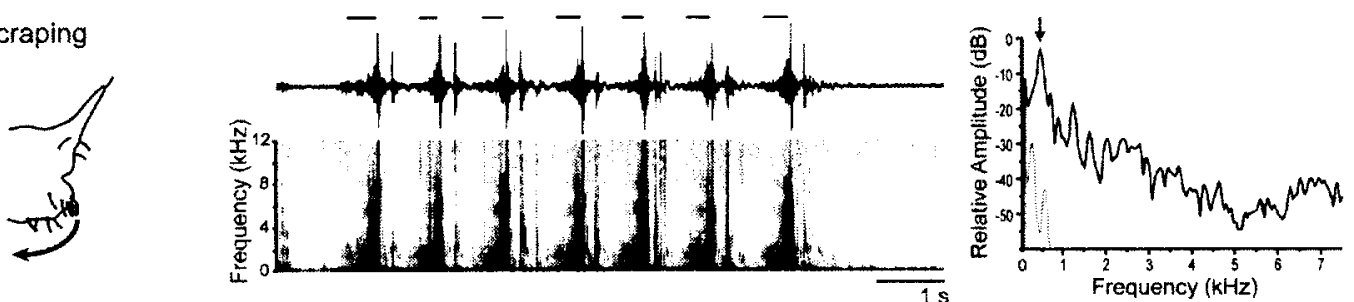

e
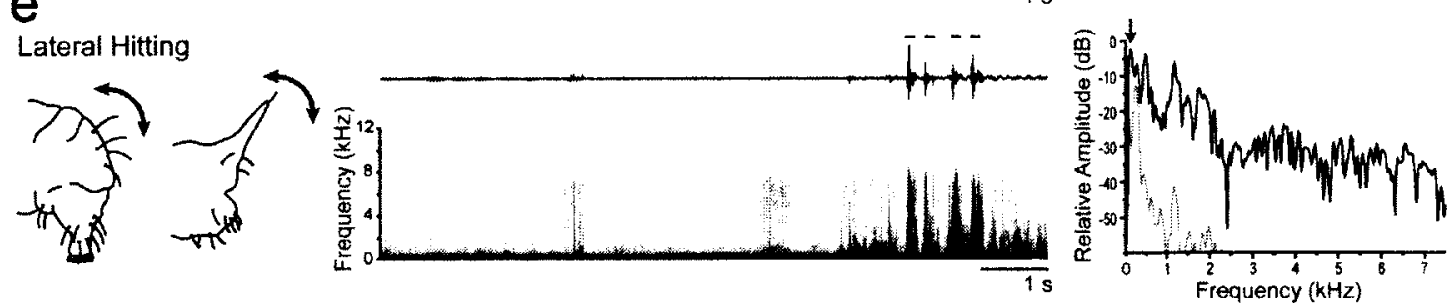
movements differed between anal segment morphologies where species with fully formed anal prolegs (Cyclidia substigmaria) used them to grasp the substrate during crawling; species with reduced prolegs (T. or, T. fluctuosa, Ochropacha duplaris and Thyatira batis) did not use them to grasp the substrate, but they were placed upon the substrate during each crawl cycle; and species that lacked anal prolegs altogether (D. arcuata, $D$. curvatula, D. falcataria, W. cultraria, $O$. rosea, and $F$. bilineata) lowered the anal segment slightly to the leaf surface during each crawl cycle. Crawling vibrations were similar in duration (Kruskal-Wallis one-way analysis of variance; $K=2.53, \mathrm{DF}=2, \mathrm{p}=$ 0.28 ), dominant frequency (Kruskal-Wallis one-way analysis of variance; $\mathrm{K}=5.71, \mathrm{DF}=$ $2, \mathrm{p}=0.057$ ) and bandwidth (Kruskal-Wallis one-way analysis of variance; at $-3 \mathrm{~dB}: \mathrm{K}=$ 2.42, $\mathrm{DF}=2, \mathrm{p}=0.30 ;$ at $-10 \mathrm{~dB}: \mathrm{K}=3.00, \mathrm{DF}=2, \mathrm{p}=0.22$ ) between species with fully formed, reduced and absent anal prolegs. Characteristics of crawling and associated vibrations are presented in Table 4.2.

Crawling towards an intruder

Crawling was also performed in a territorial context in three species (T. or, $T$.

fluctuos $a$ and $O$. duplaris), all with reduced prolegs, where the resident crawled aggressively towards the intruder (Fig. 4.5b). Crawling towards the intruder was typically followed by other territorial behaviours including biting, pushing, lateral head hitting and mandible scraping. Characteristics of crawling towards the intruder and its associated vibrations were the same as those for general crawling (Table 4.2). 
Table 4.2. Average vibration and rate data for anal segment signals.

\begin{tabular}{|c|c|c|c|c|c|c|}
\hline \multirow[t]{2}{*}{ Behaviour } & \multicolumn{5}{|c|}{$\begin{array}{l}\text { Vibration Characteristics } \\
\end{array}$} & \multirow{2}{*}{$\begin{array}{l}\text { Rate at } \\
\text { CLOSE } \\
\text { (events/5 s) }\end{array}$} \\
\hline & $\begin{array}{l}\text { Relative } \\
\text { Amplitude } \\
\text { (times the } \\
\text { baseline) }\end{array}$ & $\begin{array}{l}\text { Dominant } \\
\text { Frequency } \\
(\mathbf{H z})\end{array}$ & $\begin{array}{l}\text { Bandwidth } \\
\text { at }-10 \mathrm{~dB} \\
(\mathrm{~Hz})\end{array}$ & $\begin{array}{l}\text { Bandwidth } \\
\text { at }-3 \text { dB } \\
\text { (Hz) }\end{array}$ & $\begin{array}{l}\text { Duration } \\
\text { (ms) }\end{array}$ & \\
\hline Crawling & $\begin{array}{l}5.2 \pm 1.9 \\
(n=9)\end{array}$ & $\begin{array}{l}18.9 \pm 8.7 \\
(n=9)\end{array}$ & $\begin{array}{l}7.2 \pm 3.2 \\
(n=9)\end{array}$ & $\begin{array}{l}17.7 \pm 8.4 \\
(n=9)\end{array}$ & $\begin{array}{l}1838.2 \pm \\
1216.1 \\
(n=11)\end{array}$ & $\begin{array}{l}0.63 \pm 0.48 \\
(\mathrm{n}=3 ; \\
\text { crawling } \\
\text { towards the } \\
\text { intruder only) }\end{array}$ \\
\hline $\begin{array}{l}\text { Anal } \\
\text { scraping } \\
\text { Lateral tail } \\
\text { hitting }\end{array}$ & $\begin{array}{l}11.6 \pm 1.5 \\
(\mathrm{n}=3) \\
\text { No laser } \\
\text { recordings }\end{array}$ & $\begin{array}{l}41.5 \pm 9.4 \\
(n=3) \\
\text { No laser } \\
\text { recordings }\end{array}$ & $\begin{array}{l}7.9 \pm 1.2 \\
(\mathrm{n}=3) \\
\text { No laser } \\
\text { recordings }\end{array}$ & $\begin{array}{l}18.6 \pm 2.9(\mathrm{n} \\
=3) \\
\text { No laser } \\
\text { recordings }\end{array}$ & $\begin{array}{l}779.3 \pm 550.6 \\
(n=3) \\
207.8 \pm 59.3 \\
(n=6)\end{array}$ & $\begin{array}{l}1.5 \pm 1.1 \\
(n=3) \\
0.11 \pm 0.083 \\
(n=6)\end{array}$ \\
\hline
\end{tabular}


Anal scraping movement

Anal scraping movements were observed in 7 species during territorial encounters with conspecifics (Fig. 4.5c,d). The anal scraping movement involves scraping the terminal segment anteriorly on the leaf surface, and is typically followed by signals produced with the anterior body parts (mandible drumming, mandible scraping, lateral vibration and buzzing). Anal scraping was performed in species that had reduced anal prolegs (T. fluctuosa and T. batis), no anal prolegs (D. arcuata, D. curvatula, $D$. falcataria, F. bilineata, and W. cultraria), with modified setae (D. arcuata, D. curvatula, D. falcataria, and F. bilineata) and without modified setae (T. fluctuosa, T. batis, and $W$. cultraria). The anal scraping movement in species that lacked modified setae (with or without anal prolegs) was categorized as 'pseudo' anal scraping, as these species did not possess the structures necessary to produce the anal scraping signal. 'Pseudo' anal scraping did not differ significantly from anal scraping in duration (Wilcoxon Rank Sum Test, $Z=1.24, \mathrm{DF}=2, \mathrm{p}=0.22$ ). Amplitudes, dominant frequencies and bandwidths could not be measured for 'pseudo' anal scraping as these movements were always accompanied by signals involving the head or mandibles. Characteristics of anal scraping and its associated vibrations can be found in Table 4.2.

\section{Lateral tail hitting}

Lateral tail hitting was observed in 6 species (T. fluctuosa, O. duplaris, T. batis, F. bilineata, and $W$. cultraria) when the intruder made contact with the posterior part of the resident's body (Fig. 4.5e). Lateral hitting was performed by species that had reduced anal 
prolegs and no anal prolegs, with short and long caudal projections. Characteristics of lateral tail hitting are summarized in Table 4.2.

\section{Mapping of behavioural characters}

Behaviours associated with the anal segment as described above in the presence of a conspecific were mapped on to the phylogeny to test the hypothesis that anal scraping derives from crawling. The results indicate that general context crawling represents the ancestral condition and that crawling towards the intruder in a territorial context evolved once in the Thyatirinae at Node A (Fig. 4.6). The anal scraping movement evolved once at the node joining the Thyatirinae and Drepaninae clades (Node B), being subsequently lost twice independently in $O$. rosea and in the ancestor of $O$. duplaris $+T$. or (Fig. 4.6). Finally, lateral hitting evolved at least twice (Fig. 4.6, at Node B, and in the ancestor of $F$. bilineata $+W$. cultraria), being lost twice (Fig. 4.6, at Node $\mathrm{C}$ and in $T$. or). None of the terriorial behaviours were mutually exclusive, and one species, $T$. fluctuosa, was observed to produce all three types of behaviours during encounters with conspecifics (Fig. 4.6). Other species had varying repertoires of behaviours (Fig. 4.6).

Morphological conditions of the anal segment were also mapped onto the phylogeny to assess if they were correlated with any of the territorial behaviours (Fig. 4.6). Looking at the phylogeny, it appears that crawling towards the intruder is only performed by taxa that have reduced prolegs, do not possess a caudal projection, and do not have paddle-shaped setae. Also, species that possess modified setae always anal scrape to produce signals. However, none of the territorial behaviours were found to be 
Fig. 4.6. Reduced Bayesian tree including only those species for which territorial behaviour is known, showing the ancestral and derived conditions of anal segment morphology, PP1 setae morphology, and anal segment behaviour. Pie charts are maximum parsimony probabilities of ancestral behaviours at all nodes. 
Territorial Anal Segment Behaviours

Not territorial (general crawling only)

- Crawling towards intruder

Anal scraping

$\bigcirc$ Lateral Hitting

क
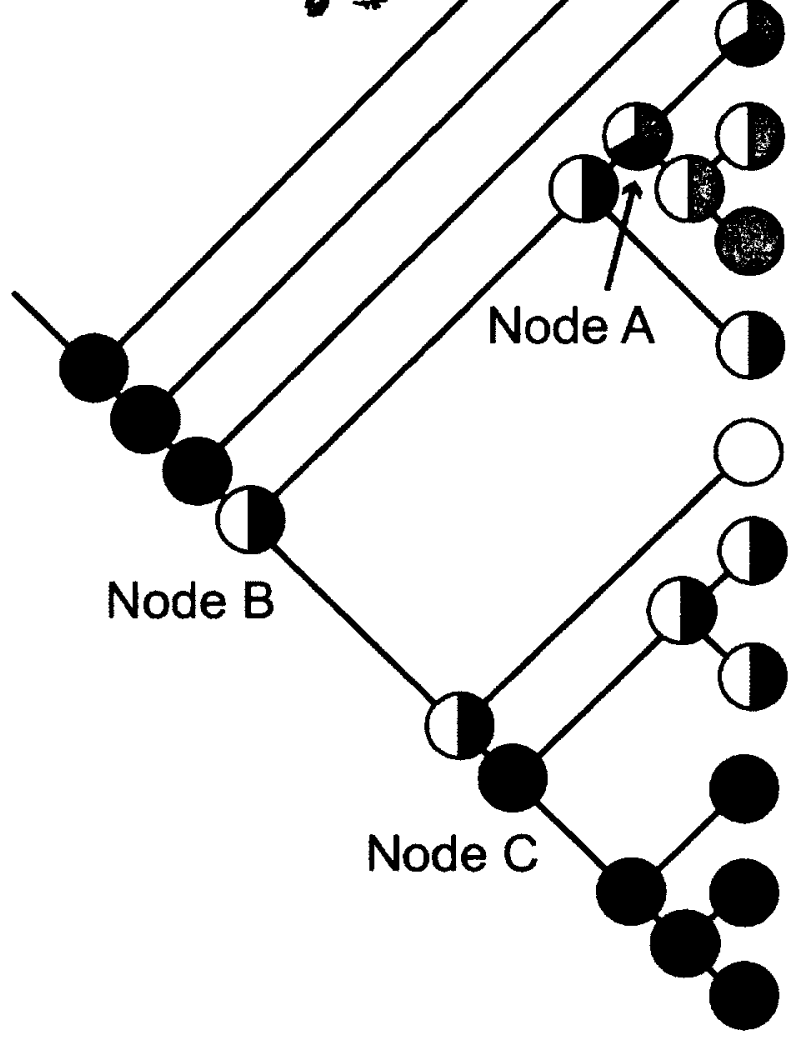

A. albifasciata

$\mathbf{O A}$

E. hainesii

OA

C. substigmaria $\triangle \square \mid \frac{\pi}{\frac{0}{5}}$

T. fluctuosa

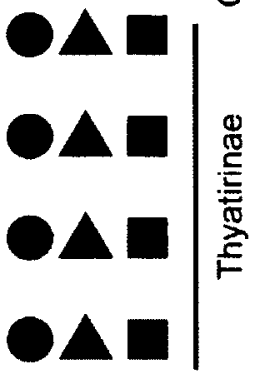

O. duplaris

T. or

T. batis

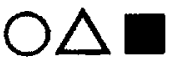

O. rosea

$O \Delta \square$

F. bilineata

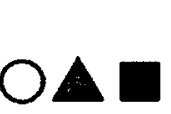

W. cultraria

D. arcuata

D. falcataria

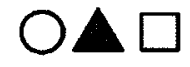

$\mathrm{OA} \square$

D. curvatula

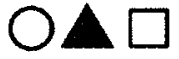

Anal Prolegs

Fully Formed

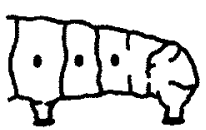

Reduced

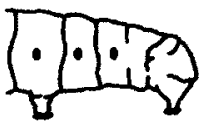

None
Caudal Projection

$\triangle$ None 3

$\Delta$ Short

$\triangle$ Long
PP1 Morphology

Unmodified<smiles></smiles>

Thickened

T

Paddle-shaped 
significantly correlated with anal proleg, caudal projection or PP1 setae condition over the phylogeny using BayesDiscrete analysis $(p>0.05, \mathrm{DF}=4)$.

\section{Comparison of vibrations to assess ritualization}

My hypothesis is that anal scraping is a ritualized form of crawling movements, and therefore I predict that anal scraping demonstrates characteristics commonly found in ritualized signals, including high conspicuousness, redundancy, and stereotypy, and contains alerting components. Anal scraping is indeed more conspicuous than crawling, producing significantly higher vibration amplitudes than general crawling in within trial comparisons (paired t-test; $\mathrm{t}=-3.60, \mathrm{DF}=12, \mathrm{p}=0.004$ ) (Fig. 4.5b). Anal scraping also has a significantly higher dominant frequency than crawling (Wilcoxon Rank Sum Test, $Z=2.04, \mathrm{DF}=1, \mathrm{p}=0.042$ ), making it more conspicuous over background noise (Fig. 4.5b). However, bandwidths did not differ between anal scraping and crawling (Wilcoxon Rank Sum Tests; $-3 \mathrm{~dB}: Z=0.74, \mathrm{DF}=1, \mathrm{p}=0.46 ;-10 \mathrm{~dB}: Z=0.92, \mathrm{DF}=1, \mathrm{p}=0.35)$. Vibrations produced by 'true' anal scraping (with no anal prolegs and the possession of modified setae) is also highly redundant, being repeated at a significantly higher rate per $5 \mathrm{~s}$ within the 20 -s immediately following resident-intruder closest contact than crawling towards the intruder, and 'pseudo' anal scraping (ANOVA; $F=17.68, \mathrm{DF}=9 ; \mathrm{p}=0.002$;

Fig. 4.5). Tests of stereotypy of duration, however, do not show any significant differences between anal scraping, 'pseudo' anal scraping and crawling (Kruskal-Wallis one-way analysis of variance; $\mathrm{K}=2.93, \mathrm{DF}=2, \mathrm{p}=0.23$ ). Finally, I did not observe any alerting components that immediately preceded any of the anal segment behaviours. 
Comparison of behavioural sequences to test the hypothesis that anal scraping derives from crawling

To test the prediction that anal scraping and crawling will be in the same order of events in a typical sequence of behaviours during encounters with conspecifics, I examined behavioural patterns during territorial encounters in 10 taxa and compared these sequences in two representative species, $T$. or (Thyatirinae), and $D$. arcuata (Drepaninae) (Fig. 4.7). The typical behavioural sequence in T. or begins with the resident crawling toward the intruder, followed by head movements including pushing and mandible scraping (Fig 4.7b, c left panel). Crawling towards the intruder is followed by pushing the intruder with the head $(72.7 \%$ probability, $z=9.60, P=<0.001, \mathrm{n}=7)$, which is in turn followed by crawling $(79.2 \%, z=6.18, P=<0.001, \mathrm{n}=7)$. Occasionally the caterpillar will follow the push with a mandible scrape $(20.8 \%, z=-0.26, P=0.79$, $\mathrm{n}=7)$, which is followed by a return to crawling $(83.9 \%, z=5.21, P=<0.001, \mathrm{n}=7)$. In $D$. arcuata, the resident begins an encounter with anal scraping followed by signalling with the mandibles (Fig 4.7b, c right panel). Anal scraping is followed by mandible drumming (74.3\%, $z=17.0, P=<0.001, \mathrm{n}=13)$, which is followed by another anal scrape $(58.9 \%, z$ $=5.53, P=<0.001, \mathrm{n}=13$ ). After a mandible drum, caterpillars will occasionally mandible scrape ( $32.5 \%, z=4.01, P=<0.001, \mathrm{n}=13)$ before returning to an anal scrape $(87.7 \%, z=10.9, P=<0.001, \mathrm{n}=13)$. Physical aggression (biting, pushing, hitting) was never observed in $D$. arcuata trials. When comparing behavioural sequences between these two species (Fig. 4.7c), my results indicate that both anal scraping and crawling occur in the same position in the behavioural sequences during an encounter (prior to movements involving the head and mandibles). 
Fig. 4.7. Sequences of behaviour in Tethea or and Drepana arcuata. (a) Video frames illustrating a typical encounter between a resident and intruder, whereby the intruder approaches the leaf shelter (1), the resident then approaches the intruder while hitting, pushing, or mandible scraping $(T$. or, scale bar $=9 \mathrm{~mm})$ or employs ritualized signal $(D$. arcuata, scale bar $=7 \mathrm{~mm}$; video credit: J. Yack) (2), and the intruder leaves (3). (b) Laser vibrometer traces of the vibrations on the leaf during such an encounter. Numbers correspond to frames in (a). Relative amplitudes are equal between species. The box encloses part of the trace that is enlarged in the colored segment below, which shows the vibrations generated by the resident when the two individuals are close together. Colors correspond to cues or signals in (c). (c) Transition diagrams showing the probability of one type of behaviour following another. Asterisks denote significantly more probable transitions (D. arcuata: $n=13 ;$. or: $n=7 ; P<0.05$ ). MS (mandible scraping); AS (anal scraping); MD (mandible drumming). 


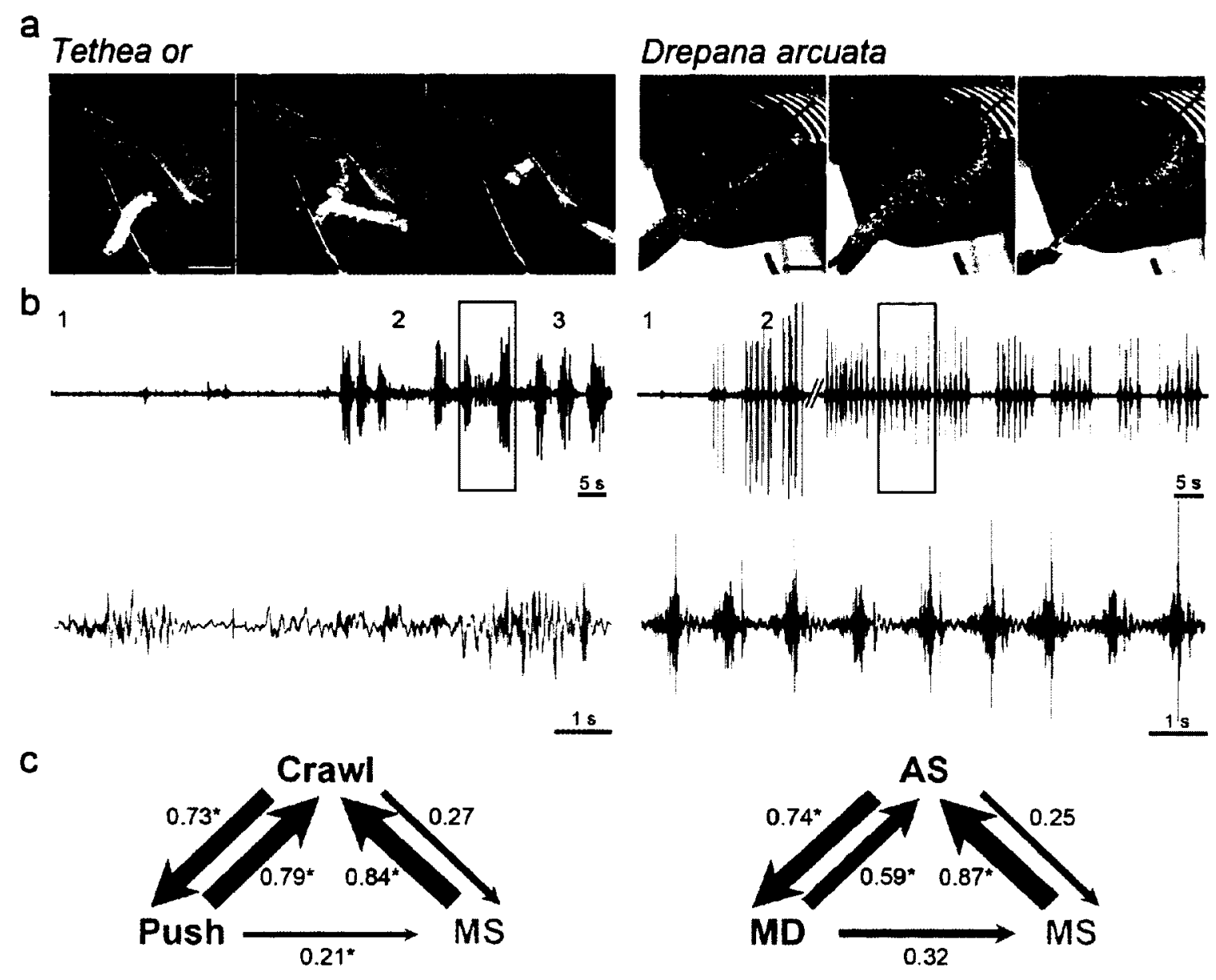


Kinematics of anal segment movements in Tethea or (crawling) and Drepana arcuata (signalling)

In this section I will describe and compare movement patterns of the anal segment during crawling in a basal species ( $T$. or), and a derived signalling species (D. arcuata). Differences in movement patterns observed between the two representative species will be used to propose a model to explain the mechanistic changes that occurred to convert from 'walking' to 'talking'.

\section{Crawling in Tethea or}

Forward crawling in $T$. or corresponds to that described in Manduca sexta, where crawling has been described in detail (Dominick and Truman, 1986; Belanger and Trimmer, 2000a, 2000b). In brief, a full crawl cycle in $T$. or involves a wave of longitudinal contractions that begins in the posterior end of the caterpillar and travels towards the anterior end. As the wave passes, each segment is lifted and carried forward using longitudinal contractions (swing phase). In segments bearing prolegs, the prolegs are then lowered and planted on the substrate (stance phase). During a crawl cycle the head can move from side to side or not at all, and telescopes forward as the wave reaches the most anterior part of the body. One entire crawl cycle in the anal segment lasts $1.4 \pm$ $0.53 \mathrm{~s}(n=7)$.

I will now describe movements specific to the terminal abdominal segments (A610) (Fig. 4.8a-c). At the beginning of the swing phase, the anal prolegs are firmly planted onto the substrate via the crochets (Fig. 4.8c, frame 1). The crochets are released, the prolegs are lifted and carried forward (Fig. 4.8c, frame 2), and then lowered towards the 
Fig. 4.8. A comparison of crawling movements in Tethea or and anal scraping movements in Drepana arcuata. (a) Schematic showing the paths of a single crawling movement in the anal prolegs in $T$. or. The distance between points represents an equal amount of time. Arrow indicates the direction of motion. (b) Total displacement (i.e. in all directions) (top) and total velocity (bottom) of the anal proleg versus normalized time of crawling movement in $T$. or. Time was normalized between trials by making the point where the swing phase changes to the stance phase equal to time $0 \mathrm{~s}$. Gray lines represent different individuals. The black line shows the trend of all the lines. (c) A series of highspeed video frames showing the sequence of movements of a single crawling cycle in $T$. or. Frame 1, the caterpillar's position before the crawl. Frame 2, the caterpillar lifts its anal prolegs and moves them forward. Frame 3, the caterpillar lowers its anal prolegs to the substrate while continuing to move them forward. Frame 4, the caterpillar plants its anal proleg on the substrate. Dots represent the position of the PP1 setae, arrows represent the direction of motion. (d) Schematic showing the paths of movement of the anal oar during a single anal scrape in $D$. arcuata. (e) A series of video frames showing the sequence of movements of a single anal scrape in D. arcuata. Frame 1 shows the caterpillar's position before the anal scrape. Frame 2, the caterpillar lowers its terminal abdominal segment to the leaf surface. Frame 3, the caterpillar scrapes its anal oars on the leaf surface and lifts its head in preparation for a mandible drum. Frame 4, the caterpillar returns its terminal abdominal segment and head to their original positions. (f) Total displacement (top) and total velocity (bottom) of the modified setae versus normalized time of anal scraping movement in $D$. arcuata. Time was normalized between trials by making the point where the scrape phase changes to the return phase equal to time $0 \mathrm{~s}$. Throughout the figure, red shows the swing phase in $T$. or and the scrape phase in $D$. arcuata, while blue represents the stance phase in $T$. or and the return phase in $D$. arcuata. 


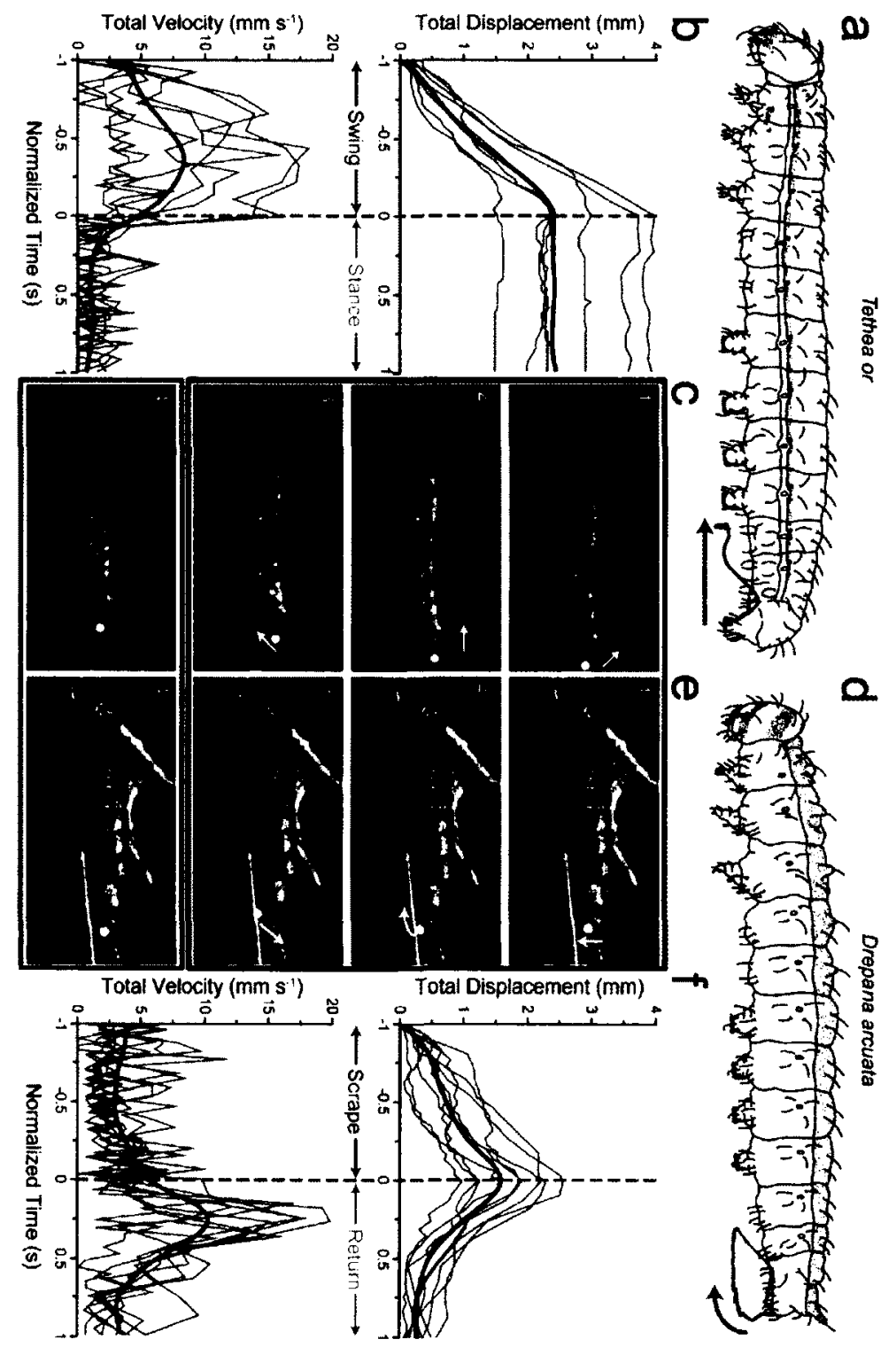


substrate (Fig. 4.8c, frame 3). The crochets are engaged, everting the plantae slightly, and the prolegs are planted on the substrate (Fig. 4.8c, frame 4). The swing phase lasts on average $505 \pm 204 \mathrm{~ms}$, and carries the proleg anteriorly by $2.7 \pm 0.8 \mathrm{~mm}$ at a mean horizontal velocity of $6.5 \pm 3.8 \mathrm{~mm} \mathrm{~s}^{-1}(n=7)$ (Fig. $\left.4.8 \mathrm{~b}\right)$. The mean duration of the stance phase, while the prolegs are firmly planted, is $848 \pm 469 \mathrm{~s}(n=7)$, and the anal prolegs remain in the same approximate position during this phase (Fig. $4.8 \mathrm{~b}$ ). The unmodified PP1 setae, located on the anal proleg were never observed to make contact with the substrate.

\section{Signalling in Drepana arcuata}

The anal scraping movement in D. arcuata involves the modified PP1 setae being lowered towards the substrate and scraped anteriorly to produce a vibration on the leaf surface (scrape phase) (Fig. 4.8d-f). The anal segment then returns at a high velocity to its original position (return phase) (Fig. 4.8d-f). The mean duration of the entire anal scrape is $1.3 \pm 0.35 \mathrm{~s}(n=9)$ (Fig. $4.8 \mathrm{f})$. The rest of the body remains relatively motionless with the head moving slightly in no discernable pattern during the anal scrape, except when a signal produced with the mandibles (mandible drumming) accompanies the anal scrape.

This paragraph will now focus on specific movements of the terminal abdominal segments (A6-10) during an anal scrape. Before the anal scrape, the modified PP1 setae and terminal abdominal segments are raised off the substrate (Fig. 4.8e, frame 1). The scraping phase begins with a slight posterior extension and lowering of the anal segment to the substrate (Fig. 4.8e, frame 2). The anal segment is then curled under slightly so that the PP1 setae make contact with the leaf and is then dragged anteriorly across the leaf 
surface (Fig. 4.8e, frame 3). As this occurs, the anal segment is curled under so that the caudal projection almost makes contact with the substrate. The setae are scraped for 597 $\pm 235 \mathrm{~ms}$, moving a total horizontal distance of $1.6 \pm 0.45 \mathrm{~mm}$ at a horizontal velocity of $2.9 \pm 1.1 \mathrm{~mm} \mathrm{~s}^{-1}$, producing a scratching sound on the leaf $(n=9)$. The setae are then quickly lifted off the substrate and re-extended approximately back to their original position at high velocity $\left(3.6 \pm 3.0 \mathrm{~mm} \mathrm{~s}^{-1}\right)$ during the return phase, to start the next anal scrape $(n=9)$ (Fig. 4.8e, frame 4).

\section{Comparison between crawling and signalling}

In summary, the crawling movement (with respect to the terminal abdominal segments (A6-10)) involves a swing phase, where the anal prolegs are lifted off the substrate, carried forward and lowered back to the substrate, and a stance phase, where the anal prolegs are firmly planted on the subtrate (Fig. $4.8 \mathrm{a}-\mathrm{c}$ ). The anal scraping movement involves a scrape phase, where the anal segment is lowered and carried forward along the substrate, and a return phase, where the anal segment returns to its original position at high velocity. Overall, the series of movements do not differ in duration (independent t-test, two-tailed, $t=0.30, \mathrm{DF}=10, \mathrm{p}>0.05$ ), but do differ in other respects. I suggest that the swing phase of crawling is homologous to the scrape phase of anal scraping based on the fact that both movements involve the anal segment being carried forward in the same manner, and that the displacement does not differ between behaviours (independent $t$-test, two-tailed, $\mathrm{t}=1.05, \mathrm{DF}=11.5, \mathrm{p}>0.05$ ) (Fig. 4.8b,f, swing vs. scrape phase). However, there are some differences between these two movements: i) during the swing phase of crawling, the anal segment is lifted off the 
substrate before being carried forward, and is then lowered at the end of the phase, where as during anal scraping, the scrape phase begins with the anal segment being lowered towards the substrate (as it begins in a raised position) (see Fig. 4.8c,e, frames 1-3 for a side-by-side comparison of the movements); and ii) the mean horizontal velocity is significantly lower during the scrape phase of the anal scraping movement (independent t-test, two-tailed, $\mathrm{t}=3.56, \mathrm{DF}=7, \mathrm{p}=0.01$ ) (Fig. 4.8,b,f, swing vs. scrape phase). The stance phase of crawling differs from the return phase of anal scraping with respect to direction of motion (Fig. 4.8c,e, frames 4), as well as displacement and velocity (Fig. $4.8 \mathrm{~b}, \mathrm{f}$, stance vs. return phase), where during the stance phase of crawling, the anal segment remains motionless, and during the return phase of anal scraping, the anal segment returns to its original raised position at high velocity. These similarities and differences will be used to propose a model (see Discussion) for how the anal scraping movement was modified from crawling.

\subsection{Discussion}

The goal of this chapter was two-fold: 1) to test the hypothesis that anal scraping derives from crawling, and 2) to propose a model for the transition between crawling and anal scraping. The results of this chapter provide the first empirical evidence for the origin and ritualization of a communication signal using a combination of morphological, behavioural and phylogenetic data. 
Testing the hypothesis that anal scraping derives from crawling

The hypothesis that anal scraping derives from crawling is supported by the following lines of evidence: 1) crawling with fully formed prolegs and unmodified PP1 setae represents the basal condition when mapped onto the phylogeny; 2) kinematic analysis demonstrates that crawling and anal scraping involve similar movement patterns (see discussion below on comparison of kinematics); 3) vibration analysis suggests that anal scraping shows more characteristics of ritualization than crawling; and 4) aggressive crawling towards an intruder and anal scraping occur in the same position in a typical sequence of behaviours between representative species. The following paragraphs will discuss each line of evidence individually, as well as the interesting variation seen between species.

Comparative morphology of the anal segment

The anal prolegs varied in morphology from fully formed to reduced to completely absent. The results of our phylogenetic mapping demonstrate that fully formed prolegs represent the basal condition, and were reduced once before being lost completely. Reduced or absent prolegs are common in other larval Lepidoptera, especially leaf-mining species which are adapted to living within the tissue of their hostplant and are no longer needed to grasp the substrate, and species that have adopted a 'looping' method of locomotion, such as in the Geometridae (Hinton, 1955). To date, there has been no hypotheses to explain the function of reduced or absent prolegs in Drepanidae, since they are neither leaf-miners nor have an alternate mode of locomotion. However, many Thyatirinae caterpillars create shelters by sewing two leaves together, 
and live in the space between (Minet \& Scoble, 1999; Riegler, 1999). These shelters are similar to leaf mines, as they have limited vertical space, and anal proleg reduction may have occurred as a result of this mode of living. Another possibility is that the anal prolegs were reduced and finally lost to facilitate anal scraping (see model below).

The anal segment also varied in the presence or absence of the caudal projection, which could be fleshy or filiform in shape. Projections from the terminal segment have been noted in a few groups of caterpillars, mainly species of Notodontidae (Hinton, 1955; Stehr, 1987), Sphingidae (Scoble, 1992) and Drepanidae (Stehr, 1987). These projections have been shown to function for defense, being eversible and used in startle (Hinton, 1955; White et al., 1983), or possibly for mimicry, mimicking the chemical-emitting osmeterium of other species (Chow \& Tsai, 1988) in Notodontidae. Since my results suggest that these structures are not correlated with any type of territorial behaviour associated with the anal segment (including lateral tail hitting), their function is currently unknown in Drepaninae. My results also demonstrate that all Drepanidae caterpillars that lack anal prolegs possess these structures, suggesting that they are modified prolegs, as in the Notodontidae (Hinton, 1955). However, the caudal projections in Drepaninae do not arise from the location of the anal prolegs, but from the more dorsal anal plate, and the planta retractor muscles in the anal segment (used to control the prolegs during crawling) do not insert on the caudal projection (see Appendix $\mathrm{C}$ for diagrams of muscles). Therefore, it is unlikely that they are modified prolegs.

The PP1 setae varied in shape from unmodified seta, to thickened seta, to various paddle-shaped modifications in Drepaninae. Non-modified PP1 seta are found in most caterpillar species, and function for tactile reception (Stehr, 1987). Modifications in the 
shape and size of the PP1 setae evolved multiple times within Drepanidae, where each variation was usually restricted to an independent evolutionary origin event. Since different shapes typically evolved only once, and shapes differed between evolutionary events, this suggests that it is the sclerotization of the seta, and not specifically the shape, that is important for enhancing signalling. It is also possible that the different shapes of modified setae are related to the type of hostplant used by the resident, as leaf shape and size are known to alter the vibrational properties of the leaf (Cocroft et al., 2006).

\section{Comparative Behaviour of Anal Segment}

Behaviours associated with the anal segment included general context crawling, crawling towards the intruder during territorial encounters, anal scraping, 'pseudo' anal scraping, and lateral tail hitting. Some other examples of insects that use their anal segments for vibrational signalling include: larvae of the sawfly, Hemicroa crocea, which anal scrape to orient other larvae to high-quality feeding sites (Hoegraefe, 1984), some sawfly larvae (Perga spp.) that drum a sclerotized portion of the abdomen on the substrate to produce percussion signals for group coordination (Carne, 1962; Fletcher, 2007), and some species of ants and caddisflies (reviewed in Virant-Doberlet \& Cokl, 2004) which scrape their abdomens to produce vibrations. My phylogeny indicates that general context crawling represents the basal condition and that the anal scraping movement evolved once in the common ancestor of the Thyatirinae, which supports the hypothesis that anal scraping derives from crawling. 
Comparison of vibrations to assess ritualization

For a signal to be effective, it must be detected and distinguished as a signal by the intended receiver. As such, ritualized signals include features that enhance their ability to be detected (increased conspicuousness, redundancy and alerting components) and recognized (stereotypy) (Cullen, 1966; Wiley, 1983; Johnstone, 1997; Bradbury \& Vehrencamp, 1998; Maynard Smith \& Harper, 2003). Increased conspicuousness, such as an increase in the amplitude of an acoustic signal, can improve the chance a receiver will detect a signal, even in noisy environments (Wiley, 1983). High redundancy, which can involve repeating a signal or using multiple signals for the same function, can reduce errors in the detection and recognition of a signal (Wiley, 1983). Both of these characteristics have been shown to play important roles in the tidbitting displays of male fowl, Gallus gallus, where females recognize the signal as distinctly different from the similar basal behavioural precursor (Smith \& Evans, 2011). In the Drepanidae, I predicted that if anal scraping derives from crawling, anal scraping will possess characteristics of a ritualized signal. I found that anal scraping was more conspicuous, having a significantly higher relative amplitude and dominant frequency than crawling, and more redundant, having a significantly higher repetition rate at close distance between the resident and the intruder. I did not, however, find evidence for increased stereotypy, perhaps because crawling is also a highly stereotyped behaviour. I also did not find evidence for an alerting component, although since anal scraping is produced first in the typical sequence of behaviours, and usually precedes signals produced by the anterior body parts, it may itself be an alerting component. Overall, my results support 
the prediction that anal scraping contains characteristics commonly observed in ritualized signals.

Sequences of behaviour

My final prediction to support the hypothesis that anal scraping derives from crawling was that anal scraping and crawling would be in the same position in a typical sequence of resident behaviour between an anal scraping and non-anal scraping species. I found that in two representative species, one that anal scrapes (D. arcuata; derived condition) and one that crawls towards the intruder (T. or; basal condition), crawling and anal scraping were both first in the typical sequence of behaviour, followed by movements involving the anterior body segments. This finding supports my hypothesis that anal scraping derives from crawling.

The evolutionary transition from crawling to signalling

Based on my results, I propose two possible scenarios for the evolutionary transition from crawling to anal scraping in the Drepanidae (Fig. 4.9). Both scenarios suggest that anal scraping ultimately derives from crawling movements as supported by the previous lines of evidence. The first scenario proposes that general context crawling with fully formed anal prolegs and unmodified setae transitioned to 'pseudo' anal scraping with reduced prolegs and unmodified setae (Fig. 4.9a). 'Pseudo' anal scraping then transitioned to both aggressive crawling towards the intruder with reduced anal prolegs and unmodified setae (in the Thyatirinae) and 'true' anal scraping with no anal prolegs and modified setae in the Drepaninae (Fig. 4.9a). This scenario is supported by my 
behavioural mapping results, which indicate that the anal scraping movement evolved in the common ancestor of the Thyatirinae and Drepaninae, before aggressive crawling evolved in the Thyatirinae (Fig. 4.6, Node B).

In this scenario, the loss of anal prolegs and evolution of modified setae may have occurred to enhance the signal. If the presence of anal prolegs reduced the efficacy of the signal, by not allowing the PP1 setae to make contact with the leaf (thereby lowering the amplitude of the signal), or by attaching to the substrate between scrapes (thereby not allowing for high repetition rates), selection would have acted to reduce the size of the anal prolegs. Modification of the PP1 setae may have evolved to increase the amplitude of vibrations or to increase the dominant frequency of the vibrations to render the signal more conspicuous over low frequency vibrations generated by background noise (e.g. wind and rain; see Barth et al., 1988; Caldwell et al., 2009; Guedes et al., 2012). Indeed, my results indicate that anal scraping with modified setae and no anal prolegs shows more characteristics of ritualization, having significantly higher repetition rates, and producing significantly higher amplitude vibrations with higher dominant frequencies than crawling (which increase signal to noise ratio, see Fig. 4.5). 'Pseudo' anal scraping, without these specialized setae or the loss of anal prolegs, may represent a transitional stage where modified setae and anal proleg loss has not yet evolved.

This first scenario, however, does not adequately explain why 'pseudo' anal scraping evolved in the first place. The second scenario proposes that general crawling with fully formed anal prolegs and unmodified PP1 setae first transitioned to aggressively crawling towards the intruder with reduced prolegs and unmodified PP1 setae, before transitioning to 'pseudo' anal scraping with reduced prolegs and unmodified setae, and 
Fig. 4.9. Schematic of the evolution of anal scraping signals in Drepanidae caterpillars.

(a) Scenario 1: General crawling (with fully formed anal prolegs and unmodified PP1 setae) transitions to 'pseudo' anal scraping (with reduced anal prolegs and unmodified PP1 setae), which then transitions to either aggressive crawling towards the intruder (with reduced anal prolegs and unmodified PP1 setae) (top) or anal scraping (with no anal prolegs and modified PP1 setae) (bottom) depending on the subfamily. Traces under diagrams show representative oscillograms of the vibrations produced by each behaviour. (b) Scenario 2: General crawling (with fully formed anal prolegs and unmodified PP1 setae) transitions to aggressive crawling towards the intruder (with reduced anal prolegs and unmodified PP1 setae), which transitions to 'pseudo' anal scraping (with reduced anal prolegs and unmodified PP1 setae), and finally to anal scraping (with no anal prolegs and modified PP1 setae). 
a

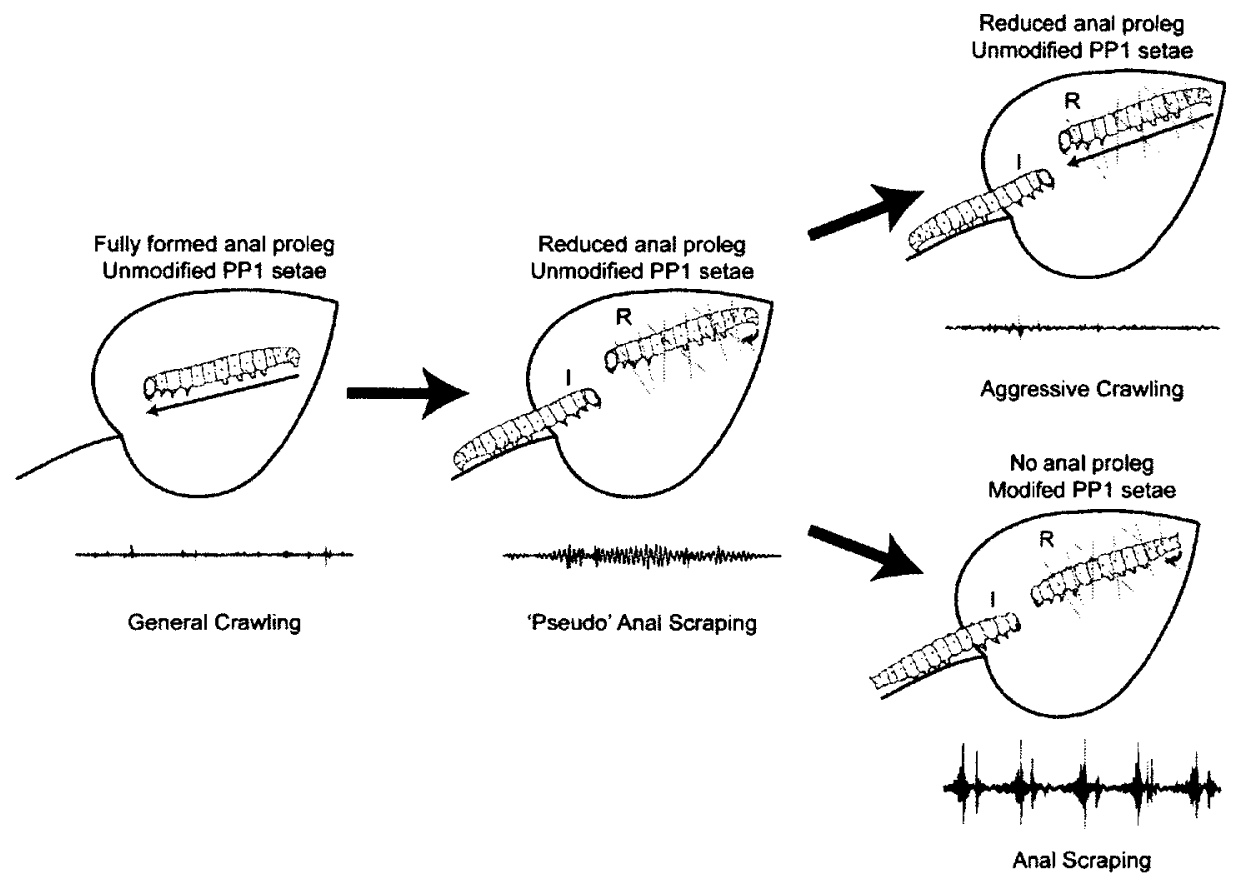

b

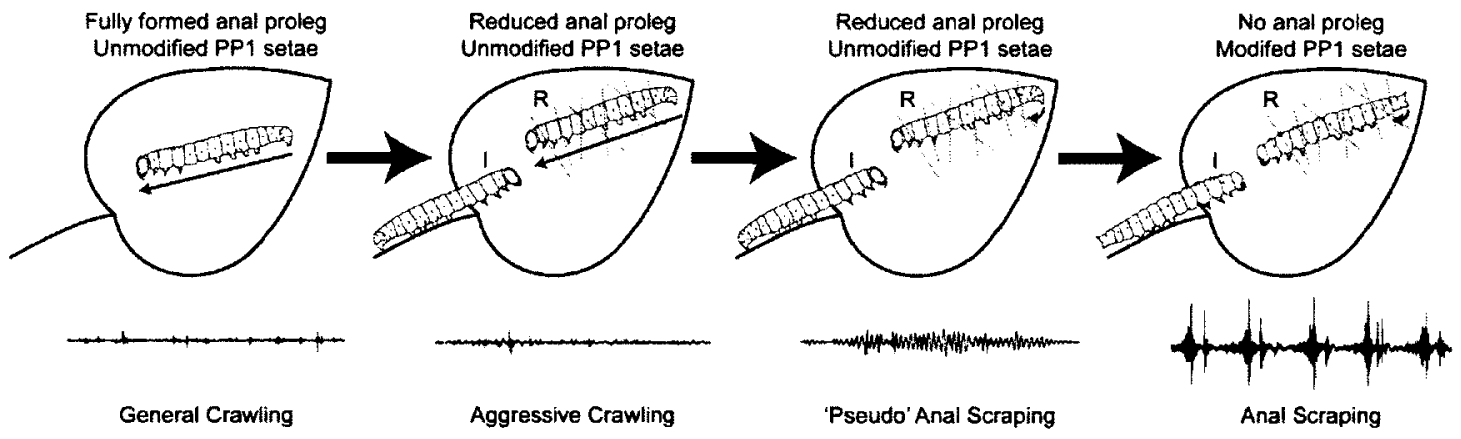


finally to anal scraping with no anal prolegs and modified setae (Fig. 4.9b). Although this scenario does not strictly follow my behaviour mapping results (suggesting that the anal scraping movement evolved before aggressive crawling), I offer it as an alternative because it is in line with the intention movement hypothesis of signal origin (Tinbergen, 1952; Brown, 1975; Bradbury \& Vehrencamp, 1998; Maynard Smith \& Harper, 2003). The results of my comparison between behavioural sequences also supports this hypothesis. The intention movement hypothesis of signal origin states that signals can be derived as intention movements, showing the sender's intention to perform a certain behaviour. For example, it is believed that foot drumming in kangaroo rats is derived from the intention to chase (Randall, 2001). In the Drepanidae, I have evidence that some species use crawling in a territorial context, where the resident crawls towards an intruder to perform physical damage (biting, hitting, pushing). If crawling towards the intruder with the intention to physically harm was common, intruders could have potentially exploited the vibrations produced by crawling to avoid physical damage by leaving the territory. The crawling behaviour became ritualized over time, because the reaction of intruder also benefitted the resident (i.e. the resident no longer had to perform a costly behaviour in order for the intruder to leave its territory). Thus, residents began to walk on the spot, or 'pseudo' anal scrape, manipulating the intruder into believing that it was crawling toward it. This 'pseudo' anal scraping then transitioned to 'true' anal scraping through the evolution of modified setae and the complete loss of anal prolegs. In this case, the initial reduction in anal prolegs before the evolution of the anal scraping movement may be attributed to the mode of living of the Thyatrinae (which live between 
two leaves, as discussed above). Future studies that include behavioural information on more taxa are needed to determine which evolutionary scenario is more likely.

\section{Alternative evolutionary transitions}

In a final alternative scenario, it is possible that another behavioural step existed between crawling and anal scraping. Many species of caterpillars, especially those travelling in processions, use chemical signals for communication (e.g. Fitzgerald, 1995; Ruf et al., 2001; Fitzgerald \& Pescador-Rubio, 2002; Fitzgerald, 2003; Colasurdo \& Despland, 2005; Costa, 2006; Pescador-Rubio et al., 2011). Many of those species have been shown to deposit pheromones by brushing the ventral surface of the tip of the abdomen against the substrate (Fitzgerald, 1995; Ruf et al., 2001; Fitzgerald \& PescadorRubio, 2002; Fitzgerald, 2003; Costa, 2006; Pescador-Rubio et al., 2011), and pheromones appear to be secreted from glandular setae found on the proximal regions of the anal prolegs and venter (Fitzgerald \& Pescador-Rubio, 2002). Therefore, the dispersal of pheromones from the anal segment may have been a transitional stage between crawling and anal scraping in Drepanidae. However, I have found no evidence of glandular setae on the anal segment in caterpillars of Drepanidae and the original function of the PP1 setae was for tactile reception (Stehr, 1987). I have also not found any evidence for the use of pheromones for marking territories in Drepanidae. In one species, D. arcuata, it was found that the presence of the resident was crucial for intruder retreat, as intruders would readily establish residency in shelters where previous residents had been removed (Yack et al., 2001). This suggests that intruders are not deterred by pheromones, but by the resident's presence/vibratory signals. Therefore, current evidence 
suggests that pheromone dispersal is not a transition stage between crawling and anal scraping.

\section{Mechanistic transition from walking to talking}

I have discussed how the behaviours may have transitioned from crawling to anal scraping, and will now focus on how this transition may have occurred in a mechanistic point of view. My results demonstrate that crawling in the anal segment comprises two phases: a swing phase, where the anal proleg are released from the substrate, lifted, carried forward and brought back down, and a stance phase where the crochets are engaged and grasp the substrate. The anal scraping movement also comprises two phases: the scrape phase, where the anal segment is lowered, curled under and scraped along the substrate, and the return phase, where the anal segment is returned to its original raised position at high velocity. I propose that the swing phase of crawling is homologous to the scrape phase of anal scraping, and that the stance phase of crawling is homologous to the return phase of anal scraping. Evidence for homology between the swing and scrape phase includes the facts that both involve the anal segment being carried forward in the same manner and the distance the anal segment travels is statistically equal between both behaviours. Differences between these two phases include a difference in initial direction of motion (the anal prolegs are raised in crawling whereas the anal segment is lowered in anal scraping), and a significantly lower velocity in the anal scrape. Differences in the direction of motion may be explained by changes in the timing of muscular contractions. During crawling, dorsal longitudinal muscles that run horizontally along the dorsal area in each segment contract sequentially, starting at the posterior end of the animal, to raise 
each segment (Belanger \& Trimmer, 2000a) (see Appendix C for diagram of pertinent muscles in $T$. or). Contraction in the next anterior segment causes each posterior segment to be carried forward (Belanger \& Trimmer, 2000a). Finally, the ventral longitudinal muscles, found horizontally along the ventral area of each segment, contract sequentially to lower each segment (Belanger \& Trimmer, 2000a). During anal scraping, however, the anal segment begins in a raised position, suggesting that the dorsal longitudinal muscles begin in a contracted position (see Appendix $\mathrm{C}$ for diagram of pertinent muscles in $D$. arcuata). The ventral longitudinal muscles then contract sequentially (as in crawling) to lower the anal segment and scrape it along the substrate. Essentially, the order of contraction remains the same between the swing phase of crawling and the scrape phase of anal scraping, except that in anal scraping the sequence has been modified to support a sustained initial contraction of the dorsal longitudinal muscles. Finally, the lower horizontal velocity of the scrape as compared to the swing phase of crawling can simply be attributed to the physical drag created by scraping the modified setae along the substrate.

I also propose that the stance phase of crawling is homologous to the return phase of anal scraping. Although the direction of motion, displacement and velocity may differ between both movements, where the prolegs remain motionless during crawling, and the anal segment returns to its original raised position at high velocity during anal scraping, I argue that muscle activity remains the same between behaviours. Before crawling, the crochets found on the ventral surface of the prolegs attach the prolegs to the substrate. The crochets are released through a contraction of the planta retractor muscles (which arise on the ventral region of the tergum near the middle of the segment, posterior to the 
spiracle, and insert on the tendon of the planta within the proleg) (Belanger \& Trimmer, 2000b; Mezoff et al., 2004). When the planta retractor muscles contract, this pulls the planta into the proleg slightly, releasing the crochets (Belanger \& Trimmer, 2000b; Mezoff et al., 2004). During the stance phase, the planta retractor muscles relax, and the planta everts, inflates medially and fans out into a broad lobe due to hydraulic pressure, re-engaging the crochets in the new position (Belanger \& Trimmer, 2000b; Mezoff et al., 2004). If a similar sequence of muscle contraction occurs during anal scraping at the end of the scrape phase, the hydraulic pressure caused by the contraction of the planta retractor muscles would return the anal segment to its original position at high velocity (along with the sustained contraction of the dorsal longitudinal muscles). This would occur because the lack of anal prolegs and crochets would render the caterpillar unable grasp the substrate with the anal segment. Therefore, both phases can be achieved using the same muscle contraction sequence, despite the differences observed in direction of motion, displacement and velocity.

Another major difference between crawling and anal scraping is that crawling movements involve the entire length of the caterpillar's body, where anal scraping movements are isolated to the terminal abdominal segments (A7-10). Results from previous studies provide insight into how crawling movements can be isolated in the terminal abdominal segments. These studies have shown that locomotor patterns in caterpillars are controlled by the interaction of segmental neural pattern generators that can be modified on the basis of sensory input (Dominick \& Truman, 1986). Each segmental ganglion receives both activating and coordinating input from higher neural centers, including the brain and subesophageal ganglion (Dominick \& Truman, 1986). 
Since crawling behaviours can occur in the first thoracic segment in larvae in which the connectives posterior to this ganglion have been severed, it is assumed that each segmental ganglion can independently produce motor patterns (Dominick \& Truman, 1986). Reversible deactivation of crawling activity has also been evoked by atropine application in isolated nerve cords, where crawling has been induced using pilocarpine, suggesting that the response is simply mediated by muscarinic-like acetycholine receptors (Johnston \& Levine, 1996). Therefore, the deactivation of crawling motor patterns in all segments up to the sixth abdominal segment in anal scraping is a plausible scenario and may be a product of an inhibition of central pattern generators in preceding ganglia by higher neural centers. Future studies examining the activity of muscles and neurons in the anal segment during crawling and anal scraping are needed to test this hypothesis.

The present chapter focuses on the evolutionary origin of anal scraping in the Drepanidae. However these caterpillars are known to also produce vibratory signals with the mandibles and anterior body segments, including mandible drumming, mandible scraping, and lateral tremulation during encounters with conspecifics. The evolutionary origins of these signals will be the focus of Chapter 5 . 


\section{ChAPTER 5}

From Hitting to Scraping: The Evolutionary Origin of MANDible SCRAPIng Signals in Drepanidae Caterpillars 


\subsection{Introduction}

Chapter 4 provided support for the hypothesis that vibratory signals produced by anal scraping with modified PP1 setae derive from movements associated with crawling. Results from Chapter 2 demonstrate that some species also produce vibrations associated with movements of the mandibles and anterior body segments. The present chapter (Chapter 5) will focus on the origin and evolution of these anterior body behaviours. Behavioural observations from 11 species reveal that different species of Drepanidae caterpillars can produce at least eight types of behaviours involving the head and mandibles during encounters with conspecifics. These behaviours include mandible drumming, mandible scraping, twitching, lateral tremulation, buzzing, lateral head hitting, pushing and biting (as described in Chapter 2). Mandibles were also found to vary in structure in 18 species, with respect to the number of distal teeth and ridges on the oral surface (see Chapter 2). This variation in morphology and behaviour associated with the anterior segments poses another opportunity to develop and test hypotheses on the evolutionary origins of vibratory signals in these caterpillars.

The purpose of this chapter, therefore, is to begin to elucidate the evolutionary origins of some of these behaviours. I will start by mapping mandible morphology and anterior body behaviour onto the phylogeny created in Chapter 3, to develop hypotheses on the evolution of signals. This will allow me to assess which behaviours are derived, and if any particular features associated with the mandibles are correlated with behaviour. The second goal of this chapter is to specifically test the hypothesis that mandible scraping derives from lateral head hitting. This hypothesis is based on the observation that both behaviours involve similar movement patterns, where the head and first few 
anterior body segments move in a lateral arc to either hit another caterpillar (lateral head hitting), or to scrape the mandibles on the surface of the leaf (mandible scraping). I

predict: 1) that lateral head hitting will be basal to mandible scraping, and will test this by mapping behaviours onto the phylogeny; 2) movements will be similar with respect to direction of motion, displacement and velocity, and will test this by comparing properties of lateral head hitting and mandible scraping within and between species; and 3) vibrations produced by mandible scraping will show more features of ritualization (conspicuousness, redundancy and stereotypy, and will contain alerting components) when compared to lateral head hitting. I will test this by directly comparing these features of ritualization between species. The final goal of this chapter is to propose some of the evolutionary transitions between the other anterior segment behaviours. I will do this by mapping all anterior body behaviours onto the phylogeny, and by comparing properties of movements, as well as vibrations between behaviours.

\subsection{Methods}

Phylogenetic mapping of anterior segment behaviour and mandible morphology

Mandible morphology, including the condition of the distal edge and oral surface, as well as the behaviours associated with the anterior body segments were previously described in Chapter 2. Variability of these traits were further characterized (see Results of this chapter), coded as discrete characters, and mapped onto the existing phylogeny of the Drepanidae (Chapter 3) in Mesquite (Maddison \& Maddison, 2009). All behaviours were scored as presence/absence binary characters. Behaviours were said to be present if they were observed at least one time in trials with conspecifics. Ancestral behaviours 
were inferred for all nodes in Mequite (Maddison \& Maddison, 2009) using parsimony analysis on a reduced phylogeny that included only those taxa for which behavior was known $(n=14)$. BayesDiscrete, in BayesTraits (Pagel \& Meade, 2006), was used to determine whether behaviours were correlated with mandible condition over the phylogeny following the method outlined in Pagel and Meade (2006).

\section{Comparison of kinematics of movements between anterior body behaviours}

Movements associated with each anterior body behaviour observed during encounters with conspecifics were compared on the basis of direction of motion, total displacement, and total velocity in 10 species. Behaviours were recorded using both standard and high-speed videography. High-speed videos were recorded using a Lightning RDT high-speed camera (High Speed Imaging, Inc., Ontario, Canada) at 500 frames per second using MiDAS 2.0 software (Xcitex, Massachussetts, U.S.A.). Regular videos were analyzed using ImageJ software (version 1.42q; Maryland, USA) to provide detailed quantitative descriptions of each movement. Surface points corresponding to the anterior edge of the head at the midline were placed in ImageJ and tracked manually through video frames. To determine the direction, total displacement, total duration and total velocity of movements, surface points were compared between the starting position and the end position of the head (except for mandible drumming). Surface points were compared between the starting position, the position when the head reached its maximum height, and the end position for mandible drumming. The number of oscillations (changes in direction) per second were also measured for lateral tremulation and buzzing to determine the repetition rates of those movements. The mean duration, displacement and 
velocity for each movement was calculated for each individual ( 5 movements per individual) and the mean for all individuals was calculated to as a grand mean. To test the hypothesis that mandible scraping derives from lateral head hitting, total duration, displacement and velocity were compared between mandible scraping and lateral head hitting, both within (in species that exhibited both behaviours) and between species using paired t-tests (within species) and independent $t$-tests (between species). All other behaviours were also compared between species on the basis of duration, displacement and velocity to help propose a model for the evolutionary transitions between behaviours. Between species comparisons were performed using ANOVAs or independent $t$-tests and post hoc analyses were done using a Tukey-Kramer HSD. To correct for size differences between species, all displacement values were normalized by the rest length of the sixth abdominal segment. All statistical comparisons used an alpha level of 0.05 , and data were checked for normal distribution using the Shapiro-Wilk W test.

\section{Comparisons of vibrations to assess signal ritualization}

Characteristics of ritualization (conspicuousness, redundancy, stereotypy and alerting components) were assessed for each type of anterior body behaviour by recording and comparing features of their associated vibrations. These characteristics were first compared between lateral head hitting and mandible scraping to test the hypothesis that mandible scraping is a ritualized signal derived from lateral head hitting.

Conspicuousness was assessed by comparing the relative amplitude of vibrations associated with lateral head hitting and mandible scraping within trials using a Wilcoxon Signed Rank Test ( $\mathrm{n}=7)$, as amplitudes could not be compared between taxa or even 
between recordings due to differences in leaf structure and size of individuals. Dominant frequencies and bandwidths at $-3 \mathrm{~dB}$ and $-10 \mathrm{~dB}$ were also compared between mandible scraping $(n=7)$ and lateral head hitting $(n=4)$ using Wilcoxon Rank Sum Tests to determine if a shift in dominant frequency may have accompanied the shift to signalling (to increase signal to noise ratio, and thus conspicuousness). Redundancy was assessed by comparing rates per $5 \mathrm{~s}$ of lateral head hitting and mandible scraping within the 20 -s period following the time of closest contact between the resident and intruder during encounters using a t-test $(n=9)$. The stereotypy of duration was also compared between lateral head hitting and mandible scraping using a t-test. Stereotypy was measured as the inverse of variability, where variability was measured as the coefficient of variation, defined as the ratio between the standard deviation and the mean, expressed in percent of the mean. Stereotypy of duration was then compared between lateral head hitting and mandible scraping using a $t$-test to determine which behaviour is more stereotyped. Alerting components were assessed by examining signalling bout data (see Chapter 2) per species and determining if mandible scraping or lateral head hitting is typically preceded by any other behaviour. All data were calculated as a mean per individual using 5 behaviours/vibrations per individual when possible. Grand means were then calculated per taxa and finally per behaviour type, to compare between behaviours, except for amplitude comparisons. All statistical comparisons used an alpha level of 0.05 , and data were checked for normal distribution using the Shapiro-Wilk W test.

Vibrations were also compared on the basis of conspicuousness, redundancy, stereotypy and alerting components between all other anterior body behaviours to help propose a model for the evolutionary transitions between behaviours. Conspicuousness 
was assessed by comparing the relative amplitude of vibrations associated with each anterior body behaviour within trials using paired $t$-tests. Dominant frequencies and bandwidths were also compared between behaviours using Kruskal-Wallis one-way analyses of variance. Redundancy was assessed by comparing rates per $5 \mathrm{~s}$ of each anterior body behaviour within the 20 -s period following the time of closest contact between the resident and intruder during encounters using an ANOVA. Additionally, the number of oscillations per second for lateral tremulation and buzzing were considered as separate events, and were compared to the other behavioural rates using an ANOVA to determine whether each oscillation contributed to the redundancy of the signal. Post hoc analyses were performed using Tukey-Kramer HSD. The stereotypy of duration was compared between each anterior body behaviour using an ANOVA. Alerting components were assessed by examining signalling bout data (see Chapter 2) for each species, and determining if any of the anterior body behaviours are typically preceded by another behaviour. All data were calculated as a mean per individual using 5 behaviours/vibrations per individual when possible. Grand means were then calculated per taxa and finally per behaviour type, to compare between behaviours, except for amplitude comparisons.

\subsection{Results}

Variation in anatomy and behaviour of the anterior body segments, as described in Chapter 2, was further characterized in the current chapter in order to map these characters onto the phylogeny. 
Comparative morphology of the mandibles for mapping

Variation in the mandibles is described with respect to the distal edge and the oral surface (Fig. 5.1). The distal edge was categorized as being smooth (having no teeth) or toothed (having at least two teeth). The oral surface was also categorized as smooth (having no ridges) or ridged (having at least one ridge).

\section{Phylogenetic mapping of mandible morphology}

Results from mapping the condition of the distal teeth and oral surface of the mandibles onto the phylogeny suggests that having a toothed distal edge and ridged oral surface represents the basal condition (Fig 5.1). Smooth distal edges evolved once in the common ancestor of Watsonalla and smooth oral surfaces evolved at least three times in Tethea or, Drepana curvatula, and the common ancestor of Watsonalla binaria + Watsonalla cultraria (Fig. 5.1).

Comparative behaviour of the anterior body segments during conspecific interactions

In Chapter 2, eight notable behaviours involving the anterior body segments were identified during conspecific interactions in 11 species. These include: mandible drumming, mandible scraping, twitching, lateral tremulation, buzzing, lateral head hitting, pushing and biting. Each of these behaviours was described in detail in Chapter 2 with respect to which species produce them, the general context in which they are performed, as well as characteristics of the behaviours, movements, and vibrations on a species by species basis. In this Chapter, I will map behaviours onto the phylogenetic tree and will provide details on the average characteristics of each behaviour across all 
Fig. 5.1. Comparative morphology and mapping of mandibles onto the phylogenetic tree of Drepanidae. (a) Morphological variation observed in the distal edge (smooth or toothed) and oral surface (smooth or ridged) of the mandibles (scale bars $=100 \mu \mathrm{m}$ ). (b) Reduced Bayesian tree including only those species for which territorial behaviour is known, showing the ancestral and derived conditions of the morphology of the distal edge and oral surface of the mandibles. Pie charts are maximum parsimony probabilities of ancestral characters at all nodes. 


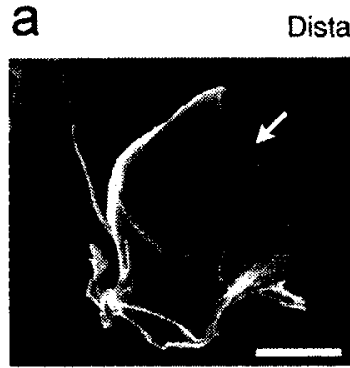

Smooth
Distal Edge

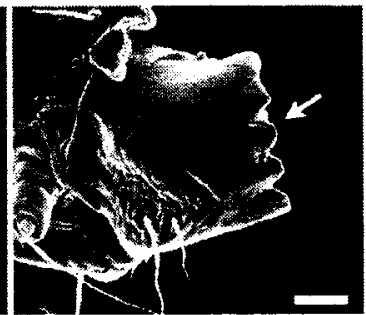

Toothed
Oral Surface

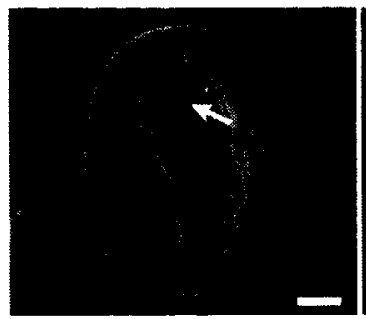

Smooth

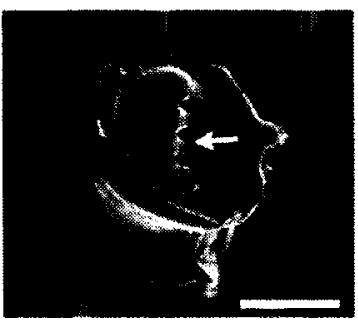

Ridged

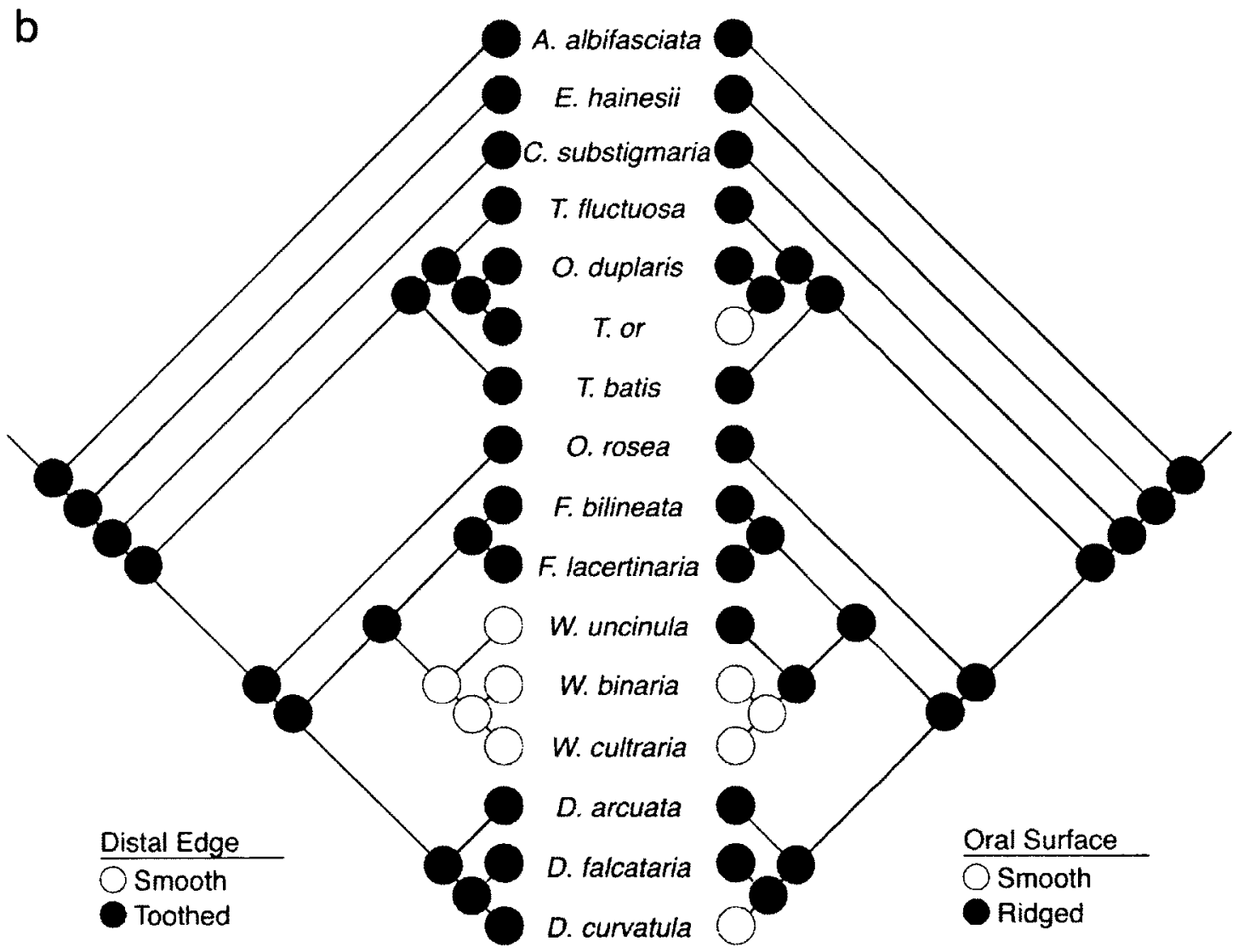


species. Mapping results as well as comparisons between movements and vibrations will be used to provide evidence for the hypothesis that mandible scraping derives from lateral head hitting and to propose evolutionary transitions between behaviours. Representatives of all 4 behaviours are shown in Figure 5.2. Detailed characteristics for each behaviour, including movement and vibration properties are presented in Table 5.1.

\section{Lateral Head Hitting}

Lateral head hitting was observed in 8 species (Tetheela fluctuosa, Ochropacha duplaris, T. or, Thyatira batis, Watsonalla cultraria, Drepana arcuata, Drepana falcataria and Drepana curvatula) and involves a quick, lateral movement of the head, thorax and first two abdominal segments directed to a nearby caterpillar (Fig. 5.2a). Hitting typically occurs when certain species are lightly touched on the anterior end by an intruding caterpillar. The movement begins with a swinging of the head in a lateral arc towards the posterior end, typically making contact with another caterpillar, with the head slightly raised off the surface of the leaf.

\section{Mandible Scraping}

Mandible scraping also involves a lateral movement of the head, thorax and first two abdominal segments (Fig. 5.2b), and was observed in 8 species (T. fluctuosa, $O$. duplaris, T. or, Oreta rosea, Falcaria lacertinaria, D. arcuata, D. falcataria, and D. curvatula). The caterpillar begins by lowering its mandibles to the leaf surface, and quickly swings the head in a lateral arc towards its posterior end. The rest of the body remains in the same approximate position during the mandible scrape, typically no other 
Fig. 5.2. The variation in anterior body behaviours observed in larvae of the Drepanidae. Schematics summarizing the movements (left panel), representative oscillograms and spectrograms of the vibrations produced by each behaviour (black lines above traces show when each behaviour occurs) (middle panel), and representative power spectra (black line) with background noise (gray line) included for comparison (right panel) for lateral head hitting (a), mandible scraping (b), mandible drumming (c), twitching (d), lateral tremulation (e), and buzzing (f). 
a
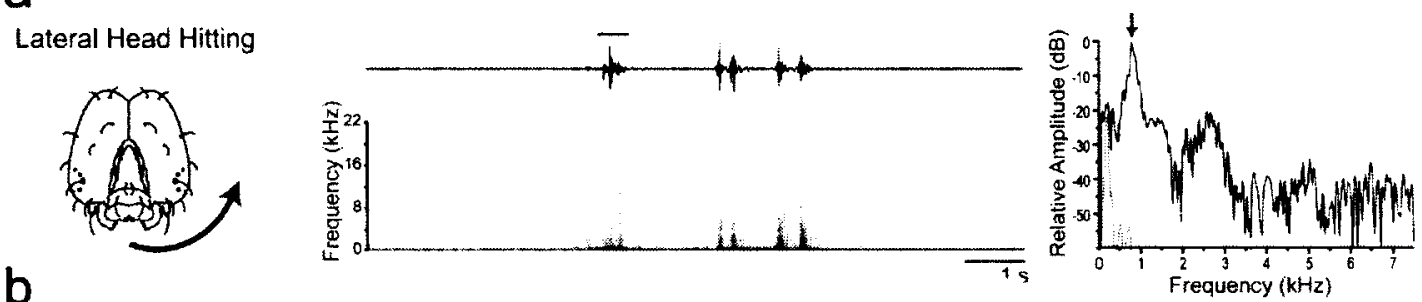

Mandible Scraping
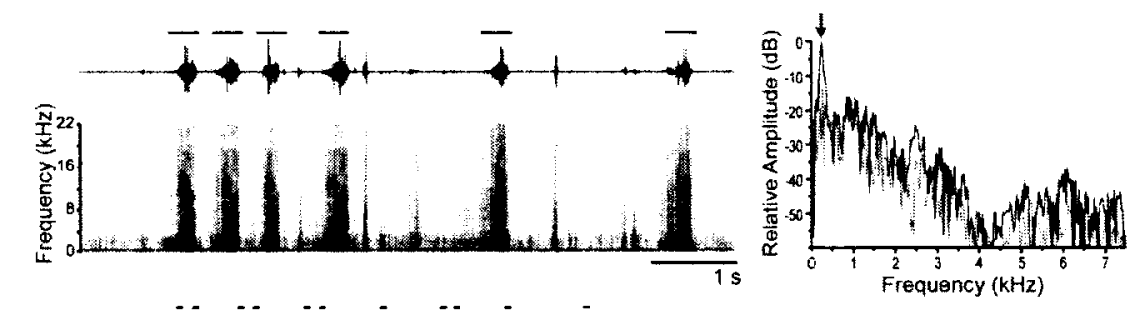

C

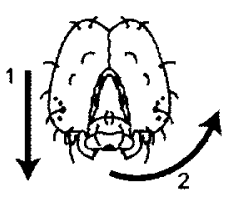

Mandible Drumming
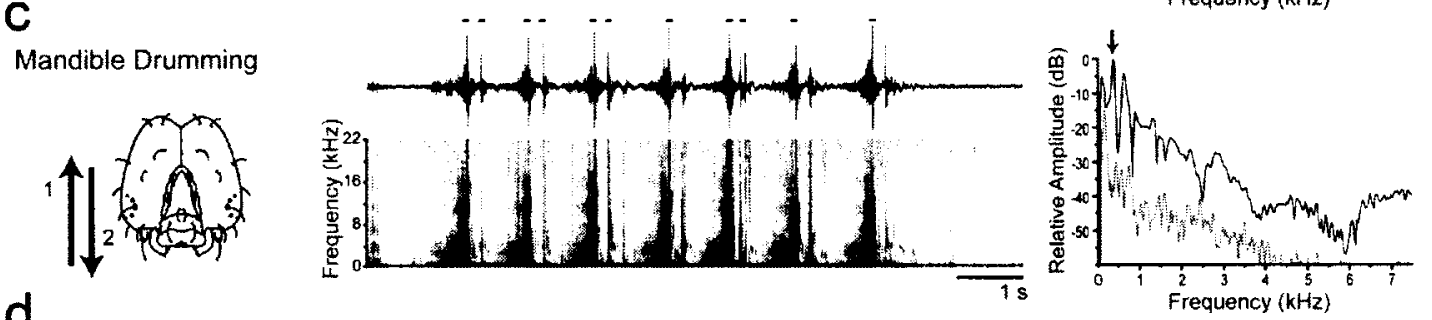

Twitching
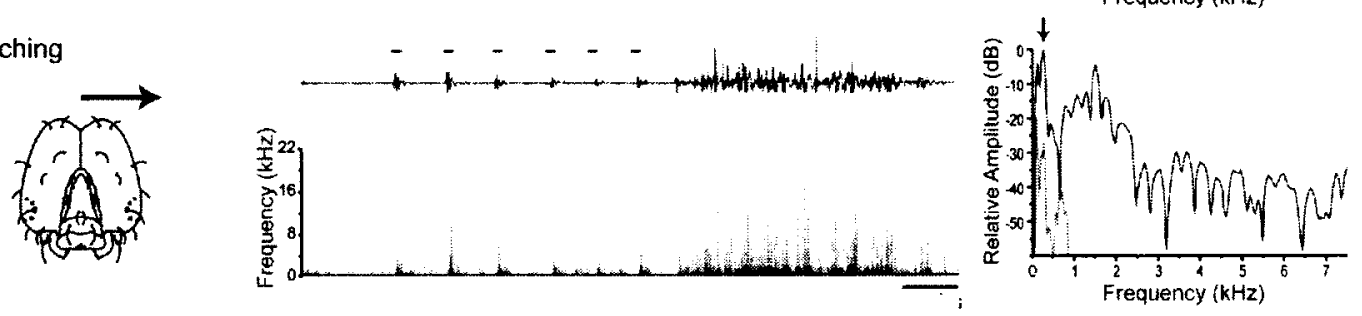

e

Lateral Tremulation
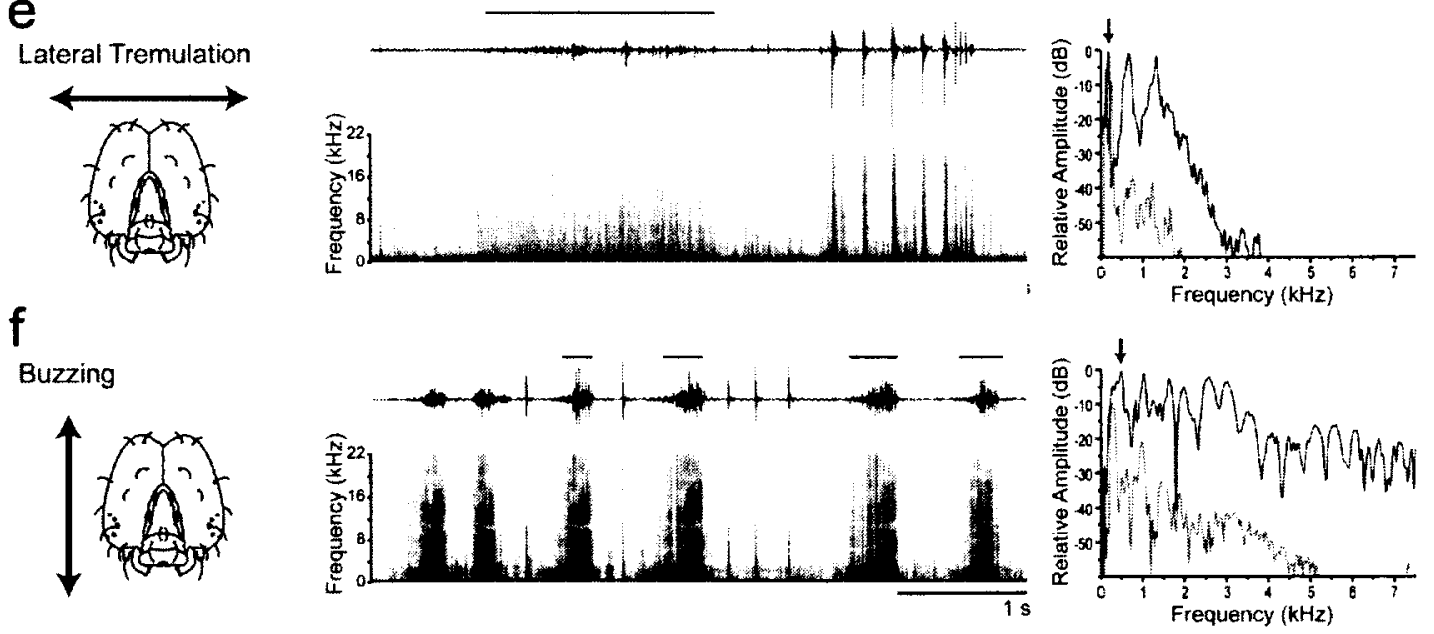
Table 5.1. Average kinematic, vibration and rate data for anterior body signals.

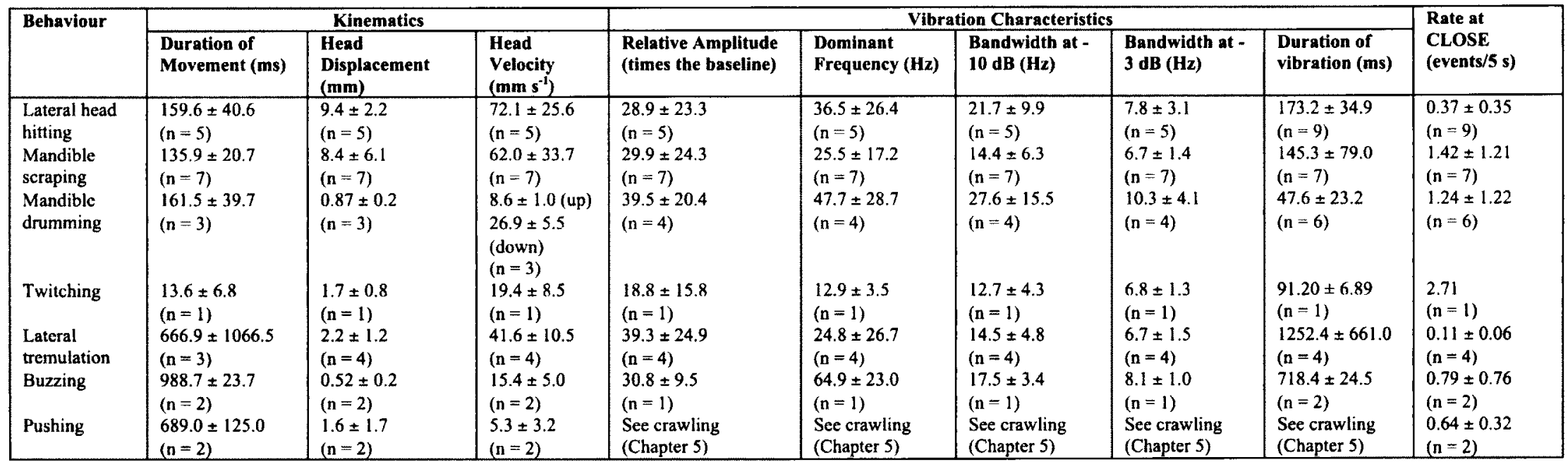


signals occur during the movement. During the scrape, the mandibles are dragged across the leaf surface to produce a vibration on the leaf. Often, the caterpillar will scrape in the other lateral direction immediately after the first scrape during signalling bouts (mean = $1.87 \pm 1.33$ scrapes/bout; $n=7)$.

\section{Mandible Drumming}

Mandible drumming was observed in 7 species (O. rosea, Falcaria bilineata, $F$. lacertinaria, W. cultraria, D. arcuata, D. falcataria, and D. curvatula) and involves the head, thorax and first two abdominal segments being lifted and then quickly lowered to strike the leaf surface (Fig. 5.2c), producing a vibration. The abdominal prolegs do not move during the mandible drum and the terminal segment may concurrently perform an anal scrape in some species. Mandible drumming can be highly repetitive, with a mean of $2.3 \pm 3.0$ drums per bout $(n=4)$.

\section{Twitching}

Twitching was only observed in one species (T. batis) and involves a quick, short, lateral movement of the head and thorax (Figure 5.2d). The rest of the body contracts slightly during the twitch.

\section{Lateral Tremulation}

Lateral tremulation was observed in 4 species (T. fluctuosa, T. batis, O.rosea, and W. cultraria) and involves quick, successive lateral movements of the head, thorax and first two abdominal segments (Fig. 5.2e) to produce a vibration. Occasionally, the head 
makes contact with the leaf surface during the lateral tremulation event. The abdominal prolegs remain firmly planted during the movement, but the anal segment may perform an anal scrape or 'pseudo' anal scrape at the same time.

Buzzing

Buzzing is similar to lateral tremulation, but occurs in the opposite direction (Fig. 5.2f). Buzzing was observed in 2 species, both belonging to Drepana (D. falcataria and D. curvatula). The head and thorax is lifted off the leaf surface during this movement, and the mandibles do not make contact with the leaf. The head moves in the vertical direction only, the abdominal prolegs remain firmly planted during the movement, and the anal segment always performs an anal scrape during the buzz.

Pushing

Pushing with the head was observed in 2 species of Thyatirinae (O. duplaris and T. or). Each push is accompanied with a forward crawl where the head makes contact with the intruder's body at the end of the crawl and pushes the intruder forward.

\section{Biting}

Biting was only observed in one species ( $T$. or). Biting was difficult observe and quantify in this species, since they live concealed between two leaves. Therefore, properties of biting are not described in detail. 


\section{Phylogenetic mapping of behavioural characters}

Maximum parsimony analysis demonstrates that territorial behaviours involving the mandibles and/or anterior body segments evolved for the first time in the common ancestor of the Thyatirinae and Drepaninae subfamilies (Fig. 5.3, Node A). The results show that both mandible drumming and lateral head hitting evolved at this node. Mandible drumming was then lost in the common ancestor of Thyatirinae (Fig. 5.3, Node B), and lateral head hitting was lost in the common ancestor of Drepaninae (Fig. 5.3, Node C). Mapping results show that twitching evolved once in T. batis, and that lateral tremulation, pushing, buzzing, mandible scraping, and lateral head hitting evolved multiple times within both the Thyatirinae and Drepaninae groups. Results provide support for the hypothesis that mandible scraping derives from lateral head hitting, as lateral head hitting is found at the most basal node of the Thyatirinae + Drepaninae (Node A). Mandible drumming was also found to be a basal behaviour, and at present, the transitional stages between behaviours are unclear.

By mapping mandible structure onto the phylogeny (Fig. 5.3), I was able to determine whether smooth or toothed distal edged, or smooth or ridged oral faced mandibles were correlated with any of the mandible behaviours over the phylogeny. Results from this analysis suggest that mandible morphology is not correlated with mandible behaviours, as none of the mandible structure categories were significantly correlated with any of the behaviours over the phylogeny using BayesDiscrete analysis ( $p$ $>0.05, \mathrm{DF}=4)$. 
Fig. 5.3. Reduced Bayesian tree including only those species for which territorial behaviour is known, showing the ancestral and derived conditions of the morphology of the distal edge and oral surface of the mandibles, and anterior body behaviour. Pie charts are maximum parsimony probabilities of ancestral behaviours at all nodes. 


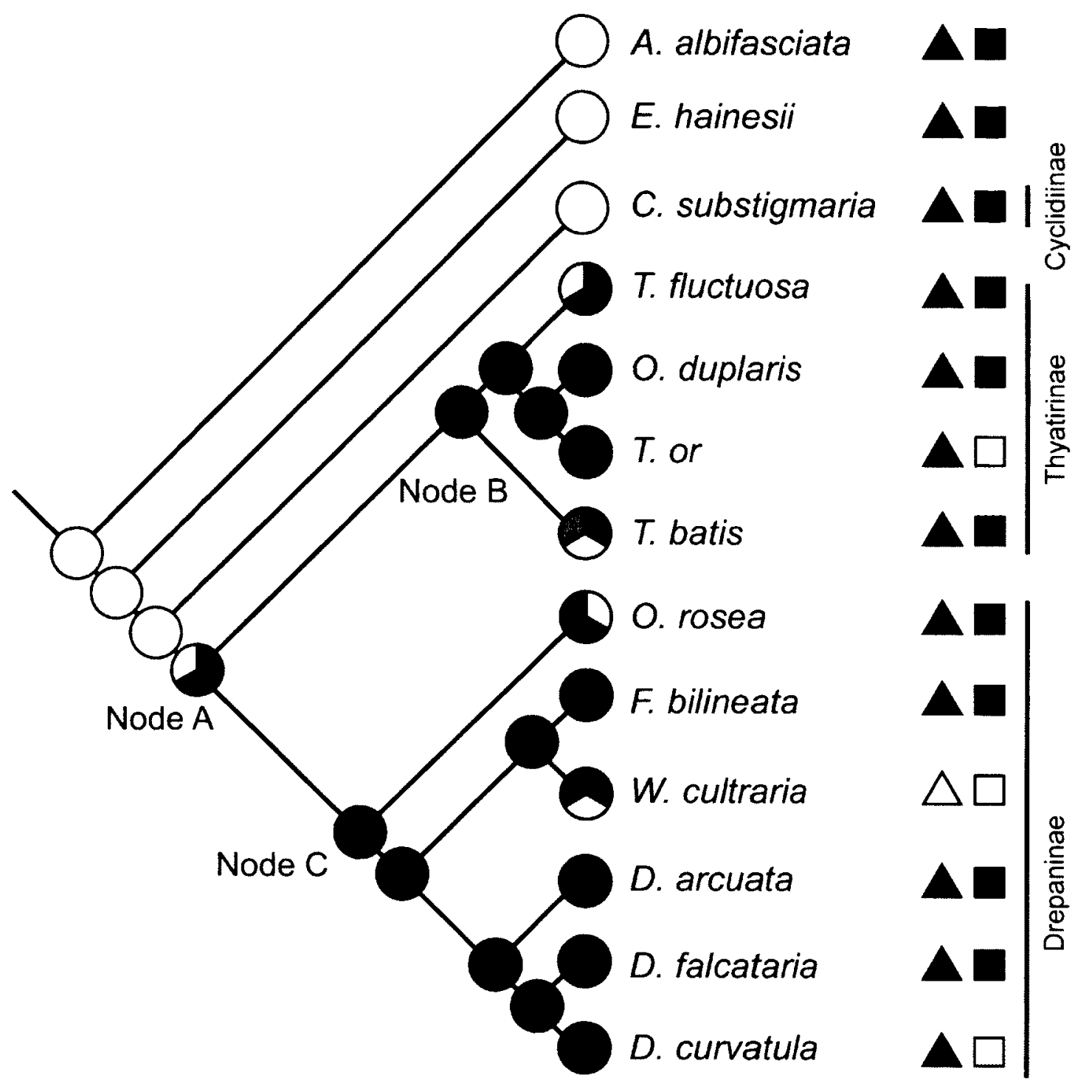

Anterior Body Behaviour

\begin{tabular}{llll}
\hline None & Mandible Drumming & $\triangle$ Smooth \\
Twitching & Lateral Tremulation & & $\Delta$ Toothed \\
Pushing & & Mandible Scraping
\end{tabular}


Comparison of movements between behaviours

I will begin this section by first comparing the movements associated with lateral head hitting and mandible scraping to provide support for my hypothesis that mandible scraping derives from lateral head hitting. I will then compare all other movements on the basis of direction of motion, duration, displacement and velocity to help propose the evolutionary transition of behaviours.

Comparison of mandible scraping and lateral head hitting movements

Between species comparisons demonstrated that lateral head hitting and mandible scraping did not differ significantly in terms of normalized displacement (independent ttest, two-tailed, $\mathrm{t}=0.45, \mathrm{DF}=8.1, \mathrm{p}=0.67$ ) or velocity (independent $\mathrm{t}$-test, two-tailed, $\mathrm{t}$ $=1.20, \mathrm{DF}=9.0, \mathrm{p}=0.26)$. They did, however differ in duration (independent $\mathrm{t}$-test, twotailed, $\mathrm{t}=-6.10, \mathrm{DF}=4.2, \mathrm{p}=0.0030$ ), with lateral head hitting being longer in duration. Within species comparisons (in species that performed both behaviours) had similar results (paired t-tests, two-tailed; displacement: $t=-1.14, D F=3, p=0.33$; velocity: $t=$ $0.29, \mathrm{DF}=3, \mathrm{p}=0.79 ;$ duration: $\mathrm{t}=3.98, \mathrm{DF}=3, \mathrm{p}=0.028$ ).

Comparison of all anterior segment movements

Lateral hitting, mandible scraping, lateral tremulation and twitching all involve lateral movements of the head and anterior body segments. These movements did not differ significantly in displacement (ANOVA, $F=2.81, D F=4, p=0.081$ ) or velocity (ANOVA, $F=1.63, \mathrm{DF}=4, \mathrm{p}=0.23$ ), but the duration of lateral head hitting was significantly longer than the other behaviours (ANOVA, $F=34.6, \mathrm{DF}=3, \mathrm{p}<0.001$ ). 
These movements also differed in the placement of the head - in lateral hitting, lateral tremulation and twitching, the head is lifted off the leaf at the beginning of the movement, and does not make contact with the leaf during the lateral movement. In mandible scraping, however, the mandibles are placed on the leaf and scraped laterally on the leaf surface during the movement.

Buzzing and mandible drumming differed from these four behaviours as they occur in the opposite direction, with the head being lifted and lowered to the leaf surface. One buzzing oscillation and the upwards movement of mandible drumming was not significantly different in terms of duration, normalized displacement or velocity (independent $t$-test, two-tailed; $\mathrm{p}>0.05$ ), but the downward movement of mandible drumming occurred at a significantly higher velocity than the upwards movement (independent $t$-test, two-tailed; $t=5.62 ; \mathrm{p}=0.01 ; \mathrm{DF}=2.12$ ). The major difference between buzzing and mandible drumming is that the buzzing movement is more repetitive, with 14.7 oscillations per second (see above), and the mandibles do not make contact with the leaf surface. Pushing involves mainly the movement of the entire body during a crawling cycle and is therefore fundamentally different from all other head movements. As mentioned above, biting could not be quantified in terms of kinematic properties.

\section{Comparisons of vibrations to assess ritualization}

Vibrations were compared on the basis of conspicuousness, redundancy, stereotypy and alerting components between lateral head hitting and mandible scraping to test the hypothesis that mandible scraping derives from lateral head hitting. Mandible 
scraping was found to be significantly higher in amplitude than lateral head hitting (Wilcoxon Signed Rank Test, $S=14.0, \mathrm{DF}=6, \mathrm{p}=0.016$ ), but did not differ from lateral head hitting in terms of dominant frequency and bandwidths at $-3 \mathrm{~dB}$ and $-10 \mathrm{~dB}$ (conspicuousness) (Wilcoxon Rank Sum Tests, $p>0.05$ ), rates at close distance (redundancy) (independent t-test, two-tailed, $t=2.20, p=0.064$ ) and stereotypy of duration (stereotypy) (independent $\mathrm{t}$-test, two-tailed, $\mathrm{t}=1.29, \mathrm{p}=0.22$ ). By examining data on signalling bouts, mandible scraping was typically preceded by anal scraping (in anal scraping species) or mandible drumming. Lateral head hitting was not typically preceded by any one behaviour.

To help determine the evolutionary transition between behaviours, vibrations were compared between all anterior body behaviours based on the characteristics of ritualization. None of the behaviours differ significantly based on dominant frequency and bandwidths at $-3 \mathrm{~dB}$ and $-10 \mathrm{~dB}$ (conspicuousness), rates at close distance (redundancy) and stereotypy of duration, normalized displacement and velocity (stereotypy) (ANOVAs; $\mathrm{p}>0.05$ ). Amplitude comparisons between behaviours (conspicuousness), within trials, demonstrate that mandible drumming is significantly higher in amplitude than mandible scraping (paired $t$-test, two-tailed; $t=-3.65 ; \mathrm{p}=0.008$; $\mathrm{DF}=7$ ), lateral tremulation (paired $t$-test, two-tailed; $t=-4.28 ; \mathrm{p}=0.025 ; \mathrm{DF}=2$ ), and lateral head hitting (paired $t$-test, two-tailed; $t=-13.67 ; \mathrm{p}=0.005 ; \mathrm{DF}=2$ ). Mandible scraping is also significantly higher in amplitude than lateral head hitting (see above). When the number of oscillations per second were factored into the rates of lateral tremulation and buzzing, these movements have significantly higher rates than all other behaviours (redundancy) (ANOVA; $F=219.2 ; \mathrm{p}<0.001 ; \mathrm{DF}=7$ ). By examining bout 
data, mandible drumming, lateral tremulation and buzzing were typically preceded or accompanied by anal scraping (in species which anal scraped). Crawling, pushing, twitching and lateral head hitting (see above) were not typically preceded by a signal.

\subsection{Discussion}

The major goals of this chapter were: 1) to map morphology and behaviour of the mandibles and anterior body segments onto the phylogeny to determine which characters are basal and derived; 2) to test the hypothesis that mandible scraping derives from lateral head hitting; and 3) to propose a model for the evolutionary transition between anterior body behaviours.

\section{Mapping mandible morphology and anterior body behaviours}

Comparative morphology of the mandibles

The mandibles varied in morphology from smooth to toothed on the distal edge, and smooth or ridged on the oral surface. The results of the phylogenetic mapping demonstrate that a toothed distal edge and ridged oral surface represents the basal condition. Mandible morphology was also not correlated with the presence or absence of any of the anterior body behaviours. This agrees with Bura (2009; 2010), who demonstrated that although mandible structure is linked to certain types of signals in some Bombycoidea caterpillar species that produce acoustic warning sounds by clicking their mandibles, it does not predict the ability to produce these signals. Studies on acridids have found that head and mandible size, and mandible morphology is closely related to the type of food consumed (reviewed in Clissold, 2007). For example, species 
that feed on hard grasses have larger heads and mandibles, and blunt, or smooth distal edged mandibles (reviewed in Clissold, 2007). These trends are not as clear in lepidopteran larvae, and mandible morphology may be more closely aligned with taxonomic relationships (Bernays, 1991). However, there are some apparent morphological similarities in mandible structure in caterpillars based on diet: those that feed on grasses have smooth distal edges, while those that feed on forbs have toothed distal edges (Brown \& Dewhurst, 1975); and species that feed on plants with reticulated veins have longer, toothed, more complexly ridged mandibles than those that feed on old, tough leaves (Bernays \& Janzen, 1988). In the Drepanidae, there does not appear to be a relationship between signalling with the mandibles and mandible structure. Since the mandibles are also used for feeding, there is perhaps less of a selection pressure to modify them for signalling, and their structure depends more on taxonomic status and diet.

Comparative behaviour of the anterior segments

Behaviours associated with the anterior body during encounters with conspecifics included mandible drumming, mandible scraping, twitching, lateral tremulation, buzzing, lateral head hitting, pushing and biting. Drumming with the head or mandibles has been described in other species of insects, including termites (Röhrig et al., 1999; Rosengaus et al., 1999), death-watch beetles (Birch \& Keenlyside, 1991), carpenter ants (Fuchs, 1976) and in a few species of caterpillars, D. arcuata (Yack et al., 2001), Sparganothis pilleriana (Russ, 1969), Drepana falcataria (Bryner, 1999, I. Hasenfuss, personal communication), Falcaria lacertinaria (I. Hasenfuss, personal communication), and 
Nordstromia lilacina and Tridrepana arikana (Sen \& Lin, 2002). I observed mandible drumming in 6 species of Drepaninae, including D. arcuata, D. curvatula, D. falcataria, $F$. bilineata, $O$. rosea and $W$. cultraria. Interestingly, I did not observe mandible drumming in any of the Thyatirinae species, perhaps because many of them live in shelters made by sewing two leaves together, and there is a lack of vertical space to mandible drum. I did, however, observe mandible scraping in Thyatirinae caterpillars, as this signal uses minimal vertical space. Mandible scraping is less frequently reported in insects, being noted in the larvae of the oriental hornet, Vespa orientalis, where they function as hunger signals (Ishay et al., 1974) and in a few species of larval Lepidoptera, D. arcuata (Yack et al., 2001), Caloptilia serotinella (Fletcher et al., 2006), D. falcataria, and F. lacertinaria (I. Hasenfuss, personal communication). My results demonstrate that mandible scraping is performed by 7 of 11 species of Drepanidae caterpillars I studied (D. arcuata, D. curvatula, D. falcataria, O. rosea, O. duplaris, T. fluctuosa, and T. or), suggesting that it may represent an important form of signalling in the group.

Tremulation (e.g. lateral tremulation or buzzing), believed to be one of the most simple and widespread vibrational signal production mechanisms in insects (Virant-Doberlet \& Cokl, 2004) and have been reported in one species of caterpillar to date, C. serotinella (Fletcher et al., 2006). Lateral tremulation and buzzing was observed in 6 out of the 11 species I studied (D. curvatula, D. falcataria, O. rosea, T. batis, T. fluctuosa and $W$. cultraria), and may be common in these species as it does not requires the use of specialized signaling structures. Finally, physically aggressive behaviours, including striking with the head, and biting have been described in two other caterpillar species to date (Depressaria pastinacella: Berenbaum et al., 1993; and Busseola fusca: Okuda, 
1989; respectively). My results demonstrate that physically aggressive behaviours is common in the Drepanidae, with 9 out of 11 species studied employing lateral head hitting during encounters with conspecifics. The results of phylogenetic mapping suggest that lateral head hitting and mandible drumming represent the basal behaviours and that lateral tremulation, pushing, buzzing, and mandible scraping evolved multiple times within both the Thyatirinae and Drepaninae groups. Many of the Drepanidae caterpillars studied to date have a repertoire of different signals and aggressive behaviours, but why produce more than one signal for the purpose of territoriality? This question, and others, will be explored in Chapter 6 of this thesis.

\section{Testing the hypothesis that mandible scraping derives from lateral head hitting}

The hypothesis that mandible scraping derives from lateral head hitting is supported by the following lines of evidence: 1) lateral head hitting represents the basal condition when mapped onto the phylogeny; 2) kinematic analysis suggests that mandible scraping and lateral head hitting involve similar movement patterns; and 3) vibration analysis provides evidence that mandible scraping has more features of ritualization than lateral head hitting, including increased conspicuousness, redundancy, stereotypy and alerting components. One can also observe this transition in behaviour by examining hitting and mandible scraping in certain species of Drepanidae. For example, $F$. bilineata, a species that only lateral head hits will sometimes scrape the mandibles on the surface of the leaf during a lateral head hit. The incidental vibration produce by this movement could represent the beginning stages of the evolution of mandible scraping in this species. The shift from aggressive behaviour (lateral head hitting) to ritualized signalling 
(mandible scraping) may function to reduce the costs of physical aggression in these caterpillars. Why produce ritualized signals instead of physical aggression is another question that will be explored in Chapter 6.

\section{Alternative hypotheses}

The hypothesis that mandible scraping derives from lateral hitting, a physically aggressive behaviour, suggests that mandible scraping is an intention movement, showing the intention of the signaler to physically harm the receiver. However, signals are also proposed to evolve from protective movements, displacement activities or redirection (Morris, 1956; Brown, 1975; Bradbury \& Vehrencamp, 1998; Maynard Smith \& Harper, 2003). It is therefore possible that mandible scraping evolved from movements not associated with interactions between conspecifics. Two likely candidates for the evolutionary precursor of mandible scraping, based on similarity of movement, would be laying silk, and deterring predators. If mandible scraping is derived from laying silk, this would be classified as a displacement activity, as the original movement is not performed in the same context. Laying silk involves moving the head laterally from side to side to attach silk to the leaf (Fitzgerald et al., 1991). This lateral silk laying movement has been observed in all larvae of Drepanidae that lay silk mats or create silk shelters (personal observation), and therefore represents a basal behaviour common to this group. Rapid flexing of the body in a lateral motion is also a primitive defensive movement performed by many soft-bodied insects, including lepidopteran, dipteran and coleopteran larvae (reviewed in Brackenbury, 1999). This movement has also been observed in caterpillars of the Drepanidae when lightly touched with a paintbrush (personal observation). Both of 
these behaviours are widespread and present in the Drepanidae, and therefore either could potentially represent the evolutionary precursor of mandible scraping. However, it is more likely that these signals evolved as intention movements, because movements mimicking physically aggressive behaviours are more relevant during territorial contests, and may be better indicators of size or fighting ability, allowing contests to be resolved more quickly.

\section{Proposed evolutionary transitions in behaviour}

The results of this study suggest that all anterior body behaviours are either derived from lateral head hitting or mandible drumming, both of which were present in the common ancestor of Drepaninae and Thyatirinae (Node A). By examining the phylogeny in detail, however, it is likely that the presence of mandible drumming in the common ancestor of the Drepaninae and Thyatirinae (Node A) is an anomaly caused by low sample size in Thyatirinae species. Since Thyatirinae represents the basal subfamily, and none of the species of Thyatirinae studied to date have been found to mandible drum, it is likely that mandible drumming evolved for the first time at Node $\mathrm{C}$, the common ancestor of Drepaninae, instead. Although not suggested by the phylogeny, I believe that mandible drumming also derives from lateral head hitting, as during lateral head hitting, the head would occasionally make contact with the surface of the leaf, possibly being the precursor to mandible drumming. Results from the phylogeny, kinematic analysis and ritualization analysis also suggests that buzzing evolved from mandible drumming in some species of Drepana. 
It is also likely that mandible scraping, twitching, and lateral tremulation derive from lateral head hitting based on some support from phylogenetic, kinematic and ritualization evidence. The present phylogeny also suggests that these derived behaviours evolved independently multiple times, which may signify the importance of a shift from physically aggressive behaviours to ritualized signalling in some of these caterpillars. If contests between resident and intruder caterpillars often ended in injury or death to one of the opponents, as in other species of caterpillars (e.g. Depressaria pastinacella (Oecophoridae; Berenbaum et al., 1993), Busseola fusca (Noctuidae; Okuda, 1989) and Anthocharis cardamines (Pieridae; Baker, 1983)), signalling may have evolved to reduce the likelihood of physical damage to either opponent. Lateral hitting, a physically aggressive behaviour, however, still persists in most species, but seems to be reserved for high escalation contests, where the intruder makes physical contact with the resident (see Chapter 2 and Appendix A for details on escalation).

\section{Comparison of vibrations to assess ritualization}

Ritualization has been shown to play an important role in the evolution of signals, allowing them to be more detectable and recognizable by receivers (Cullen, 1966; Wiley, 1983; Johnstone, 1997; Bradbury \& Vehrencamp, 1998; Maynard Smith \& Harper, 2003). The present study found evidence for ritualization in terms of conspicuousness, redundancy, stereotypy and alerting components in vibrations associated with anterior body in caterpillars of the Drepanidae. Mandible scraping was found to be possess more features of ritualization than lateral head hitting, producing higher amplitude vibrations (conspicuousness), and being produced in bouts of 3-4 signals per bout (redundancy). 
Mandible scraping also was often preceded by an alerting component, anal scraping, during signalling bouts. Lateral tremulation and buzzing were also found to be highly ritualized, being significantly more repetitive during a single signalling event. This repetition of movements makes the signal more redundant, reducing errors made by the receiver in detecting and recognizing the signal (Wiley, 1983). It is also clear by examining the movements associated with mandible scraping, mandible drumming, buzzing and lateral tremulation events, that they are highly ritualized, as there is little variation in the direction of motion (i.e. mandible drums always begin with the head being lifted from the leaf surface and end with the mandibles striking the leaf). Therefore, I provide evidence for ritualization of anterior body behaviours in the Drepanidae.

\section{Future Studies}

In conclusion, my study provides support for the hypothesis that mandible scraping derives from lateral head hitting. The transitions between behaviours, however, are less clear. Future studies that examine the behavioural repertoire of more species (especially Thyatirinae species) will provide further insight into the evolution of anterior body behaviours in these caterpillars. 


\section{CHAPTER 6}

The Evolution of Vibratory Communication Signals in Drepanidae CaTerpillars: Ultimate Questions 


\subsection{Introduction}

The main focus of this thesis was to test hypotheses on the evolutionary origins of signals produced by Drepanidae caterpillars. In previous chapters I have shown that variation exists in territorial behaviours, signals and signal-producing structures across species of Drepanidae. I have also developed a phylogeny and used this phylogeny to answer questions concerning how anal segment and anterior body signals evolved from non-signalling behaviours, thereby focusing on proximate mechanisms of signal evolution. During the course of this study, a number of additional questions have arisen about the ultimate mechanisms of signal evolution in these caterpillars. For example, what is the function of signalling? Why do some species produce more than one type of signal? And finally, why signal instead of using physical aggression? Although seeking answers to these questions was not the original intention of this study, the data collected in previous chapters can be used to develop hypotheses for future studies. The current chapter will focus on developing and refining testable hypotheses to answer these three questions. I have also included a table summarizing the main hypotheses and predictions used to answer each of the three questions (Table 6.1). This chapter is meant to be preliminary in nature, and further analyses are required to formally test these hypotheses.

\subsection{What is the function of signalling?}

\section{Background}

Throughout this thesis, I have referred to the signals produced by Drepanidae caterpillars as functioning in territorial defense of leaf shelters or leaves. Yack et al. 
Table 6.1. Summary of questions, hypotheses and predictions tested in this chapter.

\begin{tabular}{|c|c|c|c|}
\hline Main Question & Hypothesis & Predictions & Tested? \\
\hline $\begin{array}{l}\text { What is the } \\
\text { function of } \\
\text { vibratory } \\
\text { signalling? }\end{array}$ & $\begin{array}{l}\text { Signals function for } \\
\text { territorial defense of } \\
\text { leaf shelters/leaves }\end{array}$ & $\begin{array}{l}\text { a) signals will be produced primarily by the } \\
\text { resident of the leaf shelter/leaf } \\
\text { b) signals will be elicited by the approach of the } \\
\text { intruder } \\
\text { c) signal rates will escalate as the intruder } \\
\text { approaches the resident } \\
\text { d) signalling will be followed by the resident } \\
\text { leaving the leaf shelter/leaf } \\
\text { e) residents with higher investments in the leaf } \\
\text { shelter construction (from no shelter to silk mat to } \\
\text { rolled leaf to two leaves sewn together), will have } \\
\text { higher rates of signalling (and aggressive } \\
\text { behaviours) and vice-versa }\end{array}$ & $\mathrm{Y}$ \\
\hline $\begin{array}{l}\text { Why more than } \\
\text { one type of } \\
\text { signal? }\end{array}$ & $\begin{array}{l}\text { 1. Different signal } \\
\text { types convey } \\
\text { information about } \\
\text { the motivation of the } \\
\text { resident } \\
\text { 2. Different signal } \\
\text { types increase the } \\
\text { detection and } \\
\text { recognition of } \\
\text { signals by intruders } \\
\text { 3. Different signal } \\
\text { types evolved to } \\
\text { counteract bluffing } \\
\text { 4. Different signal } \\
\text { types convey } \\
\text { different types of } \\
\text { information }\end{array}$ & $\begin{array}{l}\text { Signal types differ in spectral properties including } \\
\text { bandwidth and peak frequency and temporal } \\
\text { characteristics, including duration }\end{array}$ & $\begin{array}{l}\mathrm{Y} \\
\mathrm{N} \\
\mathrm{N}\end{array}$ \\
\hline $\begin{array}{l}\text { Why signal } \\
\text { instead of using } \\
\text { aggression? }\end{array}$ & $\begin{array}{l}\text { 1. If the chance of } \\
\text { encountering a } \\
\text { sibling as a late instar } \\
\text { is high, residents will } \\
\text { produce more signals } \\
\text { and be less } \\
\text { aggressive towards } \\
\text { intruders } \\
2 \text {. The costs of } \\
\text { aggressive behaviour } \\
\text { affects the behaviour } \\
\text { of the resident }\end{array}$ & $\begin{array}{l}\text { a) Species that lay eggs in rows/clusters will have a } \\
\text { higher ratio of signals to aggressive behaviours than } \\
\text { those that lay eggs singly } \\
\text { b) Species that are gregariousness as early instars } \\
\text { will have a higher ratio of signalling to aggressive } \\
\text { behaviour } \\
\text { If the costs of aggressive behaviour are high, } \\
\text { residents will produce more signals than physically } \\
\text { aggressive behaviours }\end{array}$ & N \\
\hline
\end{tabular}


(2001) provide strong support that in one species, Drepana arcuata, vibratory signals including mandible drumming, mandible scraping and anal scraping function for territoriality based on experimental evidence. What about the other species studied to date? Based on similarities in characteristics of behavioural encounters with conspecifics between $D$. arcuata and other species I have studied to date, I believe that the signals described in previous chapters of this thesis function for territorial defense of leaf shelters or leaves. To further test this hypotheses, I predict that: 1) signals will be produced primarily by the resident of the leaf/leaf shelter; 2 ) signals will be elicited by the approach of the intruder; 3 ) signalling rates of the resident will escalate as the intruder approaches; 4) signalling will be often followed by the intruder leaving the leaf/leaf shelter; and 5) residents with higher investments in leaf shelter construction will show higher rates of signalling (and aggressive behaviour) and vice-versa. I will test these predictions by comparing the frequency of signalling between residents and intruders (Prediction 1), rates of signalling before and during the course of encounters with conspecifics (Predictions 2 and 3), the number of trials in which the resident won to the number of trials that ended in ties or losses (Prediction 4), and shelter-building behaviour (no shelter, silk mat, rolled/folded leaf, or two leaves tied together) to rates of signalling and aggressive behaviour (Prediction 5).

\section{Methods}

The following methods use data collected from conspecific interactions and general observations as described in Chapter 2. All statistical comparisons used an alpha 
level of 0.05 , and data were checked for normal distribution using the Shapiro-Wilk W test.

Prediction 1 . Signals will be produced primarily by the resident

The frequency of intruder signalling was compared to that of the resident using a paired t-test (grouped by species to allow for differences in signalling between species). Frequency of intruder and resident signalling was measured as the number of trials in which the intruder or resident signaled over the total number of trials. Signals included mandible scraping, mandible drumming, anal scraping, lateral tremulation and buzzing.

Prediction 2. Signals will be elicited by the approach of the intruder

The average distance between the resident and the intruder at first signal was calculated to demonstrate when residents typically begin signalling. Overall signalling rates (all signals combined) were also compared in the $5 \mathrm{~min}$ period before the trial to the signalling rates during the trial (average signalling rates at FAR, MID and CLOSE stages of intruder approach; see Chapter 2 for details on how rates were calculated at different stages of intruder approach) using a Wilcoxon Rank Sum Test to determine whether residents signal more while alone on the leaf or with an intruder.

Prediction 3. Signal rates will increase as the intruder approaches

Overall signalling rates (all signals combined) were compared at three stages of intruder approach - FAR, MID and CLOSE, using a repeated measures ANOVA (grouped by species, to account for differences in signalling rates between species) to 
determine if signal rates escalate as the intruder approaches. Post hoc analyses were done using pair wise paired t-tests. Changes in signal rate of individual signals was also examined by species in Chapter 2 and Appendix A.

Prediction 4. Signalling will be followed by the intruder usually leaving the leaf/leaf shelter.

Data on frequency of resident wins (when the intruder left the leaf) were compared to those of ties (when neither left the leaf) and losses (when the resident left the leaf) using a Kruskal-Wallis one-way analysis of variance. Post hoc analysis was done using pair wise Wilcoxon Rank Sum Tests. Only trials in which the resident signaled at least once were used.

Prediction 5. Residents with higher investments in their leaf shelter will have higher rates of signalling (and physical aggression)

Signalling rate was defined as the rate of all signals combined per $5 \mathrm{~s}$ at CLOSE distance (the point when the intruder first made contact with the resident). Aggressive behaviour rates and overall behaviour rates (signals + aggressive behaviours) were calculated in the same manner. These rates were then compared to data on shelter building behaviour as described in Chapter 2 (no shelter, silk mat, rolled/folded leaf, or two leaves sewn together) using an ANOVA to determine if there is a relationship between overall/signalling/aggressive rates and shelter-building behaviour. The aggressive behaviour rates did not follow a normal distribution and were therefore compared using a Wilcoxon Rank Sum Test. The number of signal types was also 
compared between leaf shelter types using an ANOVA to determine if species with a larger investment in leaf shelter produced more types of signals. Post Hoc analyses were completed using a Tukey Kramer HSD.

Results

Prediction 1 . Signals will be produced primarily by the resident

Overall, residents signaled at least once in significantly more trials than did intruders (paired $t$-test, $t=7.36, D F=9, p<0.001$ ). Figure $6.1 \mathrm{a}$ shows signalling rates of a resident and an intruder in average trials of Falcaria bilineata. For further information on the frequency of intruder signalling in other species, see Chapter 2 and Appendix I.

Prediction 2. Signals will be elicited by the approach of the intruder

On average, residents first signaled when the intruder came within $14.4 \pm 10.7$ $\mathrm{mm}$ of the resident. Overall average signalling rates (of all signals combined) were significantly higher after the trial began (average of rates at FAR, MID and CLOSE) than during the $5 \mathrm{~min}$ period before the trial $(0.0 \pm 0.0$ vs. $2.15 \pm 2.48$; Wilcoxon Rank Sum, $\mathrm{Z}$ $=-3.84, \mathrm{DF}=1 ; \mathrm{p}<0.001)$. Figure $6.1 \mathrm{~b}$ demonstrates a representative trial in $F$. bilineata, showing the distance at first signal and resident signalling rates before and during the trial. For further information on other species, see Chapter 2 and Appendix I.

Prediction 3. Signal rates will increase as the intruder approaches

Overall signalling rates (all signals combined) escalated significantly as the intruder approached the resident, where signalling rates significantly increased from FAR to CLOSE (repeated measures ANOVA, $F=8.54, \mathrm{DF}=2, \mathrm{p}=0.01$ ). Individual signal 
Fig. 6.1. Average and representative trial data in Falcaria bilineata. (a) Resident and intruder signalling over 20 encounters. Mean distance (+SD) between resident and intruder larvae at the beginning of each 5-s interval (top graph). Signalling rate of residents (middle graph) and intruders (bottom graph) before and after trials, and for the first $80 \mathrm{~s}$ and last $80 \mathrm{~s}$ of each trial. Red denotes average mandible drum rate per 5-s interval, and blue denote average anal scrape rate per 5-s interval. (b) Resident signalling during a single agonistic encounter (238 s). Schematic of the different stages of the encounter (left panel). Frame 1: the resident (R) is feeding as the intruder (I) moves along the twig toward the leaf before the trial. Frame 2: the resident begins to signal as the intruder enters the leaf. Frame 3: the resident signals continuously as the intruder makes contact. Frame 4: the resident stops signalling as the intruder walks away and eventually leaves the leaf. Arrows indicate the path of the intruder across the leaf. Oscillogram illustrating the vibrational signals made by the resident throughout the encounter (top right). Numbers correspond with frames from (left panel) and timescale corresponds to (bottom right). Mean distance between resident and intruder at the beginning of each 5-s interval (middle right) and the number of mandible drums (MD) and anal scrapes (AS) in consecutive 5-s intervals, including $1 \mathrm{~min}$ before the trial, and $1 \mathrm{~min}$ after intruder departure (bottom right). Time scale is the same for both distance and signalling graphs. 


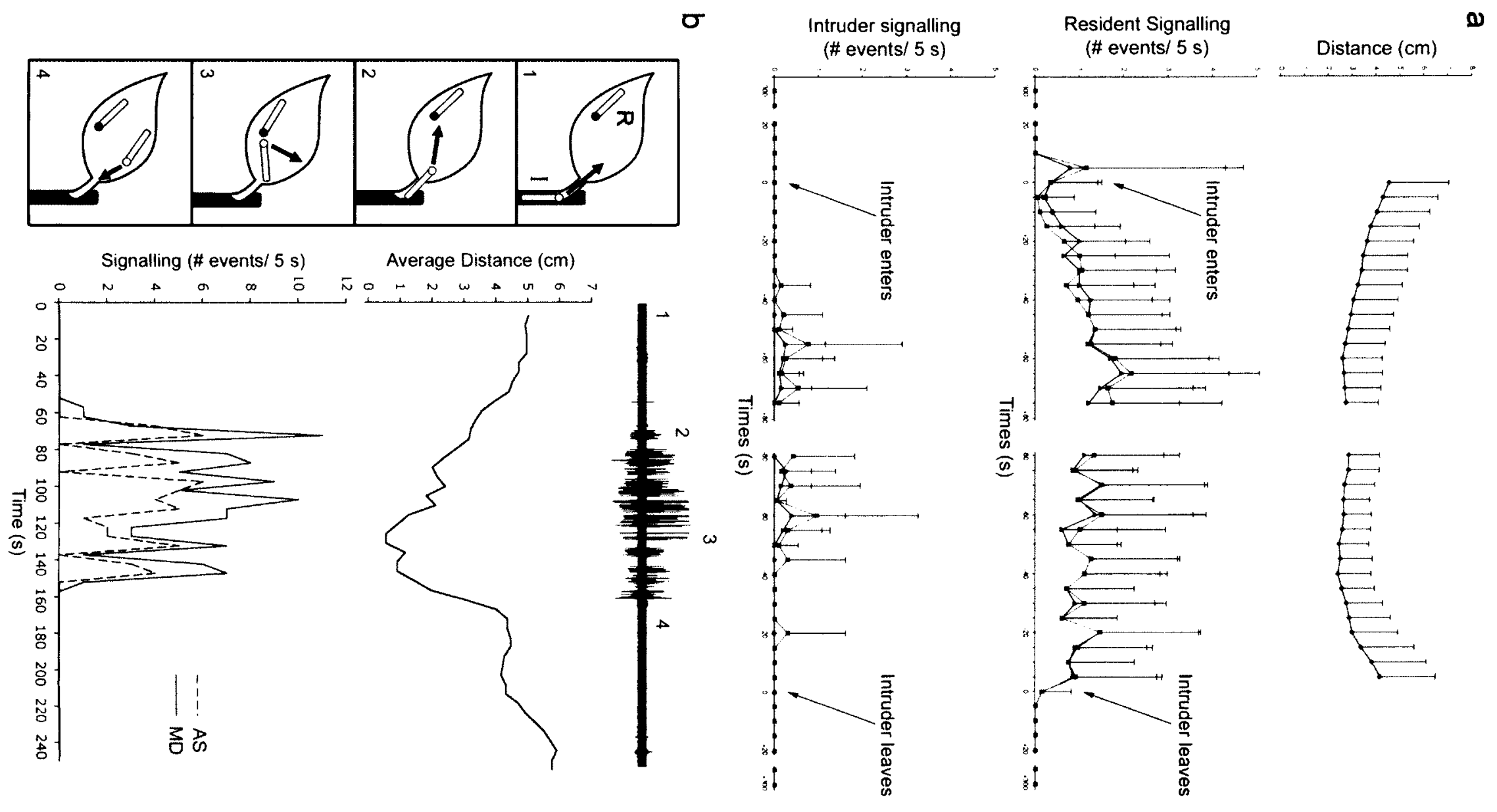


rates also increased in certain species between different stages of intruder approach (See Chapter 2 and Appendix A). Figure 6.1 demonstrates the changes signalling rates as the intruder approaches the resident in $F$. bilineata. For further information on other species, see Chapter 2 and Appendix I.

Prediction 4 . Signalling will be followed by the intruder leaving the leaf/leaf shelter Residents had significantly more encounter wins than losses when they signaled at least once (Kruskal-Wallis one-way analysis of variance; $Z=9.73, D F=2, p=0.008$ ). Some species, such as $T$. or, never lost an encounter, while in other species, such as $T$. batis, all encounters ended in a tie. See Chapter 2 for details on outcomes of encounters in all species studied to date. Figure 6.1 shows the point at which the intruder leaves in $F$. bilineata.

Prediction 5. Residents with higher investments in their leaf shelter will have higher rates of signalling (and physical aggression)

Signalling, aggressive behaviour, and overall combined rates were compared to shelter building behaviour (mat only, folded leaf, two leaves sewn together) to determine if residents with higher investments in leaf shelters have higher rates in signalling and physical aggression (Fig. 6.2). Rates of signalling, aggressive behaviour and overall combined signalling and aggressive behaviour were not significantly different between shelter types (overall: Fig. $6.2 b$, ANOVA, $F=1.92, D F=2, p=0.22$ signalling: Fig. $6.2 c$, ANOVA, $F=3.35, D F=2, p=0.095$; aggressive behaviour: Fig. 6.2d, Wilcoxon Rank Sum, $Z=5.79, D F=2, p=0.055)$. Number of signal types was also compared to shelter 
Fig. 6.2. The relationship between shelter type and overall signalling and aggressive behavioural rates. (a) Phylogeny of taxa used in comparative analysis with data for overall (signalling and aggressive rates combined), signalling and aggressive behavioural rates, and number of signal types, respectively, with photographs (from left to right) of no shelter $(O$. rosea; scale bar $=1 \mathrm{~cm})$, silk mat $(F$. bilineata; scale bar $=5 \mathrm{~mm}$; photo credit: J. Yack), rolled leaf (D. arcuata; scale bar $=3 \mathrm{~mm}$; photo credit: J. Yack) and two leaves tied together $(T$. or; scale bar $=1 \mathrm{~cm})$. (b) The relationship between shelter type and overall behavioural rate. (c) The relationship between shelter type and signalling rate. (d) The relationship between shelter type and aggressive behavioural rate. (e) The relationship between shelter type and number of signal types. Caterpillars that build folded leaf shelter have significantly more signal types (ANOVA, $F=4.90, D F=2, p=$ 0.047). 


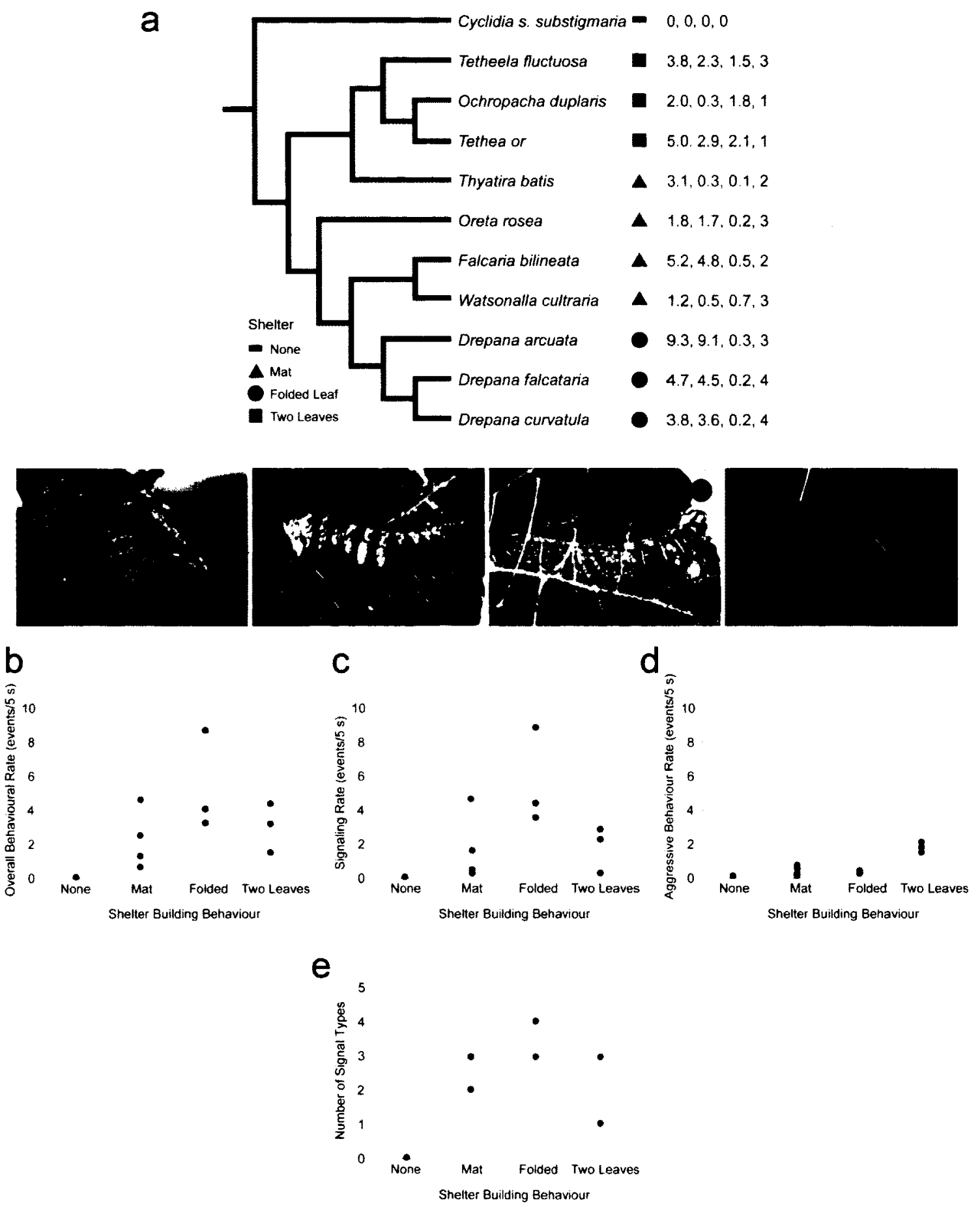


building behaviour to determine if species with higher investments in leaf shelters produce more types of signals. Number of signal types significantly differed between shelter types, with species that fold leaves producing the most signal types (Fig. 6.2e; ANOVA, $\mathrm{F}=4.90, \mathrm{DF}=2, \mathrm{p}=0.047)$

\section{Discussion}

In this section I tested the hypothesis that the signals described in Chapter 2 of this thesis (including mandible scraping, mandible drumming, anal scraping, lateral tremulation and buzzing) function for territorial defense of leaf shelters or leaves in Drepanidae caterpillars. Support for this hypothesis comes from the following lines of evidence. First, signals are produced primarily by residents of leaf shelter or leaves, where residents produced at least one signal in significantly more trials than did intruders. Second, signals are elicited by the approach of an intruder, as residents were never observed to signal while they were alone on the leaf before the trial, and only began signalling once the intruder was presumably close enough to be detected. Third, signals escalate in rate as the intruder approaches, with signalling rates significantly increasing between FAR and CLOSE stages of intruder approach. Gradation in signalling rate may act to express changes in the motivational state of the resident, and is a common feature of protracted territorial encounters (Brown, 1975; Baker, 1983; Maynard Smith \& Harper, 2003). Enquist et al. (1990) also argue that contests should begin with less costly, but less informative acts that progress to more costly acts as the risk of threat increases. Thus, when the intruder is at a far distance, it poses little threat and the resident begins with low cost signalling (lower rates) to reserve energy and avoid attracting predators. As the intruder approaches, the risk increases, and the resident uses more costly signals 
(increased rates). Higher signal repetition rates as the intruder approaches may also act to ensure the intruder receives the message by increasing the redundancy of the signal. Fourth, resident signalling is followed by the intruder leaving the shelter. Residents retained their shelters or leaves in most trials and the intruder abandoned the occupied leaf in a short amount of time, which is often the case in pair wise contests over an indivisible resource where there exists an asymmetry in ownership (Baker, 1983; Maynard Smith \& Harper, 2003).

Why would a caterpillar be territorial against conspecifics? Like many other caterpillars, some Drepanidae caterpillars invests in building a leaf shelter, which provides a more stable microclimate, protection from predators and displacement, and enhanced quality of food (Fukui, 2001). Shelters are also costly, requiring time, energy and material to build (Ruggiero \& Merchant, 1986; Fitzgerald et al., 1991; Berenbaum et al., 1993; Cappuccino, 1993; Fitzgerald, 1995). Many caterpillars have evolved ways to maintain the use of their shelters while minimizing their costs, such as using empty shelters, attempting take over of occupied shelters, or by sharing them with con- and heterospecifics (Berenbaum et al., 1993; Cappuccino, 1993; Lill et al., 2007). Shelter sharing, however, often has associated costs and is not always favourable (Cappuccino, 1993; Lill et al., 2007). It is proposed that some caterpillars protect their energetic and time investments by defending their shelters from others using vibratory signals. There have been detailed reports of vibration-mediated territorial signals in 3 species from various families, including the Gracillariidae (Caloptilia serotinella: Fletcher et al., 2006), Tortricidae (Sparganothis pilleriana: Russ, 1969) and Drepanidae (D. arcuata: Yack et al., 2001). The behaviour I have reported in this thesis is consistent with the 
behaviours observed in these other species. Therefore, if signals are used for territorial defense, my final prediction was that residents with higher investments in their leaf shelter will have higher rates of signalling and physical aggression. I did not find a significant difference in signalling, aggressive behaviour or overall combined rates with different leaf shelters. However, we do have evidence that $D$. arcuata signals more when living in shelters with more silk (J. Yack, unpublished data), and direct comparisons between $D$. arcuata, $F$. bilineata, and $O$. rosea, sympatric congeners, demonstrate that $D$. arcuata (which builds a folded leaf shelter) signals significantly more than $F$. bilineata and $O$. rosea (which only lay a silk mat). I also show that species that build folded leaf shelters produce more types of signals. This may suggest that caterpillars that have higher investment leaf shelters may have evolved additional signal types to further defend those shelters. However, this is not the case for two-leaf shelters, which are arguably has an even higher investment, requiring residents to locate two suitable leaves close enough to tie together. Since mainly the Drepana larvae build folded leaf shelters and produce more types of signals, this result could be simply due to phylogenetic relationships between species and future studies should use the comparative method to determine whether these differences are based solely on phylogeny. Future studies that include behavioural data on more species, and that use additional methods to test for levels of of defense are currently required to further test this final prediction. Finally, further studies should also examine whether Drepanidae larvae also respond to heterospecifics, but overall, my current results support the hypothesis that signals are used to advertise ownership of territories. 


\subsection{Why produce more than one type of signal?}

Background

Many Drepanidae caterpillars demonstrate a repertoire of signals during encounters with conspecifics. All six of the Drepaninae species I studied produce at least two, and up to four signal types including any combination of mandible scraping, mandible drumming, anal scraping, lateral tremulation and buzzing. For example, $D$. arcuata produces 3 types of distinct signals (see Chapter 2). Thyatirinae larvae generally produced less signal types, with two of the four species producing more than two types of signals and the other two only producing one type of signal. For example, Tethea or, produces only one signal, mandible scraping. Why might these caterpillars use more than one type of signal during territorial interactions? There have been several hypotheses to explain why animals may use such multicomponent or complex signals (Hebets \& Papaj, 2005). For example, a series of discrete signals may be used to convey information about motivation of the sender. According to the sequential assessment model (Enquist \& Leimar, 1983; 1987), behavioural repertoires are used during contests for assessment of asymmetries between contestants. As such, contests should begin with less costly but less informative acts, and if such acts do not lead either contestant to give up, they will progress to more informative, more costly acts. Therefore, behaviours should change over the course of an interaction. For example, in the cichlid fish, Nannacara anomala, fights between conspecifics have distinct phases, beginning with less costly acts, such as visual assessment, and ending in escalated fighting, including circling behaviour (Enquist et al., 1990). Based on this model, I predict that if different signal types convey information about the motivation of the resident, then signal types will change as the intruder 
approaches the resident. To test this, I will determine if signal types change within species at FAR, MID and CLOSE stages of intruder approach. The second hypothesis I will be testing is that different types of signals are used to increase the detection and recognition of the signal by receivers. As discussed in previous chapters, signal redundancy can improve the efficacy of a signal by reducing errors in the detection and recognition of a signal (Wiley, 1983). Increasing redundancy can include repeating a signal or producing a complex display with many different elements (or signal types) (Maynard Smith \& Harper, 2003). If these redundant signals differ slightly in spectral or temporal properties, it is more likely that the intended receiver will detect and recognize the overall signal. Therefore, if multiple signals evolved in the Drepanidae to increase the detection and recognition of the signal, I predict that signals types will differ in spectral and temporal properties, including bandwidth, peak frequency and duration. I will test this by comparing bandwidth, peak frequency and duration between signal types. A third hypothesis that may explain why there is more than one type of signal, is based on studies performed by Andersson (1980), who proposed that animals produce more than one kind of threat signal due to the evolution of bluffing in the system. Originally, threat signals are reliable indicators of attack, but if cheaters evolve that use the display without the intention of attacking, the signal can lose efficiency. Novel signals may then arise, that are more reliable indicators of attack, and the cycle continues. Competition will arise between signals, and both may persist due to frequency-dependent selection. Andersson (1980) also admits that since the evolution of new displays cannot usually be directly observed or experimentally manipulated, it is difficult to directly test his hypothesis. For this reason, this hypothesis will not be tested in my study. Finally, multiple signal types 
may be used to convey different types of information, and each signal may have a unique purpose or context (Maynard Smith \& Harper, 2003). The information content of each signal type is difficult to assess with the current data, and will not be tested in this chapter.

Methods

The following methods use data collected from conspecific interactions and vibration recordings as described in Chapter 2. All statistical comparisons used an alpha level of 0.05 , and data were checked for normal distribution using the Shapiro-Wilk W test.

Hypothesis 1. Different signal types convey information about motivation - Prediction 1: Signal types will change over the course of an interaction

To test the hypothesis that different signal types convey information about motivation, dominant signal types at three stages of intruder approach (FAR, MID and CLOSE; see Chapter 2 for details) were calculated for each species that produced more than one type of signal (D. arcuata, D. curvatula, D. falcataria, F. bilineata, Oreta rosea, Tetheela fluctuosa, Thyatira batis, and Watsonalla binaria). Dominant signal types were calculated by taking the signal type with the highest rate/ $5 \mathrm{~s}$ at each stage of approach. These dominant signal types were then compared between stages of intruder approach within species to determine if signal type changes as the intruder approaches the resident. 
Hypothesis 2. Different signal types are used to increase detection and recognition Prediction 1: Signal types will differ in spectral and temporal properties

Spectral and temporal properties, including dominant frequency, bandwidth at -3 $\mathrm{dB}$ and $-10 \mathrm{~dB}$, and duration were compared between mandible scraping, mandible drumming, anal scraping, lateral tremulation and buzzing within species (using only species that produced more than one signal and for which I collected LDV recordings) using ANOVAS or independent $t$-tests. Post hoc analyses were done using Tukey Kramer HSDs.

Results

Hypothesis 1. Different signal types convey information about motivation - Prediction 1: Signal types will change over the course of an interaction. Table 6.2 demonstrates the dominant signal type per species that produce more than one type of signal at each stage of intruder approach. Dominant signal types differed between FAR, MID and CLOSE stages of approach in one out of eight of species (D. arcuata) that produced more than one type of signal (Table 2; see Chapter 2). Dominant signal types changed between FAR and MID in three out of eight species (D. arcuata, D. curvatula, and F. bilineata), and between MID and CLOSE in five out of eight species (D. arcuata, D. curvatula, and $F$. bilineata, O. rosea, and T. batis) (Table 6.2; see Chapter 2 and Appendix A). Dominant signal types did not change at all at different stages of intruder approach in three out of eight species (D. falcataria, O. rosea, and W. cultraria) (Table 6.2; see Chapter 2 and Appendix A). 
Hypothesis 2. Different signal types are used to increase detection and recognition Prediction 1: Signal types will differ in spectral and temporal properties

Different signal types differed significantly in duration in all five species included in the analysis (D. arcuata, D. curvatula, D. falcataria, O. rosea, and T. fluctuosa), where lateral tremulation and anal scraping were significantly longer in duration than mandible drumming and mandible scraping, and mandible scraping was significantly longer in duration than mandible drumming. Signal types also significantly differed in dominant frequency in three species (D. arcuata, O. rosea, and T. fluctuosa), where anal scraping had a higher dominant frequency than mandible drumming and mandible scraping in $D$. arcuata (ANOVA, $\mathrm{F}=4.37, \mathrm{DF}=2, \mathrm{p}=0.04$ ); mandible scraping had a lower dominant frequency than mandible drumming and lateral tremulation in $O$. rosea (ANOVA, F = 9.54, $\mathrm{DF}=2, \mathrm{p}=0.003$ ); and mandible scraping had a higher dominant frequency than lateral tremulation in $O$. duplaris (two-tailed independent t-test, $\mathrm{t}=17.11, \mathrm{DF}=3.86, \mathrm{p}<$ 0.001 ). Bandwidths at $-3 \mathrm{~dB}$ and $-10 \mathrm{~dB}$ differed significantly between signal types in two species (O. rosea and $T$. fluctuosa), with mandible scraping being the least broadband signal in $O$. rosea, and the most broadband in $T$. fluctuosa. See Figs. 4.5 and 5.2 for examples of signals.

\section{Discussion}

The second question I asked in this chapter was: why produce more than one type of signal? Other researchers have proposed hypotheses to account for the presence of such multicomponent signals. Some of these hypotheses include: 1) different signals 
Table 6.2. Dominant signal types at FAR, MID and CLOSE stages of intruder approach by species (only including species that produce more than one type of signal). AS = anal scraping; $\mathrm{MD}=$ mandible drumming; $\mathrm{MS}=$ mandible scraping; $\mathrm{LT}=$ lateral tremulation .

\begin{tabular}{|l|l|l|}
\hline Species & Stage of Approach & Dominant Signal Type \\
\hline Drepana arcuata & FAR & MD \\
& MID & AS \\
& CLOSE & MS \\
\hline D. curvatula & FAR & AS \\
& MID & MD \\
& CLOSE & AS \\
\hline D. falcataria & FAR & AS \\
& MID & AS \\
& CLOSE & AS \\
\hline Falcaria bilineata & FAR & MD \\
& MID & AS \\
& CLOSE & MD \\
\hline O. rosea & FAR & NA \\
& MID & MD \\
& CLOSE & MS \\
\hline Tetheela fluctuosa & FAR & MS \\
& MID & MS \\
& CLOSE & MS \\
\hline Thyatira batis & FAR & NA \\
& MID & LT \\
& CLOSE & AS \\
\hline Watsonalla cultraria & FAR & NA \\
& MID & AS \\
& CLOSE & AS \\
\hline
\end{tabular}


convey information about motivation (Enquist \& Leimar, 1983; Enquist \& Leimar, 1987); 2) to increase the detection and recognition of the signal (Maynard Smith \& Harper, 2003); 3) to counteract bluffing (Andersson, 1980); and 4) to convey different types of information (Maynard Smith \& Harper, 2003). With the data I collected throughout my research, I was able to preliminarily test the first two hypotheses. If different signal types convey information about the motivation of the resident, then signal types should change over the course of an interaction, as presumably the motivation of the resident changes as the intruder approaches. My results demonstrate that, indeed, signal types changed in some species as the intruder approached the resident, although this trend was not observed in all species. This was perhaps due to low sample sizes in some species, and this prediction needs to be examined in more detail in future studies. Overall, there was also no one type of signal that was used more often at FAR, MID or CLOSE stages of intruder approach over all species.

The second hypothesis I tested was that different signal types enhance the detection and recognition of the signal by intruders. If this were so, signal types should differ in their temporal and spectral characteristics. Indeed, I found that signals did differ in temporal and spectral characteristics within species. This suggests that temporal characteristics (including duration) and spectral characteristics (including dominant frequency, and bandwidth at $-3 \mathrm{~dB}$ and $-10 \mathrm{~dB}$ ) may play a role in signal detection and processing in these caterpillars, and having more than one signal type may act to increase redundancy in the system to ensure that receivers detect and recognize the overall message. 


\subsection{Why signal instead of using physical aggression?}

Background

Why do some species use mostly physically aggressive behaviours, while others use ritualized signals during encounters with conspecifics? Fighting can be costly in terms of time and energy, and can sometimes lead to serious injury and death (Harper, 1991). Whether to settle a contest with fighting or signalling depends on a variety of factors, namely the value of the resource and the costs of fighting (Harper, 1991). Kinselection can also play a role in the decision to be physically aggressive. Reducing hostility and physical aggression towards related individuals is believed to enhance an individual's inclusive fitness (Hamilton, 1964), and many studies have found a decrease in physical aggression towards siblings and other related individuals. For example, Markman et al. (2009) demonstrated that aggression and associated injuries decreased as genetic similarity increased among groups of fire salamander (Salamandra infraimmaculata) larvae. Dobler and Kölliker (2009) also found that unrelated individuals were cannibalized earlier and more often than related individuals in nestmates of the European earwig (Forficula auricularia). In the Drepanidae, although kin recognition has not yet been studied, two life history characteristics, egg laying behaviour and gregariousness as early instars, may have an effect on the dispersal of siblings. If eggs are laid in rows instead of singly, we would expect that sibling larvae would not disperse as far, and the chances of encountering a sibling later in life would be high. The same principle can be applied to gregarious living as early instars. Some species maintain small groups (presumably siblings) as early instars, which then disperse as late instars. Again, the chances of encountering a sibling as a late instar would be higher for those 
that lived in small groups as early instars. Based on this, I predict that species that lay eggs in rows and/or are gregarious as early instars will have a higher ratio of signalling to aggressive behaviour types as late intars. This will be tested by comparing egg-laying behaviour and gregariousness as early instars with the ratio of signal to aggressive behaviour types. The cost of physical aggression may also play an important role in the decision to be physically aggressive, where if the costs of physical aggression are high, the resident will signal more. Unfortunately, I was unable to properly assess the costs of physical aggression in Drepanidae caterpillars, and therefore this will not be tested in the current study.

\section{Methods}

The following methods use data collected from conspecific interactions and general observations as described in Chapter 2. All statistical comparisons used an alpha level of 0.05 , and data were checked for normal distribution using the Shapiro-Wilk W test.

Predictions 1 and 2. Species that lay eggs in rows, and/or are gregarious as early instars will have a higher ratio of signalling to aggressive behaviour

The ratio of signal to aggressive behaviour types was calculated per species by dividing the total number of signal types produced (mandible scraping, mandible drumming, anal scraping, lateral tremulation and buzzing) by the total number of aggressive behaviours (crawling towards intruder, pushing, lateral head hitting, lateral tail hitting and biting). This ratio was then compared to data on egg laying behaviour (laid 
singly/in small groups or in rows), and gregariousness as early instars (solitary or gregarious) using independent $\mathrm{t}$-tests to determine if there is a relationship between ratio of signalling to aggressive behaviour and either of these life history characteristics. The categories for eggs laid singly and in small groups had to be combined because many species, such as $O$. rosea were found to either lay eggs singly or in short rows.

\section{Results}

Predictions 1 and 2. Species that lay eggs in rows, and/or are gregarious as early instars will have a higher ratio of signals to aggressive behaviours.

There was no significant difference in ratio of signal to aggressive behaviour types between species that laid eggs in rows and those that laid them singly/in small groups (independent $t$-test, two-tailed; $t=-2.22, D F=5.02, p=0.076$ ) (Fig. 6.3). My data do demonstrate, however, that in general, the Thyatirinae caterpillars lay eggs singly, and do not have large repertoires of signals. There was also no significant difference in ratio of signal to aggressive behaviours types between species that were gregarious as early instars and those that were solitary as early instars (independent $\mathrm{t}$-test, two-tailed; $\mathrm{t}=$ $0.83, \mathrm{DF}=7.12, \mathrm{p}=0.43)($ Fig. 6.4)

\section{Discussion}

The final question I asked was: why signal instead of using physical aggression during encounters with conspecifics? I hypothesized that kin-selection and the costs of fighting may play a role in the decision to signal in the Drepanidae. To test my first hypothesis, I predicted that species of Drepanidae that lay eggs in groups and/or were 
Fig. 6.3. The relationship between egg-laying behaviour and ratio of signalling to aggressive behaviour in late instars. (a) Phylogeny of taxa used in comparative analysis with data for ratio of signalling to aggressive behaviour, with photographs of eggs laid in rows (top; $D$. arcuata; scale bar $=3 \mathrm{~mm}$; photo credit: J. Yack) and singly (bottom; $W$. cultraria; photo credit: ukleps.org; scale bar $=1 \mathrm{~mm}$ ). (b) The relationship between egglaying behaviour and ratio of signalling to aggressive behaviour. 
a

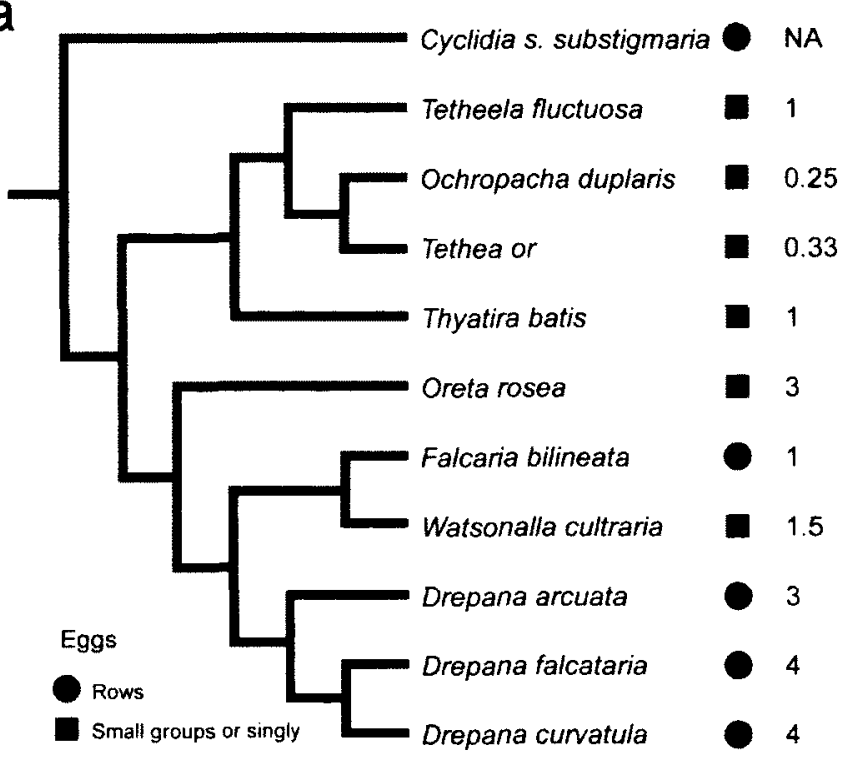

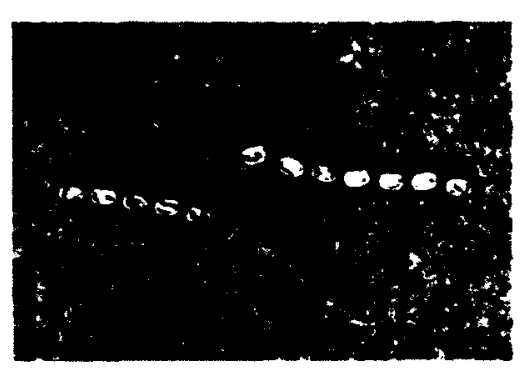

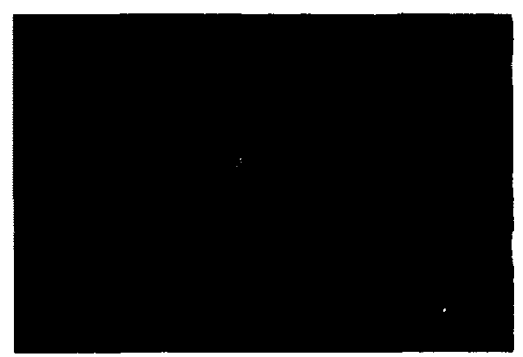

b
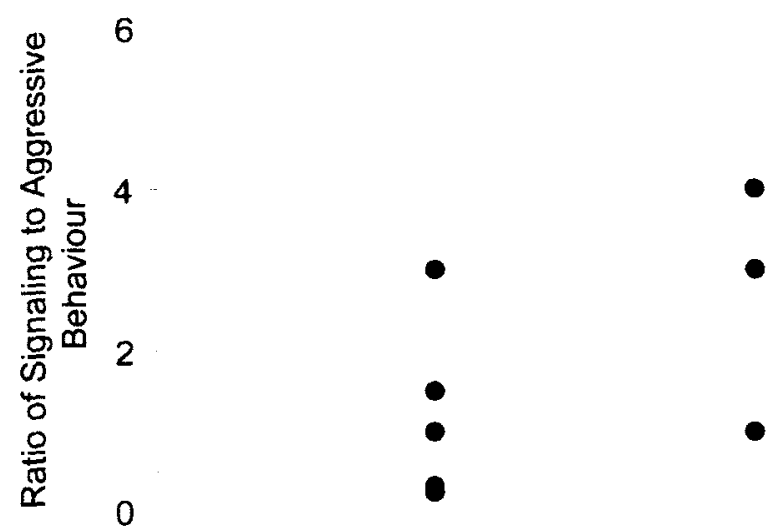

Singly/Small Groups

Rows

Egg Laying Behaviour 
Fig. 6.4. The relationship between gregariousness as early instars and ratio of signalling in late instars to aggressive behaviour. (a) Phylogeny of taxa used in comparative analysis with data for ratio of signalling to aggressive behaviour, with photographs of early instars living in groups (top; $D$. arcuata; scale bar $=1 \mathrm{~mm}$; photo credit: J. Yack) and alone (bottom; $O$. rosea; scale bar $=3 \mathrm{~mm}$ ). (b) The relationship between gregariousness as early instars and ratio of signalling to aggressive behaviour. 

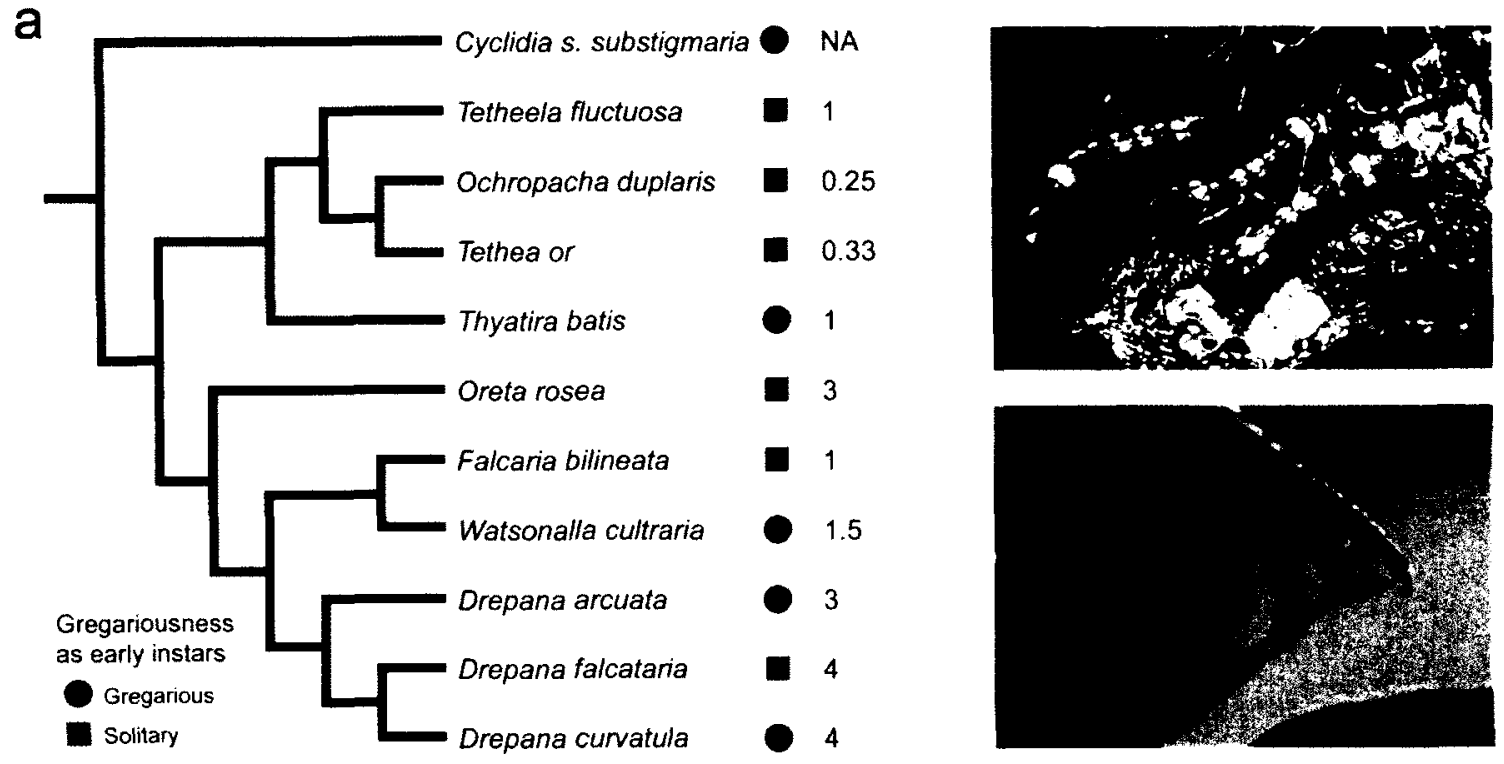

b

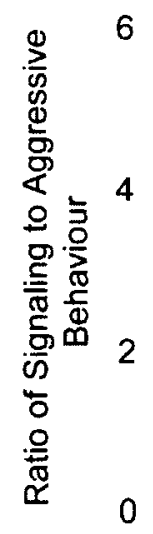

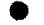

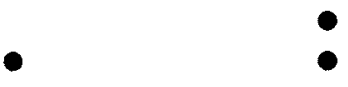

-

Gregarious

Solitary

Early Instar Behaviour 
gregarious as early instars would have a higher ratio of signalling to aggressive behaviours due to low dispersal rates from sibling groups. I did not find any evidence to suggest that egg laying behaviour and/or gregariousness as early instars are related to the ratio of signal to aggressive behaviour type in these caterpillars. This finding contrasts with other studies that found a relationship between species-relatedness and reduced rates of aggression (e.g. Dobler \& Kölliker, 2009; Markman et al., 2009). It is possible that Drepanidae larvae are able to disperse adequately from sibling groups after hatching, or after leaving early instar groups, and the probability of encountering a sibling later in life is no higher than encountering a non-sibling in species. More studies are needed to determine the dispersal abilities of larval Drepanidae in order to re-evaluate this hypothesis. My results do indicate that the Thyatirinae species generally have lower ratios of signalling to aggressive behaviours than do Drepaninae species. Further studies should look into other possible reasons for this difference between groups. My second hypothesis, that the cost of fighting affects whether to signal or use physical aggression, may provide a better explanation to answer the question, why signal instead of using physical aggression? Unfortunately because my data was not collected to specifically answer this question, I was unable to test this particular hypothesis. Future studies should collect more information on the costs of fighting, incorporating both the energetic costs and the frequency and severity of injury that results from encounters with conspecifics in order to explore this question in more detail. 


\section{General Summary}

In this chapter, I preliminarily examined three ultimate questions on the evolution of signalling in Drepanidae caterpillars (Table 6.3). First, I asked: what is the function of signalling? I provided evidence that vibratory signals in Drepanidae caterpillars function for territorial defense of leaf shelters, as they are produced primarily by the resident, are elicited by the approach of an intruder, show increasing signaling rates as the intruder approaches, and the resident signalling is followed by the intruder leaving the leaf. The second question I asked was: Why produce more than one type of signal? I demonstrated that producing more than one type of signal may function to alert the intruder of the motivation of the resident, or to ensure that the intruder detects and recognizes the signal. Finally, I asked: Why signal instead of using physical aggression? I provide evidence to suggest that kin-selection does not explain why these caterpillars signal instead of using physical aggression, and propose that future studies should focus on the costs of fighting. 
Table 6.3. Summary of questions, hypotheses, predictions and findings in this chapter.

\begin{tabular}{|c|c|c|c|}
\hline Main Question & Hypothesis & Predictions & $\begin{array}{l}\text { Supported } \\
\text { by data? }\end{array}$ \\
\hline $\begin{array}{l}\text { What is the } \\
\text { function of } \\
\text { vibratory } \\
\text { signalling? }\end{array}$ & $\begin{array}{l}\text { Signals function for } \\
\text { territorial defense of } \\
\text { leaf shelters/leaves }\end{array}$ & $\begin{array}{l}\text { a) signals will be produced primarily by the } \\
\text { resident of the leaf shelter/leaf } \\
\text { b) signals will be elicited by the approach of the } \\
\text { intruder } \\
\text { c) signal rates will increase as the intruder } \\
\text { approaches } \\
\text { d) signalling will be followed by the resident } \\
\text { leaving the leaf shelter/leaf } \\
\text { e) residents with higher investments in the leaf } \\
\text { shelter construction (from no shelter to silk mat } \\
\text { to rolled leaf to two leaves sewn together), will } \\
\text { have higher rates of signalling (and aggressive } \\
\text { behaviours) and vice-versa }\end{array}$ & $\begin{array}{l}\mathrm{Y} \\
\mathrm{Y} \\
\mathrm{Y} \\
\mathrm{Y} \\
\mathrm{N}\end{array}$ \\
\hline $\begin{array}{l}\text { Why more than } \\
\text { one type of } \\
\text { signal? }\end{array}$ & $\begin{array}{l}\text { 1. Different signal } \\
\text { types convey } \\
\text { information about } \\
\text { the motivation of the } \\
\text { resident } \\
\text { 2. Different signal } \\
\text { types increase the } \\
\text { detection and } \\
\text { recognition of } \\
\text { signals by intruders } \\
\text { 3. Different signal } \\
\text { types evolved to } \\
\text { counteract bluffing } \\
\text { 4. Different signal } \\
\text { types convey } \\
\text { different types of } \\
\text { information }\end{array}$ & $\begin{array}{l}\text { Signal types will change as the intruder } \\
\text { approaches the resident } \\
\text { Signal types differ in spectral properties } \\
\text { including bandwidth and peak frequency and } \\
\text { temporal characteristics, including duration }\end{array}$ & Yot tested \\
\hline $\begin{array}{l}\text { Why signal } \\
\text { instead of using } \\
\text { aggression? }\end{array}$ & $\begin{array}{l}\text { 1. If the chance of } \\
\text { encountering a } \\
\text { sibling as a late instar } \\
\text { is high, residents will } \\
\text { produce more signals } \\
\text { and be less } \\
\text { aggressive towards } \\
\text { intruders } \\
2 . \text { The costs of } \\
\text { aggressive behaviour } \\
\text { affects the behaviour } \\
\text { of the resident }\end{array}$ & $\begin{array}{l}\text { a) Species that lay eggs in clusters will have a } \\
\text { higher ratio of signals to aggressive behaviours } \\
\text { than those that lay eggs singly } \\
\text { b) Species that are gregariousness as early } \\
\text { instars will have a higher ratio of signalling to } \\
\text { aggressive behaviour } \\
\text { If the costs of aggressive behaviour are high, } \\
\text { residents will produce more signals than } \\
\text { physically aggressive behaviours }\end{array}$ & $\begin{array}{l}\mathrm{N} \\
\mathrm{N} \\
\text { Not tested }\end{array}$ \\
\hline
\end{tabular}


Chapter 7

GeNeral SUMmARY AND CONCLUSIONS 
The overarching goal of this thesis was to study the evolutionary origins of communication signals from non-signalling behaviours in Drepanidae caterpillars. Biologists have been interested in the evolutionary origin of signals since the time of Darwin, yet there is currently little direct evidence to support hypotheses on the evolution of signals in other model systems. This may be because it is necessary to find a system with sufficient variation in the behaviour of interest, with known phylogeny between species. I provide experimental evidence on the origin of signals using Drepanidae caterpillars as a model system. Previously, vibratory signalling in Drepanidae larvae had only been experimentally examined in one species (Drepana arcuata; Yack et al., 2001), but there was indirect evidence suggesting that vibratory signalling is widespread and variable in this group (Dyar, 1884; Federley, 1905; Nakajima, 1970; Nakajima, 1972; Bryner, 1999; Sen \& Lin, 2002; I. Hasenfuss, personal communication). The two major goals of my thesis were: 1) to test hypotheses on the non-signalling origins of vibratory signals in the Drepanidae; and 2) to provide general information on vibratory signalling in caterpillars, since little is known about this form of signalling in caterpillars to date. In Chapter 2, I documented variation in morphology and behaviour associated with conspecific interactions in representative taxa of the Drepanidae. I collected morphological data for 19 species using specimens in alcohol, and behavioural data for 11 species using live specimens. I found variation in structures associated with vibratory signalling, including morphology associated with the anal proleg, caudal projection, PP1 setae, and mandibles. Variation in behaviour associated with conspecific encounters included physical aggression without signalling (e.g. lateral head hitting, lateral tail hitting, pushing and biting) as well as vibratory signals (e.g. mandible drumming, 
mandible scraping, anal scraping, lateral tremulation and buzzing), or a lack of territorial behaviour altogether. Information on the variation in morphology, movements, vibration properties and sequences of behaviour collected in this chapter was used in subsequent chapters to test hypotheses on signal origins and to propose models on the transition from aggressive behaviour to signalling.

In order to elucidate the evolutionary origins of a signal, it was necessary to understand the phylogenetic relationships between species to provide a framework onto which variation in morphology and behaviour could be mapped. The goal of Chapter 3 was to create a phylogeny of the Drepanoidea using molecular markers, as previous phylogenies of this group had been created using only morphological data (e.g. Minet; 1991; Minet \& Scoble, 1999; Wu et al., 2009). In this chapter, I created a robust phylogeny using three genes (CAD, ND1 and 28S) onto which characters could be mapped to study the evolutionary origin of signalling. I confirmed that the Drepanoidea comprises two families, Drepanidae and Epicopeiidae, and that Drepanidae is further divided into three subfamilies, Drepanidae, Thyatirinae, and Cyclidiinae. Based on my results, I have also suggested that a third subfamily, Oretinae, be created, which concurs with other phylogenetic studies on the group.

Chapter 4 focused on testing hypotheses on the evolutionary origin of the anal scraping signal. I hypothesized that anal scraping derives from movements involved in crawling. This hypothesis was supported by the following lines of evidence: 1) crawling with fully formed prolegs and unmodified PP1 setae represented the basal condition when mapped onto the phylogeny; 2) kinematic analysis demonstrated that crawling and anal scraping involve similar movement patterns; 3 ) vibration analysis suggested that anal 
scraping has more features of ritualization than crawling; and 4) aggressive crawling towards an intruder and anal scraping occurred in the same position in a typical sequence of behaviours between representative species. I also proposed two models for the evolutionary transition between crawling and anal scraping, one that focused on the evolutionary transition between behaviours and another that focused on the muscular and neural changes that may have accompanied this transition. I found two possible scenarios for the behavioural transition from crawling to anal scraping based on the results I collected. In the first scenario, general crawling transitioned to aggressively crawling towards the intruder followed by 'pseudo' anal scraping and finally by anal scraping. In the second scenario, general crawling transitioned to 'pseudo' anal scraping followed by either aggressive crawling or anal scraping. I also provided data to propose that the swing phase of crawling is homologous to the scrape phase of anal scraping, using the same sequence of muscle contractions.

Chapter 5 tested the hypothesis that mandible scraping derives from lateral head hitting. Evidence to support this hypothesis included: 1) lateral head hitting represented the basal condition when mapped onto the phylogeny; 2) kinematic analysis suggested that mandible scraping and lateral head hitting involve similar movement patterns; and 3) vibration analysis provided some evidence that mandible scraping shows more features of ritualization than lateral head hitting. I also mapped all other behaviours performed by the anterior body segments and compared behaviours based on characteristics of the movement and vibrations to propose a model for the evolutionary transition between behaviours. 
Although my thesis research focused mainly on the proximate mechanisms of signal evolution, during the course of this study many interesting questions concerning ultimate mechanisms of signal evolution arose. I dedicated Chapter 6 to develop hypotheses to answer some of these questions, including: What is the function of signalling? Why produce more than one type of signal? Why signal instead of using physical aggression? Although the results of this chapter are preliminary, I was able to use my data set to provide some initial tests of hypotheses associated with each question. I provided evidence that vibratory signals in Drepanidae caterpillars function for territorial defense of leaf shelters or leaves, that these caterpillars produce more than one signal type possibly to increase the detection and recognition of the signal by intruders, and I suggest that future studies should focus on the costs of fighting to explain why these caterpillars use signals instead of physical aggression.

My research was the first to provide a robust molecular phylogeny of the Drepanoidea and to study the evolutionary origins of communication signals from nonsignalling behaviours using a combination of behavioural, morphological and phylogenetic data. In addition, my results have contributed further information on the characteristics and function of vibratory signals in caterpillars. My thesis research has culminated in 4 published papers to date in Nature Communications, Physiological Entomology, Journal of Insect Science, and the European Journal of Entomology, as well as two manuscripts in preparation.

Future studies should focus on sampling more taxa for phylogenetic study in order to resolve some of the relationships within the Drepanoidea, including the placements of the Epicopeiidae and Oretini which would allow us to properly place these groups 
phylogenetically. My research on the evolutionary origin of anal scraping would benefit from future studies that collect and compare electromyographic and neural data during crawling and anal scraping to provide further support for the hypothesis that anal scraping derives from crawling, and to explore the evolutionary changes to neural circuits. Another important question that still needs to be answered is how do these caterpillars detect and discriminate vibrations on the leaf. In Chapter 2, I examined the morphology of possible vibration receptors on the abdominal prolegs in these caterpillars, but to date it is unknown how vibration reception works in lepidopteran larvae. This would be an avenue that would greatly benefit from future research. Finally, future research on the morphology and behaviour of more species included in the phylogeny would help to explain why variation exists in the territorial behaviour of these species, why they signal at all, and what factors are important in determining the territorial behavioural repertoires in this interesting group of caterpillars. 


\section{REFERENCES}

Abraham, D., Ryrholm, N., Wittzell, H., Holloway, J. D., Scoble, M. J. \& Lofstedt, C. (2001). Molecular phylogeny of the subfamilies in Geometridae (Geometroidea: Lepidoptera). Molecular Phylogenetics and Evolution 20, 65-77.

Akaike, H. (1973). Information theory as an extension of the maximum likelihood principle. In Second International Symposium on Information Theory, eds. B. N. Petrov and F. Csaki), pp. 267-281. Budapest, Hungary: Akademiai Kiado.

Andersson, M. (1980). Why are there so many threat displays? Journal of Theoretical Biology 86, 773-781.

Baker, R. R. (1983). Insect territoriality. Annual Review of Entomology 28, 65-89.

Barth, F. G., Bleckmann, H., Bohnenberger, J. \& Seyfarth, E. A. (1988). Spiders of the genus Cupiennius Simon 1891 (Araneae, Ctenidae). II. On the vibratory environment of a wandering spider. Oecologia 77, 194-201.

Belanger, J. H. \& Trimmer, B. A. (2000a). Combined kinematic and electromyographic analyses of proleg function during crawling by the caterpillar Manduca sexta. Journal of Comparative Physiology A 186, 1031-1039.

Belanger, J. H. \& Trimmer, B. A. (2000b). Context dependency of a limb withdrawal reflex in the caterpillar Manduca sexta. Journal of Comparative Physiology A 186, 1041-1048.

Belshaw, R. \& Quicke, D. L. J. (1997). A molecular phylogeny of the Aphidinae (Hymenoptera: Braconidae). Molecular Phylogenetics and Evolution 7, 281-293.

Berenbaum, M. R., Green, E. S. \& Zangerl, A. R. (1993). Web costs and web defense in the parsnip webworm (Lepidoptera: Oecophoridae). Environmental Entomology 22, 791-795.

Bernays, E. A. (1991). Evolution of insect morphology in relation to plants. Philosophical Transactions of the Royal Society of London. Series B, Biological Sciences 333, 257-264. 
Bernays, E. A. \& Janzen, D. H. (1988). Saturniid and sphingid caterpillars: two ways to eat leaves. Ecology 69, 1153-1160.

Beutenmüller, W. (1898). Descriptive catalogue of the bombycine moths found within fifty miles of New York. Bulletin of the American Museum of Natural History 10, 388-391.

Birch, M. C. \& Keenlyside, J. J. (1991). Tapping behavior is a rhythmic communication in the death-watch beetle, Xestobium rufovillosum (Coleoptera: Anobiidae). Journal of Insect Behavior 4, 257-263.

Blumstein, D. T., Daniel, J. C. \& Evans, C. S. (2006). J Watcher version 1.0. http://www.jwatcher.ucla.edu/.

Bowen, J. L., Mahony, S. J., Mason, A. C. \& Yack, J. E. (2008). Vibration-mediated territoriality in the warty birch caterpillar Drepana bilineata. Physiological Entomology 33, 238-250.

Brackenbury, J. (1999). Fast locomotion in caterpillars. Journal of Insect Physiology 45, 525-533.

Bradbury, J. W. \& Vehrencamp, S. L. (1998). Principles of Animal Communication. Sunderland, Massachusetts: Sinauer Associates, Inc.

Brooks, D. R. \& McLennan, D. A. (2002). The Nature of Diversity: An Evolutionary Voyage of Discovery. Chicago: University of Chicago Press.

Brown, E. S. \& Dewhurst, C. F. (1975). The genus Spodoptera (Lepidoptera, Noctuidae) in Africa and the Near East. Bulletin of Entomological Research 65, 221-262.

Brown, J. (1975). The Evolution of Behaviour. New York: W.W. Norton.

Brown, S. G. (2006). Clicking caterpillars: acoustic aposematism in Antheraea polyphemus and other Bombycoidea, vol. M.Sc. Thesis. Ottawa, Canada: Carleton University. 
Brown, S. G., Boettner, G. H. \& Yack, J. E. (2007). Clicking caterpillars: acoustic aposematism in Antheraea polyphemus and other Bombycoidea. Journal of Experimental Biology 210, 993-1005.

Bryner, R. (1999). Drepanidae - Drépanidés. In Les Papillons et leur Biotopes: Espèces; Danger qui les menacent; Protection. Suisse et regions limitrophe, vol. 2 (ed. L. S. p. 1. P. d. 1. Nature), pp. 447-476. Switzerland: Pro Natura.

Bura, V. L. (2010). Sound production in Bombycoidea caterpillars: a comparative study of taxonomic diversity, mechanisms and function, vol. M.Sc. Thesis. Ottawa, Canada: Carleton University.

Bura, V. L., Fleming, A. J. \& Yack, J. E. (2009). What's the buzz? Ultrasonic and sonic warning signals in caterpillars of the great peacock moth (Saturnia pyri). Naturwissenschaften 96, 713-718.

Bura, V. L., Rohwer, V. G., Martin, P. R. \& Yack, J. E. (2010). Whistling in caterpillars (Amorpha juglandis, Bombycoidea): sound-producing mechanism and function. Journal of Experimental Biology 214, 30-37.

Caldwell, M. S., McKaniel, J. G. \& Warkentin, K. M. (2009). Frequency information in the vibration-cued escape hatching of red-eyed treefrogs. Journal of Experimental Biology 212, 566-575.

Cappuccino, N. (1993). Mutual use of leaf-shelters by lepidopteran larvae on paper birch. Ecological Entomology 18, 287-292.

Carazo, P. \& Font, E. (2010). Putting information back into biological communication. Journal of Evolutionary Biology 23, 661-669.

Carne, P. B. (1962). The characteristics and behaviour of the sawfly Perga affinis affinis (Hymenoptera). Australian Journal of Zoology 10, 1-34.

Castrejon, F. \& Rojas, J. C. (2010). Behavioral responses of larvae and adults of Estigmene acrea (Lepidoptera: Arctiidae) to light of different wavelengths. Florida Entomologist 93, 505-509. 
Caterino, M. S., Cho, S. \& Sperling, F. A. H. (2000). The current state of insect molecular systematics: A thriving tower of Babel. Annual Review of Entomology 45, 1-54.

Caterino, M. S., Reed, R. D., Kuo, M. M. \& Sperling, F. A. H. (2001). A partitioned likelihood analysis of swallowtail butterfly phylogeny (Lepidoptera:

Papilinonidae). Systematic Biology 50, 106-127.

Cho, S., Zwick, A., Regier, J. C., Mitter, C., Cummings, M. P., Yao, J., Du, Z., Zhao, H., Kawahara, A. Y., Weller, S., Davis, D. R., Baixeras, J., Brown, J. W. \& Parr, C. (2011). Can deliberately incomplete gene sample augmentation improve a phylogeny estimate for the advanced moths and butterflies (Hexapoda: Lepidoptera)? Systematic Biology 60, 782-796.

Chow, Y. S. \& Tsai, R. S. (1988). Protective chemicals in caterpillar survival. Experentia 45, 390-392.

Clissold, F. J. (2007). The biomechanics of chewing and plant fracture: mechanisms and implications. Advanced Insect Physiology 34, 317-372.

Cocroft, R. B. (2001). Vibrational communication and the ecology of group-living, herbivorous insects. American Zoologist 41, 1215-1221.

Cocroft, R. B. \& Rodriguez, R. L. (2005). The behavioral ecology of insect vibrational communication. BioScience 55, 323-334.

Cocroft, R. B., Shugart, H. J., Konrad, K. T. \& Tibbs, K. (2006). Variation in plant substrates and its consequences for insect vibrational communication. Ethology 112, 779-789.

Colasurdo, N. \& Despland, E. (2005). Social cues and following behavior in the forest tent caterpillar. Journal of Insect Behavior 18, 77-87.

Costa, J. T. (2006). The Other Insect Societies. Cambridge, Massachusetts: Belknap Press of Harvard University Press.

Costa, J. T. \& Pierce, N. E. (1997). Social evolution in the Lepidoptera: Ecological context and communication in larval societies. In Social Behaviour in Insects and 
Arachnids, eds. J. C. Choe and B. J. Crespi), pp. 407-442. Cambridge: Cambridge University Press.

Crane, J. (1966). Combat, display and ritualization in fiddler crabs (Ocypodidae, genus Uca). Philosophical Transactions of the Royal Society of London. Series B, Biological Sciences 251, 459-472.

Cullen, J. M. (1966). Reduction of ambiguity through ritualization. Philosophical Transactions of the Royal Society of London. Series B, Biological Sciences 251, 363-374.

Dawkins, R. \& Krebs, J. R. (1978). Animal signals: information or manipulation? In Behavioural Ecology: An Evolutionary Approach, eds. J. R. Krebs and N. B. Davies), pp. 282-309. Oxford: Blackwell Scientific Publications.

DeVries, P. J. (1990). Enhancement of symbioses between butterfly caterpillars and ants by vibrational communication. Science 24, 1104-1106.

DeVries, P. J. (1991). Call production by myrmecophilous riodinid and lycaenid butterfly caterpillars (Lepidoptera): morphological, acoustical, functional, and evolutionary patterns. American Museum Novitates 3025, 1-23.

Dobler, R. \& Kölliker, M. (2009). Kin-selected siblicide and cannibalism in the European earwig. Behavioral Ecology 10.1093, 257-263.

Dominick, O. S. \& Truman, J. W. (1986). The physiology of wandering behaviour in Manduca sexta: III. Organization of wandering behaviour in the larval nervous system. Journal of Experimental Biology 121, 115-132.

Dumortier, B. (1963). Morphology and sound emission apparatus in Arthropoda. In Acoustic Behaviour of Animals, (ed. R. G. Busnel), pp. 277-338. New York: Elsevier.

Dyar, H. G. (1884). Classification of Lepidopterous Larvae. Annals of the New York Academy of Science 8, 194-232.

Dyar, H. G. (1895). Notes on drepanid larvae. Journal of the New York Entomological Society 3, 66-69. 
Eaton, J. L. (1988). Lepidopteran Anatomy. New York: Wiley-Interscience.

Enquist, M. \& Leimar, O. (1983). Evolution of fighting behaviour: decision rules and assessment of relative strength. Journal of Theoretical Biology 102, 387-410.

Enquist, M. \& Leimar, O. (1987). Evolution of fighting behaviour: the effect of variation in resource value. Journal of Theoretical Biology 127, 187-205.

Enquist, M., Leimar, O., Ljungberg, T., Mallner, Y. \& Segerdahl, N. (1990). A test of the sequential assessment game: fighting in the cichlid fish Nannacara anomala. Animal Behaviour 40, 1-4.

Federley, H. (1905). Sound produced by Lepidopterous larvae. Journal of the New York Entomological Society 13, 109-110.

Fitzgerald, T. D. (1995). The Tent Caterpillars. Ithaca, New York: Comstock Publication Associates.

Fitzgerald, T. D. (2003). The role of trail pheromone in foraging and processionary behavior of pine processionary caterpillars Thaumetopoea pityocampa. Journal of Chemical Ecology 29, 513-532.

Fitzgerald, T. D. \& Clark, K. L. (1994). Analysis of leaf-rolling behavior of Caloptilia serotinella (Lepidoptera: Gracillaridae). Journal of Insect Behavior 7, 859-872.

Fitzgerald, T. D., Clark, K. L., Vanderpool, R. \& Phillips, C. (1991). Leaf shelterbuilding caterpillars harness forces generated by axial retraction of stretched and wetted silk. Journal of Insect Behavior 4, 21-32.

Fitzgerald, T. D. \& Costa, J. T. (1999). Collective behavior in social caterpillars. In Information Processing in Social Insects, eds. C. Detrain J. L. Deneubourg and J. M. Pasteels), pp. 379-400. Switzerland: Birkhauser.

Fitzgerald, T. D. \& Pescador-Rubio, A. (2002). The role of tactile and chemical stimuli in the formation and maintenance of the processions of the social caterpillar Hylesia lineata (Lepidoptera: Saturniidae). Journal of Insect Behavior 15, 659-674. 
Fleishman, L. J. (1992). The influence of the sensory system and the environment on motion patterns in the visual displays of anoline lizards and other vertebrates. American Naturalist 139, S36-61.

Fletcher, L. E. (2007). Vibrational signals in a gregarious sawfly larva (Perga affinis): group coordination or competitive signaling? Behavioral Ecology and Sociobiology 61, 1809-1821.

Fletcher, L. E., Yack, J. E., Fitzgerald, T. D. \& Hoy, R. R. (2006). Vibrational communication in the cherry leaf roller caterpillar Caloptilia serotinella (Gracillarioidea: Gracillariidae). Journal of Insect Behavior 19, 1-18.

Fred, M. S. \& Brommer, J. E. (2010). Olfaction and vision in host plant location by Parnassius apollo larvae: consequences for survival and dynamics. Animal Behaviour 79, 313-320.

Fuchs, S. (1976). An informational analysis of the alarm communication by drumming behavior in nests of carpenter ants (Camponotus, Formicidae, Hymenoptera). Behavioral Ecology and Sociobiology 1, 315-336.

Fukui, A. (2001). Indirect interactions mediated by leaf shelters in animal-plant communites. Population Ecology 43, 31-40.

Galef, B. G. \& Giraldeau, L.-A. (2001). Social influences on foraging in vertebrates: causal mechanisms and adaptive functions. Animal Behaviour 61, 3-15.

Gillespie, J. J. (2005). A secondary structural model of the 28S rRNA expansion segments D2 and D3 for chalcidoid wasps (Hymenoptera: Chalcidoidea). Molecular Biology and Evolution 22, 1593-1608.

Grafen, A. (1990). Biological signals as handicaps. Journal of Theoretical Biology 144, 517-546.

Greenfield, M. D. (2002). Signalers and Receivers: Mechanisms and Evolution of Arthropd Communication. Oxford: Oxford University Press.

Guedes, R. N. C., Matheson, S. M., Frei, B., Smith, M. L. \& Yack, J. E. (2012). Vibration detection and discrimination in the masked birch caterpillar (Drepana arcuata). Journal of Comparative Physiology A 198, 325-335. 
Hamilton, W. D. (1964). The genetical evolution of social behaviour. I and II. Journal of Theoretical Biology 7, 1-52.

Hancock, J. M. \& Dover, G. A. (1988). Molecular coevolution among cryptically simple expansion segments of Eukaryotic 26S/28S ribosomal-RNAs. Molecular Biology and Evolution 5, 377-391.

Hancock, J. M., Tautz, D. \& Dover, G. A. (1988). Evolution of the secondary structures and compensatory mutations of the ribosomal-RNAs of Drosophila melanogaster. Molecular Biology and Evolution 5, 393-414.

Harper, D. (1991). Communication. In Behavioural Ecology; An Evolutionary Approach, eds. J. R. Krebs and N. B. Davies), pp. 374-397. Oxford: Blackwell.

Hasson, O. (1994). Cheating signals. Journal of Theoretical Biology 167, 223-238.

Hauser, M. D. (1996). The Evolution of Communication. Cambridge, Massachusetts: MIT Press.

Hebets, E. A. \& Papaj, D. R. (2005). Complex signal function: Developing a framework of testable hypotheses. Behavioral Ecology and Sociobiology 57.

Heinrich, B. (1979). Foraging strategies of caterpillars: leaf damage and possible predator avoidance strategies. Oecologia 42, 325-337.

Hill, P. S. M. (2009). How do animals use substrate-borne vibrations as an information source? Naturwissenschaften 96, 1355-1371.

Hinton, H. E. (1955). On the structure, function and distribution of the prolegs of the Panarpoidea, with a criticism of the Berlese-Imms theory. Transactions of the Royal Entomological Society of London 13, 455-540.

Hoegraefe, T. (1984). Substratum-stridulation in the colonial sawfly larvae of Hemichroa crocea (Hymenoptera, Tenthredinidae). Zoologischer Anzeiger 213, 234-241.

Holloway, J. D. (1998). The Moths of Borneo: Families Castniidae, Callidulidae, Drepanidae and Uraniidae. The Malayan Nature Journal 52, 1-155. 
Holloway, J. D., Kirby, G. \& Peggie, D. (2001). Fauna Malesiana Handbooks: The Families of Malesian Moths and Butterflies. Leiden, The Netherlands: Brill.

Hunter, M. D. (1987). Sound production in larvae of Diurnea fagella (Lepidoptera: Oecophoridae). Ecological Entomology 12, 355-357.

Huxley, J. S. (1966). A discussion on ritualization of behaviour in animals and man Introduction. Philosophical Transactions of the Royal Society of London. Series B, Biological Sciences 251, 249-271.

Hwang, U. W., Kim, W., Tautz, D. \& Friedrich, M. (1998). Molecular phylogenetics at the Felsenstein zone: Approaching the Strepsiptera problem using 5.8S and 28S rDNA sequences. Molecular Phylogenetics and Evolution 9, 470-480.

Imms, A. (1934). A General Textbook of Entomology. London, UK: Methuen \& Co.

Inoue, H. (1954). Check List of the Lepidoptera of Japan. Tokyo, Japan: Rikusuisha.

Inoue, H. (1962). Insecta Japonica, series 2, part 1. Lepidoptera: Cyclidiidae, Drepanidae. Tokyo, Japan: Hokuryukan Publishing Co.

Ishay, J., Motro, A., Gitter, S. \& Brown, M. B. (1974). Rythms in acoustical communication by oriental hornet, Vespa orientalis. Animal Behaviour 22, 741744.

Johnston, R. M. \& Levine, R. B. (1996). Crawling motor patterns induced by pilocarpine in isolated larval nerve cords of Manduca sexta. Journal of Neurophysiology 76, 3178-3195.

Johnstone, R. A. (1997). The Evolution of Animal Signals. In Behavioural Ecology, eds. J. R. Krebs and N. B. Davies), pp. 155-178. Oxford: Oxford University Press.

Kandul, N., Lukhtanov, V., Dantchenko, A., Coleman, J., Sekercioglu, C., Haig, D. \& Pierce, N. (2004). Phylogeny of Agrodiaetus Hübner 1822 (Lepidoptera: Lycaenidae) Inferred from mtDNA Sequences of COI and COII and Nuclear Sequences of EF1 - $\alpha$ : Karyotype Diversification and Species Radiation. Systematic Biology 53, 278-298. 
Katoh, K. (2009). MAFFT, version 6.717b, http://align.bmr.kyushuu. ac.jp/mafft/software/.

Kawahara, A. Y., Mignault, A. A., Regier, J. C., Kitching, I. J. \& Mitter, C. (2009). Phylogeny and Biogeography of Hawkmoths (Lepidoptera: Sphingidae): Evidence from Five Nuclear Genes. PLoS ONE 4, e5719.

Kawahara, A. Y., Ohshima, I., Kawakita, A., Regier, J. C., Mitter, C., Cummings, M. P., Davis, D. R., Wagner, D. L., De Prins, J. \& Lopez-Vaamonde, C. (2011). Increased gene sampling strengthens support for higher-level groups within leafmining moths and relatives (Lepidoptera: Gracillariidae). BMC Evolutionary Biology 11, 182.

Krebs, J. R. \& Davies, N. B. (1993). An Introduction to Behavioural Ecology. Oxford: Blackwell Scientific Publications.

Krebs, J. R. \& Dawkins, R. (1984). Animal signals: mind-reading and manipulation. In Behavioural ecology: an evolutionary approach, eds. J. R. Krebs and N. B. Davies), pp. 380-402. Oxford: Blackwell Scientific Publications.

Kristensen, N. P., Scoble, M. J. \& Karsholt, O. (2007). Lepidoptera phylogeny and systematics: the state of inventorying moth and butterfly diversity. Zootaxa, 699 747.

Kuznetzov, V. I. \& Stekolnikov, A. A. (2001). New approaches to the system of Lepidoptera of World Fauna (on the base of the functional morphology of abdomen). Proceedings of the Zoological Institute of St Petersburg 282, 1-462.

Lewis, P. O. (2001). A likelihood approach to estimating phylogeny from morphological character data. Systematic Biology 50, 913-925.

Liao, F., Wang, L., Wu, S., Li, Y. P., Zhao, L., Huang, G. M., Niu, C. J., Liu, Y. Q. \& Li, M. G. (2010). The complete mitochondrial genome of the fall webworm, Hyphantria cunea (Lepidoptera: Arctiidae). International Journal of Biological Sciences 6, 172-186.

Lill, J. T., Marquis, R. J., Walker, M. A. \& Petersen, L. (2007). Ecological consequences of shelter sharing by leaf-tying caterpillars. Entomologia Experimentalis et Applicata 124, 45-53. 
Lorenz, K. Z. (1966). Evolution of ritualization in the biological and cultural spheres. Philosophical Transactions of the Royal Society of London. Series B, Biological Sciences 251, 273-284.

Maddison, W. P. \& Maddison, D. R. (2009). Mesquite: a modular system for evolutionary analysis version 2.71 . http://mesquiteproject.org

Markman, S., Hill, N., Todrank, J., Heth, G. \& Blaustein, L. (2009). Differential aggressiveness between fire salamander (Salamandra infraimmaculata) larvae covaries with their genetic similarity. Behavioral Ecology and Sociobiology 63, 1149-1155.

Martins, E. P., Labra, A., Halloy, M. \& Tolman Thompson, J. (2004). Large-scale patterns of signal evolution: and interspecific study of Liolaemus lizard headbob displays. Animal Behaviour 68, 453-463.

Maynard Smith, J. \& Harper, D. (2003). Animal Signals. Oxford: Oxford University Press.

Mezoff, S., Takesian, A. \& Trimmer, B. A. (2004). The biomechanical and neural control of hydrostatic limb movements in Manduca sexta. Journal of Experimental Biology 207, 3043-3053.

Minet, J. (1985). Définition d'un nouveau genre au seine des Drepanoidea paléarctiques (Lep. Drepanoidea). Entomologica Gallica 1, 291-304.

Minet, J. (1991). Tentative reconstruction of the Ditrysian phylogeny (Lepidoptera, Glossata). Entomologica Scandinavica 22, 69-95.

Minet, J. (2002). The Epicopeiidae: Phylogeny and a redefinition, with the description of new taxa (Lepidoptera: Drepanoidea). Annales de la Société Entomologique de France 38, 463-487.

Minet, J. \& Scoble, M. J. (1999). The Drepanoid/Geometroid Assemblage. In Handbook of Zoology: Lepidoptera, Moths and Butterflies Vol. 1: Evolution, Systematics and Biogeography, (ed. N. P. Kristensen), pp. 301-305. Berlin, Germany: Walter de Gruyter. 
Minet, J. \& Surlykke, A. (2003). Auditory and sound producing organs. In Handbook of Zoology, Vol. IV (Arthropoda: Insecta. Lepidoptera, Moths and Butterflies, Vol. 2), (ed. N. P. Kristensen), pp. 289-323. New York: Walter de Gruyter.

Minnich, D. E. (1936). The responses of caterpillars to sounds. Journal of Experimental Zoology 72, 439-453.

Monteiro, A. (2001). Phylogeny of Bicyclus (Lepidoptera: Nymphalidae) inferred from COI, COII, and EF-1 $\alpha$ gene sequences. Molecular Phylogenetics and Evolution 18, 264-281.

Morris, D. J. (1956). The feather postures of birds and the problem of the origin of social signals. Behaviour 11, 1-12.

Moulton, J. K. \& Wiegmann, B. M. (2004). Evolution and phylogenetic utility of CAD (rudimentary) among Mesozoic-aged Eremoneuran Diptera (Insecta). Molecular Phylogenetics and Evolution 31, 363-378.

Mutanen, M., Wahlberg, N. \& Kaila, L. (2010). Comprehensive gene and taxon coverage elucidates radiation patterns in moths and butterflies. Proceedings of the Royal Society B: Biological Sciences 277, 2839-2848.

Nakajima, H. (1970). A contribution to the knowledge of the immature stages of Drepanidae occuring in Japan. Tinea 8, 167-184 + 20 pls.

Nakajima, H. (1972). Additions to the knowledge of the immature stages of Drepanidae occurring in Japan (Lepidoptera). Tinea 9, 253-256 + 4 pls.

Nakamura, M. (1981). Key to the classification of the Japanese lepidopterous pupae. Tyo to Ga 32, 1-12.

Newman, E. (1884). An Illustrated Natural History of British Butterflies and Moths. Parts 1-2. London: W. H. Allen \& Co.

Okuda, T. (1989). Aggressive characteristics of diapausing larvae of a stem borer, Busseola fusca Fuller (Lepidoptera: Noctuidae) in artificially crowded conditions. Applied Entomology and Zoology 24, 238-239. 
Packard, A. S. (1890). The life-history of Drepana arcuata, with remarks on certain structural features of the larvae and on the supposed dimorphism of Drepana arcuata and Dryopteris rosea. Boston Society of Natural History 24, 482-493.

Pagel, M. D. \& Meade, A. (2006). Bayesian analysis of correlated evolution of discrete characters by reversible-jump Markov chain Monte Carlo. American Naturalist 6, 808-825.

Pashley, D. P. \& Ke, L. D. (1992). Sequence evolution in mitochondrial ribosomal and ND-1 genes in Lepidoptera: Implications for phylogenetic analyses. Molecular Biology and Evolution 9, 1061-1075.

Patek, S. N. \& Oakley, T. H. (2003). Comparative tests of evolutionary trade-offs in a palinurid lobster acoustic system. Evolution 57, 2082-2100.

Pescador-Rubio, A., Stanford-Camargo, S. G., Páez-Gerardo, L. E., Ramírez-Reyes, A. J., Ibarra-Jiménez, R. A. \& Fitzgerald, T. D. (2011). Trail marking by caterpillars of the silverspot butterfly Dione juno huascuma. Journal of Insect Science 11, 55.

Pierce, N. E., Braby, M. F., Heath, A., Lohman, D. J., Mathew, J., Rand, D. B. \& Travassos, M. A. (2002). The ecology and evolution of ant association in the Lycaenidae (Lepidoptera). Annual Review of Entomology 47, 733-771.

Posada, D. \& Crandall, K. A. (1998). Modeltest: testing the model of DNA substitution. Bioinformatics 19, 1572-1574.

Randall, J. A. (2001). Evolution and function of drumming as communication in mammals. American Zoologist 41, 1143-1156.

Reed, E. B. (1868). A musical larva. Canadian Entomologist 1, 40.

Regier, J. C. (2008). Protocols, Concepts, and Reagents for preparing DNA sequencing templates, version 12/04/08, www.umbi.umd.edu/users/jcrlab/PCR primers.pdf.

Regier, J. C., Zwick, A., Cummings, M. P., Kawahara, A. Y., Cho, S., Weller, S., Roe, A., Baixeras, J., Brown, J. W., Parr, C., Davis, D. R., Epstein, M., Hallwachs, W., Hausmann, A., Janzen, D. H., Kitching, I. J., Solis, M. A., Yen, S.-H., Bazinet, A. L. \& Mitter, C. (2009). Toward reconstructing the evolution of advanced moths 
and butterflies (Lepidoptera: Ditrysia): an initial molecular study. $B M C$ Evolutionary Biology 9, 280.

Riegler, K. (1999). Thyatiridae - Thyatiridés. In Les Papillons et leur Biotopes: Espèces; Danger qui les menacent; Protection. Suisse et regions limitrophe, vol. 2 (ed. L. S. p. 1. P. d. 1. Nature), pp. 477-504. Switzerland: Pro Natura.

Röhrig, A., Kirchner, W. H. \& Leuthold, R. H. (1999). Vibrational alarm communication in the African fungus-growing termite genus Macrotermes (Isoptera, Termitidae). Insectes Sociaux 46, 71-77.

Ronquist, F. \& Huelsenbeck, J. P. (2003). MrBayes 3: Bayesian phylogenetic inference under mixed models. Bioinformatics 19, 1572-1574.

Rosengaus, R. B., Jordan, C., Lefebvre, M. L. \& Traniello, J. F. A. (1999). Pathogen alarm behavior in a termite: a new form of communication in social insects. Naturwissenschaften 86, 544-548.

Ruf, C., Costa, J. T. \& Fiedler, K. (2001). Trail-based communication in social caterpillars of Eriogaster lanestris (Lepidoptera: Lasiocampidae). Journal of Insect Behavior 14, 231-245.

Ruggiero, M. A. \& Merchant, H. C. (1986). Estimated energy budget for a population of eastern tent caterpillars (Lepidoptera: Lasiocampidae) in Maryland. Environmental Entomology 15, 795-799.

Rumph, J. A. \& Turner, W. J. (1998). Alternative to critical point drying for soft-bodied insect larva. Annals of the Entomological Society of America 91, 693-699.

Russ, K. (1969). Beiträge zum territorialverhalten der raupen des springwurmwicklers, Sparganothis pilleriana Schiff (Lepidoptera: Tortricidae). Pflanzenschutzberichte 40, 1-9.

Sanborn, F. G. (1868). Musical larvae. Canadian Entomologist 1, 48.

Schenkel, R. (1956). Deutung der Balzleistungen einiger Phasianiden und Tetraoniden. Ornithologischer Beobachter 53, 182-201. 
Scoble, M. J. (1992). The Lepidoptera, Form, Function and Diversity. Oxford, UK: Oxford University Press.

Scott-Phillips, T. C. (2008). Defining biological communication. Journal of Evolutionary Biology 21, 387-395.

Sen, Y. C. \& Lin, C. S. (2002). Larval morphology and host plants of Drepanidea (Lepidoptera: Drepanidae) in Southern Taiwan. Formosan Entomologist 22, 27 42.

Skou, P. (1986). The Geometroid Moths of North Europe (Lepidoptera, Drepanidae and Geometridae). Copenhagen, Denmark: E. J. Brill/Scandinavian Science Press.

Smetacek, P. (2002). Notes on new records of hooktip moths, Lepidoptera: Drepanidae, from the Kumaon and Garhwal Himalaya. Bombay Natural History Society 99, 446-454.

Smith, C. \& Evans, C. (2011). Exaggeration of display characteristics enhances detection of visual signals. Behaviour 148, 287-305.

Solis, M. A. \& Styer, L. (2003). Revision and phylogenetic analysis of Accinctapubes solis (Pyralidae: Epipaschiinae) with a larval description of an avocado-feeding species. Journal of the Lepidopterists' Society 57, 121-136.

Stamp, N. E. \& Casey, T. M. (1993). Caterpillars: Ecological and Evolutionary Constraints on Foraging. New York: Chapman and Hall.

Stehr, F. W. (1987). Order Lepidoptera. In Immature Insects, (ed. F. W. Stehr), pp. 288596. Dubuque, Iowa: Kendall/Hunt Publishing Company.

Stokoe, W. J., Stovin, G. H. T. \& South, R. (1948). The Caterpillars of British Moths: Including Eggs, Chrysalids and Food-Plants. London: Warne.

Symonds, M. R. E., Moussalli, A. \& Elgar, M. A. (2009). The evolution of sex pheromones in an ecologically diverse genus of flies. Biological Journal of the Linnean Society 97, 594-603. 
Tautz, C. \& Markl, H. (1978). Caterpillars detect flying wasps by hairs sensitive to airborne vibration. Behavioral Ecology and Sociobiology 4, 101-110.

Tautz, D., Hancock, J. M., Webb, D. A., Tautz, C. \& Dover, G. A. (1988). Complete sequences of the ribosomal-RNA genes of Drosophila melanogaster. Molecular Biology and Evolution 5, 366-376.

Taylor, C. (2009). Hearing in larvae of the monarch butterfly, Danaus plexippus, and selected other Lepidoptera, vol. M.Sc. Thesis. Ottawa, Canada: Carleton University.

Theakston, S. W. (1866). Theakston's Guide to Scarborough. Scarborough: S. W. Theakston.

Tinbergen, N. (1952). Derived activities: their causation, biological significance, origin and emancipation during evolution. Quarterly Review of Biology 27, 1-32.

Tinbergen, N. (1959). Comparative studies of the behaviour of gulls (Laridae): A progress report. Behaviour 15, 1-70.

Travassos, M. A. \& Pierce, N. E. (2000). Acoustics, context and function of vibrational signaling in a lycaenid butterfly-ant mutualism. Animal Behaviour 60, $13-26$.

Virant-Doberlet, M. \& Cokl, A. (2004). Vibrational communication in insects. Neotropical Entomology 33, 121-134.

Wagner, D. L. (2005). Caterpillars of Eastern North America. Princeton, New Jersey: Princeton Univerisity Press.

Wahlberg, N. (2003). Morphology versus molecules: resolution of the positions of Nymphalis, Polygonia, and related genera (Lepidoptera: Nymphalidae). Cladistics 19, 213-223.

Warrant, E., Kelber, A. \& Kristensen, A. (2003). Visual organs. In Lepidoptera: Moths and Butterflies Vol. 2: Morphology, Physiology and Development, (ed. N. P. Kristensen), pp. 325-359. Germany: Walter de Gruyter. 
Watson, A. (1965). A revision of the Ethiopian Drepanidae (Lepidoptera). Bulletin of the British Museum (Natural History: Entomology) Supplement 3, 1-178.

Watson, A. (1967). A survey of the extra-Ethiopian Oretinae (Lepidoptera: Drepanidae). Bulletin of the British Museum (Natural History: Entomology) 19, 149-221.

Weiss, H., Friedrich, T., Hofhaus, G. \& Preis, D. (1991). The respiratory-chain NADH dehydrogenase (complex-I) of mitochondria. European Journal of Biochemistry 197, 563-576.

Weller, S. J., Jacobson, N. L. \& Connor, W. E. (1999). The evolution of chemical defences and mating systems in tiger moths (Lepidoptera: Artiidae). Biological Journal of the Linnean Society 68, 557-578.

Weller, S. J. \& Pashley, D. P. (1995). In search of butterfly origins. Molecular Phylogenetics and Evolution 4, 235-246.

Weller, S. J., Pashley, D. P., Martin, J. A. \& Constable, J. L. (1994). Phylogeny of noctuoid moths and the utility of combining independent nuclear and mitochondrial genes. Systematic Biology 43, 194-211.

Weyh, R. \& Maschwitz, U. (1982). Individual trail marking by larvae of the scarce swallowtail Iphiclides podalirius L. (Lepidoptera; Papilionidae). Oecologia 52, 415-416.

White, T. R., Weaver, J. S. \& Agee, H. R. (1983). Response of Cerura borealis (Lepidoptera: Notodontidae) larvae to low-frequency sound. Annals of the Entomological Society of America 76, 1-5.

Wigenbusch, J. C., Warren, D. L. \& Swofford, D. L. (2004). AWTY: a system for graphical exploration of MCMC convergence in Bayesian phylogenetic inference, http://king2.scs.fsu.edu/CEBProjects/awty/awty start.php.

Wiley, R. H. (1983). The evolution of communication: information and manipulation. In Communication, eds. T. R. Halliday and P. J. B. Slater), pp. 82-113. Oxford: Blackwell.

Wilkinson, C. (1972). The Drepanidae of Nepal (Lepidoptera). Khumbu Himal, Ergebn. Forsch. Unternehmens Nepal Himalaya 4, 157-332. 
Wu, C. G., Han, H. X. \& Xue, D. Y. (2009). A pilot study on the molecular phylogeny of Drepanoidea (Insecta: Lepidoptera) inferred from the nuclear gene EF-1 $\alpha$ and the mitochondrial gene COI. Bulletin of Entomological Research 100, 207.

Yack, J. E., Smith, M. L. \& Weatherhead, P. J. (2001). Caterpillar talk: Acoustically mediated territoriality in larval Lepidoptera. Proceedings of the National Academy of Sciences 98, 11371-11375.

Yen, S.-H., Mu, J.-H. \& Jean, J.-L. (1995). The life histories and biology of Epicopeiidae of Taiwan. Transactions of the Lepidopterological Society of Japan 46, 175-184.

Zakharov, E., Caterino, M. \& Sperling, F. (2004). Molecular Phylogeny, Historical Biogeography, and Divergence Time Estimates for Swallowtail Butterflies of the Genus Papilio (Lepidoptera: Papilionidae). Systematic Biology 53, 193-215.

Zhu, H. F. \& Wang, L. Y. (1991). Fauna Sinica Insecta Vol. 3. Lepidoptera: Cyclidiidae, Drepanidae. Beijing, China: Science Press. 


\section{APPENDIX A: GeNERAL Life-History, MORPHOLOGY AND BeHAVIOUR of Additional Drepanidae Species}

This appendix presents information on the general life-history, morphological and behavioural characters of other species that I was able to study during the course of my thesis. Information from this appendix was used to test hypotheses related to the origin of signalling (Chapters 4 and 5), to help begin to answer ultimate questions on the evolution of signalling in the Drepanidae, and to provide general information on vibratory signalling in caterpillars.

\section{Live specimens}

Drepana curvatula (Drepaninae)

General life history observations relevant to conspecific interactions

Previous observations (summarized in Table 2.2) have shown that adult females of the dusky hook-tip moth, Drepana curvatula Borkhausen 1790 (Fig. A.1a) oviposit eggs in rows, where the eggs are touching and covered with scales or hairs from the female, with up to a dozen eggs in a row (Bryner, 1999; Fig. A.1b). Eggs are oviposited on species of birch (Betula spp.), alder (Alnus spp.), and sometimes oak (Quercus spp.) or willow (Salux spp.; Bryner, 1999). Early instars live in small leaf shelters either solitarily or in small groups (Bryner, 1999; Fig. A.1c,d). Late instars live solitarily in shelters made by rolling the leaf and securing it with 2 or 3 strands of silk (Bryner, 1999; Fig. A.le,f). 
Fig. A.1. Photographs demonstrating life-history characteristics relevant to territorial behaviour in the dusky hook-tip moth, Drepana curvatula. (a) Dorsal view of an adult moth in resting position (scale $=$ unknown; photo credit: www.leps.nl). (b) Group of early instar caterpillars on a skeletonized feeding spot (scale = unknown; photo credit: www.leps.nl). (c) Lateral view of a late instar caterpillar (scale bar $=5 \mathrm{~mm}$; photo credit: J. Yack). (f) Late instar caterpillar in a folded leaf-shelter (scale bar $=2.5 \mathrm{~cm}$; photo credit: J. Yack). 


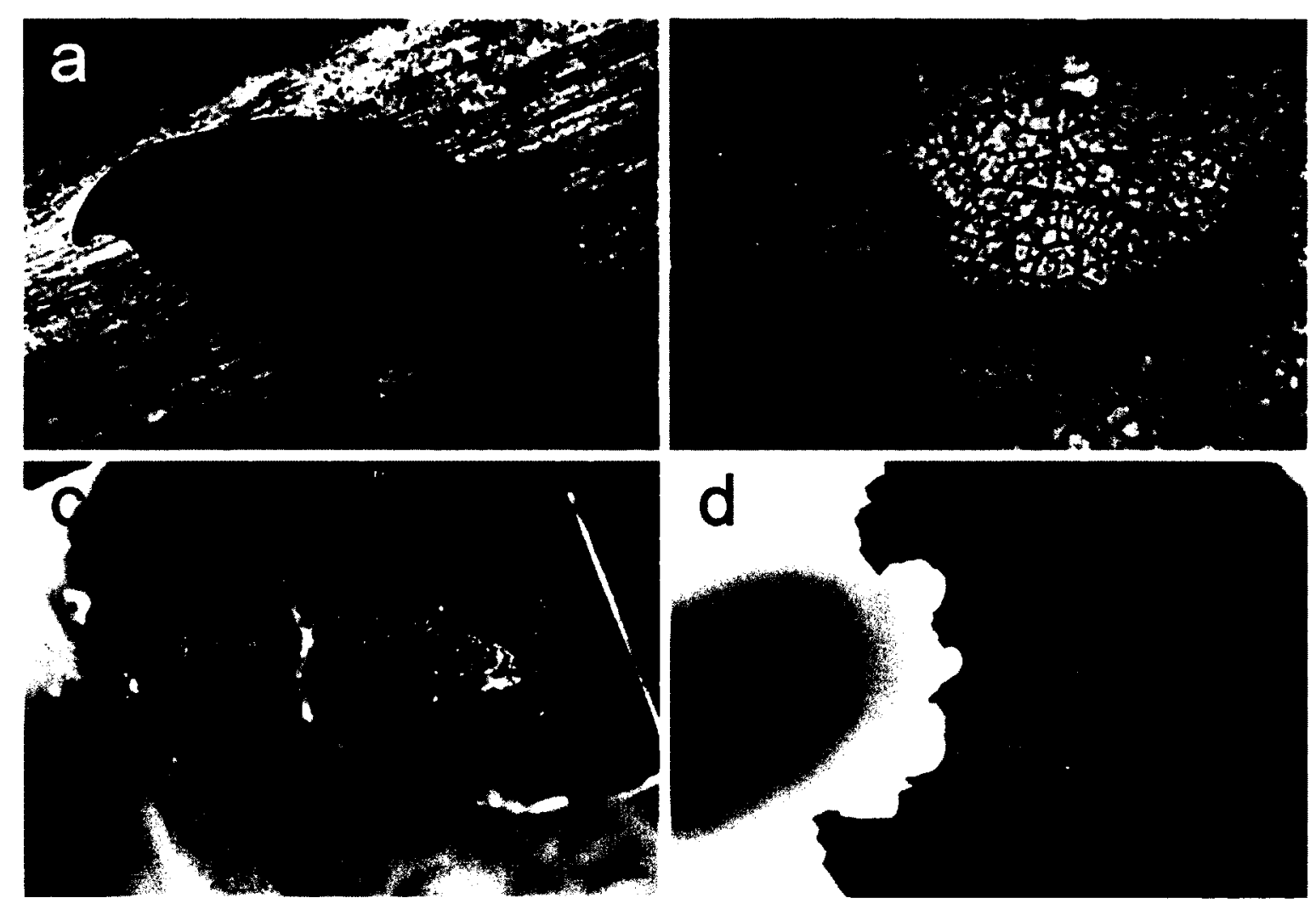


Morphology

The head capsule of late instar larvae is not flattened dorsally (Fig. A.2a,b). Mandibles have four rounded distal teeth on the incisor area and no ridges on the oral surface (Fig. A.2c). The abdominal prolegs (excluding the anal prolegs) bear three setae on the outer planta region, where SV1 and SV3 are modified (Fig. A.2d,e). Larvae do not possess prolegs on the terminal abdominal segment and the anal segment has a short fleshy caudal projection (Fig. A.2a,f,g). Larvae possess a modified PP1 seta on the anal segment, and no other modified setae on this segment (Fig. A.2f,g). Morphological characters are summarized in Table 2.3 .

Behavioural trials between conspecifics

Details on encounters with conspecifics are summarized in Table 2.4. A total of 11 encounters were staged between a resident and an intruder of similar size. Residents produced five types of behaviours during encounters, including mandible scraping, mandible drumming, anal scraping, buzzing, and lateral head hitting (Fig. A.3). Residents won $60.0 \%$ of the trials, intruders won $0 \%$ and $40.0 \%$ of the trials were ties. Residents were silent until they detected an intruder, and signaled at a latency of $84.1 \pm 131.7 \mathrm{~s}(n=$ 9) from the beginning of the trial (Fig. A.3a). The rate of resident behaviours, including mandible scraping, anal scraping and buzzing changed significantly as the intruder approached the resident (Fig. A.3b; see Table A.1 for details). Intruders signaled first in 2 out of the 11 trials, and signaled in all but 3 trials. 
Fig A.2. Morphological characters related to territorial behaviour in Drepana curvatula. (a) Lateral view of the whole caterpillar (scale bar $=1 \mathrm{~mm}$ ). (b) Anterior view of the head capsule (scale bar $=1 \mathrm{~mm}$ ). (c) SEMs of lateral and ventral (inset) views of the mandibles (scale bars $=200 \mu \mathrm{m}$ ). (d) Drawing of a lateral view of the proleg on the third abdominal segment (A3) (e) SEM of a lateral view of the proleg on A3 (scale bar $=0.5$ $\mathrm{mm}$ ). (f) Drawing of a lateral view the terminal abdominal segment (A10) with named setae. (g) SEM of a posterior view of A10 showing the location of the PP1 seta (arrow) $($ scale bar $=0.5 \mathrm{~mm})$ with a close-up of the PP1 seta $($ inset; arrow $)($ scale bar $=100 \mu \mathrm{m})$. 


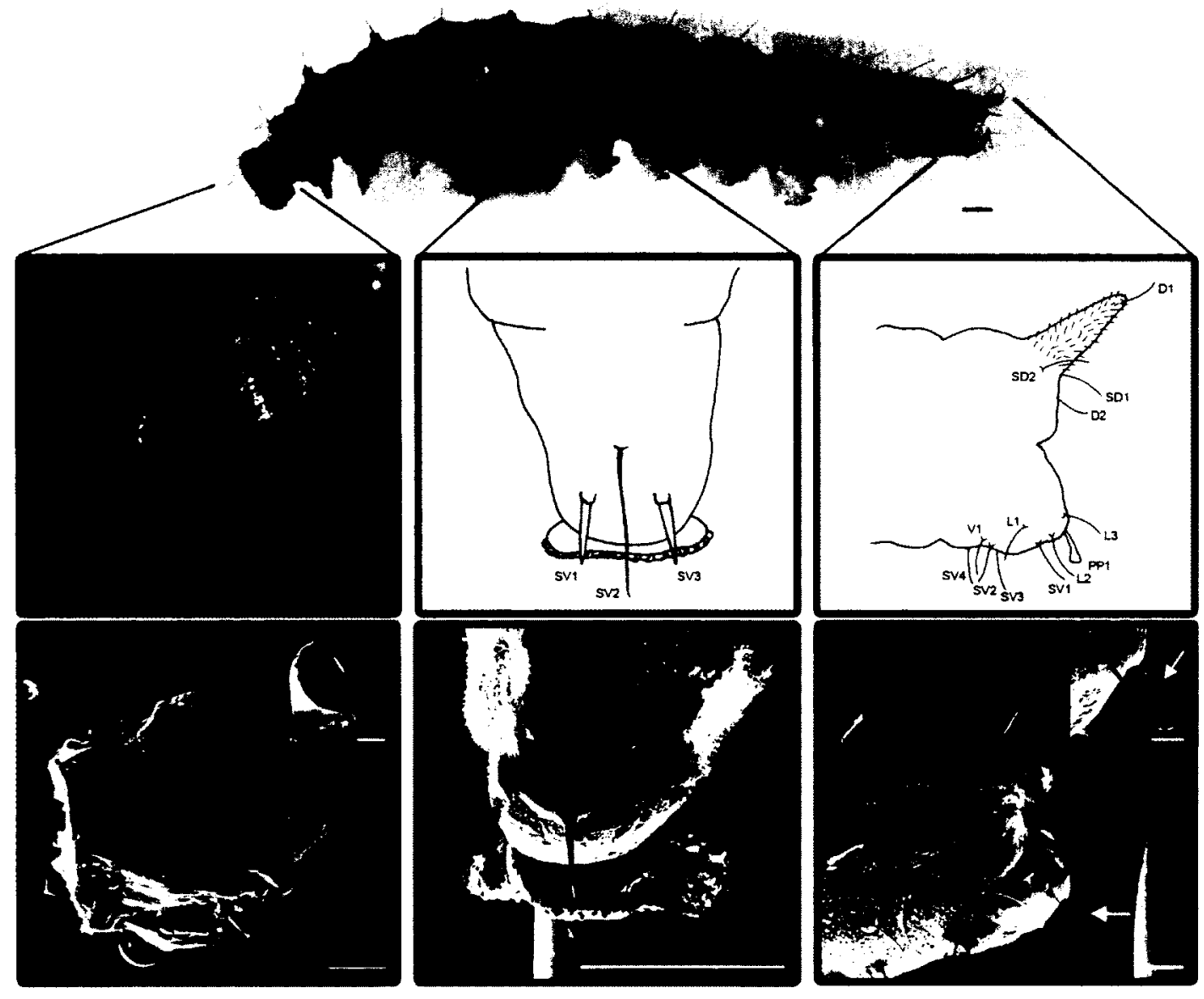


Fig. A.3. Vibration characteristics and territorial behaviour in Drepana curvatula. (a) Laser trace of an entire behavioural trial with corresponding video frames below. Numbers correspond in both the trace and the video frames, illustrating the approach of the intruder $(1=$ FAR, $2=$ MID, $3=$ CLOSE, $4=$ Intruder leaves, $F=$ First resident signal; scale bar $=1.5 \mathrm{~cm}$ ). (b) Laser vibrometer trace illustrating a series of bouts, with an enlargement of single bout and corresponding spectrogram below. Power spectra demonstrating the dominant frequencies of each vibration (right panel) (c) Mean (+SD) behavioural rates of residents at three stages of intruder approach (FAR, MID, CLOSE). Asterisks denote significant differences within each behaviour at different stages of intruder approach. All colours throughout the figure correspond to those in the box describing territorial behaviours. 

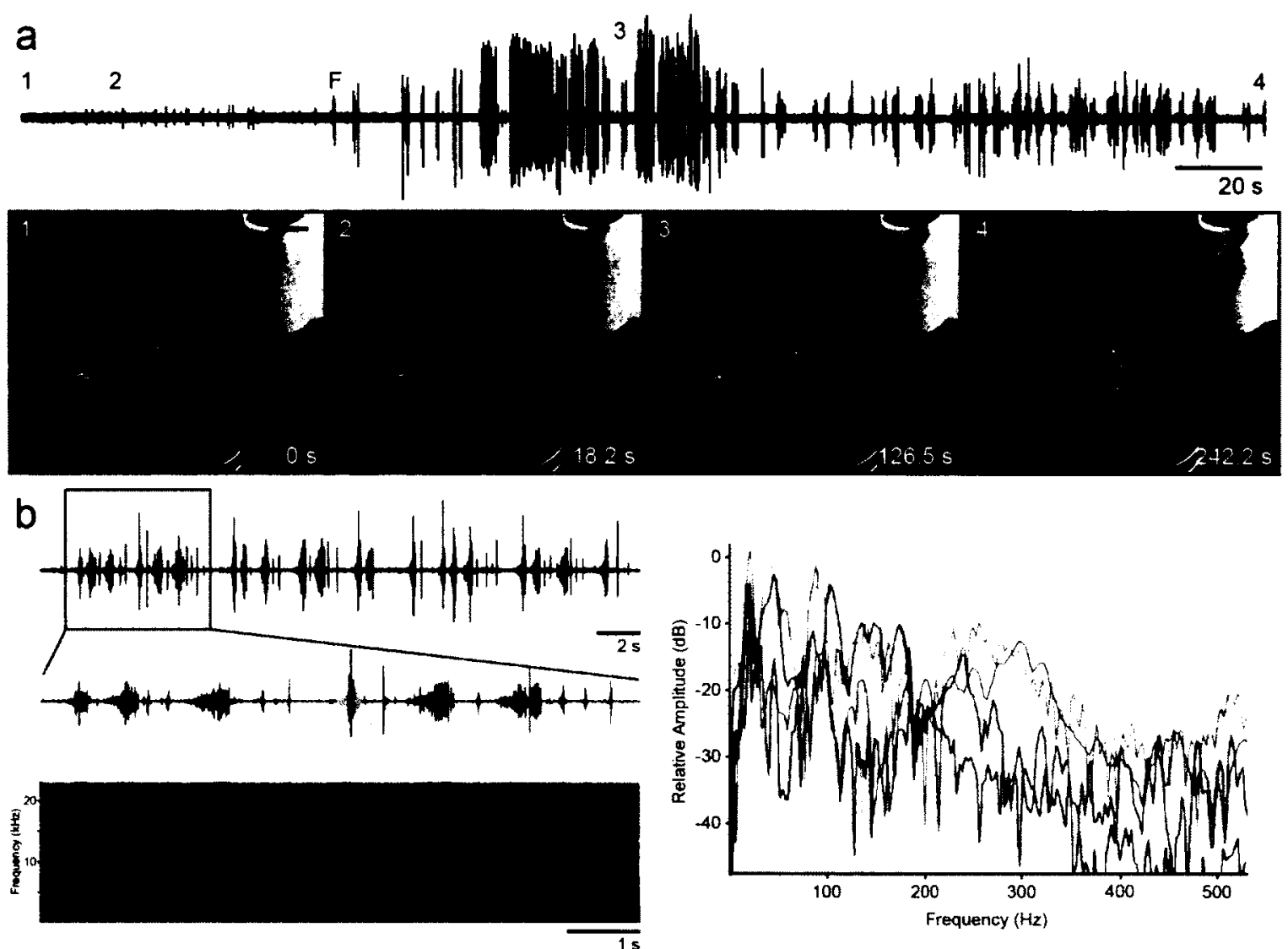

C
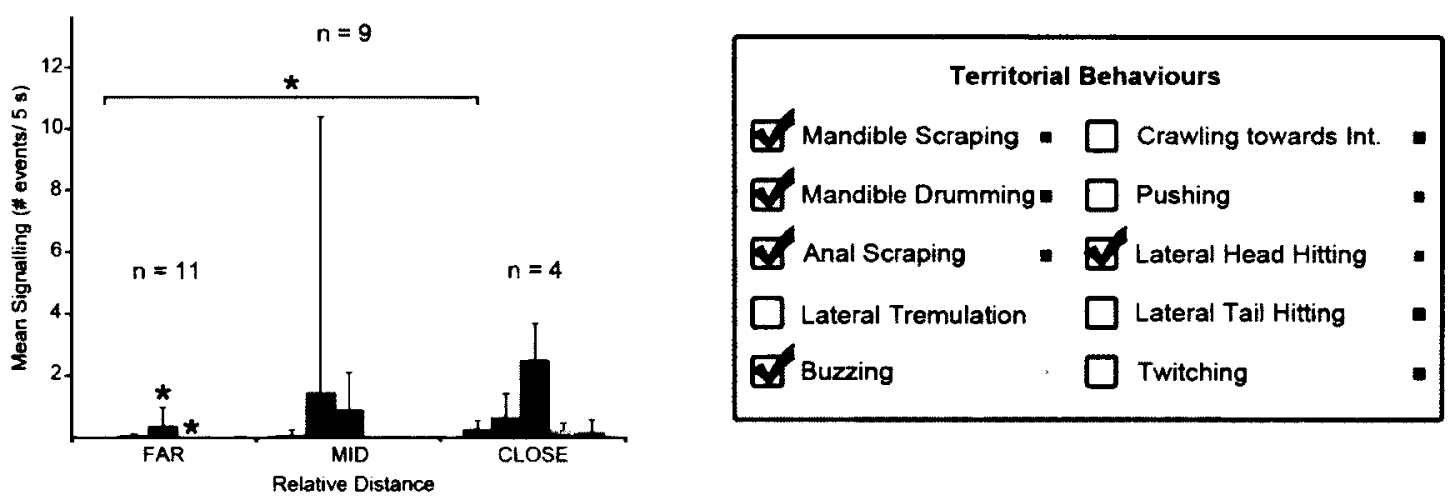
Analysis of vibrations

Vibrations are associated with five behaviours in late instar larvae during conspecific interactions - mandible scraping, mandible drumming, anal scraping, buzzing, and lateral head hitting (Fig. A.3c). Details on temporal and spectral characteristics of vibrations are summarized in Tables A.1. Vibrations and movements were similar to those described in other species in Chapter 2.

\section{Drepana falcataria (Drepaninae)}

General life history observations relevant to conspecific interactions

Previous observations (summarized in Table 2.2) have shown that adult females of the pebble hook-tip moth, Drepana falcataria Linnaeus 1758 (Fig. A.4a) in rows, on species of birch, alder, oak, willow or poplar (Bryner, 1999; Fig. A.4b). Upon hatching, early instars live solitarily or in small groups in shelters made by rolling leaves and sealing them with silk (Bryner, 1999; Fig. A.4c,d). Late instars live solitarily in more open shelters, secured with only a few threads of silk (Bryner, 1999; Fig. A.4e,f). When disturbed, larvae produce a "tic-tac" noise by drumming with their head and thorax against the side of their nest (Bryner, 1999).

\section{Morphology}

The head capsule of late instar larvae is not flattened dorsally (Fig. A.5a,b). Mandibles have five distal teeth on the incisor area and two ridges on the oral surface (Fig. A.5c). The abdominal prolegs (excluding the anal prolegs) bear three setae on the outer planta region, where SV1 and SV3 are modified (Fig. A.5d,e). Larvae do not 
Fig A.4. Photographs demonstrating life-history characteristics relevant to territorial behaviour in the pebble hook-tip moth, Drepana falcataria. (a) Lateral view of an adult moth in resting position (scale bar $=2 \mathrm{~cm}$ ). (b) Eggs covered in scales laid in a small group (scale bar $=2 \mathrm{~mm}$ ). (c) Dorsal view of an early instar larvae (scale bar $=4 \mathrm{~mm})$. (d) Solitary early instar caterpillar in a leaf shelter (scale bar $=3 \mathrm{~mm}$ ). (e) Lateral view of a late instar caterpillar (scale bar $=5 \mathrm{~mm}$ ). (f) Late instar caterpillar in a rolled leaf shelter $($ scale bar $=1.5 \mathrm{~cm})$. 


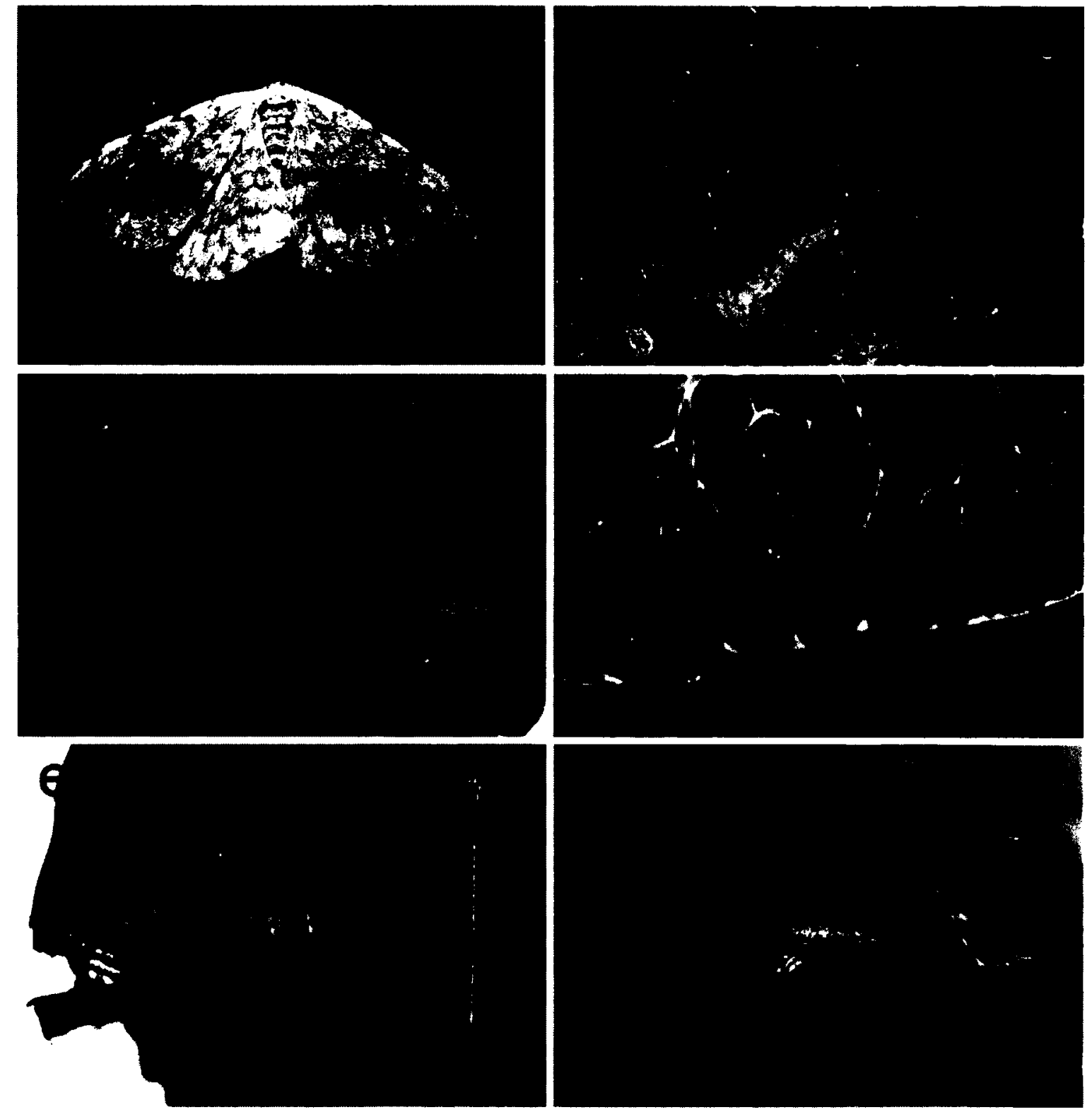


Fig. A.5. Morphological characters related to territorial behaviour in Drepana falcataria. (a) Lateral view of the whole caterpillar (scale bar $=1 \mathrm{~mm}$ ). (b) Anterior view of the head capsule (scale bar $=0.5 \mathrm{~mm}$ ). (c) SEMs of lateral and ventral (inset) views of the mandibles (scale bars $=100 \mu \mathrm{m}$ ). (d) Drawing of a lateral view of the proleg on the third abdominal segment (A3) (e) SEM of a lateral view of the proleg on A3 (scale bar $=200$ $\mu \mathrm{m}$; photo credit: T. Nevills). (f) Drawing of a lateral view the terminal abdominal segment (A10) with named setae. (g) SEM of a posterior view of A10 showing the location of the PP1 seta (arrow) with a close-up of the PP1 seta (inset; arrow) (scale bars $=100 \mu \mathrm{m})$. 


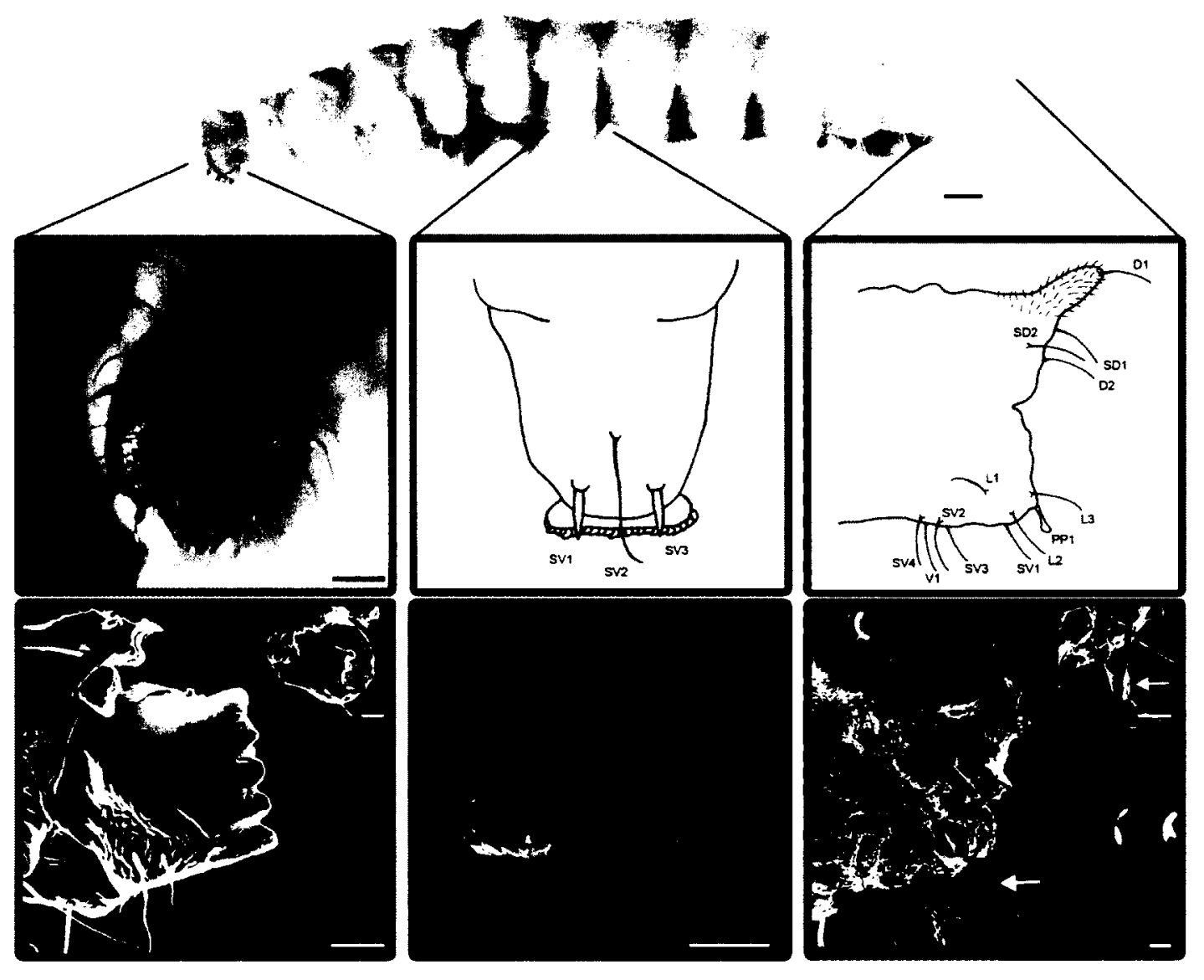


possess prolegs on the terminal abdominal segment and the anal segment has a short fleshy caudal projection (Fig. A.5a,f,g). Larvae possess a modified PP1 seta on the anal segment, and no other modified setae on this segment (Fig. A.5f,g). Morphological characters are summarized in Table 2.3 .

Behavioural trials between conspecifics

Details on encounters with conspecifics are summarized in Table 2.4. A total of 3 encounters were staged between a resident and an intruder of similar size. Residents produced five types of behaviours during encounters, including mandible scraping, mandible drumming, anal scraping, buzzing, and lateral head hitting (Fig. A.6). Residents won $100 \%$ of the trials and were silent until they detected an intruder (Fig. A.6a). The rate of resident behaviours, including mandible scraping, mandible drumming, anal scraping and buzzing changed as the intruder approached the resident, however none of these changes were significant (Fig. A.6b; see Table A.1 for details). Intruders signaled in one of the three trials.

\section{Analysis of vibrations}

Vibrations are associated with five behaviours in late instar larvae during conspecific interactions - mandible scraping, mandible drumming, anal scraping, buzzing, and lateral head hitting (Fig. A.6c). Details on temporal and spectral characteristics of vibrations are summarized in Table A.1. Vibrations and movements were similar to those described in other species in Chapter 2. 
Fig. A.6. Vibration characteristics and territorial behaviour in Drepana falcataria. (a) Laser trace of an entire behavioural trial with corresponding video frames below. Numbers correspond in both the trace and the video frames, illustrating the approach of the intruder $(1=$ FAR, $2=$ MID, $3=$ CLOSE, $4=$ Intruder leaves, $F=$ First resident signal; scale bar $=1.5 \mathrm{~mm}$ ). (b) Laser vibrometer trace illustrating a series of bouts, with an enlargement of single bout and corresponding spectrogram below. Power spectra demonstrating the dominant frequencies of each vibration (right panel) (c) Mean (+SD) behavioural rates of residents at three stages of intruder approach (FAR, MID, CLOSE). Asterisks denote significant differences within each behaviour at different stages of intruder approach. All colours throughout the figure correspond to those in the box describing territorial behaviours. 

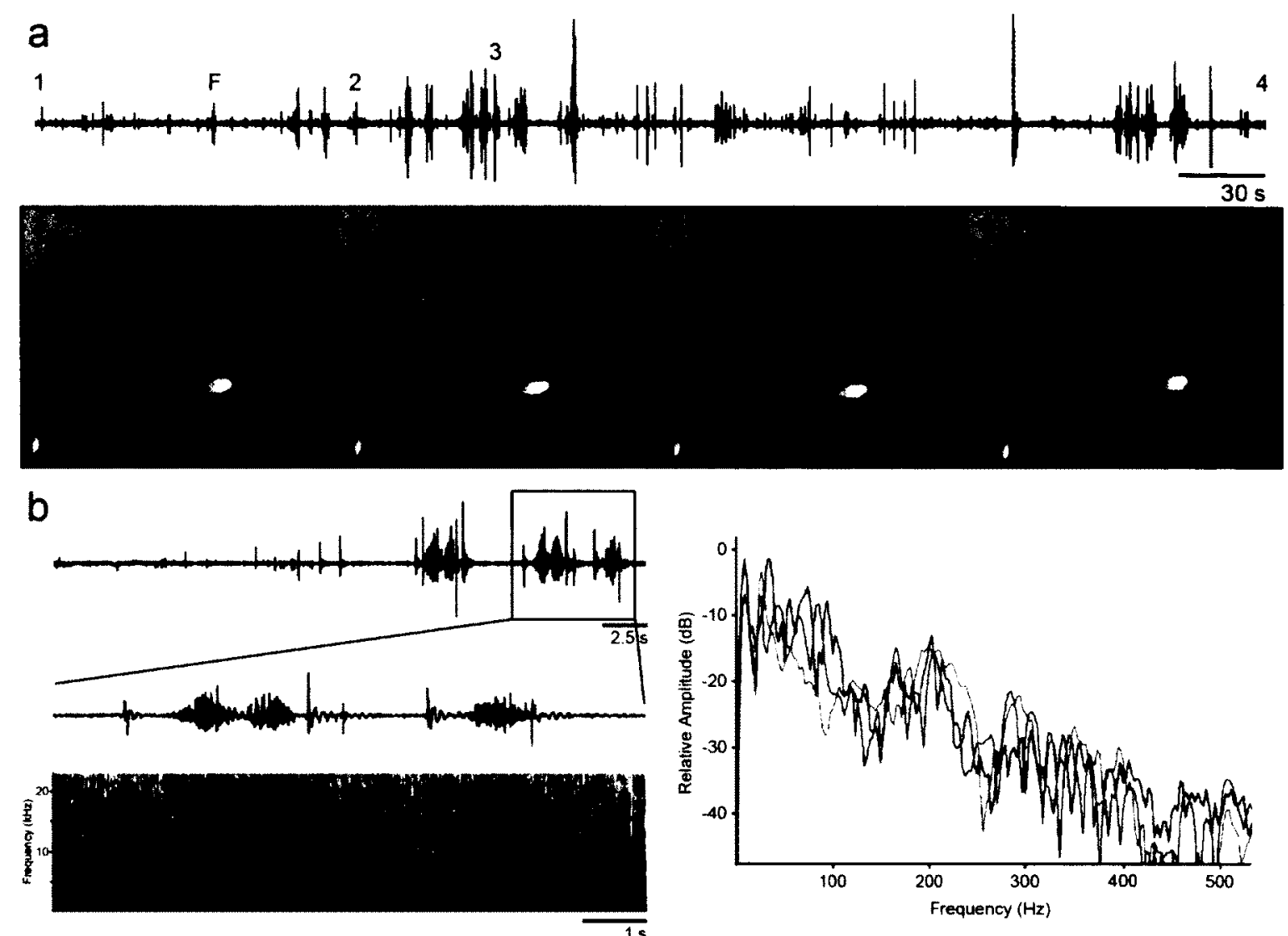

C
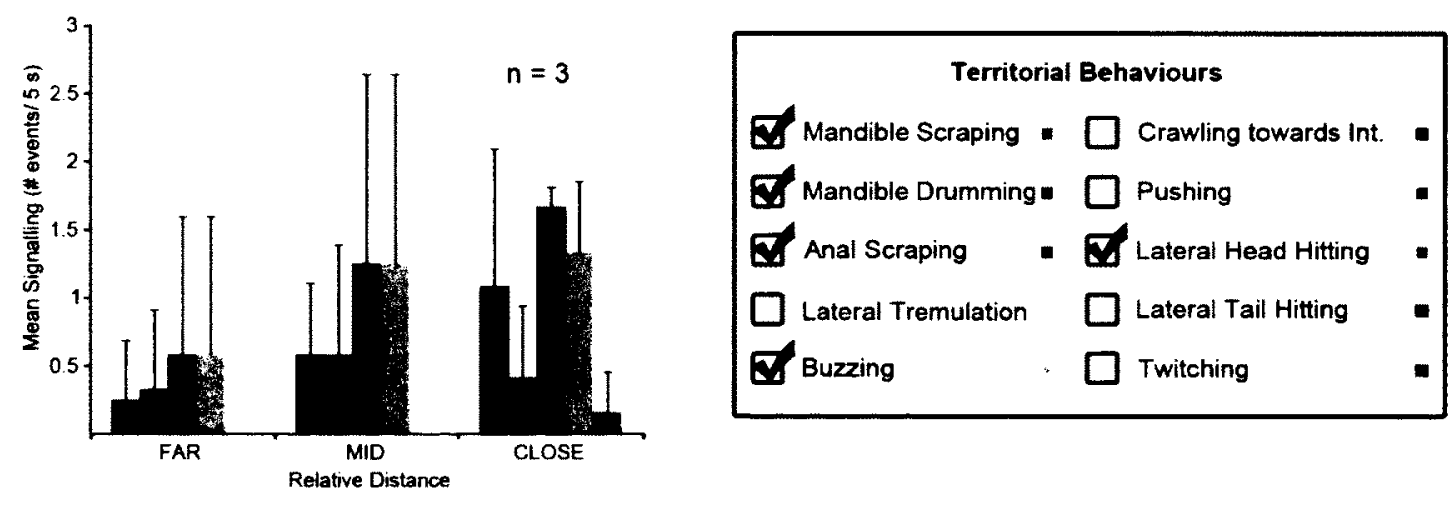
Falcaria bilineata (Drepaninae)

General life history observations relevant to conspecific interactions

Personal observations (summarized in Table 2.2) have shown that adult females of the two-lined hooktip moth, Falcaria bilineata Packard 1864 (Fig. A.7a) lay eggs in rows of $2-10$ on the upper leaf surface or on small twigs adjacent to a leaf (Fig. A.7b). Eggs are oviposited on species of birch (Betula spp.) or alder (Alnus spp). First and second instars occupy individual feeding regions at leaf edges where they skeletonize the upper leaf surface (Fig. A.7c,d). Late instars live solitarily on a silk mat (Fig. A.7e,f).

Morphology

The head capsule of late instar larvae is not flattened dorsally (Fig. A.8a,b). Mandibles have three distal teeth on the incisor area and two ridges on the oral surface (Fig. A.8c). The abdominal prolegs (excluding the anal prolegs) bear three setae on the outer planta region, where SV1 and SV3 are modified (Fig. A.8d,e). Larvae do not possess prolegs on the terminal abdominal segment and possess a short, fleshy caudal projection (Fig. A.8a,f,g). Larvae possess modified PP1 setae on the anal segment, and no other modified setae on this segment (Fig. A.8f,g). Morphological characters are summarized in Table 2.3 .

Behavioural trials between conspecifics

Details on encounters with conspecifics are summarized in Table 2.4. A total of 53 encounters were staged between a resident and an intruder of similar size. Residents produced four types of behaviours during encounters, including mandible drumming, anal 
Fig A.7. Photographs demonstrating life-history characteristics relevant to territorial behaviour in the two-lined hook-tip moth, Falcaria bilineata. (a) Lateral view of an adult moth in resting position (scale bar $=3 \mathrm{~mm}$; photo credit: J. Yack). (b) Row of eggs laid on a twig of Betula papyrifera (scale bar $=4 \mathrm{~mm}$; photo credit: J. Yack). (c) Dorsal view of an early instar larvae (scale bar $=2 \mathrm{~mm}$; photo credit: J. Yack). (d) Whole leaf view of a solitary early instar caterpillar on a skeletonized feeding spot (scale bar $=1 \mathrm{~cm}$; photo credit: S. Matheson). (e) Lateral view of a late instar caterpillar in resting position (scale bar $=2 \mathrm{~mm}$; photo credit: J. Yack). (f) Late instar caterpillar on a mat of silk (scale bar $=$ $2.5 \mathrm{~mm}$; photo credit: J. Yack). 


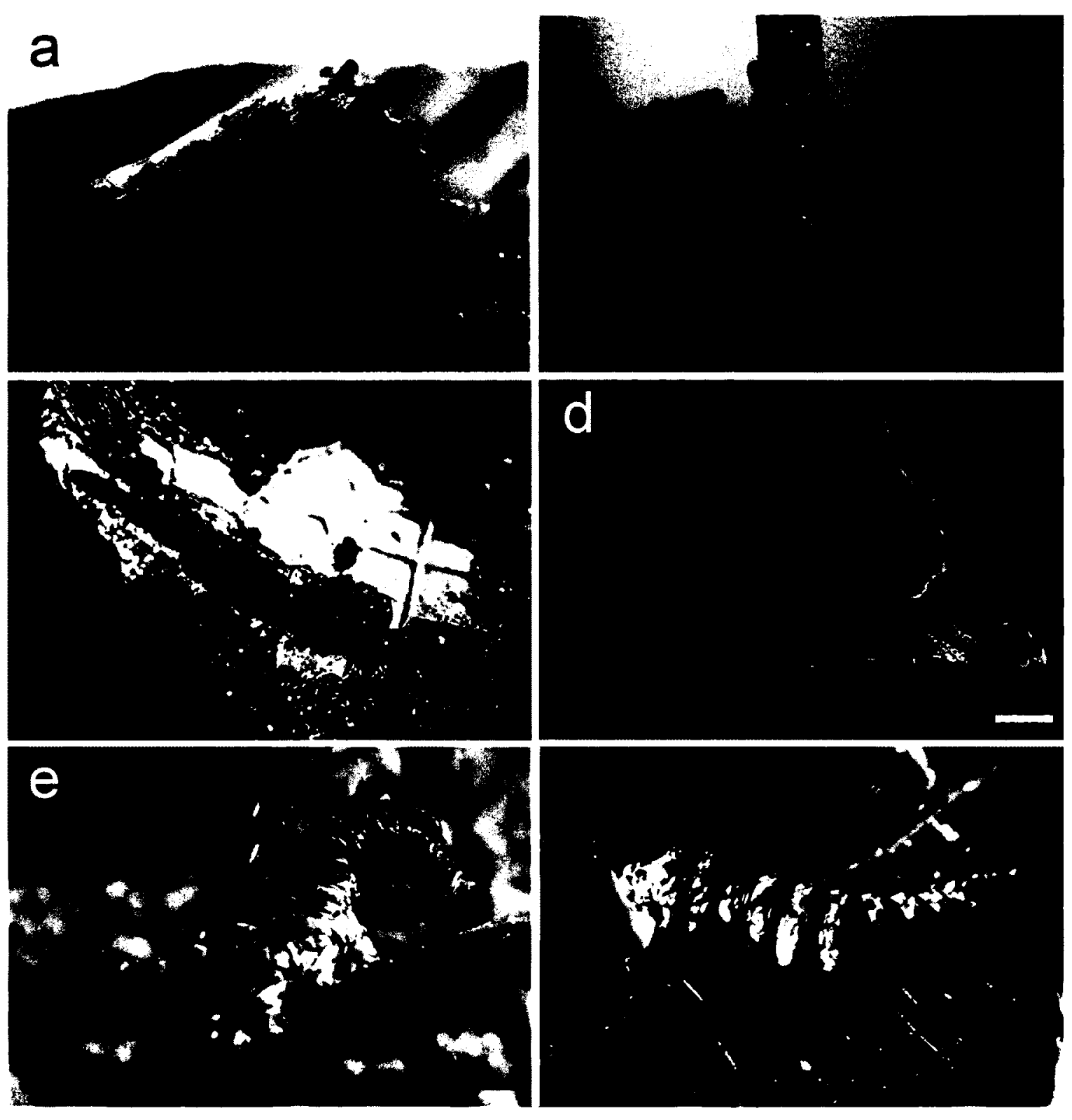


Fig. A.8. Morphological characters related to territorial behaviour in Falcaria bilineata. (a) Lateral view of the whole caterpillar. (b) Anterior view of the head capsule (scale bar $=1 \mathrm{~mm}$ ). (c) SEMs of lateral and ventral (inset) views of the mandibles (scale bars $=100$ $\mu \mathrm{m}$; photo credits: J. Yack). (d) Drawing of a lateral view of the proleg on the third abdominal segment (A3) (e) SEM of a lateral view of the proleg on A3 (scale bar $=100$ $\mu \mathrm{m}$ ). (f) Drawing of a lateral view the terminal abdominal segment (A10) with named setae. (g) SEM of a posterior view of A10 showing the location of the PP1 seta (arrow) with a close-up of the PP1 seta (inset; arrow) (scale bars $=100 \mu \mathrm{m}$; photo credits: J. Yack). 


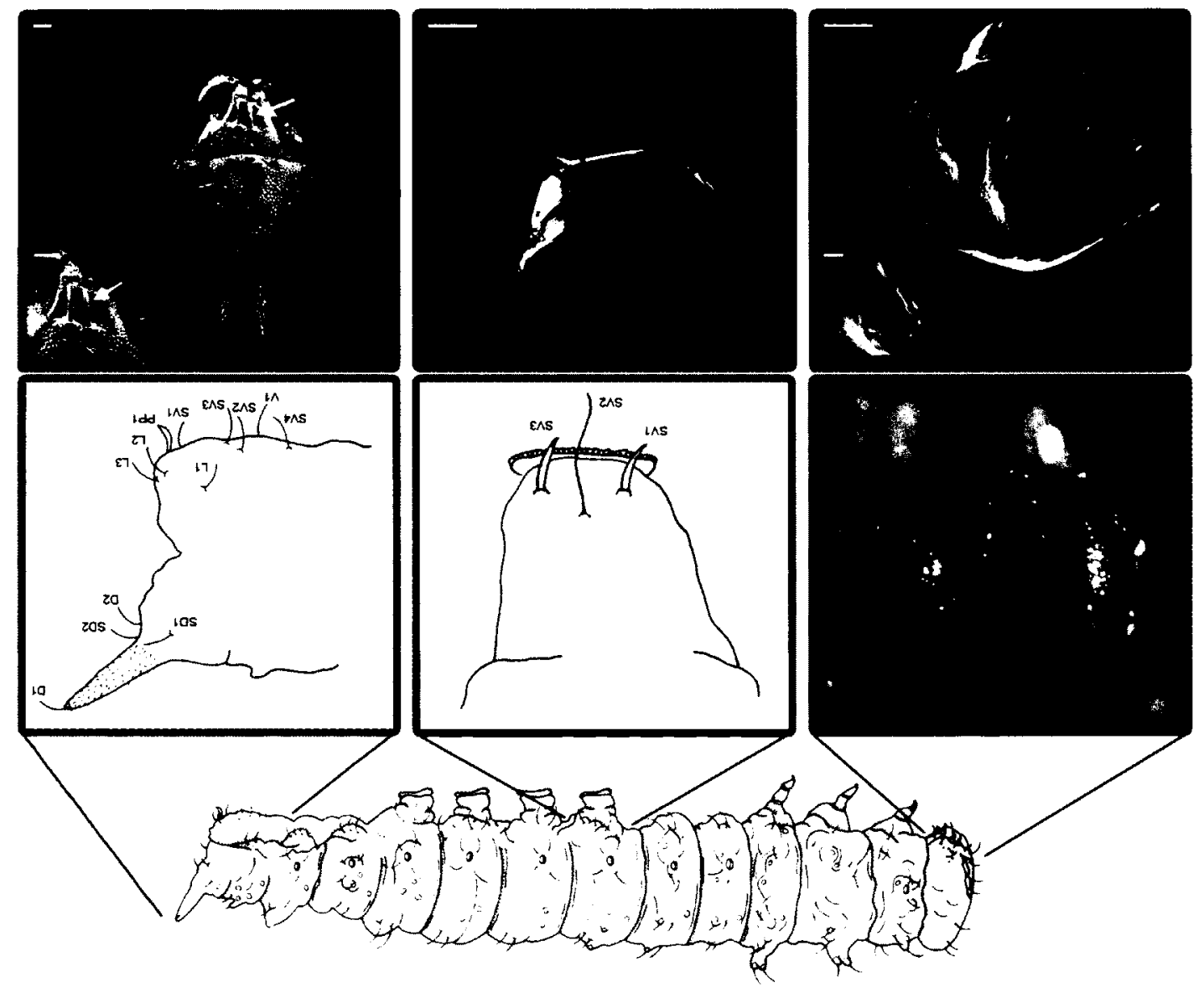


scraping, lateral head hitting, and lateral tail hitting (Fig. A.9). Signalling typically occurs in bouts, each comprising $8.2 \pm 7.6$ complexes, and lasting $6.4 \pm 10.2 \mathrm{~s}(n=18$ bouts from ten individuals). Each complex is $223 \pm 315 \mathrm{~ms}$ ( $n=104$ complexes from ten individuals) in duration, and typically comprises one or two signals. When a mandible drum and anal scrape occur together, the anal scrape almost always precedes the mandible drum. Residents won $61.5 \%$ of the trials, intruders won $5.8 \%$ of the trials and $32.7 \%$ of the contests were ties. Residents were silent until they detected an intruder, and signaled at a latency of $49.2 \pm 52.3 \mathrm{~s}(n=43)$ from the beginning of the trial (Fig. A.9a). The rate of resident behaviours, including mandible drumming, anal scraping and lateral head hitting changed significantly as the intruder approached the resident (Fig. A.9b; see Table A.1 for details). Residents signalled overall more than intruders, signalling significantly more in the first $80 \mathrm{~s}$ (paired $t$-test: $t=-5.066, P<0.001, n=20$ ) and last $80 \mathrm{~s}$ of each trial (paired $t$-test: $t=-5.178, P<0.001, n=20$ ) and were the first to signal in 43 of the 52 trials.

Analysis of vibrations

Vibrations are associated with four behaviours in late instar larvae during conspecific interactions - mandible drumming, anal scraping, lateral head hitting, and lateral tail hitting (Fig. A.9c). Details on temporal and spectral characteristics of vibrations are summarized in Table A.1. Vibrations and movements were similar to those described in other species in Chapter 2. 
Fig. A.9. Vibration characteristics and territorial behaviour in Falcaria bilineata. (a) Microphone trace of an entire behavioural trial with corresponding video frames below. Numbers correspond in both the trace and the video frames, illustrating the approach of the intruder $(1=$ FAR, $2=$ MID, $3=$ CLOSE, $4=$ Intruder leaves, $F=$ First resident signal; scale bar $=1.5 \mathrm{~cm}$ ). (b) Microphone trace illustrating a series of bouts, with an enlargement of single bout and corresponding spectrogram below. Power spectra demonstrating the dominant frequencies of each vibration (right panel) (c) Mean (+SD) behavioural rates of residents at three stages of intruder approach (FAR, MID, CLOSE). Asterisks denote significant differences within each behaviour at different stages of intruder approach. All colours throughout the figure correspond to those in the box describing territorial behaviours. 

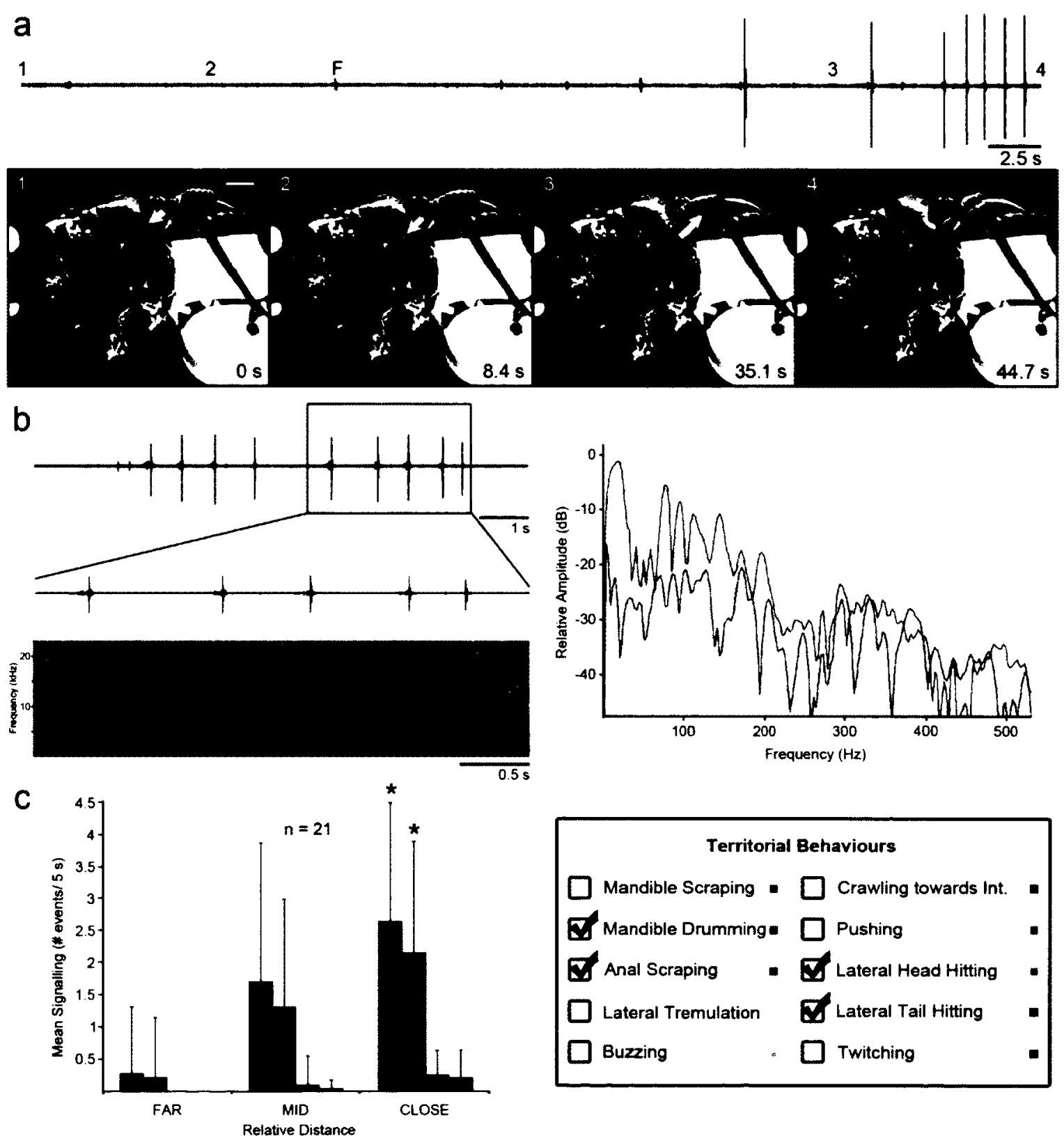
Ochropacha duplaris (Thyatirinae)

General life history observations relevant to conspecific interactions

Previous observations (summarized in Table 2.2) have shown that adult females of the common lutestring, Ochropacha duplaris Linnaeus 1761 (Fig. A.10a) oviposit eggs singly or in groups of 2-3 on species of birch, alder, oak and poplar (Riegler, 1999; Fig. A.10b). Early instars live solitarily (Riegler, 1999; Fig. A.10c,d). Late instars live solitarily in shelters made by tying two leaves together with silk (Riegler, 1999; Fig. A.10e,f).

Morphology

The head capsule of late instar larvae is not flattened dorsally (Fig. A.11a,b). Mandibles have six distal teeth on the incisor area and one ridge on the oral surface (Fig. A.11c). The abdominal prolegs (excluding the anal prolegs) bear three setae on the outer planta region, with no modifications (Fig. A.11d,e). Larvae possess reduced prolegs on the terminal abdominal segment that bear crochets (Fig. A.11a,f,g). Larvae possess no modified setae on the anal segment (Fig. A.11f,g). Morphological characters are summarized in Table 2.3.

Behavioural trials between conspecifics

Details on encounters with conspecifics are summarized in Table 2.4. A total of 6 encounters were staged between a resident and an intruder of similar size. Residents produced five types of behaviours during encounters, including mandible scraping, crawling towards the intruder, pushing, lateral head hitting and lateral tail hitting (Fig. 
Fig. A.10. Photographs demonstrating life-history characteristics relevant to territorial behaviour in the common lutestring, Ochropacha duplaris. (a) Dorsal view of an adult moth in resting position ( $\mathrm{scale}$ bar $=1.5 \mathrm{~cm}$; photo credit: lepiforum.de). (b) Two eggs laid on a leaf (scale bar $=0.5 \mathrm{~mm}$; photo credit: Karl Rasch, lepiforum.de). (c) Dorsal view of an early instar larvae (scale bar $=2 \mathrm{~mm}$; photo credit: ukleps.org). (d) Solitary early instar caterpillar on a skeletonized feeding spot (scale bar $=2 \mathrm{~mm}$; photo credit: ukleps.org). (e) Lateral view of a late instar caterpillar in resting position (scale bar $=8$ $\mathrm{mm}$ ). (f) Late instar caterpillar in a shelter made of two leaves (scale bar $=1 \mathrm{~cm}$ ). 

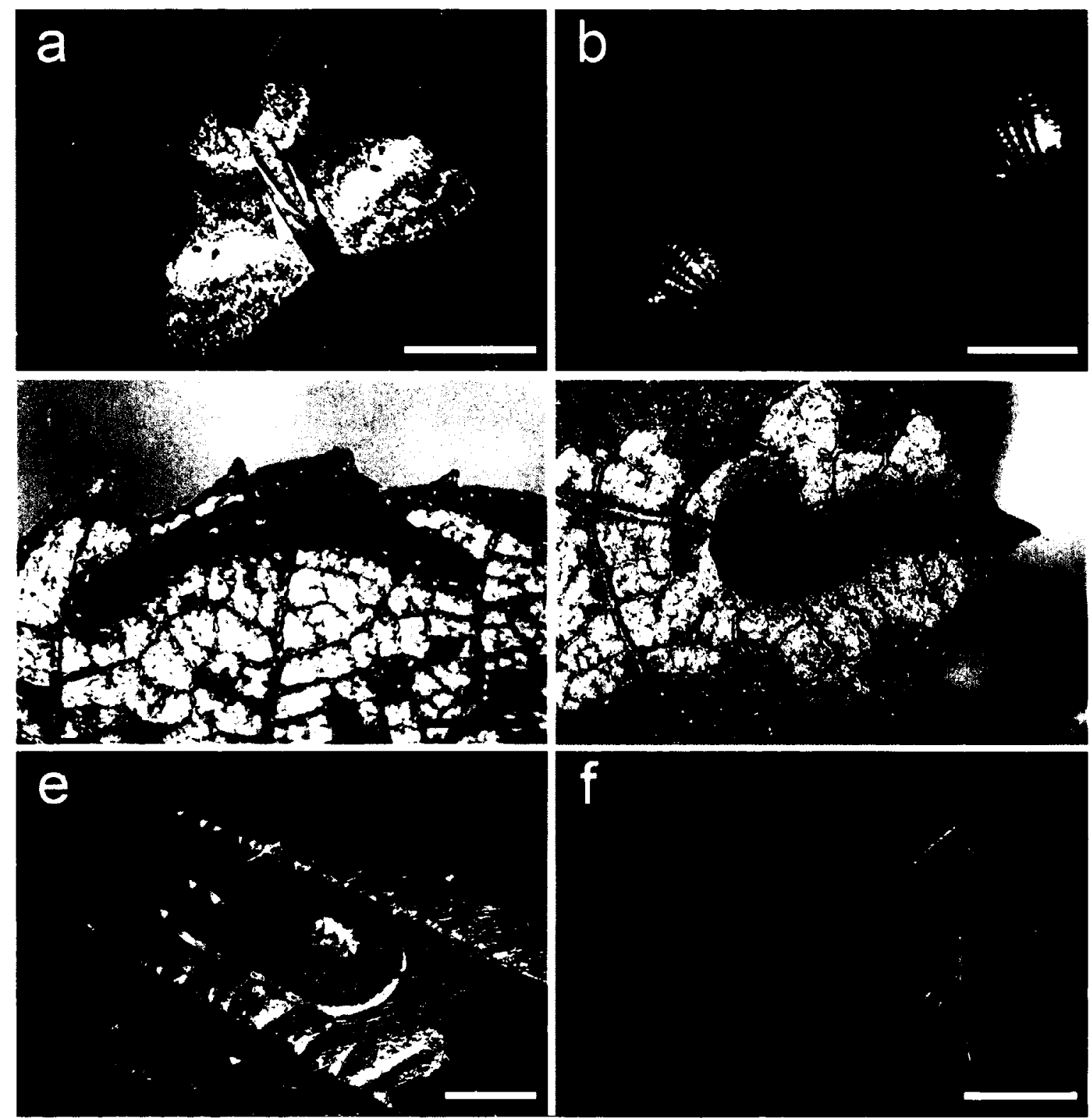
Fig. A.11. Morphological characters related to territorial behaviour in Ochropacha duplaris. (a) Lateral view of the whole caterpillar (scale bar $=1 \mathrm{~mm}$ ). (b) Anterior view of the head capsule (scale bar $=0.5 \mathrm{~mm}$ ). (c) SEMs of lateral and ventral (inset) views of the mandibles (scale bars $=200 \mu \mathrm{m}$ ). (d) Drawing of a lateral view of the proleg on the third abdominal segment (A3) (e) SEM of a lateral view of the proleg on A3 (scale bar = $200 \mu \mathrm{m}$; photo credit: T. Nevills). (f) Drawing of a lateral view the terminal abdominal segment (A10) with named setae. (g) SEM of a posterior view of A10 showing the location of the PP1 seta (arrow) with a close-up of the PP1 seta (inset; arrow) (scale bars $=200 \mu \mathrm{m})$. 


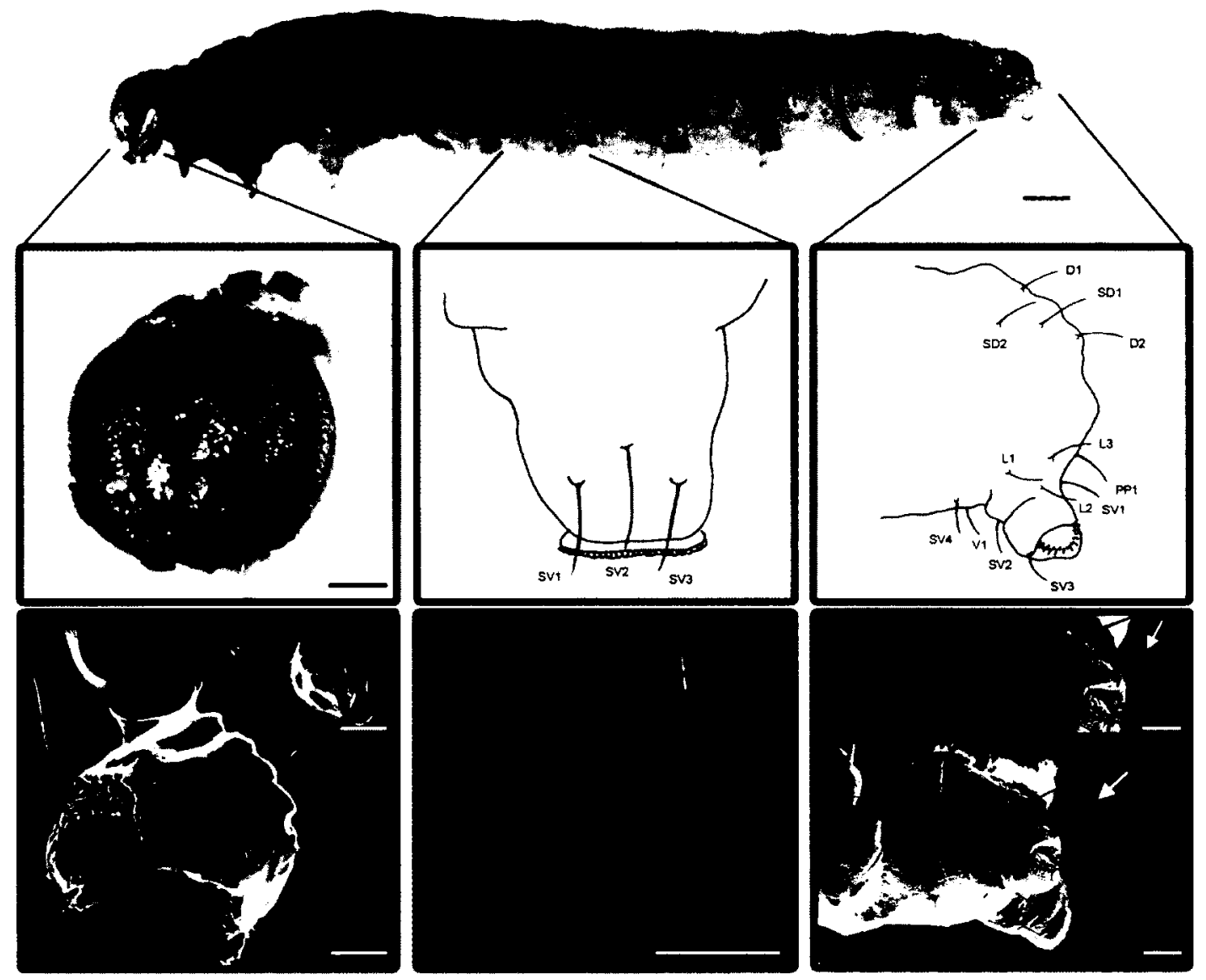


A.12). Data on trial outcomes were not calculated as no full trials were recorded on camera. The rate of resident behaviours, including lateral head hitting changed significantly as the intruder approached the resident (Fig. A.12b; see Table A.1 for details). Intruders were never observed to signal $(n=6)$.

Analysis of vibrations

Vibrations are associated with five behaviours in late instar larvae during conspecific interactions - mandible scraping, crawling towards the intruder, pushing, lateral head hitting and lateral tail hitting (Fig. A.12c). Details on temporal and spectral characteristics of vibrations are summarized in Tables A.1. Vibrations and movements were similar to those described in other species in Chapter 2.

Tetheela fluctuosa (Thyatirinae)

General life history observations relevant to conspecific interactions

Previous observations (summarized in Table 2.2) have shown that adult females of the satin carpet moth, Tetheela fluctuosa Hübner 1799-1804 (Fig. A.13a) oviposit eggs singly or rarely in pairs on the teeth of leaves of birch, alder, and poplar (Riegler, 1999; Fig. A.13b). Early instars live solitarily between two leaves, feeding at night (Newman, 1884; Riegler, 1999; Fig. A.13c,d). Late instars live solitarily in shelters constructed between two or more leaves or by folding a single leaf and securing it with (Newman, 1884; Riegler, 1999; Fig. A.13e,f). 
Fig. A.12. Vibration characteristics and territorial behaviour in Ochropacha duplaris. (a) Laser trace of an entire behavioural trial with corresponding video frames below. Numbers correspond in both the trace and the video frames, illustrating the approach of the intruder $(1=$ FAR, $2=$ MID, $3=\mathrm{CLOSE}, 4=$ Intruder leaves, $\mathrm{F}=$ First resident signal; scale bar $=8 \mathrm{~mm}$ ). (b) Laser vibrometer trace illustrating a series of bouts, with an enlargement of single bout and corresponding spectrogram below. Power spectra demonstrating the dominant frequencies of each vibration (right panel) (c) Mean (+SD) behavioural rates of residents at three stages of intruder approach (FAR, MID, CLOSE). Asterisks denote significant differences within each behaviour at different stages of intruder approach. All colours throughout the figure correspond to those in the box describing territorial behaviours. 

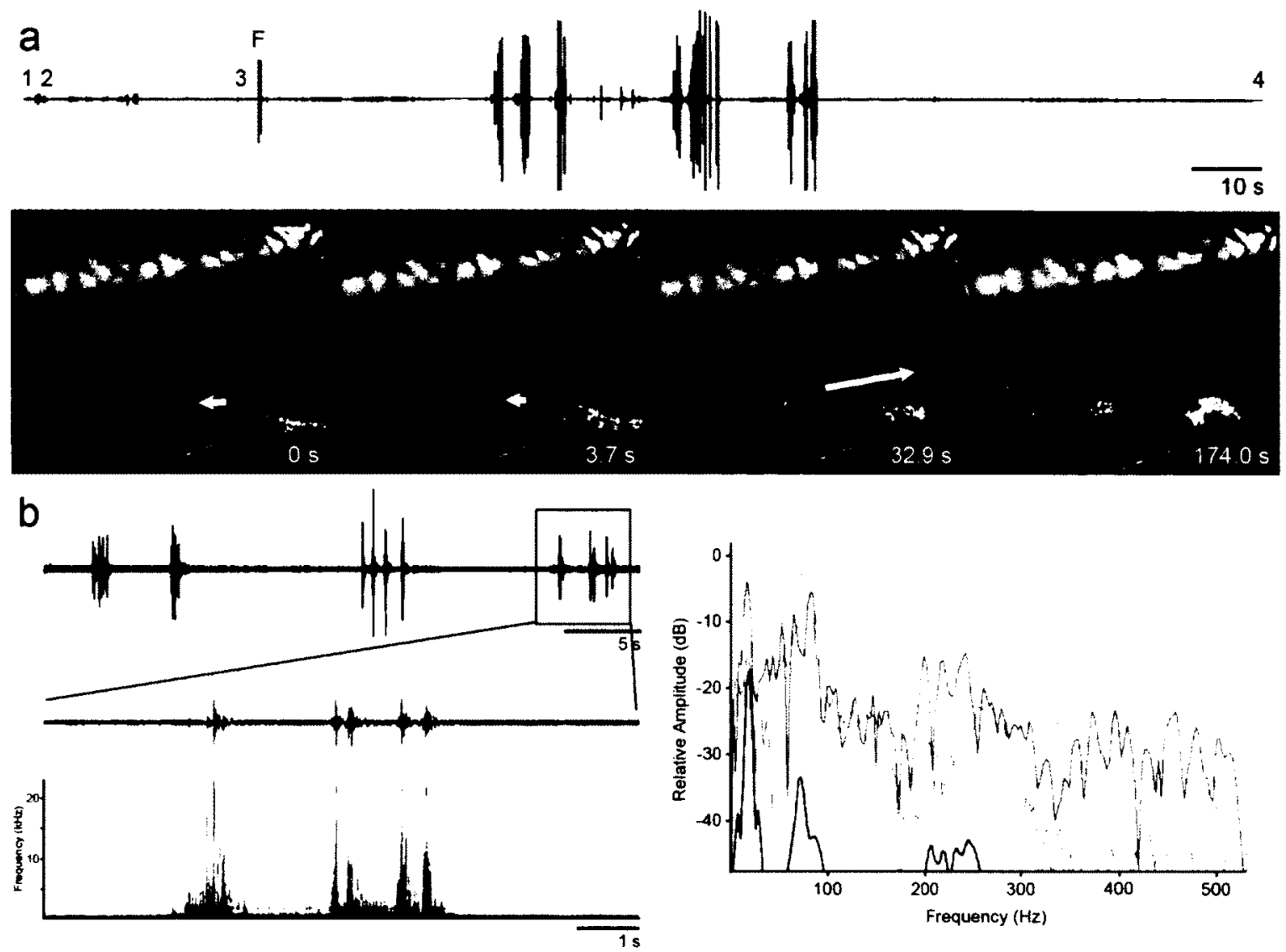

C

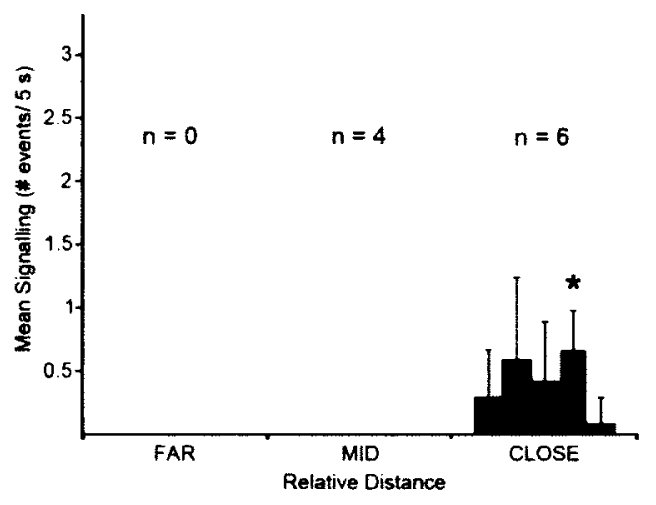

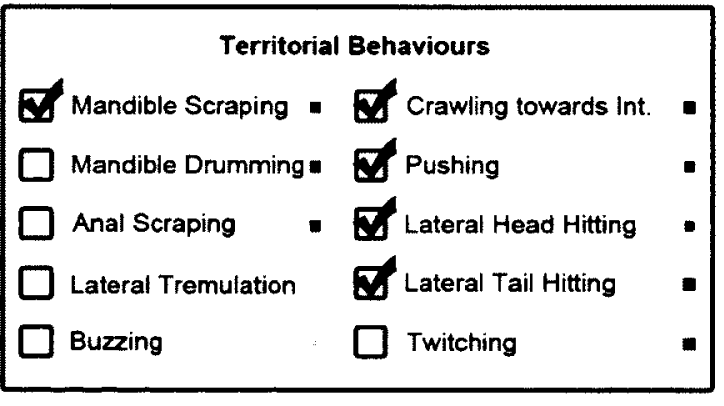


Fig. A.13. Photographs demonstrating life-history characteristics relevant to territorial behaviour in the satin carpet moth, Tetheela fluctuosa. (a) Lateral view of an adult moth in resting position (scale bar $=7 \mathrm{~mm}$; photo credit: Roy Leverton, ukleps.org). (b) Eggs laid singly or in pairs in the teeth of a leaf (scale bar $=5 \mathrm{~mm}$; photo credit: Roy Leverton, ukleps.org). (c) Lateral view of a late instar larvae (scale bar $=5 \mathrm{~mm}$ ). (d) Late instar caterpillar in a shelter made between two leaves $($ scale bar $=1.5 \mathrm{~cm})$. 


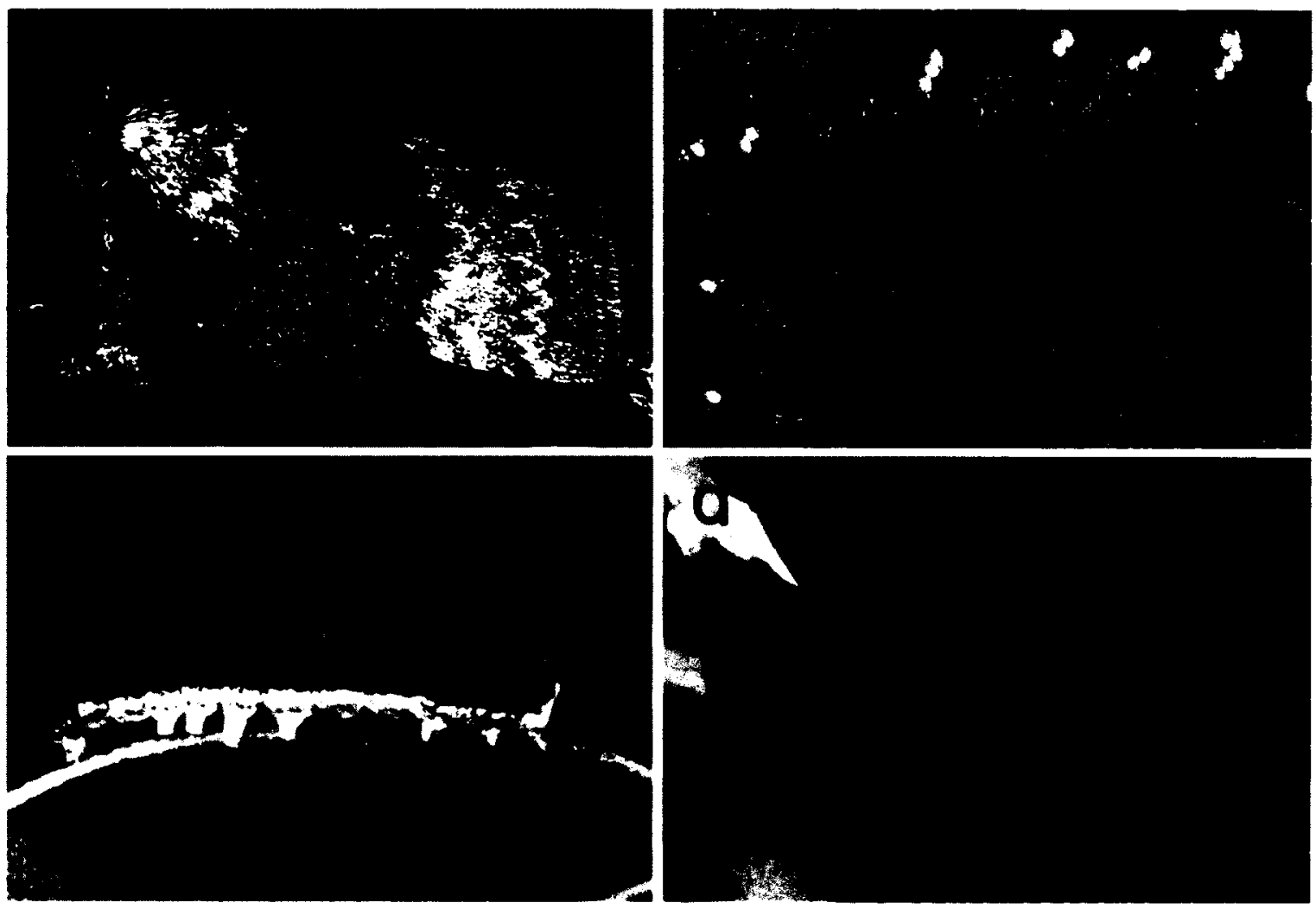


Morphology

The head capsule of late instar larvae is not flattened dorsally (Fig. A.14a,b). Mandibles have six distal teeth on the incisor area and three ridges on the oral surface (Fig. A.14c). The abdominal prolegs (excluding the anal prolegs) bear three setae on the outer planta region, with no modifications (Fig. A.14d,e). Larvae possess reduced prolegs on the terminal abdominal segment that bear crochets (Fig. A.14a,f,g). Larvae possess modified PP1 setae on the anal segment and all other setae on this segment are normal to the group (Fig. A.14f,g). Morphological characters are summarized in Table 2.3.

Behavioural trials between conspecifics

Details on encounters with conspecifics are summarized in Table 2.4. A total of 5 encounters were staged between a resident and an intruder of similar size. Residents produced six types of behaviours during encounters, including mandible scraping, lateral tremulation, anal scraping, crawling towards the intruder, lateral head hitting and lateral tail hitting (Fig. A.15). Residents won $100 \%$ of the trials $(n=1)$. Residents were silent until they detected an intruder (Fig. A.15a). The rate of resident behaviours did not change significantly as the intruder approached the resident (Fig. A.15b). Intruders were never observed to signal $(n=5)$.

Analysis of vibrations

Vibrations are associated with six behaviours in late instar larvae during conspecific interactions - mandible scraping, lateral tremulation, anal scraping, crawling 
Fig. A.14. Morphological characters related to territorial behaviour in Tetheela fluctuosa. (a) Lateral view of the whole caterpillar (scale bar $=1 \mathrm{~mm}$ ). (b) Anterior view of the head capsule (scale bar $=1 \mathrm{~mm}$ ). (c) SEMs of lateral and ventral (inset) views of the mandibles (scale bars $=200 \mu \mathrm{m}$ ). (d) Drawing of a lateral view of the proleg on the third abdominal segment (A3) (e) SEM of a lateral view of the proleg on A3 (scale bar $=250$ $\mu \mathrm{m}$ ). (f) Drawing of a lateral view the terminal abdominal segment (A10) with named setae. (g) SEM of a posterior view of A10 showing the location of the PP1 seta (arrow) with a close-up of the PP1 seta (inset; arrow) (scale bars $=250 \mu \mathrm{m})$. 


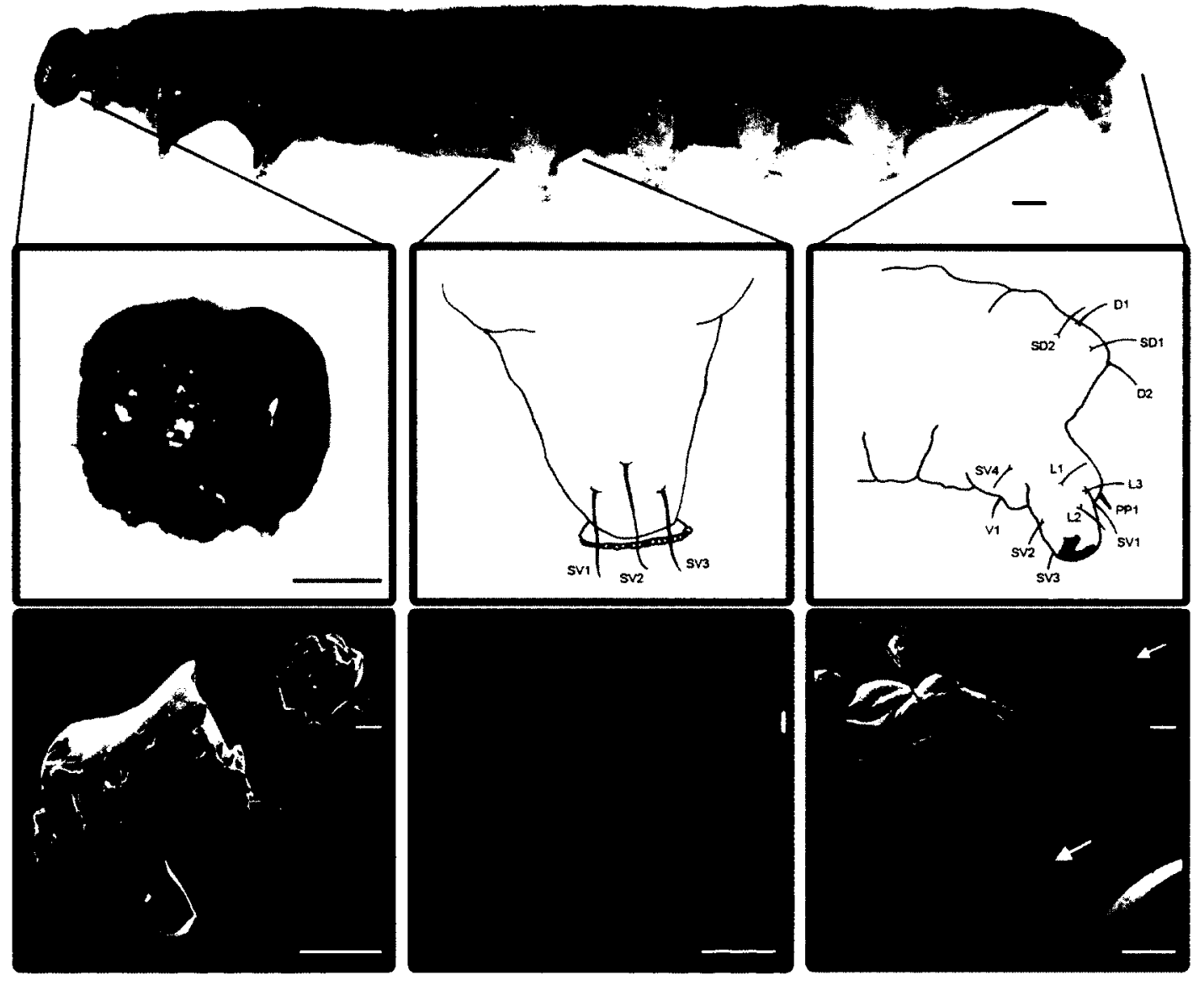


Fig. A.15. Vibration characteristics and territorial behaviour in Tetheela fluctuosa. (a) Laser trace of an entire behavioural trial with corresponding video frames below. Numbers correspond in both the trace and the video frames, illustrating the approach of the intruder $(1=$ FAR, $2=$ MID, $3=$ CLOSE, $4=$ Intruder leaves, $F=$ First resident signal; scale bar $=1 \mathrm{~cm}$ ). (b) Laser vibrometer trace illustrating a series of bouts, with an enlargement of single bout and corresponding spectrogram below. Power spectra demonstrating the dominant frequencies of each vibration (right panel) (c) Mean (+SD) behavioural rates of residents at three stages of intruder approach (FAR, MID, CLOSE). Asterisks denote significant differences within each behaviour at different stages of intruder approach. All colours throughout the figure correspond to those in the box describing territorial behaviours. 

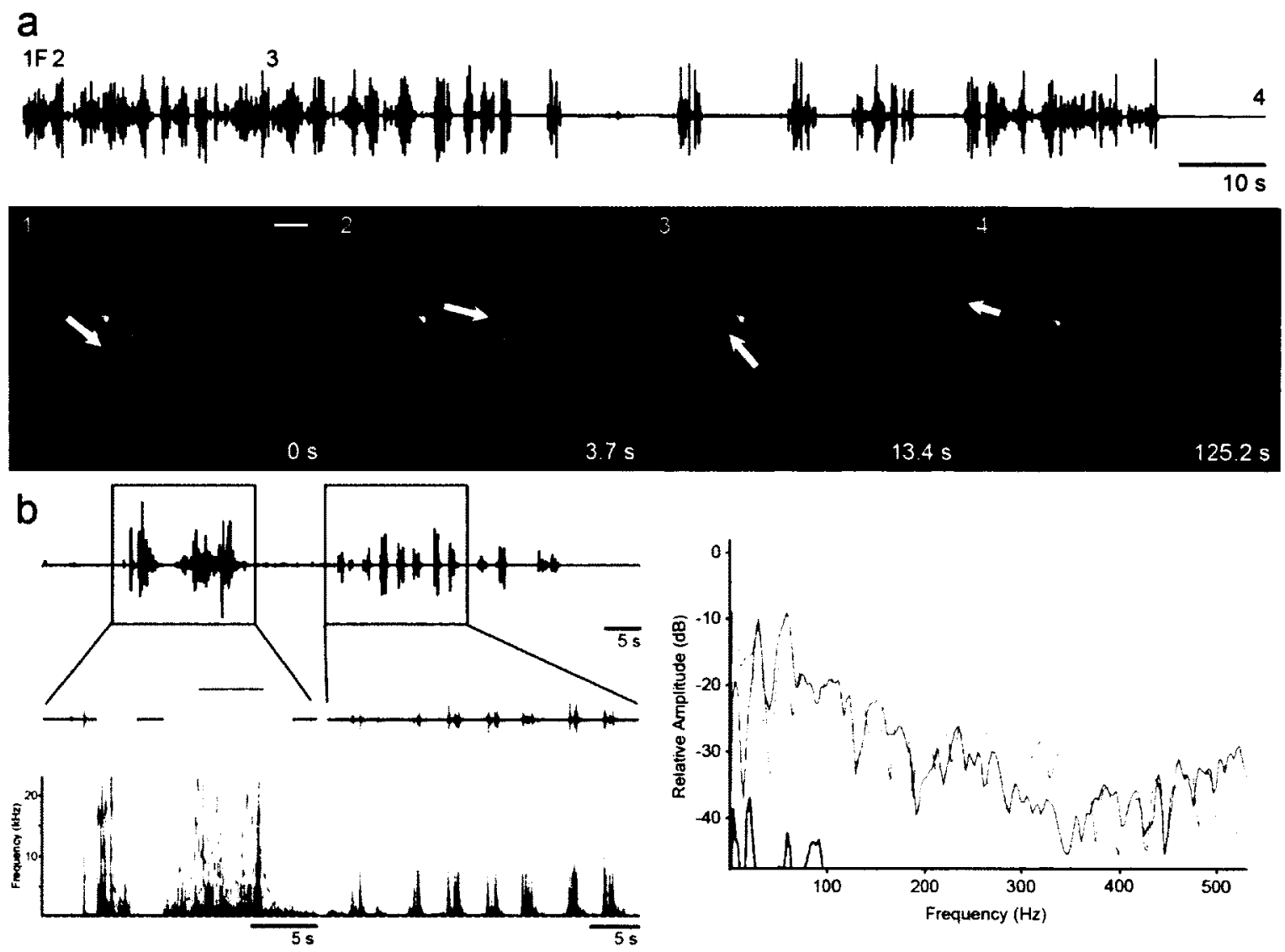

C
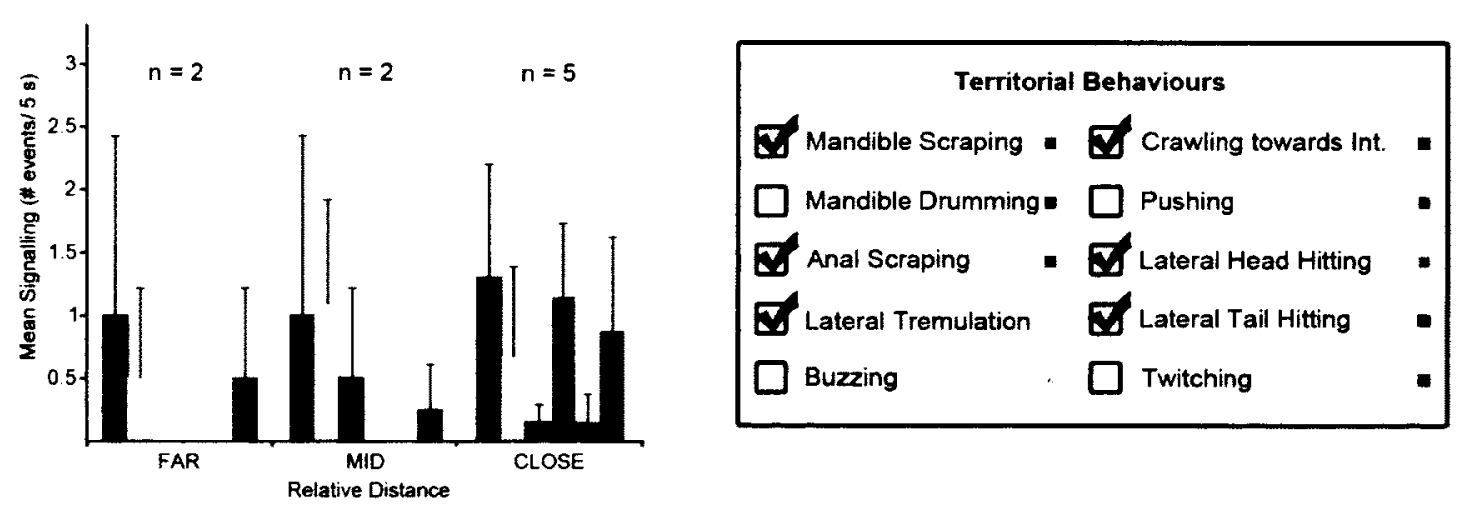
towards the intruder, lateral head hitting and lateral tail hitting (Fig. A.15c). Details on temporal and spectral characteristics of vibrations are summarized in Table A.1.

Vibrations and movements were similar to those described in other species in Chapter 2.

Thyatira batis (Thyatirinae)

General life history observations relevant to conspecific interactions

Previous observations (summarized in Table 2.2) have shown that adult females of the peach blossom, Thyatira batis Linnaeus 1758 (Fig. A.16a) lay flat, oval eggs either singly, or small groups of 2-3 on species of bramble (Rubus spp.; Riegler, 1999; Fig. A.16b). Early instars live solitarily and build a leaf shelter out of silk (Riegler, 1999; Fig. A.16c,d). Late instars live solitarily exposed on the leaf (Riegler, 1999; Fig. A.16e,f).

\section{Morphology}

The head capsule of late instar larvae is not flattened dorsally (Fig. A.17a,b). Mandibles have five distal teeth on the incisor area and three ridges on the oral surface (Fig. A.17c). The abdominal prolegs (excluding the anal prolegs) bear three setae on the outer planta region, none of which are modified (Fig. A.17d,e). Larvae possess reduced prolegs on the terminal abdominal segment that bear crochets (Fig. A.17a,f,g). Larvae do not possess any modified setae on the anal segment (Fig. A.17f,g). Morphological characters are summarized in Table 2.3 .

Behavioural trials between conspecifics 
Fig. A.16. Photographs demonstrating life-history characteristics relevant to territorial behaviour in the peach blossom, Thyatira batis. (a) Dorsal view of an adult moth in resting position $(\mathrm{scale} b a r=1.5 \mathrm{~cm}) .(\mathbf{b})$ Dorsal view of an early instar larvae (uknown scale; photo credit: Claudia Mech, lepiforum.de). (d) Dorsal view of a late instar caterpillar in resting position (scale bar $=1 \mathrm{~cm}$ ). (f) Late instar caterpillar on a leaf (scale $\mathrm{bar}=3 \mathrm{~cm})$. 


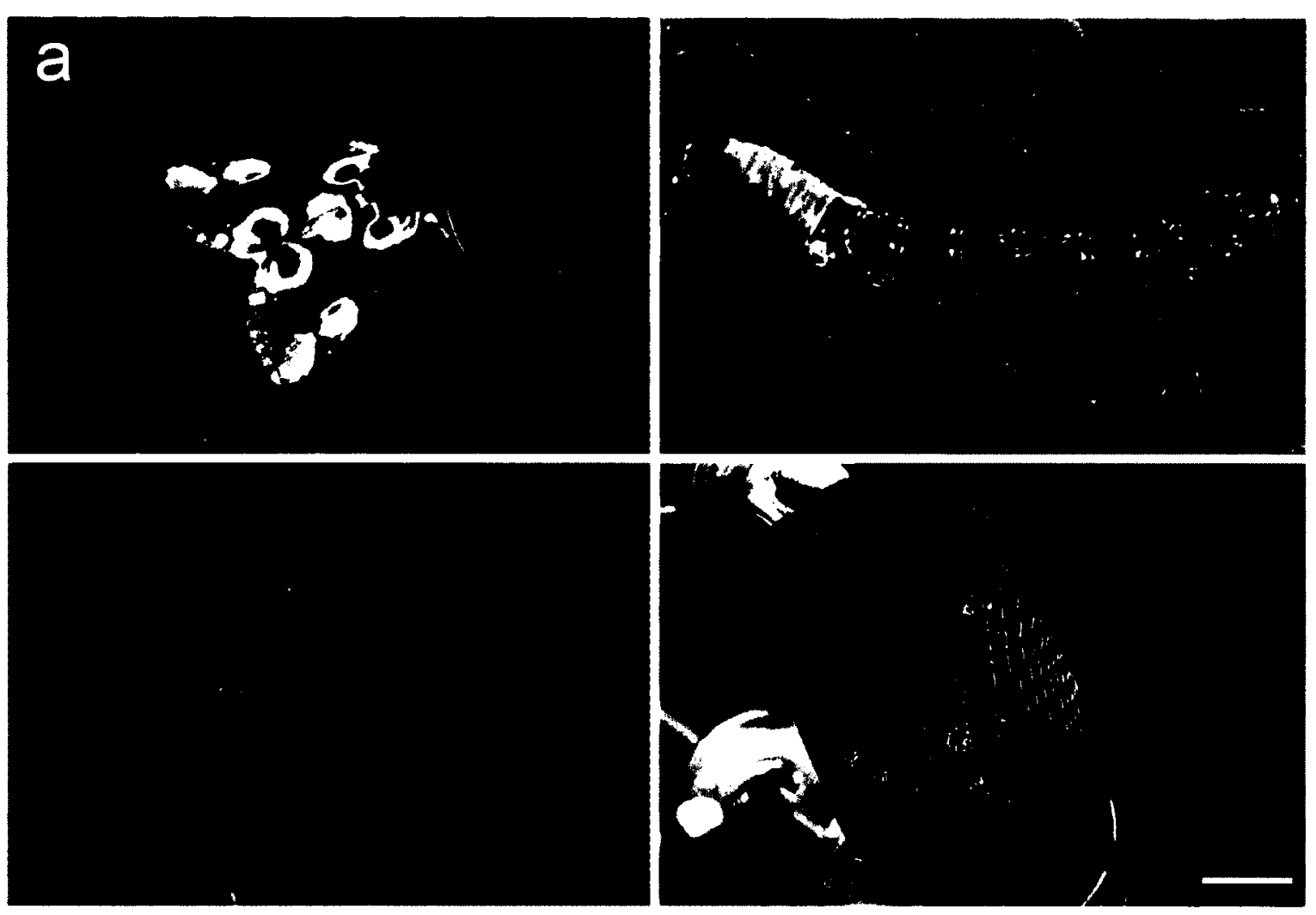


Fig. A.17. Morphological characters related to territorial behaviour in Thyatira batis. (a) Lateral view of the whole caterpillar (scale bar $=1 \mathrm{~mm}$ ). (b) Anterior view of the head capsule (scale bar $=1 \mathrm{~mm}$ ). (c) SEMs of lateral and ventral (inset) views of the mandibles (scale bars $=100 \mu \mathrm{m}$ ). (d) Drawing of a lateral view of the proleg on the third abdominal segment (A3) (e) SEM of a lateral view of the proleg on A3 (scale bar $=200 \mu \mathrm{m}$; photo credit: T. Nevills). (f) Drawing of a lateral view the terminal abdominal segment (A10) with named setae. (g) SEM of a posterior view of A10 showing the location of the PP1 seta (arrow; scale bar $=1 \mathrm{~mm})$ with a close-up of the PP1 seta (inset; arrow; scale bar = $100 \mu \mathrm{m})$. 


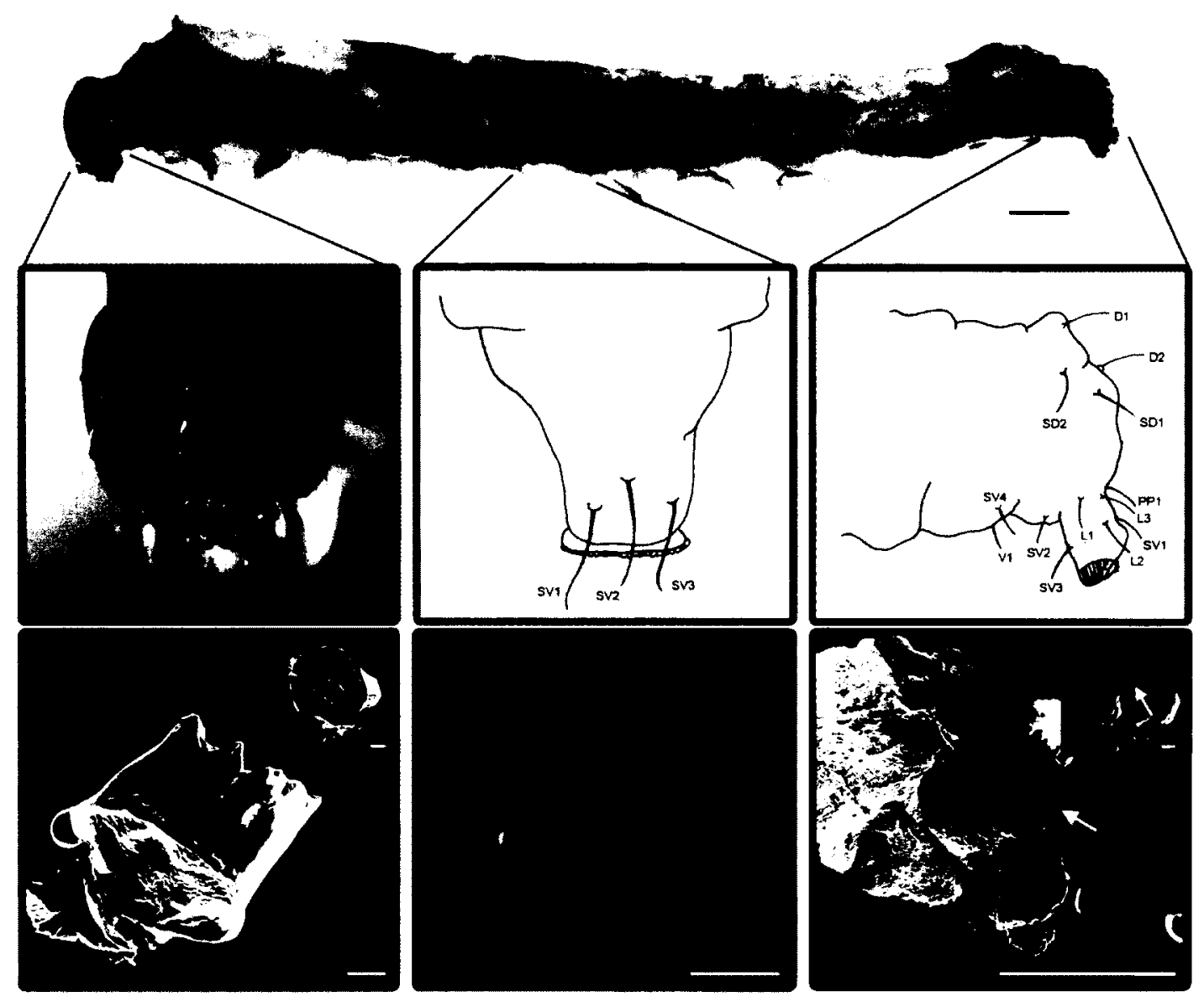


Details on encounters with conspecifics are summarized in Table 2.4. A total of 7 encounters were staged between a resident and an intruder of similar size. Residents produced five types of behaviours during encounters, including anal scraping, lateral tremulation, twitching, lateral head hitting and lateral tail hitting (Fig. A.18). Trials always ended in a tie, with the resident and intruder often sitting side by side. Residents were silent until they detected an intruder (Fig. A.18a). The rate of twitching changed significantly as the intruder approached the resident (Fig. A.18b; see Table A.1 for details). Only one intruder was observed to twitch during a trial, while no other intruder was observed to produce any other territorial behaviours $(n=7)$.

Analysis of vibrations

Vibrations are associated with five behaviours in late instar larvae during conspecific interactions - anal scraping, lateral tremulation, twitching, lateral head hitting and lateral tail hitting (Fig. A.3c). Details on temporal and spectral characteristics of vibrations are summarized in Table A.1. Vibrations and movements were similar to those described in other species in Chapter 2.

Watsonalla cultraria (Drepaninae)

General life history observations relevant to conspecific interactions

Previous observations (summarized in Table 2.2) have shown that adult females of the barred hook-tip moth, Watsonalla cultraria Fabricius 1775 (Fig. A.19a) lay eggs singly or in small groups of $2-4$, covered in scales and hairs from the adult, on species of 
Fig. A.18. Vibration characteristics and territorial behaviour in Thyatira batis. (a) Laser trace of an entire behavioural trial with corresponding video frames below. Numbers correspond in both the trace and the video frames, illustrating the approach of the intruder $(1=$ FAR, $2=$ MID, $3=$ CLOSE, $4=$ Intruder leaves, $F=$ First resident signal; scale bar $=$ $1 \mathrm{~cm}$ ). (b) Laser vibrometer trace illustrating a series of bouts, with an enlargement of single bout and corresponding spectrogram below. Power spectra demonstrating the dominant frequencies of each vibration (right panel) (c) Mean (+SD) behavioural rates of residents at three stages of intruder approach (FAR, MID, CLOSE). Asterisks denote significant differences within each behaviour at different stages of intruder approach. All colours throughout the figure correspond to those in the box describing territorial behaviours. 
a
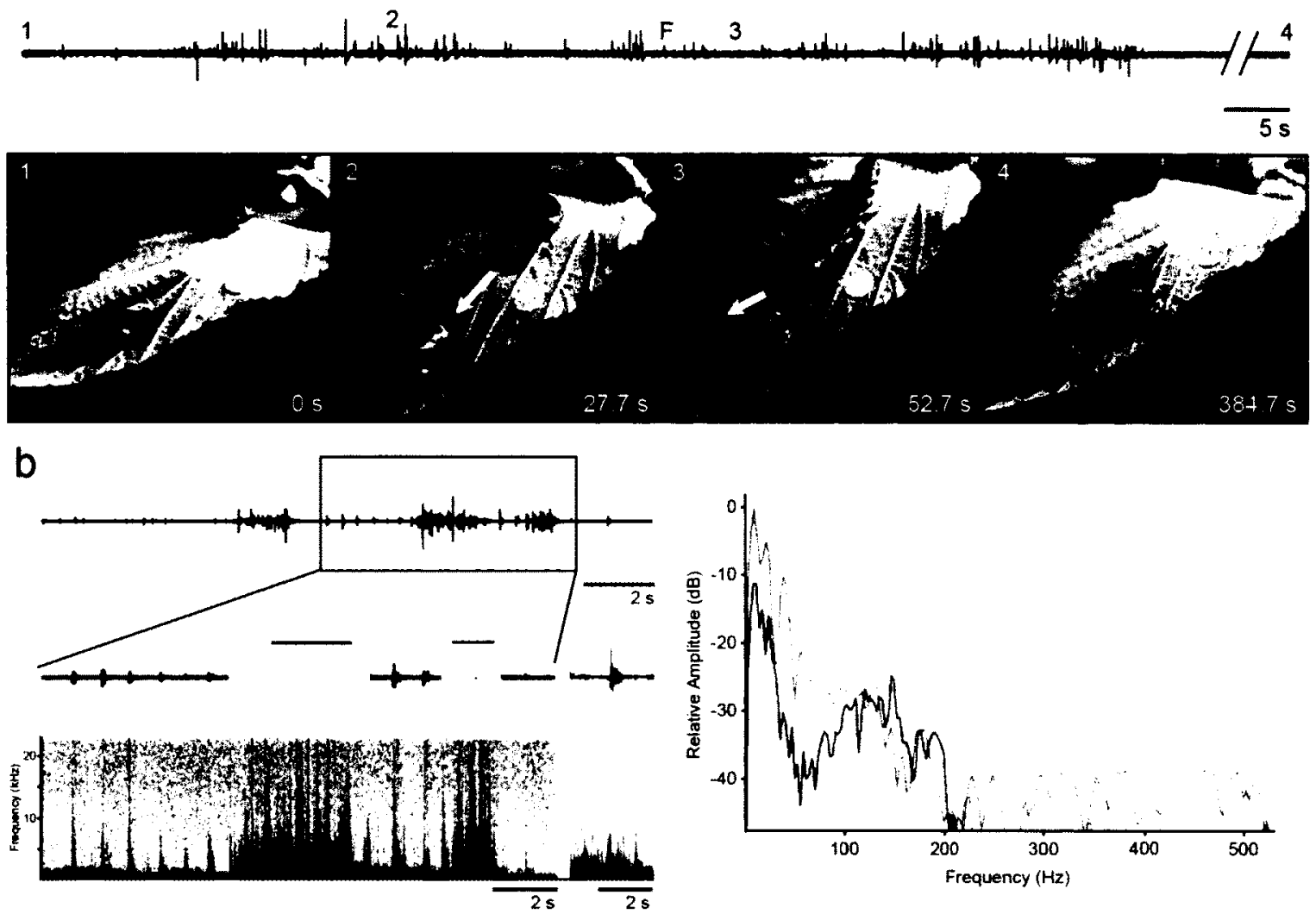

C
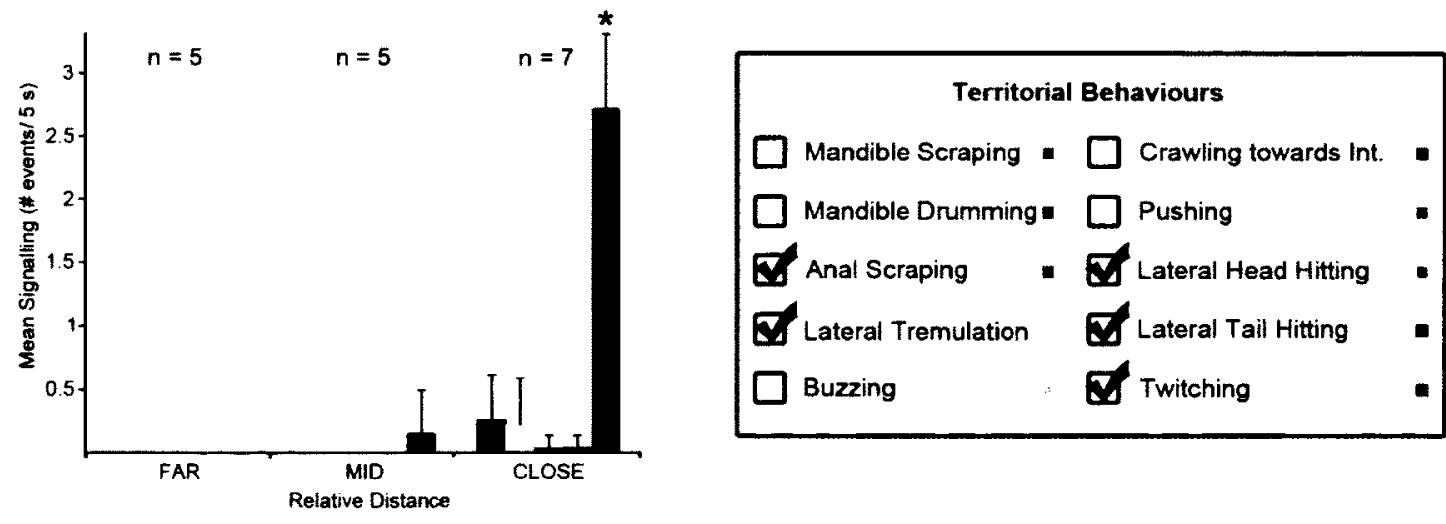
Fig. A.19. Photographs demonstrating life-history characteristics relevant to territorial behaviour in the barred hook-tip moth, Watsonalla cultraria. (a) Dorsal view of an adult moth in resting position (scale bar $=1.5 \mathrm{~cm}$; photo credit: ukleps.org). (b) Dorsal view of a single egg (scale bar $=1 \mathrm{~mm}$; photo credit: ukleps.org). (c) Lateral view of an early instar larvae in resting position (scale bar $=2 \mathrm{~mm}$; photo credit: ukleps.org). (d) Dorsal view of a solitary early instar caterpillar (scale bar $=2 \mathrm{~mm}$; photo credit: ukleps.org). (e) Lateral view of a late instar caterpillar in resting position (scale bar $=5 \mathrm{~mm}$; photo credit: ukleps.org). (f) Late instar caterpillar on a leaf (scale bar $=2.5 \mathrm{~cm}$; photo credit: J. Yack). 

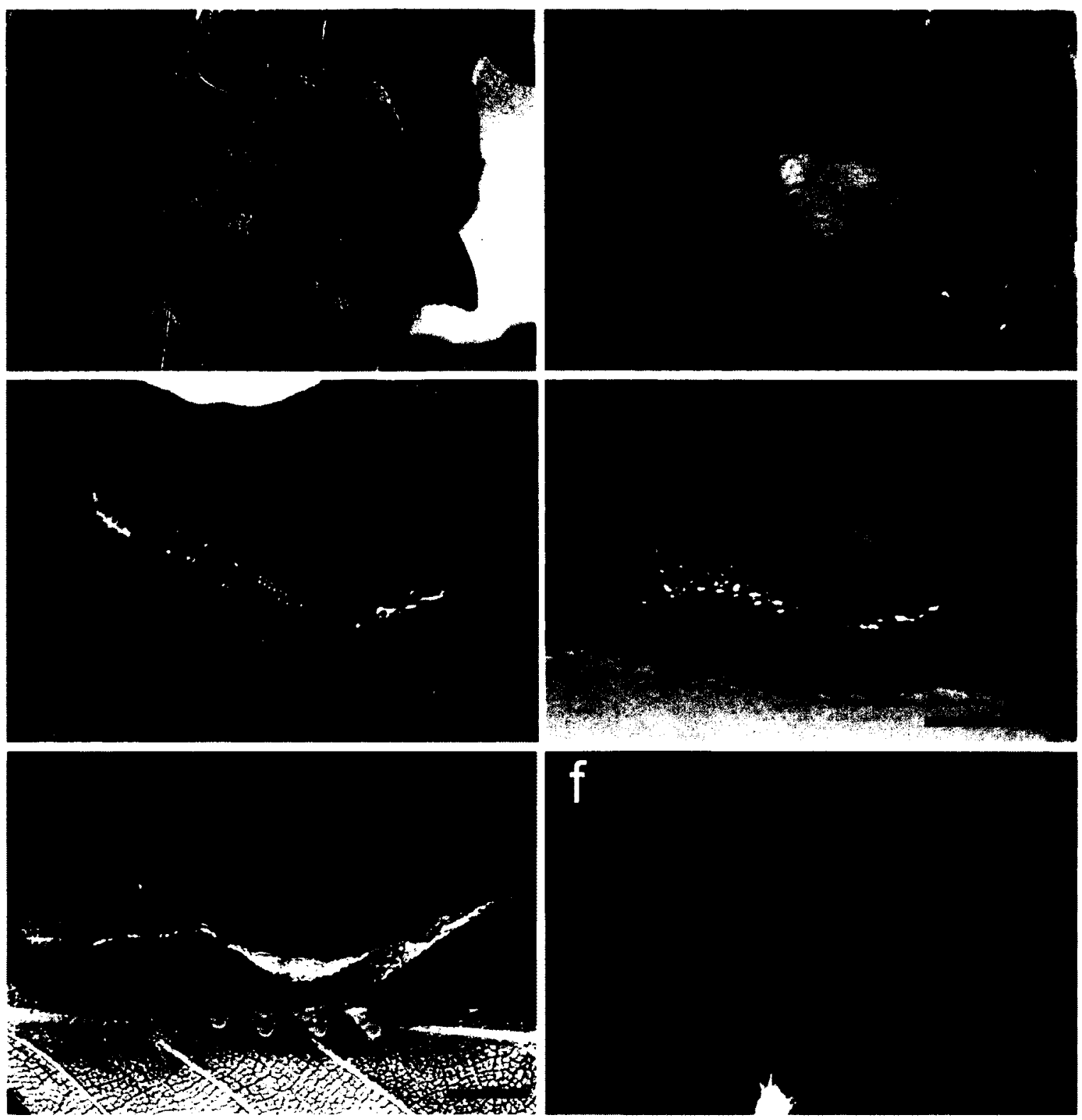
beech (Fagus spp.) or oak (Quercus spp.; Bryner, 1999; Fig. A.19b). Early instars live in small groups of 2-5 (Bryner, 1999; Fig. A.19c,d). Late instars live solitarily exposed on the leaf, or in simple shelters they construct with silk (Bryner, 1999; Fig. A.19e,f).

\section{Morphology}

The head capsule of late instar larvae is not flattened dorsally (Fig. A.20a,b). Mandibles have no distal teeth on the incisor area and no ridges on the oral surface (Fig. A.20c). The abdominal prolegs (excluding the anal prolegs) bear three setae on the outer planta region, where SV1 and SV3 are modified (Fig. A.20d,e). Larvae do not possess prolegs on the terminal abdominal segment and possess a short, fleshy caudal projection (Fig. A.20a,f,g). Larvae do not possess any modified setae on the anal segment (Fig. A.20f,g). Morphological characters are summarized in Table 2.3.

Behavioural trials between conspecifics

Details on encounters with conspecifics are summarized in Table 2.4. A total of 3 encounters were staged between a resident and an intruder of similar size. Residents produced five types of behaviours during encounters, including mandible drumming, anal scraping, lateral tremulation, lateral head hitting and lateral tail hitting (Fig. A.21). Data on trial outcomes were not calculated as no full trials were recorded on camera. Residents were silent until they detected an intruder (Fig. A.21a). The rate of resident behaviours did not change as the intruder approached the resident (Fig. A.21b). Intruders were observed to signal in one of the two trials ( 1 lateral tremulation +1 pseudo anal scrape). 
Fig. A.20. Morphological characters related to territorial behaviour in Watsonalla cultraria. (a) Lateral view of the whole caterpillar (scale bar $=2 \mathrm{~mm}$ ). (b) Anterior view of the head capsule (scale bar $=0.5 \mathrm{~mm}$ ). (c) SEMs of lateral and ventral (inset) views of the mandibles (scale bars $=100 \mu \mathrm{m}$ ). (d) Drawing of a lateral view of the proleg on the third abdominal segment (A3) (e) SEM of a lateral view of the proleg on A3 (scale bar = $200 \mu \mathrm{m}$ ). (f) Drawing of a lateral view the terminal abdominal segment (A10) with named setae. (g) SEM of a posterior view of A10 showing the location of the PP1 seta (arrow) with a close-up of the PP1 seta (inset; arrow) (scale bars $=100 \mu \mathrm{m}$ ). 


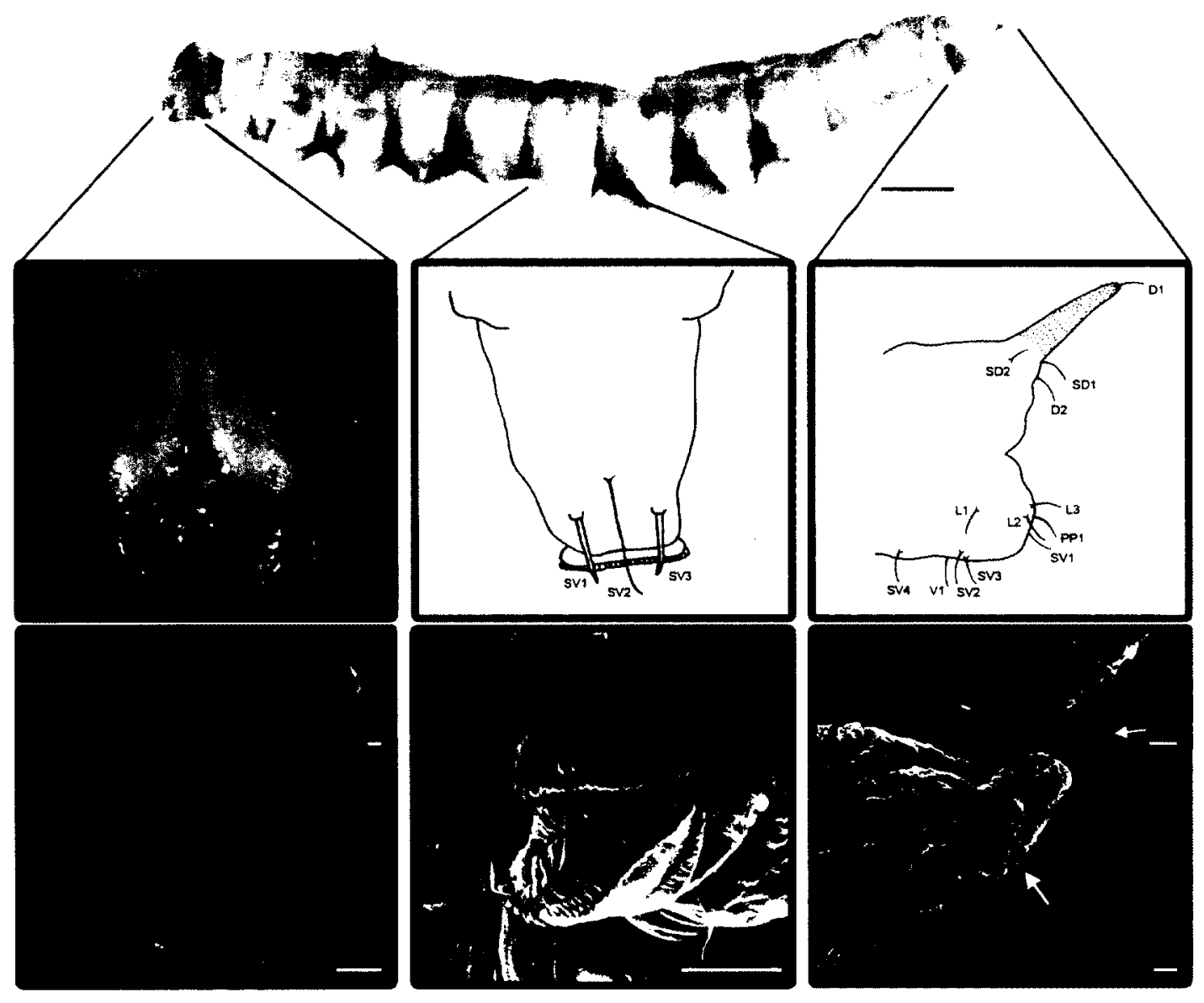


Fig. A.21. Territorial behaviour in Watsonalla cultraria. (a) Video frames of an entire behavioural trial. Numbers illustrate the approach of the intruder $(1=\mathrm{FAR}, 2=\mathrm{MID}, 3=$ CLOSE, $4=$ Intruder leaves; scale bar $=2 \mathrm{~cm}$; video credit: J. Yack). (b) Mean (+SD) behavioural rates of residents at three stages of intruder approach (FAR, MID, CLOSE). Asterisks denote significant differences within each behaviour at different stages of intruder approach. All colours throughout the figure correspond to those in the box describing territorial behaviours. 
a

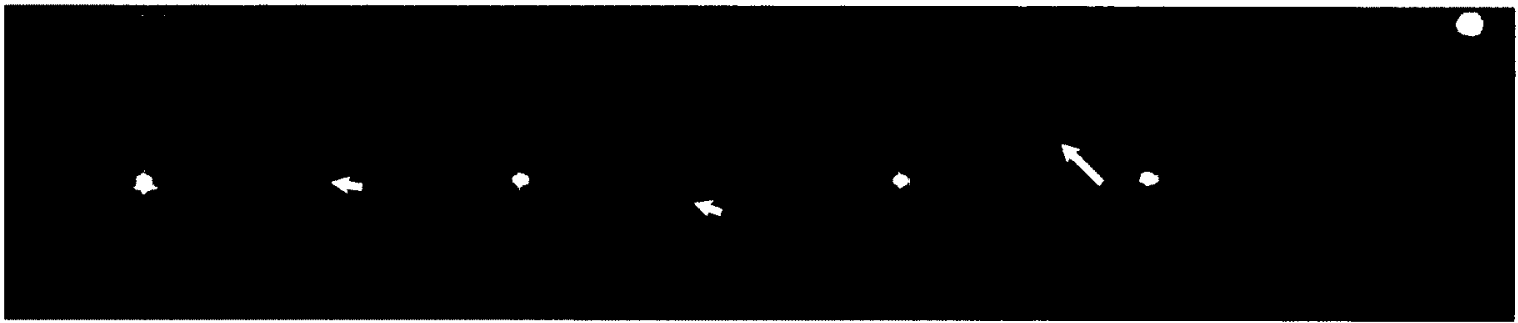

b

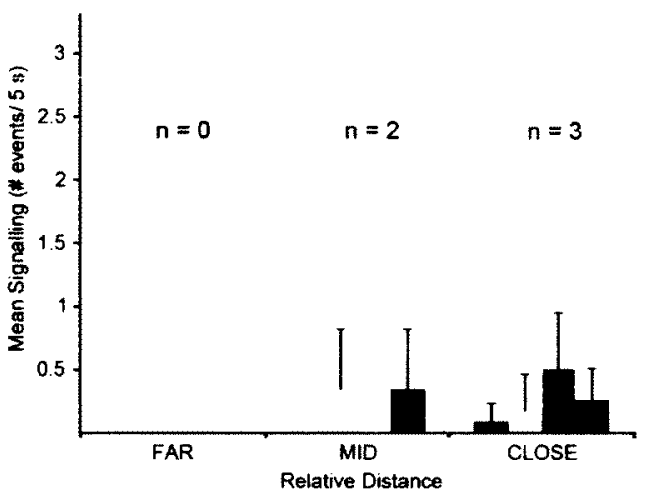

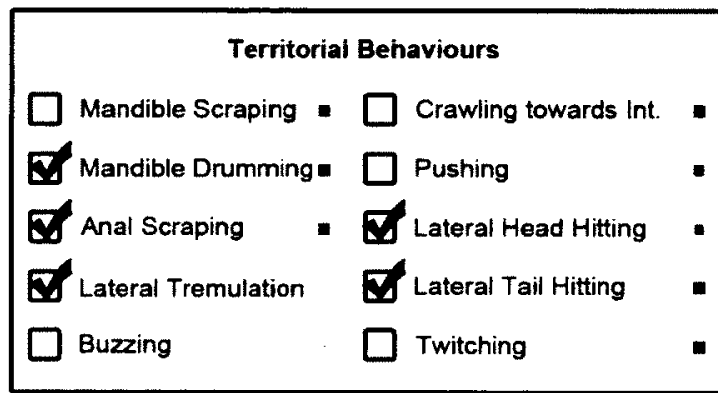


Analysis of vibrations

Vibrations are associated with five behaviours in late instar larvae during conspecific interactions - mandible drumming, anal scraping, lateral tremulation, lateral head hitting and lateral tail hitting (Fig. A.21c). Details on temporal and spectral characteristics of vibrations are summarized in Table A.1. Vibrations and movements were similar to those described in other species in Chapter 2.

\section{Specimens in alcohol}

Cilix glaucata (Drepaninae)

Morphology

The head capsule of late instar larvae is not flattened dorsally (Fig. A.22a,b). Mandibles have no distal teeth on the incisor area and four ridges on the oral surface (Fig. A.22c). The abdominal prolegs (excluding the anal prolegs) bear three setae on the outer planta region, where SV1 and SV3 are modified (Fig. A.22d,e). Larvae do not possess prolegs on the terminal abdominal segment and possess a short, fleshy caudal projection (Fig. A.22a,f,g). Larvae possess two modified setae on the anal segment (Fig. A.22f,g). Morphological characters are summarized in Table 2.3.

Falcaria lacertinaria (Drepaninae)

Morphology

The head capsule of late instar larvae is not flattened dorsally (Fig. A.23a,b). Mandibles have six rounded distal teeth on the incisor area and two ridges on the oral surface (Fig. A.23c). The abdominal prolegs (excluding the anal prolegs) bear three setae 
Fig. A.22. Morphological characters related to territorial behaviour in Cilix glaucata. (a) Lateral view of the whole caterpillar (scale bar $=2 \mathrm{~mm}$ ). (b) Anterior view of the head capsule (scale bar $=0.5 \mathrm{~mm}$ ). (c) SEMs of lateral and ventral (inset) views of the mandibles (scale bars $=100 \mu \mathrm{m}$ ). (d) Drawing of a lateral view of the proleg on the third abdominal segment (A3) (e) SEM of a lateral view of the proleg on A3 (scale bar $=200$ $\mu \mathrm{m}$ ). (f) Drawing of a lateral view the terminal abdominal segment (A10) with named setae. (g) SEM of a posterior view of A10 showing the location of the PP1 seta (arrow) with a close-up of the PP1 seta (inset; arrow) (scale bars $=100 \mu \mathrm{m})$. 


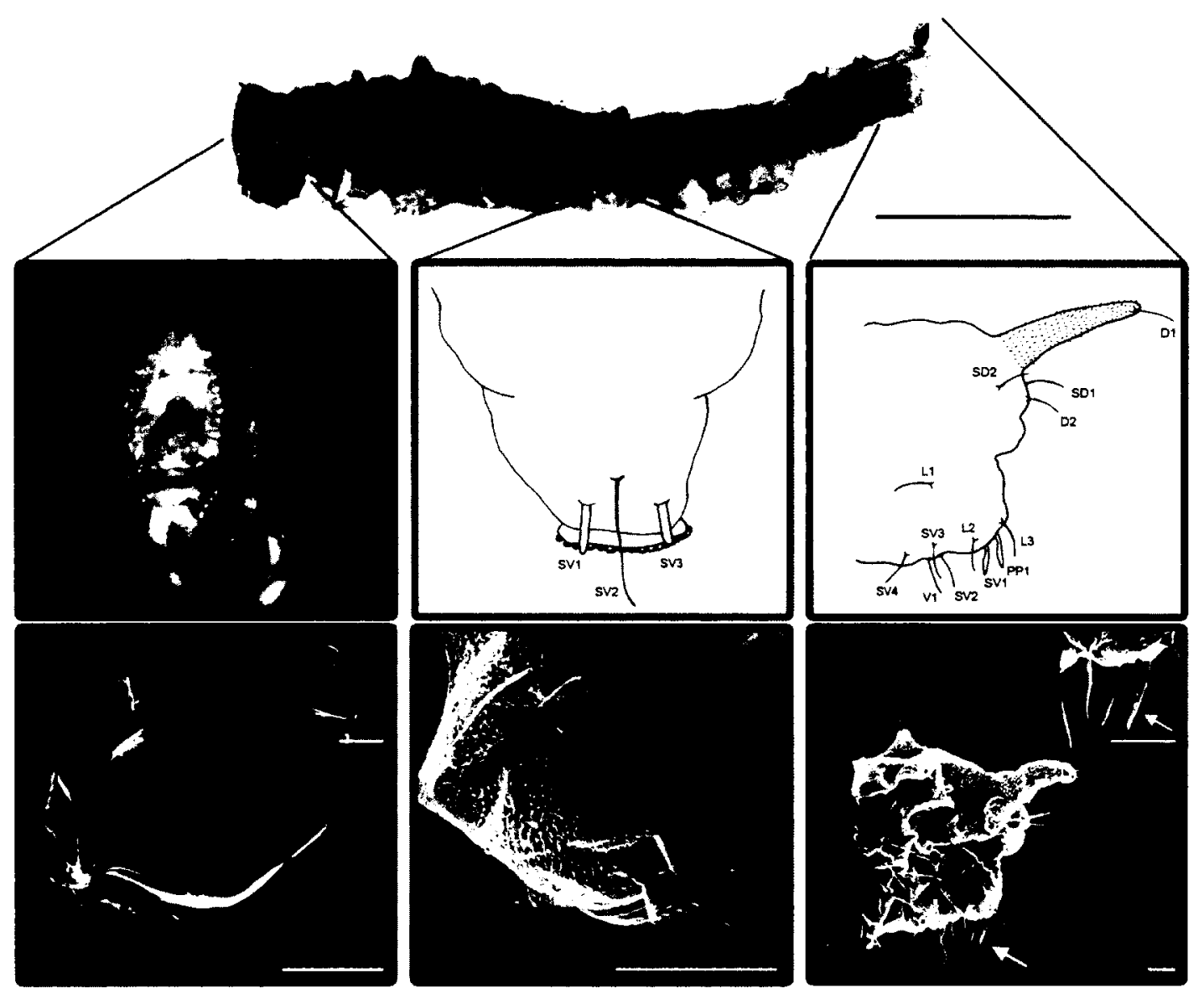


Fig. A.23. Morphological characters related to territorial behaviour in Falcaria lacertinaria. (a) Lateral view of the whole caterpillar (scale bar $=2 \mathrm{~mm}$ ). (b) Anterior view of the head capsule (scale bar $=0.5 \mathrm{~mm}$ ). (c) SEMs of lateral and ventral (inset) views of the mandibles (scale bars $=100 \mu \mathrm{m}$ ). (d) Drawing of a lateral view of the proleg on the third abdominal segment (A3) (e) SEM of a lateral view of the proleg on A3 (scale bar $=200 \mu \mathrm{m}$ ). (f) Drawing of a lateral view the terminal abdominal segment (A10) with named setae. (g) SEM of a posterior view of A10 showing the location of the PP1 seta (arrow; scale bar $=1 \mathrm{~mm}$ ) with a close-up of the PP1 seta (inset; arrow; scale bar $=10$ $\mu \mathrm{m})$. 


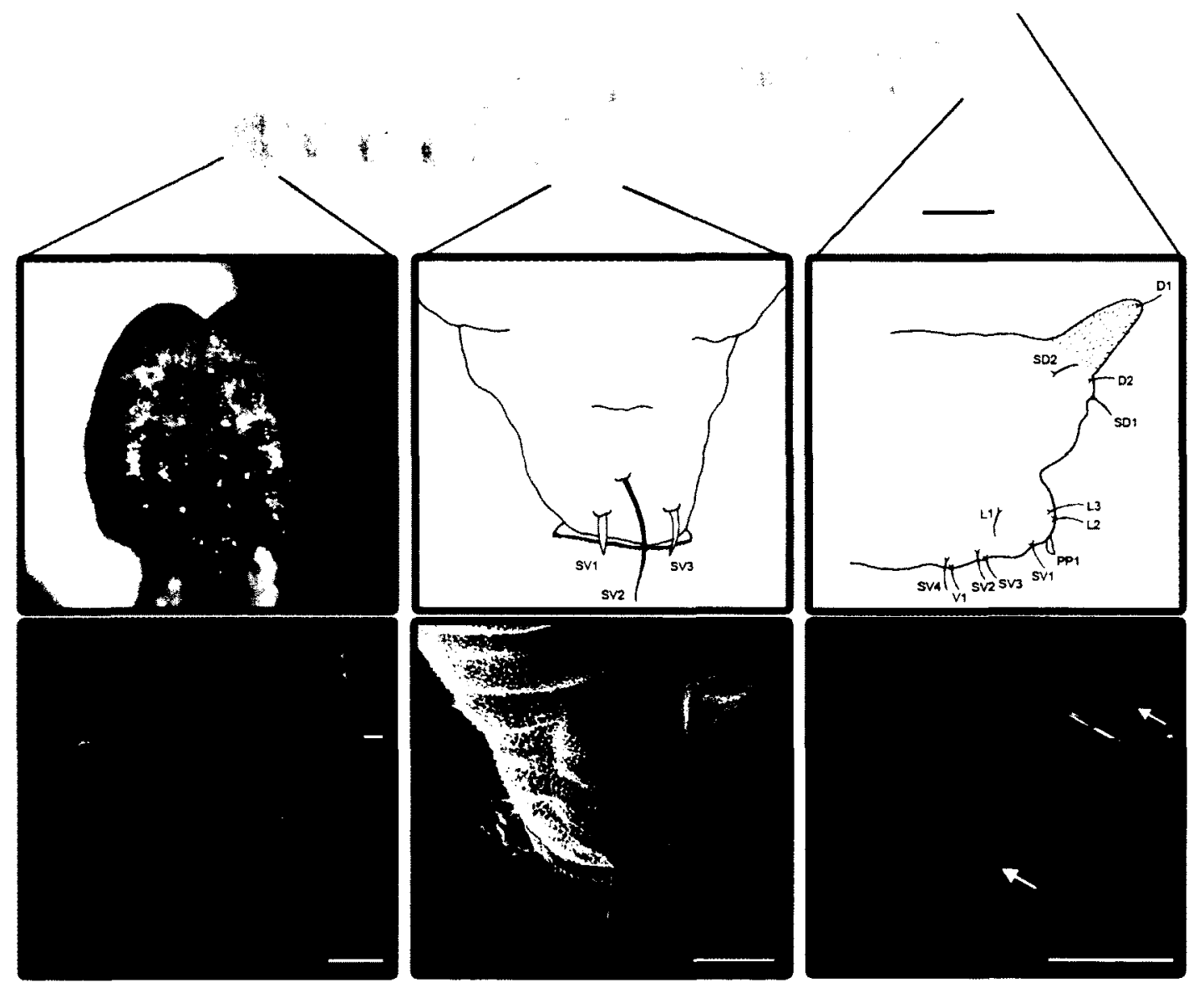


on the outer planta region, where SV1 and SV3 are modified (Fig. A.23d,e). Larvae do not possess prolegs on the terminal abdominal segment and possess a short, fleshy caudal projection (Fig. A.23a,f,g). Larvae possess modified PP1 setae on the anal segment, and no other modified setae on this segment (Fig. A.23f,g). Morphological characters are summarized in Table 2.3 .

Habrosyne pyritoides (Thyatirinae)

Morphology

The head capsule of late instar larvae is not flattened dorsally (Fig. A.24a,b). Mandibles have eight distal teeth on the incisor area and two ridges on the oral surface (Fig. A.24c). The abdominal prolegs (excluding the anal prolegs) bear three unmodified setae on the outer planta region (Fig. A.24d,e). Larvae possess reduced prolegs on the terminal abdominal segment that bear crochets (Fig. A.24a,f,g). Larvae do not possess any modified setae on the anal segment (Fig. A.24f,g). Morphological characters are summarized in Table 2.3 .

Watsonalla binaria (Drepaninae) Morphology

The head capsule of late instar larvae is not flattened dorsally (Fig. A.25a,b). Mandibles have no distal teeth on the incisor area and no ridges on the oral surface (Fig. A.25c). The abdominal prolegs (excluding the anal prolegs) bear three setae on the outer planta region, where SV1 and SV3 are modified (Fig. A.25d,e). Larvae do not possess prolegs on the terminal abdominal segment and possess a short, fleshy causal projection 
Fig. A.24. Morphological characters related to territorial behaviour in Habrosyne pyritoides. (a) Lateral view of the whole caterpillar (scale bar $=2 \mathrm{~mm}$ ). (b) Anterior view of the head capsule (scale bar $=0.5 \mathrm{~mm}$ ). (c) SEMs of lateral and ventral (inset) views of the mandibles (scale bars $=100 \mu \mathrm{m}$ ). (d) Drawing of a lateral view of the proleg on the third abdominal segment (A3) (e) SEM of a lateral view of the proleg on A3 (scale bar = $200 \mu \mathrm{m}$ ). (f) Drawing of a lateral view the terminal abdominal segment (A10) with named setae. (g) SEM of a posterior view of A10 showing the location of the PP1 seta (arrow; scale bar $=1 \mathrm{~mm}$ ) with a close-up of the PP1 seta (inset; arrow; scale bars $=100$ $\mu \mathrm{m})$ 


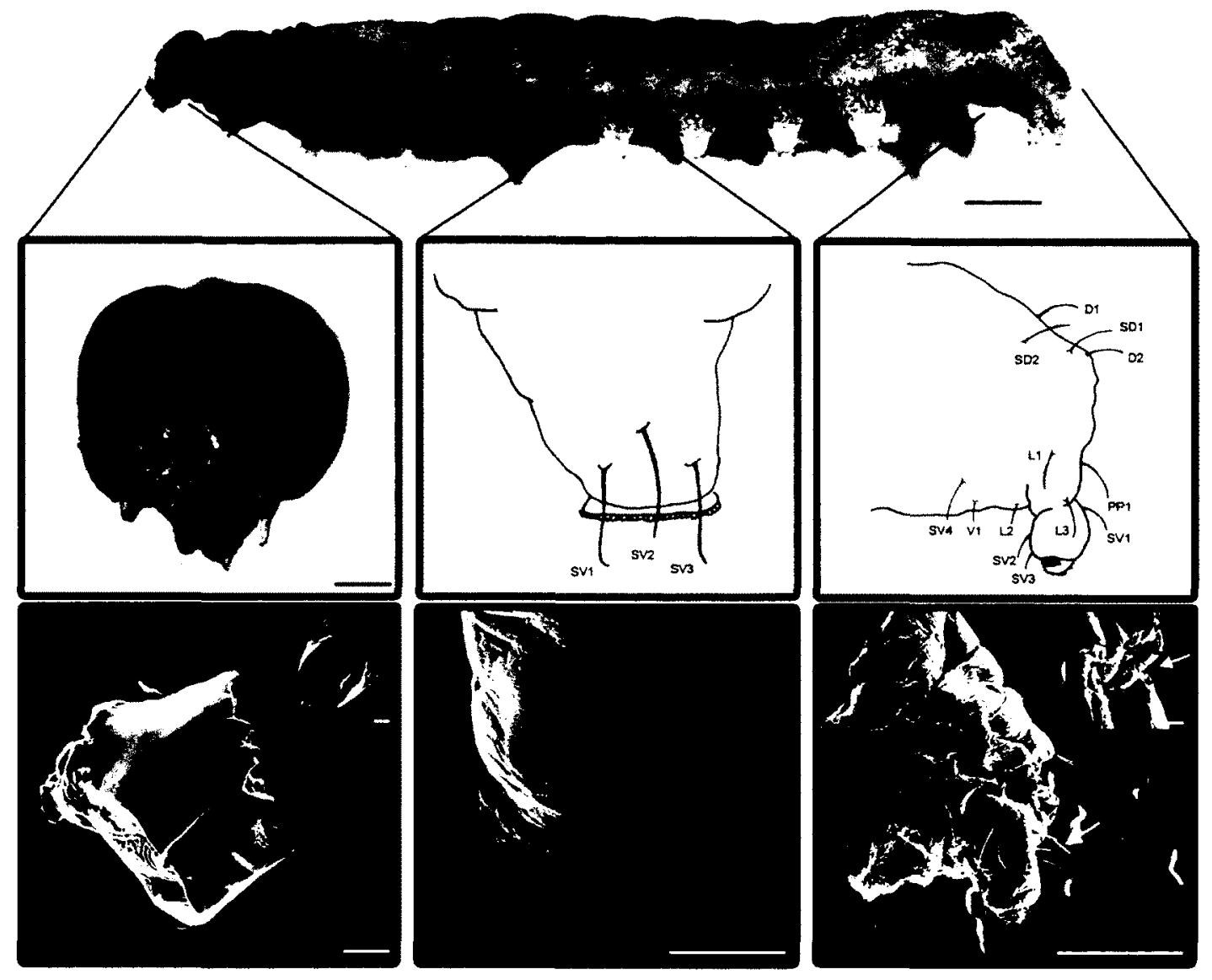


Fig. A.25. Morphological characters related to territorial behaviour in Watsonalla binaria. (a) Lateral view of the whole caterpillar (scale bar $=1 \mathrm{~mm}$ ). (b) Anterior view of the head capsule (scale bar $=0.5 \mathrm{~mm}$ ). (c) SEMs of lateral and ventral (inset) views of the mandibles (scale bars $=100 \mu \mathrm{m}$ ). (d) Drawing of a lateral view of the proleg on the third abdominal segment (A3) (e) SEM of a lateral view of the proleg on A3 (scale bar $=200$ $\mu \mathrm{m})$. (f) Drawing of a lateral view the terminal abdominal segment (A10) with named setae. (g) SEM of a posterior view of A10 showing the location of the PP1 seta (arrow; scale bar $=1 \mathrm{~mm}$ ) with a close-up of the PP1 seta (inset; arrow; scale bar $=100 \mu \mathrm{m}$ ). 


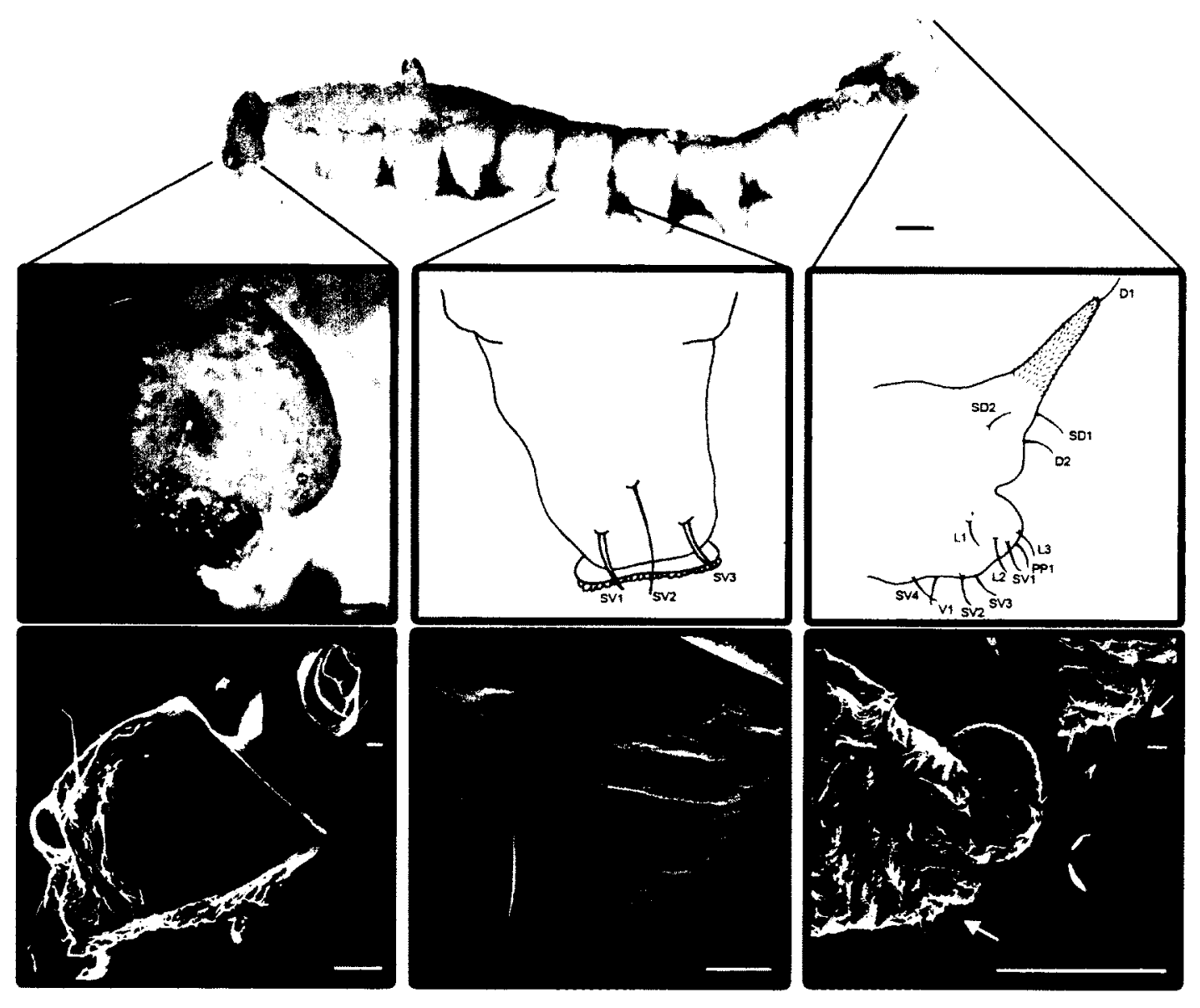


(Fig. A.25a,f,g). Larvae do not possess modified setae on the anal segment (Fig. A.25f,g). Morphological characters are summarized in Table 2.3.

Watsonalla uncinula (Drepaninae)

Morphology

The head capsule of late instar larvae is not flattened dorsally (Fig. A.26a,b). Mandibles have no distal teeth on the incisor area and one ridge on the oral surface (Fig. A.26c). The abdominal prolegs (excluding the anal prolegs) bear three setae on the outer planta region, where SV1 and SV3 are modified (Fig. A.26d,e). Larvae do not possess prolegs on the terminal abdominal segment and possess a short, fleshy causal projection (Fig. A.26a,f,g). Larvae do not possess modified setae on the anal segment (Fig. A.26f,g). Morphological characters are summarized in Table 2.3.

Summary of vibration characteristics

Temporal and spectral characteristics of vibrations by species are summarized in Table A.1. 
Fig. A.26. Morphological characters related to territorial behaviour in Watsonalla uncinula. (a) Lateral view of the whole caterpillar (scale bar $=2 \mathrm{~mm}$ ). (b) Anterior view of the head capsule (scale bar $=0.5 \mathrm{~mm}$ ). (c) SEMs of lateral and ventral (inset) views of the mandibles (scale bars $=100 \mu \mathrm{m}$ ). (d) Drawing of a lateral view of the proleg on the third abdominal segment (A3) (e) SEM of a lateral view of the proleg on A3 (scale bar = $200 \mu \mathrm{m}$; photo credit: T. Nevills). (f) Drawing of a lateral view the terminal abdominal segment (A10) with named setae. (g) SEM of a posterior view of A10 showing the location of the PP1 seta (arrow; scale bar $=1 \mathrm{~mm}$ ) with a close-up of the PP1 seta (inset; arrow; scale bars $=100 \mu \mathrm{m}$ ). 


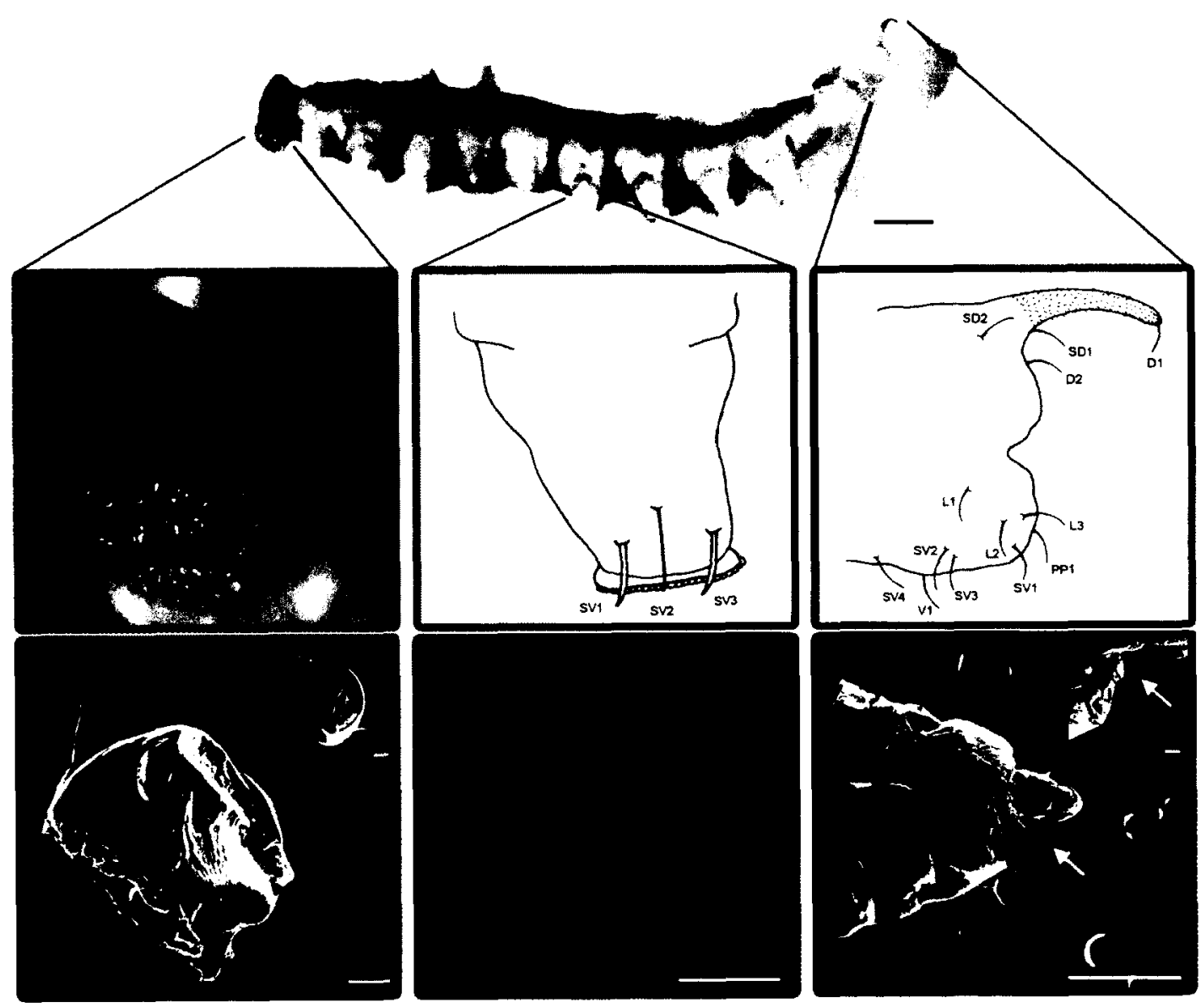


Table A.1. Temporal, spectral, relative amplitude and rate data for all vibrations produced during encounters with conspecifics in 10 species of Drepanidae. Sample sizes are given in number of signals from number of individuals.

\begin{tabular}{|c|c|c|c|c|c|c|c|c|}
\hline Taxon & $\begin{array}{l}\text { Duration of } \\
\text { Signal (ms) }\end{array}$ & $\begin{array}{l}\text { Rel. Amplitude } \\
\text { (Times } \\
\text { Baseline) }\end{array}$ & $\begin{array}{c}\text { Dominant } \\
\text { Frequency } \\
(\mathbf{H z})\end{array}$ & $\begin{array}{c}\text { Bandwidth at } \\
-3 \mathrm{~dB}(\mathrm{~Hz})\end{array}$ & $\begin{array}{l}\text { Bandwidth at } \\
-10 \mathrm{~dB}(\mathrm{~Hz})\end{array}$ & $\begin{array}{c}\text { Signals per } \\
\text { Bout }\end{array}$ & $\begin{array}{c}\text { Rate at } \\
\text { Close } \\
\text { (signals } / 5 \mathrm{~s} \text { ) }\end{array}$ & $\begin{array}{l}\text { Significant Rate } \\
\text { Changes }\end{array}$ \\
\hline \multicolumn{9}{|l|}{$\begin{array}{l}\text { MANDIBLE } \\
\text { SCRAPING } \\
\text { Drepaninae }\end{array}$} \\
\hline Drepana arcuata & $\begin{array}{l}59.2 \pm 17 \\
(n=49 \text { from } 22)\end{array}$ & $\begin{array}{l}27.2 \pm 17.3 \\
(n=20 \text { from } 4)\end{array}$ & $\begin{array}{l}17.7 \pm 11.9 \\
(n=20 \text { from } 4)\end{array}$ & $\begin{array}{l}5.2 \pm 1.3 \\
(n=20 \text { from } 4)\end{array}$ & $\begin{array}{l}12.7 \pm 3.1 \\
(\mathrm{n}=20 \text { from } 4)\end{array}$ & $\begin{array}{l}2.6 \pm 3.2 \\
(n=25 \text { from } 5)\end{array}$ & $\begin{array}{c}3.23 \pm 1.52 \\
(n=16)\end{array}$ & $\begin{array}{l}\text { MID to CLOSE } \\
(n>0\end{array}$ \\
\hline D. curvatula & $\begin{array}{l}101.0 \pm 23.8 \\
(\mathrm{n}=25 \text { from } 5)\end{array}$ & $\begin{array}{l}11.7 \pm 4.7 \\
(\mathrm{n}=10 \text { from } 2)\end{array}$ & $\begin{array}{l}22.3 \pm 5.4 \\
(\mathrm{n}=10 \text { from } 2)\end{array}$ & $\begin{array}{l}6.0 \pm 0.1 \\
(\mathrm{n}=10 \text { from } 2)\end{array}$ & $\begin{array}{l}14.0 \pm 5.5 \\
(\mathrm{n}=10 \text { from } 2)\end{array}$ & $\begin{array}{l}0.1 \pm 0.1 \\
(\mathrm{n}=40 \text { from } 9)\end{array}$ & $\begin{array}{l}0.25 \pm 0.29 \\
(\mathrm{n}=11)\end{array}$ & $\begin{array}{l}\text { FAR to CLOSE } \\
(p=0.011, n=11)\end{array}$ \\
\hline D. falcataria & $\begin{array}{l}94.3 \pm 3.1 \\
(\mathrm{n}=15 \text { from } 3)\end{array}$ & $\begin{array}{l}12.9 \pm 1.7 \\
(\mathrm{n}=18 \text { from } 5)\end{array}$ & $\begin{array}{l}12.7 \pm 6.2 \\
(\mathrm{n}=18 \text { from } 5)\end{array}$ & $\begin{array}{l}5.7 \pm 0.8 \\
(\mathrm{n}=18 \text { from } 5)\end{array}$ & $\begin{array}{l}10.6 \pm 1.7 \\
(\mathrm{n}=18 \text { from } 5)\end{array}$ & $\begin{array}{l}1.13 \pm 0.58 \\
(\mathrm{n}=15 \text { from } 3)\end{array}$ & $\begin{array}{l}1.08 \pm 1.01 \\
(n=3)\end{array}$ & $\begin{array}{l}\text { None } \\
(n=3)\end{array}$ \\
\hline Oreta rosea & $\begin{array}{l}125.6 \pm 21.4 \\
(n=69 \text { from } 17)\end{array}$ & $\begin{array}{l}31.4 \pm 14.4 \\
(\mathrm{n}=25 \text { from } 5)\end{array}$ & $\begin{array}{l}26.2 \pm 5.1 \\
(\mathrm{n}=25 \text { from } 5)\end{array}$ & $\begin{array}{l}6.8 \pm 1.3 \\
(n=25 \text { from } 5)\end{array}$ & $\begin{array}{l}14.5 \pm 3.4 \\
(n=25 \text { from } 5)\end{array}$ & $\begin{array}{l}1.6 \pm 2.0 \\
(n=71 \text { from } \\
16)\end{array}$ & $\begin{array}{l}0.81 \pm 1.5 \\
(n=18)\end{array}$ & $\begin{array}{l}\text { MID to CLOSE } \\
(p=0.001, n=18)\end{array}$ \\
\hline \multirow{4}{*}{$\begin{array}{l}\text { Thyatirinae } \\
\text { Ochropacha } \\
\text { duplaris } \\
\text { Tethea or }\end{array}$} & & & & & & & & \\
\hline & $211.2 \pm 42.6$ & $22.0 \pm 7.3$ & $32.9 \pm 12.0$ & $6.6 \pm 1.6$ & 24.3 & $2.6 \pm 1.7$ & \pm 0.37 & None \\
\hline & $(n=10$ from 4$)$ & $(\mathrm{n}=16$ from 5$)$ & $(\mathrm{n}=16$ from 5$)$ & $(\mathrm{n}=16$ from 5$)$ & $(\mathrm{n}=16$ from 5$)$ & $(n=11$ from 4$)$ & $(n=6)$ & $(\mathrm{n}=6)$ \\
\hline & $\begin{array}{l}136.7 \pm 50.8 \\
(n=40 \text { from } 8)\end{array}$ & $\begin{array}{l}21.6 \pm 12.3 \\
(n=25 \text { from } 5)\end{array}$ & $\begin{array}{l}351.1 \pm 65.2 \\
(n=25 \text { from } 5)\end{array}$ & $\begin{array}{l}17.4 \pm 1.6 \\
(n=25 \text { from } 5)\end{array}$ & $\begin{array}{l}61.2 \pm 9.5 \\
(n=25 \text { from } 5)\end{array}$ & $\begin{array}{l}4 \pm 1 \\
(n=48 \text { from } \\
11)\end{array}$ & $\begin{array}{l}2.98 \pm 2.7 \\
(\mathrm{n}=11)\end{array}$ & $\begin{array}{l}\text { FAR to CLOSE } \\
(p=0.021, n=11)\end{array}$ \\
\hline Tetheela fluctuosa & $\begin{array}{l}289.1 \pm 50.8 \\
(\mathrm{n}=20 \text { from } 5)\end{array}$ & $\begin{array}{l}82.8 \pm 28.1 \\
(\mathrm{n}=15 \text { from } 3)\end{array}$ & $\begin{array}{l}59.6 \pm 3.3 \\
(\mathrm{n}=15 \text { from } 3)\end{array}$ & $\begin{array}{l}7.5 \pm 0.9 \\
(\mathrm{n}=15 \text { from } 3)\end{array}$ & $\begin{array}{l}20.1 \pm 2.2 \\
(\mathrm{n}=15 \text { from } 3)\end{array}$ & $\begin{array}{l}1.78 \pm 0.81 \\
(\mathrm{n}=22 \text { from } 5)\end{array}$ & $\begin{array}{l}1.3 \pm 0.89 \\
(\mathrm{n}=5)\end{array}$ & $\begin{array}{l}\text { None } \\
(\mathrm{n}=5)\end{array}$ \\
\hline \multicolumn{9}{|l|}{$\begin{array}{l}\text { MANDIBLE } \\
\text { DRUMMING } \\
\text { Drepaninae }\end{array}$} \\
\hline D. arcuata & $\begin{array}{l}15.9 \pm 12.5 \\
(n=180 \text { from } 30)\end{array}$ & $\begin{array}{l}63.03 \pm 21.3 \\
(\mathrm{n}=25 \text { from } 5)\end{array}$ & $\begin{array}{l}22.0 \pm 16.9 \\
(n=25 \text { from } 5)\end{array}$ & $\begin{array}{l}7.0 \pm 2.1 \\
(n=25 \text { from } 5)\end{array}$ & $\begin{array}{l}16.3 \pm 10.4 \\
(n=25 \text { from } 5)\end{array}$ & $\begin{array}{l}20.8 \pm 9.6 \\
(n=25 \text { from } 5)\end{array}$ & $\begin{array}{l}2.98 \pm 2.0 \\
(n=16)\end{array}$ & $\begin{array}{l}\text { FAR to MID } \\
(p=0.015) \text { returned to } \\
\text { FAR at CLOSE } \\
(n=16)\end{array}$ \\
\hline & $\begin{array}{l}73.5 \pm 9.3 \\
(\mathrm{n}=20 \text { from } 5)\end{array}$ & $\begin{array}{l}20.8 \pm 11.6 \\
(\mathrm{n}=12 \text { from } 3)\end{array}$ & $\begin{array}{l}26.9 \pm 7.9 \\
(\mathrm{n}=12 \text { from } 3)\end{array}$ & $\begin{array}{l}6.8 \pm 1.5 \\
(\mathrm{n}=12 \text { from } 3)\end{array}$ & $\begin{array}{l}13.4 \pm 1.7 \\
(n=12 \text { from } 3)\end{array}$ & $\begin{array}{l}6.7 \pm 13.1 \\
(n=40 \text { from } 9)\end{array}$ & $\begin{array}{l}0.63 \pm 0.78 \\
(n=11)\end{array}$ & $\begin{array}{l}\text { None } \\
(n=11)\end{array}$ \\
\hline D. falcataria & $\begin{array}{l}62.0 \pm 1.4 \\
(\mathrm{n}=14 \text { from } 3)\end{array}$ & $\begin{array}{l}24.3 \pm 12.3 \\
(\mathrm{n}=23 \text { from } 5)\end{array}$ & $\begin{array}{l}83.3 \pm 79.0 \\
(\mathrm{n}=23 \text { from } 5)\end{array}$ & $\begin{array}{l}15.3 \pm 10.3 \\
(n=23 \text { from } 5)\end{array}$ & $\begin{array}{l}46.5 \pm 39.1 \\
(n=23 \text { from } 5)\end{array}$ & $\begin{array}{l}0.53 \pm 0.76 \\
(n=15 \text { from } 3)\end{array}$ & $\begin{array}{l}0.41 \pm 0.52 \\
(n=3)\end{array}$ & $\begin{array}{l}\text { None } \\
(n=3)\end{array}$ \\
\hline
\end{tabular}




\begin{tabular}{|c|c|c|c|c|c|c|c|c|}
\hline Taxon & $\begin{array}{l}\text { Duration of } \\
\text { Signal (ms) }\end{array}$ & $\begin{array}{l}\text { Rel. Amplitude } \\
\text { (Times } \\
\text { Baseline) }\end{array}$ & $\begin{array}{c}\text { Dominant } \\
\text { Frequency } \\
(\mathbf{H z})\end{array}$ & $\begin{array}{c}\text { Bandwidth at } \\
-3 \mathrm{~dB}(\mathrm{~Hz})\end{array}$ & $\begin{array}{l}\text { Bandwidth at } \\
-10 \mathrm{~dB}(\mathrm{~Hz})\end{array}$ & $\begin{array}{c}\text { Signals per } \\
\text { Bout }\end{array}$ & $\begin{array}{c}\text { Rate at } \\
\text { Close } \\
\text { (signals } / 5 \mathrm{~s} \text { ) }\end{array}$ & $\begin{array}{c}\text { Significant Rate } \\
\text { Changes }\end{array}$ \\
\hline Falcaria bilineata & $\begin{array}{l}37.9 \pm 13.1 \\
(n=70 \text { from } 14)\end{array}$ & No laser files & No laser files & No laser files & No laser files & $\begin{array}{l}3.8 \pm 1.2 \\
(n=14 \text { from } 5)\end{array}$ & $\begin{array}{l}2.6 \pm 1.9 \\
(\mathrm{n}=21)\end{array}$ & $\begin{array}{l}\text { MID to CLOSE } \\
(\mathrm{p}<0.001, \mathrm{n}=21)\end{array}$ \\
\hline O. rosea & $\begin{array}{l}66.9 \pm 20.1 \\
(n=81 \text { from } 19)\end{array}$ & $\begin{array}{l}50.3 \pm 19.6 \\
(n=25 \text { from } 5)\end{array}$ & $\begin{array}{l}59.0 \pm 12.4 \\
(n=25 \text { from } 5)\end{array}$ & $\begin{array}{l}12.2 \pm 3.1 \\
(n=25 \text { from } 5)\end{array}$ & $\begin{array}{l}34.2 \pm 15.4 \\
(n=25 \text { from } 5)\end{array}$ & $\begin{array}{l}2.0 \pm 1.2 \\
(\mathrm{n}=71 \text { from } \\
16)\end{array}$ & $\begin{array}{l}0.76 \pm 0.69 \\
(n=18)\end{array}$ & $\begin{array}{l}\text { MID to CLOSE } \\
(p<0.001, n=18)\end{array}$ \\
\hline W. cultraria & $\begin{array}{l}29.2 \pm 80.4 \\
(\mathbf{n}=3 \text { from } 1)\end{array}$ & No laser files & No laser files & No laser files & No laser files & $\begin{array}{l}0.2 \pm 0.3 \\
(\mathrm{n}=6 \text { from } 3)\end{array}$ & $\begin{array}{l}0.083 \pm 0.14 \\
(n=3)\end{array}$ & $\begin{array}{l}\text { None } \\
(\mathrm{n}=3)\end{array}$ \\
\hline \multicolumn{9}{|l|}{$\begin{array}{l}\text { ANAL } \\
\text { SCRAPING } \\
\text { Drepaninae }\end{array}$} \\
\hline D. arcuata & $\begin{array}{l}366.9 \pm 145.4 \\
(\mathrm{n}=112 \text { from } 30)\end{array}$ & $\begin{array}{l}13.37 \pm 11.95 \\
(n=25 \text { from } 5)\end{array}$ & $\begin{array}{l}39.8 \pm 3.9 \\
(\mathrm{n}=25 \text { from } 5)\end{array}$ & $\begin{array}{l}7.6 \pm 1.7 \\
(\mathrm{n}=25 \text { from } 5)\end{array}$ & $\begin{array}{l}17.2 \pm 1.2 \\
(\mathrm{n}=25 \text { from } 5)\end{array}$ & $\begin{array}{l}10.3 \pm 2.7 \\
(\mathrm{n}=25 \text { from } 5)\end{array}$ & $\begin{array}{l}2.84 \pm 0.75 \\
(n=16)\end{array}$ & $\begin{array}{l}\text { FAR to MID } \\
(p=0.033, n=16)\end{array}$ \\
\hline D. curvatula & $\begin{array}{l}855.0 \pm 369.2 \\
(n=42 \text { from } 9)\end{array}$ & $\begin{array}{l}11.70 \pm 12.49 \\
(\mathrm{n}=23 \text { from } 5)\end{array}$ & $\begin{array}{l}53.2 \pm 26.3 \\
(\mathrm{n}=25 \text { from } 5)\end{array}$ & $\begin{array}{l}9.6 \pm 2.0 \\
(\mathrm{n}=25 \text { from } 5)\end{array}$ & $\begin{array}{l}20.0 \pm 5.0 \\
(n=25 \text { from } 5)\end{array}$ & $\begin{array}{l}2.9 \pm 2.0 \\
(n=40 \text { from } 9)\end{array}$ & $\begin{array}{l}2.5 \pm 1.17 \\
(\mathrm{n}=11)\end{array}$ & $\begin{array}{l}\text { FAR to MID } \\
(p<0.001, n=11)\end{array}$ \\
\hline D. falcataria & $\begin{array}{l}536.9 \pm 130.7 \\
(n=11 \text { from } 3)\end{array}$ & $\begin{array}{l}9.72 \pm 5.36 \\
(n=13 \text { from } 3)\end{array}$ & $\begin{array}{l}36.2 \pm 6.7 \\
(n=22 \text { from } 5)\end{array}$ & $\begin{array}{l}7.38 \pm 2.0 \\
(\mathrm{n}=22 \text { from } 5)\end{array}$ & $\begin{array}{l}21.5 \pm 7.4 \\
(\mathrm{n}=22 \text { from } 5)\end{array}$ & $\begin{array}{l}2.6 \pm 0.7 \\
(\mathrm{n}=15 \text { from } 3)\end{array}$ & $\begin{array}{l}1.67 \pm 0.14 \\
(n=3)\end{array}$ & None $(n=3)$ \\
\hline$F$. bilineata & $\begin{array}{l}125.0 \pm 26.7 \\
(n=65 \text { from } 13)\end{array}$ & No laser files & No laser files & No laser files & No laser files & $\begin{array}{l}4.1 \pm 0.8 \\
(n=14 \text { from } 5)\end{array}$ & $\begin{array}{l}2.15 \pm 1.73 \\
(n=21)\end{array}$ & $\begin{array}{l}\text { MID to CLOSE } \\
(p<0.001, n=21)\end{array}$ \\
\hline W. cultraria* & $\begin{array}{l}532.5 \pm 105.4 \\
(\mathrm{n}=9 \text { from } 3)\end{array}$ & No laser files & No laser files & No laser files & No laser files & $\begin{array}{l}1.7 \pm 0.4 \\
(\mathrm{n}=6 \text { from } 3)\end{array}$ & $\begin{array}{l}0.25 \pm 0.25 \\
(n=3)\end{array}$ & $\begin{array}{l}\text { None } \\
(\mathrm{n}=3)\end{array}$ \\
\hline \multicolumn{9}{|l|}{ Thyatirinae } \\
\hline T. fluctuosa* & $\begin{array}{l}1513.7 \pm 110.5 \\
(n=20 \text { from } 5)\end{array}$ & See LT & See LT & See LT & See LT & $\begin{array}{l}1.0 \pm 1.2 \\
(\mathrm{n}=22 \text { from } 5)\end{array}$ & $\begin{array}{l}0.86 \pm 0.75 \\
(n=5)\end{array}$ & $\begin{array}{l}\text { None } \\
(\mathrm{n}=5)\end{array}$ \\
\hline Thyatira batis* & $\begin{array}{l}1524.9 \pm 540.5 \\
(n=20 \text { from } 6)\end{array}$ & See LT & See LT & See LT & See LT & $\begin{array}{l}0.7 \pm 0.8 \\
(\mathrm{n}=31 \text { from } 7)\end{array}$ & $\begin{array}{l}0.25 \pm 0.35 \\
(\mathrm{n}=7)\end{array}$ & $\begin{array}{l}\text { None } \\
(n=7)\end{array}$ \\
\hline \multicolumn{9}{|l|}{$\begin{array}{l}\text { LATERAL } \\
\text { TREMULATION } \\
\text { Drepaninae }\end{array}$} \\
\hline O. rosea & $\begin{array}{l}1966.3 \pm 581.0 \\
(\mathrm{n}=32 \text { from } 9)\end{array}$ & $\begin{array}{l}11.1 \pm 4.5 \\
(\mathrm{n}=6 \text { from } 5)\end{array}$ & $\begin{array}{l}55.6 \pm 18.2 \\
(n=6 \text { from } 5)\end{array}$ & $\begin{array}{l}8.5 \pm 2.1 \\
(n=6 \text { from } 5)\end{array}$ & $\begin{array}{l}20.0 \pm 7.8 \\
(n=6 \text { from } 5)\end{array}$ & $\begin{array}{l}0.4 \pm 0.4 \\
(\mathrm{n}=71 \text { from } \\
16)\end{array}$ & $\begin{array}{l}0.083 \pm 0.19 \\
(\mathrm{n}=18)\end{array}$ & $\begin{array}{l}\text { None } \\
(n=18)\end{array}$ \\
\hline W. cultraria ${ }^{* *}$ & $\begin{array}{l}483.3 \pm 125.2 \\
(\mathrm{n}=8 \text { from } 3)\end{array}$ & No laser files & No laser files & No laser files & No laser files & $\begin{array}{l}1.33 \pm 0.58 \\
(\mathrm{n}=6 \text { from } 3)\end{array}$ & $\begin{array}{l}0.17 \pm 0.29 \\
(\mathrm{n}=3)\end{array}$ & $\begin{array}{l}\text { None } \\
(\mathrm{n}=3)\end{array}$ \\
\hline \multicolumn{9}{|l|}{ Thyatirinae } \\
\hline T. fluctuos $a^{* *}$ & $\begin{array}{l}957.5 \pm 162.0 \\
(\mathrm{n}=20 \text { from } 5)\end{array}$ & $\begin{array}{l}58.2 \pm 59.0 \\
(\mathrm{n}=17 \text { from } 3)\end{array}$ & $\begin{array}{l}7.8 \pm 4.0 \\
(\mathrm{n}=17 \text { from } 3)\end{array}$ & $\begin{array}{l}5.5 \pm 0.5 \\
(\mathrm{n}=17 \text { from } 3)\end{array}$ & $\begin{array}{l}10.9 \pm 3.2 \\
(\mathrm{n}=17 \text { from } 3)\end{array}$ & $\begin{array}{l}0.76 \pm 0.03 \\
(n=22 \text { from } 5)\end{array}$ & $\begin{array}{l}0.15 \pm 0.22 \\
(\mathrm{n}=5)\end{array}$ & $\begin{array}{l}\text { None } \\
(n=5)\end{array}$ \\
\hline T. hatis** & $\begin{array}{l}1602.7 \pm 1036.9(\mathrm{n} \\
=22 \text { from } 6)\end{array}$ & $\begin{array}{l}48.8+9.5 \\
(\mathrm{n}=14 \text { from } 5)\end{array}$ & $\begin{array}{l}10.9 \pm 1.8 \\
(\mathrm{n}=14 \text { from } 5)\end{array}$ & $\begin{array}{l}6.1 \pm 0.9 \\
(\mathrm{n}=14 \text { from } 5)\end{array}$ & $\begin{array}{l}12.7 \pm 2.3 \\
(\mathrm{n}=14 \text { from } 5)\end{array}$ & $\begin{array}{l}0.49 \pm 0.51 \\
(\mathrm{n}=31 \text { from } 7)\end{array}$ & $\begin{array}{l}0.04 \pm 0.10 \\
(\mathrm{n}=7)\end{array}$ & $\begin{array}{l}\text { None } \\
(\mathrm{n}=7)\end{array}$ \\
\hline
\end{tabular}




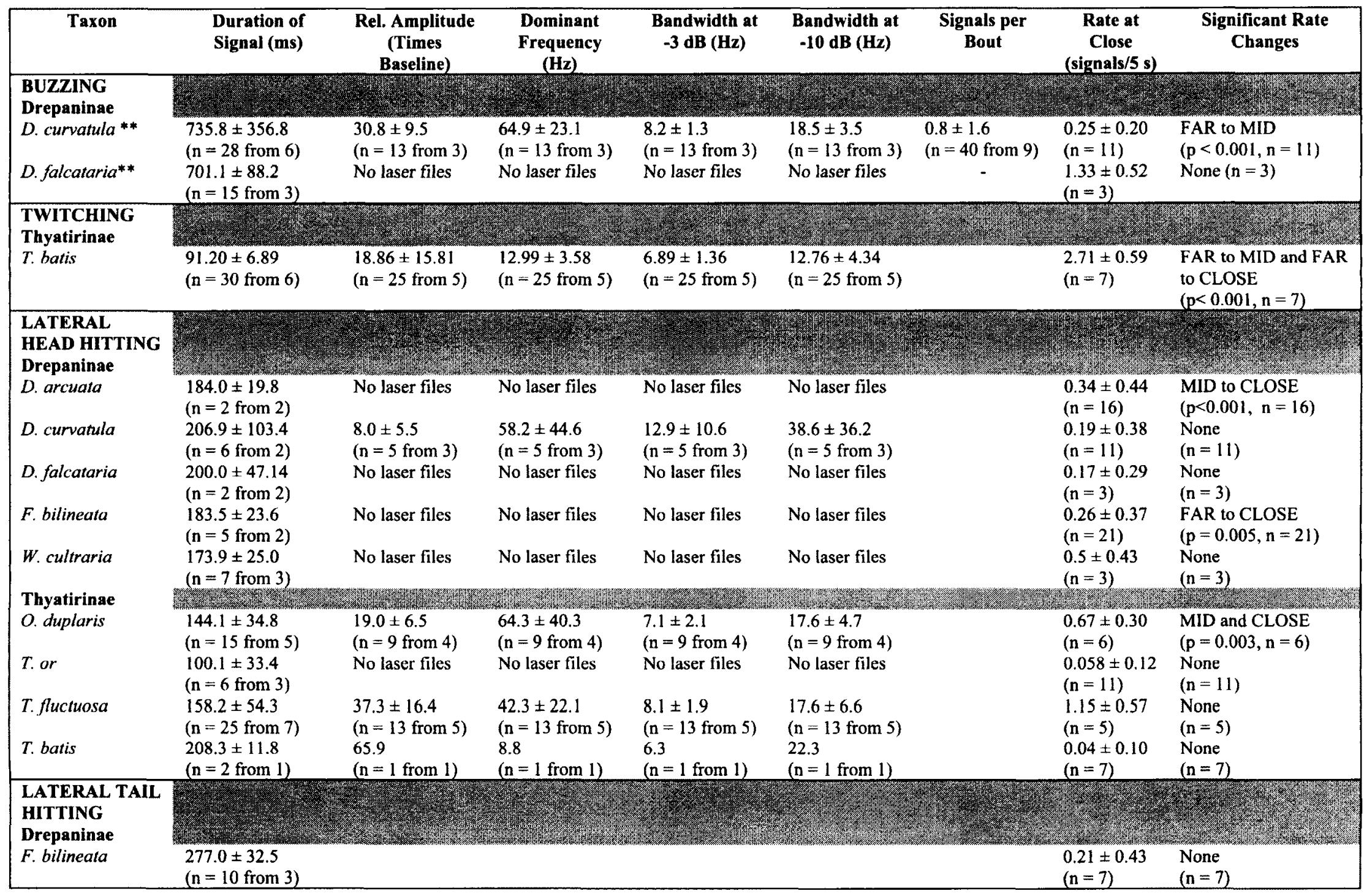




\begin{tabular}{|c|c|c|c|c|c|c|c|c|}
\hline Taxon & $\begin{array}{l}\text { Duration of } \\
\text { Signal (ms) }\end{array}$ & $\begin{array}{l}\text { Rel. Amplitude } \\
\text { (Times } \\
\text { Baseline) }\end{array}$ & $\begin{array}{c}\text { Dominant } \\
\text { Frequency } \\
\text { (Hz) }\end{array}$ & $\begin{array}{l}\text { Bandwidth at } \\
-3 \mathrm{~dB}(\mathrm{~Hz})\end{array}$ & $\begin{array}{l}\text { Bandwidth at } \\
-10 \mathrm{~dB}(\mathrm{~Hz})\end{array}$ & $\begin{array}{c}\text { Signals per } \\
\text { Bout }\end{array}$ & 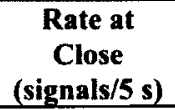 & $\begin{array}{c}\text { Significant Rate } \\
\text { Changes }\end{array}$ \\
\hline $\begin{array}{l}\text { O. rosea } \\
\text { W. cultraria }\end{array}$ & $\begin{array}{l}264.2 \pm 113.6 \\
(\mathrm{n}=10 \text { from } 3) \\
187.5 \pm 80.4 \\
(\mathrm{n}=3 \text { from } \mathrm{l})\end{array}$ & & & & & & $\begin{array}{l}0.18 \pm 0.35 \\
(\mathrm{n}=7) \\
0.0 \pm 0.0 \\
(\mathrm{n}=3)\end{array}$ & $\begin{array}{l}\text { MID to CLOSE } \\
(p=0.01, n=7) \\
\text { NA }\end{array}$ \\
\hline $\begin{array}{l}\text { Thyatirinae } \\
\text { O. duplaris } \\
\text { T. fluctuosa } \\
\text { T. batis }\end{array}$ & $\begin{array}{l}112.5 \pm 17.7 \\
(\mathrm{n}=2 \text { from } 1) \\
197.1 \pm 24.6 \\
(\mathrm{n}=13 \text { from } 5) \\
208.3 \pm 11.8 \\
(\mathrm{n}=2 \text { from } 1)\end{array}$ & & & & & & $\begin{array}{l}0.08 \pm 0.20 \\
(n=6) \\
0.15 \pm 0.22 \\
(n=5) \\
0.04 \pm 0.09 \\
(n=7)\end{array}$ & $\begin{array}{l}\text { None } \\
(n=6) \\
\text { None } \\
(n=5) \\
\text { None } \\
(n=7)\end{array}$ \\
\hline $\begin{array}{l}\text { CRAWLING } \\
\text { TOWARDS I } \\
\text { Thyatirinae }\end{array}$ & & & & & & & & \\
\hline $\begin{array}{l}\text { O. duplaris } \\
\text { T. or }\end{array}$ & & & & & & & $\begin{array}{l}0.58 \pm 0.65 \\
(n=6) \\
1.12 \pm 0.77 \\
(n=11)\end{array}$ & $\begin{array}{l}\text { None } \\
(n=6) \\
\text { FAR to MID } \\
(p=0.019, n=11) \\
\text { and MID to CLOSE } \\
(p=0.018, n=11)\end{array}$ \\
\hline T. fluctuosa & & & & & & & $\begin{array}{l}0.15 \pm 0.14 \\
(n=5)\end{array}$ & $\begin{array}{l}\text { None } \\
(\mathrm{n}=5)\end{array}$ \\
\hline $\begin{array}{l}\text { PUSHING } \\
\text { Thyatirinae }\end{array}$ & & & & & & & & 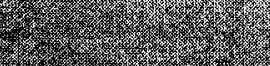 \\
\hline $\begin{array}{l}\text { O. duplaris } \\
\text { T. or }\end{array}$ & $\begin{array}{l}600.6 \pm 208.4 \\
(n=8 \text { from } 3) \\
777.4 \pm 237.1 \\
(n=8 \text { from } 3)\end{array}$ & & & & & & $\begin{array}{l}0.42 \pm 0.547 \\
(\mathrm{n}=6) \\
0.88 \pm 0.52 \\
(\mathrm{n}=11)\end{array}$ & $\begin{array}{l}\text { None } \\
(n=6) \\
\text { FAR and MID to } \\
\text { CLOSE } \\
(p>0.001, n=11)\end{array}$ \\
\hline
\end{tabular}

*represents species that 'pseudo' anal scrape

** represents species that anal scrape or 'pseudo' anal scrape concurrently with lateral tremulation or buzzing 


\section{Appendix B: Sequence Data Used for Phylogenetic Analysis}

\#NEXUS

BEGIN DATA;

DIMENSIONS NTAX $=45$ NCHAR $=1617$;

FORMAT DATATYPE $=$ DNA MISSING $=$ N GAP $=-$ INTERLEAVE ;

MATRIX

I

20

30

40

501

Accinctapubes_albifasciata

NNNNNNNNNNNNNNNNNNNNNNNNNNNNNNNNNNNNNNNNNNNNNNNNNN CCAGTTTGGATTACTGTGTTGTTAAAATTCCAAGATGGGACTTAGCAAAA CGAGTCTGGATTACTGTGTTGTCAAAATTCCAAGATGGGATCTCGCGAAA

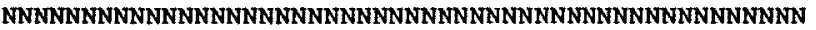
CTAGTTTAGATTATTGTGTTGTAAAAATTCCTAGGTGGGATTTGGCTAAA CAAGCTTAGATTATTGTGTTGTAAAAATTCCTCGATGGGACTTGGCGAAA CAAGTTTAGATTATTGTGTGGTAAAAATTCCTAGGTGGGATTTAGCAAAA CCAGTTTAGATTATTGTGTTGTTAAAATTCCTAGATGGGATTTGGCAAAA CAAGTTTAGATTATTGTGTTGTGAAAATTCCTCGATGGGATTTAGCTAAA CAAGTTTAGATTATTGTGTTGTGAAAATTCCTCGATGGGATTTAGCTAAA CAAGTTTAGATTATTGTGTTGTGAAAATTCCTCGATGGGATTTAGCTAAA CAAGTTTGGATTACTGCGTCGTTAAAATTCCCAGATGGGATTTGGCAAAG CAAGCTTAGACTATTGTGTTGTTAAAATTCCTAGATGGGATATGGCCAAA NNNNNNNNNNNNNNNNNNNNNNNNNNNNNNNNNNNNNNNNNNNNNNNNNNN CTAGCTTAGATTATTGTGTTGTCAAAATCCCTAGGTGGGATTTAGCTAAA CAAGCTTAGATTATTGTGTTGTCAAAATACCTAGATGGGACTTGGCTAAA

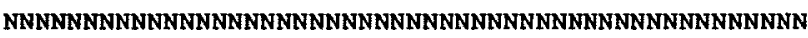
CCAGTTTGGATTATTGTGTTGTAAAAATTCCAAGGTGGGATTTAGCTAAA CTAGTTTGGATTACTGCGTTGTTAAGATACCAAGATGGGACTTAGCTAAA CCAGTTTGGATTATTGTGTTGTAAAAATTCCTAGATGGGACTTGGCAAAA CAAGTTTAGATTATTGTGTTGTCAAAATACCTAGATGGGATTTAGCTAAA CGAGTTTGGATTATTGTGTTATAAAGATTCCTAGATGGGATTTAGCGAAA

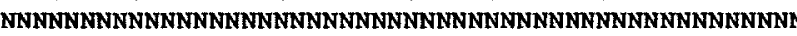
CAAGTTTAGATTATTGTGTTGTGAAAATTCCTCGATGGGATTTAGCTAAA CCAGTTTAGATTATTGTGTTGTTAAAATTCCTAGATGGGATTTGGCAAAA CAAGCTTAGATTATTGTGTTGTCAAAATACCTAGATGGGATTTAGCTAAA CGAGTTTAGATTATTGTGTTGTCAAAATCCCTAGATGGGATATGGCCAAA CCAGCTTGGATTACTGTGTAGTGAAAATTCCAAGATGGGACTTAGCAAAA NNNNNNNNNNNNNNNNNNNNNNNNNNNNNNNNNNNNNNNNNNNNNNNNNN NNNNNNNNNNNNNNNNNNNNNNNNNNNNNNNNNNATGGGACTTAGCAAAA NNNNNNNNNNNNNNNNNNNNNNNNNNNNNNNNNNNNNNNNNNNNGCAAAA CAAGTTTAGATTATTGCGTTGTCAAAATACCTAGATGGGATTTAGCAAAA NNNNNNNNNNNNNNNNNNNNNNNNNNNNNNNNNNNNNNNNNNNNNNNNNN CAAGTTTAGATTATTGTGTTGTCAAAATACCTAGATGGGATTTAGCTAAA CAAGTTTAGATTATTGTGTTGTCAAAATACCTAGATGGGATTTAGCTAAA CCAGTTTGGATTACTGCGTTGTTAAAATTCCCCGGTGGGATTTAGCAAAA CGAGCTTGGATTATTGTGTTGTAAAAATTCCACGTTGGGATCTAGCTAAG CCAGTTTGGATTATTGTGTTGTAAAAATTCCAAGGTGGGATTTAGCTAAA NNNNNNNNNNNNNNNNNNNNNNNNNNNNNNNNNNNNNNNNNNNNNNNNNN CGAGTTTGGATTATTGTGTTGTAAAAATTCCAAGATGGGATTTAGCAAAA NNNNNNNNNNNNNNNNNNNNNNNNNNNNNNNNNNNNNNNNNNNNNNNNNN

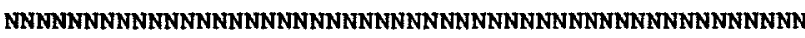

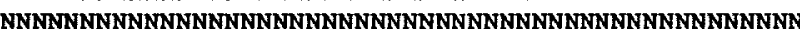
NNNNNNNNNNNNNNNNNNNNNNNNNNNNNNNNNNNNNNNNNNNNNNNNNN NNNNNNNNNNNNNNNNNNNNNNNNNNNNNNNNNNNMNNNNNNNNNNNNNN

$[50]$
Accinctapubes albifasciata Agnidra_scabiosa

Auzata_superba

Ausaris_micacea

Ausaris palleola

Cyclidia_substigmaria

Drepana arcuata

Falcaria bilineata

Drepana_curvatula

Drepana_curvatula2

$$
\begin{array}{lllll}
60 & 70 & 80 & 90 & 100] \\
. & . & . & . & .1
\end{array}
$$

NNNNNNNNNNNNNNNNNNNNNNNNNNNNNNNNNNNNNNNNNNNNNNNNNN TTTAACAGAGTGAGCACAAAAATTGGAAGCTCAATGAAAAGTGTGGGAGA TTTAACAGAGTGAGCACTAAGATTGGAAGCTCAATGAAAAGTGTAGGCGA

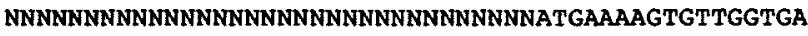
TTTAACCGAGTTAGCACAAAAATTGGAAGTTCAATGAAAAGTGTAGGCGA TTTAATAGAGTGAGCACTAAAATAGGAAGTTCAATGAAAAGTGTAGGAGA TTTAATAGAGTAAGCACCAAAATTGGAAGCTCTATGAAAAGTGTAGGCGA TTTAACAGAGTTAGTACTAAAATTGGCAGTTCTATGAAGAGTGTTGGAGA TTCAACAGAGTGAGCACTAAAATTGGAAGTTCCATGAAAAGTGTTGGTGA TTCAACAGAGTGAGCACTAAAATTGGAAGTTCCATGAAAAGTGTTGGTGA
[100]

$[100]$

$[100]$

[100]

$[100]$

[100]

[100]

$[100]$

[100]

$[100]$ 
Drepana_falcataria Ennomos_autumnaria Epicopeia_hainesii Eupaxyphasma_maxima Euthyatira pudens Habrosyne Pyritoides Lyssa_zampa Maucrauzata_maxima Microblepsis acuminata Nordstromia grisearia Ochropacha duplaris Oreta_loochooana Oreta_pulchripes oreta rosea Oreta_turpis Pseudothyatira cym. Psychostrophia melanargia Sabra_harpagula Nothus lunus

Tethea_consimilis

Tethea_taiwana

Tethea_or

Tetheela fluctuosa

Thyatira_batis

Thyatira batis 2

Tridrepaña_flava Tridrepana_unispina Watsonalla binaria Watsonalla_cultraria watsonalla_uncinula Cilix glaucata Falcaria_lacertinaria Habrosyne aurorina Jodis putata Neodaruma_tamanukii

I

Accinctapubes_albifasciata Agnidra scabiósa

Auzata superba

Ausaris_micacea

Ausaris palleola

Cyclidia_substigmaria

Drepana_ārcuata

Falcaria bilineata

Drepana curvatula

Drepana_curvatula2

Drepana falcataria

Ennomos_autumnaria Epicope $\bar{i}$ _ hainesii Euparyphasma maxima Euthyatira_pudens Habrosyne pyritoides Lyssa zampa Maucräuzata_maxima Microblepsis acuminata Nordstromia grisearia Ochropacha_duplaris oreta loochooana Oreta_pulchripes Oreta rosea Oreta turpis Pseudothyatira_cym. Psychostrophia_melanargia Sabra harpagula Nothus lunus Tethea consimilis Tethea taiwana Tethea or Tetheela fluctuosa Thyatira_batis

TTCAACAGAGTGAGCACTAAAATTGGAAGTTCCATGAAAAGTGTTGGTGA TTTAATAGAGTTAGTACGAAAATTGGAAGTTCAATGAAAAGTGTTGGAGA TTTAATAGGGTCAGCACAAAAATTGGTAGTTCAATGAAAAGTGTAGGAGA NNNNNNNNNNNNNNNNNNNNNNNNNNNNNNNNNNANNNNNNNNNNNNNNN TrTAACAGAGTGAGTACTAAAATTGGAAGTTCAATGAAAAGTGTCGGTGA TTTAATAGAGTTAGCACTAAAATTGGAAGTTCCATGAAAAGTGTTGGCGA NNNNNNNNNNNNNNNNNNNNNNNNNNNNNNNNNNNNNNNNNNNNNNNNNN TTTAATCGAGTTAGCACGAAAATTGGAAGTTCAATGAAAAGTGTGGGAGA TTTAATAGAGTAAGCACTAAAATTGGAAGCTCTATGAAGAGTGTAGGAGA TTCAATAGAGTGAGTACTAAAATTGGAAGTTCCATGAAGAGTGTAGGAGA TTTAACAGAGTAAGCACTAAAATTGGAAGTTCCATGAAAAGTGTCGGCGA TTTAACAGAGTGAGCACTAAAATCGGTAGCTCAATGAAAAGTGTAGGCGA NNNNNNNNNNNNNNNNNNNNNNNNNNNNNNNNNNNNNNNNNNNNNNNNNN TTCAACAGAGTGAGCACTAAAATTGGAAGTTCCATGAAAAGTGTTGGTGA TTTAACAGAGTTAGTACTAAAATTGGCAGTTCTATGAAGAGTGTTGGAGA TTTAATAGAGTAAGCACTAAAATTGGAAGTTCCATGAAAAGTGTGGCGA TTTAATAGAGTAAGCACAAAAATCGGAAGTTCAATGAAAAGCGTTGGGGA TTTAACAGAGTAAGTACTAAAATTGGAAGTTCCATGAAAAGCGTAGGAGA NNNNNNNNNNNGAGTACAAAAATTGGAAGTTCTATGAAAAGTGTTGGAGA TTTAACAGAGTAAGCACTAAAATCGGAAGTTCCATGAAAAGTGTCGGGGA TTTAATAGAGTAAGCACTAAAATCGGAAGTTCCATGAAAAGTGTCGGGGA TPTAACAGAGTAAGCACTAAAATAGGAAGTTCCATGAAAAGTGTCGGGGA NNNNNNNNNNNNNNNNNNNNNNNNNNNNNNNNNNNNNNNNNNNNNNNNNN TTTAACAGAGTAAGTACAAAAATCGGAAGTTCTATGAAAAGTGTTGGTGA TTTAACAGAGTAAGTACAAAAATCGGAAGTTCTATGAAAAGTGTTGGTGA TTTAACCGAGTTAGCACTAAAATAGGAAGCTCAATGAAAAGTGTTGGTGA TTCAATAGAGTGAGTACTAAAATTGGAAGTTCAATGAAAAGTGTGGGCGA TTTAATCGAGTTAGCACGAAAATTGGAAGTTCAATGAAAAGTGTGGGAGA NNNNNNNNNNNNNNNNNNNNNNNNNNNNNNNNNNNNNNNNNNNNNNNNNN TTTAACCGAGTGAGCACGAAAATTGGAAGCTCGATGAAAAGTGTGGGTGA NNNNNNNNNNNNNNNNNNNNNNNNNNNNNNNNNNNNNNNNNNNNNNNNNN NNNNNNNNNNNNNNNNNNNNNN NNNNNNNNNNNNNWNNNNNNNNNNNNNN NNNNNNNNNNNNNNNNNNNNNNNNNNNNNNNNNNNNNNNNNNNNNNNNNH NNNNNNNNNNNANNNNNNNNNNNNNNNNNNNNNRNNNNNNNNNNNNNNNN NWNNNWNNNNNNNNNNNNNNANNNNNNNNNNNNNNNNNNNNNNNNNNNNN

$[100]$

[100]

[100]

[100]

[100]

[100]

[100]

[100]

[100]

[100]

[100]

[100]

[100]

$[100]$

[100]

[100]

[100]

[100]

[100]

[100]

[100]

[ 100$]$

[100]

[100]

$[100]$

[100]

[100]

$[100]$

[100]

[100]

[100]

[100]

[ 100 ]

$[100]$

[100]

NNNNNNNNNNNNNNNNNNNAATTTTGAGGAAGCTTTTCAAAAAGCACTAA AGTTATGTCAATTGGCAGAAACTTTGAAGAAGCTTTTCAGAAAGCATTAA AGTTATGTCTATTGGTAGGAACTTTGAAGAAGCATTCCAAAAAGCATTAC AGTAATGTCAATTGGTAGAAATTTTGAAGAAGCTTTTCAAAAGGCACTCC GGTTATGTCCATTGGAAGGAATTTTGAAGAAGCATTTCAAAAAGCGTTAC AGTTATGTCAATTGGTAGAAATTTTGAAGAAGCATTCCAAAAAGCATTAA AGTTATGTCAATAGGAAGAAACTTTGAAGAGGCATTTCAGAAAGCTT'TGA AGTCATGTCGATAGGTAGAAACTTCGAAGAGGCTTTTCAAAAGGCACTAC AGTAATGTCAATTGGTAGAAATTTTGAGGAAGCCTTCCAGAAAGCACTTC AGTAATGTCAATTGGTAGAAATTTTGAGGAAGCGTTCCAGAAAGCACTTC AGTAATGTCAATTGGTAGAAATTTTGAGGAAGCCTTCCAGAAAGCACTTC AGTCATGTCAATCGGCAGAAACTTCGAAGAAGCATTTCAGAAAGCCTTGC AGTTATGTCAATTGGAAGGAATTTTGAGGAGGCATTTCAAAAAGCATTAC NNNNNNNNNNNNNNNNNGAAATTTTGAAGAGGCGTTTCAAAAAGCATTGC AGTTATGTCAATAGGAAGAAATTTTGAAGAAGCTTTTCAAAAAGCATTAC AGTAATGTCAATAGGAAGAAATTTTGAAGAGGCTTTTCAAAAAGCATTGC NNNNNNNNNNNNNNNNNNNNNNNNNNNNNNNNNNNNNNNNNNNNNNNNNN AGTTATGTCAATTGGCAGAAACTTTGAAGAAGCTTTCCAAAAAGCATTAC AGTTATGTCAATTGGCAGGAACTTCGAAGAAGCTTTCCAGAAAGCATTAC AGTTATGTCAATTGGTAGGAACTTTGAAGAAGCTTTCCAGAAAGCATTAC AGTTATGTCAATAGGAAGAAATTTCGAAGAAGCTTTTCAAAAAGCATTGC AGTTATGTCAATTGGCAGGAACTTTGAAGAAGCTTTCCAAAAAGCATTAC NNNNNNNNNGATAGGTAGAAACTTCGAAGAGGCTTTTCAAAAGGCACTAC AGTAATGTCAATTGGTAGAAATTTTGAGGAAGCCTTCCAGAAAGCACTTC AGTCATGTCGATAGGTAGAAACTTCGAAGAGGCTTTTCAAAAGGCACTAC AGTTATGTCAATAGGAAGAAATTTTGAAGAGGCTTTTCAAAAAGCATTGC AGTGATGTCTATTGGCAGAAACTTTGAGGAGGCTTTTCAAAAAGCATTAA AGTTATGTCAATTGGCAGGAACTTTGAAGAAGCTTTCCAGAAGGCACTAC AGTAATGTCTATTGGTAGAAATTTTGAAGAAGCATTCCAGAAAGCTTTAC AGTGATGTCAATAGGAAGAAATTTTGAAGAAGCTTTTCAAAAAGCATTGC AGTGATGTCAATAGGAAGAAATTTTGAAGAGGCTTTTCAAAAAGCATTGC AGTAATGTCAATAGGAAGAAATTTTGAAGAGGCTTTTCAAAAAGCATTAC NNNNNNGTCAATAGGAAGAAACTTTGAAGAGGCTTTTCAAAAGGCATTAC AGTGATGTCAATTGGAAGAAATTTTGAAGAAGCTTTTCAAAAAGCTTTAC

[150]

[150]

$[150]$

[ 150$]$

[150]

[150]

[150]

[150]

[150]

[150]

$[150]$

$[150]$

[150]

[150]

[150]

[ 150 ]

[150]

[150]

[150]

[150]

[ 150 ]

$[150]$

[150]

[150]

[150]

[150]

[150]

[150]

[150]

[150]

[150]

[150]

[150]

[ 150 ] 
Thyatira batis 2 Tridrepana_flava Tridrepana_unispina Watsonalla binaria Watsonalla_cultraria Watsonalla_uncinula Cilix glaucata Falcaria_lacertinaria Habrosyne_aurorina Jodis putata Neodaruma_tamanukii

[

Accinctapubes_albifasciata Agnidra_scabiósa

Auzata_superba

Ausaris_micacea

Ausaris palleola

Cyclidia_substigmaria

Drepana_arcuata

Falcaria bilineata

Drepana_curvatula

Drepana_curvatula2

Drepana_falcataria

Ennomos_autumnaria

Epicopeia_hainesii

Euparyphasma_maxima

Euthyatira_pudens

Habrosyne pyritoides

Lyssa_zampa

Maucrauzata_maxima

Microblepsis acuminata

Nordstromia_grisearia

Ochropacha_duplaris

Oreta loochooana

oreta_pulchripes

oreta rosea

Oreta turpis

Pseudothyatira_cym.

Psychostrophia_melanargia

Sabra_harpagula

Nothus_lunus

Tethea_consimilis

Tethea_taiwana

Tethea or

Tetheela fluctuosa

Thyatira_batis

Thyatira_batis2

Tridrepana flava

Tridrepana_unispina

Watsonalla_binaria

Watsonalla cultraria

Watsonalla_uncinula

Cilix glaucata

Falcaria lacertinaria

Habrosyne_aurorina

Jodis putata

Neodaruma_tamanukii

[

Accinctapubes_albifasciata Agnidra_scabiosa Auzata_superba

Ausaris_micacea

Ausaris palleola

Cyclidia substigmaria

Drepana_arcuata

Falcariābilineata

Drepana curvatula

AGTGATGTCAATTGGAAGAAATTTTGAAGAAGCTTTTCAAAAAGCTTTAC AGTAATGTCAATTGGAAGGAATTTTGAAGAAGCTTTCCAAAAAGCTTTAA AGTAATGTCGATTGGCAGGAACTTTGAAGAAGCCTTCCAAAAAGCATTAA AGTTATGTCAATTGGCAGAAACTTTGAAGAAGC TTTCCAAAAAGCATTAC NNNNNNNNNNNNNNNNNNNNNNNNNNNNNNNNNNNNNNNNNNNNNNNTAC AGTTATGTCAATTGGTAGAAACTTTGAAGAAGC TTTCCAAAAAGCATTAC NNNNNNNNNNNNNNNNNNNNNNNNNNNNNNNNNNNNNNNNNNNNNNNNNN

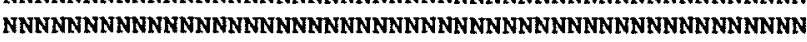

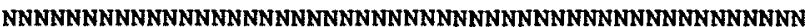

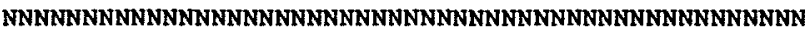

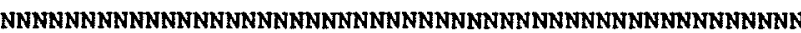

[150]

$[150]$

[150]

[150]

[150]

[150]

[150]

[150]

$[150]$

[150]

[150]

$$
\begin{array}{lllll}
160 & 170 & 180 & 190 & 200] \\
. & . & . & . & .]
\end{array}
$$

GAATGGTTGACGAAAATGTGAATGGTTTCGATCCATATGCGAAAAAAATG GAATGGTTGACGAAAATGTTAACGGTTTCGATCCATATGCAAAAAAGATT GAATGGTTGATGAAAATGTGAATGGCTTCGATCCATATGCAAAGAAAATT GAATGGATGATGAAAATGTGAATGGTTTCGATCCTTACGCGAAAAAGATC GAATGGTCGATGAAAATGTAAATGGATTTGATCCCTACGCAAAAACCATT GAATGGTAGATGAAAATGTAAACGGATTTGATCCGAATGCAAAGAAAATA GAATGGTCGATGAAAATGTGAATGGCTTCGATCCGTATGCAAAAAAAATT GAATGGTTGATGAAAATGTTAATGGTTTTGATCCATACGCGAAAAAAATG GTATGGTTGATGAAAATGTGAATGGTTTTGATCCTTACGCGAAAAAGATC GTATGGTTGATGAAAATGTGAATGGTTTTGATCCTTACGCGAAAAAGATC GTATGGTTGATGAAAATGTGAATGGTTTTGATCCTTACGCGAAAAAGATC GTATGGTTGATGAAAACGTAAATGGGTTTGACCCTAACGCAAAGAAAATT GAATGGTCGACGAAAATGTAAATGGTTTCGATCCCAATGCTAAGAAAATT GCATGGTCGATGAAAATGTTAATGGTTTTGACCCAAACGCTAAGAAAATT GTATGGTCGATGAGAATGTAAATGGTTTTGACCCAAATGCTAAGAAAATT GTATGGTGGATGAAAATGTAAATGGTTTTGACCCAAACGCTAAAAAAATT NNNNNNNNNNNNNNNNNNNNNNNNNNNNNNNNNCCCAACGCAAAAAAGATT GAATGGTTGACGAAAATGTGAATGGGTTTGACCCGTATGCGAAAAAAATT GAATGGTTGATGAAAATGTTAATGGCTTCGATCCATATGCAAAAAAGATT GAATGGTTGATGAAAACGTTAATGGCTTCGACCCGTATGCAAAAAAAATT GTATGGTTGATGAAAATGTAAATGGTTTTGACCCAAATTCTAAGAAAATT GTATGGTTGACGAAAATGTAAACGGTTTTGACCCATATGCAAAAAAACTT GAATGGTTGATGAAAATGTTAATGGTTTTGATCCGTACGCGAAACAGCTG GTATGGTTGATGAAAATGTGAATGGTTTTGATCCTTACGCGAAAAAGATC GAATGGTTGATGAAAATGTTAATGGTTTTGATCCGTACGCGAAAAAGCTG GTATGGTGGATGAAAATGTAAATGGTTTTGACCCAAACGCTAAAAAAATT GAATGGTTGACGAAAATGTAAACGGTTTTGATCCTAATGCTAAGAAGATA GAATGGTTGACGAAAATGTTAATGGTTTCGACCCATATGCAAAAAAGATT GAATGGTCGATGAAAATGTTAATGGTTTTGATCCAAACGCTAAAAAAATA GCATGGTCGATGAAAATGTAAATGGTTTTGACCCTAACGCTAAAAAAATT GCATGGTTGATGAAAATGTAAATGGTTTTGACCCAAATGCTAAGAAAATT GCATGGTTGATGAAAATGTTAATGGTTTTGACCCAAACGCTAAGAAAATT GTATGGTTGATGAAAATGTAAATGGTTTCGACCCAAATGCTAAGAAAATT GTATGGTCGATGAAAACGTAAATGGTTTTGACCCAAACGCAAAAAAAATT GTATGGTCGATGAAAACGTAAATGGTTTTGACCCAAACGCAAAAAAAATT GAATGGTTGATGAGAATGTTAATGGATTCGATCCATATGCAAAAAAAATC GGATGGTTGATGAAAACGTAAATGGATTCGATCCGTATGCAAAAAAGATT GAATGGTTGACGAAAATGTGAATGGGTTTGACCCGTATGCGAAAAAAATT GAATGGTTGACGAAAATGTGAATGGGTTTGACCCGTATGCGAAAAAAATT GAATGGTTGACGAAAATGTTAATGGGTTCGACCCGTATGCGAAAAAAATT NNNNNNNNNNNNNNNNNNNNNNNNNNNNNNNNNNNNNNNNNNNNNNNNNN

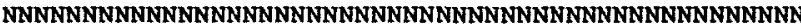
NNNNNNNNNNNNNNNNNNNNNNNNNNNNNNNNNNNNNNNNNNNNNNNNNN NNNNNNNNNNNNNNNNNNNNNNNNNNNNNNNNNNNNNNNMNNNNNNNNNH

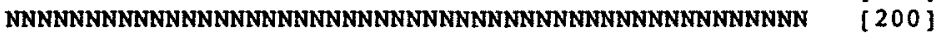

$$
\begin{array}{lllll}
210 & 220 & 230 & 240 & 250 \text { ] } \\
. & . & . & . & .]
\end{array}
$$

GGATTTTCTGATAAACAAATCGCTGCAACAATAAAAAGCACTGAAGTTGC GGTTTTTCTGATAAACAAATAGCTGCTGCCATAAAAAGTACAGAATTAGA GGTTTTTCTGATAAACAAATTGCTGCTGCCATAAAAAGCACAGAATTGGA GGATTTTCTGATAAACAAATTGCTGCTGCTATTAAAAGTACAGAGCTGGA GGTTTTTCGGACAAACAAATTGCCGTTGCGATTAAAAGTACAGAGCTGGA GGATTTTCAGATAAACAAATTTCCGTTGCTATAAAAAGCACAGAATTAGC GGTTTTTCTGATAAACAAATTGCTGCTGCCATCAAAAGTACTGAATTGGA GGCTACTCCGATAAACAAATTGCTGCTGCCATTAAAAGCACAGAATTAGA GGTTTTTCCGATAAACAAATTGCTGCTGCTATAAAAAGTACAGAATTGGA

[250]

[250]

[250]

[250]

[250]

[250]

[250]

[250]

[250] 
Drepana curvatula2 Drepana_falcataria Ennomos autumnaria Epicopeía hainesii Euparyphasma_maxima Euthyatira pudens Habrosyne pyritoides Lyssa zampa Maucrauzata maxima Microblepsis_acuminata Nordstromia_grisearia Ochropacha duplaris oreta_loochooana oreta_pulchripes oreta rosea oreta_turpis Pseudothyatira cym. Psychostrophia melanargia Sabra harpagula Nothus lunus Tethea_consimilis Tethea_taiwana Tethea or Tetheela fluctuosa Thyatira batis Thyatira batis2 Tridrepana_flava Tridrepana unispina Watsonalla binaria Watsonalla_cultraria Watsonalla uncinula Cilix_glaucata Falcaria_lacertinaria Habrosyne_aurorina Jodis putáta Neodaruma_tamanukii

1

Accinctapubes_albifasciata Agnidra scabiosa

Auzata_superba

Ausaris_micacea

Ausaris palleola

Cyclidia_substigmaria

Drepana arcuata

Falcaria bilineata

Drepana_curvatula

Drepana curvatula2

Drepana falcataria

Ennomos_autumnaria Epicopeía hainesii Euparyphasma_maxima Euthyatira_püdens Habrosyne pyritoides Lyssa_zampa Maucräuzata maxima Microblepsis acuminata Nordstromia_ḡrisearia ochropacha duplaris

Oreta loochooana oreta_pulchripes oreta rosea

Oreta_turpis Pseudothyatira_cym. Psychostrophia melanargia Sabra_harpagula Nothus lunus

Tethea consimilis Tethea_taiwana Tethea or Tetheela_fluctuosa
GGTTTTTCTGATAAACAAATTGCAGCTGCTATAAAAAGTACAGAATTGGA GGTTTTTCCGATAAACAAATTGCTGCTGCTATAAAAAGTACAGAATTGGA GGTTTTTCTGATAAACAGATAGCAGCTGCCATAAAGAGCACGGAAGTAGC GGCTTTTCTGATAAACAAATAGCAGCTGCCATTAAAAGTACTGAAGTAGC GGATTCTCAGATAAACAAATTGCTGCTGCAATAAAAAGTACTGAATTAGC GGATTCTCAGATAAGCAAATTGCTGCTGCAATTAAAAGTACTGAAGTAGC GGATTCTCTGATAAACAAATTGCCGCTGCAATAAAAAGCACTGAAGTAGC GGCTTCTCCGATAAACAAATTGCCGCCGCTATCAAAAGTACCGAAGTGGC GGCTTTTCTGATAAACAAATTGCTGCTGCCATAAAAAGTACTGAATTGGA GGCTTTTCTGATAAACAAATTGCTGCTGCCATAAAAAGTACAGAATTGGA GGCTTTTCAGATAAACAAATCGCTGCTGCGATAAAAAGTACAGAATTAGA GGGTTTTCTGACAAACAAATCGCGGCTGCAATAAAAAGCACTGAACTAGC GGCTTTTCTGATAAACAAATTGCTGCTGCCATAAAAAGTACAGAATTGGA GGCTACTCTGATAAACAAATTGCAACTGCAATTAAGAGCACTGAATTAGA GGTTTTTCCGATAAACAAATTGCTGCTGCTATAAAAAGTACAGAATTGGA GGCTACTCTGATAAACAAATTGCAACTGCAATTAAGAGCACTGAATTAGA GGATTCTCTGATAAACAAATTGCCGCTGCAATAAAAAGCACTGAACTAGC GGTTTCTCTGATAAACAAATAGCAGCTGCCATAAAAAGTACAGAAGTAGC GGCTATTCAGATAAACAAATTGCCGCTGCTATAAAAAGTACAGAATTGGA GGATTTTCTGATAAACAAATAGCTGCTGCTATAAAAAGTACCGAAGTAGC GGATTCTCCGACAAACAAATTGCAGCTGCAATAAAAAGCACTGAAGTAGC GGCTTCTCTGATAAACAAATTGCAGCTGCAATAAAAAGCACTGAAGTAGC GGTTTCTCTGACAAACAAATTGCAGCTGCAATAAAAAGCACTGAAGTAGC GGGTTCTCTGATAAACAAATTGCCGCTGCAATAAAAAGCACTGAAGTAGC GGATTCTCCGATAAACAAATTGCAGCAGCAATCAAAAGCACTGAATTAGC GGATTCTCAGATAAACAAATTGCAGCAGCAATCAAAAGCACTGAATTAGC GGATTCTCTGATAAACAAATAGCAGCTGCCATAAAAAGCACAGAGTTAGA GGATTTTCTGATAAGCAGGTTGCTGCAGCTATAAAAAGCACAGAATTAGA GGCTTTTCTGATAAACAAATTGCTGCTGCCATAAAAAGTACTGAATTGGA GGCTTTTCTGATAAACAAATTGCTGCTGCCATAAAAAGTACTGAATTGGA GGCTTTTCTGATAAACAAATTGCTGCTGCCATAAAAAGTACAGAATTGGA NNNNNNNNNNNNNNNNNNNNNNNNNNNNNNNNNNWNNNNNNNNNNNNNNN RNNNNNNNINNNNNNNNNNNNNNNNNN NNNNNNNNNNNNNNNNNNNNNNN NNNNNNNNNNNNNNNNNNNNNNNNNNNNNNNNNNNNNNNNNNNNNNNNNN KNNNNNNNNNNNNNNNNNNNNNNNNNNNNNNNNNNNNNNNNNNNNNNNNN

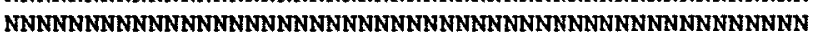

$$
\begin{array}{lllll}
260 & 270 & 280 & 290 & 300]
\end{array}
$$$$
\text { . }
$$

TGTCAGAAAACTAAGAGAAGATAATCAGATTACTCCTTTTGTAAAAAAAA CGTGAGGAAGTTGAGAGAAGAATTTAAAATTACACCATTTGTAAAACAAA TGTAAGGAAGTTAAGAGAAGAATTTAAGATTACACCATTTGTTAAACAAA CGTGAGGAAATTAAGAGAAGAATTCAAAATTACACCTTTTATAAAACAAA TGTAAGAAAGTTGAGGGAAGAATTTAAAATTACACCGTTTGTTAAACAAA GGTAAGAAAGTTGAGAGAGGAATACAAAATCACACCGTTTGTAAAACAAA CGTAAGAAAATTAAGAGAAGAGTTTAAAATAACACCTTTTGTAAAACAAA TGTGAGAAAGCTAAGAGAGGAATTCAAAATTACACCGTTTGTTAAACAAA CGTGAGAAAATTAAGAGAAGAATTCAAAATTACACCTTTTATAAAACAAA CGTGAGGAAATTAAGAGAAGAATTCAAAATTACACCTTTTATAAAACAAA CGTGAGGAAATTAAGAGAAGAATTCAAATTACACCTTTTATAAAACAAA CGTAAGAAAACTCAGAGAAGAATTCAAAATTATACCTTTTGTAAAACAAA AGTTAGAAAATTAAGAGAAGAATACAAAATTACACCATTCGTAAAACAAA CGTGAGAAAATTAAGAGAAGAATACAAAATAACGCCAT'TTGTAAAGCAAA CGTGAGAAAATTAAGGGAGGAATACAAAATTACACCTTTTGTAAAGCAAA CGTGAGAAAATTACGAGAAGAACACAAAATTACACCATTTGTAAAGCAAA TGTGAGGAAACTAAGAGAAGAATTTAAAATTACGCCTTTTGTGAAACAAA TGTGAGGAAATTAAGAGAAGAATTTAAAATAACGCCTTTTGTAAAGCAAA CGTAAGGAAGTTAAGAGAAGAATTTAGGATAACACCGTTTGTAAAACAGA CGTGAGGAAATTACGAGAAGAATTTAAAATAACACCATTTGTAAAACAAA CGTGCGAAAATTAAGGGAAGAACACAAAATTACACCATTTGTAAAACAAA TGTAAGAAAGTTAAGAGAAGAATTTAAAATAACACCATTTGTAAAACAAA TGTGCGAAAACTTAGAGAAGAATTCAAAATTACTCCATTTGTTAAACAAA CGTGAGAAAATTAAGAGAAGAATTCAAAATTACACCTTTTATAAAACAAA TGTGCGAAAACTTAGAGAAGAATTCAAAATTACTCCATTTGTTAAACAAA CGTGAGAAAATTACGGGAAGAACATAAAATTACACCATTTGTAAAGCAAA TGTTAGAAAACTAAGAGAAGATTTTAAAATAACACCATTTGTAAAACAGA TGTGAGAAAGTTGAGAGAAGAATTTAAAATTACACCATTTGTAAAACAAA TGTAAGAAAACTGAGAGAAGAATATAAAATTACACCATTTGTGAAACAAA TGTCCGAAAGTTAAGGGAGGAACACAAAATTACACCATTTGTAAAGCAAA TGTGCGAAAATTAAGGGAAGAACACAGAATTACACCCTTTGTTAAGCAAA TGTGCGAAAGTTAAGGGAAGAACACAAAATTACACCATTTGTAAAGCAAA CGTGCGAAAATTGAGGGAAGAACACAAAATTACGCCATTTGTAAAGCAAA
[300]

[300]

[300]

[300]

[300]

[300]

[300]

[300]

[300]

[300]

[300]

[300]

[300]

[300]

[300]

[300]

[300]

[300]

[300]

[300]

[300]

[300]

[300]

[300]

[300]

[300]

[300]

[300]

[300]

[300]

[300]

[300]

[300] 
Thyatira batis

Thyatira_batis 2

Tridrepana flava

Tridrepana unispina

Watsonalla_binaria

Watsonalla cultraria

Watsonalla uncinula

Cilix_glaucata

Falcaria lacertinaria

Habrosyne aurorina

Jodis putata

Neodaruma_tamanuki $i$

Accinctapubes albifasciata Agnidra_scabiosa

Auzata_superba

Ausaris micacea

Ausaris palleola

Cyclidia substigmaria

Drepana arcuata

Falcariā_bilineata

Drepana curvatula

Drepana curvatula2

Drepana_falcataria

Ennomos autumnaria

Epicopeia hainesii

Euparyphasma maxima

Euthyatira pudens

Habrosyne_pyritoides

Lyssa_zampa

Maucrauzata maxima

Microblepsis_acuminata

Nordstromia grisearia

Ochropacha_duplaris

oreta_loochooana

oreta pulchripes

oreta_rosea

oreta_turpis

Pseudothyatira cym.

Psychostrophia melanargia

Sabra_harpagula

Nothus lunus

Tethea_consimilis

Tethea_taiwana

Tethea or

Tetheela_fluctuosa

Thyatira batis

Thyatira batis 2

Tridrepaña flava

Tridrepana unispina

watsonalla_binaria

watsonalla_cultraria

Watsonalla uncinula

Cilix_glauçata

Falcaria_lacertinaria

Habrosyne aurorina

Jodis_putata

Neodaruma tamanukii

I

Accinctapubes_albifasciata

Agnidra scabiosa

Auzata_superba

Ausaris micacea

Ausaris palleola

Cyclidia_substigmaria

Drepana arcuata

Falcariābilineata
CGTAAGAAAATTAAGGGAAGAACACAAAATCACACCATTTGTCAAGCAAA CGTAAGAAAATTAAGGGAAGAACACAAAATCACACCATTTGTCAAGCAAA CGTGAGAAAATTAAGAGAAGAATTTAAGATTACACCGTTTGTCAAACAAA CGTCAGGAAGTTAAGAGAAGAGTTCAAGATTACTCCGTTTGTAAAACAAA TGTGAGgAAATTAAGAGAAGAATTTAAAATAACGCCTTTTGTAAAGCAAA TGTGAGGAAATTAAGAGAAGAATTTAAAATAACGCCTTTTGTAAAGCAAA TGTGAGGAAATTAAGAGAAGAATTTAAAATAACGCCTTTTGTAAAGAAAA NNNNNNNNNNNNNNNNNNNNNNNNNNNNNNNNNNNNNNNNNNNNNNNNNN NNNNNNNNNNNNNNNNNNNNNNNNNNNNNNNNNNNNNNNNNNNNNNNNNN NNNNNNNNNNN NNNNNNNNNNNNNNNNNNNNNNNNNNNNNNNNNNNNNAN NNNNNNNNNNNNNNNNNNNNNNNNNNNNNNNNNNNNNNNNNNNNNNNNNN NNNNNNNNNNNNNNNNNNNNNNNNNNNNNNNNNNNNNNNNNNNNNNNNNN

$$
\begin{array}{lllll}
310 & 320 & 330 & 340 & 3501 \\
. & . & . & . & .]
\end{array}
$$

TTGATACGGTGGCTGCGGAATGGCCTGCTTCAACAAATTATTTGTATCTA TTGATACAGTAGCAGCTGAATGGCCTGCATCAACAAATTATCTATTCTTG TCGATACAGTGGCAGCAGAATGGCCTGCATCAACAAACTATCTATACTTG TTGATACAGTAGCTGCTGAATGGCCGGCATCTACAAATTATTTGTACCTG TCGATACAGTTGCTGCTGAATGGCCAGCATCAACAAACTATTTGTACCTG TTGATACAGTGGCAGCAGAATGGCCTGCGTCCACTAATTATCTTTATCTC TAGACACAGTAGCAGCTGAATGGCCTGCGTCAACTAATTATTTATATTTG TTGATACAGTGGCAGCTGAATGGCCTGCATCTACTAACTATCTCTACTTG TTGATACAGTAGCGGCTGAATGGCCAGCATCAACAAATTATCTGTACTTG TTGATACAGTAGCGGCTGAATGGCCAGCATCAACAAATTATTTGTACTTG TTGATACAGTAGCGGCTGAATGGCCAGCATCAACAAATTATCTGTACTTG TTGATACAGTGGCAGCTGAATGGCCCGCTTCCACAAACTATCTTTATTTG TTGATACTGTTGCTGCTGAATGGCCAGCATCGACTAATTATCTTTATTTG TTGATACAGTAGCTGCGGAATGGCCTGCCTCTACCAATTACCTTTACTTA TAGATACAGTAGCAGCGGAATGGCCTGCCTCTACCAACTACCTTTATTTA TTGATACAGTAGCTGCGGAATGGCCTGCCACCACTAACTATCTTTACTTA TAGATACCGTAGCTGCCGAGTGGCCTGCTTCCACAAATTACCTATACTTA TTGATACAGTAGCAGCTGAATGGCCTGCATCAACAAATTATCTATACTTG TTGATACAGTAGCAGCGGAATGGCCTGCATCGACAAATTATCTATACTTG TTGATACAGTAGCTGCCGAATGGCCTGCATCAACAAATTATCTGTATTTG TTGATACTGTAGCAGCGGAATGGCCTGCCTCTACCAACTACCTTTATTTA TAGACACAGTAGCAGCTGAATGGCCTGCGTCAACAAATTATTTATACTTG TTGATACAGTAGCAGCTGAGTGGCCTGCATCAACGAACTATCTGTACTTG TTGATACAGTAGCGGCTGAATGGCCAGCATCAACAAATTATCTGTACTTG TTGATACAGTAGCAGCTGAATGGCCTGCATCAACGAACTATCTGTACTTG TTGATACAGNNNNNNNNNNNNNNNNNNNNNNNNNNNNNNNNNNNNNNNNN TTGACACTGTAGCTGCTGAATGGCCAGCGTCAACTAACTATCTCTATTTA TTGATACAGTAGCTGCTGAATGGCCTGCATCAACAAATTATCTATACTTG TAGATACTGTAGCAGCTGAATGGCCCGCAACTACAAATTATTTATATCTT TCGATACAGTAGCAGCGGAATGGCCTGCTTCTACTAATTATCTTTACTTA TCGATACAGTAGCAGCGGAATGGCCTGCCTCTACTAACTACCTTTACTTA TCGATACAGTAGCAGCGGAATGGCCTGCCTCTACTAACTACCTTTACTTA TTGATACAGTAGCAGCGGAATGGCCTGCTACTACTAACTACCTTTACTTA TTGACACAGTAGCTGCGGAATGGCCTGCCTCCACTAACTATCTTTACTTA TTGACACAGTAGCTGCGGAATGGCCTGCCTCCACTAACTATCTTTACTTA TAGATACAGTAGCAGCAGAATGGCCTGCATCAACAAACTATCTGTATTTG TTGATACCGTAGCAGCCGAATGGCCTGCATCAACAAATTATTTGTACTTA TTGATACAGTAGCAGCTGAATGGCCTGCATCAACAAATTATTTATACTTG TTGATACAGTAGCAGCTGAATGGCCTGCATCAACAAATTATCTATACTTG TTGATACAGTAGCAGCAGAATGGCCTGCATCAACAAATTATCTATACTTG

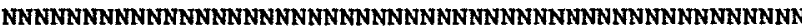

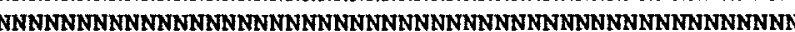
NNNNNNNNNNNNNNNNNNNNNNNNNNNNNNNNNMNNNNNNNNNNNNNNNN NNNNNNNKNNNNNNWNNNNNNNNNNNNNNNNNNNNNNNNNNNNNNNNNNN NNNNNNNNNNNNNNNNNNNNNANNNNNNNNNNNNNNNNNNNNNNNNNNNN

[350]

[350]

[350]

[350]

[350]

[350]

[350]

[350]

[ 350 ]

[ 350 ]

[350]

[350]

[350]

[350]

[350]

[350]

[350]

[350]

[350]

[350]

[350]

[350]

[350]

[ 350 ]

[ 350 ]

[350]

[350]

[350]

[350]

[350]

[350]

[350]

[350]

[350]

[350]

[350]

[350]

[350]

[350]

[350]

[350]

[350]

[350]

[350]

[350]
ACATATAATGGTAGTACACATGACTTGGATTCCCTGGAGAGTTCACAAT ACGTATAACGCAAACTCTAATGATTTAGACTTTCCTGGAAATTTCATAAT ACGTATAATGGTAATACACATGATTTAGAGTTTCCTGGTAATTTCACTAT ACATATAACGGAAATACCCACGACCTAGAGTTCCCTGGTAATTTCACTAT ACCTACAATGGTACCACGCACGACTTAGAATTCCCTGGTAACTTTACTAT ACATATAACGGTAGCACACATGATTTAGAATTTCCTGGAGATTTTGTAAT ACATATAACGGGAACACGCATGATTTAGATTTTCCAGGGAATTTCACAAT ACGTATAATGGTAATACACATGATTTAGTGTTTCCTGGAAATTTTACTAT
$[400]$

$[400]$

$[400]$

$[400]$

$[400]$

$[400]$

$[400]$

[400] 
Drepana curvatula Drepana_curvatula2 Drepana_falcataria Ennomos_autumnaria Epicopeía_hainesii Euparyphasma maxima Euthyatira_püdens Habrosyne pyritoides Lyssa zampa Maucräuzata maxima Microblepsis_acuminata Nordstromia grisearia ochropacha_duplaris oreta loochooana oreta_pulchripes oreta_rosea oreta turpis Pseudothyatira_cym. Psychostrophia melanargia Sabra harpagula Nothus lunus Tethea_consimilis Tethea taiwana Tethea_or Tetheela fluctuosa Thyatira batis Thyatira_batis2 Tridrepaña flava Tridrepana_unispina Watsonalla binaria Watsonalla cultraria Watsonalla_uncinula Cilix_glaucata

Falcaria lacertinaria Habrosyné_aurorina Jodis_putata

Neodaruma_tamanukii

!

Accinctapubes albifasciata Agnidra_scabiosa Auzata_superba

Ausaris micacea Ausaris_palleola Cyclidia substigmaria Drepana arcuata Falcaria_bilineata Drepana curvatula Drepana_curvatula2 Drepana_falcataria Ennomos autumnaria Epicopeía hainesii Euparyphasma_maxima Euthyatira pudens Habrosyne_pyritoides Lyssa_z ampa

Maucrauzata maxima Microblepsis_acuminata Nordstromia $\bar{g} r i s e a r i a$ Ochropacha_duplaris oreta_loochooana Oreta pulchripes Oreta rosea Oreta turpis Pseudothyatira cym. Psychostrophia_melanargia Sabra_harpagula Nothus_lunus Tethea_consimilis Tethea_taiwana Tethea_or

ACATATAACGGAAATACTCATGATTTAGAGTTTCCTGGTAATTTCACTAT ACATATAACGGAAATACTCATGATTTAGAGTTTCCTGGTAATTTCACTAT ACATATAACGGAAATACTCATGATTTAGAGTTTCCTGGTAATTTCACTAT ACGTACAATGGCACAACTCATGATTTAGAATTCCCAGGCGATTTGACTAT ACTTACAACGGGAGCTCACATGACTTGGAATTCCCAGGAGATTTTATCAT ACATACAATGGTAGTACACATGATCTCGAATTCCCTGGAAACTTTGTTAT ACATATAATGGTAGTACACATGATCTCGAATTCCCTGGAAACTTTGTTAT ACTTATAATGGCAGCACACATGATCTCGAATTCCCTGGAAACTTTGTAAT ACGTACAATGGAAGTTCGCATGATTTAGATTTCCCAGAAGGTTTCGTTAT ACATATAACGGGAATACCCACGACTTAGATTTTCCCGGGAATTTCACAAT ACATATAACGGAAATACGCATGACTTGGAATTTCCTGGGAATTTCACGAT ACATACAATGGGAATTCGCACGATTTAGAGTTTCCTGGAAATTTCACAAT ACTTATAATGGTAGTACACATGACCTTGAATTCCCTGGAAACTTTGTTAT ACATATAATGGGAACACGCATGATTTAGATTTTCCAGGGAATTTCACAAT ACGTATAACGGTACTACTCACGATTTAGACTTCCCTGGTACTGCTATAAT ACATATAACGGAAATACTCATGATTTAGAGTTTCCTGGTAATTTCACTAT ACGTATAACGGTACTACTCACGATTTAGACTTCCCTGGTACTGCTATAAT NNNNNNNNNNNNNNNNNNNNNNNNNNNNNNNNNNNNNNNNNNNNNNNNNN ACTTATAATGGCAGCACGCACGACCTGGAATTCCCAGGAGAGTTCATAAT ACTTATAACGGAAACACACACGATTTGGATTTTTCTGGGAATTACGTAAT ACATATAATGGCAGTACGCACGACTTAGAGTTTCCTGGCGAGTTTGTTAT ACTTATAATGGTAGTATACACGACCTTGAATTCCCTGGAAATTTTGTGAT ACTTATAATGGCTGTATACACGATCTTGAATTTCCTGGAAATTATGTCAT ACTTATAACGGTAGTATACACGACATAGAATTCCCTGGAAATTTCGTCAT ACTTATAATGGTTGTACACATGACCTTGAATTCCCTGGAAACTTTGTTAT ACTTATAACGGTAGCACACATGATCTTGAATTTCCTGGAAATTATGTAAT ACTTATAACGGTAGCACACATGATCTTGAATTTCCTGGAAATTATGTAAT ACATACAACGGCAATACACATGACTTAGACTTTCCAGGAAACTTCACTAT ACGTACAATGGTAGTACACATGATTTAGATTTTCCAGGAAATTTCACCAT ACATATAACGGGAATACCCACGACTTAGATTTTCCCGGGAATTTCACAAT ACATATAACGGGAATACCCACGACTTAGATTTTCCCGGGAATTTCACAA ACATATAACGGGAATACCCACGATTTAGATTTTCCCGGGAATTTCACAAT

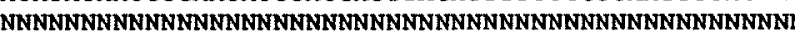
NNNNNNNNNNNNNNNNNNNNNNNNNNNNNNNNNNNNNNNNNNNNNNNNNNN SNNNNNNNNNNNNNNNNNNNNNNNNNNNNNNNNNNNNNNNNNNNNNNNNN NNNNNNNNNNNNNNNNNNNNNNNNNNNNNNNNNNNNNNNNNNNNNNNNNR

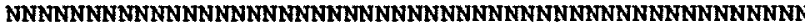

$400]$

$[400]$

$[400]$

$[400]$

$[400]$

$[400]$

[400]

[400]

$[400]$

[400]

[400]

$[400]$

[400]

[400]

[400]

[ 400 ]

$[400]$

[400]

[400]

$[400]$

[ 400 ]

[400]

$[400]$

[ 400 ]

$[400]$

$[400]$

[400]

$[400]$

$[400]$

[400]

$[400]$

[400]

[400]

$[400]$

[400]

[400]

[ 400 ]

$$
\begin{array}{lllll}
410 & 420 & 430 & 440 & 450
\end{array}
$$

GGTTCTTGGATCGGGTGTTTACAGAATAGGTAGTTCTGTGGAATTTGATT GGTATTGGGATCAGGTGTATACAGAATAGGAAGCTCGGTTGNNNNNNNNN GGTCCTAGGATCGGGTGTATATAGAATAGGAAGTTCTGTTGAATTCGACT GGTACTTGGATCAGGTGTATACAGAATAGGAAGTTCCGTTGAATTTGATT GGTTTTGGGATCTGGTGTGTACAGAATAGGTAGTTCTGTCGAATTTGACT GGTTTTAGGATCAGGAGTTTACAGAATAGGAAGCTCTGTTGAATTTGATT GGTCTTAGGATCAGGAGTATATAGAATTGGAAGCTCTGTTNNNNNNNNNN GGTTCTAGGTTCTGGTGTTTATAGAATAGGAAGCTCAGTTGAATTTGATT GGTACTGGGATCAGGTGTTTACAGAATAGGAAGTTCTGTTGAATTCGACT GGTACTGGGATCAGGTGTTTACAGAATAGGAAGTTCTGTTGAATTCGACT GGTACTGGGATCAGGTGTTTACAGAATAGGAAGTTCTGTTGAATTCGACT GGTACTTGGATCAGGAGTTTACCGAATTGGCAGCTCTGTAGAATTTGATT GGTATTAGGATCAGGCGTATACAGAATAGGAAGCTCCGTAGAATTTGATT GGTTTTAGGATCAGGTGTGTACAGAATCGGAAGCTCCGTAGAATTTGATT GGTTTTAGGATCAGGTGTATATAGAATTGGGAGCTCCGTAGAATTTGATT GGTTTTAGGATCAGGTGTATACAGAATTGGAAGCTCAGTAGAATTTGATT GGTCCTCGGATCAGGTGTTTACAGAATAGGAAGTTCCGTGGAATTCGATT GGTTCTGGGATCAGGTGTCTACAGAATAGGGAGCTCTGTTGAATTTGATT GGTTTTGGGGTCGGGTGTATATAGAATTGGGAGCTCGGTTGAATTTGACT GGTACTTGGATCAGGTGTATATAGAATAGGGAGCTCAGTTGAATTTGACI GGTTTTAGGGTCAGGCGTGTATAGAATCGGGAGCTCAGTGGAATTTGATI GGTCTTAGGATCAGGAGTATATAGAATTGGAAGCTCTGTTGAATTTGATT GGTCCTAGGCTCCGGTGTATACAGAATAGGTAGCTCTGTTGAATTTGACT GGTACTGGGATCAGGTGTTTACAGAATAGGAAGTTCTGTTGAATTCGACI GGTCCTAGGCTCCGGAGTATACAGAATAGGTAGCTCTGTTGAATTIGACT NNNNNNNNNNNNNNNNNNNNNNNNNNNNNNNNNNNNNNNNNNNNNNNNNN GGTGTTAGGGTCAGGCGTGTATAGAATAGGAAGTTCTGTTGAATTTGATT GGTTCTGGGGTCGGGTGTTTATAGAATCGGAAGCTCAGTTGAATTCGACT GGTTTTAGGTTCTGGTGTTTACAGAATAGGAAGTTCTGTTGAATTTGATT GGTTTTAGGATCAGGTGTATATAGAATTGGAAGCTCGGTAGAATTCGATT GGTTTTAGGATCAGGTGTGTATAGAATTGGGAGCTCGGTAGAATTTGACT GGTTTTAGGCTCAGGTGTATATAGAATTGGAAGTTCGGTAGAATTTGATT 
Tetheela fluctuosa

Thyatira_batis

Thyatira batis 2

Tridrepana_flava

Tridrepana_unispina

Watsonalla binaria

Watsonalla_cultraria

Watsonalla_uncinula

Cilix glaucata

Falcaria_lacertinaria

Habrosyne_aurorina

Jodis putata

Neodaruma_tamanukii

[

Accinctapubes_albifasciata

Agnidra_scabiōa

Auzata superba

Ausaris micacea

Ausaris palleola

Cyclidia substigmaria

Drepana_arcuata

Falcaria bilineata

Drepana_curvatula

Drepana_curvatula2

Drepana falcataria

Ennomos_autumnaria

Epicopeia hainesii

Euparyphasma maxima

Euthyatira pudens

Habrosyne pyritoides

Lyssa zampa

Maucráuzata_maxima

Microblepsis acuminata

Nordstromia $\bar{g}$ risearia

Ochropacha_duplaris

oreta loochooana

oreta_pulchripes

oreta_rosea

Oreta turpis

Pseudothyatira_cym.

Psychostrophia_melanargia

Sabra harpagula

Nothus_lunus

Tethea consimilis

Tethea taiwana

Tethea_or

Tethee $\bar{l}$ a fluctuosa

Thyatira_batis

Thyatira_batis2

Tridrepana flava

Tridrepana_unispina

Watsonalla binaria

Watsonalla cultraria

Watsonalla_uncinula

Cilix glaucata

Falcaria lacertinaria

Habrosyne_aurorina

Jodis putata

Neodaruma_tamanukii

I

Accinctapubes albifasciata Agnidra_scabiosa

Auzata_superba

Ausaris micacea

Ausaris_palleola

Cyclidia substigmaria

Drepana_arcuata
GGTTTTAGGGTCAGGTGTATATAGAATTGGCAGCTCAGTAGAATTTGATT GGTTTTAGGTTCAGGTGTTTATAGAATCGGAAGTTCCGNNNNNNNNNNNN GGTTITIAGGTTCAGGTGTTTATAGAATCGGAAGTTCCGTAGAATTTGATT GGTTTTGGGATCTGGTGTGTATAGAATTGGAAGTTCTGTTGAATTTGATT GGTTTTGGGCTCAGGTGTTTATAGAATCGGAAGTTCCGTTGAATTTGACT GGTTCTGGGATCAGGTGTCTACAGAATAGGGAGCTCTGTTGAGTTCGACT GGTTCTGGGATCAGGTGTCTNCAGAATAGGGAGCTCTGTTGAATTTGATT GGTTCTGGGATCAGGTGTCTATAGAATAGGGAGCTCTGTTGAATTTGACr NNNNNNNNNNNNNNNNNNNNNNNNNNNNNNNNNNNNNNNNNNNNNNNNNN NNNNNNNNNNNNNNNNNNNNNNNNNNNNNNNNNNNNNNNNNNNNNNNNNN

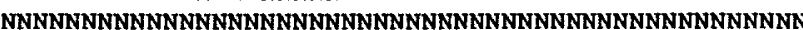
MNNINNNNNNNNNNNNNNNNNNNNNNNNNNNNNNNNNANNNNNNNNNNNNN

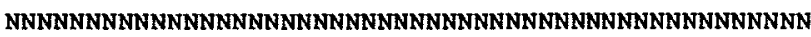

$[450]$

$[450]$

$[450]$

$[450]$

$[450]$

$[450]$

[450]

[450]

[450]

[450]

[450]

[450]

[450]

$$
\begin{array}{lllll}
460 & 470 & 480 & 490 & 500 \mathrm{~J} \\
. & . & . & . & .1
\end{array}
$$

GGTGCGCTGTTGGATGTTTAAGAGAGCTACGTAATCAAGGTAAAAAAACA NNNNNNNNNNNNNNNNNNNNNNNNNNNNNNNNNNNNNNNNNNNNNNNNNN GGTGCGCTGTTGGTTGCTTAAGAGAACTGAGAAATCAGGGAAAAAGTACC GGTGCGCTGTTGGTTGCCTTCGAGAATTGAGGAATCAGGGAAAGAAAACA GGTGTGCTGTCGGTTGCCTAAGAGAATTAAGAAATCAGGGCAAAAAAACT GGTGTGCTGTAGGCTGCTTGAGAGAACTTAGAAATCAAGGCAGAAAAACG

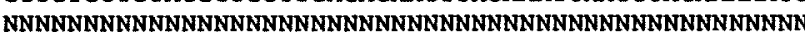
GGTGTGCAGTTGGTTGCTTAAGAGAGCTAAGAAATCAAGGTAAAAGTACA GGTGCGCTGTCGGTTGCCTCCGAGAATTGAGAAATCAGGGCAAGAATACG GGTGCGCTGTCGGTTGCCTCCGAGAACTGAGAAATCAGGGCAAGAATACG GGTGCGCTGTCGGTTGCCTCCGAGAATTGAGAAATCAGGGCAAGAATACG GGTGCGCCGTTGGGTGCTTAAGAGAACTTAGAAACCAAGGTAAAAAAACT GGTGTGCTGTGGGTTGTTTGAGAGAACTCCGAAATCAAGGCAAAAAAACG GGTGTGCNNNNNNNNNNNNNNNNNNNNNNINNNNNNNNNNNNNNNNNNNNN GGTGTGCTGTGGGTTGCTTAAGAGAACTGAGAAACCAGGGCAAAAGTACT GGTGTGCTGTAGGGTGCTTGAGAGAATTGAGAAACCAAGGCAAAAGTACT GGTGTGCTGTAGGTTGCTTGAGGGAGCTAAANNNNNNNNNNNNNNNNNNN GGTGTGCTGTTGGTTGTTTGAGAGAACTGAGAAATCAGGGTAAAAACACC GGTGTGCTGTTGGTTGCTTGAGAGAACTGAGAAATCAAGGTAAAAATACC GGTGCGCTGTTGGTTGTTTGAGAGAACTGAGAAACCAGGGCAAAAACACC GGTGTGCTGTGGGTTGCTTGAGAGAACTTAGAAATCAGGGCAAAAGTACT GGTGTGCTGTGGGTTGTCTAAGAGAACTACGAAATCAGGGCAAAAGTACA GGTGCGCAGTTGGCTGCTTAAGAGAGCTAAGAAATCAAGGCAAAAAAACT GGTGCGCTGTCGGTTGCCTCCGAGAATTGAGAAATCAGGGCAAGAATACG GGTGCGCAGTAGGCTGCTTAAGAGAGCTAAGAAATCAAGGCAAAAAAACT NNNNNNNNNNNNNNNNNNNNNNNNNNNNNNNNNNNNNNNNNNNNMNNNNN GGTGTGCTGTAGGTTGTTTGAGAGAACTTAGAAACCAAGGGAAAAAGACA GGTGTGCTGTTGGCTGTCTGAGAGAGCTGAGAAATCAAGGTAAAAAGACC GGTGTGCCGTGGGATGTCTAAGGGAATTGAGAAATCAGGGAAAAAAAACA GGTGTGCTGTAGGTTGTTTAAGAGAACTTAGAAACCAGGGCAAAAGTACI GGTGTGCTGTGGGTTGCTTAAGAGAACTTAGAAACCAGGGCAAAAGTACT GGTGTGCTGTGGGTTGCTTAAGAGAACTTAGAAATCAGGGAAAAAGTACT GGTGTGCTGTAGGTTGTTTGCGAGAACTAAGAAATCAAGGCAAAAGTACI

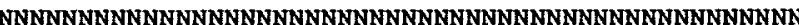
GGTGTGCTGTAGGGTGCTTGAGAGAATTAAGAAATCAAGGCAAAAGTACT GGTGTGCTGTGGGATGTCTACGAGAGTTGAGAAATCAAGGCAAAAGTACC GGTGTGCTGTCGGGTGCCTTPAGGAATTAAGAAATCAAGGCAAAAAAACT GGTGCGCACTAAANNNNNNNNNNNNNNNNNNNNNNNNNNNNNNNNNNNNN GGTGTGCTGTTGGTTGTTTGAGAGAACTGAGAAATCAGGGTAAAAACACC GGTGTGCTGTTGGTTGTTTGAGAGAACTGAGAAATCAGGGTAAAAACACC

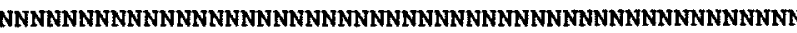

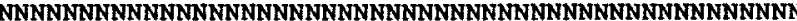

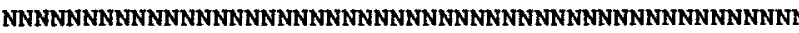

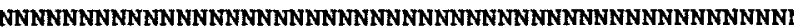
NNNNNNNNNNNNNNNNNNNNNNNNNNNNNNNNNNNNNNNNNNNNNNNNNN

$[500]$

[500]

$[500]$

[500]

$[500]$

$[500]$

$[500]$

$[500]$

$[500]$

$[500]$

$[500]$

$[500]$

$[500]$

[500]

[500]

[500]

[500]

[500]

[500]

[500]

[500]

[500]

[500]

[500]

[500]

[500]

[500]

[500]

[500]

[500]

[500]

[500]

(500)

[500]

[500]

[500]

[500]

$[500]$

(500]

[500]

$[500]$

[500]

[500]

[500]

[500]

$$
\begin{array}{lllll}
510 & 520 & 530 & 540 & 550]
\end{array}
$$

CTTATGGTAAATTACAATCCGGAAACTGTGAGCNNNNNNNNNNNNNNNNN NNNNNNNNNNNNNNNNNNNNNNNNNNNNNNNNNNNNNNNNNNNNNNNNNN ATAATGATTAACTACAATCCTGAAACTGTTAGTACTGATTATGATATGAG ATAATGGTCAACTATAATCCTGAAACTGTTAGTACTGATTATAAANNNNN ATAATGATTAACTATAATCCGGAAACTGTTAGTACAGATTATGATATGAG ATTATGATTAACTATAATCCTGAAACCGTCAGCACTGATTACGACATGAG

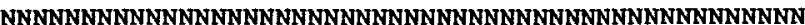

$[550]$

$[550]$

[550]

[550]

$[550]$

$[550]$

$[550]$ 
Falcaria bilineata

Drepana_curvatula

Drepana_curvatula2

Drepana_falcataria

Ennomos_autumnaria

Epicopeía hainesii

Euparyphasma_maxima

Euthyatira_püdens

Habrosyne pyritoides

Lyssa_zampa

Maucrauzata_maxima

Microblepsis acuminata

Nordstromia_grisearia

Ochropacha duplaris

Oreta loochooana

oreta_pulchripes

oreta rosea

Oreta_turpis

Pseudothyatira_cym.

Psychostrophia melanargia

Sabra_harpagula

Nothus_lunus

Tethea consimilis

Tethea taiwana

Tethea or

Tetheela fluctuosa

Thyatira_batis

Thyatira batis 2

Tridrepana_flava

Tridrepana_unispina

Watsonalla binaria

Watsonalla_cultraria

Watsonalla_uncinula

Cilix glaucata

Falcaria_lacertinaria

Habrosyne_aurorina

Jodis putata

Neodaruma_tamanuki i

Accinctapubes_albifasciata

Agnidra_scabiosa

Auzata superba

Ausaris micacea

Ausaris_palleola

Cyclidia substigmaria

Drepana_ärcuata

Falcariábilineata

Drepana_curvatula

Drepana_curvatula2

Drepana falcataria

Ennomos_autumnaria

Epicopeía_hainesii

Euparyphasma maxima

Euthyatira_pudens

Habrosyne_pyritoides

Lyssa zampa

Maucráuzata_maxima

Microblepsis acuminata

Nordstromia grisearia

ochropacha_duplaris

oreta loochooana

Oreta_pulchripes

oreta rosea

Oreta turpis

Pseudothyatira_cym.

Psychostrophia_melanargia

Sabra harpagula

Nothus_lunus

Tethea_consimilis

Tethea_taiwana

ATCATGGTTAACTACAATCCTGAAACTGTTAGTACTGATTATGATATGAG ATAATGGTTAACTACAATCCTGAAACTGTTAGTACTGATTATGATATGAG ATAATGGTTAACTATAATCCTGAAACTGTTAGTACTGATTATGATATGAG ATAATGGTTAACTATAATCCTGAAACTGTTAGTACTGATTATGATATGAG ATTATGGTCAATTACAACCCTGAAACTGTGAGTACTGACTATGATATGAG ATAATGGTTAATTACAATCCTGAAACTGTCAGCACTGATTATGACATGAG NNNNNNNNNNNNNNNNNNNNNNNNNNNNNNNNNNNNNNNNNNNNNNNNNN ATTATGGTTAATTATAACCCTGAGACTGTTAGTACCGACTATGACATGAG ATTATGGTAAATTATAACCCTGAGACGGTAAGTACTGATTATGACATGAG NNMNNNNNNNNINNNNNNNNNNNNNNNNNNNNNNNNNNNNNNNNNNNNNNNN ATAATGGTTAACTATAATCCTGAAACTGTCAGCACAGATTATGACATGAG ATAATGGTTAACTATAATCCTGAAACTGTCAGTACTGACTATGATATGAG ATAATGGTTAATTACAACCCTGAAACTGTCAGTACCGATTACGATATGAG ATTATGGTCAATTATAACCCTGAGACTGTTAGTACTGACTATGACATGAG ATCATGATTAATTACAACCCTGAAACAGTCAGTACTGATTACGATATGAG ATAATGGTGAATTACAATCCAGAAACTGTAAGCACAGACTACGACATGAG ATAATGGTTAACTACAATCCTGAAACTGTTAGTACTGATTATGATATGAG ATAATGGTGAATTACAATCCAGAAACTGTGAGCACAGACTACGACATGAG

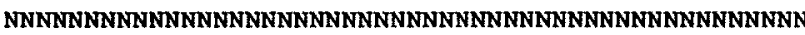
ATTATGGTCAACTACAATCCAGAGACCGTCAGCACTGATTACGATATGTG GTAATGGTTAACTACAATCCAGAAACTGTAAGTACTGACTATGACATGAG ATTATGATTAATTATAATCCGGAAACTGTCAGTACCGACTATGATATGAG ATCATGGTAAATTATAACCCTGAGACTGTTAGTACTGACTATGACATGAG ATCATGATAAATTATAACCCTGAGACTGTTAGTACTGATTATGACATGAG ATCATGGTAAATTATAACCCTGAGACTGTTAGTACTGACTATGACATGAG ATTATGGTAAATTATAACCCCGAGACTGTTAGTACTGACTATGACATGAG NNNNWNNNNNNNNNNNNNNNNNNNNNNNNNNNNNNNNNNNNNNNNNNNNN ATTATGGTAAATTACAACCTTGAGACTGTTAGTAATGATTATGACATGAG ATAATGGTTAACTACAACCCAGAAACTGTGAGTACTGACTATGACATGAG ATAATGGTCAACTACAACCCAGAAACAGTGAGTACCGATTATGACATGAG NNNNNNNNNNNNNNNNNNNNNNNNNNNNNNNNNNNNNNNNNNNNNNNNNN ATAATGGTTAACTATAATCCTGAAACTGTCAGCACAGATTATGACATGAG ATCATGGTTAACTATAATCCTGAAACTGTCAGCACAGATTATGACATGAG NNNNNNNNNNNNNNNNNNNNNNNNNNNNNNNNNNNNNNNNNNNNNNNNNN NNNNNNNNNNNNNNNNNNNNNNNNNNNNNNNNNNNNNNNNNNNNNNNNNN

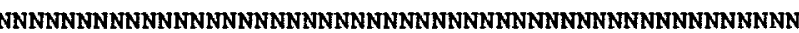

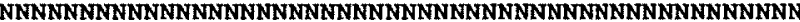
NNNNNNNNNNNNNNNNNNNNNNNNNNNNNNNNNNNNNNNNNNNNNNNNNN

$$
\begin{array}{lllll}
560 & 570 & 580 & 590 & 6001 \\
. & . & . & . & .]
\end{array}
$$

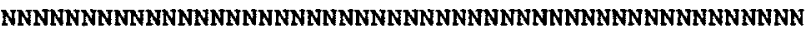
NNNNNNNNNNNNNNANNNNNNNNNNNNNNNNNNNNMNNNNNNNNNNNNNN TGACAGATTGTACTTTGAAGAAATTTCATTCGAGGTTGTAATGGATATTT NWNNNNNNNNNNWNNNNNNNNNNNNNNNNNNNNNNNNNNNNNNNNNNNNNNN TGACCGATTATATTTCGAAGAAATATCTTTTGAAGTTGTGATGGATATTT TGACAGATTGTATTTNGAAGAAATTTCCTTCGAAGTAGTCATGGATATTT NNNNNNNNNNNNNNNNNNNNNNNNNNNNNNNNNNNNNNNNNNNNNNNNNN TGATCGATTGTAC'TTTGAAGAAATATCATTCGAGGTGGTAATGGACAT'T CGACAGACTGTATTTTGAAGAGATATCATTTGAAGTTGTAATGGATATTT CGACAGACTGTATTTTGAAGAGATATCATTTGAAGTTGTAATGGATATTT CGACAGACTGTATTTTGAAGAGATATCATTTGAAGTTGTAATGGATATTT CGACCGGCTTTATTTTGAAGAAATATCCTTTGAAGTTAAANNNNNNNNNN CGACAGATTATACTTTGAAGAAATTTCTTTTGAGGTAGTTATGGATATTT NNNNNNNNNNNNNNNNNNNNNNNNNNNNNNNNNNNNNNNNNNNNNNNNNNN TGACAGATTGTACTTTGAAGAAATATCTTTTGAGGTTGTTATGGATATTT TGACAGATTGTACTTCGAAGAAATATCNTTCGAGGTTGTAATGGATATTT NNNNNNNNNNNNNNNNNNNNNNNNNNNNNNNNNNNNNNNNNNNNNNNNNN TGATCGATTGTACTTTGAAGAAATATCATTCGAAGTTGTAATGGATATTT TGATCGATTGTATTTCGAAGAAATATCATTCGAAGTTGTAATGGATATTT TGATCGACTGTACTTCGAAGAAATATCTTTCGAGGTTGTTATGGATATTT TGACAGGTTGTACTTTGAAGAAATATCTTTTGAGGTTGTTATGGATATTT TGACCGGTTATACTTCGAAGAAATATCATTCGAGGTTGTTATGGATATTT CGACAGATNNNNNNNNNNNNNNNNNNNNNNNNNNNNNNNNNNNNNNNNNNN CGACAGACTGTATTTTGAAGAGATATCATTTGAAGTTGTAATGGATATTT CGACAGATTATACTTTGAAGAAATATCGTTTGAAGTCGTCATGGATATTT NNNNNNNNNNNNNNNNNNNNNNNNNNNNNNNNNNNNNNNNNNNNNNNNNNNNN TGACAGATTGTACTTTGAAGAAATCTCATTTGAAGTGGTAATGGATATCT CGACCGATTGTATTTTGAAGAAATATCATTCGAGGTTGTAATGGATATTT TGATAGATTATATTTCGAGGAAAAANNNNNNNNNNNNNNNNNNNNNNNNN TGATAGATTGTACTTTGAAGAAATATCTTTTGAGGTTGTTATGGATATTT TGATAGATTATATTTTGAAGAAATATCTTTTGAGGTTGTTATGGACATTT

$[600]$

$[600]$

$[600]$

[600]

$[600]$

$[600]$

$[600]$

$[600]$

$[600]$

$[600]$

$[600]$

$[600]$

$[600]$

$[600]$

[600]

[600]

[600]

[600]

[600]

[600]

[600]

[600]

[600]

[600]

[600]

[600]

[600]

[600]

[600]

[600]

[600] 
Tethea or

Tetheela fluctuosa

Thyatira batis

Thyatira_batis 2

Tridrepaña_flava

Tridrepana unispina

Watsonalla_binaria

Watsonalla_cultraria

Watsonalla uncinula

cilix glaucata

Falcaria lacertinaria

Habrosyne_aurorina

Jodis_putata

Neodaruma_tamanukii

1

Accinctapubes_albifasciata Agnidra_scabiosa

Auzata_superba

Ausaris micacea

Ausaris palleola

Cyclidia_substigmaria

Drepana arcuata

Falcaria_bilineata

Drepana_curvatula

Drepana curvatula2

Drepana_falcataria

Ennomos_autumnaria

Epicopeia hainesii

Euparyphasma_maxima

Euthyatira_pudens

habrosyne pyritoides

Lyssa_zampa

Maucrauzata_maxima

Microblepsis_acuminata

Nordstromia_grisearia

ochropacha_duplaris

oreta_loochooana

oreta_pulchripes

oreta rosea

Oreta turpis

Pseudothyatira_cym.

Psychostrophia_melanargia

Sabra_harpagula

Nothus_lunus

Tethea consimilis

Tethea_taiwana

Tethea-or

Tetheela_fluctuosa

Thyatira batis

Thyatira batis 2

Tridrepana_flava

Tridrepana_unispina

watsonalla binaria

Watsonalla_cultraria

Watsonalla_uncinula

Cilix glaucata

Falcaria_lacertinaria

Habrosyne_aurorina

Jodis_putata

Neodaruma_tamanukii

I

Accinctapubes_albifasciata Agnidra_scabiósa

Auzata superba

Ausaris micacea

Ausaris palleola

Cyclidia_substigmaria
TGATAGATTGTACTTTGAAGAAATATCTTTTGAGGTTGTTATGGATATTT TGACAGATANNNNINNNNNNNNNNNNNNNNNNNNNNNNNNNNNNNNNNNNN

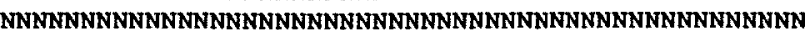
TGATGATTANNNNNNNNNNNNNNNNNNNNNNNNNNNNNNNNNNNNNNNNNNN CGATAGATTGTACTTCGAGGAAATATCATTCGAAGTTGTAATGGATATTT TGATAGATTGTATTTCGAAGAAATATCATTCGAAGTCGTGATGGATATCT NNNNNNNNNNNNNNNNNNNNNNNNNNNNNNNNNNNNNNNNNNNNNNNNNN TGATCGATTGTACTTTGAAGAAATATCATTCGAAGTTGTAANGGATATTT TGATCGATTGTACTTTGAAGAAATATCATTTGAAGTTGTAATGGATATTT NNNNNNNNNNNNNNNMNNNNNNNNNNNNNNNNNNNNNNNNNNNNNNNNNN

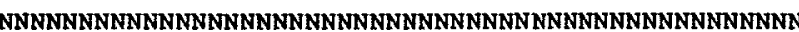

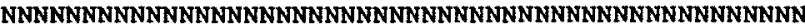

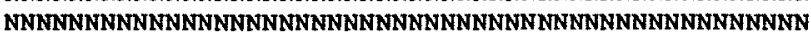

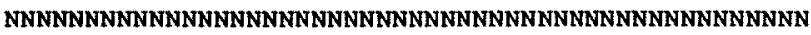

$[600]$

$[600]$

$[600]$

$1600]$

[600]

$[600]$

$[600]$

$[600]$

$[600]$

$[600]$

$[600]$

$[600]$

$[600]$

[600]
NNNNNNNNNNNNMNNNNNNNNNNNNNNNNNNNNNNNNNNNNNNNNNNNNNN NMNNNNNNNNNNNNNNNNNNNNNNNNNNNNNNNNNNNNCCGTTCAGGGGT ATAACCTCGAACATCCTAATGGAATTATTTTATCANNNCCGTTCAGGGGT NNWNNNNNNNNNNNNNNNNNNNNNNNNNNNNNNNNNNNNCCGTTCAGGGGT ACAATCTTGAGCGTCCTAATGGCGTTATTCTGTCAAAACCGTTCAGGGGT ACAACATAGAACATCCTAATGGTGTCATTTTGTCTNNNCCGTTCAGGGGT NNNNNNNNNNNNNNNNNNNNNNNNNNNNNNNNNNNNNNCCGTTCAGGGGT ATAATCTCGAACATCCTGTTGGAGTTATTTTGTCNNNACCGTTCAGGGGT ATAATCTCGAACACCCTAATGGTATTATTTTGTCNNNACCGTTCAGGGGT ATAATCTCGAACACCCTAATGGTATTATTTTGTCAAAACCGTTCAGGGGT ATAATCTCGAACACCCTAATGGTATTATTTTGTCNNNACCGTTCAGGGGT NNNNNNNNNNNNNNNNNNNNNNNNNNNNNNNNNNNNNNCCGTCCAGGGGT ACAATATTGAACATCCGAATGGGGTTATTTTATCCNNNNNNNNNATCGGG NNNNNNNNNNNNNNNNNNNNNNNNNNNNNNNNNNNNNNNCCGTTCAGGGGT ATAACATCGAACATCCTAGTGGTGTAATATTATCAAAACCGTTCAGGGGT ATAATATCGAACATCCTAGCGGTGTAATATTATC-AATCCGTTCAGGGGT NNNNNNNNNNNNNNNNNNNNNNNNNNNNNNNNNNNNNNCCGTTCAGGGGT ATAATCTCGAGCATCCTGACGGAGTTATTTTGTCTNMNCCGTTCAGGGGT ACAATCTCGAACATCCCAACGGTGTTATTTTATCTAAACCGTTCAGGGGT ACAATCTTGAACATCCTAATGGTGTTATATTATCACNNNCGTTCAGGGGT ATAATATCGAACATCCTAGCGGTGTAATATTATCNNNNNNNNNNNNNNNN ATAACCTTGAACACCCTAATGGTGTTATACTATCNNNACCGTTCAGGGGT NNNNNNNNNNNNNNNNNNNNNNNNNNNNNNNNNNNNNNCCGTTCAGGGGT ATAATCTCGAACACCCTAATGGTATTATTTTGTCANNNCCGTTCAGGGGT ATAATCTTGAATATCCTGATGGTGTTATATTGTCGNNNCCGTTCAGGGGT

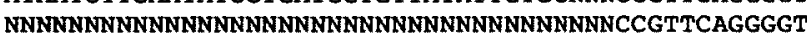
ACAATATTGAACATCCTAACGGTGTCATTTTGTCCNNNNNNNNNATCGGG ATAATCTCGAACAACCTAATGGTGTTATTTTATCGNNNCCGTTCAGGGGT NNNNNNNNNNNNNNNNNNNNNNNNNNNNNNNNNNNNNNNCCGTTCAGGGGT ATAATATTGAACATCCCAGCGGCGTAATATTATCAAAACCGTTCAGGGGT ATAAAAANNNNNNNNNNNNNNNNNNNNNNNNNNNNNNNCCGTTCAGGGGT ATAATATAGAACATCCTAGCGGCGTAATATTATCAAAACCGTTCAGGGGT NNNNNNNNNNNNNNNNNNNNNNNNNNNNNNNNNNANNNCCGTTCAGGGGT NANNNNNNNNNNNNNNNNNNNNNNNNNNNNNNNNNNNNCCGTTCAGGGGT

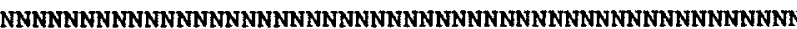
ATAATCTTGAGCATCCCAATGGTGTTATTCTATCAAAACCGTTCAGGGGT ATAACCTTGAACATCCTAATGGTGTTATTTTATCAAAACCGTTCAGGGGT NNNNNNNNNNNNNNNNNNNNNNNNNNNNNNNNNNNNNNCCGTTCAGGGGT ATAATCTCGAGNNNNNNNNNNNNNNNNNNNNNNNNNNNCCGTTCAGGGGT ATAATCTCGAGCATCCTGACGGTGTTATTTTGTCTAAACCGTTCAGGGGT NNNNNNNNNNNNNNNNNNNNNNNNNNNNNNNNNNNNNNCCGTTCAGGGGT NNNNNNNNNNNNNNNNNNNNNNNNNNNNNNNNNNNNNNNCGTTCAGGGGT NNNNNNNNNNNNNNNNNNNNNNNNNNNNNNNNNNNNNNCCGTTCAGGGGT NNNNNNNNNNNNNNNNNNNNNNNNNNNNNNNNNNNNNNCCGTCCAGGGGT MNNNWNNNNNNNNNNNNNNNNNNNNNNNNNNNNNNNNNCCGTTCAGGGGT

$$
\begin{array}{lllll}
660 & 670 & 680 & 690 & 7001 \\
. & . & . & . & .]
\end{array}
$$

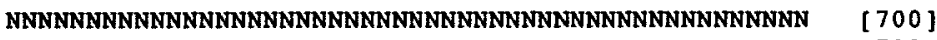
AAACCTGCGAAACTCGAATGAACGAACGGGGAGATTCATCGTCACTCCTC [700] AAACCTGCGAAACTCGAATGAACGAACGGGGAGATTCATCGTCACTCCGC [700] AAACCTGCGAAACTCGAACGAATGAACGGGAAGATTCAACGTTCACCCGC [700] AAACCTGCGAAATTCGAATGAGTGAACGGGGAGATTCAGCGCTATCCCGC [700] AAACCTGCGAAACTCGAATGAACGAACGGGGAGATTCATCGTCACTCCGC [700] 
Drepana arcuata Falcaria_bilineata Drepana curvatula

Drepana_curvatula2 Drepana falcataria Ennomos autumnaria Epicopeia_hainesii Euparyphasma_maxima Euthyatira pudens Habrosyne_pyritoides Lyssa zampa

Maucrauzata_maxima Microblepsis_acuminata Nordstromia_grisearia

ochropacha_duplaris oreta_loochooana oreta pulchripes oreta_rosea oreta turpis Pseudothyatira cym. Psychostrophia_melanargia Sabra_harpagula

Nothus lunus Tethea_consimilis Tethea_taiwana

Tethea or

Tetheela_fluctuosa Thyatirabatis

Thyatira_batis2 Tridrepaña_flava Tridrepana unispina Watsonalla binaria Watsonalla_cultraria Watsonalla_uncinula Cilix_glaucata Falcaria lacertinaria Habrosyne aurorina Jodis_putáta Neodaruma_tamanukii

[

Accinctapubes_albifasciata Agnidra_scabiosa

Auzata superba

Ausaris_micacea

Ausaris palleola

Cyclidia_substigmaria

Drepana_arcuata

Falcaria bilineata

Drepana_curvatula

Drepana curvatula2

Drepana falcataria

Ennomos_autumnaria Epicopeía_hainesii Euparyphasma_maxima Euthyatira pudens Habrosyne pyritoides Lyssa_zampa Maucrāuzata_maxima Microblepsis_acuminata Nordstromia_ḡrisearia ochropacha_duplaris

oreta loochooana oreta_pulchripes oreta_rosea

Oreta turpis

Pseudothyatira_cym. Psychostrophia melanargia Sabra_harpagula Nothus_lunus

Tethea_consimilis
AAACCTGCGAAACTCGAATGAACGAACGGGGAGATTCATCGTCACTCCGC AAACCTGCGAAACTCGAATGAACGAACGGGGAGATTCATCGTCACTCCGC AAACCTGCGAAACTCGAATGAGTGAACGGGGAGATTCATCGCTAGCTCGC AAACCTGCGAAACTCGAATGAGTGAACGGGGAGATTCATCGCTAGCTCGC AAACCTGCGAAACTCGAATGAACGAACGGGGAGATTCATCGTCACTCCGC AAACCTGCGAAACTCGAATGAACGAACGGAGAGATTCATCGTCATTCCTC GTACCTGCGAA-CTC-GATGAACGAACGGGGAGATTCATCGTTATTCCGC AAACCTGCGAAACTCGAATGAACGAACGGGGAGATTCATCGTCATTCCGC AAACCTGCGAAACTTGAATGAATGAACGGGGAGATTCATCATCATTCCGC AAACCTGCGAAACTCGAATGAACGAACGGGGAGATTCATCGTCACTCCGC AAACCTGCGAAACTCGAATGAACGAACGGAGAGATTCATCGTTATTCCGC AAACCTGCGAAACTCGAATGAACGAACGGGGAGATTCATCGTCACTCGGC AAACCTGCGAAACTCGAATGAACGAACGGGGAGATTCATCGTCACTCCGC AAACCTGCGAAACTCGAATGAACGAACGGGGAGATTCATCGTCACTCCGC NNNNNNNNNNNNNNNAAATGAACGAACGGGGAGATTCATCGTCATTCCAC AAACCTGCGATACTCGAATGAACGAACGGGGAGATTCATCGTCATTCCGC AAACCTGCGAAACTCGAATGAACGAACGGGGAGATTCATCGTCATTCCGC AAACCTGCGAAACTCGAATGAACGAACGGGGAGATTCATCGTCATTCCGC AAACCTGCGAAACTCGAATGAACGAACGGGGAGATTCATCGTCATTCCGC AAACCTGCGAAACTCGAATGAACGAACGGGGAGATTCATCGTCATTCCGC GTAC-TGCGAA-CTC-GATGAACGAACGGGGAGATTCATCGTCACTCCGC AAACCTGCGAAACTCGAATGAACGAACGGGGAGATTCATCGTCACTCCGC AAACCTGCGAAACTCGAATGAACGAACGGAGAGATTCATCGTCACTCCGC AAACCTGCGAAACTCGAATGAACGAACGGGGAGATTCATCGTCACTCCTC AAACTTGCGAAACTCGAATGAACGAACGGGGAGATTCATCGTCACTCCGC AAACCTGCGAAACTCGAATGAACGAACGGGGAGATTCATCGTCATTCCGC AAACCTGCGAAACTCGAATGAACGAACGGGGAGATTCATCGTCATTCCTC AAACCTGCGAAACTCGAATGAACGAACGGGGAGATTCATCGTCATTCCGC

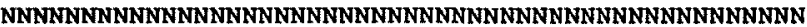
AAACCTGCGAAACTCGAATGAACGAACGGGGAGATTCATCGTCACTCCGC AAACCTGCGAAACTCGAATGAACGAACGGGGAGATTCATCGTCACTCCGC AAACCTGCGAAACTCGAATGAACGAACGGGGAGATTCATCGTCACTCCGC AAACCTGCGAAACTCGAATGAACGAACGGGGAGATTCATCGTCACTCCGC AAACCTGCGAAACTCGAATGAACGAACGGGGAGATTCATCGTCACTCCGC AAACCTGCGAAACTCGAATGAACGAACGGGGAGATTCATCGTCATTCGGC AAACCTGCGAAACTCGAATGAACGAACGGGGAGATTCATCGTCACTCCGC AAACCTGCGAAACTCGAATGAACGAACGGGGAGATTCATCGTCATTCCGC AAACCTGCGAAACTCGAATGAACGAACGGAGAGATTCATCGTCATTCCTC AAACCTGCGAAACTCGAATGAACGAACGGGGAGATTCATCGTCATTCCGC
710
720
730
740
$750]$

RNNNWNNNNNNNNNNNNNNNNNNNNNNNNNNNNNNNNNNNNNNNNNNNNNN GGCGTACGCGCGGGCGCC--TCGATGTCGAA-ACG_-_._-_-ATCTC GGCGTACGTGCGAGCGCA--ACGATGTCG---CCG--_------ATCTC GACGTGAGAGCGTGGT----CTGATGCC-_-_-_-_-_-_---_GACTC GCCGTGCGAATGTGTG-_--TTGATGCT-_-_-_____-_-_-_GTCTC GGCGTACGTGCGCGCGCC--TCGATGTC--GTCCG--_-_-_---ATCTC GGCGTACGTGCGCGCGCC--TCGATGTCGCTTCCGCGTCGCCCTCGCGGC GGCGTACGTGCGGGCGCC--ACGATGTC--GTCCG-_--_----ATCTC GGCGTGAGAACGTGGT-_--TTGATGCC-_-_-__-__-_-_GCCTT GGCGTGAGAACGTGGT--- -TTGATGCC-_-_-_-_-_-_-_GCCTT GGCGTACGTGCGCGCGCC - -TCGATGTCGCGTCCGCGTCGCCCTCGCGGC GGTGCACTTGCGTGCGT---TCGATGTT---ATCG----------GCTTC GGCGTACGGGCGCGCGCC--TCGATGTCG---CCG-_-_._-_-_GCTTC GGCGTACTGGCGGGTACCTTTCGATGTC---ACCG-_-_-_---GTCTC GGCATG---GCGGACGAGTCTCGATGCTACTATTG-_-_-_-_-GGCGTACGTGCGTGCGCC--TCGATGTCGCG-TCG-_-_-_-_-_GCTTC GGCGCGCTGGCACGTCT---GCGATGCG--GTTCG---------GCTTC GGCGTACGTGCGCGCGCC-ATCGATGTC---ACCG-_-_-_-_-_ATTTC GGCGTACGTGCGGGCGCA--TCGATGTC-.-ACCG-_.....-.-ATCTC GGCGTACGCGCGGGCGCC--TCGATGTG--TCGCA-_----_--_CCCTT GGCGTACGGGCGGGCGCC--TCGATGTC-.-ACCG-_-_-_--ATCTC GGCGTACCGTGCGGTGCC--ACGATGTC---ACCG-_-_-_---ATTTC GGCGTACCGTGCGGTGCC--ACGATGTC-_-ACCG-_-__-_-_ATTTC GGCGTACCGTGCGGTGCC--ACGATGTC--GTTCG---_-----GTTTC GGCGTACCGTGCGGTGCC--ACGATGTC---ACCG-_-_-_---ATTTC GGCGTACGGCCGGTCGCC--TCGATGCTTCG-TCG---------ACTTC GGCGTACGAGCGCGCGCC--TCGATGCC--G-CCG-_-_-_-_-_GCTPC GGCGTACGTGCGGGCGCC--ACGATGTC---ACCG----------ATCTC GGCGCGACGGGGCGTCTC--TCGATGGC--GGTCG-_-_-_----GCTTC GGCGTACGGGCGGGCGCC--TCGATGTC---ACCG-_-_-_---ATCTC
$[750]$

[737]

[735]

[ 729 ]

[729]

[736]

[748]

[736]

[729]

[729]

[748]

[734]

[733]

[737]

[ 732 ]

[736]

[735]

[736]

[735]

(736]

[735]

[735]

[735]

[736]

[735]

$[737]$

[732]

[735]

[736]

[735] 
Tethea taiwana

Tethea_or

Tetheela fluctuosa

Thyatira batis

Thyatira_batis 2

Tridrepana flava

Tridrepana_unispina

watsonalla binaria

Watsonalla cultraria

watsonalla uncinula

cilix_glaucata

Falcaria lacertinaria

Habrosyne _aurorina

Jodis putata

Neodaruma_tamanukii

Accinctapubes albifasciata Agnidra_scabiosa

Auzata_superba

Ausaris micacea

Ausaris_palleola

Cyclidia_substigmaria

Drepana arcuata

Falcariábilineata

Drepana curvatula

Drepana_curvatula2

Drepana_falcataria

Ennomos autumnaria

Epicopeía hainesi

Euparyphasma_maxima

Euthyatira pudens

Habrosyne pyritoides

Lyssa zampa

Maucrauzata_maxima

Microblepsis__acuminata

Nordstromia grisearia

Ochropacha duplaris

oreta_loochooana

oreta pulchripes

oreta rosea

oreta_turpis

Pseudothyatira cym.

Psychostrophia_melanargia

Sabra_harpagula

Nothus lunus

Tethea_consimilis

Tethea taiwana

Tethea or

Tetheela_fluctuosa

Thyatira batis

Thyatira_batis 2

Tridrepaña_flava

Tridrepana unispina

Watsonalla_binaria

Watsonalla_cultraria

Watsonalla uncinula

Cilix_glaućata

Falcāia lacertinaria

Habrosyne_aurorina

Jodis_putata

Neodaruma tamanukii

I

Accinctapubes_albifasciata

Agnidra scabiosa

Auzata_superba

Ausaris micacea

Ausaris_palleola
GGCGTACGGGCGGGCGCC--TCGATGTC---ACCG - - GGCGTACGGGCGGGTGCC--TCGATGTC-- ACCG-_-_---ATCTC GGCGTACGGGCGGGTGCC--TCGATGTC---GTCG--------ACCTC GGCGTACTCGCCGGCGCC--TCGATGTC---ACCG----------ATCTC NNNNNNNNNNNNNNNNNNNNNNNNNNNNNNNNNNNNNNNNNNNNNNNNNN GGCGTACGGGCGGTCGCT-DCGATGTT--GTCCG-_------ATTTC GGCGTACGCGCGGTCGCT--TCGATGCT--GTCGG-_-1---ATTTC GGCGTACTCGCGGGCGCC--TCGATGTC---ACCG--------ATCTC GGCGTACTCGCGGGCGCC--TCGATGTC-1-ACCG-_-_---_-ATCTC GGCGTACTGGCGGGCGCC--TCGATGTC---ACCG------ --ATCTC GGCGTACGCGCGGGCGCA--TCGATGCC--GCACG---------GTCTC GGCGTACGTGCGGGCGCC--ACGATGTC--GTCCG---------ATCTC GGCGTACGACCGGACACC--TCGATGCTCACATCG---------GCCTC GGCGCACATGCGTTGAT---TCGATGTC-_-TTCG-_-_-_-_GCCTC GGCGTACGGGCGGGTACC--TCGATGTC---ACCG-----m-ATCTC
$735]$

[735]

[735]

[735]

[750]

$[736]$

[736]

[735]

$[735]$

[735]

[736]

$[736]$

[738]

[734]

[735]
8001

. $]$
NNNNNNNNNNNNNNNNNNNNNNNNNNNNNNNNNNNNNNNNNNNNNNNNNN GGTCGTG---GCGGCACGGGTCTCGC-GCGTCGACGTCCGAGGACGGCG GATCG----GGCGGCACGTGTCTCGT-ACGTAGACGTCCGCGGACGGCG AATGG-------GAGCACATGCAGCGC-TTCTTGACGTCCGCGGGAGGCG TACCGAGTACGGTGAAATGCGCCTTCC-GTAACG----TCGCGGGTGGCG GGTCGT----GCGACACGACGCGCGT-ACGTCGACGTCCGCGGACGGCG GGCCGTGAC--GCGACACGGGTCGCGC-ACGTCGACGTCCGCGGACGGCG GGTCG ---GGCGGTACGGGTCTCGT-ACGTCGACGTCCGCGGACGGCG ATTGG----- AAGCACGGACTGCGC-CTCTTGACGTCCGCGAGGGGCG ATTGG------AAGCACGGACTGCGC-CTCTTGACGTCCGCGAGGGGCG GGCCGTGAC--GCGACACGGGTCGCGC-ACGTCGACGTCCGCGGACGGCG GGTCG--- - TTGGCACTGCGCGCGC-TCGT-AGCGTCCGGGGACGGCG GGCCG-----GTCGGCACGGGTCGTGT-CCGTCGACGTCCGCGGACGGCG GATCG - - -GGCGGCACGGGTCTCGT-GAGTCGACGTCCGCGGACGGCG -----ATATAGGGGCACGAGATACGT-TAGTCATTAGCTACGGATGGCG GGTCGC--- GCGACACGGGTCGCGT-ACGTCGACGTCCGTGGACGGCG GGTCG-----ATTCGCACGCGATTGGC-CAGTTCGCGTCCGTGGACGGCG GATCG-- - -GGCGGCACGGGTCGCGT-ACGTCGACGTCCGCCGACGGCG GGTCG----GGCGGCACGGGTCCCGT-ACGTCGACGTCCGCGGACGGCG AACCG-GGTGCGAGTCACGGGTCCCGC-GCGTCGACGTCCGCGGACGGCG GGTCG-----GGCGGCACGGGTCCCGT-TCGTCGACGTCCGCGGACGGCG GATCG---- GGCGGCACGGGTCCGTG-CGGTCGACGTTCGCGGACGGCG GATCG---- -GGCGGCACGGGTCCGTG-CGGTCGACGTTCGCGGACGGCG GATCG--- AGCGACACGGGTCCGTG-CGGTCGACGTTCGCGGACGGCG GATCG----GGCGGCACGGGTCCGTG-CGGTCGACGTTCGCGGACGGCG GGTCGC----GAGGCACGGGCTCCGT-CCGTCGACGTCCGTGGACGGCG GGTCG----GCCGGCACGGGTCGCGT-TCGTCCACGTCCGCGGACGGCG GGTCG----GGCGGCACGGGTCTCGT-ACGTCGACGTCCTCGGACGGCG ACTG--TACGACTGTCACGGAGCGCC--GCGTCAGTGTCCGGGGACGGCG GGTCG----GGCGGCACGGGTCCCGT-CCGTCGACGTCCGAGGACGGCG GGTCG----GGCGGCACGGGTCCCGT-CCGTCGACGTCCGCGGACGGCG GGTCG-----GGCGGCACGGGTCCCGT-CCGTCGACGTCCGTGGACGGCG GGTCG----GCAGGCACGGGTCCCGT-CCGTCGACGTCCGCGGACGGCG GGTCG----GGCGGCACGGGTCCGGC-GCGTCGACGTCCGTGGACGGCG NNNNWNNNNNNNNNNNNNNNNNNNNNNNNNNNNNNNNNNNNNNNNNNNNN GGTCG----GGCAACACGTGCGCCGC-TCGTCGACGTCCGCGGACGGCG GGTCA-----GTCAGCACGTGCGCCGC-TCGTCGACGTCCGCGGACGGCG GGTCG-- --GGCGGCACGGGTCCCGC-GAGTCGACGTCCGCGGACGGCG GGTCG----GGCGGCACGGGTCCCGC-GAGTCGACGTCCGCGGACGGCG GGTCG--- GGCGGCACGGGTCCCGC-TAGTCGACGTCCGCGGACGGCG GACCGT---_GCGGCACGTGTCCTGTCGCGTCGACGTCCGCCGACGGCG GGTCG-----GGCGGTACGGGTCTCGT-ACGTCGACGTCCGCGGACGGCG GGTCGCACTGTGCGGCACGGGTTCCGT-TCGTCGACGTCCGTGGACGGCG GGTCG-----TGGGCACGTGTCGCGT-ACGT-AGCGTCCGGGGACGGCG GGTCG----GGCGGCACGGGTCTCGT-CCGTCGACGTCCGTGGACGGCG

$[800]$

[782]

[779]

$[771]$

[774]

[780]

[795]

[780]

[771]

[771]

[795]

[776]

[777]

[781]

[775]

[780]

[779]

$[780]$

[779]

[784]

[779]

[779]

[779]

[780]

[779]

[781]

[776]

[779]

[782]

[779]

[779]

[779]

[779]

[ 779$]$

[800]

[780]

[780]

[ 779 ]

[779]

[779]

[781]

[780]

[ 787 ]

[776]

[779]
810
820
830
840
850 ]

NNNNNNNNNNNNNNNNKNNNNNNNNNNNNNNNNNNNNNNNNNNNNNNNNN TGCACTTCTCCCTCAGTAATACATCGCGACCCGTTCGATGTCGGTCTAAG TGCACTTCTCCCTCAGTAATACATCGCGACCCGTTCGATATCGATCTAAG TGTACTTCTTCCTTAGTAAAACATCGCAACTCGTTTGAGGTACGGCCAAG TGTACTTCTCCCTTAGTAAAACATCGCGACTCGTTCGAGGCGTGTCTAAG 
Cyclidia substigmaria Drepana_arcuata Falcaria bilineata Drepana_curvatula Drepana_curvatula2 Drepana falcataria Ennomos_autumnaria Epicopeía hainesii Euparyphasma maxima Euthyatira pudens Habrosyne pyritoides Lyssa_zampa Maucrauzata_maxima Microblepsis_acuminata Nordstromia_grisearia Ochropacha duplaris oreta loochooana Oreta_pulchripes oreta rosea

Oreta turpis Pseudothyatira_cym. Psychostrophia_melanargia Sabra_harpagula Nothus_lunus Tethea_consimilis Tethea_taiwana Tethea_or Tetheela fluctuosa Thyatira batis Thyatira_batis 2 Tridrepana flava Tridrepana_unispina Watsonalla_binaria Watsonalla cultraria Watsonalla-uncinula cilix glaucata

Falcaria lacertinaria Habrosyné_aurorina Jodis putata Neodaruma_tamanukii

[

Accinctapubes albifasciata Agnidra_scabiōa Auzata_superba

Ausaris micacea Ausaris_palleola Cyclidia_substigmaria

Drepana_arcuata

Falcaria_bilineata Drepana curvatula

Drepana_curvatula2 Drepana_falcataria Ennomos autumnaria Epicopeía hainesii Euparyphasma maxima Euthyatira_pudens Habrosyne_pyritoides Lyssa zampa

Maucrauzata maxima Microblepsis̄_acuminata Nordstromia_grisearia Ochropacha_duplaris oreta_loochooana Oreta pulchripes Oreta rosea Oreta_turpis Pseudothyatira cym. Psychostrophia_melanargia Sabra_harpagula Nothus_lunus
TGCACTTCTCCCTCAGTAATACATCGCGACCCGTTCGATGTCGGTCTAAG TGCACTTCTCCCTCAGTAATACATCGCGACCCGTTCGATGTCGGTCTAAG TGCACTTCTCCCTCAGTAATACATCGCGACCCGTTCGATGTCGGTCTAAG TGTACTTCTCCTTTAGTAAAACATCGCCACTCGTTTAAGGTACGTCCAAG TGTACTTCTCCTTTAGTAAAACATCGCCACTCGTTTAAGGTACGTCCAAG TGCACTTCTCCCTCAGTAATACATCGCGACCCGTTCGATGTCGGTCTAAG TGCACTTCTCTCTTAGTAATACATCGCGACCCGTTCGATGTCGGTCTAAG TGCACTTCTCCCTCAGTAATACATCGCGACCCGTTCGATGTCGGTCTAAG TGCACTTCTCCCTCAGTAATACATCGCGACCCGTTCGATGTCGGTCTAAG TGCACTTTTCCCTCAGTAATACATCGCGACCTGTTTGATGCCGGTCTAAG TGCACTTCTCCCTCAGTACGACATCGCGACCCGTTCGATGTCGGTCTAAG TGCACTTCTCTCTTAGTAATACATCGCGACCCGTTAGATGTCGGTCTAAG TGCACTTCTCCCTCAGTAATACATCGCGACCCGTTCGATGTCGGTCTAAG TGCACTTCTCCCTCAGTAATACATCGCGACCCGTTCGATGTCGGTCTAAG TGCACTTCTCCCTCAGTAATACATCGCGACCCGTTCGATGTCGGTCTAAG TGCACTTCTCCCMCAGTAATACATCGCGACCCGTTCGATGTCGGTCTAAG TGCACTTCTCCCTCAGTAATACATCGCGACCCGTTCGATGTCGGTCTAAG TGCACTTCTCCCTCAGTAATACATCGCGACCCGTTCGATGTCGGTCTAAG TGCACTTCTCCCTCAGTAATACATCGCGACCCGTTCGATGTCGGTCTAAG TGCACTTCTCCCTCAGTAATACATCGCGACCCGTTCGATGTCGGTCTAAG TGCACTTCTCCCTCAGTAATACATCGCGACCCGTTCGATGTCGGTCTAAG TGCACTTCTCCCTCAGTAATACATCGCGACCCGTTCGATGTCGGTCTAAG TGCACTTCTCCCTCAGTAATACATCGCGACCCGTTCGATGTCGGTCTAAG TGCACTTCTCTCTCAGTAATACATCGCGACCCGTTCGATGTCGACCTACG TGCACTTCTCCCTCAGTAATACATCGCGACCCGTTCGATGTCGGTCTAAG TGCACTTCTCCCTCAGTAATACATCGCGACCCGTTCGATGTCGGTCTAAG TGCACTTCTCCCTCAGTAATACATCGCGACCCGTTCGATGTCGGTCTAAG TGCACTTCTCCCTCAGTAATACATCGCGACCCGTTCGATGTCGGTCTAAG TGCACTTCTCCCTCAGTAATACATCGCGACCCGTTCGATGTCGGTCTAAG

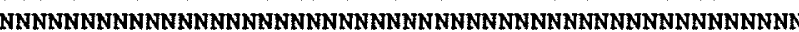
TGCACTTCTCCCTCAGTAATACATCGCGACCCGTTCGATGTCGGTCTAAG TGCACTTCTCCCTCAGTAATACATCGCGACCCGTTCGATGTCGGTCTAAG TGCACTTCTCCCTCAGTAATACATCGCGACCCGTTCGATGTCGGTCTAAG TGCACTTCTCCCTCAGTAATACATCGCGACCCGTTCGATGTCGGTCTAAG TGCACTTCTCCCTCAGTAATACATCGCGACCCGTTCGATGTCGGTCTAAG TGCACTTCTCCCTCAGTAATACATCGCGACCCGTTCGATGTCGGTCTAAG TGCACTTCTCCCTCAGTAATACATCGCGACCCGTTCGATGTCGGTCTAAG TGCACTTCTCCCTCAGTAATACATCGCGACCCGTTCGATGTCGGTCTAAG TGCACTTCTCTCTTAGTAATACATCGCGACCCGTTCGATGTCGGTCTAAG TGCACTTCTCCCTCAGTAATACATCGCGACCCGTTCGATGTCGGTCTAAG

$[830]$

[845]

$[830]$

[821]

[821]

$[845]$

[826]

[827]

[831]

[825]

[830]

$[829]$

[830]

$[829]$

[834]

[829]

[829]

[829]

[830]

$[829]$

[831]

[826]

$[829]$

[832]

[829]

[829]

[829]

[829]

[829]

[850]

$[830]$

[830]

$[829]$

[829]

[829]

[831]

$[830]$

(837)

$[826]$

[ 829]

$$
\begin{array}{lllll}
860 & 870 & 880 & 890 & 9001 \\
. & . & . & . & .]
\end{array}
$$

NNNNNNNNNRNNNNNNNNNNNNNNNNNNNNNNNNNNNNNNNNNNNNNNNN CGCCGTTCGGGAGCCCCATTGT-----GCCTCTCG-GGGT---CACTTT CGCCGTTCGGGAGCCCCATTGT------ACCTTTCG-GGGT---CACTTT TGTCGTTAAGCAAAAGT-TTTTGTTTTACAACAATGAGTTTTGTTTTAGC TGACGTTGGACCTCGTTCCTTTGT---TCTCCTGCGGGTG---CAACAA CGCAGTTCGGGAGCCCCGTCGTGC----CTCTCAACGGGGG---CGCGGT CGCCGTTCGGGAGCCCGGTTGCG-----CTCCCCTCGGGGA---CGCTGC CGCCGTTCGGGAGCCCCATCGT-----ACCTTTCG-GGGT---CACGGT CGTCGCTAAACAAGATTTTTTTGTTTTGCCACATTGAGTTTTGTTTCAGC CGTCGCTAAACAAGATTTTTTTGTTTTGCCACATTGAGTTTTGTTTCAGC CGCCGTTCGGGAGCCCGGTTGCG-----CTCCTCTCGGGGA---CGCTGC TGCCTTTCGGGAGTCTCCGTTTCTAGTTCGCTAGTTPTGGA--_-CGCCGTCCGGGAGTCCCGTCTCCCC---CCCTCGCGGGGGG--TGGGGC CGCCGTTCGGGAGCCCCATAGTGC----CCCCTAGC-GGGA---CACTGT CGCCGTACAAGCGCGCCGTTCGGGAGCCCCATAGTGC----GCCCTCGC-GGGA---CACTGT CGTCGCACGGGAGCC_-_._- ACCGTTGTGCGGTTTCGGCCGC CTCGGTTCGGGAGCCCCATTGTG----_CTTTAGCGAGGT---CACTGT CGCCGTTCGGGAGCCCCATTGT-----ACCCCTCG-GGGT---CACTGT CGCCGTCCGGGAGCCCCGTCGCG----CCCCTCGCGGGGT--CCGCGGC CGCCGTTCGGGAGCCCCATTGCG----ACCCTC---GGGC---CGCTGT CGCCGTPCGGGAGCCCCGTTGT-----GCCCTCAC-GGGT---CGCAGC CGCCGTTCGGGAGCCCCGTTGT------GCCCTCAC-GGGT---CGCAGC CGCCGPTCGGGAGCCCCGTTGT-_---GCCCTCAC-GGGT---CATAGC CGCCGTTCGGGAGCCCCGTTGT-_-_-GCCCTCAC-GGGT--_CGCAGC CGCCGTTCGGGAGCCCCACGGTG----TCCCTCAC-GGGT---CACTGT CGCCGTTCGGGAGTACCATCGTCGC---CCTC-----GGGC---GGCGGC CGCCGTTCGGGAGCCCCATCGT-_-_-ACCTCTCG-GGGT---CACGGT CGCTGTTCGGGCGTACTGCGGTC----ACCCTCGC-GGGC---GGTCGT
[900]

$[872]$

(869)

$[870]$

[867]

[873]

$[887]$

[870]

[871]

[871]

[887]

$[867]$

[871]

[873]

$[838]$

[872]

[866]

[872]

[869]

[877]

[868]

[869]

$[869]$

[870]

[869]

[872]

[865]

[869]

[873] 
Tethea consimilis

Tethea_taiwana

Tethea or

Tetheela fluctuosa

Thyatira_batis

Thyatira batis2

Tridrepana_flava

Tridrepana_unispina

Watsonalla binaria

Watsonalla_cultraria

watsonalla_uncinula

Cilix glaucata

Falcaria_lacertinaria

Habrosyne_aurorina

Jodis putata

Neodaruma_tamanukii

[

Accinctapubes_albifasciata Agnidra_scabiosa

Auzata superba

Ausaris_micacea

Ausaris palleola

Cyclidia substigmaria

Drepana_arcuata

Falcaria bilineata

Drepana_curvatula

Drepana_curvatula2

Drepana falcataria

Ennomos_autumnaria

Epicopeia hainesii

Euparyphasma maxima

Euthyatira_pudens

Habrosyne_pyritoides

Lyssa_zampa

Maucrauzata_maxima

Microbleps is acuminata

Nordstromia grisearia

Ochropacha_duplaris

oreta loochooana

Oreta_pulchripes

oreta rosea

Oreta turpis

Pseudothyatira_cym.

Psychostrophia melanargia

Sabra harpagula

Nothus_lunus

Tethea_consimilis

Tethea taiwana

Tethea_or

Tetheela fluctuosa

Thyatira batis

Thyatira_batis 2

Tridrepana flava

Tridrepana_unispina

Watsonalla_binaria

Watsonalla cultraria

Watsonalla_uncinula

Cilix glaucata

Falcaria lacertinaria

Habrosyne_aurorina

Jodis putata

Neodaruma tamanukii

[

Accinctapubes albifasciata Agnidra_scabiosa

Auzata superba

Ausaris_micacea
CGCCGTTCGGGAGCCCCACGGTG-----TCCCCCCC-GGGC---CACCGT CGCCGTTCGGGAGCCCCACGGCG-----ACTCTC---GGGT---CACCGT CGCCGTTCGGGAGCCCCACGGTG-----TCCCTC---GGGT---CACTGT CGCCGTTCGGGAGCCCCATAGTG-_---CCCCTCGC-GGGG-- - TACTGT CGCCGTTCGGGAGCCCCATAGCG------TCCCTC---GGGT---CGCTGT NNNNNNNNNNNNNNNNNNNNNNNNNNNNNNNNNNNNNNNNNNNNNNNNNN CTTCGTCCGGGAGCCCGTGCGCA-----CCTCTCGCGGGGT---CGCGTA CTTCGTCCGGGAGCCCGTGCGCA-_---_CTCTCGCGGGGT--_CGCGTA CGCCGTTCGGGAGCCCCATCGT------ACCCCTCG-GGGT---CACTTP CGCCGTTCGGGAGCCCCATCGT------ACCCCTCG-GGGT---CACTTT CGCCGTTCGGGAGCCCCATTGTGC----ACCTTTCG-GGGT---CACTTT CGCCGTTCGGGAGCCCAGCGGCGTGTTGCCCTTCGCGGGGTCGCCGCCGT CGCCGTTCGGGAGCCCCATCGT------ACCTTTCG-GGGT---CACGGT CGCCGTTCGGGAGCCCCATAGTG-----TCCTTTAC-GGGT---_CACTGT TGCCCTCCGGGAGTCTTCGCTTC--_-_-CTTGTGTTGTGTA-_-_._CGCCGTTCGGGAGCCCCATTGTA-_-_-_CCCTTCAC-GGGG---CACTGT

$$
\begin{array}{lllll}
910 & 920 & 930 & 940 & 950] \\
. & . & . & . & .1
\end{array}
$$

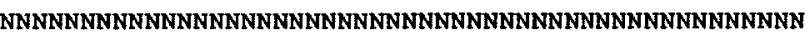
GG-_-_-GACCGT -_._._- GACGTG-CGCCGACCGGCCGTCGTACGGTA GG-----GACCGT-------GACGTG-CGCCGATCGGTTGTCGTACGGTA

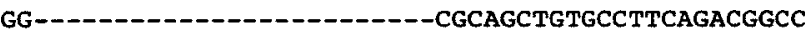
GGAGTTTGGTTCC-_-_-_-GGCGC--CGCCGGCATGCCATTGGACGGTA GG---- GACCGC--_-_-GACTGT-CGCCGACCGGCCGTCGGACGGTA CG--_--GACCGC------GACGTG-CGCCGACCGGCTGTCGTACGGTA GG-----GACCGC------GACGTG-CGCCGACCGGCCGTCGTACGGTA AG---_-_--_--_-_-_-_--_GCAGGCGTGCCTTTAGACGGTC AG-_-_CG--.--GACCGC-..---GACGTG-CGCCGACCGGCTGTCGTACGGTA -----TACCGT------GAAGTG-CACCGACCGGCTGTTGGACGGTA GG--.--TACCGT------GACGGA-CGCCGACCGGCTGTCGGACGGTA GG--_--GACCGT-_-_-_GACGTG-CGCCGACCGGCCGTCGGACGGTA -_-_-_GGTAGT -..-_-_GACGAG-CGCCGACCGGGCAACAGACTGTA GG-----GACCGT-------GACGTG-CGCCGACCGGCCGTCGGACGGTA CGATGGTGACCGT------_CGCGAA-CGCCGACCGGCTGTCTGACGGTA GG----GACCGT-_--_-_GACTTG-AGCCGACCGGCTGTCGTACGGTA GG-_-_-GACCGC -...-.-GACGTG-CGCCGACCGGCCGTCGTACGGTA TG-----GACCGT-------GACGTG-CGCCGACCGGCCGTCGGACGGTA GG-----GACCGC------GACGTG-CGCCGACCGGCCGTCGGACGGTA GG----_GACCGC-------GACGTG-CGCCGACCGGCTGTCGTACGGTA GG----GACCGC------GACGTG-CGCCGACCGGCTGTCGTACGGTA GG---- GACCGC------GACGTG-CACCGACCGGCCGTCGTACGGTA GG-----GACCGC------GACGTG-CGCCGACCGGCTGTCGTACGGTA GG-----GACCGT-------GACGTG-CGCCGACCGGCCGTCGGACGGTA GG-_- TACCGT-_-_-GACGGA-CGCCGACCGGCCGTCGGACGGTA

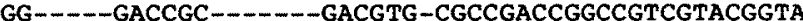
AG-----TACCG-------GACGGA-CGCCGGCCGGCTGTCGGACGGTA GG--.--GACCGC------GACGTG-CGCCGACCGGCCGTCGGACGGTA GG-----GACCGC-------GACGTG-CGCCGACCGGCCGTCGGACGGTA GG--_--GACCGC------GACGTG-CGCCGACCGGCCGTCGGACGGTA GG----GACCGC------GACGTG-CGCCGACCGGCCGTCGGACGGTA GG-----GACCGT-_------GACGTG-CGCCGACCGGCCGTCGGACGGTA

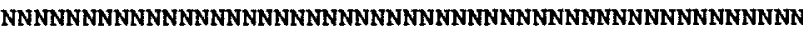
CG-----GACCGTTCACACAGACAAT-AGCCGACCGGCCGTCGTACGGTA CG----GACCGATCAAACAGACAAT-AGCCGACCGGCCGTCGTACGGTA GG----_GACCGC-_---_GACGTG-CGCCGACCGGCCGTCGTACGGTA GG-_..-GACCGC_.....--GACGTG-CGCCGACCGGCCGTCGTACGGTA GG-..-_GACCGC-...-..-GACGTG-CGCCGACCGGCCGTCGTACGGTA TG----_GACCGC------GACGTG-CGTCGACCGGCCGTCGTACGGTA GG-----GACCGC-------GACGTG-CGCCGACCGGCCGTCGTACGGTA GG-----GACCGT------GACGTG-CGCCGACCGGCCGTCGGACGGTA -.---GACCGC-----GAGGTGTCACCGACCGGCCGTCGGACGGTA GG-_---GACCGC-_-_-_GACGTG-CGCCGACCGGCCGTCGGACGGTA

$$
\begin{array}{lllll}
960 & 970 & 980 & 990 & 1000
\end{array}
$$

NNNNNNNNNNNNNNNNNNNNNNNNNNNNNNNNNNNNNNNNNNNNNNNNNN TGAA-T_-_. TG-AC_._._._._._._._GAAACGCGCACGCGTTCC TAAG-T-_--TG-AC-_-_-_-_-_-_GAATCGCGTACGCGTTTT AG-_- 
Ausaris palleola

Cyclidia_substigmaria

Drepana arcuata

Falcaria_bilineata

Drepana_curvatula

Drepana curvatula2

Drepana_falcataria

Ennomos_autumnaria

Epicopeia hainesii

Euparyphasma maxima

Euthyatira pudens

Habrosyne_pyritoides

Lyssa_zampa

Maucrauzata maxima

Microblepsis_acuminata

Nordstromia_grisearia

Ochropacha duplaris

oreta_loochooana

oreta_pulchripes

oreta rosea

oreta-turpis

Pseudothyatira_cym.

Psychostrophia melanargia

Sabra_harpagulà

Nothus_lunus

Tethea_consimilis

Tethea_taiwana

Tethea_or

Tetheela_fluctuosa

Thyatira batis

Thyatira batis 2

Tridrepaña_flava

Tridrepana_unispina

Watsonalla binaria

Watsonalla_cultraria

Watsonalla uncinula

Cilix_glaucata

Falcaria_lacertinaria

Habrosyne aurorina

Jodis_putata

Neodaruma_tamanuki.i.

[

Accinctapubes_albifasciata Agnidra_scabiosa

Auzata superba

Ausaris_micacea

Ausaris palleola

Cyclidia substigmaria

Drepana_arcuata

Falcaria bilineata

Drepana_curvatula

Drepana_curvatula2

Drepana falcataria

Ennomos_autumnaria

Epicopeia_hainesii

Euparyphasma maxima

Euthyatira_pudens

habrosyne_pyritoides

Lyssa_zampa

Maucrauzata_maxima

Microblepsis acuminata

Nordstromia_grisearia

Ochropacha_duplaris

oreta loochooana

oreta_pulchripes

Oreta_rosea

Oreta turpis

Pseudothyatira_cym.

Psychostrophia_melanargia

Sabra_harpagula

GCGAGGC-...

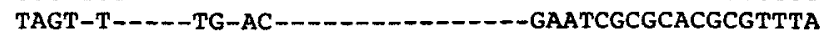
TCAT----_-TG-AA-_-_--ACATTTGACGAATCGCGCACGCGTACA TACA-T_-_--TG-AC-_-_-_-_-_-_-_GAATCGCGCACGCGTTTC CG-_-_-_._-AGATCGCGCACGCGTATG

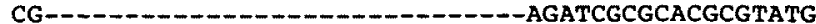
TCAT----.-TG-AA-_--.- ACATTTGACGAATCGCGCACGCGTACA GATT-_-_--TG-AT-_-_-_._._-_GAAACGCTCACGCGCTAG

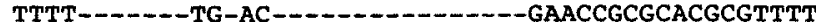
TCAT-CATACATA-AC-_._-_._-_-_AATCGCGCACGCGTACA TAAA-_-_- AT-_-_-_-_AATCGCGCACGCGTATC

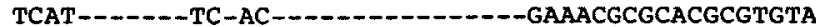
TAATGT-----TT-AG--_-_-_-_----_GAATCGCGCACGCGTTTA TATTGTTATATTG-AC-_._-_-_._._-GAATCGCGCACGCGTTTA TAAA-T----TG-AC-_-_-_-_._-_-GAACCGCGCACGCGTTTC TTGTGTCATGGTA-_-_-_-_._-_GAATCGCGCACGCGTTTC TCAC-T - . - - TA-AC - _. TAAA-CATT--TG-AC--_-_-_-_-_--GAATCGCGCACGCGTTTC TAAA-CATT--TG-AC-_-_-_-_-_---_GAATCGCGCACGCGTTTC TAAC-AATT--TG-AC-_-_-_-_-_---GAATCGCGCACGCGTTAC TAAA-CATT--TG-AC-_-_-_-_-_-_--GAATCGCGCACGCGTTTC TCAT-T----CA-TG-_-_-_-_...--GAATCGCGCACGCGTTAC

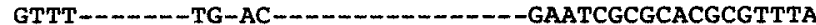
TAAA-T--- TG-AC-_-_-_-_-_GAATCGCGCACGCGTTTC

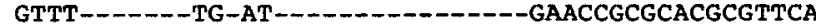
TCAC-T-----TA-AC--_-_-_-_-_.--GAATCGCGCACGCGTTTA TCAC-T----AA-TC--_TCAC-T-_-- TA-AC-_._-_._-_-_GAAACGCGCACGCGTACC TCAC-T----TA-AC-_-_-_-_-_--GAATCGCGCACGCGTAC-

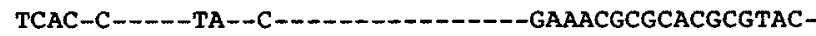
NNNNNNNNNNNNNNNNNNNNNNNNNNNNNNNNNNNNNNNNNNNNNNNNNN TAAT-_._._. AAATTTGTTATATGTGACGAATCGCGCACGCGTTTC TAAT--..-- AAATATGTTATTATTGACGAATCGCGCACGCGTTTC TAAA-T_-_.-TG-AC_-_._-_._-_-_-_GAACCGCGCACGCGTTTC TAAA-T-_-_-TG-AC-_-_-_-_-_-_GAACCGCGCACGCGTTTC

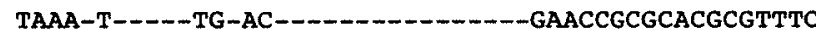
TAATGT-----GG-ACAATACACAATATATAGGAATCGCGCACGCGTTAC TACA-T-----TG-AC--..........-GAATCGCGCACGCGTTTC TCAT -T-_-_CA-TG-_-_-_-_-_GAATCGCGCACGCGTGTT GTTT-_-..-CATAC-_-_._-_._-_GAAACGCGCACGCGCTCG

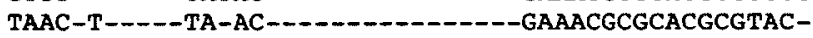

$$
\begin{array}{lllll}
1010 & 1020 & 1030 & 1040 & 1050] \\
\cdot & \cdot & . & . & .]
\end{array}
$$

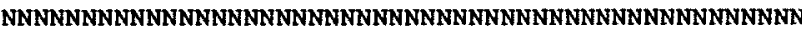
TA------GCGCGTCAGGCCCGACGCAAGGCAACGTCGTATT-TCCAATG AT-_-_-_GCGCGTCCGGCCCGACGCAAGGCAACGTCGTA--DCCGATG TA------ACGCGCCCAGC-CTATTCGAGGTGACTTT----- ACGCGTCCGGT-CGACGCAAGGCGACGTCGTT---GCCGACC CG--.--OGCGCGTCCGGCCCGACGCAAGGCAACGTCGTA---TCCCGTG TT--TGAAACGCGTCCGGCCCGACGCAAGGCAACGTCGTATTTCTCGTTA AT------GCGCGTCCGGCCCGACGCAAGGCAACGTCGTA---TCCTATG AA--_-- ACGCGCCCGGC-TAATGCGAGGTGACCTCGTA-....-..-AA------ACGCGTCCGGC-TAATGCGAGGTGACCTCGTA-_-..-...TT--TGAAACGCGTCCGGCCCGACGCAAGGCAACGTCGTATTTCTCGTTA CG------CGCGTCAGGCCCGACGCAAGGCAACGTCGTA---TTCCGCG CA---D-ACGCGTCCGGCCCGACGCAAGGTTACGTCGTC---GTCTGCG CT--- - AGCGCGTCCGGCCCGACGCAAGGCAACGTCGTA---TCCAGCG TA------GCGCGTCCGGTGCGACGCAAAGTA-CGTTGTA---TCCTTTA CACATACAGCGCGTCCGGCCCGACGCAAGGCAACGTCGTA-_-TCCTACG --------ACGCGTCCGGCCCGACGCAAGGTATCGTAGTC---ATCTGTT AC-..--.GCGCGTCCGGCCCGACGCAAGGCAACGTCGTA---TCCAATG AC------GCGCGTCCGGCCCGACGCAAGGCAACGTCGTA---TCCAATG GC------ACGCGTCCGGCCCGACGCAAGGCAACGTCGTC---GCCCTGG TA------GCGCGTCCGGCCCGACGCAAGGCTACGTCGTA---TCCAATG TA-----TGCGCGTCCGGCCCGACGCAAGGCAACGTCGTA---TCCGATT TA-----TGCGCGTCCGGCCCGACGCAAGGCAACGTCGTA---TCCGATT TA-2--DTGCGCGTCCGGCCCGACGCAAGGCAACGTCGTA---TCCGATT TA-_- TGCGCGTCCGGCCCGACGCAAGGCAACGTCGTA---TCCGATT AG-------CGCGTCCGGCCCGACGCAAGGCAACGTCGTA---TCCTACG CA------ACGCGTCCGGCCCGACGCAAGGCAACGTCGTA---TCCCGCG AC--_-_-GCGCGTCCGGCCCGACGCAAGGCAACGTCGTA---TCCAATG

[1050]

[979]

[974]

[945]

[973]

[978]

[1007]

[975]

[949]

[949]

[1007]

[968]

[ 975$]$

[ 984 ]

[937]

[982]

[975]

[983]

[ 974 ]

[986]

[972]

[978]

[978]

[979]

[978]

[976]

[969]

[974] 
Nothus Iunus

Tethea_consimilis

Tethea_taiwana

Tethea or

Tethee'̃a_fluctuosa

Thyatira batis

Thyatira_batis 2

Tridrepaña flava

Tridrepana unispina

Watsonalla_binaria

Watsonalla cultraria

Watsonalla_uncinula

Cilix_glaucata

Falcaria_lacertinaria

Habrosyne_aurorina

Jodis_putāta

Neodaruma_tamanukii

l

Accinctapubes_albifasciata

Agnidra_scabiosa

Auzata_superba

Ausaris micacea

Ausaris palleola

Cyclidia_substigmaria

Drepana arcuata

Falcaria_bilineata

Drepana_curvatula

Drepana curvatula2

Drepana_falcataria

Ennomos_autumnaria

Epicopeia hainesii

Euparyphasma_maxima

Euthyatira pudens

Habrosyne_pyritoides

Lyssa_zampa

Maucrauzata maxima

Microblepsis_acuminata

Nordstromia_grisearia

Ochropacha duplaris

oreta_loochooana

oreta_pulchripes

Oreta rosea

oreta_turpis

Pseudothyatira cym.

Psychostrophia melanargia

Sabra_harpagula

Nothus lunus

Tethea_consimilis

Tethea_taiwana

Tethea or

Tetheela fluctuosa

Thyatira_batis

Thyatira batis 2

Tridrepaña_flava

Tridrepana unispina

Watsonalla binaria

Watsonalla_cultraria

Watsonalla_uncinula

Cilix glaucata

Falcaria_lacertinaria

Habrosyne aurorina

Jodis putata

Neodaruma_tamanukii

l

Accinctapubes_albifasciata Agnidra_scabiósa

Auzata_superba

CG---2--CGCGTCCGGCCCGACGCAAGGCGTCGTCGTATT-TCTCATT

CA-_--ACGCGTCCGGCCCGACGCAAGGCAACGTCGTA---TCCCACG

TT---_-GCGCGTCCGGCCCGACGCAAGGCAACGTCGTATCCTCCGACC

-1-0-ACGCGTCCGGCCCGACGCAAGGCAACGTCGTA---TCCTGCG

TA-----GCGCGTCCGGCCCGACGCAAGGCAACGTCGTA---TCCTTCG TA--_---ACGCGTCCGGCCCGACGCAAGGCAACGTCGTG---TCCGGCG NNNNNNNNNNNNNNNNNNNNNNNNNNNNNNNNNNNNNNNNNNNNNNNNNNN AT-_-_- ACGCGTCCGGCCCGACGCAAGACAACGTCGTA---TCACGAG TA------ACGCGTCCGGCCCGACGCAAGGCAACGTCGTA---TCGAGAG

GC------GCGCGTCGGGCCCGACGCAAGGCAACGTCGTA---TCCTATG GC-----GCGCGTCGGGCCCGACGCAAGGCAACGTCGTA---TCCTATG GC------GCGCGTCAGGCCCGACGCAAGGCAACGTCGTA---TCCTATG TA---_-_GCGCGTCCGGCCCGACGCAAGGCAACGTCGTC---TCCGGTG AT------GCGCGTCCGGCCCGACGCAAGGCAACGTCGTA---TCCTATG TA---- AGCGCGTCCGGCCCGACGCAAGGCAACGTCGTA---TCCTACG T------CGCGTCCGGCCCGACGCAAGGCAACGTCGTA---TCCCTCC TA_....-GCGCGTCCGGCCCGACGCAAGGCAACGTCGTA-_-TCCAATG

$[977]$

$[975]$

[975]

[971]

[974]

[971]

[1050]

[997]

$[997]$

[974]

$[974]$

[976]

[1003]

[975]

[984]

[964]

[974]

$\begin{array}{lllll}1060 & 1070 & 1080 & 1090 & 1100] \\ . & . & . & . & .]\end{array}$

NNNNNNNNNNNNNNNNNNNNNNNNNNNNNNNNNNNNNNNNNNNNNNNNNN TCCTGCCCGAGCGCGGACGT-CGGTGCGGCGCGCCTGT-CGTCGCAGCCG TCCTGCCCGAGTGCGGACGT-CGGTGCGGCGCGTCTGT-TGTCGCCGCCG TACTCCCTA-_-_._-_-_GAGTGTATTGTCCCTGC-_-_GAGTGCTG TCCTGCCCGAGTGCGGAGTC--GGTGCGTTGTCCCTGT-GGCTGCCG--TCCTGCCACAGCGCGGACTC-GGGTGCGGCGCGCCTGT-CGTCGCTGCCG TTCTGCCCGAGTGCGAATTC-GAGTGCGGCGCGTCTGP-TGTCGCCGCCG TCCTGCCCGAGTGCGGACGT-CGGTGCGGCGCGCCTGT-CGTCGCTGCCG --CTCGCGA-_.-_-_._-_GAGTGCGTTATCCCT-_-_-_-_GTGCTG --CTCGCGA-_._-_._-_-_GAGTGCGTTATCCCT-_-_-_-_GTGCTG TTCTGCCCGAGTGCGAATTC-GAGTGCGGCGCGTCTGT-TGTCGCCGCCG TCCTGCCCGAGTGCGGACGT-AGATGCGGCGCGCCTGT-CGTTGCAGCCC TCCTGCCCGTGTGCGGACGT-GGGCGCGGCGCGCCTGT-CGTCGCAGCCG TCCTGCCCGAGTGCGGACGT-CGGTGCGGCGCGCCTGT-CGTCGCTGCCG TCC-GCCAAAGTGCGGACGG-TCATACGAC----TTGTATGTCGCCGTCG TCCTGCCCGAGTGCGGACGT-CGGTGCGGCGCGCCTGT-CGTCGCTGCCG TCCTGCCCAAGTGCGGACGT-GGATGCTGCGCGCCTGTGTATCGCCGCCG TCCTGCCCGAGTGCGGACGT-CGGTGCGGCGCGTCTGT-CGTCGCAGCCG TCCTGCCCGAGCGCGGACGT-AGGTGCGGCGCGCCTGT-CGTCGCAGCCG TCCTGCCCGTGTGCGGACTCGGGGTGCGGCGCGCCTGT-CGTCGCCGCCG TCCTGCCCAAGTGCGGACGT-CGGTGCGGCGCGCCTGT-CGTCGCTGCCG TCCTGCCCGAGTGCGGACGT-TGGTGCGGCGCGCCTGT-TGTCGCAGCCG TCCTGCCCGAGTGCGGACGT-TGGTGCGGCGCGCCTGT-TGTCGCAGCCG TCCTGCCCAAGTGCGGACGT-TGGTGCGGCGCGCCTGT-CGTCGCAGCCG TCCTGCCCGAGTGCGGACGT-TGGTGCGGCGCGCCTGT-TGTCGCAGCCG TCCTGCCCGAGTGCGGACGT-CGGTGCGGCGCGCCTGT-CGTCGCTGCCC TCCTGCCCGTGTGCGGACGT-GGGTGCGGCGCGCCTGC-CGTCGCAGCCC TCCTGCCCGTGTGCGGACGT-AGGTGCGGCGCGCCTGT-TGTCGCCGCCG CTCTGCCTGTGCGCGGACGT-GGGTGCGGCGCGCCTGT-CGTCGCTGCCG TCCTGCCCGAGTGCGGACTT-GGGTGCGGCGCGCCTGC-CGTCGCAGCCG TCCTGCCCGAGTGCGGACGT-CGGTGCGGCGCGCCTGT-CGTCGCTGCCG TCCTGCCACAGTGCGGACGT-GGGTGCGGCGCGCCTGT-CGTCGCTGCCC TCCTGCCCGAGTGCGGACGT-CGGTGCGGCGCGCCTGT-CGTCGCTGCCG TCCTGCCACAGTGCGGACGT-CGGTGCGGCGCGCCTGT-CGTCGCAGCCG NNNNNNNNNNNNNNNNNNNNNNNNNNNNNNNNNNNNNNNNNNNNNNNNNNN TCCTGCCCGTGCGCGGACTC-GAGTGCGGCGCGTCTGT-TGTCGCCGCCC TCCTGCCTTTGTGCGGACTA-GCGTGCGGCGCGTCTGT-TGTCGCAGCCC TCCTGCCCGAGTGCGGACGT-CGGTGCGGCGCGCCTGT-CGTCGCTGCCC TCCTGCCCGAGTGCGGACGT-CGGTGCGGCGCGCCTGT-CGTCGCTGCCG TCCTGCCCGAGTGCGGACGT-CGGTGCGGCGCGCCTGT-CGTCGCTGCCG TCCTGCCCGAGCGCGGACGT-CGGTGCGGCGCGTCTGT-TGTCGCAGCCG TCCTGCCCGAGTGCGGACGT-CGGTGCGGCGCGCCTGT-CGTCGCTGCCG TCCTGCCCGTGTGCGGACGT-CGGTGCGGCGCGCCTGT-CGTCGCCGCCO TCCTGCCCGAGTGCGGAAGA-GGGTGCGGCGCGCCTGT-CGTCGCTGCCG TCCTGCCCGAGTGCGGACGT-AGGTGCGGCGCGCCTGT-CGTCGCTGCCG

$$
\begin{array}{lllll}
1110 & 1120 & 1130 & 1140 & 1150] \\
. & . & . & . & .]
\end{array}
$$

NNNNNNNNNNNNNNNNNNNNNNNNNNNNNNNNNNMNNNNNNNNNNNNNNN TGC-AGTCTCTGACA-T-_-GTGCGCGTCTCTGTCTGCGATGATTCAGTT TGC-AGTCTCTGACA-T---GTACGCGTCTCTGTCTGCGATGATTCAGTT

$[1150]$

$[1072]$

[1067] 
Ausaris micacea

Ausaris_palleola

Cyclidiäsubstignaria

Drepana arcuata

Falcariābilineata

Drepana curvatula

Drepana curvatula2

Drepana_falcataria

Ennomos autumnaria

Epicopeía hainesii

Euparyphasma_maxima

Euthyatira pudens

Habrosyne pyritoides

Lyssa zampa

Maucrauzata maxima

Microblepsis_acuminata

Nordstromia grisearia

Ochropacha_duplaris

oreta_loochooana

Oreta pulchripes

oreta_rosea

oreta_turpis

Pseudothyatira cym.

Psychostrophia melanargia

Sabra_harpagula

Nothus lunus

Tethea_consimilis

Tethea_taiwana

Tethea_or

Tetheela_fluctuosa

Thyatira batis

Thyatira_batis 2

Tridrepaña flava

Tridrepana unispina

Watsonalla_binaria

Watsonalla_cultraria

Watsonalla uncinula

Cilix_glaucata

Falcaria_lacertinaria

Habrosyne aurorina

Jodis_putata

Neodaruma tamanukii

Accinctapubes_albifasciata

Agnidra scabiosa

Auzata_superba

Ausaris micacea

Ausaris palleola

Cyclidia_substigmaria

Drepana arcuata

Falcaria_bilineata

Drepana curvatula

Drepana curvatula2

Drepana_falcataria

Ennomos autumnaria

Epicopeia hainesii

Euparyphasma_maxima

Euthyatira püdens

Habrosyne pyritoides

Lyssa_zampa

Maucrauzata maxima

Microblepsis_acuminata

Nordstromia_grisearia

ochropacha_duplaris

oreta_loochooana

Oreta_pulchripes

Oreta rosea

Oreta_turpis

Pseudothyatira cym.

Psychostrophia_melanargia
AGT-TGCTTTGGGCT-----GTGCGAGACTAT-_-_GCGATGATTAAGCT -AT-TCTCTCGGACT-_._-_GTGCGCTTCTGTCTGCGATGGTTCAGAT TGC-AGTCTCGGACA-TCAAGTGCGCGTCTCTGTCTGCGATGATTCAGTT TGT-AGTCTCGGACA--C--GTGCGCGTCTCTGTCTGCGATGTTACAGTT TGC-AGTCTCGGACA-T---GTGCGCGTCTCTGTCTGCGATGATTCAGCT AGT-AGCTTCGGGCT-----GTGCGAGACTTGAT--GCGATGATTAAGC? AGT-AGCTTCGGGCT-----GTGCGAGACTTGAT--GCGATGATTAAGCT TGT-AGTCTCGGACA--C--GTGCGCGTCTCTGTCTGCGATGATTCAGTI TGC-TGTCTCTGACC-_--_GTGTGCGTATCTGTCTGCGATGATTCAGTT TGC-AGTCTCGGACT-T---GTGCGTGTATCTGTCTGCGATGATTCAGTT TGC-AGTCTCGGACA-T---GTGCGCGTCTCGGTCTGCGATGATTCAGTT TGC-AATCTCGGACC-T---GTGTGCGTCTCAGTCAGCGATGGATCAGTT TGC-AGTCTCGGACA-T---GTGCGCGTCTCGGTCTGCGATGAT-----TGC-AGTCTCGGACT-_-_-GTGCGCGTCTCTGTCTGCGATGATTCAGTT TGC-TGTCTCGGACA-T---GTGCGCGTCTCTGTCTGCGATGATTCAGTT TGT-TGTCTCGGACA-T---GTGCGCGTCTCTGTCTGCGATGATTCAGTT TGCTTGTCTCGGACA-T---GTGCGCGTCTCTGTCTGCGATGATTCAGTT TGC-AGTCTCGGACA-T---GTGCGCGTCTCGGTCTGCGATGATTCAGTT TGC-TGTCTCGGACA-T---GTGCGCGTCTCTGTCTGCGATGATTCAGTT TGC-TGTCTCGGACA-T---GTGCGCGTCTCTGTCTGCGATGATTCAGTT TGC-TGTCTCGGACA-T---GTGCGCGTCTCTGTCTGCGATGATTCAGTT TGC-TGTCTCGGACA-T-_-GTGCGCGTCTCTGTCTGCGATGATTCAGTT TGC-AGTCTCGGACA-T---GTGCGCGTCTCTGTCTGCGATGATTCAGTT TGC-AGTCTCGGACC-T-_-GTGCGCGTATCTGTCTGCGATGATTCAGTT TGC-TGTCTCGGACA-T---GTGCGCGTCTCTGTCTGCGATGATTCAGTT TGC-AGTCTCGGACT----_GTGCGCGTCTCTGTCTGCGATGATTCAGTT TGC-AGTCTCGGACA-T---GTGCGCGTCTCGGTCTGCGATGATTCAGTT TGC-AGTCTCGGACA-T---GTGCGCGTCTCGGTCTGCGATGATTCAGTI TGC-AGTCTCGGACA-T--_GTGCGCGTCTCGGTCTGCGATGATTCAGTT TGC-AGTCTCGGACACT---GTGCGCGTCTCGGTCTGCGATGATTCAGTT TGC-AGTCTCGGACA-T---GTGCGCGTCTCTGTCGGCGATGATTCAGTT NNNNNNNNNNNNNNNNNNNNNNNNNNNNNNNNNNNNNNNNNNNNNNNNNN TGC-AGTCTCGGACATT---GTGCGCGTCTCCGTCTGCGATGATTCAGTI TGT-CGTCTCGGACATT---GTGCGCGTCTCCGTCTGCGATGATTCAGTT TGT-TGTCTCCGACA-T-_-GTGCGCGTCTCTGTCTGCGATGATTCAGTT TGT-TGTCTCCGACA-T---GTGCGCGTCTCTGTCTGCGATGATTCAGTT TGT-TGTCTCTGACA-T--_GTGCGCGTCTCTGTCTGCGATGATTCAGTI TGC-AGTCTCGGACACT---GTGCGCGTCTCCGTCTGCGATGATTCAGTT TGC-AGTCTCGGACA-T-_-GTGCGCGTCTCTGTCTGCGATGATTCAGTT TGC-AGTCTCGGACT--C--GTGCGCGTCTCTGTCTGCGATGATICAGTT TG--TGTCTCGGACT-----GTGCGCGTCTCTGTCTGCGATGATTCAGTT TGC-AGTCTCGGACA-T---GTGCGCGTCTCGGTCTGCGATGATTCAGTI
NNNNNNNNNNNNNNNNNTATTTTGGCAGA----AAAATGTAATGGTTTTA TCGGGCACTCGC----CTATTTTGGCAGAA---AAAATGTAATGATTTTA TCGGGCACTCGC----CTATTTTGGCAGA-_--AAAATGTAATGATTTTA TCGGGCACTTGCAGGACTATTTTGGCAGAG---AAATTGTAGTGGTTTTA TCGGGCACACGCAGGACTATTTTGGCAGAAAAGAAAATGTGATGGTTTTA TCGGGCACTCGCANNNNNNNNNNNNNNNNNNNNNNNNNWNNNNNNNNNNN TCGGGCACTCGCANNNNNNNNNNNNNNNNNNNNNNNNNNNNNNNNNNNNN TCGGGCACTCGCANNNNNNNNNNNNNNNNNNNNNNNNNNNNNNNNNNNNN TCGGGCACTCGCANNNNNNNNNNNNNNNNNNNNNNNNNNNNNNNNNNNNN TCGGGCACTCGCAGGANNNNNNNNNNNNNNNNNNNNNNNNNNNNNNNNNN TCGGGCACTCGCANNNNNNNNNNNNNNNNNNNNNNNNNNNNNNNNNNNNN TCGGGCACTCGCAGGACTATTTTGGCAGA----AAAATGTAATGATTPTA TCGGGCACTCGCANNNNNNNNNNNNNNNNNNNNNNNNNNNNNNNNNNNNN TCGGGCACTCGCNNNNNNNNNNNNNNNNNNNNNNNNNNNNNNNNNNNNNN TCAGGCACTCGCAGGANNNNNNNNNNNNNNNNNNNNNNNNNNNNNNNNNN - - -CAGTCGGCTCCNNNNNNNNNNNNNNNNNNNNNNNNNNNNNNNNNN TCGGGCACNNNNNNNNCTATTTTGGCAGA----TAAGTGTGTTGATTTTA TCGGGCACTCGCANNNNNNNNNNNNNNNNNNNNNNNNNNNNNNNNNNNNN TCGGGCACTCGCAGGANNNNNNNNNNNNNNNNNNNNNNNNNNNNNNNNNN TCGGGCACTCGCANNNNNNNNNNNNNNNNNNNNNNNNNNNNNNNNNNNNN TCGGGCACTCGCAGGACTATTTTGGCAGAA---AAAATGTAATGGTTTTA TCGGGCACTCGCANNNNNNNNNNNNNNNNNNNNNNNNNNNNNNNNNNNNN TCGGGCACTCGCNNNNNNNNNNNNNNNNNNNNNNNNNNNNNNNNNNNNNN TCGGGCACTCGCANNNNNNNNNNNNNNNNNNNNNNNNNNNNNNNNNNNNN TCGGGCACTCGCNNNNNNNNNNNNNNNNNNNNNNNNNNNNNNNNNNNNNN TCGGGCACTCGCANNNNNNNNNNNNNNNNNNNNNNNNNNNNNNNNNNNNN TCGGGCACTCGCNNNNNNNNNNNNNNNNNNNNNNNNNNNNNNNNNNNNNN
[1196]

[1115]

[1109]

[1066]

[1108]

[1124]

[1150]

[1118]

[1069]

[ 1069 ]

[1150]

[1106]

[1118]

[1127]

[1076]

[1114]

[1114]

[1126]

[1117]

[1131]

[11112]

[1121]

[1121]

[1122]

(1121)

[1119]

[1112] 


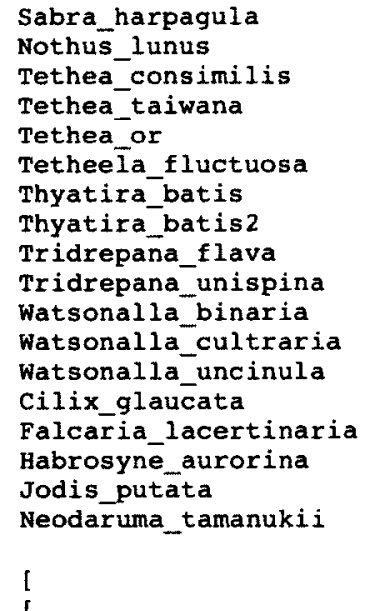

Accinctapubes_albifasciata Agnidra_scabiosa

TCGGGCACTCGCANNNNNNNNNNNNNNNNNNNNNNNNNNNNNNNNNNNNN TCGGGCACTCGCAGGACTATTTTGGCAGAA---ANAATGTGATGATTTTA TCGGGCACTCGCAGGANNNNNNNNNNNNNNNNNNNNNNNNNNNNNNNNNN TCGGGCACTCGCAGGACTATTTTGGCAGAA---AAAATGTAATGGTTTTA TCGGGCACTCGCAGGACTATTTTGGCAGAG---AAAATGTAATGGTTTTA TCGGGCACTCGCAGGACTATTTTGGCAGAA---AAAATGTGATGGTTTTA TCGGGCACTCGCANNNNNNNNNNNNNNNNNNNNNNNNNNNNNNNNNNNNN

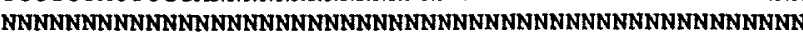
TCGGGCACTCGCAGGACTATTTTGGCAGAA---AAAATGTAGTGATTTTA TCGGGCACTCGCAGGACTATTTTGGCAGAA---AAGATGTGGTGGTTTTA TCGGGCACTCGCAGGACTATTTTGGCAGAAA--AAGATGTGATGATTTTA TCGGGCACTCGCNNNNNNNNNNNNNNNNNNNNNNNNNNNNNNNNNNNNNNN TCGGGCACTCGCAGGANNNNNNNNNNNNNNNNNNNNNNNNNNNNNNNNNN TCGGGCACTCGCANNNNNNNNNNNNNNNNNNNNNNNNNNNNNNNNNNNNI TCGGGCACTCGCANNNNNNNNNNNNNNNNNNNNNNNNNNNNNNNNNNNNN TCGGGCACTCGCNNNNNNNNNNNNNNNNNNNNNNNNNNNNNNNNNNNNNN TCGGGCACTCCCNNNNNNNNNNNNNNNNNNNNNNNNNNNNNNNNNNNNNN TCGGGCACTCGCAGGACTATTTTGGCAGAG---AAAATGTAATGGTTTTA

$$
\begin{array}{lllll}
1210 & 1220 & 1230 & 1240 & 1250] \\
. & . & . & . & .]
\end{array}
$$

GAAATCATAAATGTAT-_---AATTTATTATATAAGTAGTAAATGTTAGAAATCATAAATATATGTT-- -TATTAA-TATATATGTAGTAAGTGATAGAACTCATAAATATATATA---GTTAATATATATATATAGTATTTGATAGAATTCATAAATATATATT---ATTAACATATATATATAGTATATGTT-GAAATCATAAATATATA------AGATTTATATATGTAGT-AATTATANNNNNNNNNNNNNNNNNNNNNNNNNNNNNNNNNNNNNNNNNNNNNNNNNNNNNNNNNNNNINNNNHNNNNNNNNNNNNNNNNNNNNNNNNNNNNNNNNNNNNNNNNNNNNNNNNNNNNNNNNNNNNNNNNNNNNNNNNNNNNNNNNN -

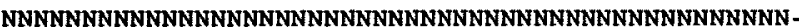
NNNNNNNNNNNNNNNNNNNNNNNWNNNNNNNNNNNNNNNNNNNNNNNNN NNNNNNNNNNNNNNNNNNNNNNNNNNNNNWNNNNNNNNNNNNNNNNNNNGAATTCATAAATGTATAA----TTTTAATTATATAAATAGTATATGTTTNNNNNNNNNNNNNNNNNNNNNNNNNNNNNNNNNNNNNNNNNNNNNNNNNNNNNNNNNNNNNNNNNNNNNNNNNNNNNNNNNN NNNNNNNNNNNWNNNN-

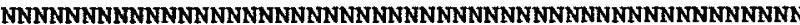
NNNINNNNNNNNNNNNNNNNNNNNNNNNNNNNNNNNNNNNNNNNNNNNNN GAAGTCATNAATATATATT---ATTTAAATATATAGATAGTATATGTTTNNNNNNNNNNNNNNNNNNNNNNNNNNNNNNNNNNNNNNNNNNNNNNNNNN NNNNNNNNNNNNNNNNNNNNNNNNNWNNNNNNN NNNNNNNNNNNNNNNNN NNNNNNNNNNNNNNNNNNNNNNNNNNNNNNNNNNNNNNNNNNNNNNNNNGAAGTCATAAATATATA-----ATTTAATTATATAAATAGTAAATGATANWNNNNNNNNNNNNNNNNNNNNNKNNNNNNNNNNNNNNNNNNNNNNNNN FNNNNNNNNNNNNNNNNNNNNNNNNNNNNNNNNNNNNNNNNNNNNNNNA SNNNNNNNRNNNNNNNNNNNNNNNNNNNNNNNNNNNNNNNNNNNNNNNN-

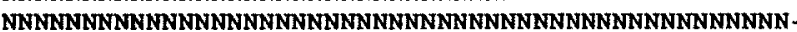

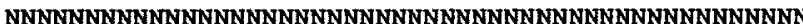
NNNNNNNNNNNNNNNNNNNWNNNNNNNNNNNNNNNNNNNNNNNNNNNNN NNNNNNNNNNNNNNNNNNNNNNNNNNNNNNNNNNNNNNNNNNNNNNNNNA GAATTCATNTATATATG--_--ATTAAATTATATAGGTAGTA-ATGATANNNNNNNNNNNNNNNNNNNNNNNNNNNNNNNNNNNNNNNNNNNNNNNNNN GAAGTCATAAATATATA-----ATTTAATTATATAAATAGTAAATGATAGAAGTCATAAATGTATA-----ATTAAATTATATAAATAGTAAATGATAGAAGTCATTTATATATATGTATATTTAATTATATAGATAGTAAATGATANNNNNNNNNNNNNNNNNNNNNNNNNNNNNNNNNNNNNNNNNNNNNNNNNNNNNNNNNNNNNNNNNNNNNNNNNNNNNNNNNNNNNNNNNNNNNNNNNNN GAAATCATAAATATATA-_--- - ATAAATATATATGTAGTA-ATTTTAGAAATCATNAATATATA-----AATTATTTATATATGTAGTA-ATTATAGAAATCATAAATATATAT----TTGTAA-TATATATGTAGTA-ATGATANNNNNNNNNNNNNNNNNNNNNNNNNNNNNNNNNNNNNNNNNNNNNNNNNNNNNNNNNNNNNNNNNNNNNNNNNNNNNNNNNNNNNNNNNNNNNNNNNNR

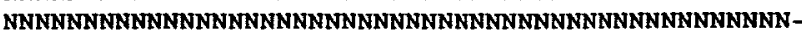

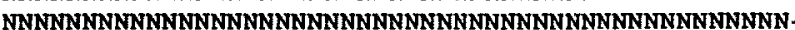
NNNNNNNNNNNNINNNNNNNNNNNNNNNNNNNNNNNNNNNNNNNNNNNNN NNNNNNNNNNNNNNNNNNNNNNNNNNNNNNNNNNNWNNNNNNNNNNNNNGAAGTCATAAATATATA-_- -ATTAAATTATATAAATAGTATATGATA-

[117]

[ 11116 ]

[1118]

[11115]

[1 11111 ]

[1 1115 ]

[11114]

[ 1200$]$

[1138]

[ 1138 ]

[1115]

[1117]

[1119]

[1147]

[ 11118 ]

[ 1127 ]

[ 1105 ]

[1114]

[ 1239$]$

[ 1160 ]

[1155]

[1111]

[1149]

[1173]

[ 1199 ]

[ 1167 ]

[1118]

[1118]

[ 1199 ]

[1151]

[1167]

[ 1176 ]

[ 1126 ]

[1164]

[1160]

[1175]

[1167]

[1180]

[1156]

[1170]

[1170]

[1171]

[1170]

[1169]

[ 1161 ]

[1167]

[1159]

[1168]

[ 1159 ]

[1155]

[ 1164 ]

[1163]

[ 1250 ]

[1179]

[1181]

[1158]

[1166]

[1169]

[1196]

[1167]

[1177]

[1154]

[1158]
1260
1270
1280
1290
$1300]$
.] 
Auzata superba Ausaris_micacea Ausaris palleola Cyclidia substigmaria Drepana arcuata Falcaria bilineata Drepana_curvatula Drepana_curvatula2 Drepana falcataria Ennomos_autumnaria Epicopeia hainesii Euparyphasma maxima Euthyatira_püdens Habrosyne pyritoides Lyssa_zampa Maucrauzata_maxima Microblepsis acuminata Nordstromia_grisearia Ochropacha_duplaris Oreta loochooana Oreta_pulchripes Oreta rosea

oreta turpis Pseudothyatira_cym. Psychostrophia_melanargia Sabra harpagula Nothus_lunus Tethea consimilis Tethea_taiwana Tethea_or Tetheela fluctuosa Thyatira_batis Thyatira_batis 2 Tridrepaña flava Tridrepana_unispina Watsonalla_binaria Watsonalla cultraria Watsonalla_uncinula Cilix glaucata Falcaria lacertinaria Habrosyne aurorina Jodis putata Neodaruma_tamanukii

I

Accinctapubes albifasciata Agnidra_scabiosa Auzata_superba Ausaris micacea Ausaris palleola Cyclidia_substigmaria Drepana arcuata Falcaria_bilineata Drepana_curvatula Drepana_curvatula2 Drepana_falcataria Ennomos autumnaria Epicopeia hainesii Euparyphasma_maxima Euthyatira püdens Habrosyne_pyritoides Lyssa_zampa Maucráuzata maxima Microblepsis_acuminata Nordstromia_grisearia Ochropacha duplaris oreta_loochooana oreta pulchripes oreta rosea oreta_turpis Pseudothyatira_cym.
TTAAAAGATATTAATTTAATTATTTTGGGTATATTAATATTAATTGTTGG --AATTGATATTAAATTAGTTTTTATAGGATTATTATTATTAATTATTGG TTTAATGATTTAAAATTAGTTTTTTTTGGTTTATTATTTATAATTATTGG NNAATAGATGTTATTTTAATTATTATTGGTAGTTTAATTATAATTGTAGG NNAATTGATATAAAATTAATTTTTATTGGGTTATTATTATTAATTATTGG NNTAAAGATGTTAATTTAATTTTTTTAGGCATTATTATTATATTTATTGG NNAATTGATATAAAATTAATTTTTATTGGTTTATTATTATTGATTATTGG NNAATTGATATAAAATTAATTTTTATTGGGTTATTATTATTAATTATTGG NNNNNTGATATAAAATTAATTTTTATTGGGTTATTATTATTAATTATTGG TTAAATGATATAATTTTAATTATTATTGGTTTATTAATTTTAGTTTTAGG NNNAATGATTTAATTATGATTTTTTTAGGGGTATTAATTTTAATTTTAGG NNTAATGATATAATTTTAATTTATTTAGGTATATTAATTTTAATTTTAGG NNNNNNNNNNNNNNNNNNNNNNNNNNNNNNNNNNNNNNNNNNNNNNNNNN NNNNNNNNNNNNNNNNNNNNNNNNNNNNNNNNNNNNNNNNNNNNNNNNNN ATAAATGATATTPTATTAATTTTTATTGGGTTTATTATTTTAATTTTGGG NNGATAGATATTTTTTTAATTTTTATTGGTTTAATTATTTTAATTATTGG MNNNNNNNNNNNNNNNNNNNNNNNNWNNNNNNNNNNNNNNNNNNNNNNNN NNNAATGATTTAATTTTGATTTTTTTTGGTTTATTAATTMTAATTATTGG TTTAATGATATTATTTTAATTTATTTAGGAATATTAATTTMATTGTAGG NNAATAGATTTAGTTTTAATTTATTTAGGGATAATTATTATGATTATTGG NNAATAGATTTAGTTTTAATTTATTTAGGGATAATTATTATGATTATTGG NNAATAGATTTAATTTTAATTTATATGGGTATAATTATTATAATTATTGG NNAATAGATTTAGTTPTAATT'TATTTAGGGATAATTATTATGATTATTGG NNNNNNNNNNNNNNNNNNNNNNNNNNNNNNNNNNNNNNNNNNNNNNNNNN NNAAAAGATTTAATTATAATTTTTATTGGTATGTTGGTGTTAATTTTAGG NNNNNNNNNNNNNNNNNNNNNNNNNNNNNNNNNNNNNNNNNNNNNNNNNN TTATTAGATATAATTATAATATTAATTGGTATATTAATTATTATTTTAGG NNNNNNNNNNNNNNNNNNNNNNNNNNNNNNNNNNNNNNNNNNNNNNNNNN TTAAATGATATTATTTTAATTTATTTAGGAATATTAATTTTAATTATTGG TTAAATGATATTATTTTAATTAATTTAGGTATATTAATTTTAATTGTAGG TTAAATGATATTATTTTAATTTATTTAGGAATGCTAATTTTAATTGTAGG NNTAATGATATTATTTTAATTTATTTAGGAATATTAATTTTAATTTTAGG NNNNNNNNNNNNNNNNNNNNNNNNNNNNNNNNNNNNNNNNNNNNNNNNNN ATTAAAGATATTAATTTGATTATTGTTGGATTTTTAATTTTAGTTGTTGG ATAAAAGATTTAATTTTAATTTTTATTGGGTTATTAATTTTAATTGTTGG TTAAAAGATTATATTTTGATTTTTTTAGGTATATTAATTTTAATTATTGG NNAAAAGATTATATTTTGATTTTTTTAGGTATATTAATTTTAATTATTGG NNNNNNNNNNNNNNNNNNNNNNNNNNNNNNNNNNNNNNNNNNNNNNNNNN NNAATAGATATAAAATTAATTTTTATTGGGTTTTTAATTTTAATAGTTGG NNTAAAGATATTAATTTAATTTTTTTAGGTATTATTATTATATTTATTGG NNNNNNNNNNNNNNNNNNNNNNNNNNNNNNNNNNNNNNNNNNNNNNNNNN NNTTTTGATTTATTTTTAATTATTTTGGGGTTAGTAATTTTAGTTTTAGG TTAAATGATATTATTTTAATTTATTTAGGGATATTAATTTTAATTGTAGG

$$
\begin{array}{lllll}
1310 & 1320 & 1330 & 1340 & 1350] \\
. & \cdot & . & . & .1
\end{array}
$$

GGTTPTAATTGGAGTAGCTTATTTAACTTTATTAGAACGAAAATTATTAG GGTTTTAATTGGGGTTGCTTATTTAACTTTATTAGAGCGTAAAGTTTTAG GGTATTAATTGGGGTCGCTTTTTTGACTTTATTAGAACGTAAAGTTTTAG TGTTTTAATTGCTGTTGCWTTTTTAACTTTATTAGAACGTAGGGTTTTAG GGTTTTAATTGGGGTTGCTTTTTTGACTTTATTAGAGCGTAAGGTTTTAG AGTGTTAATTGGAGTTGCTTTTTTAACATTATTAGAACGTAAAGTTTTAG GGTTTTAATTGCAGTTGCTTTTTTAACATTATTAGAACGTAAGGTTTTAG GGTATTAATTGGGGTCGCTTTTTTAACTTTATTAGAACGTAAAGTTTTAG AGTTTTAATTGCAGTTGCTTTTTTAACGTTATTAGAACGTAAGGTTTTAG GGTTTTAATTGCAGTTGCTTTTTTAACATTATTAGAACGPAAGGTTTTAG AGTTTTAATTGCAGTTGCTTTTTTAACCTTATTAAAACGTAAGGTTTTAG GGTTTTAATTGGTGTAGCATTTTTAACTTTATTAGAACGTAAAGTTTTAG GGTATTAATTGGTGTTGCTTTTTTAACATTATTAGAACGTAAACTTTPAG AGTATTAGTGGGGGTAGCTTTTTTAACTTTATTAGAACGTAAAGTATTAG NNNNNNNNNNNNNNNNNNNNNNNNNNNNNNNNNNNNNNNNNNNNNNNNNN NNWNNNNNNNNNNNNNINNNNNNNNNNNNNNNNNNNNNNNNNNNNNNNNNN GGTTTTAATTAGAGTAGCTTATTTAACTTTATTAGAGCGAAAATTATTAG TGTTTTAGTTGGGGTTGCCTGTTTAACTTTATTAGAGCGAAAAGTTTTAG NNNNNNNNNNNNNNNNNNNNNNNNNNNWNNNNNNWNNNNNNNNNNNNNNN TATTTTAATTGGTGTTGCTTTTTTAACTTTATTAGAGCGAAAATTATTAG AGTAATAGTTGGAGTTGCTTTTTTAACATTACTAGAACGTAAAGTTTTAG GGCATTGATTGGGGTAGCTTTTTTGACTTTATTTGAGCGTAAAATTTTAG GGCATTGATTGGGGTAGCTTTTTTGACTTTATTTGAGCGTAAAATTTTAG AGCTTTGGTTGGGGTAGCTTTTTTAACTTTATTAGAGCGTAAGGTTTTAG GGCATTGATTGGGGTAGCTTTTTTGACTTTATTTGAGCGTAAAATTTTAG NWNNWNNNNNNNNNNNNNNNNNNNNWNNNNNNNNNNNNNNNNNNNNNNNN
[ 1339 ]

[1260]

[1255]

[1209]

[1249]

[1273]

[1299]

$[1267]$

[1218]

[1218]

[1299]

[1251]

[1267]

[1276]

$[1226]$

[1264]

[ 1260 ]

$[1275]$

[ 1267]

[1280]

[1256]

[1270)

[1270]

[1271]

[1270]

[1269] 
Psychostrophia melanargia Sabra harpagula Nothus lunus

Tethea_consimilis

Tethea_taiwana

Tethea or

Tetheela_fluctuosa

Thyatira_batis

Thyatira batis 2

Tridrepaña_flava

Tridrepana_unispina

Watsonalla binaria

Watsonalla_cultraria

Watsonalla uneinula

Cilix_glaucata

Falcaria_lacertinaria

Habrosyne aurorina

Jodis_putata

Neodaruma_tamanuki $i$

[

Accinctapubes_albifasciata Agnidra_scabiosa

Auzata superba

Ausaris_micacea

Ausaris palleola

Cyclidia_substigmaria

Drepana_arcuata

Falcaria bilineata

Drepana_curvatula

Drepana_curvatulaz

Drepana falcataria

Ennomos autumnaria

Epicopeía hainesii

Euparyphasma maxima

Euthyatira_püdens

Habrosyne_pyritoides

Lyssa zampa

Maucráuzata_maxima

Microblepsis acuminata

Nordstromia grisearia

ochropacha_duplaris

oreta loochooana

Oreta pulchripes

Oreta_rosea

oreta turpis

Pseudothyatira_cym.

Psychostrophia_melanargia

Sabra harpagula

Nothus_lunus

Tethea_consimilis

Tethea taiwana

Tethea_or

Tetheela_fluctuosa

Thyatira batis

Thyatira_batis 2

Tridrepaña flava

Tridrepana_unispina

watsonalla_binaria

Watsonalla cultraria

Watsonalla_uncinula

Cilix_glaucata

Falcaria lacertinaria

Habrosyne_aurorina

Jodis putata

Neodaruma_tamanukii

[

Accinctapubes_albifasciata
GGTATTAATTGGTGTGGCTTTTTTGACTTTATTAGAACGTAAAGTTTTAG NNNNNNN NNNNNNNNNNNNNNNNNNNNNNNNNNNNNNNNNNNNNNNNNNN TGTATTAATTGGGGTTGCATTTTTAACTTTATTAGAACGTAAATTATTAG NNNNNNNNNNNNNNNNNNNNNNNNNNNNNNNNNNNNNNNNNNNNNNNNNN TGTTTTAGTGGGGGTAGCTTTTTTAACTTTATTAGAACGTAAAGTTTTAG AGTATTAGTAGGGGTGGCTTTTTTAACTTTATTAGAACGTAAGGTTTTAG AGTTTTAGTAGGAGTTGCTTTTTTAACTTIATTAGAGCGGAAAGTCTTAG GGTATTAGTAGGAGTTGCTTTTTTAACTTTATTAGAACGTAAAGTTTTAG NNNNNNNNNNNNNNNNNNNNNNNNNNNNNNNNNNNNNNNNNNNNNNNNNN GGTATTGATTGGGGTAGCTTTTTTAACTTTATTAGAACGAAAAGTTTTAG AGTTTTAGTTGGTGTCGCTTTTTTAACTTTGTTAGAGCGGAAAGTTTTAG AGTTTTAATTGGAGTTGCTTTTTTAACTTTATTAGAACGAAAAGTATTAG AGTTTTAATTGGAGTTGCTTTTTTAACTTTATTAGAACGAAAAGTATTAG NNNNNNNNNNNNNNNNNNNNNNNNNNNNNNNNNNNNNNNNNNNNNNNNNN AGTTTTAATTGGGGTTGCTTTTTTAACTTTATTAGAACGAAAAGTTTTAG GGTMTPAATTGGGGTTGCTTTTTTAACTTTGTTAGAACGTAAAGTTCTAG NNNNNNNNNNNNNNNNNNNNNNNNNNNNNNNNNNNNNNNNNNNNNNNNNE GGTTTTAATTGGGGTTGCTTTTTTAACTTTATTAGAGCGAAAAGTTTTAG AGTTTTAGTGGGTGTTGCTTTTTTAACTTTGTTAGAACGTAAAGTATTAG

$$
\begin{array}{lllll}
1360 & 1370 & 1380 & 1390 & 14001 \\
. & . & . & . & .1
\end{array}
$$

GTTATATTCAAATTCGAAAAGGGCCTAATAAAGTTGGATTTATAGGTATT GTTATATTCAAATTCGTAAAGGTCCTAATAAATTAGGTATTATAGGATTA GTTATACTCAAACTCGAAATGGCCCTAATAAGTTGGGATTAATAGGATTA GTTATATTCAAACTCGTAAAGGCCCAAATAAATTGGGATTTATAGGATTA GTTACATTCAACTTCGTAAAGGTCCTAATAAATTAGGTTTTATAGGATTA GTTATATTCAAATCCGAAAAGGTCCTAATAAAGTTGGATTAATAGGGGTT GTTATATTCAAATTCGTAAAGGTCCTAATAAATTAGGATTTATAGGATTA GTTATATTCAGATTCGTAAAGGCCCTAATAAATTAGGTTTAATTGGTTTA GTTATATTCAAATTCGTAAAGGACCTAATAAATTAGGTTTTATAGGGATA GTTATATTCAAATTCGTAAAGGTCCTAATAAATTAGGATTTATAGGATTA GTTATATTCAAATTCGTAAAGGACCTAATAAATTAGGTTTTATGGGAATA GTTATATTCAGATTCGAAAAGGTCCTAATAAAGTTGGTTTTATAGGAATT GCTATATTCAGTTACGTAAAGGACCTAATAAAGTTGGTTTATTAGGGATT GTTATATTCAAATTCGTAAAGGTCCTAATAAAGTPGGATTTATAGGTATT NNNNNNNNNNNNNNNNNNNNNNNWNNNNNNNNNNNNNNNNNNNNNNNNNN NNNNNNNNNNNNNNWNNNNNNNNNNNNNN NNNNNNNNNNNNNNNNNNNNN GTTATATTCAAATTCGAAAGGGGCCAAATAAGGTTGGTTATTTAGGAATT GTTATATTCAAATTCGTAAAGGTCCCAATAAATTAGGTATTTTTGGGATT NNNNNNNNNNNNNNNNNNNNNNNNNNNNNNNNNNNNNNNNNNNNNNNNNN GTTACATTCAAATTCGAAAAGGTCCTAATAAGTTGGGTTTGATTGGGATA GTTATATTCAAATTCGTAAAGGTCCTAATAAAGTTGGATTTATAGGAATT GTTATATTCAAATTCGTAAAGGTCCTAATAAAGTTGGATTTAGAGGTTTA GTTATATTCAAATTCGTAAAGGTCCTAATAAAGTTGGATTTAGAGGTTTA GTTACATTCAGATTCGTAAAGGGCCTAATAAAGTTGGATTTAATGGGCTA GTTATATTCAAATTCGTAAAGGTCCTAATAAAGTTGGATTTAGAGGTTTA NNNNNNNNNNNNNNNNNNNNNNNNNNNNNNNNNNNNNNNNNNNNNNNNNN GTTACATTCAATTACGAAAAGGTCCTAATAAGGTTGGTTTAATAGGAATT NNNNNNNNNNNNNNNNNNNNNNNNNNNNNNNNNNNNNNNNNNNNNNNNNN GATATATTCAAATTCGTAAAGGTCCTAATAAATTAGGATTTATAGGTATT NNNNNNNNNNNNNNNNNNNNNNNNNNNNNNNNNNNNNNNNNNNNNNNNNN GTTATATTCAAATTCGTAAAGGACCTAATAAAGTTGGTTTTATAGGAGTP GTTATATTCAAATTCGTAAGGGCCCTAATAAAGTTGGTTTTATAGGGATT GCTATATTCAAATCCGTAAAGGTCCTAATAAAGTTGGTTTAATGGGAATT GTTATATTCAAATTCGTAAAGGTCCTAATAAAGTTGGATTTATAGGAATT NNNNNNNNNNNNNNNNNNNNNNNNNNNNNNNNNNNNNNNNNNNNNNNNNN GTTATATTCAAATTCGGAAAGGCCCTAATAAATTAGGATTTCTTGGGTT GTTATATTCAAATTCGTAAAGGTCCTAATAAATTAGGTTTATTAGGGTTA GTTATATTCAGATTCGTAAAGGTCCTAATAAATTAGGAGTTATAGGCTTA GTTATATTCAGATTCGTAAAGGTCCTAATAAATTAGGAGTTATAGGCTTA NWNNNNNNNHNNNNNNNNNNNNNNNNNNNNNNNNNNNNNNNNNNNNNNNN GTTATATTCAACTCCGTAAAGGGCCTAATAAATTAGGTATTTTAGGAATT GTTATATTCAGATTCGTAAAGGCCCTAATAAATTAGGTTTAATTGGTTTA NNNNNNNNNNNNNNNNNNNNNNNNNNNNNNNNNNNNNNNNNNNNNNNNNN GATATATTCAAATTCGTAAAGGTCCTAATAAAGTAGGTTATATTGGGATT GTTATATTCAAATTCGTAAGGGTCCTAATAAAGTTGGGTTTATAGGAATT

[1389]

$$
\begin{array}{lllll}
1410 & 1420 & 1430 & 1440 & 14501 \\
. & * & . & . & .1
\end{array}
$$


Agnidra_scabiosa Auzata_superba Ausaris micacea Ausaris palleola Cyclidia_substigmaria Drepana arcuata Falcariábilineata Drepana_curvatula Drepana_curvatula2 Drepana_falcataria Ennomos_autumnaria Epicopeía hainesii Euparyphasma maxima Euthyatira pudens Habrosyne_pyritoides Lyssa_zampa

Maucrauzata maxima Microblepsis_acuminata Nordstromia_grisearia Ochropacha duplaris Oreta_loochooana oreta_pulchripes oreta rosea oreta_turpis Pseudothyatira_cym. Psychostrophia_melanargia Sabra_harpagula Nothus_lunus

Tethea_consimilis Tethea_taiwana Tethea or Tetheela_fluctuosa Thyatira_batis Thyatira batis 2 Tridrepaña_flava Tridrepana_unispina Watsonalla binaria Watsonalla_cultraria Watsonalla_uncinula Cilix glaucata Falcaria_lacertinaria Habrosyne_aurorina Jodis putáta Neodaruma_tamanukii

I

Accinctapubes_albifasciata Agnidra_scabiosa

Auzata superba Ausaris_micacea Ausaris palleola Cyclidia_substigmaria Drepana_arcuata Falcariābilineata Drepana_curvatula Drepana_curvatula2 Drepana_falcataria Ennomos_autlimnaria Epicopeía hainesii Euparyphasma_maxima Euthyatira_pudens Habrosyne_pyritoides Lyssa_zampa Maucráuzata_maxima Microblepsis_acuminata Nordstromia_grisearia Ochropacha_duplaris Oreta loochooana oreta_pulchripes Oreta rosea

Oreta turpis
TTACAGCCATTTTCAGATGCTATTAAATTATTTAATAAGGAGCAAATT'TA TCACCCCCTTTCTCTGACGCTATTAAATTATTTAGTAAAGAACACACTTC TCACACCCTTTTTCAGACGCTATTAAATTATTTAATAAAGAACAAATTTC TTACAGCCCTTTTCTGACGCTATTAAGTTATTTAGTAAGGAGCAAACTTT TTACAGCCTTTTTCTGATGCTATTAAGTTATTTACTAAAGAACAAACTTA TTACAGCCTTTTTCTGATGCTATTAAATTATTTAATAAAGAACAAACATA TTACAGCCTTCTTCTGATGCAATTAAGTTATTTACAAAAGAACAAACTTA TTACAGCCTTTTTCTGATGCTATTAAATTATTTAATAAAGAACAAACATA TTACAGCCTTTTTCTGATGCTATTAAATTATTTAATAAAGAACAAACATA TTACAGCCTTTCTCTGATGCTATTAAATTATTTAATAAAGAACAAACATA TTACAGCCTTTTTCTGATGCTATTAAATTATTTACTAAAGAACAAACTTT TTACAGCCTTTTTCTGATGCAATTAAATTATTTACTAAAGAACAAACTTA TTACAACCTTTTTCTGATGCTATTAAATTATTTACTAAAGAACAAACTTA NNNNNNNNNNNNNNNNNNNNNNNNNNNNNNNNNNNNNNNNNNNNNNNNNN NNNNNNNNNNNNNNNNNNNNNNNNNNNNNNNNNNNNNNNNNNNNNNNNNN TTACAACCTTTTTCTGATGCTATTAAGTTATTTACTAAAGAACAAACTTT TTACAGCCTTTTGCTGATGCTATTAAATTATTTAGTAAGGAGCAATCTTA NNNNNNNNNNNNNNNNNNNNNNNNNNNNNNNNNNNNNNNNNNNNNNNNNN TTACAGCCTTTTTCAGATGCTATTAAGTTATTTAGAAAAGAACAAACTGT TTACAACCTTTTTCTGATGCTATTAAATTATTTACTAAAGAACAAACTTA TTACAGCCTTTTTCAGATGCAATTAAATTATTTACTAAGGAACAAATTTA TTACAGCCCTTTTCAGATGCAATTAAATTATTTACTAAGGAACAAATTTA TTACAGCCTTTTTCAGATGCTATTAAATTATTCACTAAAGAACAAGCTTA TTACAGCCTTTTTCAGATGCAATTAAATTATTTACTAAGGAACAAATTTA NNNNNNNNNNNNNNNNNNNNNNNNNNNNNNNNNNNNNNNNNNNNNNNNNN TTACAGCCTTTTTCTGATGCTATTAAATTATTTACTAAAGAACAAACTTA NNNNNNNNNNNNNNNNNNNNNNNNNNNNNNNNNNNNNNNNNNNNNNNNNN TTACAGCCTTTTTCTGATGCAATTAAATTATTTACAAAAGAACAAACTTA NNNNNNNNNNNNNNNNNNNNNNNNNNNNNNNNNNNNNNNNNNNNNNNNNN TTACAACCTTTTTCTGATGCTATTAAATTATTTACTAAAGAACAAACTTA TTGCAACCTTTTTCTGATGCTATTAAATTATTTACAAAAGAACAAACTTA TTACAGCCTTTTTCTGATGCTATTAAATTATTTACCAAAGAACAAACTTA TTACAGCCTTTTTCTGATGCTATTAAATTATTTACAAAAGAACAAACTTA NNNNNNNNNNNNNNNNNNNNNNNNNNNNNNNNNNNNNNNNNNNNNNNNNN TTACAGCCTTTTTCAGATGCTATTAAGTTATTTTGTAAAGAACAAACTTA TTACAGCCTTTTTCTGATGCAATTAAATTATTTTGTAAGGAACAAACTTA TTACAACCTTTTTCTGATGCTATTAAATTATTTAGAAAAGAACAAACTTA TTACAACCTTTTTCTGATGCTATTAAATTATTTAGAAAAGAACAAACTTA NNNNNNNNNNNNNNNNNNNNNNNNNNNWNNNNNWNNNNNNNNNNNNNNNN ATACAGCCTTTTTCAGATGCTATTAAGTTATTTAGAAAAGAACAAACTTA TTACAGCCTTTTTCTGATGCAATTAAGTTATTTACAAAAGAACAAACTTA NNNNNNNNNNNNNNNNNNNNNNNNNNNNNNNNNNNNNNNNNNNNNNNNNN TTACAACCTTTTTCTGATGCAATTAAATTATTCACAAAAGAACAAACTTA TTACAGCCTTTTTCTGATGCTATTAAATTATTTACTAAAGAACAAATTTA

$$
\begin{array}{lllll}
1460 & 1470 & 1480 & 1490 & 1500] \\
. & . & . & . & .1
\end{array}
$$

CCCAATAAATTCTAATTATATTTCTTATTATTTTTCTCCTGTAGTTAGAT TCCTGTTTTATCTAATTATTTAGTTRATTATTTTTCTCCTATTATAAGTT CCCCATTTTATCAAATTATTTAATTTATTATTTCTCCCCCGCTCTTAGAT TCCTAGATTATCAAATTATCTTATTTATTATTACTCCCCTATTTTTAGAT TTTAGTAATTTCTAATTATATAATTTATTATTTTTCTCCTATTATTAGAT TCCTAATTTTCTAATTATATAAGATATTATTTTTCTCCTGTTTTAAGAT CCCTATATTATCTAATTATTTAATTTATTATTTTTCTCCAATTGTTAGAT TCCTTTTTTATCTAATTATTTAATTTATTATTTTTCTCCTGTCATTAGTT CCCTATAATATCTAATTATTTGATTTATTATTTTTCTCCTATTGTTAGAT CCCTATATTATCTAATTATTTAATTTATTATTTTTCTCCAATTGTTAGAT TCCTATAATATCTAATTATTTAATTTATTATTTTTCTCCTATTGTTAGAT TCCTTTATATTCAAATTATTTTTCTTATTATTTTTCTCCTGTAATTAGAT TCCCATATATTCAAATTATTTATCTTATTATTTTTCTCCTGTTATTAGAT TCCAATATTTTCTAATTATTTAGTTTATTATTTTTCTCCTGTTGTGAGAT

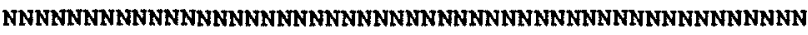

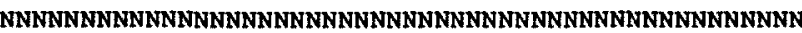
TCCATTATATTCAAATTATTTATCTTATTATTTTTCTCCTGTTGTTAGTT TCCTATTATTTCTAATTTTTTAATTTATTACTTTTCTCCTGTAATTAGTT NNNNNNNNNNNNNNNNNNNNNNNNNNNNNNNNNNNNNNNNNNNNNNNNNN ACCTTTAATATCTAATTATTTAGTCTACTATTTTTCTCCTATTTTAAGTT TCCTATATTTTCTAATTATTTAGTATATTATTTTTCTCCTGTAATTAGAT TTTAACTTTATCTAATTATTTAATTTATTATTTTTCTCCTATTATTAATT TTTAACTTTATCTAATTATTTAATTTATTATTTTTCTCCTATTATTAATT TTTGATTTTATCTAATTATTTAATCTATTATTTTTCTCCTATTATTAATT TTTAACTTTATCTAATTATTTAATTATTATTTTTCTCCTATTATTAATT
[1489]

[1410]

[1405]

[1359]

[1399]

[1423]

[1449]

[1417]

[ 1368 ]

[1368]

[ 1449 ]

[ 1401 ]

[ 1417 ]

[1426]

[1376]

[1414]

[1410]

[1425]

[1417]

[ 1430]

[1406]

[1420]

[1420]

[1421]

[1420] 
Pseudothyatira cym.

Psychostrophia_melanargia Sabra harpagula

Nothus_lunus

Tethea_consimilis

Tethea taiwana

Tethea_or

Tetheela_fluctuosa

Thyatira batis

Thyatira_batis 2

Tridrepaña flava

Tridrepana_unispina

Watsonalla binaria

watsonalla cultraria

Watsonalla uncinula

Cilix_glaucata

Falcaria lacertinaria

Habrosyne_aurorina

Jodis_putata

Neodaruma_tamanukii

[

Accinctapubes_albifasciata

Agnidra_scabiosa

Auzata_superba

Ausaris micacea

Ausaris palleola

Cyclidia_substigmaria

Drepana arcuata

Falcaria_bilineata

Drepana_curvatula

Drepana curvatula2

Drepana_falcataria

Ennomos autumnaria

Epicopeia hainesii

Euparyphasma_maxima

Euthyatira pudens

Habrosyne_pyritoides

Lyssa_zampa

Maucrauzata maxima

Microblepsis acuminata

Nordstromia_grisearia

ochropacha duplaris

oreta_loochooana

Oreta_pulchripes

Oreta rosea

oreta turpis

Pseudothyatira_cym.

Psychostrophia melanargia

Sabra_harpagula

Nothus lunus

Tethea_consimilis

Tethea_taiwana

Tethea or

Tetheela fluctuosa

Thyatira_batis

Thyatira batis 2

Tridrepana flava

Tridrepana unispina

Watsonalla binaria

Watsonalla_cultraria

watsonalla_uncinula

Cilix glaucata

Falcaria_lacertinaria

Habrosyne_aurorina

Jodis putata

Neodaruma_tamanukii

NNNNNNNNNNNNNNNNNNNNNNNNNNNNNNNNNNNNNNNNNNNNNNNNNN TCCACTATATTCTAATTATTTATCTTATTATTTTTCTCCCATTATTAGAT NNNNNNNNNNNNNNNNNNNNNNNNNNNNNNNNNNNNNNNNNNNNNNNNNN TCCAATATTTTCTAATTATTTAAGATATTATTTTTCTCCTATTATTAGTT

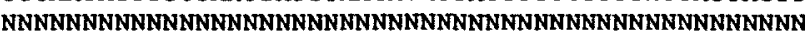
TCCTATATTTTCTAATTATTTAGTTTATTATTTTTCTCCTGTTGTTAGAT TCCTATATTTTCTAATTATTTAGTTTATTATTTTTCACCTGTGATTAGAT TCCTATATTTTCTAATTATTTGGTTTATTATTTTTCTCCTGTAATGAGAT TCCTATATTTTCTAATTATTTAGTTTATTATTTTTCTCCTGTAGTTAGAT NNNNNNNNNNNNNNNNNNNNNNNNNNNNNNNNNNNNNNNNNNNNNNNNNN TCCTTTAATTTCTAATTATTTTATTTATTATTTTTCTCCTGTTATTAGTT TCCPTTAATGTCTAATTATATTATTTATTATTTTTCTCCTATTATTAGAT TCCTATTATATCTAATTATTTAGTTTATTATTTTTCTCCTGTAATTAGAC TCCTATTATATCTAATTATTTAGTTTATTATTTTTCTCCTGTAATTAGAC NNNNNNNNNNNNNNNNNNNNNNNNNNNNNNNNNNNNNNNNNNNNNNNNNN TCCGTTATTATCTAATTATTTTATTTATTATTTTTCTCCTGTTGTTAGAT TCCTTTTTTATCTAATTATTTAATTTATTATTTTTCTCCTGTTATTAGTI NNNNNNNNNNNNNNNNNNNNNNNNNNNNNNNNNNNNNNNNNNNNNNNNNN TCCCTTATATTCAAATTATTTTTCTTATTATTTTTCTCCTAATATTAGAT TCCTATATTTTCAAATTATTTAATTTATTATTTTTCTCCTGTAGTTAGAT

$\begin{array}{lllll}1510 & 1520 & 1530 & 1540 & 1550] \\ . & . & . & . & .]\end{array}$

TTATTTTATCTTTATTAATTTGATTAATTATTCCTTATTATTTTAATATA TTATTTTATCTTTAATAATATGAATATTAATTCCTTATTATTTTAATTTA TTATTTTCTCTTTAATAATTIGAATATTAACCCCTTATTATTTTAATATA TTATTTTATCTTTAATGATTTGAAGTTTAACTCCTTATTTTTTTAATATA TTATTTTATCTTTAATAATTTGAGTTTTAATTCCTTATTATTTTAATATA TTATTTTATCTTTAATAATTTGAATGTTAATTCCTTATTATTTTAATATA TTATTTTATCATTAATAGTTTGAAGATTAATTCCTTATTTTTTTTAATATA TTATTATATCTTTATTAATTTGAACTTTAATTCCTTATTATTTTAATATA TTATTTTATCTTTAATAGTTTGAAGATTAATTCCTTATTTTTTTAATATA TTATTTTATCATTAATAGTTTGAAGATTAATTCCTTATTTTTTTAATATA TTATTTTATCTTTAATAGTTTGAAGATTAGTTCCTTATTTTTTTAATATA TTATTTTATCTTTAATAATTTGAATATTAATTCCTTACTATTTTAATTTG TTATTTTATCTTTAATAATTTGAATTTTATTTCCTTATTATTTTAATATA TTATTTTATCTTTAATAATTTGAATATTAATTCCTTATTATTTTAATATA NNNNNNNNNNNNNNNNNNNNNNNNNNNNNNNNNNNNNNNNNNNNNNNNNN NNNNNNNNNNNNNNNNNNNNNNNNNNNNNNNNNNNNNNNNNNNNNNNNNNN TTATTTTATCTTTAATGATTTGAATATTAATTCCTTATTATTTTAATATA TTATTTTATCTTTAATGGTTTGGATTTTAATTCCTTATTATTTTAATATC NNNNNNNNNNNNNNNNNNNNNNNNNNNNNNNNNNNNNNNNNNNNNNNNNNN TTATATTATCTTTAATAATTTGAATGTTAATTCCTTATTATTTTAATATA TTATATTATCTTTAATAATTTGAATATTAATTCCTTATTATTTTAATTTA TTATACTGGCGTTAATAATTTGAATATTAATTCCTTATTATTTTAATATA TTATACTGGCGTTAATAATTTGAATATTAATTCCTTATTATTTTAATATA TTATACTAGCTTTAATAATTTGAATGTTAATTCCTTATTATTTTAATATA TTATACTGGCGTTAATAATTTGAATATTAATTCCTTATTATTTTAATATA NNNNNNNNNNNNNNNNNNNNNNNNNNNNNNNNNNNNNNNNNNNNNNNNNN TTATTTTATCGTTATTAATTTGAATATTAATTCCTTATTATTTTAATTTA NNNNNNNNNNNNNNNNNNNNNNNNNNNNNNNNNNNNNNNNNNNNNNNNNN TTATTITATCTTTAATAATTTGAATAATAATTCCTTATTATTTTAATATA NNNNNNNNNNNNNNNNNNNNNNNNNNNNNNNNNNNNNNNNNNNNNNNNNN TTATTTTATCTTTAATAATTTGAATATTGATTCCTTATTATTTTAATATA TTATTTTATCTCTAATAATTTGAATATTAATTCCTTATTATTTTAATATA TTATTTTATCTTTAATAATTTGAATATTAATTCCTTATTATTTTAATATA TTTTTTTATCTTTAATAATTTGAATGTTAATTCCTTATTATTTTAATATA NNNNNNNNNNNNNNNNNNNNNNNNNNNNNNNNNNNNNNNNNNNNNNNNNN TTATTTTATCTTTAATAATTTGGTCTTTAATTCCTTATTATTTTAATATA TTATTTTGTCTTTGATAGTTTGATCTTTAATTCCTTATTATTATAATATA TTATATTGTCTTTAATAGTTTGGATATTAATTCCTTATTATTTTAATATA TTATATTGTCTTTAATAGTTTGGATATTAATTCCTTATTATTTTAATATA NNNNNNNNNNNNNNNNNNNNNNNNNNNNNNNNNNNNNNNNNNNNNNNNNN TTATTTTATCTATGATAATTTGAACTTTAATTCCTTATTATTTTAATATA TTATTATATCTTTATTAATTTGAACTTTAATTCCTTATTATTTTAATATA NNNNNNNNNNN NNNNNNNNNNNNNNNNNNNNNNNNNNNNNNNNNNNNNNN TTATTTTATCTTTAAAAATTTGAATATTAATTCCTTATTATTATAATATA TTATTTTATCTTTAATAATTTGAATATTAATTCCTTATTATTTTAATATA

[1419]

[1411]

[1417]

[1409]

[1418]

[1409]

[1405]

[1414]

[1413]

[1500]

[1429]

[1431]

[1408]

[1416]

[1419]

[1446]

[1417]

[1427]

[1404]

[1408]
[1539]

[1460]

[1455]

[1409]

[1449]

[1473]

[1499]

[1467]

[1418]

[1418]

[1499]

[1451]

[1467]

[1476]

[1426]

[1464]

[1460]

[1475]

[1467]

[1480]

[1456]

[1470]

[1470]

[1471]

[1470]

[1469]

[1461]

[1467]

[1459]

[1468]

[1459]

[1455]

[1464]

[1463]

[1550]

[1479]

[1481]

[1458]

[1466]

[1469]

[1496]

[1467]

[1477]

[1454]

[1458] 
Accinctapubes albifasciata Agnidra_scabiōsa Auzata superba

Ausaris micacea

Ausaris_palleola

Cyclidia substigmaria

Drepana arcuata

Falcariābilineata

Drepana curvatula

Drepana_curvatula2

Drepana_falcataria

Ennomos autumnaria

Epicopeía hainesii

Euparyphasma maxima

Euthyatira pudens

Habrosyne_pyritoides

Lyssa zampa

Maucrauzata maxima

Microblepsis_acuminata

Nordstromia grisearia

ochropacha_duplaris

oreta_loochooana

Oreta pulchripes

oretarosea

oreta turpis

Pseudothyatira_cym.

Psychostrophia_melanargia

Sabra harpagula

Nothus lunus

Tethea_consimilis

Tethea taiwana

Tethea or

Tethee $\bar{l}$ a_fluctuosa

Thyatira batis

Thyatira_batis 2

Tridrepaña flava

Tridrepana unispina

Watsonalla_binaria

Watsonalla cultraria

Watsonalla uncinula

Cilix_glaucata

Falcaria lacertinaria

Habrosyne_aurorina

Jodis putata

Neodaruma tamanukii

Accinctapubes albifasciata

Agnidra_scabiosa

Auzata superba

Ausaris micacea

Ausaris_palleola

Cyclidia_substigmaria

Drepana arcuata

Falcariábilineata

Drepana curvatula

Drepana curvatula2

Drepana_falcataria

Ennomos autumnaria

Epicopeía hainesii

Euparyphasma maxima

Euthyatira pudens

Habrosyne pyritoides

Lyssa_zampa

Maucrauzata maxima

Microblepsis_acuminata

Nordstromia grisearia

Ochropacha duplaris

Oreta_loochooana

Oreta_pulchripes

oreta_rosea
ATTAATTTTAATTTAGGAATTTTATTTTTTTTATGTTGCACAAGAANNNN ATTAGATTTAATTTAGGTATTTTATTTTTTTTNNNNNNNNNNNNNNNNNN GTTAGATTTAATTTAGGTATTTTATTTTTTTTCCCTTGTTTAAGAGTGGG ATTAGATTTAATTTAGGGGTTTTATTTTTTTTCCC'TTGTATTAGTTTAGG ATTAGTTTTAATTTAGGGATTTTATTTTTTTTYCCTTPAATTAGTTGGGG ATTAGTTTTAATTTAGGGGTTTTATTTTTTTTATGTTGTACAAGAGTTGG ATTAGATTTAATTTAGGTGTGTTATTTTTTTT-TCTTGTATTAGAATAGG ATTAGTTTTAATTTAGGGATATTATTTTTTTTTTCTTGTATTAGTGTTGG ATTAGATTTAATTTAGGGGTATTATTTTTTTTTTCTTGTATTAGATTATG ATTAGATTTAATTTAGGTGTGTTATTTTTTTT-TCTTGTATTAGAATAGG ATTAGATTTAATTTAGGTGTATTATTTTTTTTTTCTTGTATTAGATTATG ATTAGATTTAATTTAGGTATTTTATTTTTTTTTTGTTGTACTAGTTTAGG TTAAGATTTAATTTGGGGGTTTTATTTTTTTTTTGCGTTACTAGTTTGGG ATTAATTTTAATTTAGGAATTTTATTTTTTCTTTGTTGTACAAGTTTAGG NNNNNNNNNNNNNNNNNNNNNNNNNNNNNNNNNNNNNNNNNNNNNNNNNN NNNNNNNNNNNNNNNNNNNNNNNNNNNNNNNNNNNNNNNNNNNNNNNNNN ATTAGATTTAATTTAGGTTTANNNNNNNNNNNNNNNNNNNNNNNNNNNNNN ATTAGATTTAACTTAGGGTTTTTATATTTTTTTTCTGTTATTAGTGTTGG NNNNNNNNNNNNNNNNNNNNNNNNNNNNNNNNNNNNNNNNNNNNNNNNNN ATTAGCTTTAATTTAGGGTTTTTATTTTTTTTTTCTTGTATTAGAGTTGG ATTAGATTTAATTTAGGAATTTTATTTTTTCTTTGCTGTACAAGTTTAGG ATTAGTTTTAATTTAGGGATATTATTTTTTTTTTCTTGTATTAGAGTTTC ATTAGTTTTAATTTAGGGATATTATTTTTTTTTTCTTGTATTAGAGTTTC ATTAGTTTTAATTTGGGGATGTTATTTTTTTTTTCTTGTATTAGAGTTTC ATTAGTTTTAATTTAGGGATATTATTTTTTTTTTCTTGTATTAGAGTTTC NNNNNNNNNNNNNNNNNNNNNNNNNNNNNNNNNNNNNNNNNNNNNNNNNN ATTAGATTTAATTTAGGTATTTTATTTTTTTTTTGCTGCACTAAATTAGG NNNNNNNNNNNNNNNNNNNNNNNNNNNNNNNNNNNNNNNNNNNNNNNNNN ATTAGATTTAGATTAGGTTTATTATTTTTTTNNNNNNNNNNNNNNNNNNN NNNNNNNNNWNNNNNNNNNNNNNNNNNNNNNNNNNNNNNNNNNNNNNNNN ATTAGATTTAATTTAGGTATTTTATTTTTTTTTTGTTGTACTAGTTTAGG ATTAGATTTAATTTAGGGGTTTTATTTTTTCTTTGTTGTACTAGATTGGG ATTAGATTTAATTTAGGTATTTTATTTTTTTTTTGTTGTACTAGTTTAGG ATTACATTTAATTTAGGGGTTTTATTTTTTTTATGTTGTACTAGAATAGG NNNNNNNNNNNNNNNNNNNNNNNNNNNNNNNNNNNNNNNNNNNNNNNNNN GTTAGATATAATTTAGGTATATTATTTTTTTTTCCTTGCATTAGATTAGG ATTAGTTTTAATTTAGGGGTTTTATTTTTTTTTCCTTGTATTAGATTGGG ATTAGATTTAATTTAGGGATTTTATTTTTTTTTCCTGGTATTAGAGTAGG ATTAGATTTAATTTAGGGATTTTATTTTTTTTTTCTTGTATTAGAGTAGG NNNNNNNNNNNNNNNNNNNNNNNNNNNNNNNNNNNNNNNNNNNNNNNNNN ATTATGTATAATTTAGGTTTATTATTTTTTTTTTCTTGTATTAGATTAGG ATTAGTTTTAATTTAGGGATATTATTTTTTTTTTCTTGTATTAGTGTTGC NNNNNNNNNNNNNNNNNNNNNNNNNNNNNNNNNNNNNNNNNNNNNNNNNE ATAGTNNNNNNNNNNNNNNNNNNNNNNNNNNNNNNNNNNNNNNNNNNNNN ATTAGATTTAATTTAGGGATTTTGTTTTTTCTTTGTTGTACTAGTTTAGG
NNNNNNNNNNNNNNNNN NNNNNNNNNNNNNNNNN GGTTTACCCTATTATAG AGTATACACGGTAATAA GGTTTATAGAGTTATAG AGTTTATACTGTAATAG AGTTTATACTATTATA AGTTTATACAGTTATA

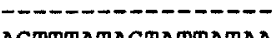

AGTTTATACTATTATA AGTNNNNNNNNNNNNNN GGTTPATACTGTAATNN GGTTTATACATTAATAA TGTTTATACTGTTATAG NNNNNNNNNNNNNNNNN NNNNNNNNNNNNNNNNN NNNNNNNNNNNNNNNNN AGTPTACACAATTATAA NNNNNNNNNNNNNNNNN GGTTTATATAGTGATAA GGTTTATACTGTAATAA AGTCTATACTGTTATAA AGTCTATACTGTTATAA TGTTTATACAGTTATGA
[1606]

[1527]

[1522]

[1476]

[1516]

[1540]

[1565]

[1534]

[1468]

[1484]

[1566]

[1518]

[1534]

[1543]

[1493]

[1531]

$[1527$ ]

[1542]

[ 1534 ]

[1547]

[1523]

[1537]

[1537]

[1538] 


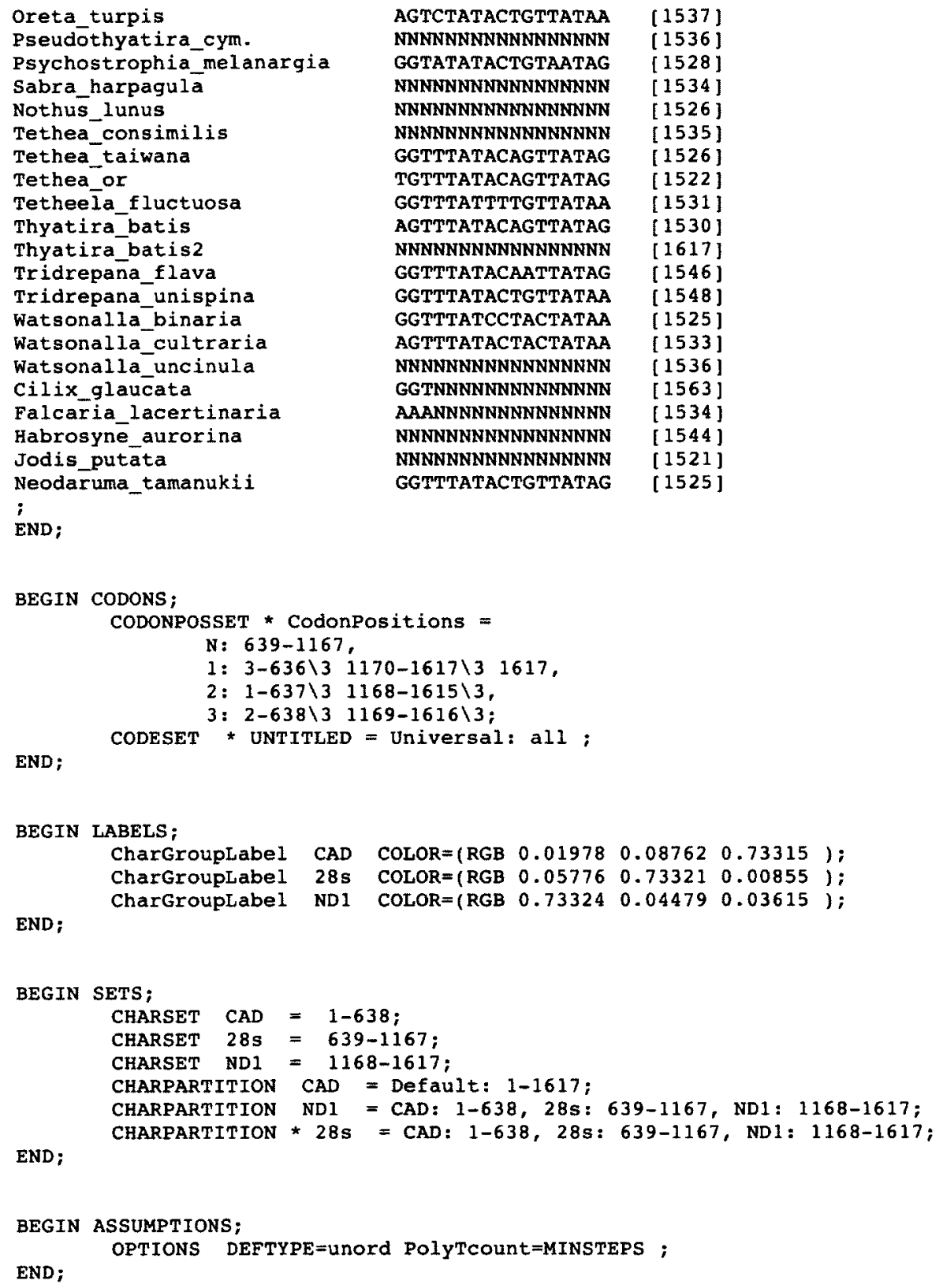

END;

BEGIN LABELS;

CharGrouplabel CAD COLOR $=($ RGB $0.01978 \quad 0.08762 \quad 0.73315)$ );

CharGroupLabel $28 \mathrm{~s} \quad$ COLOR $=\left(\begin{array}{lllll}\text { RGB } & 0.05776 & 0.73321 & 0.00855\end{array}\right)$;

END ;

CharGroupLabel ND1 COLOR $=\left(\begin{array}{lllll}R G B & 0.73324 & 0.04479 & 0.03615\end{array}\right)$;

BEGIN SETS;

CHARSET CAD $=1-638$;

CHARSET $28 \mathbf{s}=639-1167$;

CHARSET ND1 $=1168-1617$;

CHARPARTITION CAD = Default: $1-1617$;

CHARPARTITION ND1 = CAD: 1-638, 28s: 639-1167, ND1: 1168-1617;

END;

CHARPARTITION * 28s = CAD: 1-638, 28s: 639-1167, ND1: 1168-1617;

BEGIN ASSUMPTIONS;

OPTIONS DEFTYPE=unord POIY'TCOUnt=MINSTEPS ;

END; 


\section{APPENDix C: Muscles of The ANAl SEgment in Drepana arCUata AND TETHEA OR}

Muscles were examined in two representative species, one with reduced anal prolegs (Tethea or) and another without anal prolegs (Drepana arcuata) in order to help propose a model for the mechanistic changes that accompanied the transition from crawling to anal scraping (Chapter 5).

\section{Methods}

The last five segments (A6-A10) of the larval abdomen of two representative species, $T$. or $(n=6)$ and D. arcuata $(n=10)$, preserved in $80 \%$ ethanol, were dissected. This was done by cutting at either the dorsal or ventral midline and pinning the body open, or by cutting at both the dorsal and ventral midlines to create a parasaggital section. The viscera and loose fat of the body cavity were removed, leaving only the muscles intact. The muscles of A6-A10 were examined in detail with an Olympus dissection microscope (SZX12, Olympus, Japan), and were drawn and photographed using a PixeLink Megapixel firewire camera (PLA642) attached to the microscope. Muscles were examined, identified based on origins and insertion points, and named according to (Eaton, 1988). 


\section{Results}

Tethea or

As in $M$. sexta (see Eaton, 1988), in the last five abdominal segments of $T$. or, the dorsal longitudinal muscles run parallel to each other, dorsal to the spiracles, arising on the tergal antecostae of the previous segment and inserting on the posterior edge of the tergal antecostae of the next segment (Fig. C.1a). The ventral longitudinal muscles also run parallel to each other, but arise on the sternal antecostae of the previous segment and insert on the posterior edge of the sternal antecostae of the next segment. All other body muscles are lateral to the dorsal and ventral longitudinal muscles. The planta retractor muscles arise on the ventral region of the tergum near the middle of the segment, posterior to the spiracle, and insert on the tendon of the planta. In the anal segment, the planta retractor muscles insert on the tendon of the planta, arising ventral to the ventral longitudinal muscles, at the location where the two most ventral dorsal longitudinal muscles should arise, or just ventral to the anus on the posterior edge of the sternum.

\section{Drepana arcuata}

As in $T$. or, the dorsal and ventral longitudinal muscles arise on the tergal and sternal antecostae, respectively, of the previous segment and insert on the posterior edge of the tergal and sternal antecostae of the next segment (Fig. C.1b). The planta retractor muscles found in the sixth abdominal segment arise on the ventral region of the tergum near the middle of the segment, posterior to the spiracle, and insert on the tendon of the planta. In the anal segment, since $D$. arcuata lacks anal prolegs, three groups of muscles insert on the ventral edge of the sternum, arising on the pleural region near the anus. 
Fig. C.1. Muscles of the abdominal segments 6 - 10 in a caterpillar with a reduced anal proleg (Tethea or) (a) and a caterpillar with no anal proleg (Drepana arcuata) (b). $\mathrm{DL}=$ dorsal longitudinal muscles; $\mathrm{VL}=$ ventral longitudinal muscles; $\mathrm{PRM}=$ planta retractor muscles. 
a

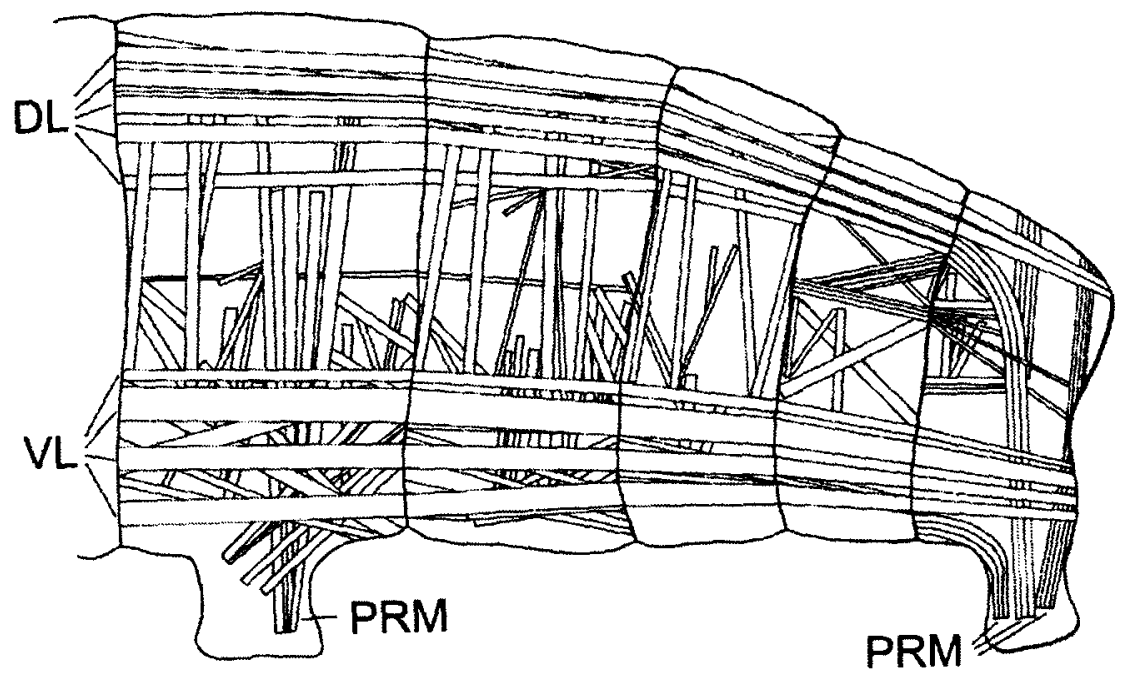

b

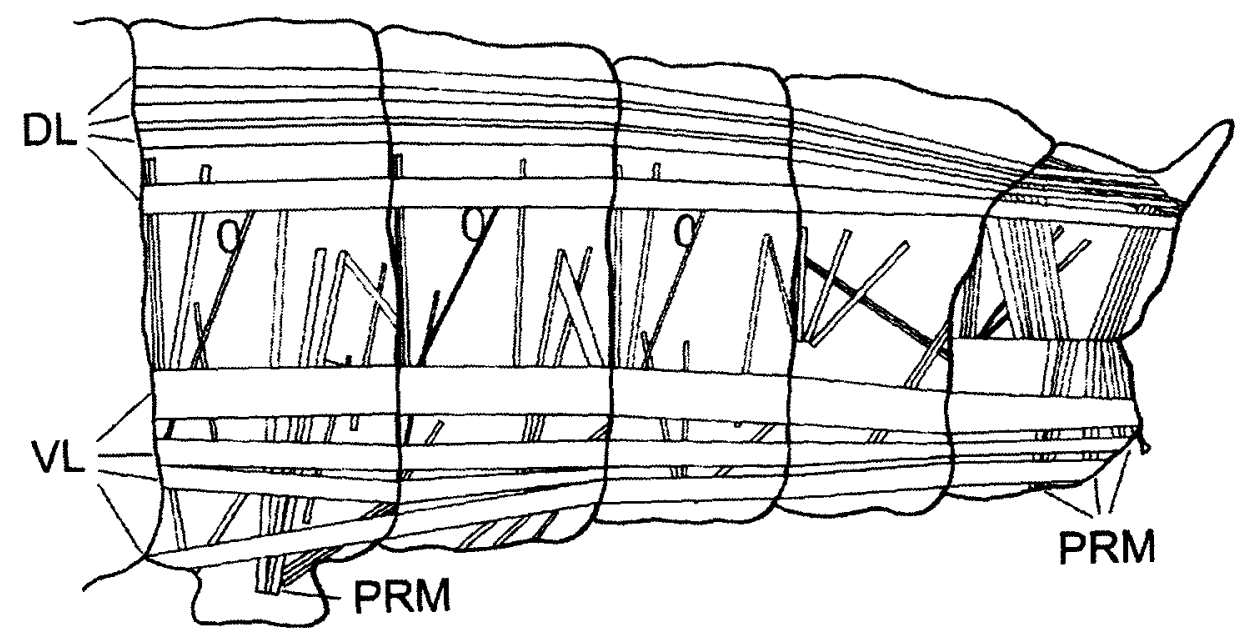

